\title{
Análisis espacial y temporal de la actividad pesquera y de los recursos pesqueros sobre la Plataforma Norte de la Península de Paria y en el Norte del Golfo de Paria.
}

TECHNICAL REPORT · MAY 2006

DOI: $10.13140 / R G \cdot 2 \cdot 1 \cdot 4260.6243$

1 AUTHOR:

William Senior

Universidad Estatal de la Península de Santa...

78 PUBLICATIONS 155 CITATIONS

SEE PROFILE 


\section{INFORME FINAL}

\section{VOLUMEN VI}

\section{COMPONENTE PESQUERIAS Y RECURSOS PESQUEROS}

Análisis espacial y temporal de la actividad pesquera y de los recursos pesqueros sobre la Plataforma Norte de la Península de Paria y en el Norte del Golfo de Paria.

Coordinador del Proyecto:

William Senior

Coordinador Pesquerías:

Freddy Arocha

Autores (en orden alfabético):

Arocha, F., Mendoza, J., Lodeiros, C., Prieto, A., Elquezabal, E., Ruíz, L., Alió, J., Altuve, D., Gómez, G., Guzmán, R., Lárez, A., Marcano, J., y Marcano, L

Informe preparado para la Gerencia de Seguridad Industrial, Ambiente e Higiene Ocupacional, Proyecto Mariscal Sucre.

\section{Elaborado por:}

\section{CAMUDOCA}

Consultora Ambiental de la Universidad de Oriente

camudoca@cantv.net

Av. Fernandez de Zerpa. Edf. La Maravilla.

Piso 2. Tlf: 0293-4320736

Cumaná, Mayo 2006 


\section{HOJA DE CONTROL DE CAMBIOS}

\begin{tabular}{|c|c|c|c|}
\hline $\begin{array}{l}\text { Tipo de Documento: A.1.2 } \\
\text { Título: : Informe Final Componente Pesquerías. }\end{array}$ \\
\hline Fecha & \multicolumn{1}{|c|}{ Actividad } & Responsables & Firma \\
\hline $16 / 04 / 2006$ & RevisiónCoordinador Pesquerías & Prof. Freddy Arocha & \\
\hline $18 / 04 / 2006$ & Revisión Técnica & Prof. Rubén Aparicio & \\
\hline $24 / 04 / 2006$ & Revisión Técnica y Edición & Prof. Julián Castañeda & \\
\hline $03 / 05 / 2006$ & Revisión Coordinador General & Prof. William Senior & \\
\hline $08 / 05 / 2006$ & Revisión Control de Calidad & Lic. Rafael Lemus & \\
\hline 23/05/2006 & Revisión Final y Aprobación & Prof. Andrés Lemus & \\
\hline
\end{tabular}




\section{TABLA DE CONTENIDO}

Pág.

LISTA DE TABLAS ......................................................................................................................... VI

LISTA DE FIGURAS ……………….............................................................................................. IX

I.- INTRODUCCIÓN.................................................................................................................... 1

II.- ANALISIS DE LA ACTIVIDAD PESQUERA Y RECURSOS PESQUEROS AL NORTE DE LA

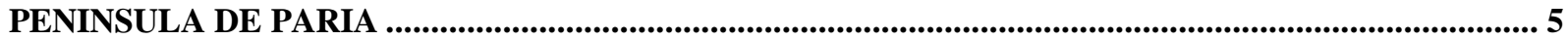

II.1 Pesquería ARTESAnal Costanera MultiesPeCífICA …...................................................... 5

II.1.1 Caracterización de las comunidades pesqueras al norte del Estado Sucre ................................... 6

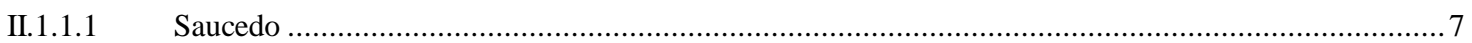

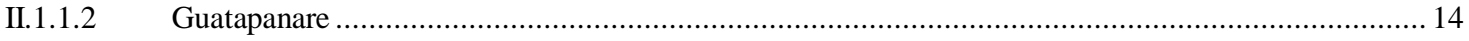

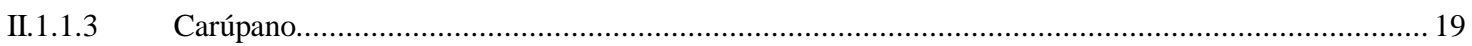

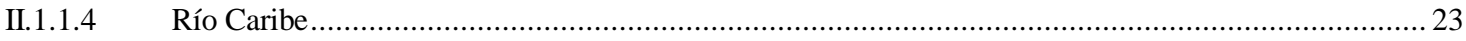

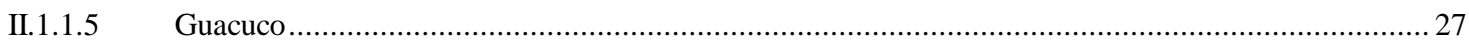

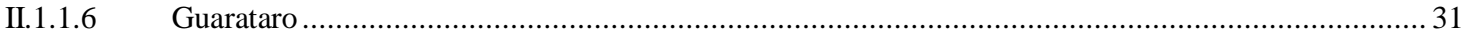

II.1.2 Análisis de los indicadores pesqueros y socio-económicos en las comunidades al norte del Estado

Sucre

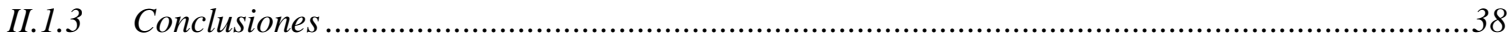

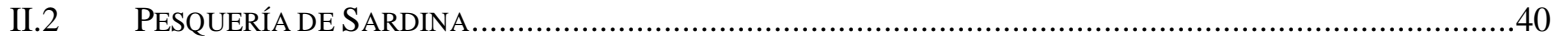

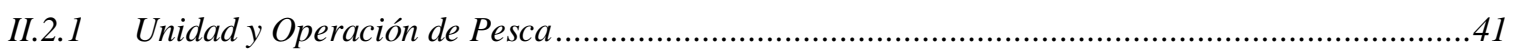

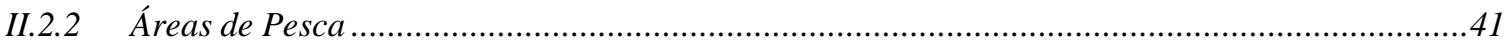

II.2.3 Variación de los desembarques, el esfuerzo y la abundancia relativa............................................42

II.2.4 Variación espacial y temporal de la biomasa de sardina ..............................................................44

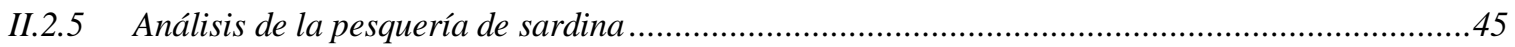

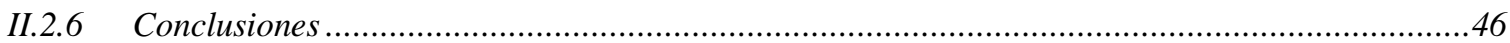

II.3 Pesquería ARTeSAnal de Media Altura Demersal ….............................................................47

II.3.1 Evolución de la captura y esfuerzo total ....................................................................................49

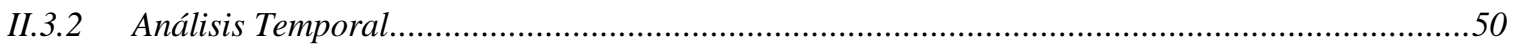

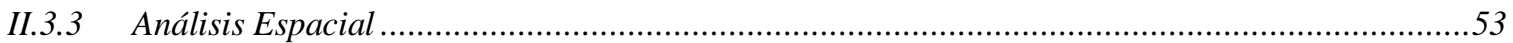

II.3.4 Análisis de los recursos pesqueros capturados por la pesquería artesanal de media altura

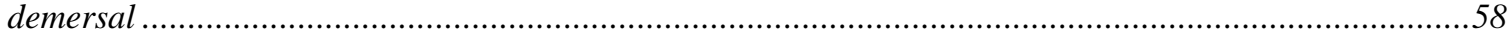

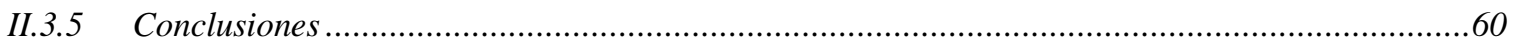

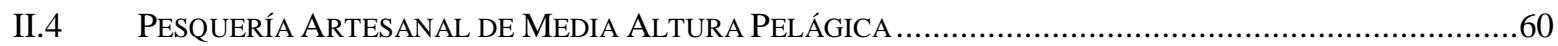

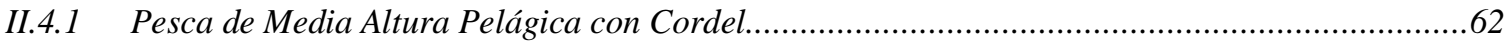

II.4.2 Pesca de Media Altura Pelágica con Palangre .........................................................................65 
II.4.3 Análisis de los recursos pesqueros capturados por la pesquería artesanal de media altura pelágica...... .71

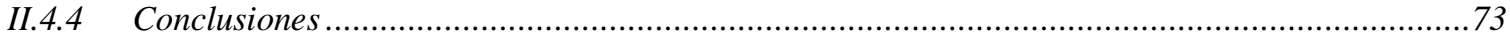

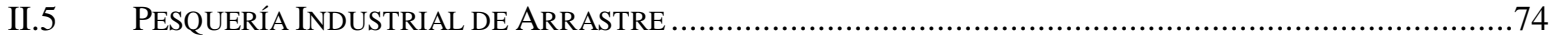

II.5.1 Distribución espacial y temporal de las especies demersales del norte de la Península de Paria.76

II.5.2 Análisis de los recursos pesqueros capturados por la pesquería industrial de arrastre..............100

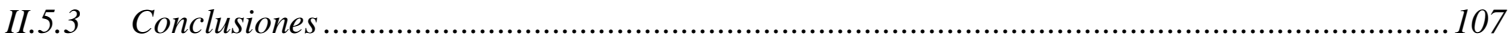

II.6 Estimaciones de Biomasa Por el Método De Área BARRIDA SOBRe LA PNPP........................108

II.6.1 Operación de captura de muestras y observaciones sobre el sustrato en el área de estudio .......114

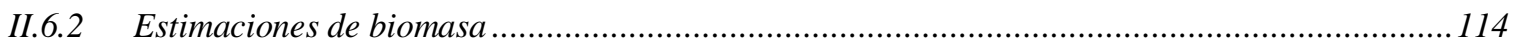

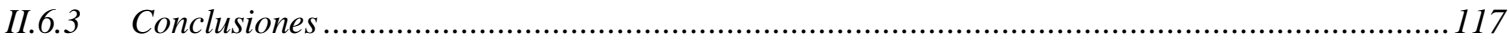

\section{III.- ANALISIS DE LA ACTIVIDAD PESQUERA Y RECURSOS PESQUEROS AL NORTE DEL}

III.1 Pesquería ARtesanal Costanera MultiesPecificA

III.1.1 Caracterización de las comunidades pesqueras al norte del GP..................................119

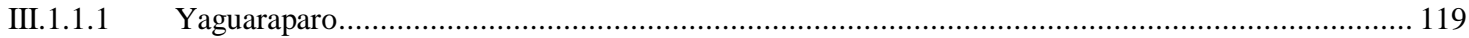

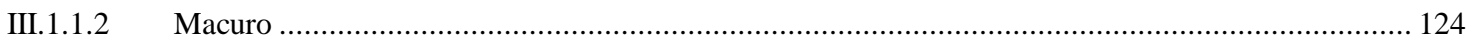

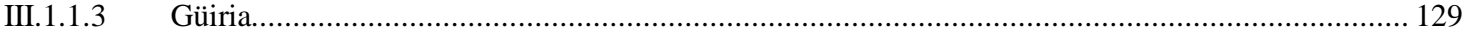

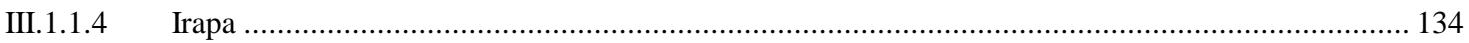

III.1.2 Análisis de los indicadores pesqueros y socio-económicos de las comunidades pesqueras al

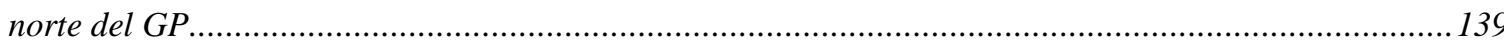

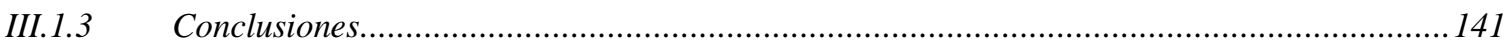

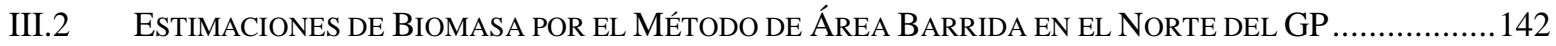

III.2.1 Observaciones sobre el Sustrato y Mareas en la Zona de Estudio.....................................146

III.2.2 Parámetros Ambientales en las Estaciones de Muestreos. ............................................... 147

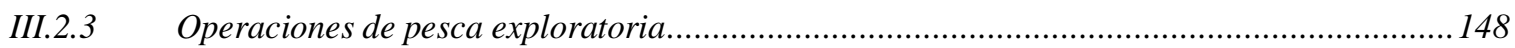

III.2.4 Cuantificación y composición de los grupos demersales.................................................151

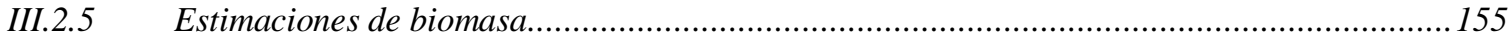

III.2.6 Análisis de las Estimaciones de Biomasa por Área Barrida en el norte del GP...................161

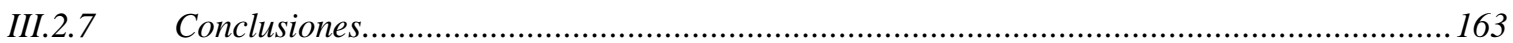

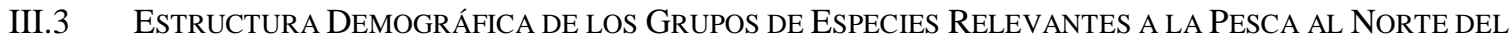

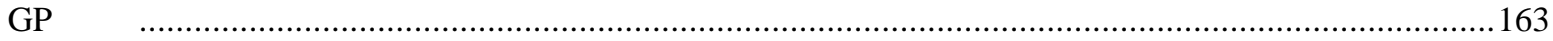

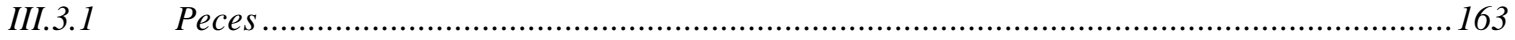

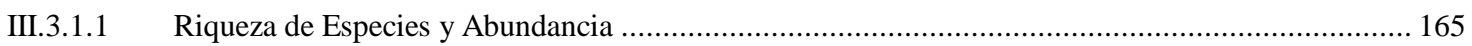

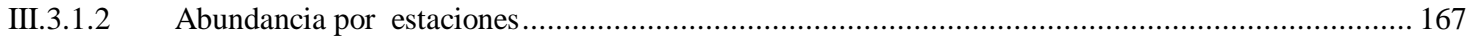

III.3.1.3 Especies registradas con tren de arrastre playero .................................................................. 172

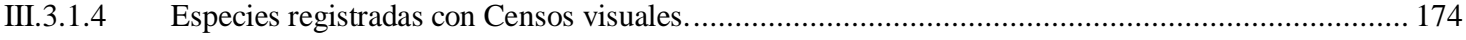

III.3.1.5 Estructura Demográfica por Especie................................................................................ 176 
III.3.2 Análisis de la estructura demográfica de las comunidades de peces al norte del GP. 201

III.3.3 Conclusiones. .205

III.3.4 Invertebrados (Crustáceos y Moluscos) …...........................................................206

III.3.4.1 Abundancia y Estructura Demográfica por Especie ................................................................. 207

III.3.5 Análisis de la estructura demográfica de las comunidades de invertebrados al norte del Golfo

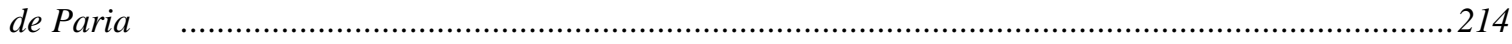

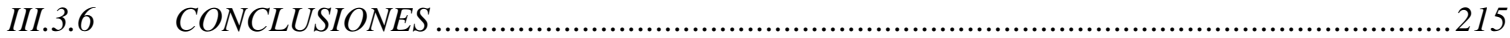

IV.- EVALUACION DE LOS BANCOS DE MOLUSCOS BIVALVOS AL NORTE DE LA PENÍNSULA DE PARIA Y EN EL NORTE DEL GOLFO DE PARIA..........................................216

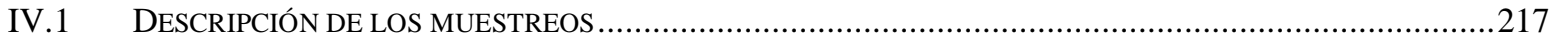

IV.2 ESPECIES CON POTENCIALIDAD COMERCIAL IDENTIFICADAS .........................................218

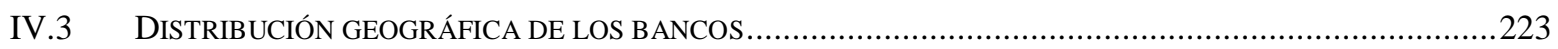

IV.3.1 Primera campaña (Período de Sequía) ......................................................................223

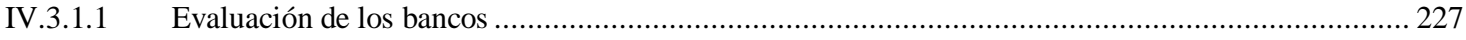

IV.3.1.2 Distribución de la talla de las especies e índice de condición de los bancos ...................................230

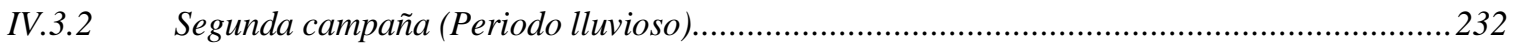

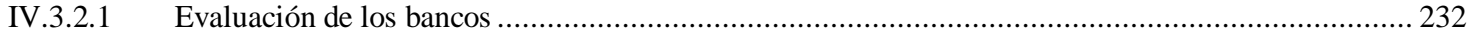

IV.3.2.2 Distribución de la talla de las especies e índice de condición de los bancos ................................. 234

IV.4 ANÁlisis de los Bancos DE MOLUSCOS BIVALVOS AL NORTE DE LA PENÍNSUla DE PARIA Y EN EL

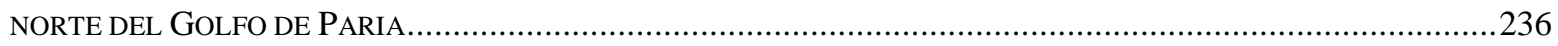

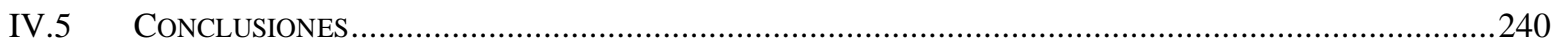

V.- $\quad$ ANÁLISIS GENERAL DE LA ACTIVIDAD PESQUERA Y POBLACIONES DE RECURSOS MARINOS EXPLOTADOS COMERCIALMENTE (PECES E INVERTEBRADOS) EN EL ÁREA DEL

PMS

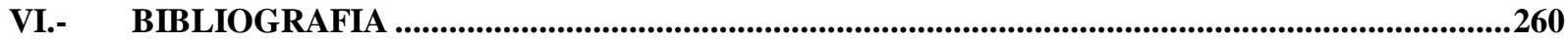

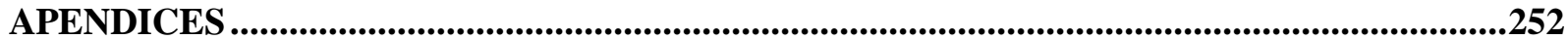




\section{INDICE DE TABLAS}

Pág.

TABLA II-1.- NÚMERO Y TIPO DE ENCUESTAS A COMUNIDADES PESQUERAS SELECCIONADAS PARA EL ESTUDIO. .... 6

TABLA II-2.- CARACTERÍSTICAS DE LA FLOTA DE SAUCEDO

TABLA II-3.- PRINCIPALES ESPECIES CAPTURADAS POR LA FlOTA ARTESANAL DE SAUCEDO, SEGÚN ENCUESTAS REALIZADAS A PESCADORES ARTESANALES

TABLA II-4.- COMPORTAMIENTO POR TEMPORADA ALTA Y BAJA DE LA ABUNDANCIA RELATIVA (KG/DÍA) DE LAS

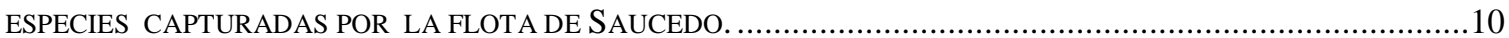

TABLA II-5.- CARACTERÍSTICAS DE LA FLOTA DE GUATAPANARE.

TABLA II-6.- PRINCIPALES ESPECIES CAPTURADAS POR LA FLOTA ARTESANAL DE GUATAPANARE SEGÚN ENCUESTAS REALIZADAS A PESCADORES ARTESANALES.......................................................................

TABLA II-7.- COMPORTAMIENTO POR TEMPORADA ALTA Y B AJA DE LA ABUNDANCIA RELATIVA (KG/DÍA) DE LAS ESPECIES CAPTURADAS POR LA FLOTA DE GUATAPANARE.

TABLA II-8.- CARACTERÍSTICAS DE LA FLOTA DE CARÚPANO

TABLA II-9.-PRINCIPALES ESPECIES CAPTURADAS POR LA FLOTA ARTESANAL DE CARÚPANO, SEGÚN ENCUESTAS REALIZADAS A PESCADORES ARTESANALES.

TABLA II-10.-COMPORTAMIENTO POR TEMPORADA ALTA Y BAJA DE LA ABUNDANCIA RELATIVA (KG/DÍA) DE LAS ESPECIES CAPTURADAS POR LA FLOTA DE CARÚPANO.

TABLA II-11.-.- CARACTERÍSTICAS DE LA FLOTA DE RÍO CARIBE.

TABLA II-12.-PRINCIPALES ESPECIES CAPTURADAS POR LA FLOTA ARTESANAL DE RÍO CARIBE SEGÚN ENCUESTAS REALIZADAS A PESCADORES ARTESANALES

TABLA II-13.-COMPORTAMIENTO POR TEMPORADA ALTA Y BAJA DE LA ABUNDANCIA RELATIVA (KG/DÍA) DE LAS ESPECIES CAPTURADAS POR LA FLOTA DE RÍO CARIBE.

TABLA II-14.-CARACTERÍ́STICAS DE LA FLOTA DE GUACUCO.

TABLA II-15.-COMPOSICIÓN DE LAS PRINCIPALES ESPECIES CAPTURADAS POR LA FLOTA ARTESANAL DE GUACUCO, SEGÚN ENCUESTAS REALIZADAS A PESCADORES ARTESANALES.

TABLA II-16.-COMPORTAMIENTO POR TEMPORADA ALTA Y BAJA DE LA ABUNDANCIA RELATIVA (KG/DÍA) DE LAS

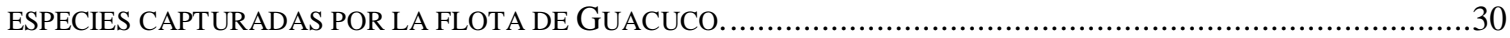

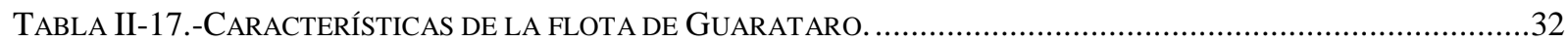

TABLA II-18.-COMPOSICIÓN DE LAS PRINCIPALES ESPECIES CAPTURADAS POR LA FLOTA ARTESANAL DE GUARATARO, SEGÚN ENCUESTAS REALIZADAS A PESCADORES ARTESANALES.

TABLA II-19.-COMPORTAMIENTO POR TEMPORADA ALTA Y BAJA DE LA ABUNDANCIA RELATIVA (KG/DíA) DE LAS ESPECIES CAPTURADAS POR LA FLOTA DE GUARATARO EN TEMPORADA ALTA Y BAJA.

TABLA II-20.-VARIACIÓN DE LAS CAPTURAS, ESFUERZO Y ABUNDANCIA RELATIVA DE LA PESQUERÍA DE SARDINA EN EL NORTE DEL ESTADO SUCRE DURANTE EL PERÍODO 2001-2004.

TABLA II-21.-VARIACIÓN ESTACIONAL PROMEDIO (2001-2004) DE LA CAPTURA, ESFUERZO Y ABUNDANCIA RELATIVA DE LA PESQUERÍA DE SARDINA POR PUERTO DE DESEMBARQUE EN NORTE DEL ESTADO SUCRE. ...43 
TABLA II-22.-RUBROS Y ESPECIES SELECCIONADAS PARA EL ANÁLISIS DE LA DISTRIBUCIÓN ESPACIO-TEMPORAL AL NORTE DE LA PENÍNSULA DE PARIA

TABLA II-23.-ESTACIONES A CUBRIR EN LA CAMPAÑA DE ESTIMACIÓN DE BIOMASA POR EL MÉTODO DE ÁREA BARRIDA SOBRE LA PNPP

TABLA II-24.-POSICIÓN DE LOS LANCES EFECTUADOS SOBRE LA PNPP DURANTE EL MUESTREO REALIZADO A BORDO DE LA EMBARCACIÓN JANNADOMARY ENTRE LOS DÍAS 28 Y 29/OCT/2005.

TABLA II-25.-DISTANCIA DE BARRIDO EN LOS LANCES EFECTUADOS SOBRE LA PNPP DURANTE EL MUESTREO REALIZADO A BORDO DE LA EMBARCACIÓN JANNADOMARY ENTRE LOS DÍAS 28 Y 29/OCT/2005.

TABLA II-26.-ESTIMACIÓN DE LA BIOMASA (KG/KM²) DE ESPECIES DEMERSALES SELECCIONADAS, EN LAS ESTACIONES EVALUADAS SOBRE LA PNPP DURANTE EL MUESTREO REALIZADO A BORDO DE LA EMBARCACIÓN JANNADOMARY ENTRE LOS DÍAS 28 Y 29/OCT/2005.

TABLA III-1- COMUNIDADES PESQUERAS SELECCIONADAS PARA EL ESTUDIO.

TABLA III-2.- CARACTERÍSTICAS DE LA FLOTA DE YAGUARAPARO.

TABLA III-3- PRINCIPALES ESPECIES CAPTURADAS POR LA FLOTA ARTESANAL DE YAGUARAPARO SEGÚN ENCUESTAS REALIZADAS A PESCADORES ARTESANALES.

TABLA III-4.- COMPORTAMIENTO POR TEMPORADA ALTA Y BAJA DE LA ABUNDANCIA RELATIVA (KG/DÍA) DE LAS ESPECIES CAPTURADAS POR LA FLOTA DE YAGUARAPARO.

TABLA III-5.- CARACTERÍSTICAS DE LA FLOTA DE MACURO.

TABLA III-6.- PRINCIPALES ESPECIES CAPTURADAS POR LA FlOTA ARTESANAL DE MACURO SEGÚN ENCUESTAS REALIZADAS A PESCADORES ARTESANALES.

TABLA III-7.- COMPOSICIÓN DE LAS PRINCIPALES ESPECIES CAPTURADAS POR LA FLOTA ARTESANAL DE MACURO SEGÚN ENCUESTAS REALIZADAS A PESCADORES ARTESANALES

TABLA III-8- CARACTERÍSTICAS DE LA FLOTA DE GÜIRIA. 130

TABLA III-9- PRINCIPALES ESPECIES CAPTURADAS POR LA FLOTA ARTESANAL DE GÜIRIA SEGÚN ENCUESTAS REALIZADAS A PESCADORES ARTESANALES.

TABLA III-10- COMPORTAMIENTO POR TEMPORADA ALTA Y BAJA DE LA ABUNDANCIA RELATIVA (KG/DÍA) DE LAS ESPECIES CAPTURADAS POR LA FLOTA DE GÜIRIA

TABLA III-11- CARACTERÍSTICAS DE LA FLOTA DE IRAPA. 135

TABLA III-12- PRINCIPALES ESPECIES CAPTURADAS POR LA FLOTA ARTESANAL DE IRAPA SEGÚN ENCUESTAS REALIZADAS A PESCADORES ARTESANALES.

TABLA III-13- COMPOSICIÓN DE LAS PRINCIPALES ESPECIES CAPTURADAS POR LA FLOTA ARTESANAL DE IRAPA SEGÚN ENCUESTAS REALIZADAS A PESCADORES ARTESANALES

TABLA III-14- CARACTERÍSTICAS ESTRUCTURALES DEL ARTE DE PESCA UTILIZADO PARA ESTIMACIONES DE BIOMASA POR ÁREA BARRIDA EN EL NORTE DEL GP.

TABLA III-15- RESULTADOS DE LOS PARÁMETROS FÍSICO-QUÍMICOS OBSERVADOS EN LAS MASAS DE AGUA SUPERFICIALES DURANTE LA PRIMERA CAMPAÑA AL NORTE DEL GOLFO DE PARIA. 
TABLA III-16- LOCALIDADES, POSICIONES, CAPTURAS, DURACIÓN Y DISTANCIA BARRIDA POR LA RED 'CHICA' DURANTE LA PRIMERA CAMPAÑA EN LA COSTA NORTE DEL GOLFO DE PARIA (COD.: CÓDIGO; E1-9: ESTACIONES ; ESTRATOS I (0-5 M) Y II (5-10 M); 1-3: NÚMERO DEL LANCE).

TABLA III-17- COMPOSICIÓN DE ENTES TAXONÓMICOS OBSERVADOS DURANTE LAS CAMPAÑAS DE PROSPECCIÓN PESQUERA EN LA COSTA NORTE DEL GP.

TABLA III-18- RENDIMIENTOS Y PORCENTAJES POR FAMILIAS DE MAYOR IMPORTANCIA EN LAS CAPTURAS POR CAMPAÑA DE EXPLORACIÓN.

TABLA III-19- BIOMASA TOTAL (KG/KM²) ESTIMADA PARA CADA ESTACIÓN AL NORTE DEL GP DURANTE LAS CAMPAÑAS DE PROSPECCIÓN PESQUERA.

TABLA III-20- BIOMASA (KG/KM²) ESTIMADA PARA CADA GRUPO (FAMILIA) DE IMPORT ANCIA PESQUERA AL NORTE DEL GP DURANTE LAS CAMPAÑAS DE PROSPECCIÓN PESQUERA.

TABLA III-21- EsPECIES DE PECES, NÚMERO DE INDIVIDUOS (№ IND.), PORCENTAJE RELATIVO (\%), PESO Y PORCENTAJE RELATIVO, RECOLECTADOS EN Playa DORADA, COSTA NORTE DEL GP

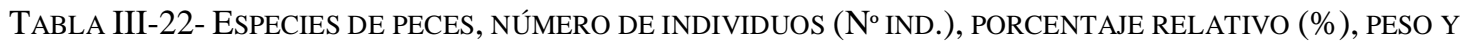
PORCENTAJE RELATIVO, RECOLECTADOS EN LAS GARZAS, COSTA NORTE DEL GP.

TABLA III-23- LISTA DE FAMILIAS Y NÚMERO DE ESPECIES OBSERVADAS (CENSOS VISUALES) EN LA COSTA NORTE DEL GP DURANTE LA SEGUNDA CAMPAÑA. ASTERISCOS REFIEREN A ESPECIES NO CAPTURADAS EN LOS MUESTREOS

TABLA III-24.- ESPECIES IDENTIFICADAS CON SU UBICACIÓN SISTEMÁTICA 208

TABLA III-25.- ABUNDANCIA EN NÚMERO DE ORGANISMOS CAPTURADOS DE CRUSTÁCEOS...............................208

TABLA III-26.- BIOMASA (G) DE CRUSTÁCEOS CAPTURADOS. 208

TABLA III-27.- TALLA PROMEDIO Y SU DESVIACIÓN ESTÁNDAR (SD) DE LAS ESPECIES CAPTURADOS DE CRUSTÁCEOS

TABLA III-28.- ESPECIES IDENTIFICADAS CON SU UBICACIÓN SISTEMÁTICA.

TABLA III-29.- ABUNDANCIA EN NÚMERO DE ORGANISMOS CAPTURADOS DE CRUSTÁCEOS...............................212

TABLA III-30.- BIOMASA (G) DE CRUSTÁCEOS CAPTURADOS.

TABLA III-31.- TALLA PROMEDIO Y SU DESVIACIÓN ESTÁNDAR ( $S D$ ) DE LAS ESPECIES CAPTURADOS DE CRUSTÁCEOS

TABLA IV-1.- LISTA DE ESPECIES DE MOLUSCOS CON VALOR COMERCIAL. LAS ESPECIES ESTÁN NOMBRADAS Y UBICADAS SISTEMÁTICAMENTE.

TABLA IV-2.- PARÁMETROS DE EVALUACIÓN DE LOS BANCOS DE MOLUSCOS DE LA COSTA NORTE DE LA PENÍNSULA DE PARIA. $1^{\text {RA }}$ EXPEDICIÓN EXPLORATORIA DE LBAPMS.

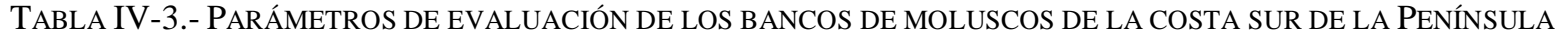
DE PARIA.

TABla IV-4.- PARÁMETROS DE EVALUACión DE LOS B ANCOS DE LA COSTA NORTE DE LA PENínSUla DE PARIA. 233

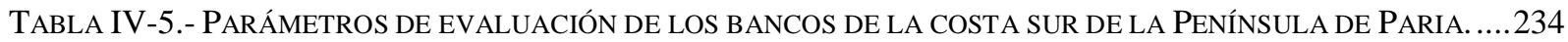




\section{INDICE DE FIGURAS}

Pág.

FIGURA II-1.- ÁREAS DE PESCA POR COMUNIDAD PESQUERA DE LAS FLOTAS ARTESANALES COSTANERAS MULTIESPECIFICAS.

FIGURA II-2.- ÁREAS DE PESCA DE LAS FLOTAS ARTESANALES MULTIESPECIFICAS Y ABUNDANCIA RELATIVA DEL PROMEDIO DEL TOTAL DE RUBROS QUE CAPTURAN LAS FLOTAS DURANTE LA TEMPORADA ALTA.

FIGURA II-3.- ÁREAS DE PESCA DE LAS FLOTAS ARTESANALES MULTIESPECIFICAS Y ABUNDANCIA RELATIVA DEL TOTAL DE RUBROS QUE CAPTURAN LAS FLOTAS DURANTE LA TEMPORADA BAJA.......................................12

FigURA II-4.- ÁREAS DE PESCA DE LA FLOTA QUE CAPTURA SARDINA EN EL NORTE DEL ESTADO SUCRE. .42

FigURA II-5.- DISTRIBUCIÓN HORIZONTAL DE LA BIOMASA DE SARDINA ESTIMADA MEDIANTE PROSPECCIONES DE HIDROACÚSTICA (FUENTE: FLASA,1999).

FIGURA II-6.- DISTRIBUCIÓN DE LAS CAPTURAS DE SARDINA POR SECTORES DE PESCA DEL NORORIENTE DE VENEZUELA: PERÍODO 2000 -2004

Figura II-7.- Desembarques totales (TM) DE SARdina EN LOS PUERTOS BASE DE GuACA Y Puerto SANTO ENTRE 1985 Y 2004

FiguRA II-8.- EVOLUCIÓN DE LAS CAPTURAS TOTALES (KG) POR ESPECIE EN LA PESQUERÍA ARTESANAL DE MEDIA ALTURA DEMERSAL EN El NORTE DE LA PENÍNSUla De PARIA.

FiguRA II-9.- EVOLUCIÓN DE LAS CAPTURAS TOTALES (KG) POR ESPECIE EN LA PESQUERÍA ARTESANAL DE MEDIA ALtURA DEMERSAl EN El NORTE DE LA Península De PARia.

FIGURA II-10.- EVOLUCIÓN POR TRIMESTRE DEL ESFUERZO (NÚMERO DE ANZUELOS) EN LA PESQUERÍA ARTESANAL DE MEDia ALTURA DEMERSAL CON PALANGRE EN El NORTE DE LA PENÍNSUla DE PARIA..

FIGURA II-11.- EVOLUCIÓN POR TRIMESTRE DEL ESFUERZO (CORDEL) EN LA PESQUERÍA ARTESANAL DE MEDIA ALTURA DEMERSAl CON CORDEl EN El NORTE DE LA PENÍNSUla DE PARIA.

FIGURA II-12.- EVOLUCIÓN POR TRIMESTRE DE LA ABUNDANCIA RELATIVA (CPUE, KG/100 ANZUELOS) POR ESPECIE EN LA PESQUERÍA ARTESANAL DE MEDIA ALTURA DEMERSAL CON PALANGRE EN EL NORTE DE LA PENÍNSUla DE PARIA.

FIGURA II-13.- EVOLUCIÓN POR TRIMESTRE DE LA ABUNDANCIA RELATIVA (CPUE, KG/CORDEL) POR ESPECIE EN LA PESQUERÍA ARTESANAL DE MEDIA ALTURA DEMERSAL CON CORDEL EN EL NORTE DE LA PENÍNSULA DE PARIA.

FIGURA II-14.- ABUNDANCIA RELATIVA PROMEDIO TRIMESTRAL PARA LAS ESPECIES MÁS IMPORTANTES CAPTURADAS POR LA PESQUERÍA ARTESANAL DE MEDIA ALTURA DEMERSAL CON PALANGRE, MERO FRAILE (ARRIBA) Y PARGO COLORADO (ABAJO).

FIGURA II-15.- ABUNDANCIA RELATIVA PROMEDIO TRIMESTRAL PARA EL CUNARO CAPTURADO POR LA PESQUERÍA ARTESANAL DE MEDIA ALTURA DEMERSAL CON PALANGRE. 
FIGURA II-16.- ABUNDANCIA RELATIVA PROMEDIO TRIMESTRAL PARA LAS ESPECIES MÁS IMPORTANTES CAPTURADAS POR LA PESQUERÍA ARTESANAL DE MEDIA ALTURA DEMERSAL CON CORDEL, PARGO COLORADO (ARRIBA) Y CUNARO (ABAJO).

FIGURA II-17.- ABUNDANCIA RELATIVA PROMEDIO TRIMESTRAL PARA EL MERO FRAILE CAPTURADO POR LA PESQUERÍA ARTESANAL DE MEDIA ALTURA DEMERSAL CON CORDEL.

FIGURA II-18.- EVOLUCIÓN POR TRIMESTRE DEL ESFUERZO (CORDEL) Y CAPTURA TOTAL EN LA PESQUERÍA ARTESANAL DE MEDiA ALTURA PELÁGICA CON CORDEL EN EL NORTE DE LA PENÍNSULA DE PARIA.

FIGURA II-19.- EVOLUCIÓN POR TRIMESTRE DE LA ABUNDANCIA RELATIVA (CPUE, KG/CORDEL) POR ESPECIE EN LA PESQUERÍA ARTESANAL DE MEDIA ALTURA PELÁGICA CON CORDEL EN EL NORTE DE LA PENÍNSULA DE PARIA.

FIGURA II-20.- ABUNDANCIA RELATIVA PROMEDIO TRIMESTRAL PARA LA ESPECIE MÁS IMPORTANTE CAPTURADA POR LA PESQUERÍA ARTESANAL DE MEDIA ALTURA PELÁGICA CON CORDEL, EL CARITE-SIERRA (KGM)......65

FIGURA II-21.- EVOLUCIÓN POR TRIMESTRE DEL ESFUERZO (ANZUELOS) Y CAPTURA TOTAL EN LA PESQUERÍA ARTESANAL DE MEDIA ALTURA PELÁGICA CON PALANGRE EN EL NORTE DE LA PENÍNSUla DE PARIA.

FIGURA II-22.- DISTRIBUCIÓN PROPORCIONAL DE LA CAPTURA POR ESPECIE EN LA PESQUERÍA ARTESANAL DE MEDiA ALTURA PELÁGICA CON PALANGRE EN EL NORTE DE LA PENÍNSUlA DE PARIA. (WHM, AGUJA BLANCA; SAI, PEZ VELA; BUM, AGUJA AZUL; DOL, DORADO; WHA, PETO; YFT, ATÚN ALETA AMARILLA; BLF, ATÚN ALETA NEGRA; SHK, TIBURONES).

FIGURA II-23.- EVOLUCIÓN POR TRIMESTRE DE LA CAPTURA POR ESPECIE EN LA PESQUERÍA ARTESANAL DE MEDIA ALTURA PELÁGICA CON PALANGRE EN EL NORTE DE LA PENÍNSUla DE PARIA.

FIGURA II-24.- EVOLUCIÓN POR TRIMESTRE DE LA ABUNDANCIA RELATIVA (CPUE, KG/100 ANZUELOS) POR ESPECIE EN LA PESQUERÍA ARTESANAL DE MEDIA ALTURA PELÁGICA CON PALANGRE EN EL NORTE DE LA PENÍNSUlA DE PARIA.

FIGURA II-25.- PROMEDIO TRIMESTRAL DE LA ABUNDANCIA RELATIVA PARA EL DORADO (DOL) CAPTURADO POR LA PESQUERÍA ARTESANAL DE MEDIA ALTURA PELÁGICA CON PALANGRE.

FIGURA II-26.- PROMEDIO TRIMESTRAL DE LA ABUNDANCIA RELATIVA PARA LOS ISTIOFÓRIDOS (ISTIO) CAPTURADO POR LA PESQUERÍA ARTESANAL DE MEDIA ALTURA PELÁGICA CON PALANGRE. ....

FIGURA II-27.- PROMEDIO TRIMESTRAL DE LA ABUNDANCIA RELATIVA PARA LOS TIBURONES (SHK) CAPTURADO POR LA PESQUERÍA ARTESANAL DE MEDIA ALTURA PELÁGICA CON PALANGRE.

FIGURA II-28.- MICROPOGONIAS FURNIERI. DISTRIBUCIÓN ESPACIAL Y TEMPORAL (TRIMESTRAL) DE LA ABUNDANCIA POR AÑOS COMBINADOS PARA EL PERÍODO 2000-2003.

FIGURA II-29.- MICROPOGONIAS FURNIERI. DISTRIBUCIÓN ESTACIONAL (TRIMESTRAL) POR ESTRATOS DE PROFUNDIDAD POR AÑO.

FIGURA II-30.- DiSTRIBUCIÓN DÍA-NOCHE POR AÑO DE LAS ESPECIES SELECCIONADAS QUE SON OBJETO DE LAS CAPTURAS DE LA PESQUERÍA DE ARRASTRE INDUSTRIAL, PERÍODO 2000-2003.

FIGURA II-31.- ORTHOPRISTIS RUBER. DISTRIBUCIÓN ESPACIAL Y TEMPORAL (TRIMESTRAL) DE LA ABUNDANCIA POR AÑOS COMBINADOS PARA EL PERÍODO 2000-2003. 
FIGURA II-32.- ORTHOPRISTIS RUBER. DISTRIBUCIÓN ESTACIONAL (TRIMESTRAL) POR ESTRATOS DE PROFUNDIDAD Y AÑO.

FigURA II-33.- SELENE SETAPINNIS. DISTRIBUCIÓN ESPACIAL Y TEMPORAL (TRIMESTRAL) DE LA ABUNDANCIA POR AÑOS COMBINADOS PARA EL PERÍODO 2000-2003.

FIGURA II-34.- SELENE SETAPINNIS. DISTRIBUCIÓN ESTACIONAL (TRIMESTRAL) POR ESTRATOS DE PROFUNDIDAD POR AÑO.

FigURA II-35.- PRIACANTHUS ARENATUS. DisTRIBUCIÓN ESPACIAL Y TEMPORAL (TRIMESTRAL) DE LA ABUNDANCIA

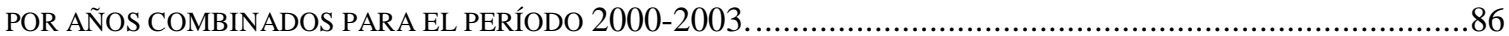

FiguRA II-36.- PRIACANTHUS ARENATUS. DistRIBUCIÓN ESTACIONAL (TRIMESTRAL) POR ESTRATOS DE PROFUNDIDAD POR AÑO.

FIGURA II-37.- HAEMULON STEINDACHNERI. DISTRIBUCIÓN ESPACIAL Y TEMPORAL (TRIMESTRAL) DE LA ABUNDANCIA POR AÑOS COMBINADOS PARA EL PERÍODO 2000-2003.

FigURA II-38.- HAEMULON STEINDACHNERI. DiSTRIBUCIÓN ESTACIONAL (TRIMESTRAL) POR ESTRATOS DE PROFUNDIDAD POR AÑO.

FIGURA II-39.- FARFANTEPENAEUS BRASILIENSIS. DISTRIBUCIÓN ESPACIAL Y TEMPORAL (TRIMESTRAL) DE LA ABUNDANCIA POR AÑOS COMBINADOS PARA EL PERÍODO 2000-2003.

FIGURA II-40.- FARFANTEPENAEUS BRASILIENSIS. DISTRIBUCIÓN ESTACIONAL (TRIMESTRAL) POR ESTRATOS DE PROFUNDIDAD POR AÑO.

FIGURA II-41.- OCTOPUS VULGARIS. DISTRIBUCIÓN ESPACIAL Y TEMPORAL (TRIMESTRAL) DE LA ABUNDANCIA POR AÑOS COMBINADOS PARA EL PERÍODO 2000-2003.

FigURA II-42.- OCTOPUS VULGARIS. DISTRIBUCIÓN ESTACIONAL (TRIMESTRAL) POR ESTRATOS DE PROFUNDIDAD POR AÑO

FIGURA II-43.- LOLIGO PLEI/LOLIGO PEALEI. DISTRIBUCIÓN ESPACIAL Y TEMPORAL (TRIMESTRAL) DE LA ABUNDANCIA POR AÑOS COMBINADOS PARA EL PERÍODO 2000-2003.

FiguRA II-44.- LOLIGO PLEI/LOLIGO PEALEI. DistRIBUCIÓN ESTACIONAL (TRIMESTRAL) POR ESTRATOS DE PROFUNDIDAD POR AÑO.

FIGURA II-45.- ESTACIONES SELECCIONADAS PARA LAS ESTIMACIONES DE BIOMASA POR EL MÉTODO DE ÁREA BARRIDA SOBRE LA PNPP.

FigURA II-46.- DISTRIBUCIÓN PORCENTUAL DE LA BIOMASA (KG/KM²) DE LAS ESPECIES SELECCIONADAS DURANTE LA CAMPAÑA DE LA EMBARCACIÓN JANNADOMARI.

FIGURA III-1.- ESTACIONES DE MUESTREO PARA ESTIMACIONES DE BIOMASA POR ÁREA BARRIDA EN EL NORTE DEL GP.

FIGURA III-2.- RESULTADO DEL LA PRUEBA LSD DE PROMEDIOS TRANSFORMADOS DE CAPTURA/LANCE POR ESTACIONES DE MUESTREO (SE TRANSFORMÓ LA BIOMASA A LOGX(PESO+1).

FIGURA III-3.- DISPERSIÓN Y DISTRIBUCIÓN DE TALLAS DE PECES MENORES DE 500 MM, CAPTURADOS DURANTE LA PRIMERA (A, B) Y SEGUNDA (C,D) CAMPAÑA EN LA COSTA NORTE DEL GP.

FIGURA III-4.- DisTRIBUCIÓN DE LA BIOMASA TOTAL (KG/KM² $)$ EN EL ESTRATO COSTERO (0-15 M) AL NORTE DEL

GP EN MARZO 2005 
FIGURA III-5.- DISTRIBUCIÓN DE LA BIOMASA TOTAL (KG/KM²) EN EL ESTRATO COSTERO (0-15 M) AL NORTE DEL GP EN SEPTIEMBRE 2005

FIGURA III-6.-.- NÚMERO DE ESPECIES POR ORDEN CAPTURADAS CON RED DE ARRASTRE ARTESANAL TIPO 'CHICA' EN LAS CAMPAÑAS DE ÁREA BARRIDO AL NORTE DEL GP: MARZO 2005 (ROJO), SEPTIEMBRE 2005 (AZUL).

FIGURA III-7.- NÚMERO DE ESPECIES POR FAMILIA CAPTURADA CON RED DE ARRASTRE ARTESANAL TIPO 'CHICA'

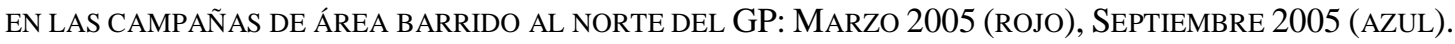

FIGURA III-8.- DISTRIBUCIÓN PORCENTUAL DE LAS ESPECIES MÁS ABUNDANTES CAPTURADAS MEDIANTE RED DE ARRASTRE ARTESANAL TIPO ‘CHICA’ EN LAS CAMPAÑAS DE ÁREA B ARRIDO AL NORTE DEL GP.

FIGURA III-9.-NÚMERO DE ESPECIES DE PECES Y ORGANISMOS POR LOCALIDAD RECOLECTADAS AL NORTE DEL GP DURANTE LAS CAMPAÑAS DE ÁREA BARRIDO: MARZO 2005 (BARRAS ROJAS), SEPTIEMBRE 2005 (BARRAS AZULES).

FIGURA III-10.-. DISTRIBUCIÓN DE TALLAS DE L. SYNAGRIS DURANTE LAS CAMPAÑAS DE ÁREA BARRIDA EN EL NORTE DEL GP (MARZO 2005, BARRAS ROJAS; SEPTIEMBRE 2005, BARRAS GRIES).

FIGURA III-11.- DisTRIBUCIÓN DE TALLAS DE $D$. RHOMBEUS DURANTE LAS CAMPAÑAS DE ÁREA BARRIDA EN EL NORTE DEL GP (MARZO 2005, BARRAS ROJAS; SEPTIEMBRE 2005, BARRAS GRIES).

FIGURA III-12.- DiSTRIBUCIÓN DE TALLAS DE E. GULA DURANTE LAS CAMPAÑAS DE ÁREA BARRIDA EN EL NORTE DEL GP (MARZO 2005, BARRAS ROJAS; SEPTIEMBRE 2005, BARRAS GRIES).

FIGURA III-13.- DiSTRIBUCIÓN DE TALLAS DE E. ARGENTEUS DURANTE LAS CAMPAÑAS DE ÁREA BARRIDA EN EL NORTE DEL GP (MARZO 2005, BARRAS ROJAS; SEPTIEMBRE 2005, BARRAS GRIES).

FIGURA III-14.-. DISTRIBUCIÓN DE TALLAS DE P.HARROWERI DURANTE LAS CAMPAÑAS DE ÁREA BARRIDA EN EL NORTE DEL GP (MARZO 2005, BARRAS ROJAS; SEPTIEMBRE 2005, BARRAS GRIES).

FIGURA III-15.-. DISTRIBUCIÓN DE TALLAS DE O. MUCRONATUS DURANTE LA CAMPAÑA DE ÁREA BARRIDA EN EL NORTE DEL GP EN MARZO 2005.

FIGURA III-16.- DisTRIBUCIÓN DE TALLAS DE S.AURITA DURANTE LA CAMPAÑA DE ÁREA BARRIDA EN EL NORTE DEL GP EN SEPTIEMBRE 2005.

FigURA III-17.-. DistRIBUCIÓN DE TALlAS DE C. PSITTACUS DURANTE LAS CAMPAÑAS DE ÁREA BARRIDA EN EL NORTE DEL GP (MARZO 2005, BARRAS ROJAS; SEPTIEMBRE 2005, BARRAS GRIES) ...................................186

FIGURA III-18.- DISTRIBUCIÓN DE TALLAS DE $C$. SPIXII DURANTE LAS CAMPAÑAS DE ÁREA BARRIDA EN EL NORTE DEL GP (MARZO 2005, BARRAS ROJAS; SEPTIEMBRE 2005, BARRAS GRIES).

FIGURA III-19.- DiSTRIBUCIÓN DE TALLAS DE $H$. PASANY DURANTE LAS CAMPAÑAS DE ÁREA BARRIDA EN EL NORTE DEL GP (MARZO 2005, BARRAS ROJAS; SEPTIEMBRE 2005, BARRAS GRIES).

FigURA III-20.-. DISTRIBUCIÓN DE TALLAS DE H. HERZBERGII DURANTE LA CAMPAÑA DE ÁREA BARRIDA EN EL NORTE DEL GP EN MARZO 2005.

FIGURA III-21.-. DISTRIBUCIÓN DE TALLAS DE S. RASTRIFER DURANTE LAS CAMPAÑAS DE ÁREA BARRIDA EN EL NORTE DEL GP (MARZO 2005, BARRAS ROJAS; SEPTIEMBRE 2005, BARRAS GRIES). 
FIGURA III-22.-. DiSTRIBUCIÓN DE TALLAS DE S. VOMER DURANTE LA CAMPAÑA DE ÁREA BARRIDA EN EL NORTE DEL GP EN MARZO 2005

FIGURA III-23.- DiSTRIBUCIÓN DE TALLAS DE LAS ESPECIES DE INVERTEBRADOS MÁS IMPORTANTES CAPTURADAS CON RED DE ARRASTRE ARTESANAL TIPO ‘CHICA’ EN LA PRIMERA CAMPAÑA AL NORTE DEL GOLFO DE PARIA.

FiguRA III-24.- DiSTRIBUCIÓN DE TALLAS DE LAS ESPECIES DE INVERTEBRADOS MÁS IMPORTANTES CAPTURADAS CON RED DE ARRASTRE ARTESANAL TIPO 'CHICA' EN LA SEGUNDA CAMPAÑA AL NORTE DEL GOLFO DE PARIA.

FIGURA IV-1.- DistribUCIÓN ESPACIAL DE LOS BANCOS DE MOLUSCOS IDENTIFICADOS DURANTE LAS CAMPAÑAS DEL PMS.

FIGURA IV-2.- DiSTRIBUCIÓN DE TALLAS (LONGITUD MÁXIMA) DE LAS DIFERENTES ESPECIES EN LOS BANCOS MÁS

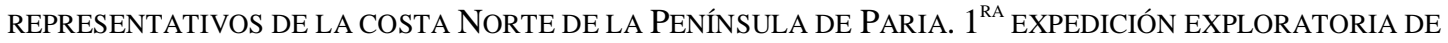
LBAPMS

FIGURA IV-3.- DiSTRIBUCIÓN DE TALLAS (LONGITUD MÁXIMA) DE LAS DIFERENTES ESPECIES EN LOS BANCOS MAS REPRESENTATIVOS DE LA COSTA SUR DE LA PENÍNSUla DE PARIA. $1^{\text {Ra }}$ EXPEDICIÓN EXPLORATORIA DE LBAPMS 232

FIGURA IV-4.- DiSTRIBUCIÓN DE TALLAS (LONGITUD MÁXIMA) DE LAS DIFERENTES ESPECIES EN LOS BANCOS MÁS REPRESENTATIVOS DE LA COSTA NORTE DE LA PENÍNSUla DE PARIA.

FIGURA IV-5.- DiSTRIBUCIÓN DE TALLAS (LONGITUD MÁXIMA) DE LAS DIFERENTES ESPECIES EN LOS BANCOS MÁS REPRESENTATIVOS DE LA COSTA SUR DE LA PENÍNSUla DE PARIA. 


\section{INDICE DE FOTOS}

Pág.

FOTO III-1.- RED 'CHICA’ UTILIZADA EN LAS CAMPAÑAS PARA ESTIMACIONES DE BIOMASA POR ÁREA BARRIDA AL NORTE DEL GP 145

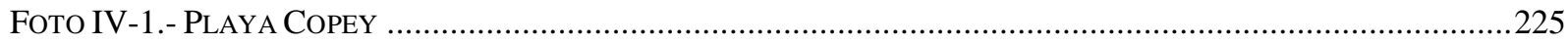

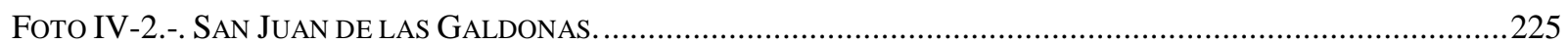

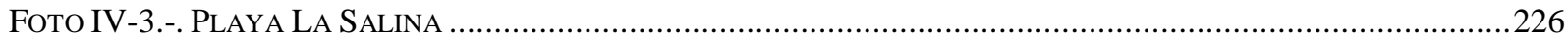

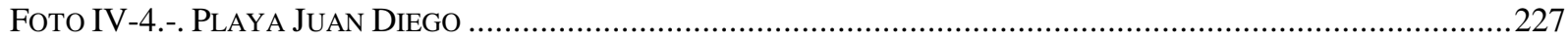




\section{I.- INTRODUCCIÓN}

La Organización de las Naciones Unidas para la Alimentación y la Agricultura (FAO), indica que los datos de la producción pesquera venezolana alcanzaron la cifra de 524.000 toneladas en el año 2003, lo cual representó para ese año alrededor del $0,6 \%$ de la producción mundial de la pesca. Si bien a nivel mundial la contribución nacional es relativamente modesta, nuestro país se presenta como un importante productor pesquero en el ámbito regional, puesto que las capturas venezolanas en el 2003 representaron alrededor del 20\% del total correspondiente a la región norte de Suramérica, Mar Caribe y Golfo de México.

Los rubros que más contribuyeron a la producción nacional en el 2003 fueron el atún aleta amarilla, capturado principalmente por la flota industrial de cerco en el Pacífico Oriental con un total de alrededor de 90.000 toneladas, la sardina capturada en la región nororiental (área de influencia directa del PMS), por la flota artesanal de chinchorros y cercos, con un total de aproximadamente 142.000 toneladas y la pesca de arrastre artesanal de pepitona en el nororiente del país con un total de alrededor de 46.000 toneladas (área de influencia indirecta del PMS). Estas tres especies representaron alrededor del $53 \%$ del total de la producción nacional reportado en 2003. A nivel de la economía nacional la contribución del sector pesquero es relativamente modesta, puesto que representa alrededor del 0,5\% del Producto Interno Bruto (PIB). Sin embargo, en algunos estados del país como Sucre, Delta Amacuro, Nueva Esparta y Falcón representa un componente fundamental de la economía de esas regiones y contribuye significativamente en los diferentes sectores económicos a la generación de empleos y al valor agregado de la producción.

Por otra parte, el sector pesquero satisface los requerimientos del mercado nacional y genera excedentes para la exportación. En años recientes la exportaciones venezolanas han venido disminuyendo desde un máximo de alrededor de 153 millones de dólares de EEUU en el año 2000 hasta un mínimo de aproximadamente 66 millones de dólares de EEUU en el año 2003. Los rubros más importantes en las exportaciones venezolanas de productos pesqueros en el último año mencionado fueron los camarones congelados que representaron el $53 \%$ del 
valor de las exportaciones, las sardinas congeladas que alcanzaron el 15\% del valor exportado y los cangrejos (jaibas) que representaron el $11 \%$ del total del valor de las exportaciones en el año 2003. De estas actividades exportadoras, la sardina congelada es la de desarrollo más reciente, ya que era prácticamente inexistente a principios de la década de 1990.

En nuestro país la pesca artesanal juega un papel de primer orden en la producción de productos pesqueros tanto frescos como procesados. Se estima que más del $70 \%$ de la producción pesquera nacional marítima se desembarca en la región nororiental del país, especialmente en los estados Sucre y Nueva Esparta. Por otro lado, en esta región tiene particular relevancia la pesca artesanal y se estima que alrededor del $80 \%$ de la producción pesquera marítima artesanal proviene de la región nororiental.

La plataforma continental de la región nororiental de Venezuela se caracteriza por su elevada productividad biológica. Esta productividad está estrechamente asociada a la presencia de afloramientos ("upwelling") costeros de aguas frías y ricas en nutrientes inducidos por el régimen de vientos predominantes. En efecto, los vientos Alisios que soplan del este-noreste desde noviembre hasta mayo desplazan las aguas superficiales, las cuales son reemplazadas por aguas sub-superficiales frías y ricas en nutrientes, lo cual desencadena el desarrollo de una abundante y diversa trama trófica. Por otro lado, durante el resto del año cuando disminuye la predominancia de los vientos Alisios, las fuertes precipitaciones inducen la crecida de los ríos de la región, especialmente el Río Orinoco, lo cual constituye una fuente adicional de nutrientes que se incorporan al medio marino (Aparicio, 2003; Varela et al., 2003).

Esta elevada productividad y la extensión de la plataforma continental determinan que el área mencionada sea una de las regiones más productivas del Mar Caribe y el hábitat de importantes recursos pesqueros que han sido aprovechados por el hombre desde tiempos precolombinos (Méndez-Arocha, 1963; Suárez y Bethencourt, 1994). En la actualidad la región nororiental contribuye con 
más del $70 \%$ de la producción pesquera realizada en aguas bajo jurisdicción venezolana (Mendoza y Arocha, 1999).

Los recursos pesqueros de la región han permitido el desarrollo de diversas pesquerías artesanales e industriales que operan fundamentalmente en los alrededores de la Isla de Margarita y en el norte de la Península de Paria, así como también en el Golfo de Paria y en el margen Atlántico del Delta del Orinoco.

Los artes de pesca utilizados en las pesquerías artesanales son bastante diversos e incluyen artes de anzuelo (cordeles y palangres), artes de red (filetes de fondo y de superficie, redes de cerco, chinchorros sardineros, etc.) y nasas. Por otro lado, entre las embarcaciones predomina el peñero, pero también están presentes las llamadas piraguas (lanchas de motor central diesel con cubierta, pero sin toldilla ni cabina) y las lanchas. Estas últimas suelen dividirse en lanchas de media altura y altura, según las áreas de pesca utilizadas lo cual depende en buena medida de las dimensiones de las embarcaciones (Ginés, 1972).

Numerosas especies son explotadas por estas pesquerías artesanales. Como ya se mencionó anteriormente las de mayor volumen de producción corresponden a la sardina y a la pepitona, las cuales en su mayoría son destinadas a las industrias enlatadoras. Entre las especies de alto valor comercial se encuentran el pargo, el mero, el carite, el dorado y la langosta, las cuales son frecuentemente destinadas a los mercados externos, mientras que otras especies de menor valor tales como la catalana, el corocoro, el tajalí, el jurel y las cabañas son destinadas al mercado nacional de consumo en fresco.

Por otra parte, la pesca de arrastre industrial que opera en la región tiene sus puertos bases en Guanta, Cumaná y Güiria. El número total de barcos de arrastre es de aproximadamente 260 unidades, siendo Cumaná el puerto más importante con alrededor de 100 embarcaciones (Marcano et al., 1999).

Esta flota realiza su labor en aguas de la plataforma continental hasta aproximadamente $100 \mathrm{~m}$ de profundidad, con la mayor parte del esfuerzo concentrado en la Plataforma Norte de la Península de Paria (PNPP) y alrededores de la Isla de Margarita, así como también en el Golfo de Paria (GP) y la fachada 
Atlántica. Las especies objetivo de esta pesquería son los camarones, representados básicamente por tres especies (blanco, rosado y marrón), pero también se capturan numerosas especies de moluscos (pulpo, calamar y vieira) y peces (catalana, corocoro, roncador, curvina, curvinata, etc.).

En este informe se presenta un análisis temporal y espacial de los índices pesqueros de capturas por especies, esfuerzo de pesca y captura por unidad de esfuerzo (CPUE) como índice de abundancia relativa nominal de las principales pesquerías de la PNPP, según información disponible en las bases de datos generadas por investigadores del Instituto Nacional de Investigaciones Agrícolas (INIA). Así mismo se presenta un análisis de la biomasa demersal estimada por área barrida en el estrato costero al norte GP y de la fauna de interés comercial obtenida por el método de arrastre artesanal con información levantada en el presente estudio. También se incluye un análisis sobre la localización, extensión, y potencialidad de los bancos de moluscos bivalvos en toda el área de influencia directa del PMS.

Es preciso señalar que la cantidad y calidad de la información varía según el tipo de pesquería y las especies capturadas. Los datos son de relativa buena calidad para la pesquería industrial de arrastre, las pesquerías de media altura y la pesquería artesanal de sardina. Sin embargo, la cobertura espacio-temporal de la pesquería artesanal costanera multiespecífica se hizo en base al levantamiento de información en campo durante dos temporadas del PMS, por lo tanto, es de menor calidad debido a la dispersión de los sitios de desembarques, la diversidad de artes de pesca utilizados y a las especies capturadas. La obtención de datos de buena calidad en esta pesquería implicaría un costo elevado (que no está contemplado para este estudio) en los esquemas de muestreo.

Aun están por analizarse los resultados obtenidos de la campaña de prospección pesquera para estimar la biomasa demersal en la PNPP, dicho análisis será presentado en fecha acordada con la Gerencia PDVSA-CVP-PMS. 


\section{II.- ANALISIS DE LA ACTIVIDAD PESQUERA Y RECURSOS PESQUEROS AL NORTE DE LA PENINSULA DE PARIA}

\section{II.1 Pesquería Artesanal Costanera Multiespecífica}

La costa norte del Estado Sucre tiene un área marina costera de una alta productividad biológica que ofrece condiciones muy favorables para la pesca, las cuales son aprovechadas por los pescadores artesanales de la zona. Existen alrededor de 4.300 embarcaciones menores en el Estado Sucre, especialmente peñeros, que se dedican a la pesca artesanal, de las cuales un número pequeño se dedica a la pesca de sardina y pepitona y el resto principalmente a la pesca artesanal multiespecífica con diversos artes de pesca como el cordel, palangre y filetes (Cárdenas et al., 1991; Cárdenas, 1999). Estas embarcaciones se distribuyen a lo largo de la costa en más de un centenar de comunidades pesqueras que frecuentemente no tienen otros medios de subsistencia. La dispersión espacial de estas comunidades, el difícil acceso en muchos casos y la diversidad de especies explotadas y artes de pesca empleados han impedido que se establezca un esquema sistemático de seguimiento de estas pesquerías. Recientemente se obtuvo información sobre las actividades pesqueras de las comunidades del Estado Sucre que permiten tener una visión general de las pesquerías que operan en el área del PMS (Mendoza y Arocha, 1999, 2004), y que sirve como base para reducir la falta de información y focalizar la atención en áreas y usos específicos de la actividad pesquera a propósito de la exploración y explotación de gas y petróleo en el PMS. En tal sentido, se seleccionaron comunidades importantes y con historia pesquera en el área del PMS con el propósito de describir la actividad pesquera y determinar la distribución espacio-temporal del esfuerzo de pesca y las capturas de las especies pelágicas y demersales explotadas por la pesca artesanal costanera de las comunidades pesqueras en el área del PMS.

Las comunidades para el estudio fueron seleccionadas previo análisis del catastro pesquero lo que permitió determinar la importancia de las mismas para la región. Se consideró el número de embarcaciones, población y tradición pesquera. 
Las comunidades seleccionadas fueron Carúpano, Río Caribe, Guacuco, Guarataro, Saucedo y Guatapanare. El plan de monitoreo aplicado se fundamentó en encuestas y entrevistas directas al pescador e inspecciones en la comunidad; método que facilitó y brindó la oportunidad de establecer un dialogo fluido y familiar con el pescador, lo cual permitió que el mismo actuara sin presiones y ofreciera, de manera espontánea y en lenguaje sencillo, la información solicitada. A través de mapas sencillos, insertos en las encuestas y mediante lenguaje coloquial, con algunas orientaciones al pescador, se pudo conocer las áreas de distribución del esfuerzo de pesca, las especies capturadas y los meses de mayor y menor abundancia. De igual forma la información suministrada por los pescadores permitió conocer las características de las embarcaciones (eslora, manga, número y potencia de motores, así como el número de pescadores, las artes de pesca y sus características). Adicionalmente se obtuvo información social y económica de las comunidades pesqueras involucradas.

\section{II.1.1 Caracterización de las comunidades pesqueras al norte del Estado Sucre}

En términos generales se realizaron 30 encuestas de 'Inspección Pesquera' y 95 encuestas de 'Diagnostico Pesquero', las cuales se distribuyen tal como se expresa en la Tabla II-1.

Tabla II-1.- Número y tipo de encuestas a comunidades pesqueras seleccionadas para el estudio.

\begin{tabular}{|c|c|c|}
\hline Comunidad Pesquera & Inspección Pesquera & Diagnóstico Pesquero \\
\hline Carúpano & 5 & 15 \\
Río Caribe & 5 & 15 \\
Guacuco & 5 & 15 \\
Guarataro & 5 & 15 \\
Saucedo & 5 & 19 \\
Guatapanare & 5 & 16 \\
TOTAL & $\mathbf{3 0}$ & $\mathbf{9 5}$ \\
\hline
\end{tabular}




\section{II.1.1.1 SAUCEDO}

$\underline{\text { Características de la flota }}$

En los últimos 20 años la flota artesanal de Saucedo se ha mantenido relativamente estable con un número de embarcaciones que ha variado entre 40 y 50 unidades de tipo peñero (Cárdenas, 1999). En el presente estudio se observaron un total de 40 embarcaciones de las cuales 35 se encontraban operativas. Esto representa alrededor de 105 puestos de trabajo en el sector primario de la pesca en esta comunidad. Las embarcaciones que conforman la flota de Saucedo se caracterizan por presentar un tamaño (eslora) que las ubica entre los 5 - $11 \mathrm{~m}$, con un promedio de 7,48 $\mathrm{m}$ y un promedio de $1,95 \mathrm{~m}$ de manga. En su mayoría, las embarcaciones operan con 3 pescadores, propulsadas por motores fuera de borda (principalmente de marca Yamaha) con una potencia que varía entre 40 a $75 \mathrm{HP}$, y que utilizan un motor por embarcación (Tabla II-2). Estas embarcaciones operan alrededor de 10 horas/día en faenas diarias por la orilla, alejándose pocas millas (24) de su comunidad. Realizan sus labores 6 días a la semana.

Tabla II-2.- Características de la flota de Saucedo

\begin{tabular}{|l|c|c|c|c|c|c|}
\hline & Mín & Máx & Promedio & $\mathbf{N}^{0}$ Total & Operativas & $\mathbf{N}^{0}$ del Anzuelo \\
\hline Eslora(m) & 5 & 11 & 7,48 & - & - & - \\
Manga & 1,6 & 2,8 & 1,95 & - & - & - \\
Potencia Motor (HP) & 40 & 75 & 42 & - & - & - \\
No de Pescadores/Embarc. $^{\circ}$ & 3 & 3 & 3 & - & - & - \\
Embarcaciones & - & - & - & 40 & 35 & - \\
Red Filete & - & - & - & 35 & - & 5,6 \\
Cordel & - & - & - & 60 & - & \\
& & & & & & \\
\hline
\end{tabular}

\section{Artes de Pesca}

La flota artesanal costanera de Saucedo utiliza como arte principal el filete superficial. Entre las que utilizan ese tipo de arte se cuentan 25 embarcaciones. En segundo término, están 10 embarcaciones que utilizan el filete fondero. En líneas generales, los filetes son de 300 a $500 \mathrm{~m}$ de largo, tienen una altura de 10 a $12 \mathrm{~m}$, y la abertura de malla es de $4 \mathrm{~cm}$. Otro arte utilizado es el cordel, que es utilizado para pescar a la viva con anzuelos del № 5 y 6; aunque este arte es utilizado en un número reducido de embarcaciones (3 a 5 ). 


\section{$\underline{\text { Áreas de Pesca }}$}

La flota artesanal costanera de Saucedo, por lo general realiza su actividad pesquera principalmente en las áreas costeras, alejándose pocas millas (2 a 4) de la comunidad, pero también opera por la costa norte del Estado Sucre entre Saucedo y el Morro de Puerto Santo (Figura II-1); los lugares de referencia que mencionan los pescadores cuando pescan fuera del área costera, están en los alrededores de Margarita, Puerto la Cruz y Mochima.

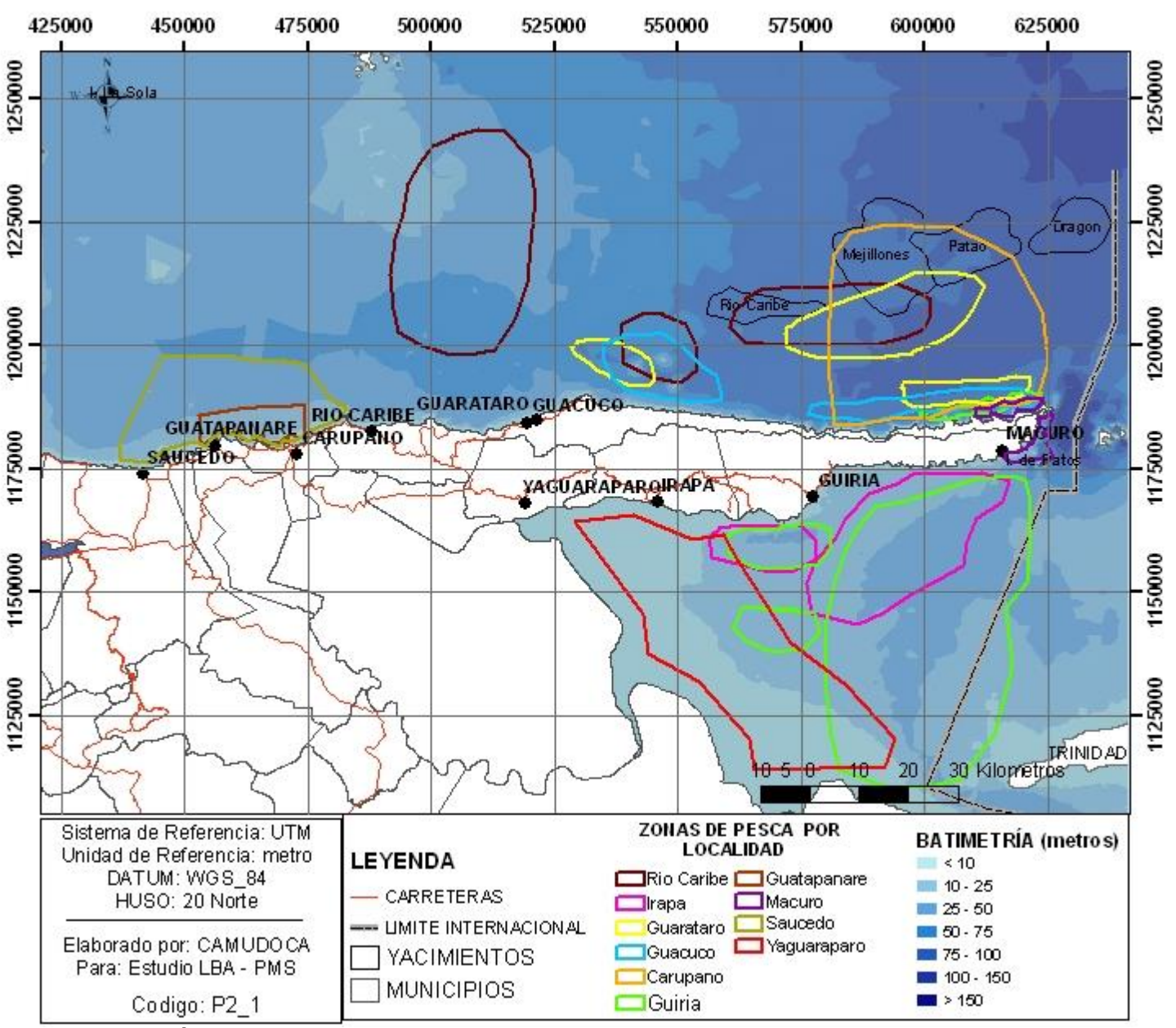

Figura II-1.- Áreas de pesca por comunidad pesquera de las flotas artesanales costaneras multiespecificas. 


\section{Composición de la captura}

El análisis de la información obtenida de los pescadores permite señalar que las capturas de la flota artesanal de Saucedo están principalmente representadas por unas 9 familias de peces, 10 géneros y 6 especies identificadas (Tabla II-3). En base a la información suministrada, las especies de la Tabla II-3 son las de mayor interés comercial de las capturas desembarcadas por la flota.

Tabla II-3.- Principales especies capturadas por la flota artesanal de Saucedo, según encuestas realizadas a pescadores artesanales

\begin{tabular}{|c|c|c|}
\hline FAMILIA & NOMBRE COMUN & NOMBRE CIENTIFICO \\
\hline SCOMBRIDAE & Carite Lucio & Scomberomorus cavalla \\
& Cabaña blanca & \\
CENTROPOMIDAE & Rábalo & \\
RACHYCENTRIDAE & Bacallao & Centropomus $s p$. \\
RAJIDAE & Raya & Rachycentron canadus \\
ARIIDAE & Raja sp. \\
MUGILIDAE & Lisa & Arius sp. \\
HAEMULIDAE & Pez Burro & Mugil curema \\
CARCHARHINIDAE & Cazón & Anisotremus surinamensis \\
POMATOMIDAE & Anchoaprionodon sp. \\
& & Pomatomus saltator \\
\hline
\end{tabular}

\section{Distribución temporal de la abundancia de los recursos pesqueros}

Temporada Alta

La información suministrada permite inferir sobre los meses de mayores capturas para la flota. Al respecto, los pescadores entrevistados señalan un período claro de abundancia alta comprendido entre mayo y septiembre. Se observa además, que la abundancia promedio para el período alto puede llegar a superar los 135,0 $\mathrm{kg} /$ día por embarcación (Tabla II-4). En la misma tabla se muestra también la composición de las capturas por especie, los valores de abundancia máxima señalados por los pescadores ( $\mathrm{kg} / \mathrm{día}$ ) y el valor porcentual para la temporada de pesca. En este sentido se señala que las especies más importantes fueron el caritelucio con valores de hasta $325 \mathrm{~kg} /$ día ( 24\%), la anchoa con $315 \mathrm{~kg} / \mathrm{día}(\sim 23 \%)$, la cabaña-blanca con 295 kg/día ( 22\%) y el cazón con $225 \mathrm{~kg} /$ día ( 17\%); que en su conjunto representaron el $\sim 86 \%$ de los valores de abundancia ( $\mathrm{kg} / \mathrm{día}$ ) de la flota en 
el período de máximas capturas. La distribución espacial de la abundancia relativa del total de los recursos desembarcados durante la temporada alta se presenta en la Figura II-2.

Tabla II-4.- Comportamiento por temporada alta y baja de la abundancia relativa (kg/día) de las especies capturadas por la flota de Saucedo.

\begin{tabular}{|c|c|c|c|c|c|c|}
\hline ESPECIES & CPUE T. Alta & $\%$ & Meses T. Alta & CPUE T. Baja & $\%$ & Meses T. Baja \\
\hline Carite & 325 & 23,99 & MAY-SEP & 13 & 8,33 & OCT-ABR \\
Anchoa & 315 & 23,25 & MAY-SEP & 16 & 10,26 & OCT-ABR \\
Cabaña & 295 & 21,77 & MAY-SEP & 8 & 5,13 & OCT-ABR \\
Róbalo & 20 & 1,48 & MAY-SEP & 15 & 9,62 & OCT-ABR \\
Bacallao & 45 & 3,32 & MAY-SEP & 17 & 10,90 & OCT-ABR \\
Raya & 65 & 4,80 & MAY-SEP & 40 & 25,64 & OCT-ABR \\
Bagre & 45 & 3,32 & MAY-SEP & 17 & 10,90 & OCT-ABR \\
Lisa & 10 & 0,74 & MAY-SEP & 5 & 3,21 & OCT-ABR \\
Pez Burro & 10 & 0,74 & MAY-SEP & 5 & 3,21 & OCT-ABR \\
Cazón & 225 & 16,61 & MAY-SEP & 20 & 12,82 & OCT-ABR \\
Promedio & $\mathbf{1 3 5 , 5 0}$ & & & & & \\
Pan & & & & & & \\
\hline
\end{tabular}




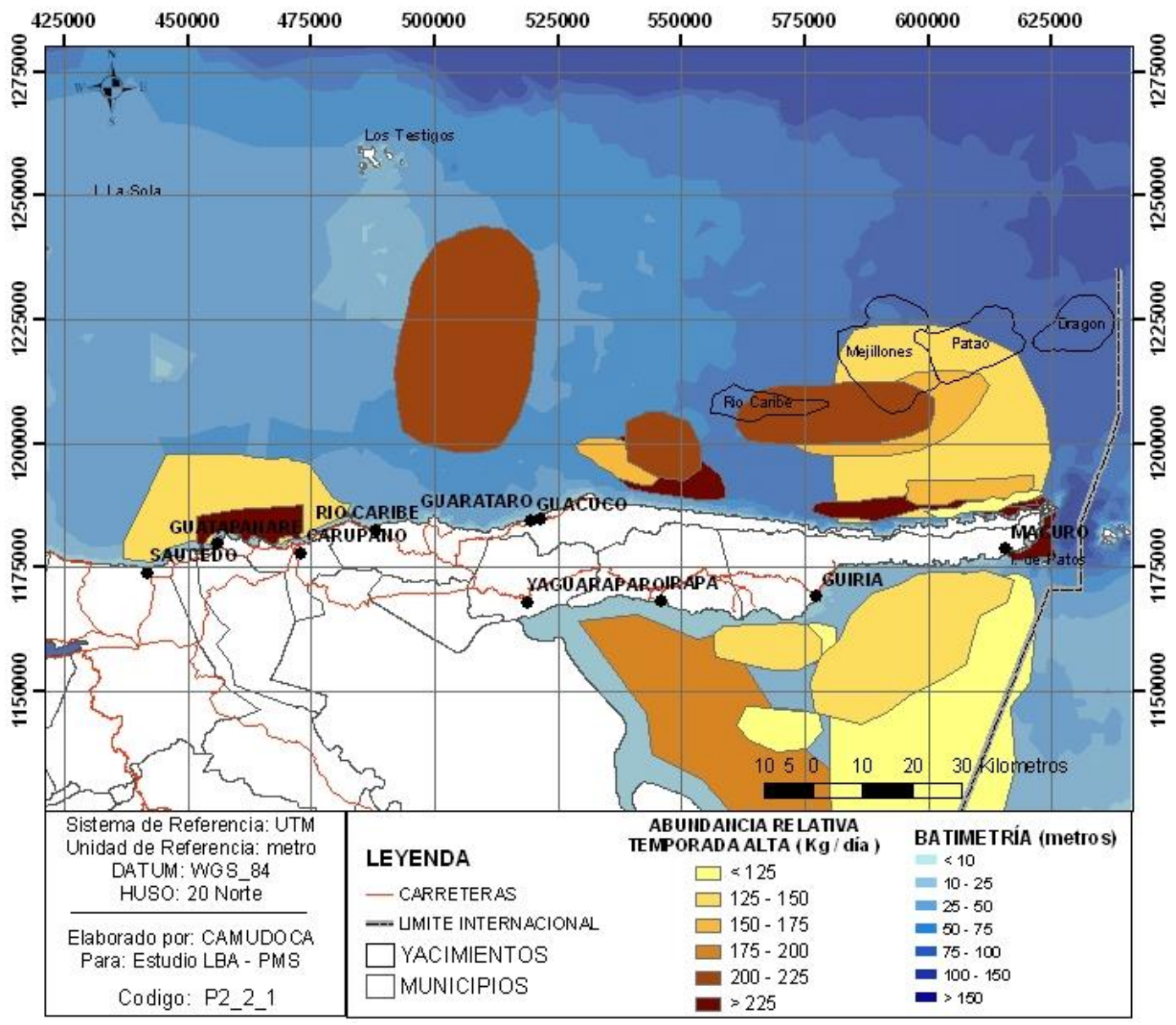

Figura II-2.- Áreas de pesca de las flotas artesanales multiespecificas y abundancia relativa del promedio del total de rubros que capturan las flotas durante la temporada alta.

\section{Temporada Baja}

Respecto a la temporada baja de producción, la Tabla II-4 permite señalar que la misma se ubica en el período de octubre a abril; observándose que en esta época la abundancia promedio del total se ubicaría alrededor de $15 \mathrm{~kg} /$ día. La composición de las capturas por especie y sus valores de abundancia relativa promedio y porcentual indican que la raya o chucho con $40 \mathrm{~kg} /$ día (25\%), cazón con $20 \mathrm{~kg} / \mathrm{día}$ ( 13\%), bagre con $17 \mathrm{~kg} /$ día (10\%), el bacallao/cobia con $17 \mathrm{~kg} / \mathrm{día}(10 \%)$, y la anchoa con $16 \mathrm{~kg} / \mathrm{día}(10 \%)$ constituyeron las especies de mayor importancia. Estas ocuparon el $68 \%$ de los niveles de abundancia relativa de la flota en la temporada 
baja. La distribución espacial de la abundancia relativa del total de los recursos desembarcados durante la temporada baja se presenta en la Figura II-3.

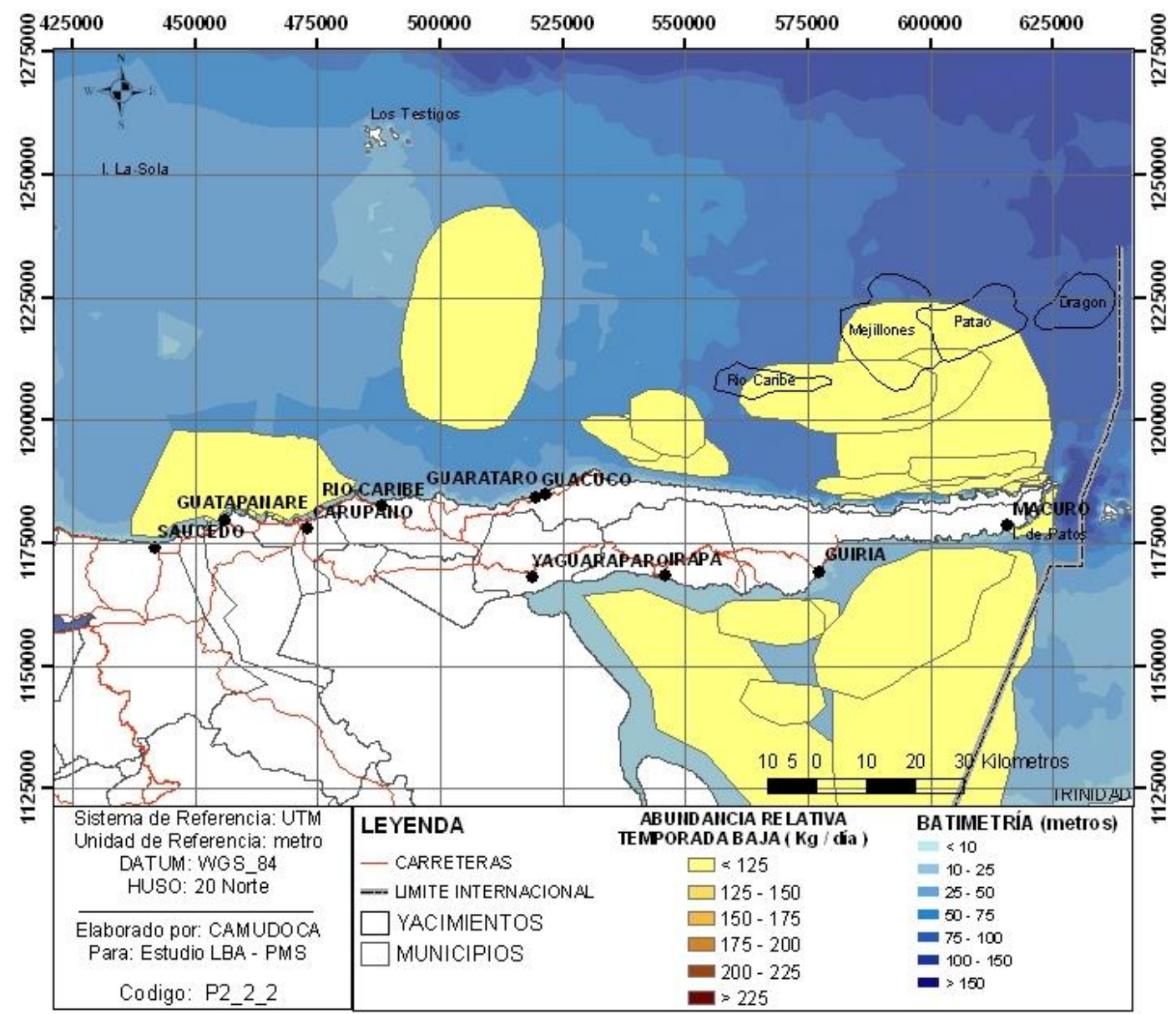

Figura II-3.- Áreas de pesca de las flotas artesanales multiespecificas y abundancia relativa del total de rubros que capturan las flotas durante la temporada baja.

\section{Aspectos socioeconómicos}

Por lo general, el nivel de instrucción que caracteriza a los pescadores artesanales de Saucedo y su núcleo familiar, se ubica en los niveles de primaria completa e incompleta con un $26 \%$ y $34 \%$, respectivamente. Mientras que los niveles de secundaria completa y secundaria incompleta ocuparon el $24 \%$ y $8 \%$, respectivamente. Un porcentaje muy bajo correspondió a los niveles de educación técnica superior universitaria y universitaria incompleta. Estos valores no muestran 
marcadas diferencias con los señalados para la misma comunidad en un estudio (Convenio UDO-LAGOVEN) mucho más exhaustivo realizado a mediados de 1990 (Anónimo, 1994).

La actividad pesquera que realiza la flota, por lo general, se caracteriza por campañas diarias de pesca con un consumo de combustible diario que en promedio está en el orden de los $240 \mathrm{lt}$, a razón de $70 \mathrm{Bs} / \mathrm{tt}$. Mientras que el consumo de aceite es de alrededor de $8 \mathrm{It} /$ día, a razón de $5.000 \mathrm{Bs} / \mathrm{t}$, lo cual implica un costo medio por salida de alrededor de Bs. 40.000 diarios. Entre los gastos importantes que realizan los patrones o dueños de embarcaciones, está el mantenimiento semestral que le hacen a los motores, que puede variar entre Bs. 500.000 y 1.200.000. De igual manera el gasto anual de mantenimiento que se le hace a las embarcaciones se ubica entre Bs. 700.000 y 1.800 .000 . Otros gastos de mantenimiento de la flota son los realizados para la compra de insumos de pesca por pérdidas o daño de los mismos, como por ejemplo la compra de hilo de red, que supera los Bs. 100.000/mes y de anzuelos alcanzando Bs. $35.000 /$ mes. Estos insumos son comprados en Carúpano o en la propia comunidad de Saucedo. Considerando los valores mencionados se puede estimar que los costos operativos mensuales por embarcación se ubicarían alrededor de Bs 1.700.000.

En lo que concierne a los beneficios económicos de la actividad pesquera, se observó que el mayor porcentaje (43\%) de los pescadores entrevistados reciben ingresos entre 360.000 y $540.000 \mathrm{Bs} / \mathrm{mes}$, mientras que un $29 \%$ se ubican con ingresos entre 540.000 y $720.000 \mathrm{Bs} / \mathrm{mes}$. Un $21 \%$ recibe entre 180.000 y 360.000 $\mathrm{Bs} / \mathrm{mes}$, y un $7 \%$ manifestó recibir ingresos mensuales superiores a $720.000 \mathrm{Bs} / \mathrm{mes}$. Utilizando el valor del salario mínimo como referencia, estos niveles de ingresos representan una mejoría con respecto a los valores estimados en 1994 cuando aproximadamente el $60 \%$ de los entrevistados declaró ingresos familiares inferiores al salario mínimo (Anónimo, 1994).

Por otro lado, existe poca infraestructura de apoyo a la producción (solamente rancherías y carpinterías de ribera) y los combustibles y lubricantes se obtienen de una estación de servicio vecina. Entre los aspectos de importancia que afectan a los 
pescadores artesanales de Saucedo están la inseguridad (piratería marina), la deficiencia en los servicios de agua potable y la ausencia de un muelle pesquero con los servicios conexos (surtidores de combustible, por ejemplo). Como aspectos positivos de la comunidad los pescadores señalan las vías de acceso y la tranquilidad de vivir en Saucedo.

\section{II.1.1.2 GuATAPANARE}

Características de la flota

En años anteriores el número de embarcaciones en esta comunidad ha fluctuado entre 60 y 70 embarcaciones con una tendencia a la disminución en el período reciente (Cárdenas, 1999). Actualmente se estima que en esta comunidad operan 42 embarcaciones de un total de 50 contabilizadas. Se estima que el número total de empleos directos en el proceso de captura se ubicaría alrededor de 160 pescadores. Las embarcaciones que conforman la flota de Guatapanare se caracterizan por presentar un tamaño de 6 - 10,3 m de eslora y un rango de manga entre 1,45-2,40 m. Cuando la actividad se realiza con trenes liseros y trenes de ahorque, las embarcaciones faenan con 4 pescadores; pero cuando la actividad se efectúa con trenes de argolla, la actividad requiere un número mayor de pescadores ( 25). Las embarcaciones son propulsadas por motores fuera de borda con una potencia mínima de 40 HP y máxima de 125 HP (Tabla II-5). Estas embarcaciones operan entre 6 y 10 horas/día en faenas diarias, por lo general 5 días a la semana.

Tabla II-5.- Características de la flota de Guatapanare.

\begin{tabular}{|l|c|c|c|c|c|c|}
\hline & Min & Max & Promedio & $\mathbf{N}^{\circ}$ Total & Operativas & Longitud Red (m) \\
\hline Eslora(m) & 6 & 11 & 7,87 & - & - & - \\
Manga & 1,45 & 2,40 & 1,99 & - & - & - \\
Potencia Motor (hp) & 40 & 125 & 61 & 50 & - & - \\
№ de Pescadores & 4 & 25 & - & - & - & - \\
Embarcaciones & - & - & - & 50 & 42 & - \\
Tren lisero & - & - & - & 8 & 8 & $360-1620$ \\
Tren de ahorque & - & - & - & 8 & 10 & $360-500$ \\
Tren de argolla & - & - & - & 2 & 16 & 360 \\
Buceo & - & - & - & 8 & 8 & - \\
\hline
\end{tabular}

\section{$\underline{\text { Artes de Pesca }}$}


Se utiliza como arte de pesca, el tren lisero cuya longitud puede llegar hasta 30 piezas de $54 \mathrm{~m}$ c/u, una altura de 12 a $15 \mathrm{~m}$ y una abertura de malla de 2 a $4 \mathrm{~cm}$. También se utiliza el tren de ahorque, que por lo general tiene una longitud de 9 paños, cada uno de $54 \mathrm{~m}$, una altura de 12 a $15 \mathrm{~m}$ y un apertura de malla de 4 a 6 $\mathrm{cm}$. Es importante mencionar que existe la utilización del tren de argolla o "maquina sardinera", el cual está compuesto por una red de cerco o argolla. El arte tiene entre $1.200-1.500 \mathrm{~kg}$ (aproximado) de red, de $1 \times 1 \mathrm{~cm}$ de diámetro de malla, $360 \mathrm{~m}$ de longitud y $50 \mathrm{~m}$ de altura. El arte opera normalmente a profundidades mayores de 50 $\mathrm{m}$, donde la captura de sardina debe ser extraída y colocada en botes una vez calado el arte. A profundidades menores, cercanas a la costa, se usa el arte denominado mandinga, el cual es parecido al tren de argolla, pero que a diferencia de este último, los plomos son reforzados con pesas de concreto (peones) para fijar la red al fondo y evitar el escape de las capturas. Con este arte, a diferencia del tren de argolla, la captura de sardina puede permanecer hasta 4 días en el encierre. En una "maquina sardinera" pueden laborar hasta 25 personas.

La pesca por buceo es otro método de pesca empleado por algunos pescadores de Guatapanare. Este método se utiliza para la extracción de mejillones, actividad que realizan durante casi todo el año. Generalmente, a esta actividad se dedican alrededor de 8 embarcaciones. El mejillón extraído es destinado para su comercialización a 'mejilloneras' de la comunidad, quienes preparan encurtidos para la venta al detal.

\section{Áreas de Pesca}

La información analizada permitió inferir que la flota artesanal costanera de Guatapanare realiza mayoritariamente su actividad pesquera en áreas costeras dentro de la primera milla, pero pueden operar hasta 5 millas de la costa. El área de pesca está comprendida entre las poblaciones de Guaca y Carúpano (Figura II-1).

\section{$\underline{\text { Composición de las capturas }}$}

El análisis de la información obtenida permite señalar, que las capturas de la flota artesanal de Guatapanare están principalmente representadas por unas 4 familias de peces, 6 géneros y 5 especies identificadas, además de una especie de 
molusco (mejillón). De acuerdo a la información suministrada, del conjunto de especies que constituyen la captura desembarcada por esta flota, las especies de mayor interés comercial aparecen en la Tabla II-6.

Tabla II-6.- Principales especies capturadas por la flota artesanal de Guatapanare según encuestas realizadas a pescadores artesanales.

\begin{tabular}{|c|c|c|}
\hline FAMILIA & NOMBRE COMUN & NOMBRE CIENTIFICO \\
\hline MUGILIDAE & LISA & Mugil lisa \\
& LEBRANCHE & Mugil crema \\
ENGRAULIDAE & SARDINA & Sardinella aurita \\
SCOMBRIDAE & CABAÑA BLANCA & Sarda sarda \\
& CABANAA & Auxis $s p$. \\
POMATOMIDAE & CARITE & Scomberomorus $s p$. \\
MYTILIDAE & ANCHOA & Pomatomus saltator \\
\hline
\end{tabular}

Distribución temporal de la abundancia de los recursos pesqueros

Temporada Alta

Los pescadores entrevistados de la comunidad de Guatapanare informaron que los meses de mayor abundancia corresponden al período de enero a agosto para el caso de la lisa y el lebranche, los meses de mayo a septiembre para el caso de la sardina y los meses de marzo a septiembre para el caso de los peces pelágicos medianos (Tabla II-7). Destacando que para la sardina el período de mayo a septiembre es de gran importancia, puesto que los desembarques representan el $99 \%$ del total con valores de alrededor de $114.000 \mathrm{~kg} / \mathrm{día}$. Los resultados sobre la composición de las capturas por especie y sus valores de abundancia relativa promedio/día y porcentual durante la temporada alta de pesca, evidencian que, exceptuando la sardina, el resto de las especies apenas conforman el $1 \%$ de la abundancia relativa promedio/día de la flota. Sin embargo, no dejan de ser despreciables ya que el caso de la lisa y el lebranche las mayores abundancias corresponden a 315 y $215 \mathrm{~kg} / \mathrm{día}$, respectivamente. Mientras que para el carite, la cabaña y la anchoa, los niveles de abundancia reportados para esta temporada son del orden de $240 \mathrm{~kg} /$ día, $230 \mathrm{~kg} / \mathrm{día}$ y $170 \mathrm{~kg} /$ día, respectivamente. La abundancia relativa total de la flota para una temporada alta puede alcanzar niveles de abundancia superiores a los $115.000 \mathrm{~kg} / \mathrm{d}$ ía representado casi exclusivamente por la 
sardina. La distribución espacial de la abundancia relativa del total de los recursos desembarcados durante la temporada alta se presenta en la Figura II-2.

Tabla II-7.- Comportamiento por temporada alta y baja de la abundancia relativa ( $\mathrm{kg} / \mathrm{d}$ día) de las especies capturadas por la flota de Guatapanare.

\begin{tabular}{|c|c|c|c|c|c|c|}
\hline ESPECIES & \multicolumn{1}{c}{ CPUE T. Alta } & $\%$ & \multicolumn{1}{c|}{ Meses T. Alta } & CPUE T. Baja & $\%$ & Meses T. Baja \\
\hline LISA & 315,00 & 0,27 & ENE-AGO & 5,00 & 0,30 & SEP-DIC \\
LEBRANCHE & 215,00 & 0,19 & ENE-AGO & 3,83 & 0,23 & SEP-DIC \\
SARDINA & $114.000,00$ & 98,98 & MAY-SEP & $1.666,67$ & 98,83 & ENE-MAR \\
CARITE & 240,00 & 0,21 & MAR-SEP & 4,00 & 0,24 & OCT-FEB \\
CABAÑA & 230,00 & 0,20 & MAR-SEP & 4,25 & 0,25 & OCT-FEB \\
ANCHOA & 170,00 & 0,15 & MAR-SEP & 2,67 & 0,16 & OCT-FEB \\
& & & & & & \\
Promedio & \multirow{2}{234,0}{} & & & $\mathbf{3 , 9 5}$ & & \\
& & & & & & \\
\hline
\end{tabular}

Temporada Baja

Los meses de enero a marzo son considerados de poca abundancia de sardina por los pescadores (Tabla II-7). La composición de las capturas por especie y sus niveles de abundancia relativa promedio y porcentual para el período señalado refleja el mismo patrón que para la temporada alta. La abundancia relativa total de la flota puede alcanzar unos $1.600 \mathrm{~kg} /$ día, donde casi el 99\% de los desembarques son de sardina. La distribución espacial de la abundancia relativa del total de los recursos desembarcados durante la temporada baja se presenta en la Figura II-3.

\section{Aspectos socioeconómicos}

Los datos suministrados por los pescadores artesanales de Guatapanare evidencian, que tanto ellos como su núcleo familiar, se ubican en dos niveles de educación predominantes (primaria completa-30\% y secundaria incompleta-45\%). Estos valores indicarían un leve mejoramiento en el nivel de escolaridad al compararlos con los obtenidos hace más de 10 años en la misma comunidad (Anónimo, 1994).

Se evidenció que la actividad pesquera que realiza esta flota es diaria, operando 5 días a la semana. Las embarcaciones tienen un consumo diario de combustible que en promedio está alrededor de 60-240 It/día, a razón de $70 \mathrm{Bs} / \mathrm{tt}$, con un consumo de aceite de 2 It/día, a razón de 5.000 Bs/lt. Dependiendo de la 
intensidad de la actividad, pueden llegarse a consumos de 720 lt/día de combustible en el caso de los trenes sardineros. Entre los gastos mayores que realizan los dueños de embarcaciones, se mencionan el mantenimiento semestral que le hacen a los motores, este monto puede variar entre Bs. 300.000 y 700.000 , dependiendo del grado de desgaste del mismo. De igual manera, el gasto anual de mantenimiento que se le hace a las embarcaciones se ubica entre Bs. 500.000 y 1.000.000. En los casos particulares de grupos de pescadores que trabajan con máquinas de argolla, se mencionan gastos anuales en pintura que pueden alcanzar hasta Bs.2.000.000. En el caso de las redes, los gastos pueden puede alcanzar Bs.12.000.000 al año, y en repuestos para motores pueden alcanzar Bs. 20.000.000 por unidad de pesca. Si bien la diversidad de los artes y modalidades de pesca presentes no facilitan la estimación de los costos operativos, se puede estimar que los costos por embarcación se ubicarían alrededor de Bs. 925.000 mensuales.

En cuanto a los beneficios económicos de la actividad pesquera, la información reveló que un $66 \%$ recibe ingresos entre 180.000 y $360.000 \mathrm{Bs} / \mathrm{mes}$, un $17 \%$ recibe ingresos menores a $180.000 \mathrm{Bs} /$ mes, otro $17 \%$ indicó recibir ingresos superiores a $720.000 \mathrm{Bs} / \mathrm{mes}$. Al comparar estos valores con los observados a mediados de la década de 1990 y utilizando como referencia el salario mínimo mensual no se aprecia cambios significativos en el nivel de ingresos de los pescadores de Guatapanare (Anónimo, 1994). A pesar de los altos rendimientos obtenidos en la pesca de sardina, es probable que estos ingresos relativamente bajos reflejen el efecto de la regulación del precio de la sardina que permanece inalterado desde el año 2003 en Bs. 75/kg.

Por otra parte, en la comunidad existe cierta infraestructura de apoyo a la producción como rancherías, carpintería de ribera y taller de reparación de motores. Vale también destacar la presencia de una unidad industrial para el procesamiento de productos pesqueros (sardina, atún y pepitona), la cual capta la mayor parte de la producción local de sardina. El resto de las especies se comercializa a través de caveros transportistas, a excepción del mejillón el cual se vende localmente. Los aspectos más relevantes señalados por los pescadores que afectan la actividad 
pesquera son la ausencia de surtidores de combustible, la piratería marina y el efecto negativo de las embarcaciones de arrastre en los caladeros de pesca.

\section{II.1.1.3 CARÚPANO}

\section{Características de la flota}

La flota artesanal de Carúpano se ha ubicado en los últimos años 20 años entre 50 y 60 embarcaciones (Cárdenas, 1999). En el presente estudio se contabilizó un total de 56 embarcaciones del tipo peñero, de las cuales se estimó que solamente 30 estaban operativas. Se puede estimar que el número de empleos directos en el sector primario de la pesca artesanal se ubicaría alrededor de 120 puestos de trabajo. Las embarcaciones que conforman la flota de Carúpano se caracterizan por presentar un tamaño (eslora) que las ubica entre los 7-10 $\mathrm{m}$ y de 2,46 $\mathrm{m}$ de manga. En su mayoría, las embarcaciones operan con 4 pescadores, son propulsadas por motores fuera de borda (principalmente de marca Yamaha) con una potencia que varía entre 25 a $75 \mathrm{HP}$, pero la mayoría utilizan motores de $40 \mathrm{HP}$ ( Tabla II-8). Por lo general, se efectúan 2 campañas al mes operando unas 10 horas diarias, con una duración de 8 a 12 días.

Tabla II-8.- Características de la flota de Carúpano

\begin{tabular}{|l|c|c|c|c|c|c|}
\hline & Mín & Máx & Promedio & $\mathbf{N}^{\circ}$ Total & Operativas & $\mathbf{N}^{\circ}$ del Anzuelo \\
\hline Eslora $(\mathrm{m})$ & 7 & 10 & 8,62 & - & - & - \\
Manga & 2,05 & 2,8 & 2,47 & - & - & - \\
Potencia Motor (HP) & 25 & 75 & 40 & - & - & - \\
$\mathrm{N}^{\circ}$ de Pescadores & 3 & 4 & 4 & - & - & - \\
Embarcaciones & - & - & - & 56 & 30 & - \\
Palangre & - & - & - & - & 30 & 6,7 y 8. \\
Cordel & - & - & - & - & 96 & $5,6,7,8,11$ y 12 \\
\hline
\end{tabular}

\section{Artes de Pesca}

La flota artesanal costanera de Carúpano utiliza como artes de pesca, cordeles y palangres. El cordel constituye el principal arte, estimándose que un $80 \%$ de la flota operativa utiliza alrededor de 96 cordeles en sus faenas, mientras que un $20 \%$, utiliza palangres (1 por embarcación). Los cordeles por lo general utilizan anzuelos $N^{\circ} 5,6,7,8,11$ y 12 , mientras que los palangres pescan con anzuelos $N^{\circ}$ 6,7 y 8 . 
Áreas de Pesca

La flota artesanal costanera de Carúpano, realiza su actividad pesquera principalmente en las áreas ubicadas entre Mejillones y Uquire (Figura II-1). La pesca se realiza sobre un amplio rango de profundidades que van de los $30 \mathrm{~m}$ hasta los $100 \mathrm{~m}$ profundidad.

\section{Composición de la captura}

El análisis de la información obtenida de los pescadores permite señalar que las capturas de la flota artesanal de Carúpano están principalmente representadas por unas 10 familias de peces, 14 géneros y 10 especies identificadas (Tabla II-9). En base a la información suministrada por una muestra de 15 pescadores encuestados, las especies presentadas en la Tabla II-9 conforman el $99 \%$ de los desembarques de la flota.

Tabla II-9.-Principales especies capturadas por la flota artesanal de Carúpano, según encuestas realizadas a pescadores artesanales.

\begin{tabular}{|c|c|c|}
\hline FAMILIA & NOMBRE COMUN & NOMBRE CIENTIFICO \\
\hline POMATOMIDAE & Anchoa & Pomatomus saltator \\
CARCHARHINIDAE & Cazcharhinus sp. \\
SERRANIDAE & Mero & Rhizoprionodon porosus \\
CARANGIDAE & Cataco & Tranephelus sp. \\
PRIACANTHIDAE & Jurel & Caranx hippos \\
& Catalana & Priacanthus arenatus \\
SCIAENIDAE & Curvinata & Cynoscion sp. \\
& Roncador & Micropogonias furnieri \\
& Tonquicha & Cynoscion jamaicensis \\
LUTJANIDAE & Pargo & Lutjanus sp. \\
SPHYRAENIDAE & Cunaro & Rhomboplites aurorubens \\
HAEMULIDAE & Picua & Sphyraena sp. \\
TRICHIURIDAE & Corocoro & Orthopristis ruber \\
\hline
\end{tabular}

Distribución temporal de la abundancia de los recursos pesqueros

Temporada Alta

La información suministrada permite inferir sobre los meses de mayores capturas para la flota. Los pescadores encuestados señalan un período claro de alta abundancia comprendido entre junio-diciembre. Se observa además que la 
abundancia promedio para el período alto se ubica en 131,98 kg/día (Tabla II-10). En la misma tabla se muestra también, la composición de las capturas por especie y su abundancia relativa ( $\mathrm{kg} / \mathrm{día}$ ) y porcentual para la temporada de pesca. En este sentido, se señala que las especies más importantes fueron el tajalí con máximos de 767 kg/día (48\%), el cataco con 117 kg/día (11\%), el jurel con 100 kg/día (6\%) y el cunaro con $100 \mathrm{~kg} /$ día (6\%); que en su conjunto representaron el $71 \%$ de los valores de abundancia señalados por los pescadores para la flota. La distribución espacial de la abundancia relativa del total de los recursos desembarcados durante la temporada alta se presenta en la Figura II-2.

Tabla II-10.-Comportamiento por temporada alta y baja de la abundancia relativa ( $\mathrm{kg} / \mathrm{d}$ día) de las especies capturadas por la flota de Carúpano.

\begin{tabular}{|c|c|c|c|c|c|c|}
\hline ESPECIES & $\begin{array}{c}\text { CPUE T. } \\
\text { Alta }\end{array}$ & $\%$ & $\begin{array}{c}\text { Meses T. } \\
\text { Alta }\end{array}$ & $\begin{array}{c}\text { CPUE T. } \\
\text { Baja }\end{array}$ & $\%$ & $\begin{array}{c}\text { Meses T. } \\
\text { Baja }\end{array}$ \\
\hline Corocoro & 32,50 & 2,05 & JUN-DIC & 9,00 & 4,68 & ENE-MAY \\
Catalana & 80,91 & 5,11 & JUN-DIC & 17,55 & 9,12 & ENE-MAY \\
Anchoa & 36,43 & 2,30 & JUN-DIC & 5,86 & 3,04 & ENE-MAY \\
Cataco & 176,67 & 11,15 & JUN-DIC & 22,50 & 11,69 & ENE-MAY \\
Mero & 57,50 & 3,63 & JUN-DIC & 13,75 & 7,14 & ENE-MAY \\
Pargo & 73,13 & 4,62 & JUN-DIC & 10,00 & 5,20 & ENE-MAY \\
Curvina & 33,33 & 2,10 & JUN-DIC & 11,33 & 5,89 & ENE-MAY \\
Cazón & 91,67 & 5,79 & JUN-DIC & 14,17 & 7,36 & ENE-MAY \\
Tajalí & 766,67 & 48,41 & JUN-DIC & 43,33 & 22,51 & ENE-MAY \\
Jurel & 100,00 & 6,31 & JUN-DIC & 20,00 & 10,39 & ENE-MAY \\
Picua & 35,00 & 2,21 & JUN-DIC & 10,00 & 5,20 & ENE-MAY \\
Cunaro & 100,00 & 6,31 & JUN-DIC & 15,00 & 7,79 & ENE-MAY \\
Promdedio & $\mathbf{1 3 1 , 9 8}$ & & & $\mathbf{1 6 , 0 4}$ & & \\
\hline
\end{tabular}

Temporada Baja

Respecto a la temporada baja de producción, la Tabla II-10 permite señalar que la misma se ubica en el período enero-mayo; observándose que en esta época la abundancia promedio total puede alcanzar valores de 16,04 kg/día. La composición de las capturas por especie y sus valores de abundancia relativa promedio y porcentual indican que el tajalí con $43 \mathrm{~kg} /$ día (23\%), cataco con 23 $\mathrm{kg} /$ día (12\%), jurel con $20 \mathrm{~kg} /$ día (10\%) y la catalana con $18 \mathrm{~kg} / \mathrm{día}(9 \%)$, constituyeron las especies de mayor importancia. Estas ocuparon el 54\% de los niveles de abundancia relativa de la flota en la temporada baja. La distribución 
espacial de la abundancia relativa del total de los recursos desembarcados durante la temporada baja se presenta en la Figura II-3.

\section{Aspectos socioeconómicos}

El nivel de instrucción que caracteriza a los pescadores artesanales y su núcleo familiar se ubica en los niveles de primaria completa e incompleta. Estos valores son significativamente inferiores a los del conjunto del Municipio Bermúdez y de la ciudad de Carúpano, según los resultados obtenidos de la evaluación socioeconómica de los proyectos costa afuera.

La actividad pesquera que realiza la flota de Carúpano, por lo general, se caracteriza por campañas de 10 a 12 días de pesca ( 2 al mes), con un consumo de combustible que en promedio está entre 600 y 700 It/campaña, a razón de unos 70 Bs/lt. El consumo de aceite por campaña es de unos 10 lt A razón de Bs. 4.500/lt. El mantenimiento semestral que le hacen a los motores, puede variar entre Bs. 1.300.000 y Bs. 1.500.000. De igual manera el gasto anual de mantenimiento que se le hace a las embarcaciones se ubica entre Bs. 1.000 .000 y Bs. 1.400.000. Entre otros gastos de la flota se mencionan los de alimentos, que por lo general están entre los Bs. 200.000 - 300.000 por campaña de pesca y los del hielo (generalmente utilizan 1.000-1.200 kg/campaña por un costo promedio de Bs. 64.000). Estos valores permiten estimar de manera preliminar que los costos operativos mensuales por unidad de esta flota se ubicarían alrededor de Bs. 1.140.000.

Respecto a los beneficios económicos de la actividad pesquera, se observó que el mayor porcentaje (75\%) de los pescadores entrevistados reciben ingresos superiores a $720.000 \mathrm{Bs} / \mathrm{mes}$, mientras que un $20 \%$ se ubican entre 540.000 y $720.000 \mathrm{Bs} / \mathrm{mes}$ y un $5 \%$ recibe entre 180.000 y $360.000 \mathrm{Bs} / \mathrm{mes}$. Estos valores son superiores a los observados en otras comunidades pesqueras y probablemente estén relacionados con el beneficio derivado de realizar campañas de pesca relativamente largas y el elevado precio relativo de lagunas de las especies capturadas, tales como el pargo y el mero.

Las características de Carúpano como centro urbano ofrecen mayor apoyo en términos de infraestructura a los productores pesqueros, como por ejemplo, 
muelle, planta de hielo, ferretería marina, taller de reparación de motores y estación de combustible. Asimismo, los pescadores pueden colocar directamente sus productos a nivel de consumidor o en el mercado municipal, lo cual les permite obtener mejores precios. Entre otros aspectos de importancia socioeconómica, los pescadores artesanales de Carúpano manifestaron que la inseguridad en la zona costera (piratería marina), la interferencia con embarcaciones de arrastre y la ausencia de políticas crediticias eficientes son elementos que afectan su actividad productiva.

\section{II.1.1.4 RíO CARIBE}

Características de la flota

La evolución del número de peñeros en esta comunidad presenta una tendencia creciente en los últimos 20 años (Cárdenas, 1999), al pasar de alrededor de 60 embarcaciones en 1985 a unas 100 embarcaciones operativas en la actualidad. Se puede estimar que esta flota genera alrededor de 300 puestos de trabajo directos en el sector primario de la actividad pesquera. Las embarcaciones que conforman la flota de Río Caribe se caracterizan por presentar un tamaño de $6,5-7,0 \mathrm{~m}$ de eslora y un rango de manga entre $1,50 \mathrm{~m}$ y $1,70 \mathrm{~m}$. Generalmente, las embarcaciones faenan con 3 pescadores, propulsadas por motores fuera de borda con una potencia de $40 \mathrm{HP}$ (Tabla II-11). Las faenas de pesca son diarias, operando en promedio unas 10 horas de pesca/día durante 6 días a la semana. La tabla 5 permite señalar que la flota artesanal costanera de Río Caribe está conformada por unas 120 embarcaciones de las cuales unas 100 están operativas.

Tabla II-11.-.- Características de la flota de Río Caribe.

\begin{tabular}{|l|c|c|c|c|c|c|}
\hline & Min & Máx & Promedio & $\mathbf{N}^{\circ}$ Total & Operativas & $\mathbf{N}^{\circ}$ del Anzuelo \\
\hline Eslora $(\mathrm{m})$ & 6,5 & 7 & 6,55 & - & - & - \\
Manga & 1,5 & 1,7 & 1,6 & - & - & - \\
Potencia Motor (HP) & 40 & 40 & 40 & - & - & - \\
$\mathrm{N}^{\circ}$ de Pescadores/Emb. & 3 & 3 & 3 & - & - & - \\
Embarcaciones & - & - & - & 120 & 100 & - \\
Cordel & - & - & - & - & 300 & $5,7,8,9$ y 11 \\
\hline
\end{tabular}

\section{Artes de Pesca}

Utilizan como arte de pesca el cordel con ballestilla (especie de arco construido con una varilla de cobre o hierro galvanizado y plomada en el centro, del 
cual penden de 3 a 5 rendales con anzuelos). Los anzuelos suelen ser del $N^{\circ} 5,7,8$, 9,11 . Generalmente se utiliza un cordel por pescador, y en promedio la flota operativa utiliza unos 300 cordeles.

\section{Áreas de Pesca}

La información analizada permitió inferir que la flota artesanal costanera de Río Caribe realiza su actividad pesquera en áreas del Bajo Cumberland y en áreas al este del Cabo Tres Puntas alrededor de un bajo existente en la zona. También faenan en los alrededores del yacimiento Rio Caribe, en áreas cercanas a Tacarigua y en áreas ubicadas al norte de Copey y Mejillones (Figura II-1). Las faenas de pesca son realizadas entre profundidades que van desde los $30 \mathrm{~m}$ hasta $75 \mathrm{~m}$, aproximadamente.

\section{Composición de las capturas}

El análisis de la información obtenida permite señalar, que las capturas de la flota artesanal de Río Caribe están principalmente representadas por unas 6 familias de peces, unos 9 géneros y 8 especies identificadas (Tabla II-12). Éstas, de acuerdo a la información suministrada representan las especies de mayor interés comercial que conforman la captura desembarcada por la flota.

Tabla II-12.-Principales especies capturadas por la flota artesanal de Río Caribe según encuestas realizadas a pescadores artesanales.

\begin{tabular}{|c|c|c|}
\hline FAMILIA & NOMBRE COMUN & NOMBRE CIENTIFICO \\
\hline POMATOMIDAE & Anchoa & Pomatomus saltator \\
CARANGIDAE & Cataco & Trachurus lathami \\
PRIACANTHIDAE & Catalana & Priacanthus arenatus \\
& Curvinata & Cynoscion sp. \\
SCIAENIDAE & Roncador & Micropogonias furnieri \\
& Tonquicha & Cynoscion jamaicensis \\
& Cabaña negra & Auxis thazard \\
SCOMBRIDAE & Cabaña blanca & Sarda sarda \\
& Carite & Scomberomorus sp. \\
TRICHIURIDAE & Tajalí & Trichiurus lepturus \\
\hline
\end{tabular}




\section{Distribución temporal de la abundancia de los recursos pesqueros}

Temporada Alta

Los pescadores entrevistados de la comunidad de Río Caribe informaron que los meses de mayor abundancia corresponden al período abril-octubre, destacando que en particular para el tajalí, el período de abril a mayo es de gran importancia (Tabla II-13). Los resultados sobre la composición de las capturas por especie y sus valores de abundancia y porcentual, durante la temporada alta de pesca, evidencian que el tajalí con $746 \mathrm{~kg} /$ día (36\%), fue la especie de mayor importancia, seguido de las especies cabaña blanca con 292 kg/día (14\%), cabaña negra con 209 kg/día (10\%), catalana $204 \mathrm{~kg} / \mathrm{día}$ (10\%) y anchoa con $200 \mathrm{~kg} /$ día (10\%), las cuales representaron el $80 \%$ del abundancia relativa promedio/día de la flota. Mientras que la abundancia relativa promedio de la flota para una temporada alta puede alcanzar niveles de abundancia superiores a los $200 \mathrm{~kg} / \mathrm{día}$. La distribución espacial de la abundancia relativa del total de los recursos desembarcados durante la temporada alta se presenta en la Figura II-2.

\section{Temporada Baja}

Los meses de enero a marzo son considerados de poca abundancia por los pescadores (Tabla II-13). Al respecto la composición de las capturas por especie y sus niveles del promedio de abundancia relativa y porcentual para el período señalado, muestran que la abundancia relativa promedio total de la flota puede alcanzar unos 14,0 kg/día. En cuanto a los niveles de abundancia relativa promedio por especie, se observa que la curvinata con $21 \mathrm{~kg} /$ día (15\%), la tonquicha con 20 kg/día (14\%), el tajalí con 15 kg/día (11\%), la cabaña pintada con 16 kg/día (11\%) y anchoa con $15 \mathrm{~kg} / \mathrm{día}(11 \%)$, conformaron los grupos de especies de mayor aporte (62\%) a la abundancia relativa de la flota en temporada baja. La distribución espacial de la abundancia relativa del total de los recursos desembarcados durante la temporada baja se presenta en la Figura II-3. 
Tabla II-13.-Comportamiento por temporada alta y baja de la abundancia relativa (kg/día) de las especies capturadas por la flota de Río Caribe.

\begin{tabular}{|c|c|c|c|c|c|c|}
\hline ESPECIES & $\begin{array}{c}\text { CPUE T. } \\
\text { Alta }\end{array}$ & $\%$ & Meses T. Alta & CPUE T. Baja & $\%$ & Meses T. Baja \\
\hline Tajalí & 746,43 & 36,13 & ABR-OCT & 14,93 & 10,70 & ENE-MAR \\
Carite & 104,64 & 5,06 & ABR-OCT & 10,57 & 7,58 & ENE-MAR \\
Catalana & 203,57 & 9,85 & ABR-OCT & 7,64 & 5,48 & ENE-MAR \\
Curvinata & 110,63 & 5,35 & ABR-OCT & 21,25 & 15,23 & ENE-MAR \\
Cataco & 125,45 & 6,07 & ABR-OCT & 12,27 & 8,80 & ENE-MAR \\
Roncador & 25,00 & 1,21 & ABR-OCT & 10,50 & 7,53 & ENE-MAR \\
Cabaña negra & 208,75 & 10,10 & ABR-OCT & 11,50 & 8,24 & ENE-MAR \\
Cabaña blanca & 291,67 & 14,12 & ABR-OCT & 15,83 & 11,35 & ENE-MAR \\
Tonquicha & 50,00 & 2,42 & ABR-OCT & 20,00 & 14,34 & ENE-MAR \\
Anchoa & 200,00 & 9,68 & ABR-OCT & 15,00 & 10,75 & ENE-MAR \\
Promdedio & $\mathbf{2 0 6 , 6 1}$ & & & $\mathbf{1 3 , 9 5}$ & & \\
\hline
\end{tabular}

\section{Aspectos socioeconómicos}

Los datos suministrados por los pescadores artesanales de Río Caribe evidencian, que tanto ellos como su núcleo familiar se ubican en dos niveles de educación predominantes (primaria incompleta y primaria completa). Estos valores indican que el sector pesquero artesanal en Río Caribe tiene niveles educativos inferiores a los observados en el total de la población del Municipio Arismendi y del resto de la población de Río Caribe, según los resultados de las encuestas aplicadas durante la evaluación socio-económica de los proyectos costa afuera.

Las embarcaciones tienen un consumo diario de combustible que en promedio está en alrededor de $120 \mathrm{lt}$, a razón de $70 \mathrm{Bs} / \mathrm{lt}$ y un consumo de aceite de aproximadamente 4 It/día a un costo de Bs. 4.500/tt. Entre los gastos mayores que realizan los dueños de embarcaciones, se mencionan el mantenimiento semestral que le hacen a los motores, cuyo monto puede variar entre Bs. 400.000-1.800.000, dependiendo del grado de desgaste del mismo. De igual manera el gasto anual de mantenimiento que se le hace a las embarcaciones se ubica entre Bs.720.000 y 1.800.000. Otros gastos, considerados menores, son los realizados para la compra de insumos de pesca por pérdida o daño de los mismos, dichos gastos están entre Bs. 4.000 y 15.000 por semana. Considerando estos valores se puede estimar que 
el costo operativo de las embarcaciones de Río Caribe se ubicaría alrededor de Bs. 1.000 .000 mensuales.

En cuanto a los beneficios económicos de la actividad pesquera, la información reveló que un 64\% recibe ingresos mensuales superiores a 720.000 $\mathrm{Bs} / \mathrm{mes}$, un $22 \%$ entre 180.000 y $360.000 \mathrm{Bs} /$ mes y un $14 \%$ recibe entre 360.000 y $540.000 \mathrm{Bs} / \mathrm{mes}$. Estos valores indican que los ingresos mensuales declarados por los pescadores entrevistados superan los ingresos medios estimados para los habitantes del Municipio Arismendi y de Río Caribe, según las estimaciones realizadas durante la evaluación socio-económica de los proyectos costa afuera, en los cuales alrededor del $58 \%$ de la población de Río Caribe declaró ingresos mensuales inferiores a Bs. 360.000 .

Por otro lado, la comunidad cuenta con diversos servicios de infraestructura pesquera como: muelle, expendio directo de pescado al consumidor, taller para reparación de motores, carpinterías de ribera, depósitos de motores e implementos de pesca y una sede para la asociación de pescadores. Entre otros aspectos importantes que afectan su actividad productiva, los pescadores de Río Caribe señalaron la piratería marina y el efecto negativo de las embarcaciones de arrastre en los caladeros de pesca.

\section{II.1.1.5 GUACUCO}

$\underline{\text { Características de la flota }}$

En los últimos 20 años el número de embarcaciones en esta comunidad ha variado entre 30 y 50 embarcaciones con una tendencia al incremento en el número de peñeros en años recientes (Cárdenas, 1999). En este estudio se contabilizaron un total de 50 botes de los cuales solamente la mitad se encontrarían operativos. Estas cifras implican que actualmente se dispone de alrededor de 75 puestos de trabajo en la fase extractiva y que un número similar de pescadores se encuentran sin trabajo. Las embarcaciones que conforman la flota artesanal de Guacuco, por lo general, presentan un tamaño que se ubica entre los 6-7 $\mathrm{m}$ de eslora y una longitud de manga entre 1,4-1,7 m (Tabla II-14). Las embarcaciones operan con 3 pescadores y 
utilizan motores fuera de borda con una potencia de $40 \mathrm{HP}$. Las campañas de pesca son diarias, pescando unas 12 horas de pesca/día, durante 6 días a la semana.

Tabla II-14.-Características de la flota de Guacuco.

\begin{tabular}{|l|c|c|c|c|c|c|}
\hline & Min & Max & Promedio & $\mathbf{N}^{\circ}$ Total & Operativas & $\mathbf{N}^{\circ}$ del Anzuelo \\
\cline { 2 - 6 } Eslora $(\mathrm{m})$ & 6 & 7 & 6,25 & - & - & - \\
Manga & 1,4 & 1,7 & 1,5 & - & - & - \\
Potencia Motor (HP) & 40 & 40 & 40 & - & - & - \\
$\mathrm{N}^{\circ}$ de Pescadores & 3 & 3 & 3 & - & - & - \\
Embarcaciones & - & - & - & 50 & 25 & - \\
Cordel & - & - & - & - & 75 & $5,6,9,10$ \\
Palangre & - & - & - & - & 25 & 6 \\
\hline
\end{tabular}

\section{$\underline{\text { Artes de Pesca }}$}

Las embarcaciones de Guacuco utilizan como artes de pesca el cordel con ballestilla (por lo general utilizan un cordel/pescador), y el palangre. Los palangres están conformados por secciones de 200 a 400 anzuelos, con anzuelos del $N^{\circ} 6$. Mientras que los cordeles están conformados por 3 ó 4 anzuelos, siendo los más comunes los de los $N^{\circ} 5,6,9$ y 10.

\section{Áreas de Pesca}

La flota artesanal costanera de Guacuco realiza su actividad pesquera en áreas costeras, en la zona comprendida entre San Juan de Unare y Tacarigua, a profundidades que van desde los 10 a los $75 \mathrm{~m}$. Sin embargo, también faenan hacia la zona costera ubicada entre Cacao y Uquire, alcanzando a pescar en profundidades que van desde los $30 \mathrm{~m}$ y hasta los $100 \mathrm{~m}$ (Figura II-1).

Composición de las capturas

En general las capturas de la flota artesanal de Guacuco están principalmente representadas por 10 familias de peces, 16 géneros y 12 especies identificadas (Tabla II-15). Este grupo de especies conforman las de mayor interés comercial, según la información suministrada por los pescadores encuestados. 
Tabla II-15.-Composición de las principales especies capturadas por la flota artesanal de Guacuco, según encuestas realizadas a pescadores artesanales.

\begin{tabular}{|c|c|c|}
\hline FAMILIA & NOMBRE COMUN & NOMBRE CIENTIFICO \\
\hline POMATOMIDAE & Anchoa & Pomatomus saltator \\
\hline CARCHARHINIDAE & Cazón & $\begin{array}{c}\text { Carcharhinus sp. } \\
\text { Rhizoprionodon porosus }\end{array}$ \\
\hline SERRANIDAE & Mero & Epinephelus sp. \\
\hline CARANGIDAE & $\begin{array}{l}\text { Cataco } \\
\text { Jurel }\end{array}$ & $\begin{array}{l}\text { Trachurus lathami } \\
\text { Caranx hipoos }\end{array}$ \\
\hline PRIACANTHIDAE & $\begin{array}{l}\text { Catalana } \\
\text { Curvinata }\end{array}$ & $\begin{array}{l}\text { Priacanthus arenatus } \\
\text { Cynoscion sp. }\end{array}$ \\
\hline SCIAENIDAE & $\begin{array}{l}\text { Roncador } \\
\text { Tonquicha }\end{array}$ & $\begin{array}{l}\text { Micropogonias furnieri } \\
\text { Cynoscion jamaicensis }\end{array}$ \\
\hline LUTJANIDAE & $\begin{array}{l}\text { Pargo } \\
\text { Cunaro }\end{array}$ & $\begin{array}{l}\text { Lutjanus sp. } \\
\text { Rhomboplites aurorubens }\end{array}$ \\
\hline SCOMBRIDAE & $\begin{array}{c}\text { Cabaña negra } \\
\text { Cabaña blanca } \\
\text { Carite }\end{array}$ & $\begin{array}{c}\text { Auxis thazard } \\
\text { Sarda sarda } \\
\text { Scomberomorus sp. }\end{array}$ \\
\hline $\begin{array}{l}\text { CORYPHAENIDAE } \\
\text { TRICHIURIDAE }\end{array}$ & $\begin{array}{l}\text { Dorado } \\
\text { Tajalí }\end{array}$ & $\begin{array}{l}\text { Coryphaena hippurus } \\
\text { Trichiurus lepturus }\end{array}$ \\
\hline
\end{tabular}

Distribución temporal de la abundancia de los recursos pesqueros

Temporada Alta

Los pescadores entrevistados de la comunidad Guacuco coincidieron en señalar un período amplio de abundancia relativa máxima para la flota en la temporada alta, el cual ubicaron entre marzo y octubre (Tabla II-16). En cuanto a la composición de las especies y sus valores de abundancia relativa promedio/día y porcentual, durante la referida temporada de pesca, puede señalarse que el tajalí con $780 \mathrm{~kg} /$ día (27\%), fue la de mayor importancia, seguido del cataco con $567 \mathrm{~kg} / \mathrm{día}$ (19\%), la anchoa con $350 \mathrm{~kg} /$ día (12\%) y cazón con $325 \mathrm{~kg} /$ día (11\%). Este grupo de especies representaró el $69 \%$ de la abundancia relativa promedio/día de la flota. La abundancia relativa del promedio total de especies capturada por la flota para el período indicado se estimó en 242,89 kg/día. La distribución espacial de la abundancia relativa del total de los recursos desembarcados durante la temporada alta se presenta en la Figura II-2.

Temporada Baja

La Tabla II-16, muestra también, que los pescadores indicaron que los meses de diciembre a febrero son de bajas capturas, pudiendo alcanzar niveles promedio 
totales que pueden alcanzar los $30 \mathrm{~kg} /$ día. En cuanto a la composición de las capturas por especie y los niveles de abundancia relativa promedio (kg/día) y porcentual para el referido período, las encuestas evidencian que el tajalí con 74 $\mathrm{kg} /$ día (21\%), cunaro con $50 \mathrm{~kg} /$ día (14\%) cataco con $50 \mathrm{~kg} /$ día (14\%) y la tonquicha con $38 \mathrm{~kg} / \mathrm{día}$ (11\%) conformaron los grupos de especies de mayor aporte $(60 \%)$ a la abundancia relativa de especies que captura la flota. La distribución espacial de la abundancia relativa del total de los recursos desembarcados durante la temporada baja se presenta en la Figura II-3.

Tabla II-16.-Comportamiento por temporada alta y baja de la abundancia relativa ( $\mathrm{kg} / \mathrm{día}$ ) de las especies capturadas por la flota de Guacuco.

\begin{tabular}{|c|c|c|c|c|c|c|}
\hline ESPECIES & $\begin{array}{c}\text { CPUE T. } \\
\text { Alta }\end{array}$ & $\%$ & $\begin{array}{c}\text { Meses T. } \\
\text { Alta }\end{array}$ & $\begin{array}{c}\text { CPUE T. } \\
\text { Baja }\end{array}$ & $\%$ & $\begin{array}{c}\text { Meses T. } \\
\text { Baja }\end{array}$ \\
\hline Tajalí & 780,00 & 26,76 & MAR-OCT & 74,00 & 20,68 & DIC-FEB \\
Mero & 150,00 & 5,15 & MAR-OCT & 16,40 & 4,58 & DIC-FEB \\
Curvinata & 92,00 & 3,16 & MAR-OCT & 19,00 & 5,31 & DIC-FEB \\
Cazón & 325,00 & 11,15 & MAR-OCT & 33,75 & 9,43 & DIC-FEB \\
Roncador & 55,00 & 1,89 & MAR-OCT & 9,50 & 2,65 & DIC-FEB \\
Pargo & 206,00 & 7,07 & MAR-OCT & 18,40 & 5,14 & DIC-FEB \\
Jurel & 160,00 & 5,49 & MAR-OCT & 6,00 & 1,68 & DIC-FEB \\
Anchoa & 350,00 & 12,01 & MAR-OCT & 32,50 & 9,08 & DIC-FEB \\
Cataco & 566,67 & 19,44 & MAR-OCT & 38,33 & 10,71 & DIC-FEB \\
Cunaro & 100,00 & 3,43 & MAR-OCT & 50,00 & 13,97 & DIC-FEB \\
Tonquicha & 100,00 & 3,43 & MAR-OCT & 50,00 & 13,97 & DIC-FEB \\
Dorado & 30,00 & 1,03 & MAR-OCT & 10,00 & 2,79 & DIC-FEB \\
Promdedio & $\mathbf{2 4 2 , 8 9}$ & & & $\mathbf{2 9 , 8 2}$ & & \\
\hline
\end{tabular}

\section{Aspectos socioeconómicos}

La información suministrada por los pescadores artesanales de la comunidad de Guacuco en relación al nivel educativo, evidencia un patrón similar al resto de las comunidades analizadas, caracterizado por niveles de primaria incompleta y primaria completa. Estos valores coinciden con los resultados de la evaluación socioeconómica de los proyectos en ejecución costa afuera, en la cual también se señala que alrededor del $20 \%$ de la población de esta comunidad no ha recibido ningún tipo de instrucción escolar.

Según los pescadores entrevistados, las embarcaciones tienen un consumo diario promedio de combustible aproximado a 120 lt/día, a razón de unos 70 Bs/lt y 
un consumo de aceite de 4 It/día a Bs 4.500/lt. Entre los gastos mayores que realizan los dueños de embarcaciones, se menciona el mantenimiento semestral que le hacen a los motores, monto que varia entre Bs 300.000 y 800.000 , dependiendo del grado de desgaste del mismo. De igual manera, el gasto anual de mantenimiento que se le hace a las embarcaciones se ubica entre Bs.500.000 y 2.000.000. Otros gastos considerados menores son los realizados para compra de insumos de pesca, como "nylon" y anzuelos, por pérdida o daño de los mismos, éstos gastos por lo general varían entre Bs10.000 y 50.000 semanales. En función de estas cifras se puede estimar que el valor promedio mensual de los costos operativos de las embarcaciones de esta comunidad se ubicaría en aproximadamente Bs. 960.000.

Respecto a los beneficios económicos de la actividad pesquera, la información permitió inferir que un $66 \%$ recibe ingresos entre 180.000 y $360.000 \mathrm{Bs} / \mathrm{mes}$, un $17 \%$ manifestó recibir ingresos menores a 180.000 Bs/mes y otro $17 \%$ indicó recibir ingresos superiores a 720.000,00 Bs/mes. Esta distribución de ingresos es ligeramente mayor a la reportada para el conjunto del Municipio Arismendi en las estimaciones realizadas durante la evaluación socio-económica de los proyectos en ejecución costa afuera.

Esta comunidad cuenta con poca estructura de apoyo a la producción pesquera, ya que solamente se señala la presencia de rancherías y depósitos para aparejos de pesca y combustible. Entre los aspectos que inciden negativamente en la actividad productiva, los pescadores señalaron la ausencia de surtidores de combustible, ferretería marina, el robo de motores y las interferencias con las embarcaciones de arrastre industrial.

\section{II.1.1.6 GUARATARO}

\section{Características de la flota}

En el presente estudio se contabilizaron un total de 60 embarcaciones de tipo peñero, de las cuales solamente el $50 \%$ estaba en condiciones operativas. El número de puestos de trabajo directos generados por esta flota artesanal se ubicaría en alrededor de 90. Las embarcaciones que conforman la flota de Guarataro se caracterizan por presentar un tamaño que va desde los $6-8 \mathrm{~m}$ de eslora y 1,56 m 
promedio de manga (Tabla II-17). Las embarcaciones faenan con 3 pescadores, son propulsadas por motores fuera de borda con una potencia de $40 \mathrm{HP}$. Las campañas de pesca son diarias, operando alrededor de 12 horas por día, durante 6 días a la semana.

Tabla II-17.-Características de la flota de Guarataro.

\begin{tabular}{|l|c|c|c|c|c|c|}
\hline & Min & Max & $\begin{array}{c}\text { Promedi } \\
0\end{array}$ & N$^{\circ}$ Total & Operativas & $N^{\circ}$ del Anzuelo \\
\cline { 2 - 7 } Eslora $(\mathrm{m})$ & 6 & 8 & 6,54 & - & - & - \\
Manga & 1,4 & 1,7 & 1,56 & - & - & - \\
Potencia Motor (HP) & 40 & 40 & 40 & - & - & - \\
No de Pescadores & 3 & 3 & 3 & - & - & - \\
Embarcaciones & - & - & - & 60 & 30 & - \\
Cordel & - & - & - & - & 150 & $5,6,8$ \\
Palangre & - & - & - & - & 100 & $5,6,8$ \\
\hline
\end{tabular}

\section{Artes de Pesca}

Las embarcaciones de Guarataro utilizan como artes de pesca el cordel y el palangre, ambos tipos de arte tienen igual importancia para la flota. Se utilizan alrededor de 150 cordeles y 100 palangres para las faenas de pesca. Los cordeles por lo general son de tres 3 anzuelos y los palangres están armados con secciones de 200 hasta 1.000 anzuelos. Indistintamente del tipo de arte, el número del anzuelo por lo general es del $\mathrm{N}^{\circ} 5,6, \mathrm{y} 8$.

\section{Áreas de Pesca}

La flota artesanal costanera de Guarataro concentra su actividad en áreas costeras ubicadas entre San Juan de Unare y Tacarigua, a profundidades que pueden ir desde los $10 \mathrm{~m}$ hasta los $75 \mathrm{~m}$. También señalaron como áreas de pesca importantes las zonas costeras ubicadas entre Copey y Uquire en la costa norte de la península, donde pueden pescar a profundidades que van desde los $30 \mathrm{~m}$ a los 100m; particularmente en la zona ubicada entre Mejillones y Uquire (Figura II-1).

Composición de las capturas

El análisis de las encuestas permite señalar, que las capturas de la flota artesanal de Guarataro están principalmente representadas por 10 familias de peces, 15 géneros y 12 especies identificadas (Tabla II-18). 
Tabla II-18.-Composición de las principales especies capturadas por la flota artesanal de Guarataro, según encuestas realizadas a pescadores artesanales.

\begin{tabular}{|l|l|l|}
\hline \multicolumn{1}{|c|}{ FAMILIA } & NOMBRE COMUN & NOMBRE CIENTIFICO \\
\hline POMATOMIDAE & Anchoa & Pomatomus saltator \\
CARANGIDAE & Cataco & Trachurus lathami \\
CORYPHAENIDAE & Jurel & Caranx hippos \\
CARCHARHINIDAE & Dorado & Rhizoprionodon porosus \\
HAEMULIDAE & Cazón & Carcharhinus sp. \\
LUTJANIDAE & Corocoro & Orthopristis ruber \\
& Cunaro & Romboplites aurorubens \\
SCIAENIDAE & Pargo & Lutjanus sp. \\
& Curvinata & Cynoscion sp. \\
TRICHIURIDAE & Roncador & Micropogonias furnieri \\
SERRANIDAE & Tonquicha & Cynoscion jamaicensis \\
& Tajalí & Trichiurus lepturus \\
SCOMBRIDAE & Mero & Epinephelus sp. \\
& Cabaña negra & Auxis thazard \\
& Cabaña pintada & Euthynnus alletteratus \\
\hline
\end{tabular}

Distribución temporal de la abundancia de los recursos pesqueros

Temporada Alta

La información suministrada por los pescadores de Guarataro permitió inferir sobre los meses de mayor abundancia para la flota, en este sentido los entrevistados coincidieron en señalar que el período de mayor abundancia relativa corresponde de abril a octubre (Tabla II-19). Se observa que el tajalí con $811 \mathrm{~kg} / \mathrm{día}(33 \%)$ fue la especie de mayor importancia en los desembarques referidos por los pescadores, seguido por la cabaña pintada con $300 \mathrm{~kg} /$ día (12\%), el cataco con $225 \mathrm{~kg} / \mathrm{día}$ (9\%), la cabaña negra con $200 \mathrm{~kg} /$ día (8\%), carachana con 177 kg/día (7\%) y el carite con $150 \mathrm{~kg} / \mathrm{día}(6 \%)$; las cuales en conjunto representaron el 75\% del abundancia relativa

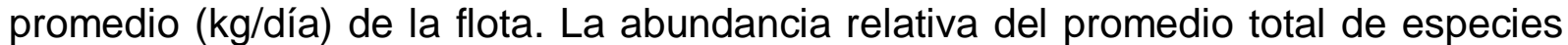
capturadas por la flota se estimó en unos $174,56 \mathrm{~kg} / \mathrm{día}$. La distribución espacial de la abundancia relativa del total de los recursos desembarcados durante la temporada alta se presenta en la Figura II-2. 
Temporada Baja

Los pescadores entrevistados señalaron al período de enero a marzo, como bajos en abundancia relativa (Tabla II-19). Se observa que durante el referido período la flota alcanzó niveles promedio del total de abundancia relativa cercanos a $17 \mathrm{~kg} /$ día. En cuanto a los abundancia relativa por especie se observa que el tajalí con $71 \mathrm{~kg} / \mathrm{día}$ (30\%), vuelve a ser la especie más importante, seguida de la cabaña pintada con $23 \mathrm{~kg} /$ día (10\%), la cabaña negra y el cataco con $20 \mathrm{~kg} /$ día (8\%), respectivamente y el corocoro con $18 \mathrm{~kg} / \mathrm{día}(7,5 \%)$, estos conformaron el grupo de especies de mayor aporte a la abundancia relativa total de especies que captura la flota con $71,5 \%$. La distribución espacial de la abundancia relativa del total de los recursos desembarcados durante la temporada baja se presenta en la Figura II-3.

Tabla II-19.-Comportamiento por temporada alta y baja de la abundancia relativa (kg/día) de las especies capturadas por la flota de Guarataro en temporada alta y baja.

\begin{tabular}{|l|c|c|c|c|c|c|}
\hline ESPECIES & $\begin{array}{c}\text { CPUE T. } \\
\text { Alta }\end{array}$ & $\%$ & $\begin{array}{c}\text { Meses T. } \\
\text { Alta }\end{array}$ & $\begin{array}{c}\text { CPUE T. } \\
\text { Baja }\end{array}$ & $\%$ & $\begin{array}{c}\text { Meses T. } \\
\text { Alta }\end{array}$ \\
\hline Mero & 61,90 & 2,53 & ABR-OCT & 5,43 & 2,31 & ENE-MAR \\
Anchoa & 110,00 & 4,50 & ABR-OCT & 4,00 & 1,70 & ENE-MAR \\
Cazón & 82,86 & 3,39 & ABR-OCT & 12,17 & 5,17 & ENE-MAR \\
Curvinata & 70,00 & 2,86 & ABR-OCT & 4,86 & 2,06 & ENE-MAR \\
Tajalí & 811,11 & 33,19 & ABR-OCT & 70,56 & 29,98 & ENE-MAR \\
Carachana & 176,67 & 7,23 & ABR-OCT & 8,00 & 3,40 & ENE-MAR \\
Roncador & 38,75 & 1,59 & ABR-OCT & 9,50 & 4,04 & ENE-MAR \\
Corocoro & 80,00 & 3,27 & ABR-OCT & 18,33 & 7,79 & ENE-MAR \\
Tonquicha & 57,50 & 2,35 & ABR-OCT & 15,00 & 6,37 & ENE-MAR \\
Carite & 150,00 & 6,14 & ABR-OCT & 15,00 & 6,37 & ENE-MAR \\
Cabaña pintada & 300,00 & 12,28 & ABR-OCT & 22,50 & 9,56 & ENE-MAR \\
Cabaña negra & 200,00 & 8,18 & ABR-OCT & 20,00 & 8,50 & ENE-MAR \\
Cataco & 225,00 & 9,21 & ABR-OCT & 20,00 & 8,50 & ENE-MAR \\
Dorado & 80,00 & 3,27 & ABR-OCT & 10,00 & 4,25 & ENE-MAR \\
Promdedio & $\mathbf{1 7 4 , 5 6}$ & & & 16,81 & & \\
\hline
\end{tabular}

\section{Aspectos socioeconómicos}

Los pescadores artesanales de Guarataro y su núcleo familiar, se ubican en el nivel de educación primaria incompleta y un porcentaje menor tiene la primaria completa. Al comparar estos resultados con los obtenidos durante la evaluación socio-económica costa afuera se aprecia que los niveles de instrucción de los 
pescadores y sus familias son inferiores a los observados para el conjunto de la comunidad.

Las embarcaciones de Guarataro, según los pescadores encuestados, tienen un consumo diario de combustible que en promedio está en unos 120 It, a razón de unos $70 \mathrm{Bs} / \mathrm{lt}$ y un consumo de aceite de unos 3 It/día a Bs. 4.500/lt. Entre los gastos mayores que realizan los dueños de embarcaciones, se mencionan el mantenimiento semestral que le hacen a los motores, por lo general este monto puede variar entre Bs500.000 y 800.000 , dependiendo del grado de desgaste que tengan los mismos. De igual manera el gasto anual de mantenimiento que se le hace a las embarcaciones se ubica entre Bs800.000 y 1.000 .000 . Entre otros gastos que se mencionan, son los realizados para la compra de insumos de pesca por pérdidas 0 daños, que alcanzan entre los Bs15.000 y 50.0000 semanales. Estas cifras implican que los costos mensuales operativos de las embarcaciones de Guarataro se ubicarían en aproximadamente Bs. 840.000 .

En relación a los beneficios económicos de la actividad pesquera, se observó que un $50 \%$ de los pescadores entrevistados reciben ingresos entre 360.000 y $540.000 \mathrm{Bs} / \mathrm{mes}$, un $33 \%$ entre 180.000 y $360.000 \mathrm{Bs} / \mathrm{mes}$ y un $16 \%$ ingresos superiores a 720.000,00 Bs/mes. Esta distribución del ingreso muestra valores más elevados a los estimados para el conjunto de la población de Guarataro durante la evaluación económica de los proyectos costa afuera.

Por otro lado, la comunidad cuenta con algunas estructuras de apoyo a la producción como rancherías, depósitos para combustibles y aparejos de pesca y taller para reparación de motores. Los aspectos señalados por los pescadores de Guarataro como limitantes de la actividad productiva, son los relacionados con robo de motores y la interferencia con las embarcaciones de arrastre industrial. 


\section{II.1.2 Análisis de los indicadores pesqueros y socio-económicos en las comunidades al norte del Estado Sucre}

En las 6 comunidades estudiadas el número total de embarcaciones artesanales se estimó en 376, de las cuales alrededor del 70\% estaban operativas. El total de empleos directos generados por estas embarcaciones operativas se estimó 850 puestos de trabajo en el sector primario de la pesca artesanal en estas comunidades. El análisis del número de embarcaciones contabilizadas en el presente estudio y su comparación con la evolución numérica de la flota desde mediados de 1980 (Cárdenas, 1999) indica que, a excepción de Río Caribe y en menor medida Guacuco, el número de embarcaciones en las comunidades estudiadas se ha mantenido relativamente estable durante los últimos 20 años. Este indicador es importante ya que también permite determinar la capacidad del sector primario de la pesca artesanal a generar puestos de trabajo. En este sentido, se puede inferir que el sector pesquero artesanal presenta una tendencia al estancamiento en el tamaño de la flota y los puestos de trabajo generados y que, por lo tanto, no es capaz de absorber las necesidades crecientes de estas comunidades. Otro factor de interés es la proporción de las embarcaciones que se encuentran operativas, que en el presente estudio varió desde un máximo de $87 \%$ en Saucedo hasta un mínimo de $50 \%$ en Guacuco y Guarataro. Por lo general, una embarcación se considera que no está operativa cuando presenta evidentes signos de falta de mantenimiento y de uso. Estas condiciones se presentan frecuentemente cuando los dueños de las embarcaciones se ven imposibilitados de adquirir motores nuevos, los cuales representan la mayor erogación financiera que deben enfrentar los pescadores artesanales. En el área de estudio, las poblaciones de Guacuco y Guarataro presentaron los menores índices de operatividad, lo que probablemente esté relacionado con el relativo aislamiento de estas comunidades y los menores valores obtenidos de la venta del pescado en poblaciones de estas características. Por otro lado, es importante considerar el auge delictivo (narcotráfico) en la costa nororiental de la Península de Paria, lo cual puede relacionarse con el frecuente robo de 
motores al que hacen referencia los pescadores de las diversas comunidades estudiadas.

Por otro lado, los resultados indican que las flotas artesanales costaneras multiespecíficas de Carúpano, Río Caribe, Guacuco y Guarataro, realizan su actividad pesquera a lo largo de la costa norte de la Península de Paria y en los casos específicos de Río Caribe, Guarataro y Carúpano las áreas de pesca incluyen los alrededores de los yacimientos del proyecto PMS. Mientras que las flotas pesqueras artesanales de Saucedo y Guatapanare tienen un área de pesca más localizada y cercana a sus puertos base. La orientación del esfuerzo de cada flota está sujeta a la abundancia de los recursos y a la estacionalidad de los mismos durante el año, lo cual incide en el modo de operatividad de la flota y en los beneficios económicos que pueden derivarse de la actividad pesquera. Así, por ejemplo, en la comunidad de Saucedo, en la temporada alta predominan especies pelágicas de alto valor como la anchoa y el carite, mientras que en la temporada baja el esfuerzo se dirige hacia especies demersales, como el bagre y las rayas, de menor valor en el mercado. De las comunidades analizadas las más atípicas estarían conformadas por Guatapanare, debido a la predominancia de la pesca de sardina, y Carúpano cuya modalidad de pesca es por campañas (generalmente de 8 a 12 días), las cuales cubren áreas en la PNP, operando en aguas que pueden llegar a alcanzar profundidades de hasta $150 \mathrm{~m}$.

De manera general, según las declaraciones de los pescadores, los recursos pesqueros tienden a presentar mayores abundancias durante el segundo semestre del año. De acuerdo con la percepción de los pescadores, exceptuando el caso de la pesquería de sardina de Guatapanare, los valores de abundancia en la temporada baja pueden llegar a ser menos del $10 \%$ de los valores observados en la temporada alta. Es evidente que las fluctuaciones estacionales de los recursos y de los precios obtenidos de la venta tendrán un efecto notorio sobre el nivel de ingreso de los pescadores y la rentabilidad de la actividad pesquera artesanal.

Los niveles de ingresos declarados por los pescadores encuestados tienden a ser superiores a los devengados por el conjunto de los pobladores de las diferentes 
comunidades. Sin embargo, existen diferencias marcadas en la distribución del ingreso entre las diferentes comunidades. Guatapanare, Guacuco y Guarataro son las comunidades que presentan los menores ingresos. En el caso de Guatapanare, probablemente se deba al bajo de precio de venta controlado de la sardina, mientras que en Guacuco y Guarataro, probablemente se deba al relativo aislamiento de estas comunidades, lo cual incide negativamente sobre el precio de venta de las diferentes especies explotadas. Por otro lado, es importante hacer notar que los pescadores artesanales laboran sobre la base del sistema de "partes" y no perciben ningún otro beneficio socio-económico que normalmente derivan de las relaciones laborales en nuestro país (aguinaldos, vacaciones, seguro social, entre otros).

Las informaciones suministradas por los pescadores permitieron estimar a nivel mensual los costos operativos de las embarcaciones de las diversas comunidades analizadas. El máximo valor (Bs. 1.700.000) se presentó en la comunidad de Saucedo, mientras que el mínimo (Bs. 840.000) correspondió a la población de Guarataro. En líneas generales, los gastos en aceite y gasolina representan la mayor erogación y luego el costo de mantenimiento de los motores. En la mayor parte de las comunidades estos 3 factores representaron más del $75 \%$ de los gastos operativos en los que incurren los pescadores en la realización de sus faenas de pesca. La excepción fué Carúpano donde estos factores representaron solamente el $36 \%$ de los gastos operativos mensuales, debido al peso (44\%) del rubro alimentos para la realización de campañas de larga duración que caracteriza a la flota de esta comunidad.

\section{II.1.3 Conclusiones}

- La Distribución espacio temporal del esfuerzo de pesca de las flotas que operan al norte, noreste y noroeste de la Península de Paria, está asociada a la abundancia de los recursos. Esto define dos temporadas de pesca una de altos rendimientos en el segundo semestre del año y otra de bajos rendimientos a principios de año. 
- Dos modalidades de pesca definen la actividad pesquera en la costa norte de la península de Paria: la flota campañera de Carúpano y las flotas de pesca diaria en el resto de las comunidades. La comunidad de Guatapanare se distingue del resto por la predominancia de la pesquería de sardina.

- Los rendimientos totales de las flotas artesanales de la mayor parte de las comunidades analizadas en los períodos de mayor abundancia están soportados principalmente en las especies: Tajalí, cabañas, cataco, Anchoa y Curvinas.

- El número de embarcaciones en la mayor parte de las comunidades estudiadas no ha variado durante los últimos 20 años, lo que indica un cierto estancamiento durante este lapso de tiempo. Ello limita la capacidad del sector para absorber mano de obra y aumentar la producción pesquera.

- El aceite, la gasolina y el mantenimiento de los motores son los factores más importantes en los costos operativos de las embarcaciones.

- La piratería marina, la ausencia de infraestructura de apoyo a la pesca, la interferencia de la pesca de arrastre y la ausencia de créditos son percibidos por los pescadores como los factores que más negativamente impactan sobre la actividad pesquera artesanal. 


\section{II.2 Pesquería de Sardina}

La sardina, Sardinella aurita, es un pez pelágico de amplia distribución, que en Venezuela se concentra principalmente en el nororiente donde representa el recurso pesquero más importante. La costa norte del Estado Sucre es una de las áreas más productivas para la pesquería de sardinas en cuanto a volumen de capturas, representando el $45 \%$ del total de la captura en Venezuela (Freon y Mendoza, 2003). La producción se destina a la elaboración de conservas, harina de pescado, a la exportación de productos congelados (troncos y sardina entera) y al consumo en fresco; lo cual significa que el recurso sardinero representa una importante fuente de proteínas y de empleo en todas las fases del proceso (captura, procesamiento y comercialización) (Guzmán, 2000). Debido a la elevada importancia que tiene la sardina en la región, se realizan monitoreos continuos del recurso, que incluyen parámetros biológicos, pesqueros y poblacionales, con la finalidad de interpretar las variaciones en la distribución, abundancia y comportamiento, para así conocer el estado de explotación del recurso.

En el presente análisis se utilizó la información de la pesquería de sardina realizada en la costa norte del Estado Sucre; específicamente en el área

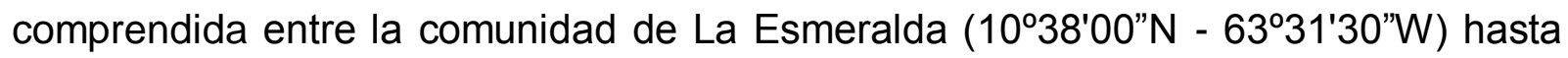
el Morro de Puerto Santo $\left(10^{\circ} 44^{\prime} 00^{\prime \prime} \mathrm{N}\right.$ - 63010'00”W). La información sobre estimaciones de desembarques (TM), esfuerzo (calada), índice de abundancia relativa basado en la captura por unidad de esfuerzo (TM/calada) e información relacionada con las unidades de pesca, se generó a partir de planillas de producción suministrada por las plantas procesadoras, inspectorías de pesca, así como del control de desembarques en las comunidades que se dedican a la pesca de sardina. A efectos del análisis se usó como referencia la serie histórica de la pesquería en la zona de estudio que comprende el lapso desde 1985 al 2000, así como los resultados de estudios sobre biomasa y dinámica poblacional. 


\section{II.2.1 Unidad y Operación de Pesca}

La pesquería de sardinas es de tipo artesanal, y se realiza con dos tipos de artes: el tipo "chinchorro sardinero" y la red de cerco conocida localmente como "máquina de argollas o tren de argollas". Este último es de uso exclusivo en el área descrita en el apartado anterior. La faena de pesca requiere de un número de pescadores que oscila entre 5 y 20 a bordo de un número variable de embarcaciones (que varia entre 3 y 7 ), equipadas generalmente con motores fuera de borda y en algunos casos con motor central. La faena se realiza generalmente durante el día, y algunas veces, durante la noche. En el caso de la pesca con chinchorro, este se "remolca" con dos o más embarcaciones hacia lugares de menor profundidad donde la captura es confinada para su comercialización. La duración del confinamiento depende de la demanda, y generalmente dura de 1 a 10 días. En la pesca con tren de argolla, la captura es retirada del arte de pesca el mismo día en que se realiza. El acarreo de la captura desde el sitio de lance y/o confinamiento hasta su destino, se realiza mediante lanchas propiedad de las plantas procesadoras de sardinas o de camiones con cavas refrigeradas.

\section{II.2.2 Áreas de Pesca}

La pesquería de sardina en la costa norte del Estado Sucre se realiza en el eje La Esmeralda - Morro de Puerto Santo. Esta área geográfica está conformada por las localidades de La Esmeralda, Guaraguao, Lebranche, Guatapanare, Guaca, Playa Escondido, Taquién, La Iglesia, Patilla, Güiria de la Playa, Copacabana, Copey, Playa Grande, Carúpano, Las Playuelas, Puerto Santo y El Morro de Puerto Santo, las cuales son conocidas como sitios de referencia en la pesca de sardina. Los lances o faenas de pesca se realizan a una distancia que no supera las 5 millas desde la costa, en profundidades que oscilan entre 12 y $21 \mathrm{~m}$. Guaca y el Morro de Puerto Santo son las comunidades principales de los sitios de desembarque de la pesquería de sardina en el área de estudio (Figura II-4). Mientras que las áreas aledañas a La Piedra y Playa Escondido, y alrededor del Morro de Puerto Santo, han sido señaladas como las más productivas. 


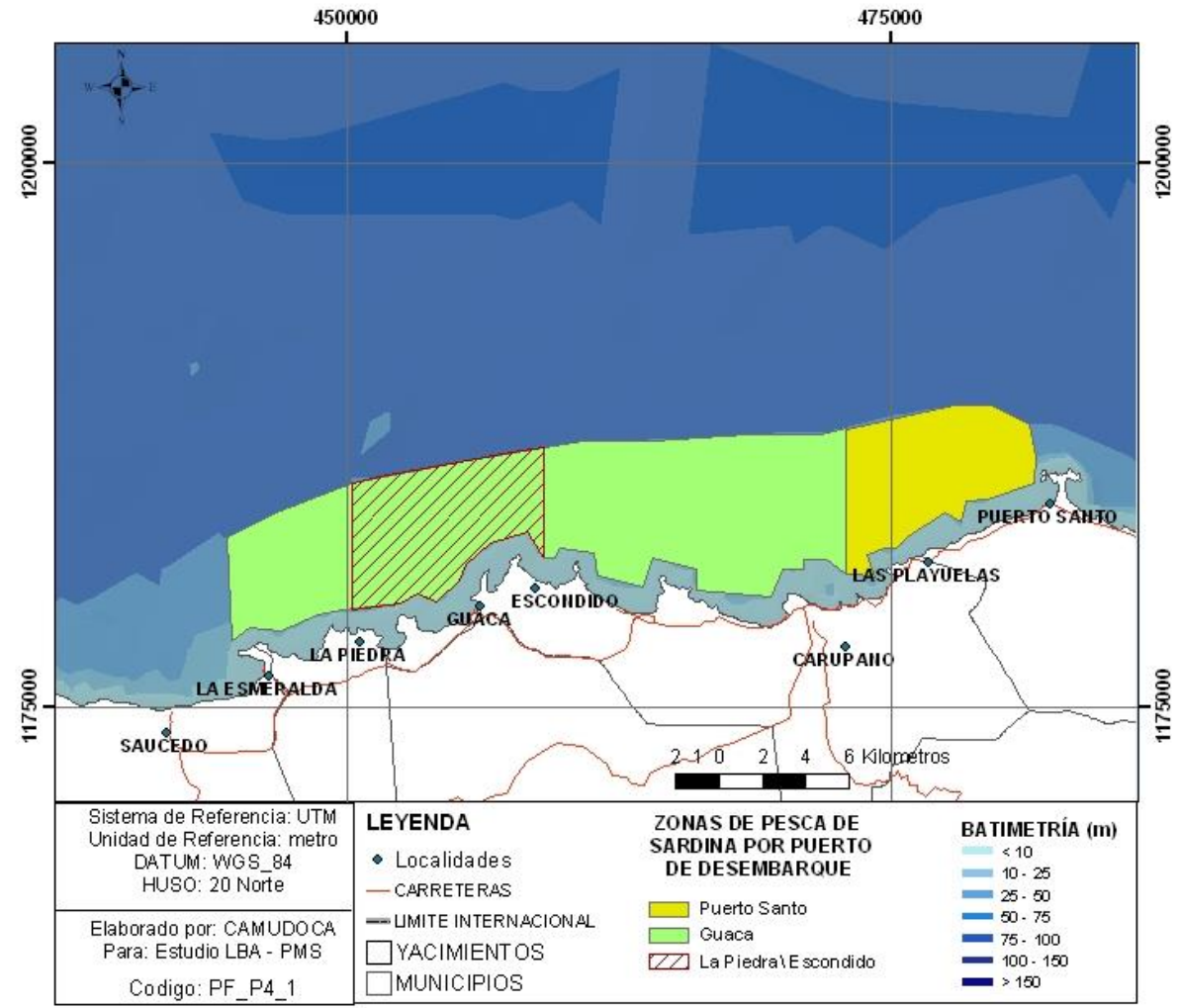

Figura II-4.- Áreas de pesca de la flota que captura sardina en el norte del Estado Sucre

\section{II.2.3 Variación de los desembarques, el esfuerzo y la abundancia relativa}

La extracción de sardina en el área de estudio se ha mantenido alrededor de las 50.000 TM en los últimos tres años de la serie histórica analizada (2001-2004), observándose un máximo que alcanzó 55.461 TM en el 2002 para luego observarse un ligero descenso sostenido hacia el final de la serie (Tabla II-20). El esfuerzo de pesca, sigue un patrón similar al de los desembarques, al presentarse el 2002 como el año en el cual se registró el mayor número de caladas (2.370 caladas). Sin embargo, durante el último año (2004) se observa un incremento en el número de caladas con respecto al año anterior, sin un incremento en los desembarques. Los niveles de abundancia relativa en el área de estudio muestran un incremento sostenido durante los tres primeros años de la serie de tiempo, pero en el último año se observa un descenso en los niveles de abundancia (Tabla II-20). 
Tabla II-20.-Variación de las capturas, esfuerzo y abundancia relativa de la pesquería de sardina en el norte del Estado Sucre durante el período 2001-2004.

\begin{tabular}{|c|c|c|c|}
\hline AÑO & $\begin{array}{c}\text { CAPTURA } \\
\text { (TM) }\end{array}$ & $\begin{array}{c}\text { ESFUERZO } \\
\text { (caladas) }\end{array}$ & $\begin{array}{c}\text { CPUE } \\
\text { (TM/caladas) }\end{array}$ \\
\hline 2001 & 40.322 & 1.851 & 21,78 \\
2002 & 55.461 & 2.370 & 23,40 \\
2003 & 52.500 & 2.050 & 25,61 \\
2004 & 50.950 & 2.265 & 22,49 \\
\hline
\end{tabular}

La distribución del volumen de los desembarques por puerto en el norte del Estado Sucre muestra que el Morro de Puerto Santo aporta el mayor volumen con el $62,32 \%$ del total de toneladas métricas desembarcadas, seguido de Guaca con el $37,68 \%$ (Tabla II-21). Además, se aprecia que la abundancia relativa es mayor durante el segundo y tercer trimestre del año para el período de estudio en ambos puertos de desembarque.

Tabla II-21.-Variación estacional promedio (2001-2004) de la captura, esfuerzo y abundancia relativa de la pesquería de sardina por puerto de desembarque en norte del Estado Sucre.

\begin{tabular}{|cccc|}
\hline \multicolumn{4}{c|}{ PUERTO DE GUACA (desde La Esmeralda hasta Carúpano) } \\
\hline TRIMESTRE & CAPTURA (TM) & ESFUERZO (caladas) & CPUE (TM/caladas) \\
I & 3.501 & 152 & 23,03 \\
II & 5.195 & 207 & 25,1 \\
III & 6.306 & 264 & 23,89 \\
IV & 4.300 & 188 & 22,87 \\
\hline \multicolumn{5}{|c}{} \\
\hline PUERTO DEL MORRO DE PTO. SANTO (desde Las Playuelas hasta el Morro) \\
\hline TRIMESTRE & CAPTURA (TM) & ESFUERZO (caladas) & CPUE (TM/caladas) \\
I & 7.828 & 363 & 21,56 \\
II & 6.056 & 226 & 26,79 \\
III & 8.005 & 314 & 25,49 \\
IV & 10.345 & 447 & 23,14 \\
\hline
\end{tabular}

El área comprendida entre La Piedra y Playa Escondido se destaca como la más productiva de toda el área de pesca que corresponde a los desembarques del puerto de Guaca, al contribuir con el 38\% de la captura en la zona de Guaca (Figura II-4). Mientras que el área aledaña al Morro es la de mayor aporte contribuyendo con el $60 \%$ de los desembarques correspondientes a Puerto Santo. 


\section{II.2.4 Variación espacial y temporal de la biomasa de sardina}

Los resultados de prospecciones de hidroacústica (Cárdenas y Achury, 2000), indican que la mayor abundancia de sardina se encuentra al este, sureste y norte de la isla de Margarita, alrededor de las Islas de Coche y Cubagua, la costa norte del Morro de Pto. Santo, el Golfo de Cariaco, y al oeste de la Península de Araya (Figura II-5). En la costa norte del Estado Sucre, desde La Esmeralda hasta Cabo Tres Puntas, los cardúmenes se distribuyen en la columna de agua entre 3 - $30 \mathrm{~m}$ y son mas frecuentes en un radio de 10 millas de la costa. Las Prospecciones de hidroacústica y valores de eco-integración indican que en zonas de mar abierto la abundancia es inferior, evidenciando una línea de referencia próxima a los $63^{\circ} 50^{\prime} \mathrm{W}$, no obstante se tienen registros de acústica y pescas hasta los $66^{\circ} \mathrm{W}$.

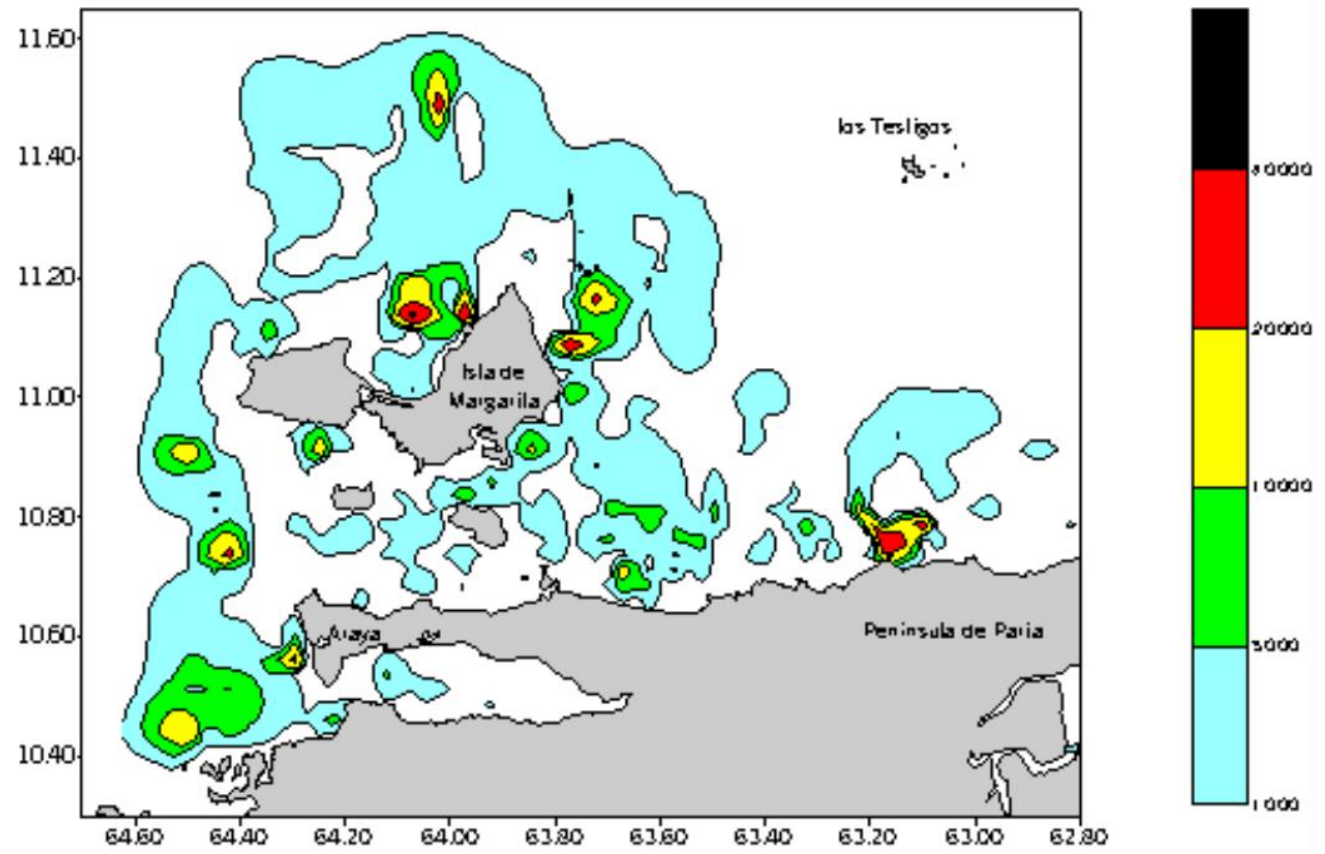

Figura II-5.- Distribución horizontal de la biomasa de sardina estimada mediante prospecciones de hidroacústica (fuente: FLASA,1999).

Es importante destacar que el patrón de distribución horizontal de biomasa observado mediante prospecciones de hidroacústica según el cual las zonas de mayor abundancia en la región nororiental se ubican al sureste de la Isla de Margarita y norte del Estado Sucre se hace evidente a través de las estadísticas de 
la pesquería al comprobarse que los sectores de Margarita y costa norte del Estado Sucre (área Carúpano) registran la mayor producción de sardina con aportes de 48\% y $46 \%$, respectivamente (Figura II-6).

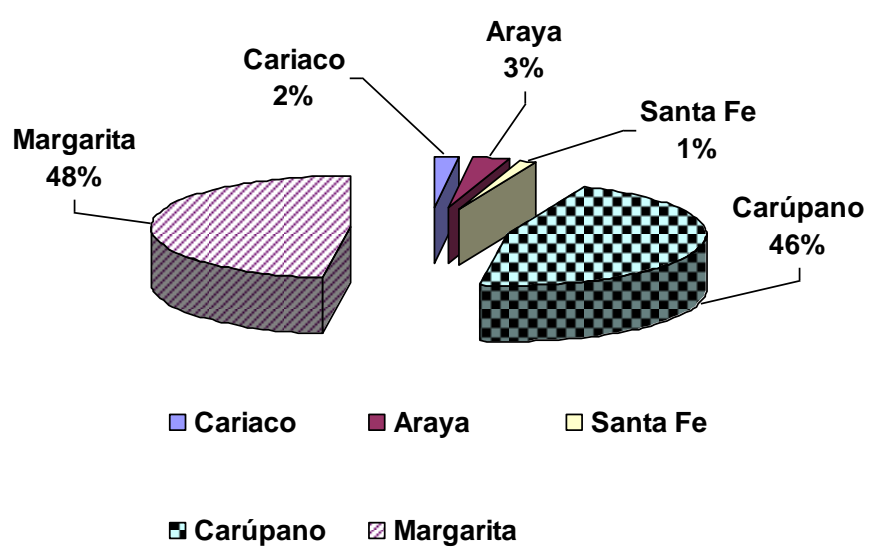

Figura II-6.- Distribución de las capturas de sardina por sectores de pesca del nororiente de Venezuela: período $2000-2004$

\section{II.2.5 Análisis de la pesquería de sardina}

La variabilidad interanual del recurso sardina es una característica propia de los pequeños peces pelágicos que ha sido relacionada con factores ambientales y de explotación. En Venezuela, la región nororiental está influenciada por un régimen de vientos que controla la hidrodinámica e induce eventos de surgencia que estimula la productividad del sistema marino-costero y contribuye a las mayores concentraciones de sardina en esta región del país. En el caso de la sardina del nororiente de Venezuela, el afloramiento es el factor que más influye en las variaciones interanuales de los niveles de abundancia relativa (Freón et al.,1991). Un posible reflejo de ello es la variación observada en el periodo analizado (2001 - 2004), y en la serie histórica 1985 -2000, en la cual se observó un crecimiento sostenido al pasar de 9.000 TM a 63.000 TM para el lapso 1985 -1997, una disminución notoria entre 1998 -2000, para ubicarse en 54.000 TM (captura promedio) (Figura II-7). Mientras que los niveles de abundancia relativa comenzaron un descenso de $50 \mathrm{TM} /$ calada a 20 TM/calada en años recientes (Guzmán, 2001). Existen otros factores abióticos, como la turbidez y rangos de mareas que también podrían afectar la abundancia 
relativa de la sardina. Sobre ellos se ha sugerido la hipótesis que ese tipo de factores influyen en la disponibilidad del recurso y como consecuencia en la capturabilidad con el "tren de argolla" al verse reducido el numero de lances positivos durante el periodo de 1997-2000 según estudios recientes (Guzmán, 2001). Otro aspecto que puede haber contribuido al descenso en los niveles de abundancia en la zona, es el de las operaciones de pesca durante el día y la noche que podrían incidir en el comportamiento del recurso. La variación en el comportamiento puede reflejarse en la distribución de la estructura de tallas que son capturadas por el arte, donde la captura podría estar constituida por tallas pequeñas, lo cual actuaría negativamente en la salud del stock.

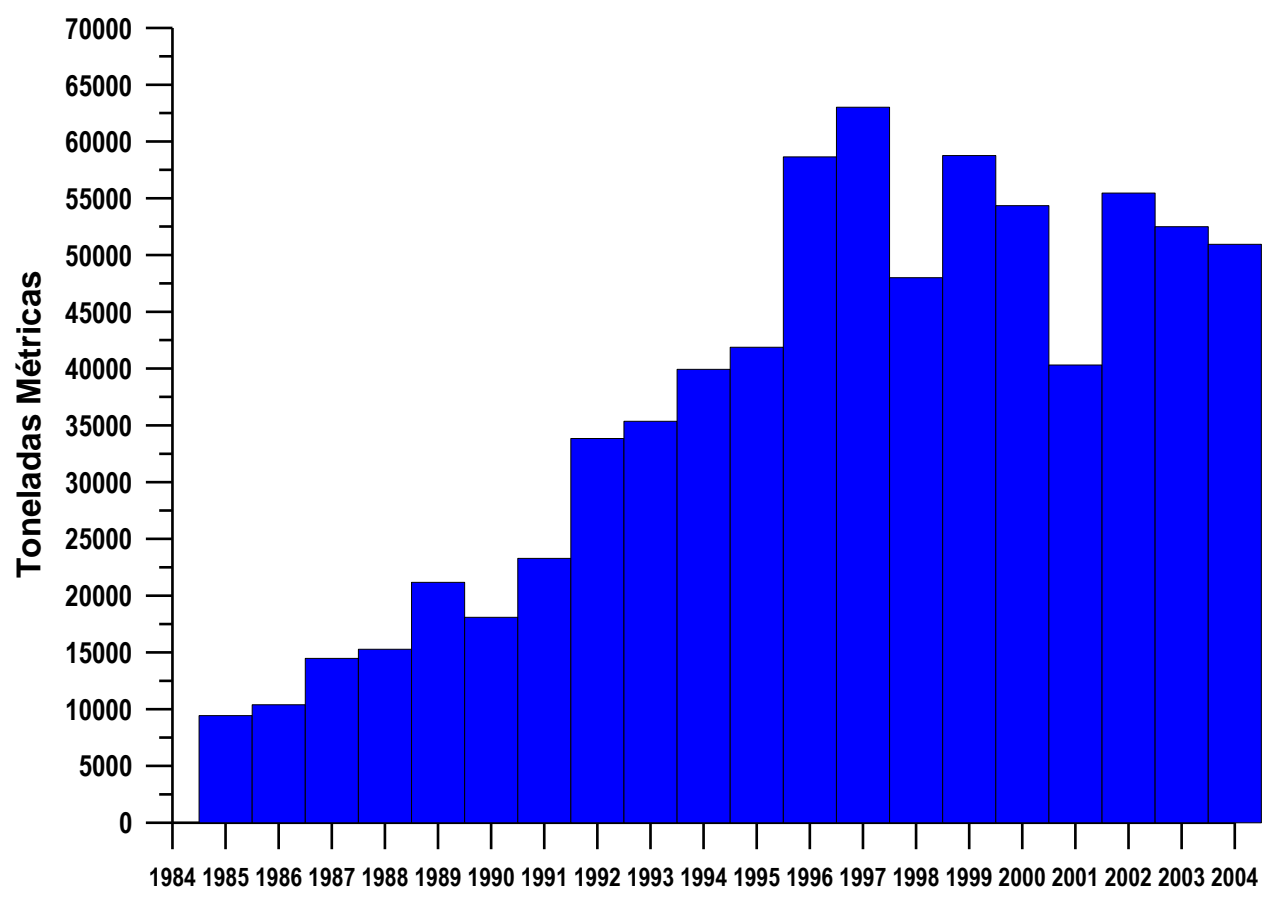

Figura II-7.- Desembarques totales (TM) de sardina en los puertos base de Guaca y Puerto Santo entre 1985 y 2004

\section{II.2.6 Conclusiones}

- Se observa un descenso sostenido (leve) en los niveles de abundancia relativa en el área de estudio para los años más recientes.

- No existe evidencia científica del origen del descenso en los niveles de abundancia relativa de años recientes. 
- Se requiere tener estimaciones anuales de biomasa de sardina por el método de eco-integración (hidroacústica) para contar con estimados confiables, los cuales permitirían establecer la posible ocurrencia de fallas en el reclutamiento anual.

\section{II.3 Pesquería Artesanal de Media Altura Demersal}

La abundancia de recursos pesqueros demersales en aguas de la plataforma continental y del talud, tanto en la jurisdicción venezolana como en la de países vecinos, ha permitido el desarrollo de una actividad de pesca artesanal conocida en nuestro país como 'Media Altura Demersal'. Esta actividad es ejercida por embarcaciones del tipo lancha con eslora comprendida entre 8 y $14 \mathrm{~m}$, generalmente con cubierta y cabina, aunque muchas de ellas solamente presentan una toldilla, y motor diesel central. La tripulación promedio comprende 1 patrón, 1 motorista y 4 marinos y realizan campañas de pesca de alrededor de 10 días de duración. Los artes de pesca más utilizados son las líneas de mano o cordeles y el palangre. La mayor parte de las embarcaciones dispone de radios (VHF y SSB), instrumentos de posicionamiento y ecosondas.

La pesca de media altura demersal experimentó un importante desarrollo, especialmente a partir de la década de 1980, cuando el régimen de cambios diferenciales y políticas crediticias del Estado atrajeron importantes inversiones hacia el sector, lo cual se tradujo en un incremento notable del número de embarcaciones (Mendoza y Lárez, 1996).

Se estima que alrededor de 400 embarcaciones se dedican a la pesca de media altura demersal en el oriente del país (Lárez, 1999), de las cuales alrededor del $80 \%$ están basadas en la Isla de Margarita (especialmente, Juan Griego y Boca de Río, Boca de Pozo y Robledal en Península de Macanao) y el resto en el estado Sucre (especialmente, en el Morro de Puerto Santo y Güiria).

Las principales especies explotadas por esta pesquería son el pargo colorado (Lutjanus purpureus), el mero fraile (Epinephelus flavolimbatus) y el cunaro (Rhomboplites aurorubens). El pargo colorado habita preferentemente sobre fondos 
rocosos en la plataforma y talud continentales en profundidades entre $30 \mathrm{~m}$ y $160 \mathrm{~m}$. El mero fraile también frecuenta fondos rocosos, pero su distribución batimétrica es más amplia, encontrándose en fondos entre 35 m y 350 m; los individuos de mayores tallas suelen distribuirse a profundidades mayores a los $100 \mathrm{~m}$. El cunaro se encuentra sobre fondos duros o de cascajo, generalmente entre $40 \mathrm{~m}$ y $100 \mathrm{~m}$ de profundidad (Cervigón, 1993). Estas especies se capturan con cordel y palangre de fondo. Sin embargo, el pargo colorado y el cunaro son más frecuentes en la pesca con cordel, mientras que el mero fraile es más abundante en las capturas de los palangres. En este apartado se analiza la distribución espacio-temporal del esfuerzo de pesca y las capturas de las especies de peces demersales explotadas por la pesquería de media altura demersal en la PNPP.

La localización geográfica del sitio de operaciones por campaña se realizó tomando en consideración las bitácoras de pesca, donde el área de la PNPP fue subdividida en sub-áreas de aproximadamente $165 \mathrm{~km}^{2}$. Posteriormente con la ayuda de cartas batimétricas se ubicaron las profundidades y tipo de fondo de las sub-áreas (Ginés, 1982). En función de la posición geográfica y la profundidad informada por los pescadores se procedió a fijar las coordenadas de la operación de pesca con una resolución aproximada en un radio de $10 \mathrm{~km}$.

La información pesquera sobre el esfuerzo y la captura se obtuvo mediante encuestas realizadas a los patrones de las embarcaciones artesanales de media altura en los diferentes puertos de Nueva Esparta y Sucre, donde las especies objetivo son el pargo y el mero. Además, se utilizó la información existente en las bitácoras de pesca recopiladas por el INIA y el INAPESCA en los estados Sucre y Nueva Esparta para el período del análisis (2000-2003). La información utilizada representa entre 8 y $10 \%$ de los desembarques totales de la flota para cada año de la serie analizada.

La medida del esfuerzo pesquero en esta pesquería es el número de anzuelos por día de pesca para las embarcaciones palangreras y el número de cordeles o líneas por día de pesca para las cordeleras. La captura y esfuerzo total muestreado por trimestres, así como las zonas de pesca y especie para cada arte se obtuvo del 
análisis de las bitácoras recopiladas como la sumatoria de los valores mensuales. La captura por unidad de esfuerzo (CPUE) obtenida al dividir la captura total por especie entre el respectivo esfuerzo pesquero, se utilizó como índice de abundancia relativa para esta pesquería.

\section{II.3.1 Evolución de la captura y esfuerzo total}

La evolución de las capturas totales muestreadas (cordeles y palangres) de pargo colorado (L. purpureus), mero fraile (E. flavolimbatus) y cunaro ( $R$. aurorubens) en la PNPP muestran una tendencia decreciente hacia el final de la serie (Figura II8). En el caso del mero se observa que luego de un máximo alcanzado de 48 TM en el año 2001, las capturas decrecen hasta alcanzar un valor cercano a las 0,8 TM en los dos últimos años. En lo que se refiere al pargo colorado se observa un volumen de capturas de $10 \mathrm{TM}$, muy similar durante toda la serie. La captura de cunaro muestra valores similares al inicio y al final de la serie, después de alcanzar un máximo en 2001 con 33 TM, muestra valores decrecientes hasta alcanzar 17 TM en 2003.

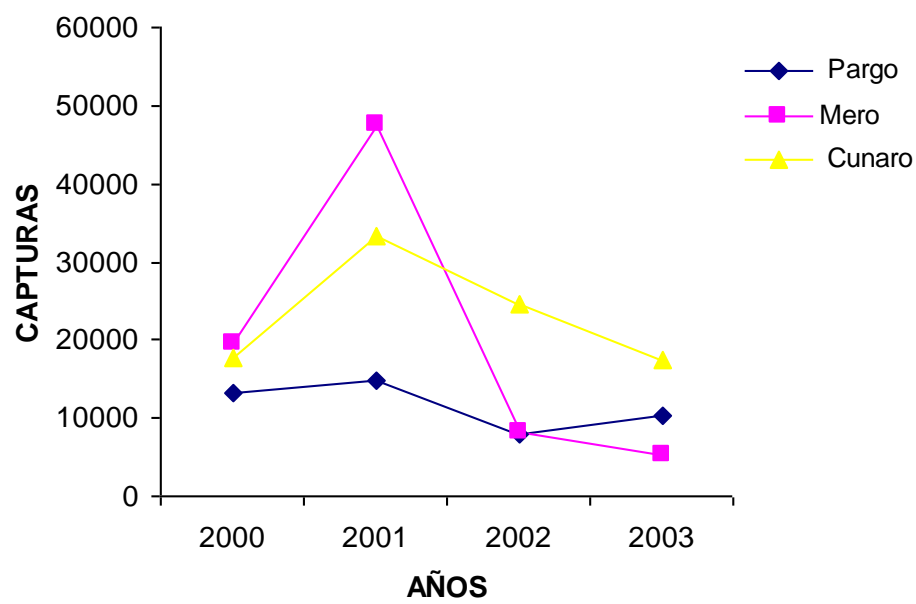

Figura II-8.- Evolución de las capturas totales (kg) por especie en la pesquería artesanal de media altura demersal en el norte de la Península de Paria.

Las especies objetivo de esta pesquería son capturadas con dos tipos de arte de pesca. El mero se pesca mayoritariamente con palangre, y el pargo, se pesca con cordel. La abundancia relativa del pargo colorado ( $\mathrm{kg} /$ cordel-día) se muestra estable 
durante los tres primeros años de la serie, con un aumento importante en el último año (Figura II-9). Mientras que en el mero ( $\mathrm{kg} / 100$ anzuelos-día), luego de alcanzar un máximo en el 2001, la abundancia tiende a disminuir para el resto de la serie.

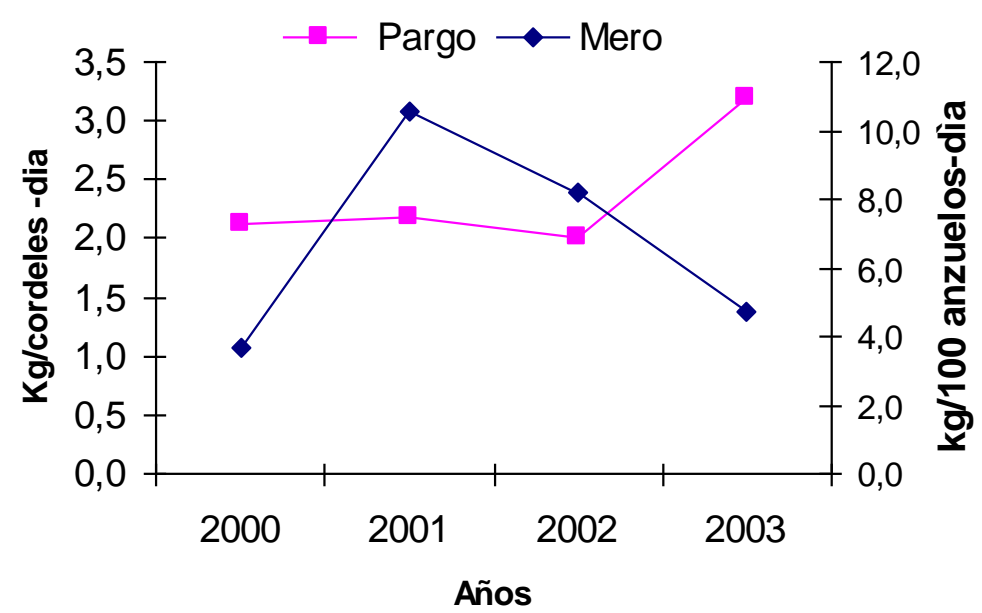

Figura II-9.- Evolución de las capturas totales (kg) por especie en la pesquería artesanal de media altura demersal en el norte de la Península de Paria.

\section{II.3.2 Análisis Temporal}

\section{Esfuerzo}

La evolución del esfuerzo de pesca de las embarcaciones palangreras por trimestre para el período 2000-2003 muestra valores mayores en el primer trimestre de cada año, a excepción del año 2000 cuando registró el valor mayor en el tercer trimestre. Valores bajos del esfuerzo de pesca en el cuarto trimestre son característicos en esta pesquería (Figura II-10). En el caso de la pesquería con cordel (Figura II-11), el esfuerzo presenta valores elevados en el primer, segundo y tercer trimestre del año, sin un patrón definido. Similarmente a la pesca con palangre, durante el cuarto trimestre, se presentan los niveles menores de esfuerzo en el área de pesca. 


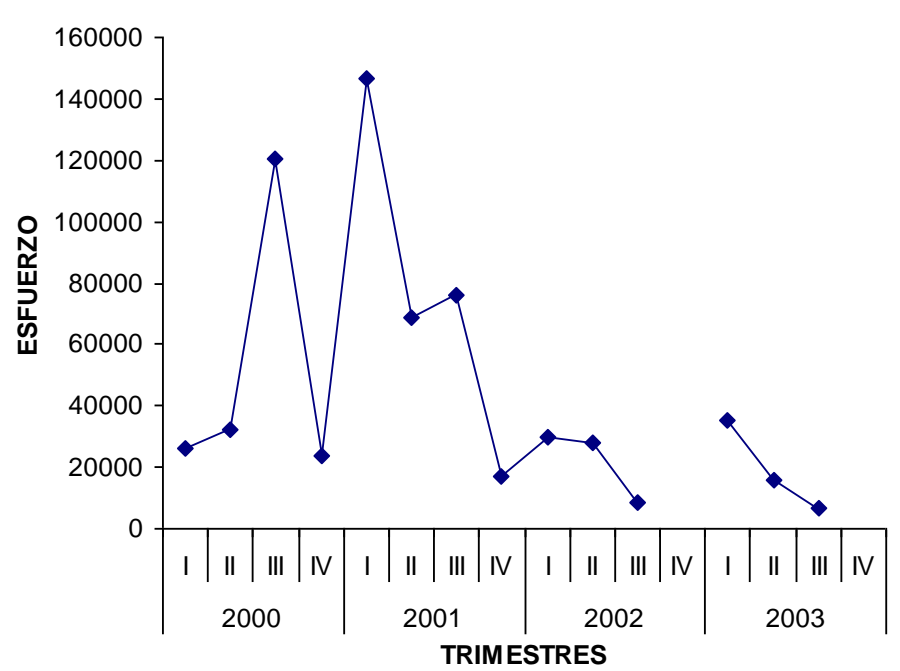

Figura II-10.- Evolución por trimestre del esfuerzo (número de anzuelos) en la pesquería artesanal de media altura demersal con palangre en el norte de la Península de Paria.

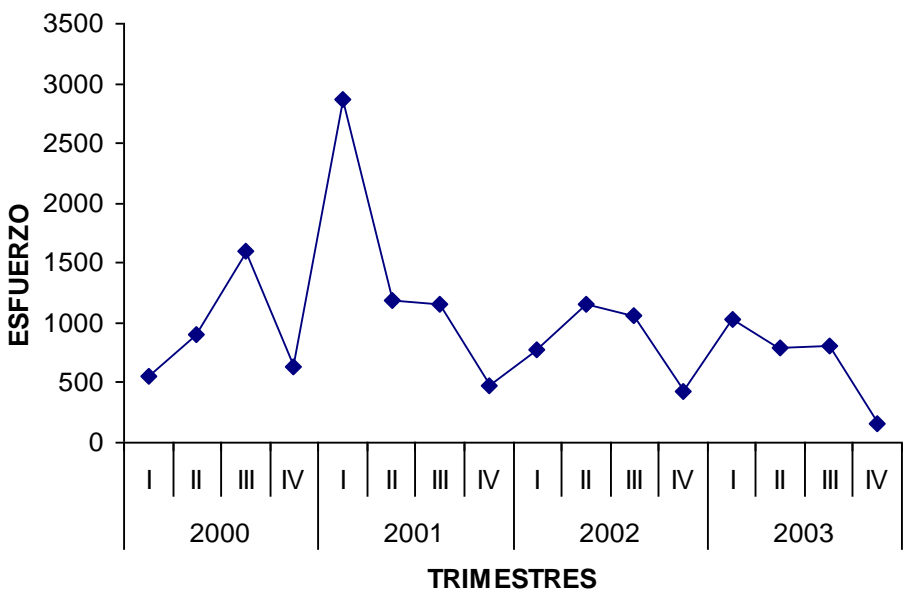

Figura II-11.- Evolución por trimestre del esfuerzo (cordel) en la pesquería artesanal de media altura demersal con cordel en el norte de la Península de Paria.

\section{Abundancia relativa}

En el caso de la pesquería con palangre, cuyo objetivo principal es el mero fraile, los niveles de abundancia relativa muestran una tendencia general decreciente, al variar de 13,3 kg/100 anzuelos-día en el primer trimestre del 2000 a 2,9 kg/100anzuelos-día para el final de la serie (Figura II-12). Si bien los niveles máximos de abundancia se mantienen relativamente altos, durante casi toda la serie de tiempo, los mismos no reflejan una estacionalidad interanual. En el caso de las 
otras especies capturadas por esta pesquería (pargo colorado y cunaro), el pargo colorado presenta la mayor abundancia relativa. En términos generales, la abundancia relativa del pargo colorado parece recuperarse en el último año de la serie a niveles del 2000, luego de unos años de baja abundancia relativa. Mientras que en el caso del cunaro, los niveles de abundancia son bastante bajos debido al carácter incidental de esta especie en la pesquería con palangre.

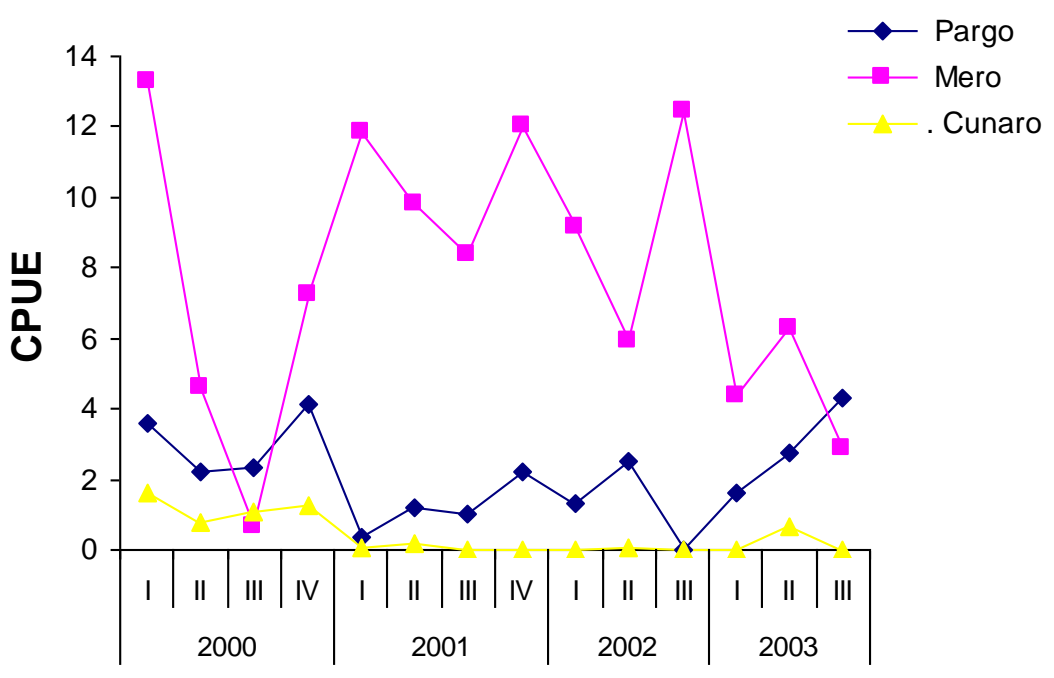

TRIMESTRES

Figura II-12.- Evolución por trimestre de la abundancia relativa (CPUE, kg/100 anzuelos) por especie en la pesquería artesanal de media altura demersal con palangre en el norte de la Península de Paria.

En la pesquería con cordel, cuyo objetivo principal es el pargo colorado, se observa el predominio en los niveles de abundancia relativa ( $\mathrm{kg} /$ cordel-día) del cunaro, con una marcada abundancia relativa máxima en los últimos trimestres de cada año (Figura II-13). La abundancia relativa del pargo colorado muestra una tendencia relativamente estable entre los periodos de la serie. El mero fraile presenta una tendencia decreciente en la abundancia relativa; sin bien los periodos de abundancia relativa máxima se mantienen estables durante casi toda la serie, los niveles de abundancia relativa caen sostenidamente en los últimos periodos de la serie. 


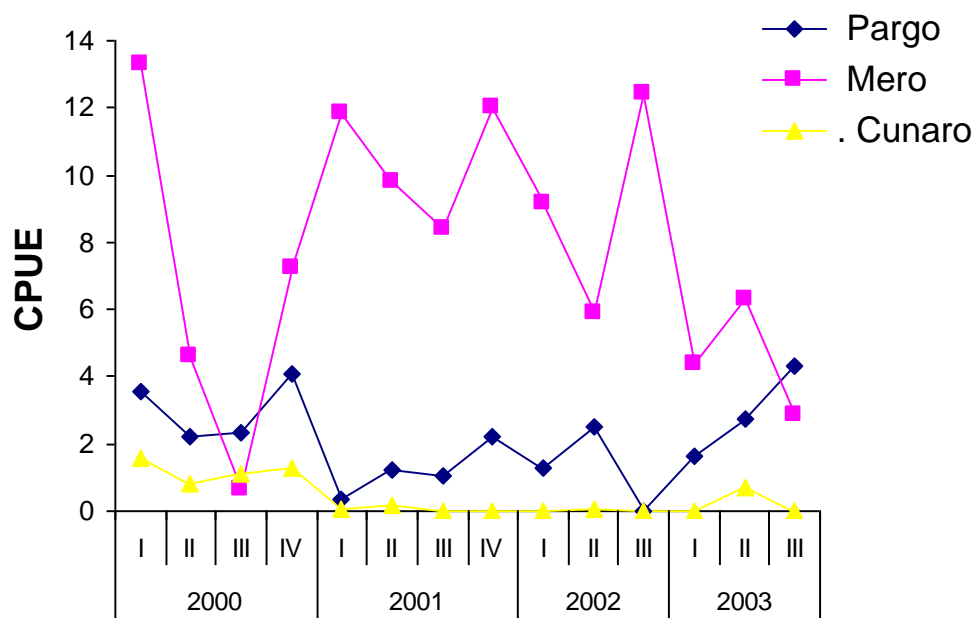

TRIMESTRES

Figura II-13.- Evolución por trimestre de la abundancia relativa (CPUE, $\mathrm{kg} / \mathrm{cordel}$ ) por especie en la pesquería artesanal de media altura demersal con cordel en el norte de la Península de Paria.

\section{II.3.3 Análisis Espacial}

\section{Palangre}

La distribución espacial de la abundancia relativa de las tres especies capturadas por la pesquería con palangre revela que los niveles elevados se encuentran alrededor de Los Testigos durante el primer trimestre, mientras que durante el tercer trimestre los niveles más elevados se encuentran al norte de los yacimientos gasíferos objeto de explotación por parte del PMS (Figura II-14 y Figura II-15). En el segundo y cuarto trimestre, los niveles importantes de abundancia relativa del pargo colorado se presentan hacia el oeste de Los Testigos. La distribución espacial de la abundancia relativa del mero fraile, objetivo principal de la pesquería con palangre, revela que las mayores concentraciones están ubicadas al norte de los yacimientos durante las cuatro trimestres del año. Concentraciones de abundancia relativa menores se pueden encontrar en los alrededores de Los Testigos y al oeste del Archipiélago. 

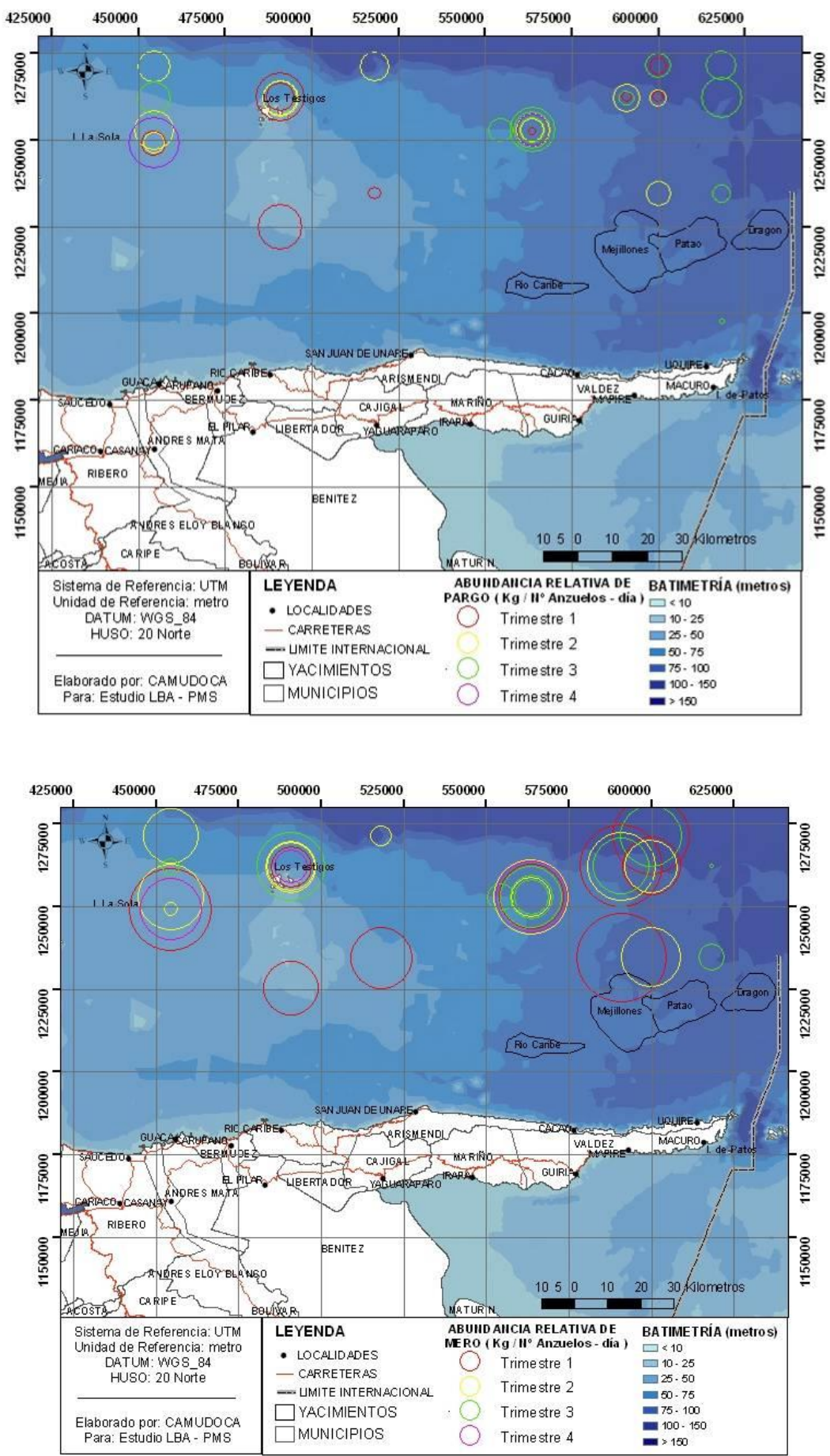

Figura II-14.- Abundancia relativa promedio trimestral para las especies más importantes capturadas por la pesquería artesanal de media altura demersal con palangre, mero fraile (arriba) y pargo colorado (abajo).

En el caso del cunaro, especie de carácter incidental en la pesca con palangre, la distribución espacial de la abundancia relativa indica que las concentraciones importantes se encuentran alrededor de Los Testigos durante el 
primer, segundo y último trimestre del año; mientras que en el tercer trimestre las concentraciones importantes se ubican al norte de los yacimientos.

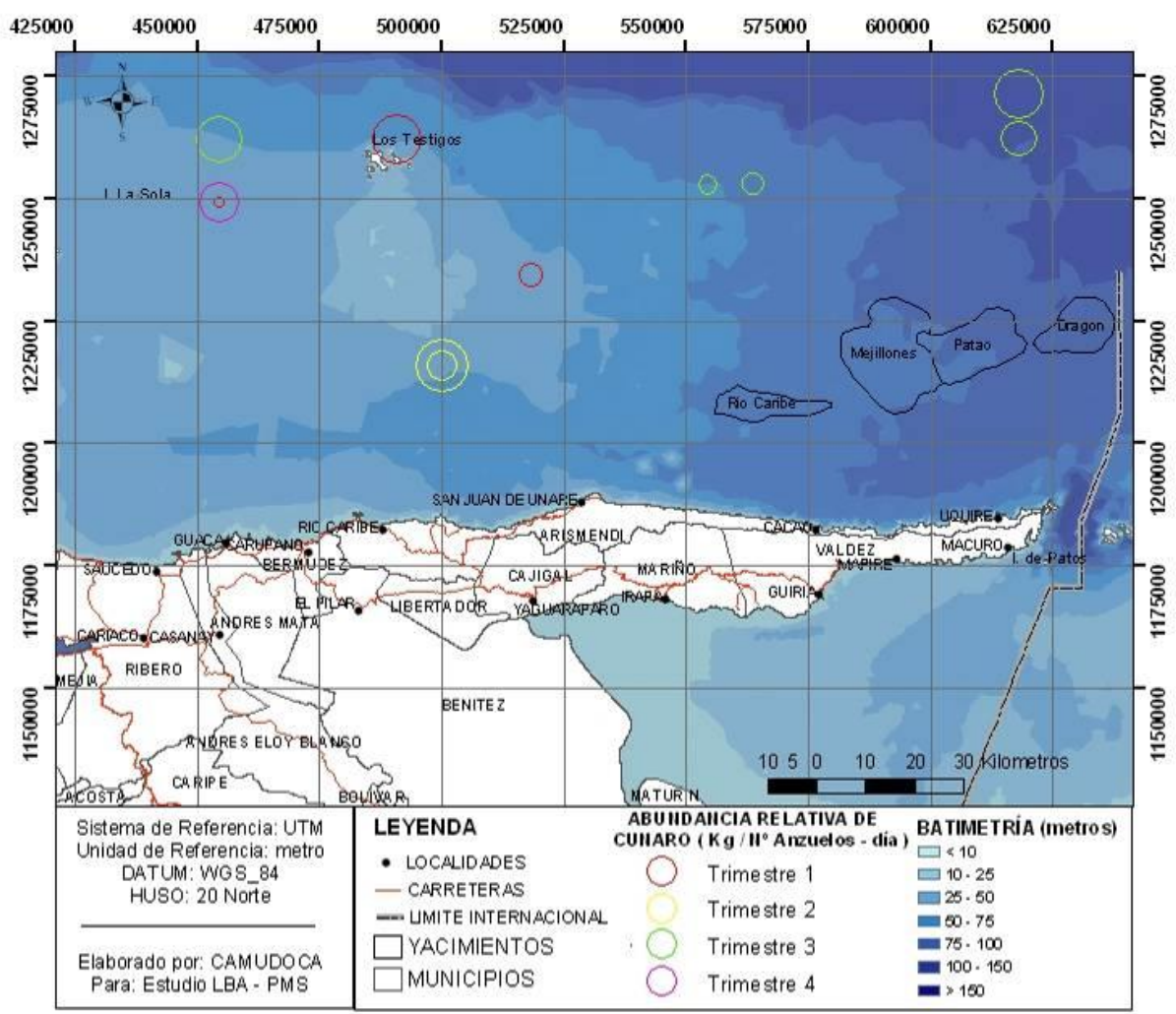

Figura II-15.- Abundancia relativa promedio trimestral para el cunaro capturado por la pesquería artesanal de media altura demersal con palangre.

\section{$\underline{\text { Cordel }}$}

La distribución espacial de la abundancia relativa de las especies capturadas por la pesquería con cordel revela que los niveles elevados se encuentran alrededor de Los Testigos durante casi todo el año, mientras que durante el segundo, tercer y cuarto trimestre, los niveles más elevados se encuentran al norte de los yacimientos (Figura II-16 y Figura II-17). Los niveles importantes de abundancia relativa del pargo colorado, especie objetivo de esta pesquería, se concentran alrededor de Los Testigos durante el primer y tercer trimestre, aunque también se encontraron concentraciones importantes en el resto del periodo. En el segundo y cuarto trimestre se observan importantes concentraciones al norte de los yacimientos, aunque también hay concentraciones de menor magnitud el resto del año. En el caso del 
cunaro, especie que muestra niveles crecientes en la pesquería con cordel, la distribución espacial de la abundancia relativa indica que las concentraciones importantes se encuentran al norte de los yacimientos durante el segundo y tercer trimestre. Durante el segundo, tercer y último trimestre del año se observan importantes concentraciones al norte de la Península de Paria alrededor de Cabo Tres Puntas; mientras que en el primer trimestre las concentraciones aparecen en el Bajo Cumberland y al sur de Los Testigos.

La abundancia relativa del mero fraile se presenta al norte de los yacimientos durante el primer, tercero, cuarto trimestre del año en concentraciones importantes al igual que en los alrededores de Los Testigos durante el segundo trimestre 


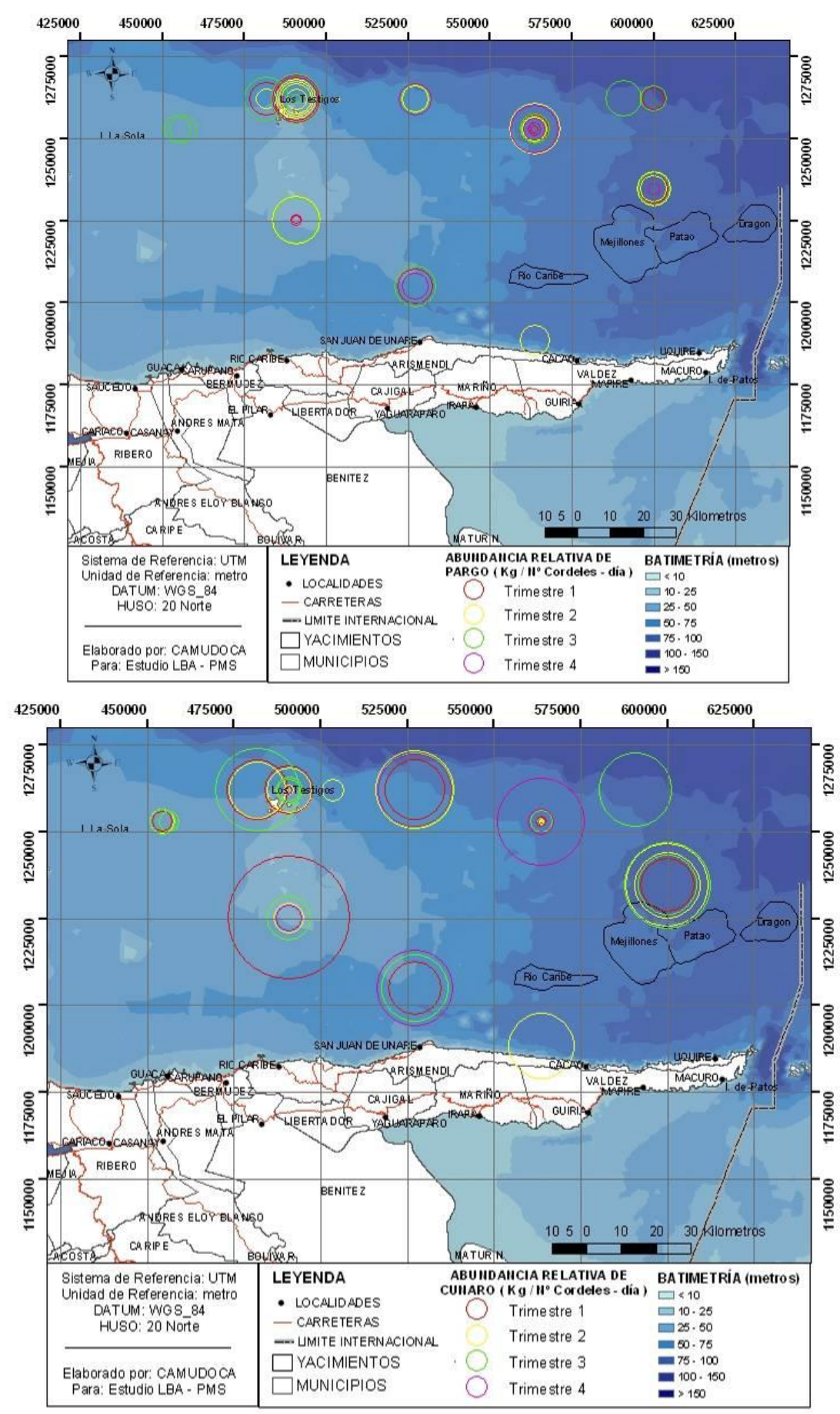

Figura II-16.- Abundancia relativa promedio trimestral para las especies más importantes capturadas por la pesquería artesanal de media altura demersal con cordel, pargo colorado (arriba) y cunaro (abajo). 


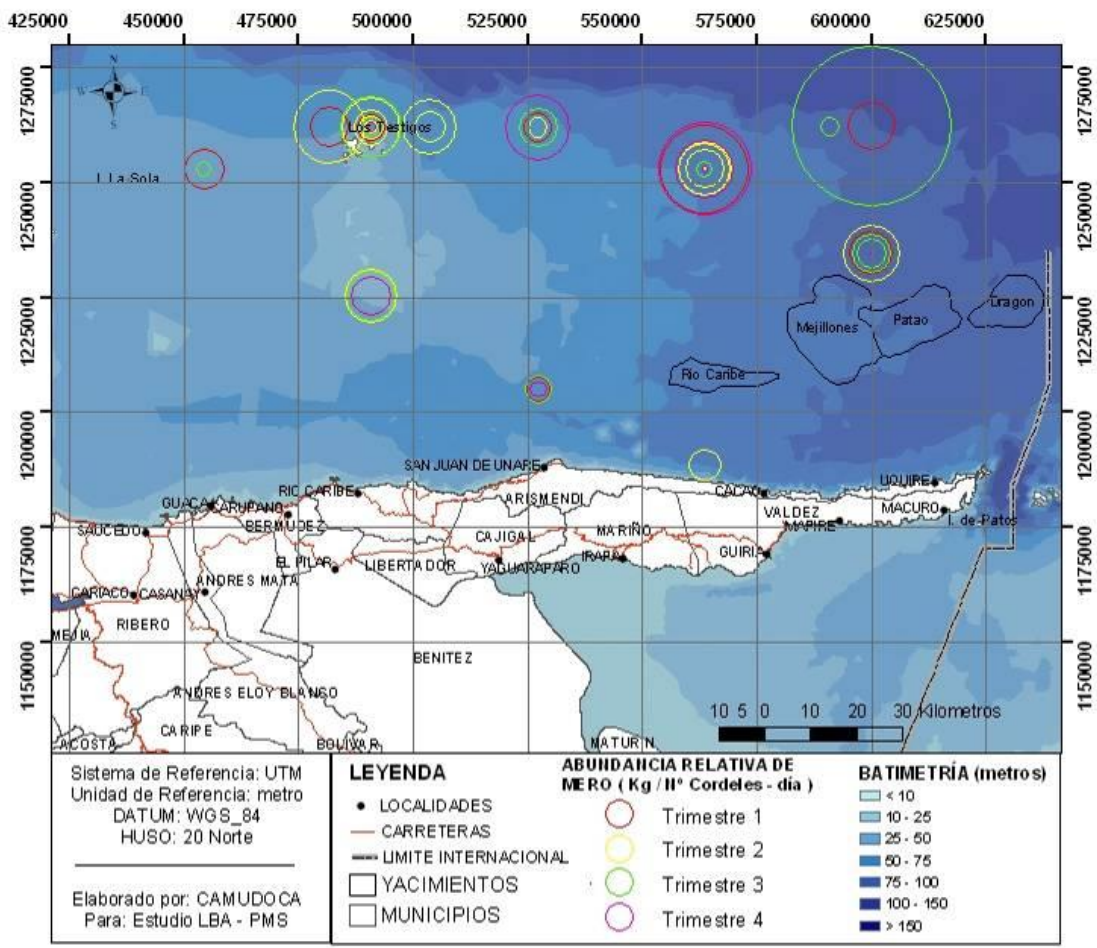

Figura II-17.- Abundancia relativa promedio trimestral para el mero fraile capturado por la pesquería artesanal de media altura demersal con cordel.

\section{II.3.4 Análisis de los recursos pesqueros capturados por la pesquería artesanal de media altura demersal}

La composición de las capturas con cordel de la flota artesanal de media altura demersal en la PNPP indica que el pargo colorado (L. purpureus), y el mero fraile (E. flavolimbatus) tradicionalmente representan las especies objetivos de la flota de media altura demersal. El cunaro ( $R$. aurorubens) que se capturaba de manera incidental, pero desde el 2001 un número creciente de embarcaciones optaron por dirigir su esfuerzo de pesca a la captura de esta especie. Esto probablemente obedece a la baja en las capturas de las especies objetivo, así como a demandas del mercado y al notable incremento en el precio de venta a nivel de productor (Lárez, 1999). 
En términos de la actividad pesquera, el esfuerzo de pesca tiende a disminuir en el primer y segundo trimestre, lo cual indica que el esfuerzo se traslada parcialmente a otras áreas de pesca tales como: oeste de la Isla de Margarita, norte de La Blanquilla, sureste de Trinidad y margen Atlántico venezolano (Lárez y Mendoza, 1999).

El índice de abundancia relativa (CPUE) de la pesquería que utiliza palangre muestra al mero fraile como especie objetivo a lo largo de la serie analizada. Su abundancia relativa presenta una variación espacio-temporal interanual, manteniéndose similar en el primer y cuarto trimestre durante los años 2000 y 2001, y solo en el primer trimestre para el resto de la serie analizada. La distribución observada en el primer y cuarto trimestre coincide con la captura de mero fraile realizada con cordel, de donde se puede inferir que existen agregaciones de la especie en las zonas de pesca que pueden estar asociadas a la historia de vida de esta especie, concretamente a la reproducción (Smith,1978).

Los niveles de abundancia relativa más altos en el pargo colorado tienden a presentarse en el tercer trimestre del año en ambas pesquerías. Sin embargo, el patrón no está definido ya que se observan niveles importantes de abundancia relativa en los otros trimestres, pero en años distintos, lo que indica que no existe una estacionalidad definida para la abundancia del pargo colorado en el área de estudio.

En la pesquería con cordel, los niveles de abundancia relativa del cunaro, evidencian el cambio de la especie objetivo de esta pesquería, al observarse que durante los dos últimos años los niveles de abundancia relativa se incrementan progresivamente a partir del segundo trimestre hasta alcanzar el máximo en el cuarto trimestre. Sin embargo, parece que los niveles elevados que se concentran entre el primer y cuarto trimestre pueden obedecer a concentraciones de esta especie en las zona de pesca en respuesta a etapas de su historia de vida (reclutamiento o reproducción), la cual no es conocida en el área.

La distribución espacial de los niveles de abundancia de las especies capturadas por la pesca de media altura demersal con cordel y palangre en el área 
del Proyecto Mariscal Sucre presentan una elevada variabilidad como ocurre en especies de peces que tienen movimientos importantes en una amplia región marina (Arreguin-Sánchez et al., 1996). La elevada concentración de las especies consideradas podría ser un reflejo de agregaciones relacionadas con la historia de vida de cada una de ellas y de las que no se tiene información biológica que permita caracterizar el tipo de agregación y su relación con el hábitat donde se encuentran.

\section{II.3.5 Conclusiones}

- En las pesquerías demersales, la especie predominante capturada con palangre es el mero fraile (Epinephelus flavolimbatus), y con cordel, el cunaro (Rhomboplites aurorubes), la cual se captura incidentalmente en la pesca con palangre.

- El pargo colorado (Lutjanus purpureus), especie objetivo en la pesca con cordel, ha disminuido significativamente en las capturas, orientando la flota a la captura del cunaro (Rhomboplites aurorubens).

- La distribución espacio-temporal del pargo colorado, mero fraile y cunaro no muestra una estacionalidad definida en el área de estudio, pero posiblemente está relacionada con agregaciones asociadas a la historia de vida de cada especie (reproducción, reclutamiento) y condicionada por los cambios ambientales que ocurren en su hábitat esencial.

\section{II.4 Pesquería Artesanal de Media Altura Pelágica}

La abundancia de recursos pesqueros pelágicos en aguas de la plataforma continental y del talud ha permitido el desarrollo de una actividad de pesca artesanal conocida en nuestro país como de 'Media Altura Pelágica'. Esta actividad, al igual que en la pesquería artesanal de media altura demersal, es ejercida por embarcaciones del tipo lancha con eslora comprendida entre 8 y 14 m, generalmente con cubierta y cabina, aunque muchas de ellas solamente presentan una toldilla, y motor diesel central. La mayor parte de las embarcaciones dispone de radios (VHF y SSB), instrumentos de posicionamiento y ecosondas. Los artes de pesca más 
utilizados con las líneas de mano o cordeles y el palangre. No obstante, las embarcaciones tienden a ser polivalentes y pueden ejercer actividades de pesca tanto pelágica como demersal.

La flota artesanal de media altura pelágica posee características particulares desde el punto de vista operacional. Durante el segundo y tercer trimestre del año, principalmente desde abril hasta septiembre, muchas embarcaciones operan con líneas de mano (cordeles) y dirigen su esfuerzo a la captura del carite-sierra (Scomberomorus cavalla), capturando también otras especies entre las que se encuentran la picúa (Sphiraena barracuda), el dorado (Coryphaena hippurus), el peto (Acanthocybium solandri), y pequeños escómbridos como las cabañas, Auxis thazard, Euthynnus alleteratus y Sarda sarda. El resto del año, una fracción importante de las mismas embarcaciones, operan con palangre derivante 0 de superficie y dirigen su esfuerzo a la captura de peces de pico de la familia Istiophoridae entre los que se encuentran las agujas, blanca (Tetrapturus albidus) y azul (Makaira nigricans), y el palagar o pez vela (Istiophorus albicans).

En esta pesquería, durante los últimos años, se ha dirigido una porción importante del esfuerzo pesquero hacia la captura del dorado (Coryphaena hippurus), especie que ha alcanzado buenos precios en el mercado. También se capturan incidentalmente diversas especies de túnidos entre las que se pueden citar el atún aleta amarilla (Thunnus albacares), el atún albacora ( $T$. alalunga), el atún aleta negra ( $T$. atlanticus), así como también el peto ( $A$. solandri) y tiburones de varias especies (Marcano, 1999). En este apartado se analiza la distribución espaciotemporal del esfuerzo de pesca y las capturas de las especies de peces pelágicas (dorado, carite, agujas, y tiburones) explotadas por la pesquería de media altura pelágica en la PNPP.

La información estadística de la pesquería de media altura pelágica con cordel y palangre fue recolectada mediante visitas quincenales a los puertos de desembarque del estado Sucre: Carúpano y Morro de Puerto Santo y del estado Nueva Esparta: Juangriego, Bella Vista y Boca de Pozo. Adicionalmente, se recolectaron bitácoras de pesca en los mismos puertos. La información recolectada 
consistió en: nombre de la embarcación, fecha de salida y de llegada, tiempo efectivo de pesca, sitio de pesca y coordenadas geográficas, número de pescadores, arte de pesca, número de cordeles, número de anzuelos en el palangre, desembarques $(\mathrm{kg})$ por especie. La información fue procesada en consideración al área de influencia del PMS y fueron agrupadas por trimestre, año y área geográfica en cuadrantes aproximados de $2 \mathrm{~km}^{2}$. El esfuerzo pesquero en la pesca con cordel está expresado en cordeles-día y en la pesca con palangre en número de anzuelos-día. La captura es registrada en $\mathrm{kg}$ por especie. El índice de abundancia relativa utilizada es la captura por unidad de esfuerzo (CPUE) estimada como la captura de cada especie (kg) dividido entre el número de cordeles por día, en el caso de la pesca con cordel, y entre el número total anzuelos-día en el caso de los palangreros.

\section{II.4.1 Pesca de Media Altura Pelágica con Cordel.}

Esfuerzo y capturas

El esfuerzo de pesca en esta pesquería presenta una clara señal estacional en los dos últimos años de la serie, siendo éstos más elevados en el tercer trimestre (Figura II-18). Mientras que en los dos primeros años, la señal máxima aparece en el segundo y primer trimestre. Las capturas controladas en el área de influencia del proyecto responden al patrón observado en el esfuerzo pesquero aplicado durante el período analizado. 


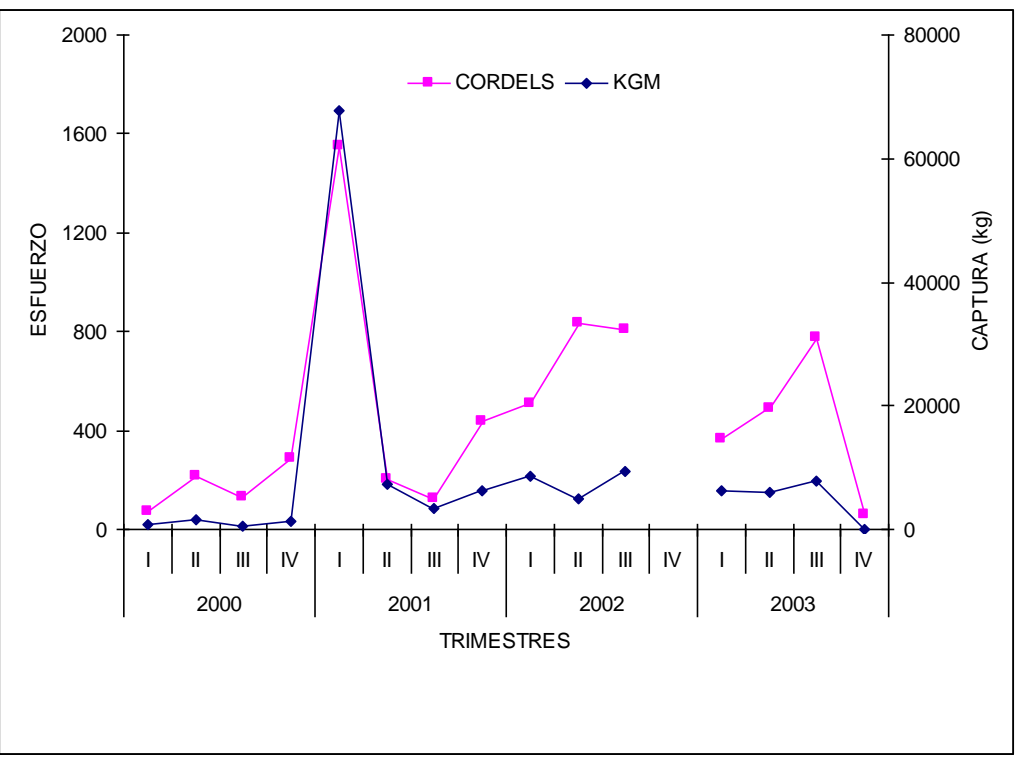

Figura II-18.- Evolución por trimestre del esfuerzo (cordel) y captura total en la pesquería artesanal de media altura pelágica con cordel en el norte de la Península de Paria.

Abundancia relativa

Los niveles de abundancia relativa expresados en CPUE, evidencian al caritesierra como la especie objetivo de la pesca con cordel (Figura II-19). La tendencia general en la abundancia relativa del carite-sierra es hacia la disminución progresiva a partir de la máxima abundancia relativa ( $>44 \mathrm{~kg} /$ cordel-día) observada en el primer trimestre del 2001, hasta niveles de $2 \mathrm{~kg} /$ cordel-día en el último periodo de la serie. Sin embargo, hay que considerar que los niveles de esfuerzo pesquero en el último trimestre del año suelen ser los más bajos del año. Por otro lado, los niveles de abundancia de las otras especies importantes capturadas por la pesquería (e.g., carite pintado, dorado, y picúa) con cordel son opacados por los del carite-sierra. Entre estas especies, el dorado es la que mas abunda y presenta cierto grado de estacionalidad a mediados del año. 


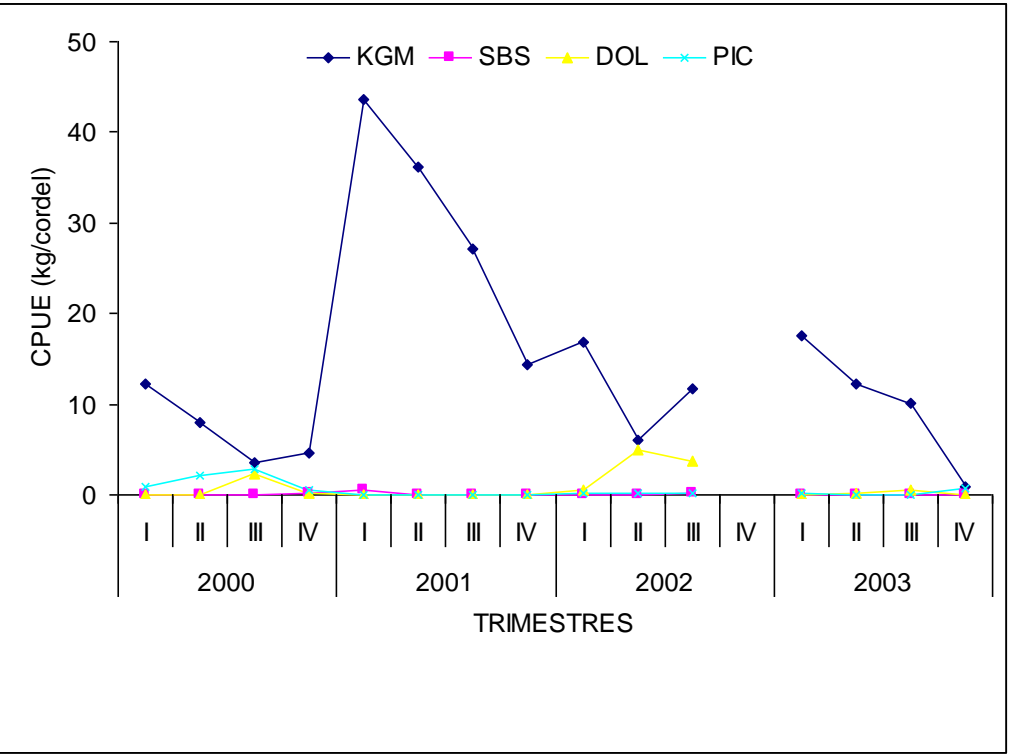

Figura II-19.- Evolución por trimestre de la abundancia relativa (CPUE, kg/cordel) por especie en la pesquería artesanal de media altura pelágica con cordel en el norte de la Península de Paria.

\section{Distribución espacial}

La distribución espacial de la abundancia relativa del carite-sierra, considerado como la especie más importante de esta pesquería, revela que los niveles más elevados se encuentran alrededor de Los Testigos durante casi todo el año; mientras que durante el primero, segundo, y tercer trimestre, se observan niveles importantes en los alrededores del yacimiento Río Caribe y unos niveles de abundancia relativa considerables al noreste de las yacimientos (Figura II-20). En el último trimestre, los niveles de abundancia relativa en los alrededores de los yacimientos son bajos. 


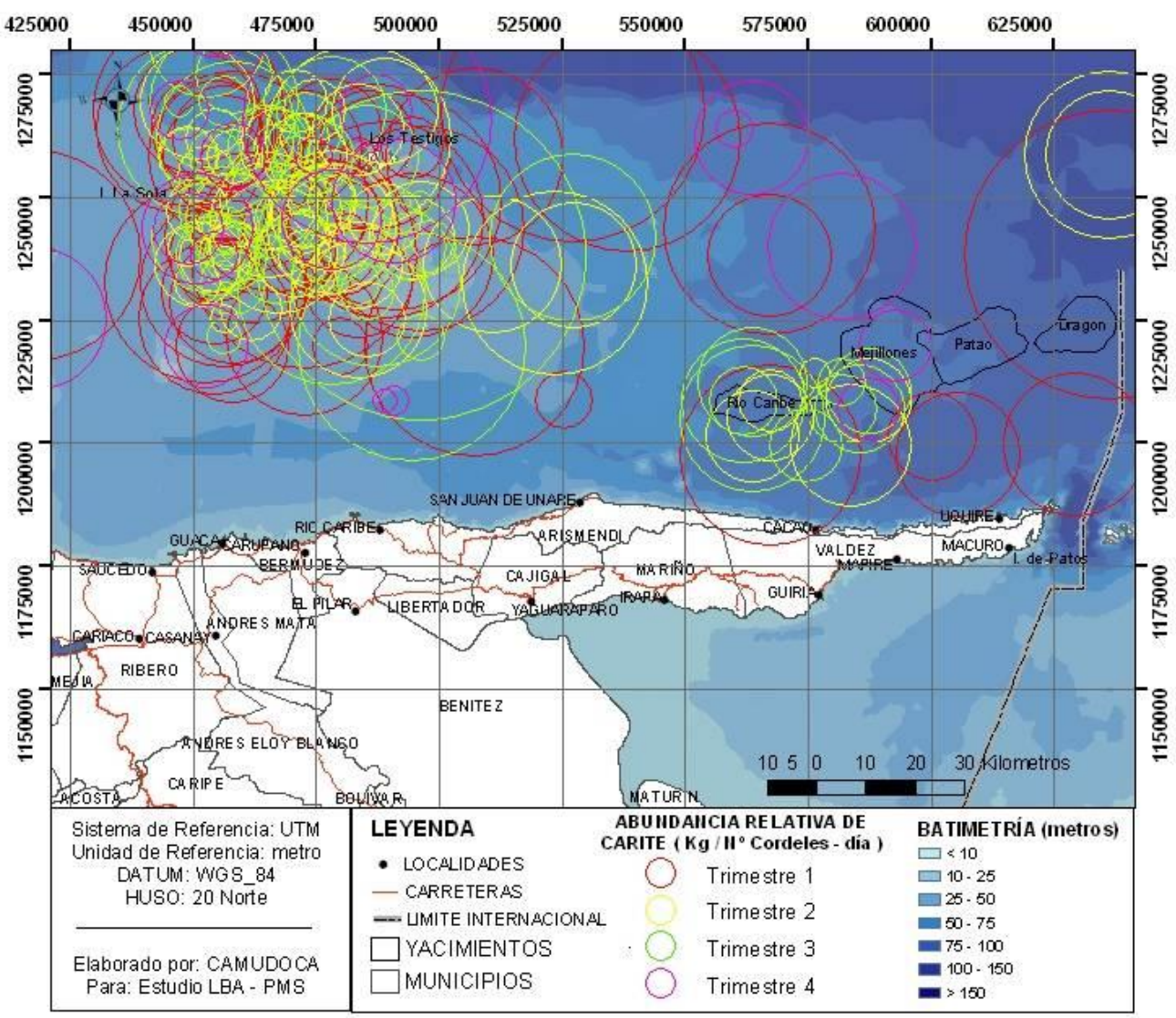

Figura II-20.- Abundancia relativa promedio trimestral para la especie más importante capturada por la pesquería artesanal de media altura pelágica con cordel, el carite-sierra (KGM).

\section{II.4.2 Pesca de Media Altura Pelágica con Palangre}

\section{Esfuerzo y capturas}

El esfuerzo de pesca en esta pesquería presenta los valores más elevados en el segundo trimestre del 2001 y 2002; mientras que en los años 2000 y 2003 los valores máximos se observan en el tercer y primer trimestre (Figura II-21). Las capturas controladas en el área de influencia del proyecto, presentan un patrón similar al del esfuerzo pesquero aplicado en el período 2000-2003. 


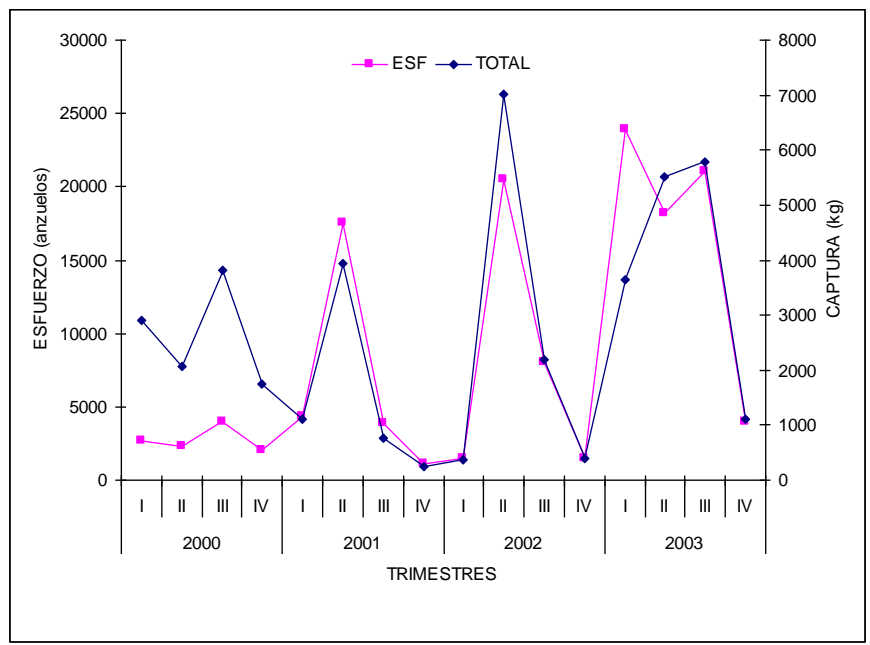

Figura II-21.- Evolución por trimestre del esfuerzo (anzuelos) y captura total en la pesquería artesanal de media altura pelágica con palangre en el norte de la Península de Paria.

Las especies más importantes capturadas en la pesquería con palangre son el dorado, la aguja blanca, y el palagar o pez vela, las cuales representan el objetivo de la pesquería siendo un $65 \%$ del total de la captura para la serie de tiempo analizada, y del cual, el dorado representa el 54\% (Figura II-22). Entre las otras especies que son capturadas por esta pesquería hay especies de túnidos, entre los que se encuentran el atún aleta amarilla y el atún aleta negra (15\%), y también se consiguen varias especies de tiburones de la familia Carcharhinidae con un $7 \%$ del total de la captura registrada durante el periodo de tiempo analizado. 


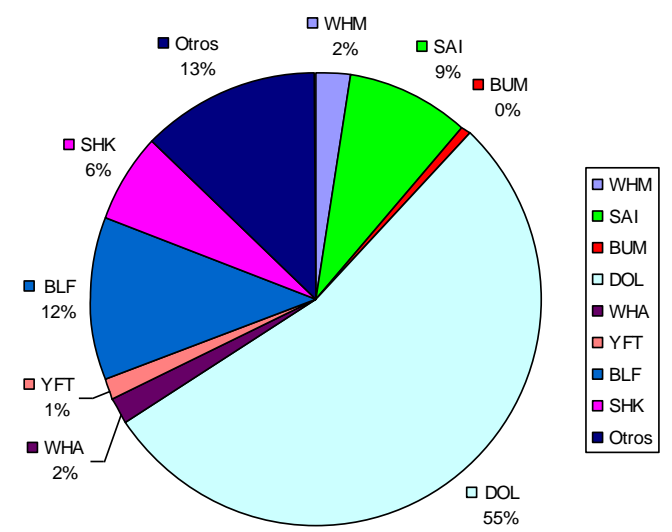

Figura II-22.- Distribución proporcional de la captura por especie en la pesquería artesanal de media altura pelágica con palangre en el norte de la Península de Paria. (WHM, aguja blanca; SAI, pez vela; BUM, aguja azul; DOL, dorado; WHA, peto; YFT, atún aleta amarilla; BLF, atún aleta negra; SHK, tiburones).

La evolución de las capturas de dorado en la PNPP no muestra una tendencia definida (Figura II-23), aunque parece que las mismas tienen un auge durante el segundo y tercer trimestre del año. En el caso del palagar o pez vela se observa que las capturas importantes se produjeron en la primera mitad del año 2003. El resto de las especies no presentan un patrón definido de capturas debido a lo escaso de las mismas en la PNPP.

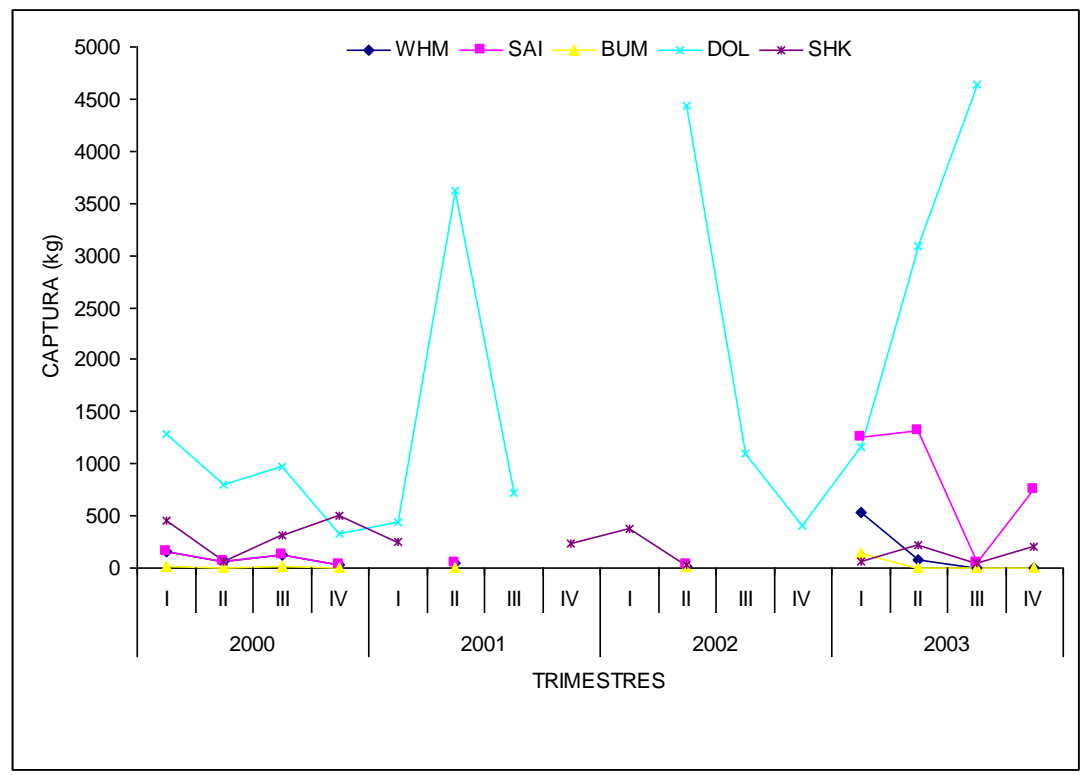

Figura II-23.- Evolución por trimestre de la captura por especie en la pesquería artesanal de media altura pelágica con palangre en el norte de la Península de Paria.

Abundancia relativa 
Los niveles de abundancia relativa expresados en CPUE, evidencian al dorado y a los tiburones como la especie y rubro con los mejores niveles de abundancia relativa de la pesca con palangre para el periodo analizado en la PNPP (Figura II-24). La tendencia general en la abundancia del dorado durante la temporada de pesca es hacia una estabilización (alrededor de $20 \mathrm{~kg} / 100$ anzuelos-día) a partir de la máxima abundancia relativa ( $>45 \mathrm{~kg} / 100$ anzuelos-día). Mientras que en el caso de los tiburones, la abundancia relativa parece incrementarse en periodos de capturas bajas de dorado, al menos durante los tres primeros años de la serie. Por otro lado, la abundancia relativa de istiofóridos (aguja blanca y palagar) es baja en la PNPP, aunque en el último año de la serie, la abundancia relativa del palagar muestra un aumento importante, particularmente en el último trimestre del año.

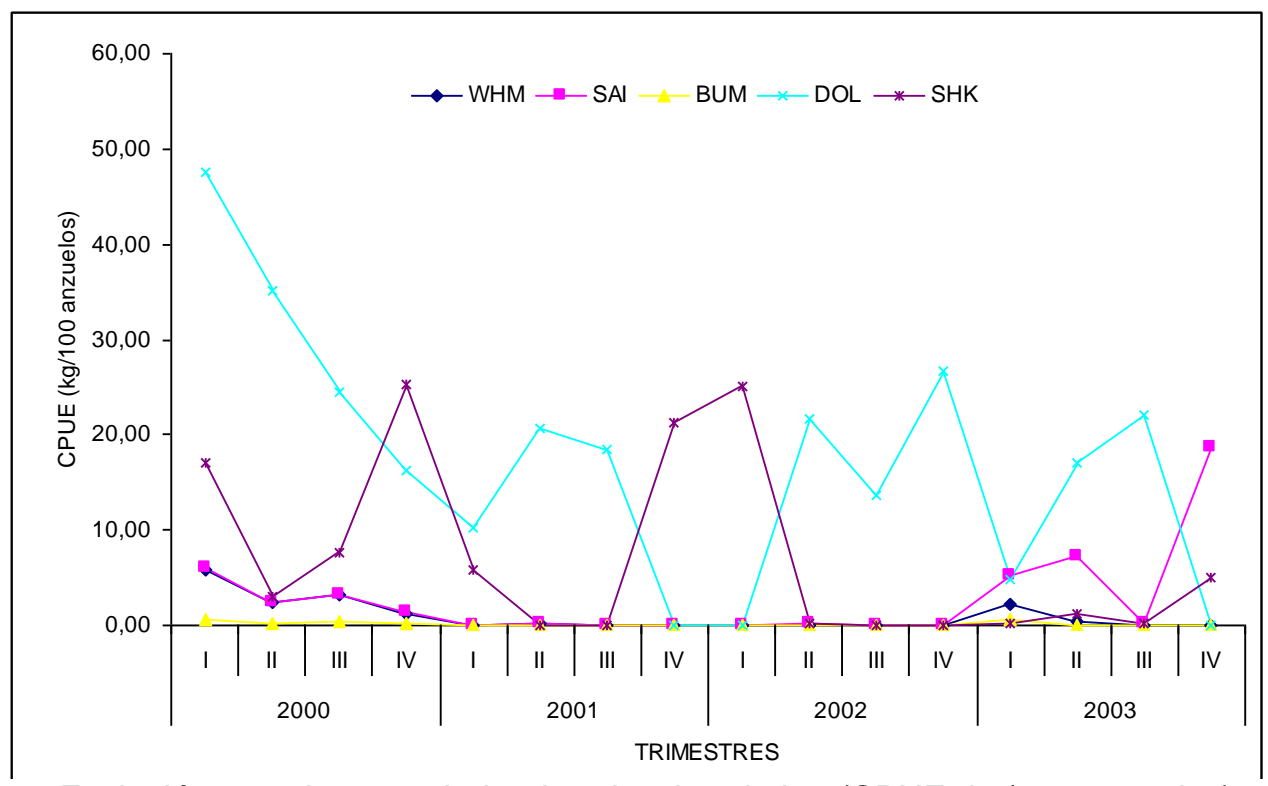

Figura II-24.- Evolución por trimestre de la abundancia relativa (CPUE, kg/100 anzuelos) por especie en la pesquería artesanal de media altura pelágica con palangre en el norte de la Península de Paria.

\section{Distribución espacial}

La distribución espacial de la abundancia relativa de los tres grupos de especies capturados por la pesquería con palangre revela que los niveles elevados se encuentran distribuidos según la(s) especie(s). En el caso del dorado, los mayores niveles de abundancia relativa están alrededor de los yacimientos durante el primer trimestre y al oeste de los yacimientos (al norte de Cabo Tres Puntas) durante el 
segundo trimestre; mientras que durante el tercer y cuarto trimestre los niveles más elevados se encuentran en el Banco Cumberland (Figura II-25).

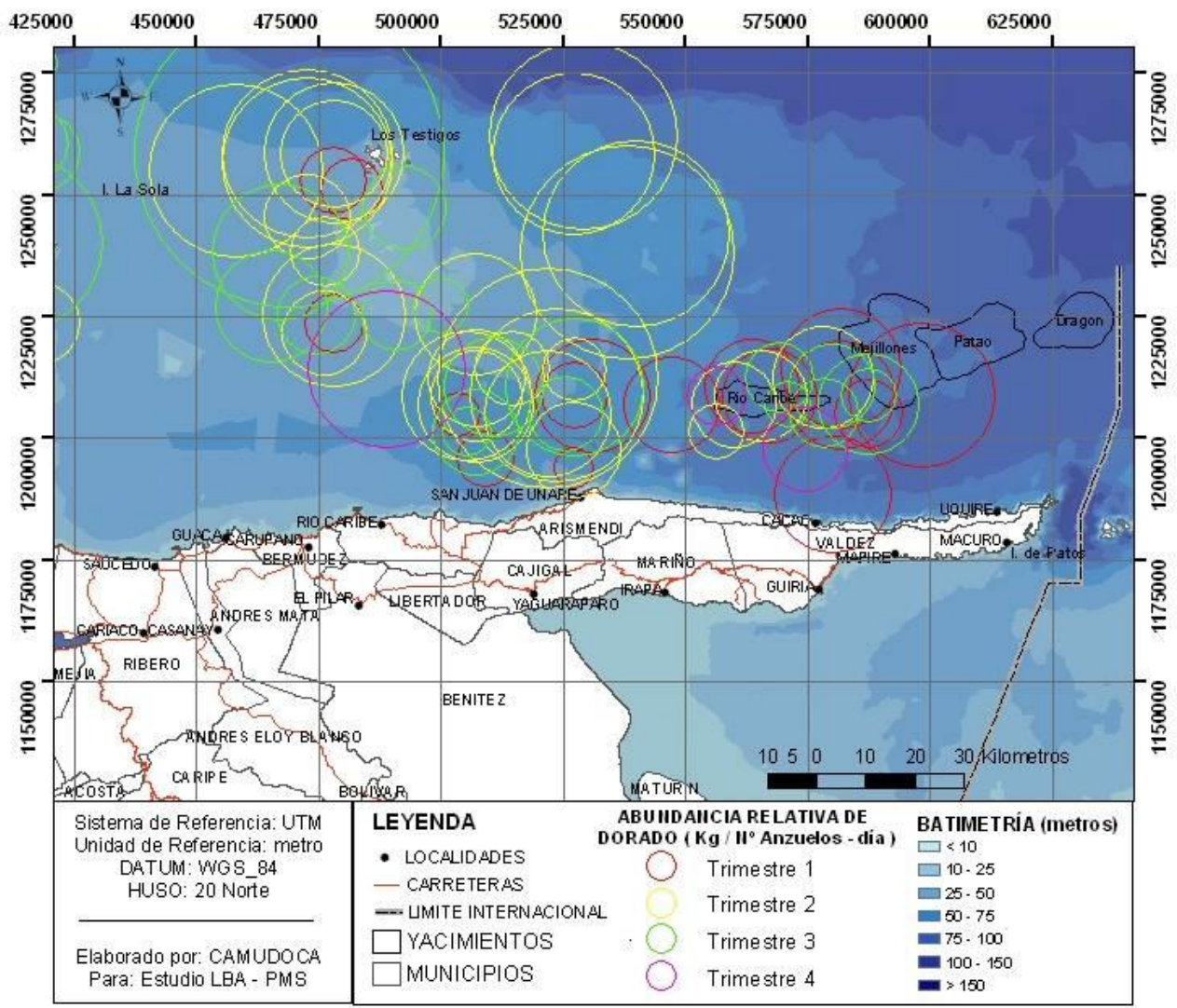

Figura II-25.- Promedio trimestral de la abundancia relativa para el dorado (DOL) capturado por la pesquería artesanal de media altura pelágica con palangre.

La distribución espacial de la abundancia relativa en istiofóridos, revela que las mayores concentraciones están ubicadas al oeste de los yacimientos (al norte de Cabo Tres Puntas) durante el primer y segundo trimestre del año, y alrededor de los yacimientos en el tercer trimestre del año. Concentraciones de abundancia relativa menores se pueden encontrar en los alrededores de Los Testigos en el último trimestre del año (Figura II-26). 


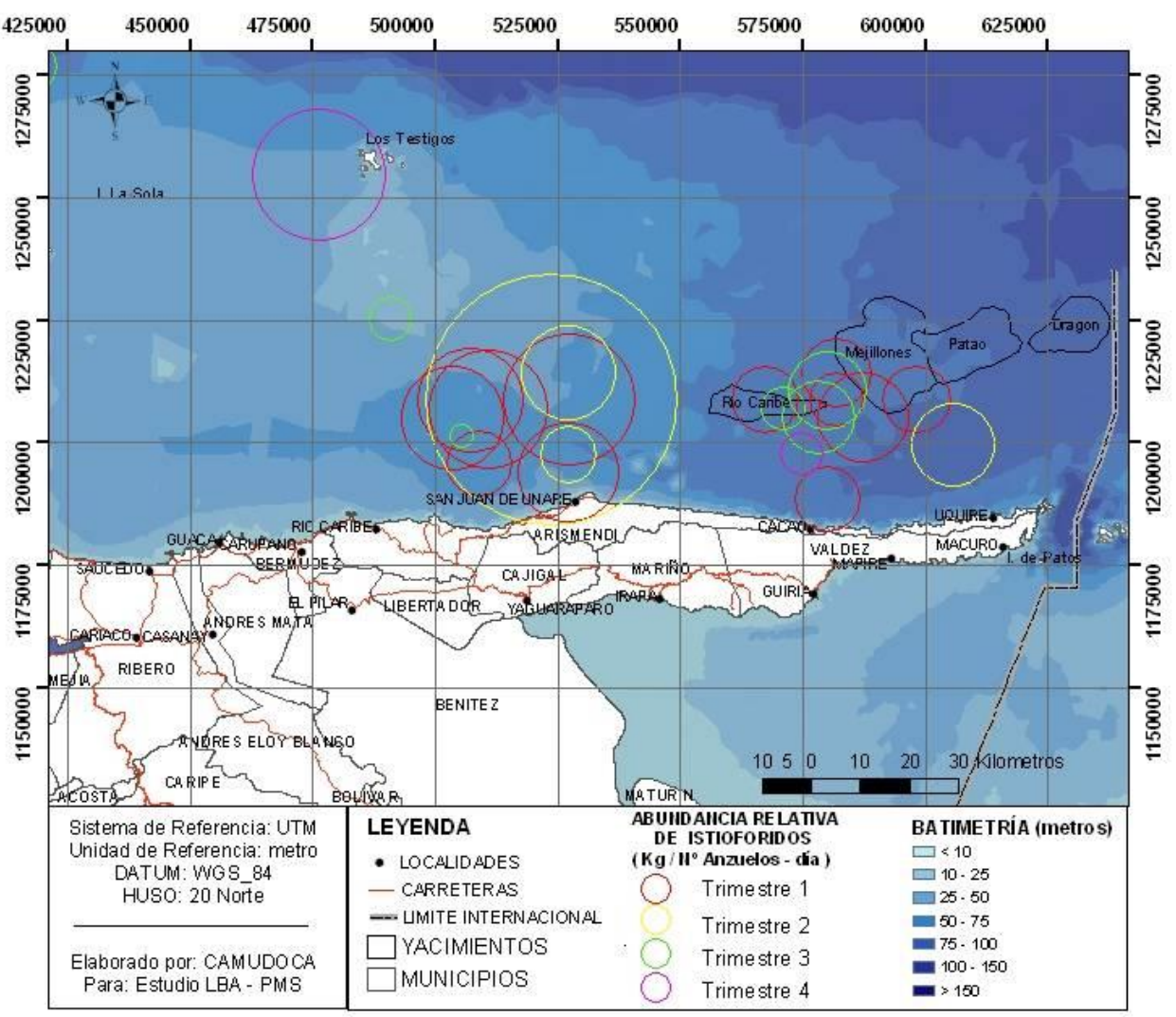

Figura II-26.- Promedio trimestral de la abundancia relativa para los istiofóridos (ISTIO) capturado por la pesquería artesanal de media altura pelágica con palangre.

En el caso de los tiburones, que viene siendo un grupo de especies de carácter incidental importante en la pesca con palangre, la distribución espacial de la abundancia relativa indica que las concentraciones importantes se encuentran alrededor de los yacimientos durante el tercer y cuarto trimestre, al oeste de los yacimientos (al norte de Cabo Tres Puntas) durante el segundo trimestre, y en los alrededores de Los Testigos durante el primer trimestre del año (Figura II-27). 


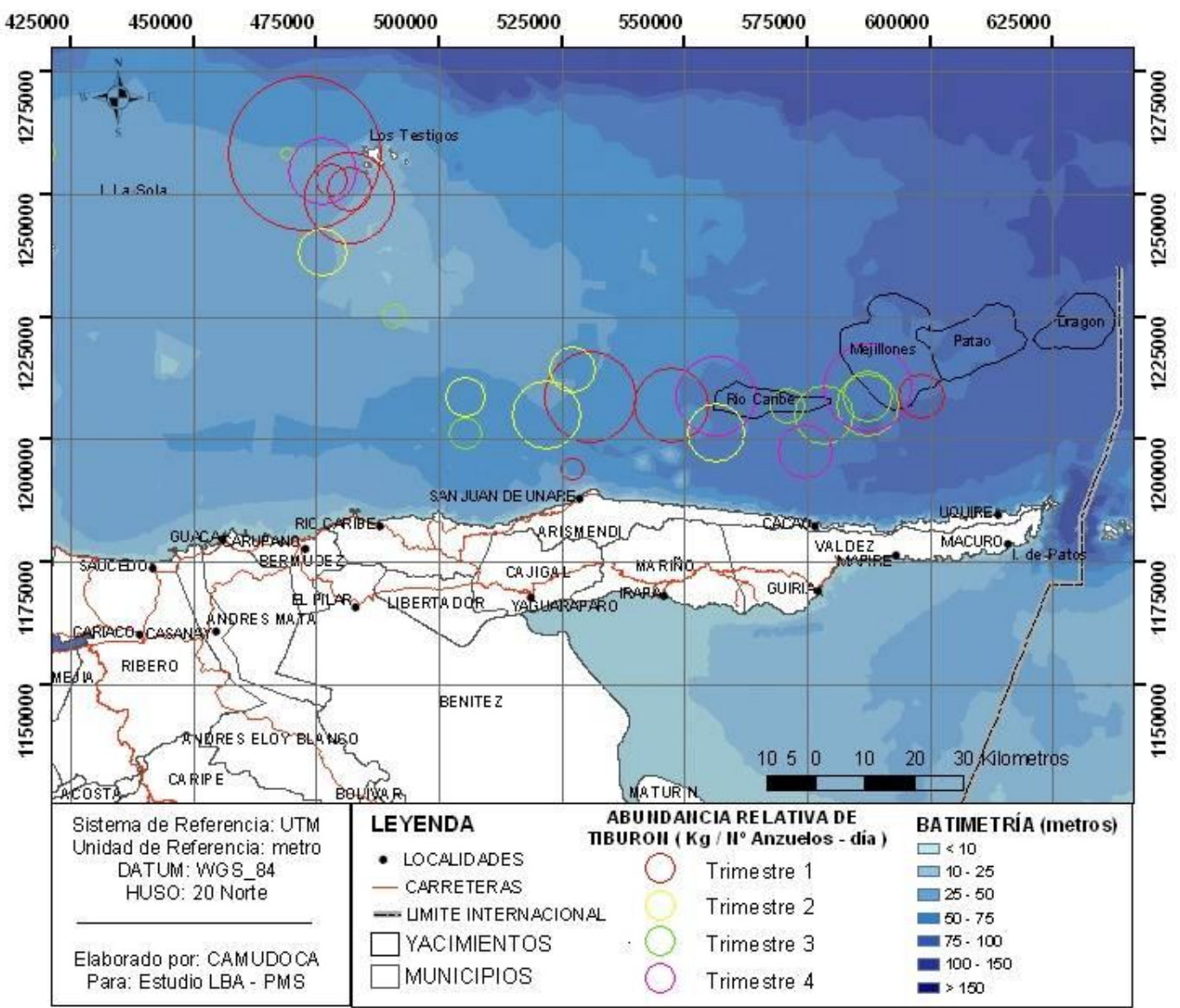

Figura II-27.- Promedio trimestral de la abundancia relativa para los tiburones (SHK) capturado por la pesquería artesanal de media altura pelágica con palangre.

\section{II.4.3 Análisis de los recursos pesqueros capturados por la pesquería artesanal de media altura pelágica}

Los resultados muestran que las especies Scomberomorus cavalla, Coryphaena hippurus, junto con el grupo de especies de istiofóridos y de tiburones carcharrínidos conforman los recursos pesqueros mas importantes de la PNPP. Las dos primeras constituyen las especies objetivo de la pesquería con cordel (caritesierra, Scomberomorus cavalla) y la pesquería con palangre (dorado, Coryphaena hippurus). Los desembarques de ambos representan ingresos económicos importantes para los pescadores que dirigen su esfuerzo a la captura de estas especies (Marcano et al., 1995, 1998).

La distribución espacio-temporal del carite-sierra reflejó que los mayores niveles de abundancia relativa provienen de la zona alrededor del Archipiélago Los 
Testigos y en menor proporción al norte de la Península de Paria. En líneas generales, las mayores capturas de carite-sierra se realizan en la zona Atlántica, en el área al este de la Isla de Margarita y los alrededores del Archipiélago de los Testigos (Marcano, 2003). El carite-sierra es una especie migratoria-costera que probablemente realiza migraciones relacionadas con la historia de vida de la especie (e.g., alimentación o reproducción). Es posible que en este caso, el movimiento del carite-sierra hacia la zona de influencia del PMS, parece estar más relacionado con el movimiento de la sardina (Sardinella aurita) la cual constituye su principal alimento.

En la pesquería artesanal de media altura con palangre se registran variaciones importantes en el esfuerzo pesquero que se distribuye en el área de la PNPP y están relacionadas con la abundancia relativa de las especies que captura esta pesquería. El dorado, $C$. hippurus, la especie más importante en esta pesquería, es considerada como altamente migratoria y los niveles elevados de abundancia relativa en aguas venezolanas se deben a migraciones relacionadas con la reproducción (Arocha et al., 1999). Es por ello que la variación en la abundancia relativa del dorado, observada en el área del PMS, está sujeta a migraciones estacionales en aguas caribeñas venezolanas.

Otro grupo importante de especies del cual es objeto esta pesquería, son los istiofóridos (aguja blanca, pez vela o palagar y en menor grado la aguja azul), que al igual que el dorado, son especies altamente migratorias. Dependiendo de la especie, los movimientos pueden ser por alimentación y/o reproducción (Arocha y Marcano, 2005). La especie con niveles de abundancia mas elevados en el área es el pez vela o palagar, debido a que es la especie mas costera de los istiofóridos. La aguja blanca es la segunda especie en importancia, pero no es muy abundante en el área de la PNPP, debido probablemente a que sus movimientos están asociados a la alimentación de presas encontradas en la columna de agua al borde de la plataforma continental o en cañones formados por las islas oceánicas venezolanas (Arocha y Marcano, 2005), lo cual la aleja del área de la PNPP. 
Algunas especies de tiburones de la familia Carcharhinidae que forman un componente importante de la captura en esta pesquería, son consideradas como captura incidental. La abundancia relativa de estas especies en el área de la PNPP parece estar asociada a migraciones estacionales debido a que algunas de ellas son especies altamente migratorias y otras son migratorias costeras. Dada la escasa información sobre la composición de las capturas, por especie, es difícil asociar el tipo de abundancia relativa, a patrones de comportamiento de las especies de tiburones encontradas en el área la PNPP.

\section{II.4.4 Conclusiones}

- En la pesquería artesanal de media altura pelágica la especie predominante con palangre es el dorado (Coryphaena hippurus), y con cordel es el caritesierra (Scomberomorus cavalla). Ambas representan ingresos económicos importantes por ser las especies de mayor valor comercial en la pesquería artesanal.

- El carite-sierra (Scomberomorus cavalla) como especie objetivo en las capturas con cordel ha disminuido significativamente su rendimiento, orientandose la flota a la captura del dorado (Coryphaena hippurus) en los dos últimos años.

- La distribución espacio temporal del carite-sierra, dorado, istiofóridos y tiburones muestra una estacionalidad relacionada con movimientos asociados a la historia de vida (reproducción y/o alimentación) de las distintas especies que se encuentran en la PNPP. Ello se debe a que las especies capturadas por esta pesquería son de tipo migratorio-costero (Scomberomorus cavalla y algunos tiburones), o altamente migratorias (Coryphaena hippurus, istiofóridos y algunos tiburones). 


\section{II.5 Pesquería Industrial de Arrastre}

El objetivo de esta actividad corresponde a la determinación de la distribución espacio-temporal del esfuerzo de pesca y las capturas de las especies de peces e invertebrados explotados por la pesquería de arrastre en la PNPP. En este sentido, se hizo un análisis preliminar de la información existente, partiendo del estudio preparado por el Instituto Oceanográfico de la Universidad de Oriente (IOV-UDO) sobre 'Los Recursos Pesqueros del Oriente de Venezuela' que aparece en el 'Diagnostico Socio-Económico de los Proyectos Costa Afuera-PDVSA', así como también de los volúmenes del informe sobre 'Las Pesquerías y Recursos Pesqueros del Oriente de Venezuela' elaborado por el grupo de pesquerías del IOV-UDO para PALMAVEN/PDVSA. Otro informe revisado fué el generado a partir de los cruceros del B/O Fridtjof Nansen en 1988 en la zona de la plataforma nororiental.

El análisis de dichos informes llevaba como objetivo seleccionar el grupo de especies de peces demersales e invertebrados que son relevantes para el análisis espacial que se requiere en el presente estudio. El análisis reveló que existen alrededor de más de 40 especies de peces de interés comercial que son capturadas por las embarcaciones de arrastre industrial operando en el área de estudio. Sin embargo, más del 70\% de los desembarques está representado por alrededor de 15 rubros entre invertebrados y peces; estando los invertebrados conformados por camarones, cangrejos, vieiras y cefalópodos.

Este análisis condujo a seleccionar las nueve especies más importantes desde el punto de vista de las capturas y desembarques de la pesquería de arrastre comercial, y que son el objetivo principal de esta pesquería. En este grupo, dos especies forman parte de un rubro (Calamar); el resto se identifica con una especie (Tabla II-22). En el caso del calamar, que involucra a dos especies, se utilizó la información existente (Arocha y Urosa, 1991) la cual permitió identificar la temporalidad y distribución espacial de ambas especies, de manera que permita una extrapolación para cada una. 
Tabla II-22.-Rubros y especies seleccionadas para el análisis de la distribución espacio-temporal al norte de la Península de Paria.

\begin{tabular}{llc}
\multicolumn{1}{c}{ Rubro } & \multicolumn{1}{c}{ Especies } & $\begin{array}{c}\text { Frecuencia } \\
\text { en los }\end{array}$ \\
Camarón manchado & Farfantepenaeus brasiliensis & 19 \\
Calamar o Lúria & Loligo plei, Loligo pealei & 8 \\
Pulpo & Octopus vulgaris & 15 \\
Corocoro & Orthopristis ruber & 6 \\
Catalana & Pricanthus arenatus & 5 \\
Roncador & Micropogonias furnieri & 4 \\
Lamparosa & Selene setapinnis & 4 \\
Cherechere & Haemulon steindachneri & 2
\end{tabular}

En el análisis histórico para la determinación de la distribución espaciotemporal del esfuerzo de pesca y las capturas de las especies de peces e invertebrados explotados por la pesquería de arrastre en la PNPP se utilizó uno de los métodos tradicionales para la obtención de información de poblaciones de peces explotadas. Dicha información consiste en datos provenientes de los monitoreos de desembarques y datos provenientes de los monitoreos a bordo de las embarcaciones, los cuales proveen información sobre la distribución espacial y temporal de las especies (tanto mensuales como diurno/nocturno). Este tipo de información permite tener un conocimiento más detallado sobre las poblaciones de peces de mayor importancia en el área de estudio. En este informe se presenta un análisis de la distribución temporal (trimestral y día - noche) y espacial (cuadrante y profundidad) de los índices de abundancia relativa de un grupo de siete especies (y un rubro compuesto por dos especies) demersales de la plataforma que se consideraron como las más importantes, para el período 2000-2003.

El área de estudio definida para el presente análisis fue dividida en cuadrantes de 30×30 millas, de acuerdo a como está establecido para las estadísticas pesqueras en Venezuela desde 1965 (Marcano, 1990; Mendoza et al., 1994). Para el caso de las estadísticas pesqueras del sector industrial de arrastre, el área de estudio la conforman nueve cuadrantes donde opera la flota, con puertos bases en la región 
oriental de Venezuela. La fuente de datos utilizada para los análisis del presente informe proviene de la información sobre volúmenes de desembarque y esfuerzo efectivo de pesca (estimado) estratificado por cuadrante, profundidad y por trimestre, registrados en cuadernos de pesca (o bitácoras) que han sido recolectados por el Laboratorio de Pesca Demersal del INIA-Sucre/Nueva Esparta durante el período 2000-2003. La información es producto de una muestra seleccionada que representa aproximadamente el $20 \%$ del total de los cuadernos de pesca presentados al INAPESCA por las embarcaciones que operan en áreas de pesca situadas alrededor de la Isla de Margarita y norte de la Península de Paria. Para efectos de este estudio, la medida de abundancia (o Captura Por Unidad de Esfuerzo - CPUE) utilizada es la unidad de biomasa definida como el número de kilogramos de una especie por unidad de tiempo, que para efectos de la pesquería de arrastre industrial es una hora. Es preciso señalar que el índice de abundancia escogido es de carácter nominal, ya que supone la estabilidad de variables biológicas de una especie (mortalidad, vulnerabilidad y disponibilidad) y no considera la variabilidad del esfuerzo en el tiempo (cambios en el poder de pesca). Por ello se le denomina índice de 'abundancia relativa nominal', que estará referido en el texto como abundancia, o abundancia relativa.

\section{II.5.1 Distribución espacial y temporal de las especies demersales del norte de la Península de Paria}

\section{Micropogonias furnieri (Roncador)}

La distribución espacial y temporal de la abundancia relativa nominal del $M$. furnieri es amplia en las costas orientales del país durante los años 2000-2003, aunque se observa una alta variabilidad en los niveles de abundancia relativa entre las distintas áreas geográficas. Los niveles de abundancia más altos se ubican en Los Frailes/La Sola y cerca de Los Testigos (cuadrantes 217 y 218), así como al norte de la Península de Paria, específicamente en el cuadrante 318 (Figura II-28). Se observa un descenso en la abundancia de $M$. furnieri en dirección hacia los yacimientos, siendo menor en los cuadrantes donde estos se ubican (el cuadrante 
220 descrito en el texto como 'off shore' o alejado de la costa y el cuadrante 320 descrito en el texto como cercano a la costa o costero). Una mayor abundancia se observa en los cuadrantes 220 y 320 durante el primer semestre del año, mientras que en los cuadrantes hacia el oeste de los yacimientos, la abundancia es aproximadamente equitativa durante los diferentes trimestres del año.

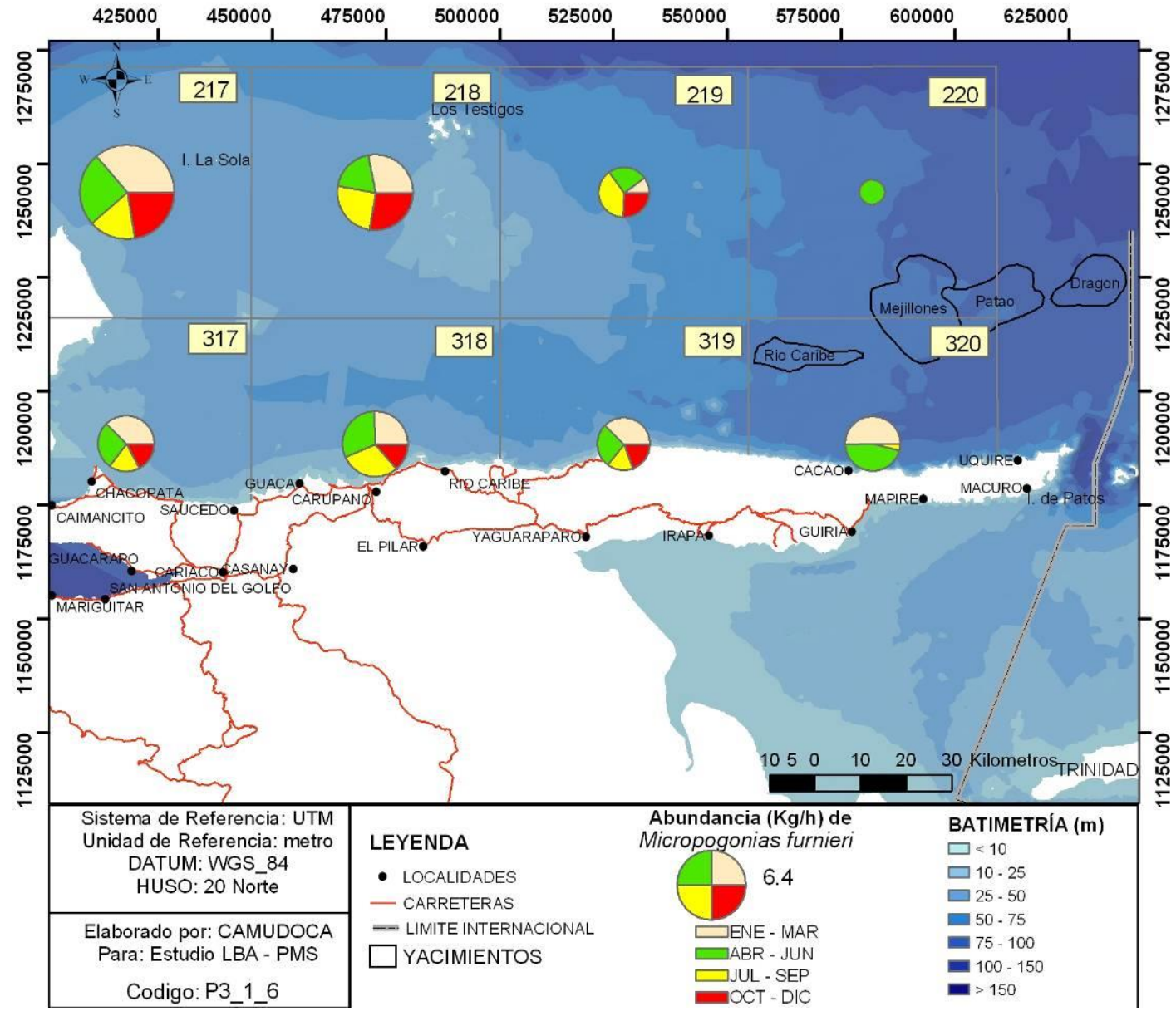

Figura II-28.- Micropogonias furnieri. Distribución espacial y temporal (trimestral) de la abundancia por años combinados para el período 2000-2003.

El análisis temporal de los niveles de abundancia de $M$. furnieri por estratos de profundidad indica que la especie fue más abundante entre $64 \mathrm{~m}$ y $108 \mathrm{~m}$ de profundidad en 2000 y el primer semestre de 2001, con valores que oscilaron entre 1,5 y $9 \mathrm{~kg} / \mathrm{h}$, acentuándose su presencia entre 91-99 m, durante el tercer semestre del 2000, con un indicador de abundancia cercano a los $10 \mathrm{~kg} / \mathrm{h}$. En el 2001, la especie resulto ser más abundante entre 100-108 m, y durante el primer trimestre del 
año, con un valor superior a los $8 \mathrm{~kg} / \mathrm{h}$ (Figura II-29). En contraste, la distribución desde el segundo semestre 2001 a 2003 muestra que la especie se concentra entre 20 y $45 \mathrm{~m}$ de profundidad.
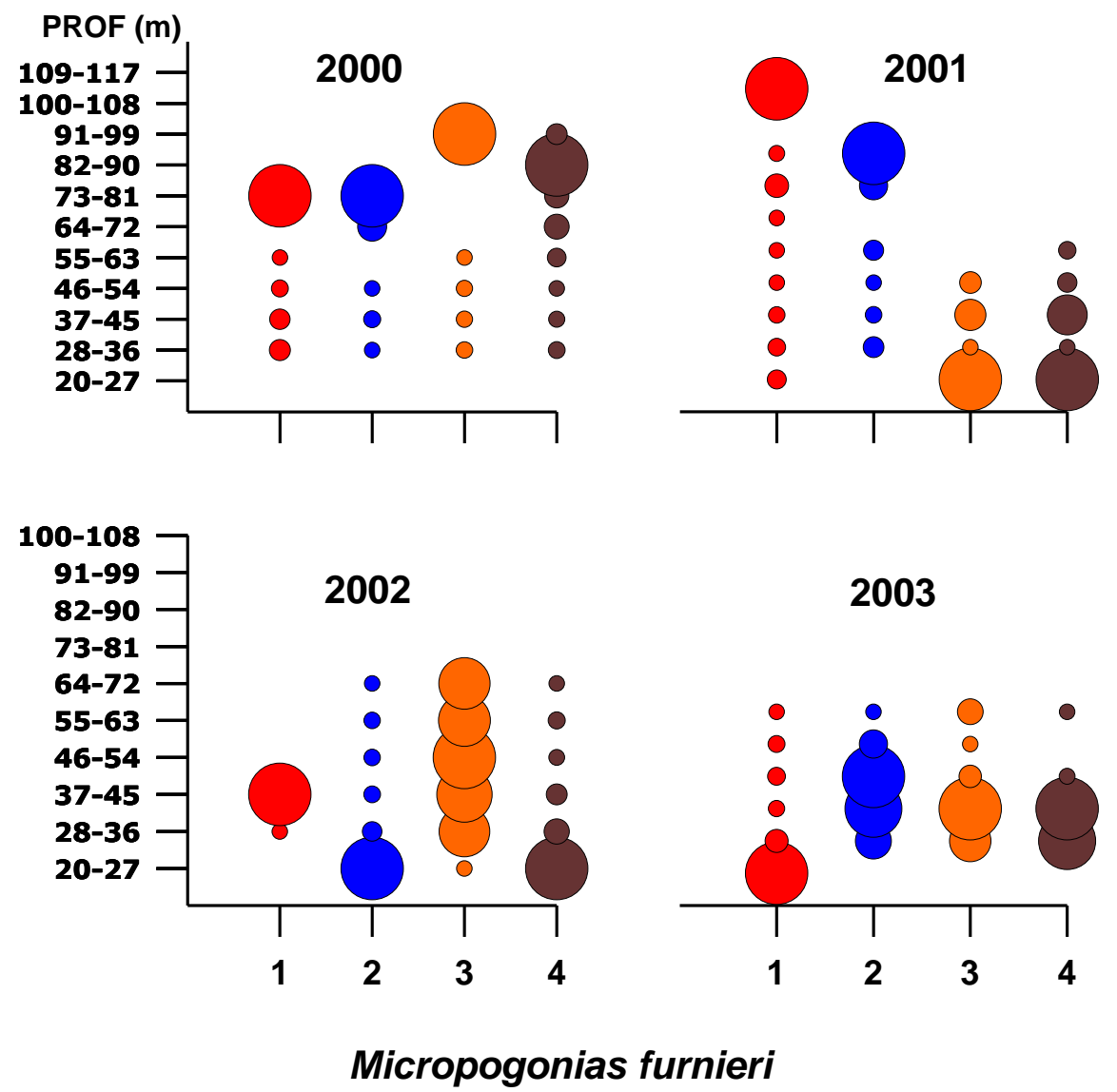

Figura II-29.- Micropogonias furnieri. Distribución estacional (trimestral) por estratos de profundidad por año.

En relación al análisis periódico diario de la abundancia, no parecen existir fuertes diferencias entre los niveles de abundancia durante el día y la noche, con tendencia a ser más abundante durante el día. Sin embargo, los niveles de abundancia observados son relativamente bajos, ya que no superan $1 \mathrm{~kg} / \mathrm{h}$, en ninguno de los cuatro años evaluados (Figura II-30). 

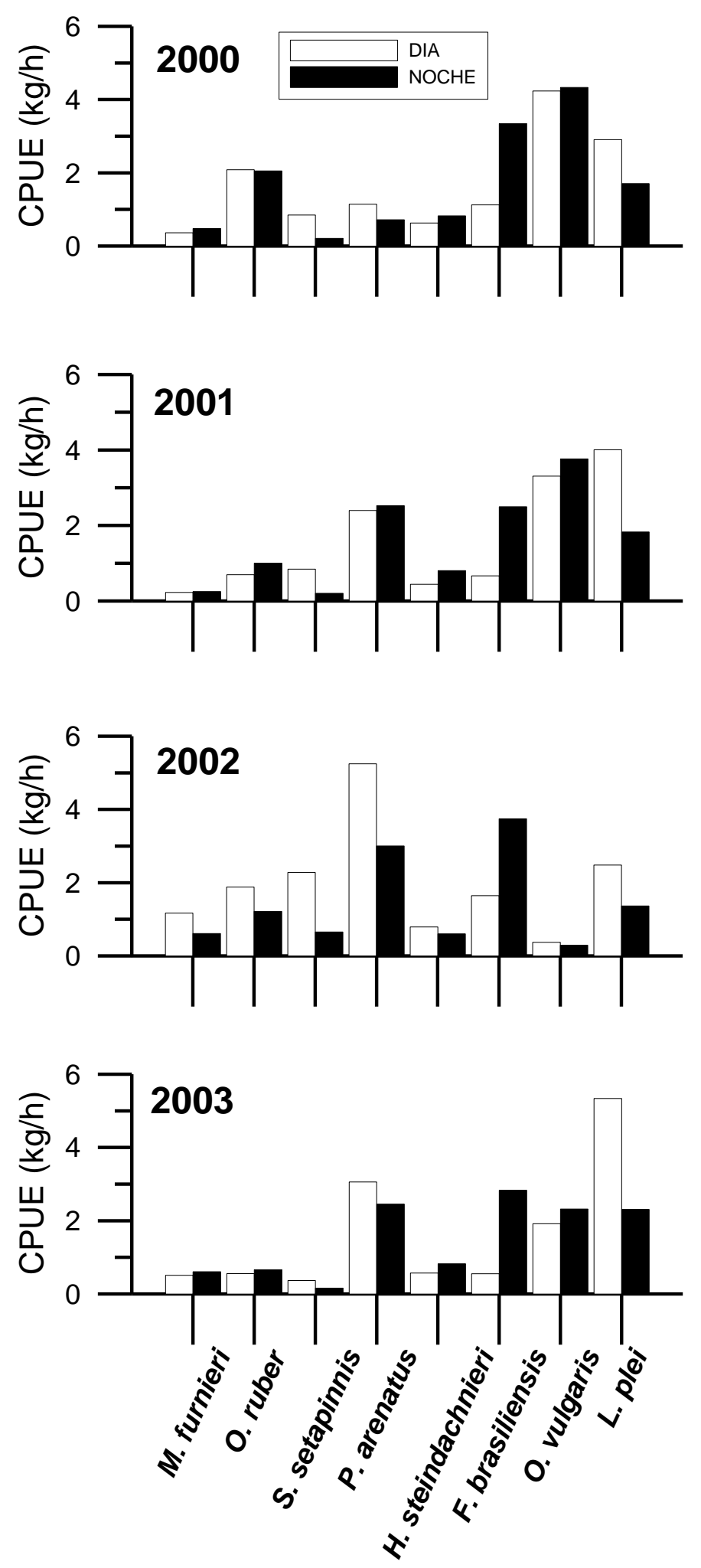

Figura II-30.- Distribución día-noche por año de las especies seleccionadas que son objeto de las capturas de la pesquería de arrastre industrial, período 2000-2003. 


\section{Orthopristis ruber (Corocoro)}

La distribución espacial y temporal de la abundancia relativa nominal de $O$. ruber revela que es también una especie con amplio rango de distribución, encontrándose en toda el área de estudio. Sin embargo, las zonas de mayor abundancia se ubican en los cuadrantes 216 y 317, disminuyendo la abundancia progresivamente en dirección hacia los yacimientos (Figura II-31). Sin embargo, esta tendencia no ocurre en el cuadrante al norte de los yacimientos (220), donde se observa un ligero incremento en la abundancia con respecto al cuadrante ubicado al oeste (219). La abundancia estacional de O. ruber mantiene una distribución aproximadamente equitativa en los cuadrantes más al oeste de los yacimientos (salvo el 317). Sin embargo, en los cuatro cuadrantes más cercanos a los yacimientos, se observa una variación estacional, como es el caso de los cuadrantes 319 y 219 , donde $O$. ruber predomina durante el cuarto y tercer trimestre, respectivamente. Por otra parte, en los cuadrantes de los yacimientos, la abundancia predomina durante el segundo trimestre del año. 


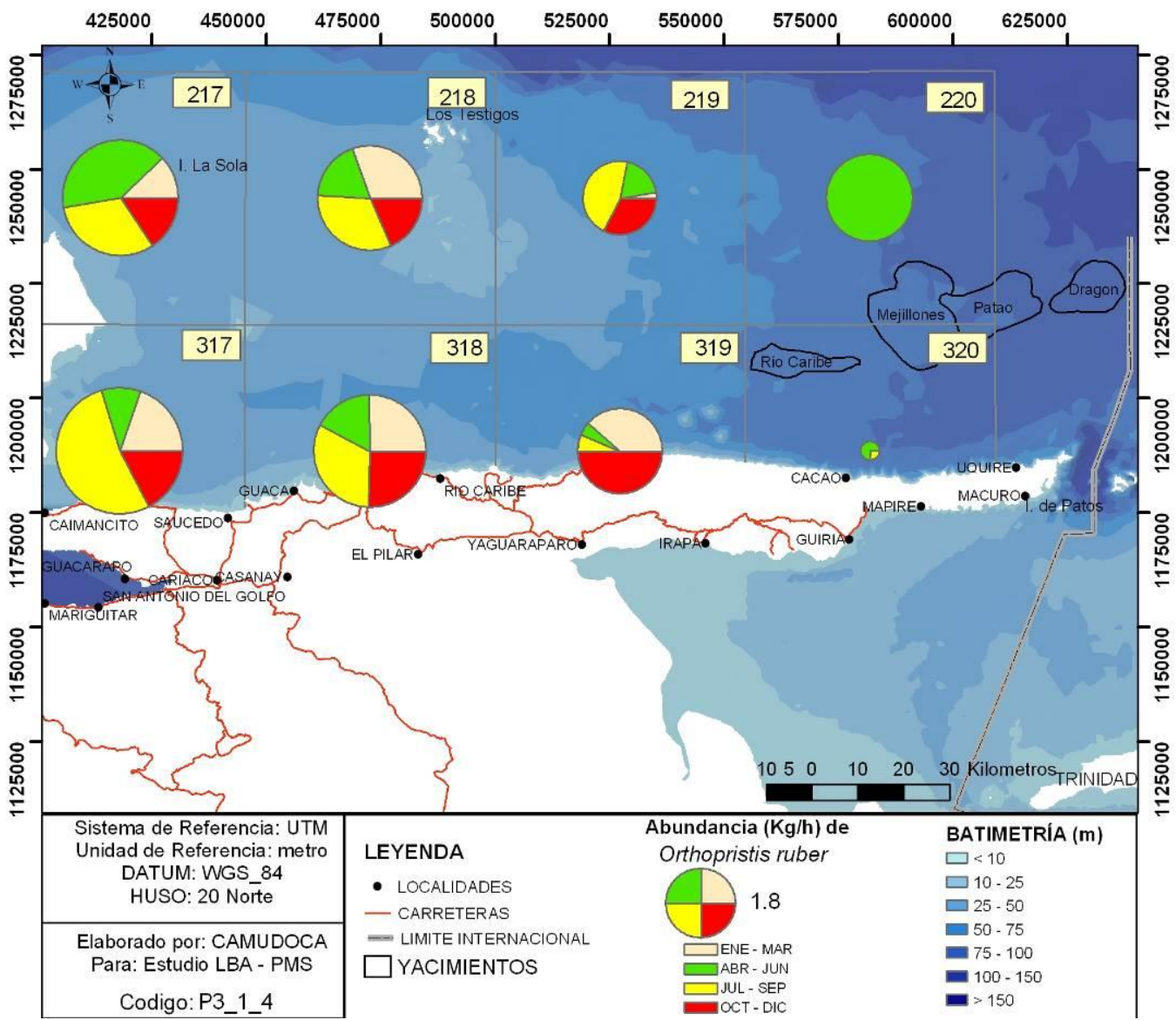

Figura II-31.- Orthopristis ruber. Distribución espacial y temporal (trimestral) de la abundancia por años combinados para el período 2000-2003.

El análisis temporal de los niveles de abundancia de $O$. ruber por estratos de profundidad indica que la especie fue más abundante en los estratos de menor profundidad, entre 20 y $54 \mathrm{~m}$, y disminuye de manera progresiva con la profundidad. La especie resultó ser más abundante durante el primer trimestre de los años 2000 y 2001, con excepción del estrato 28-36 m, del 2000, que resultó ser más abundante en el tercer trimestre, y en el cuarto durante el 2001, en el estrato de profundidad de 37-45 m (Figura II-32). Durante el 2002, la especie presentó su mayor abundancia en el estrato $82-90 \mathrm{~m}$, seguido por los estratos $37-45$ y $20-27$, con mayores abundancias durante el segundo y tercer trimestres del año. En 2003 la mayor abundancia se registró entre 20-27 m durante el primer trimestre del año. 

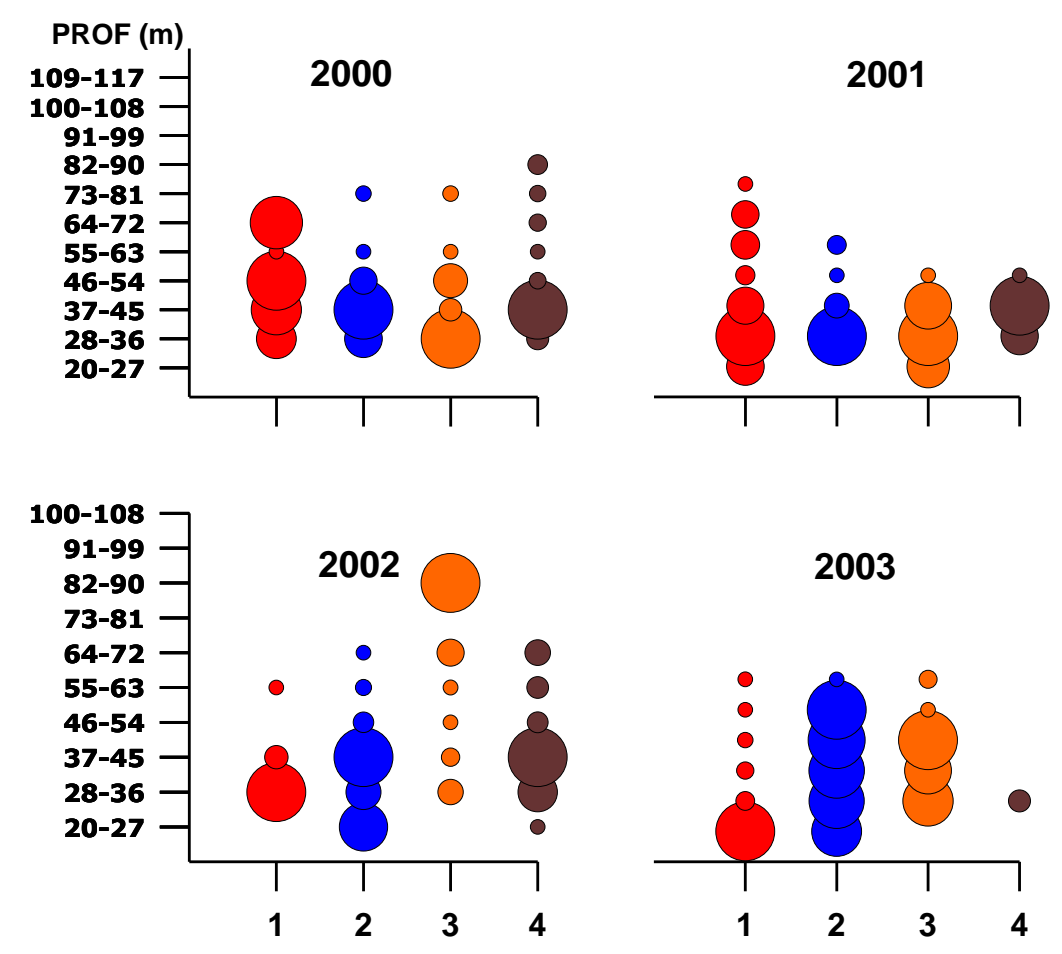

\section{Orthopristis ruber}

Figura II-32.- Orthopristis ruber. Distribución estacional (trimestral) por estratos de profundidad y año.

En relación al análisis periódico de la abundancia, no parece haber un patrón definido, pues existen ligeras diferencias entre día y noche, cuyo patrón cambia de un año a otro. En 2000 y 2003 no se aprecian diferencias entre los niveles de abundancia diurno y nocturno, ubicándose este indicador entre 0,6 y $2 \mathrm{~kg} / \mathrm{h}$, mientras que para el 2001, se observa una superioridad de la abundancia durante la noche, con valor alrededor de $1,5 \mathrm{~kg} / \mathrm{h}$, y en el 2002 se observa una mayor y significativa abundancia durante el día, con rendimientos de $1,9 \mathrm{~kg} / \mathrm{h}$ de día en comparación con $1,2 \mathrm{~kg} / \mathrm{h}$ de noche (Figura II-30).

Selene setapinnis (Lamparosa)

La distribución espacial y temporal de la abundancia relativa nominal de $S$. setapinnis revela que las áreas de mayor abundancia se localizaron en los cuadrantes 218 y 219 adyacentes a Los Testigos (Figura II-33). En los cuadrantes costeros $(317,318,319$ y 320$)$ la abundancia de $S$. setapinnis es baja, característica propia de especie pelágica. Sin embargo, se observa que de los cuadrantes 
costeros, el que está al sur de los yacimientos es donde se observa la mayor abundancia, posiblemente por las características batimétricas de la zona. En los cuadrantes alejados de la costa $(217,218,219$ y 220), la abundancia estacional es más marcada durante el segundo trimestre del año, particularmente en el que está al norte de los yacimientos. En los cuadrantes costeros, la abundancia parece alternase entre el primer y tercer trimestre del año.

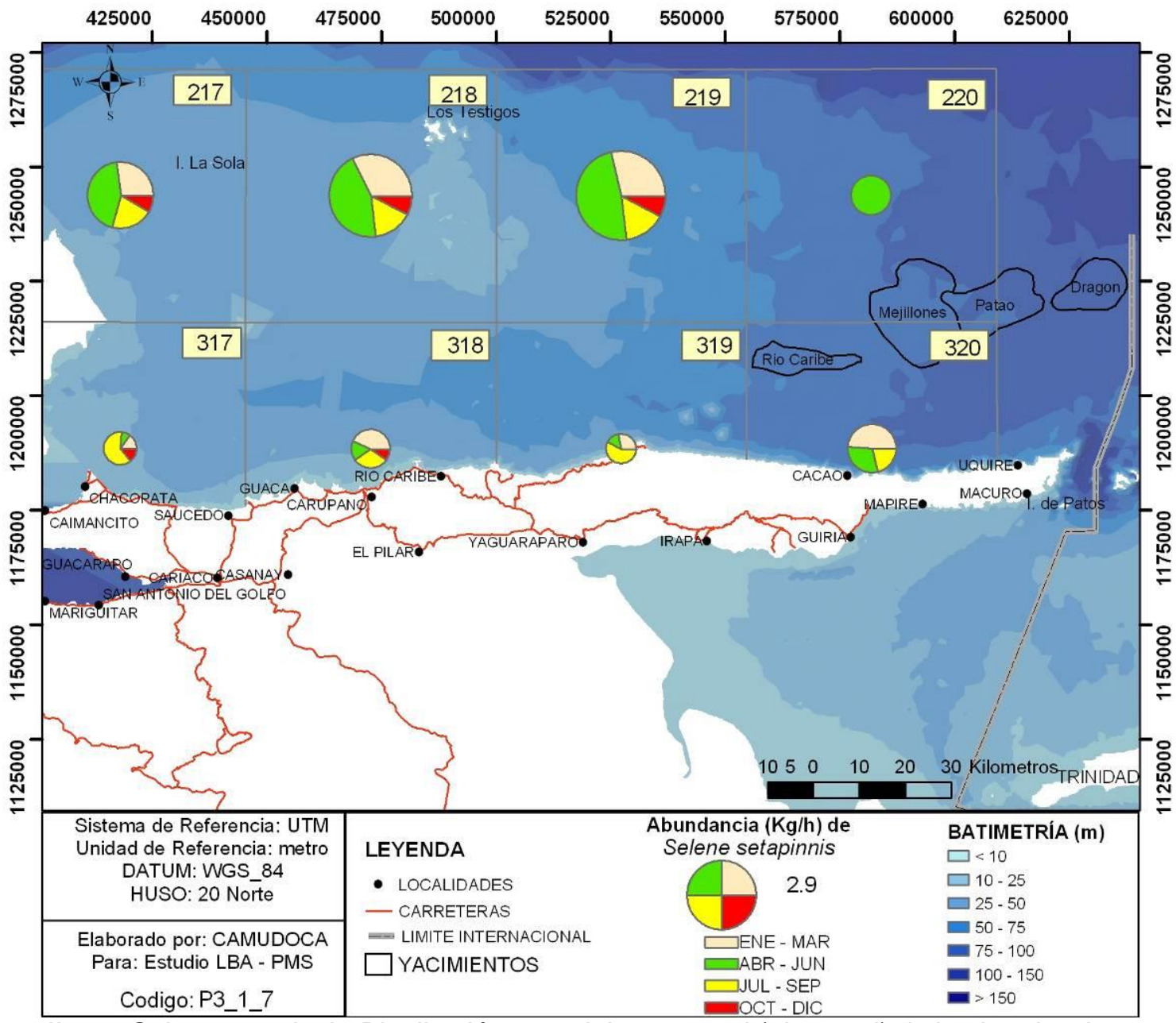

Figura II-33.- Selene setapinnis. Distribución espacial y temporal (trimestral) de la abundancia por años combinados para el período 2000-2003.

El análisis temporal de los niveles de abundancia de $S$. setapinnis por estratos de profundidad indica que la especie se distribuye en un amplio intervalo de profundidades, entre 20 y 117 m, lo cual posiblemente está asociado a su condición de especie pelágica. Los mayores niveles de abundancia se observaron a 
profundidades comprendidas entre de 46-72 m, durante el año 2000, y siempre durante el primer y segundo trimestres (Figura II-34). En el 2001, su distribución batimétrica fue más amplia, localizándose a profundidades comprendidas entre 20 y 81 metros, y, al igual que el año anterior, en los dos primeros trimestres del año, con indicadores de abundancia superiores a los 0,5 kg/h. En 2002 se registró una distribución bimodal con la profundidad, con mayores abundancias en los intervalos 20-27 y 64-72 m, durante el tercer y cuarto trimestres del año. En 2003 la mayor abundancia se registró en el intervalo 20-27 m durante el primer trimestre del año, en el segundo trimestre en el intervalo 37-54 m, en el tercer trimestre en el intervalo 64$72 \mathrm{~m}$, y en el cuarto trimestre la abundancia es muy baja pero se acerca a estratos menos profundos $(28-36 \mathrm{~m})$.

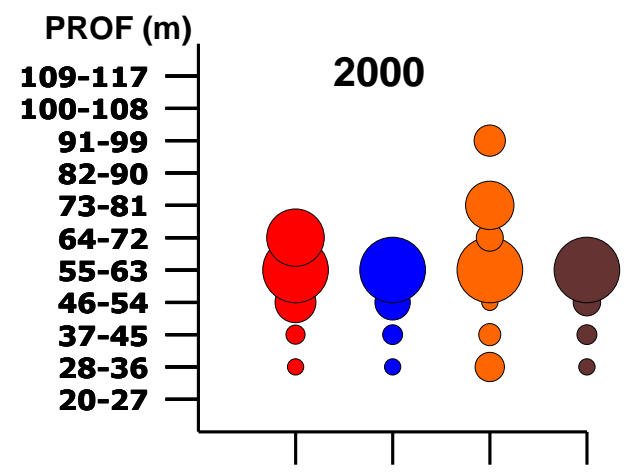

\section{1}

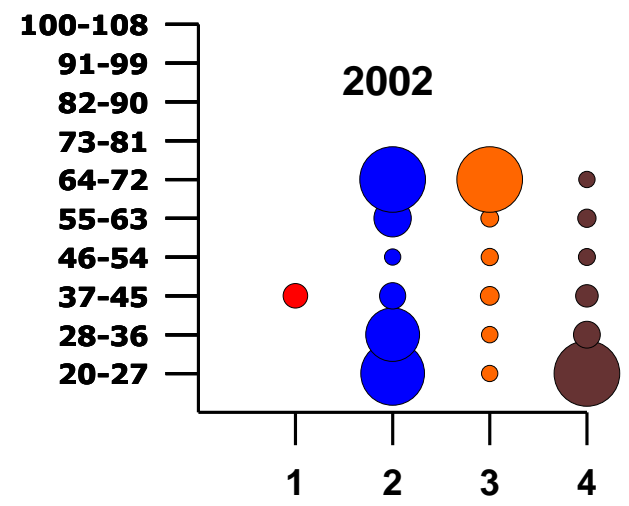

2003

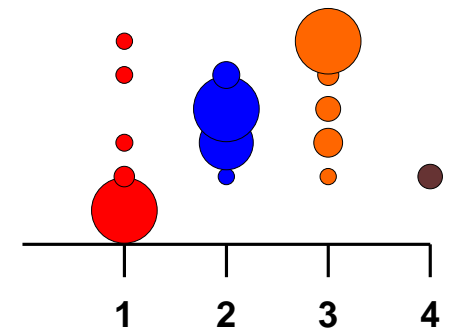

\section{Selene setapinnis}

Figura II-34.- Selene setapinnis. Distribución estacional (trimestral) por estratos de profundidad por año. 
En relación al análisis periódico o estacional de la abundancia, los niveles de abundancia resultaron ser significativamente superiores durante el período diurno, con indicadores de abundancia hasta $6,5 \mathrm{~kg} / \mathrm{h}$ (Figura II-30).

\section{Priacanthus arenatus (Catalana)}

La distribución espacial y temporal de la abundancia relativa nominal de $P$. arenatus para los años evaluados, revela que es una especie con amplio rango de distribución espacial en la región, aunque con niveles de abundancia relativamente bajos. Sin embargo, las áreas de mayor abundancia se ubican alrededor de Los Testigos y Cabo Tres Puntas, en los cuadrantes 219 y 319, respectivamente (Figura II-35). En los cuadrantes próximos a los yacimientos, la densidad de la especie es mayor en el cuadrante costero. La mayor abundancia estacional se observa en el cuarto trimestre del año en la zona donde la presencia de $P$. arenatus es mayor (218), mientras que en los cuadrantes más al oeste, la abundancia estacional es similar entre trimestres. Alrededor de los yacimientos, la mayor presencia de la especie en áreas costeras se manifiesta principalmente en el primer y tercer trimestres del año, pero en el cuadrante 'offshore' (220) $P$. arenatus aparece sólo durante el segundo trimestre del año. 


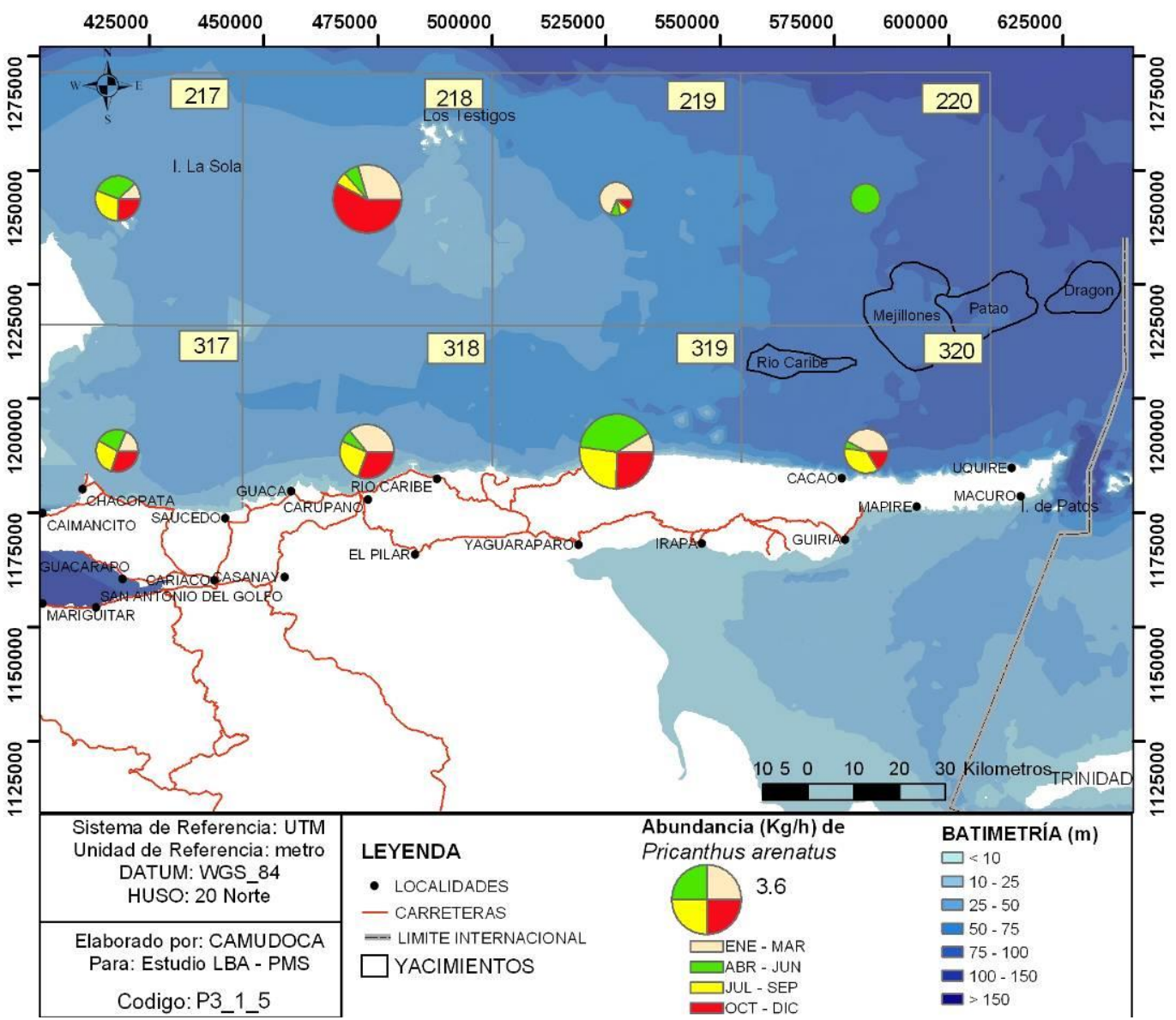

Figura II-35.- Priacanthus arenatus. Distribución espacial y temporal (trimestral) de la abundancia por años combinados para el período 2000-2003.

El análisis temporal de los niveles de abundancia de $P$. arenatus por estratos de profundidad indica que la especie se distribuye dentro de un amplio rango de profundidad, con una distribución unimodal con máximos en los estratos 55-81 y 91 99 y durante los dos primeros semestres del año 2000 (Figura II-36). Durante el 2001, la distribución batimétrica de la especie fue más amplia, con niveles de abundancia máximos en los estratos 37- $72 \mathrm{~m}$ y muy particularmente en el estrato 109-117, donde se llegaron a observar niveles de abundancia hasta de $14 \mathrm{~kg} / \mathrm{h}$. y durante el segundo y tercer trimestres del año. En 2002 y 2003 la especie resultó ser más abundante en el estrato de profundidad 64-72 m. Durante 2002, la especie mostró mayores densidades en los estratos intermedios $(54-72 \mathrm{~m})$ durante los dos primeros trimestres del año y el cuarto, y durante el tercer trimestre en los estratos más profundos. En 2003 las mayores abundancias fueron encontradas en los 
estratos intermedios (54-72m), registrándose las mayores abundancias en los primeros dos trimestres del año.
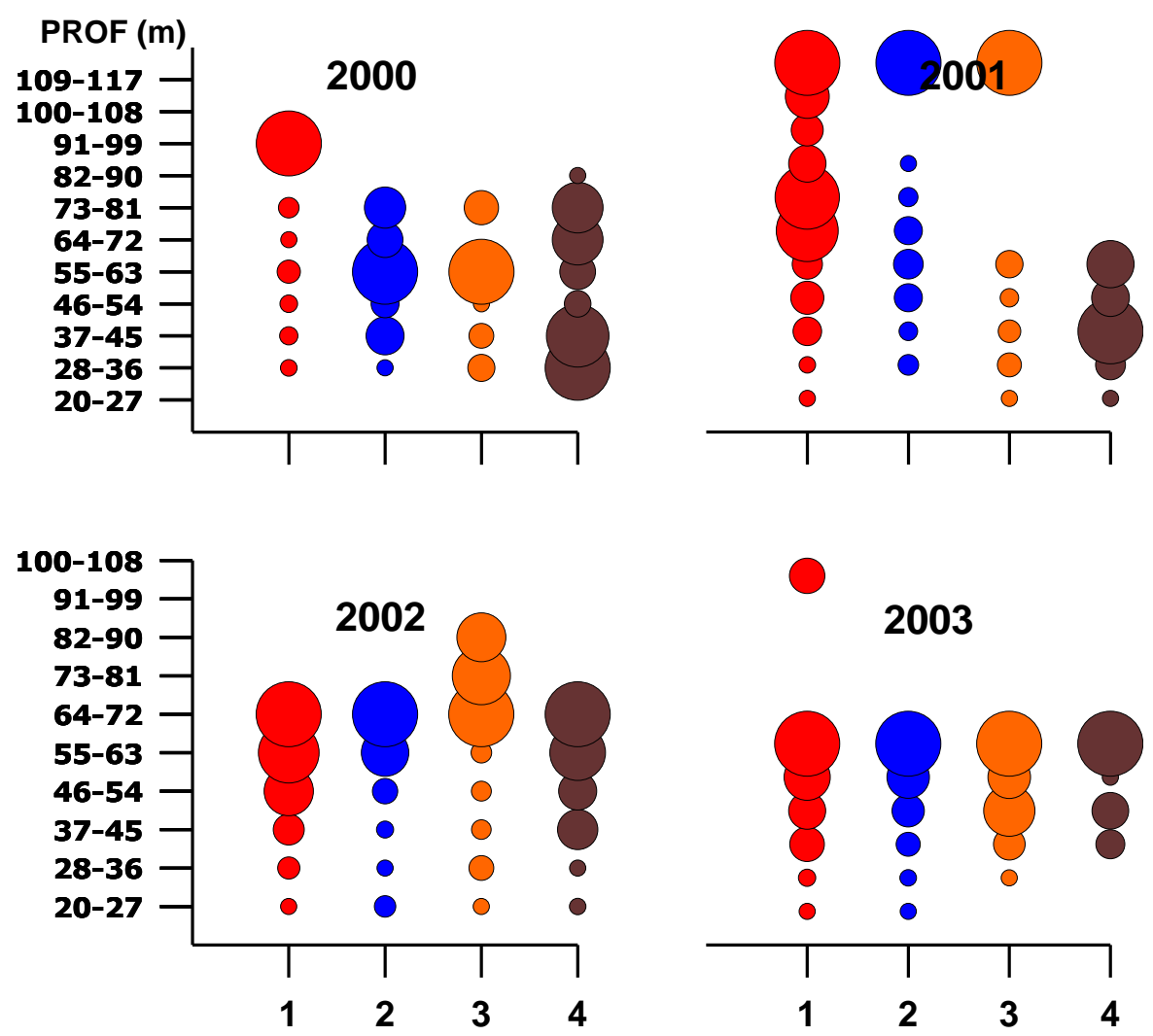

\section{Priacanthus arenatus}

Figura II-36.- Priacanthus arenatus. Distribución estacional (trimestral) por estratos de profundidad por año.

En relación al análisis periódico de la abundancia, durante el año 2000 la especie resultó ser más abundante durante el día, con un indicador de abundancia ligeramente superior a $1,3 \mathrm{~kg} / \mathrm{h}$, mientras que durante el período nocturno este indicador se mantuvo alrededor de $0,5 \mathrm{~kg} / \mathrm{h}$. Durante el año 2001 no se aprecian diferencias entre los niveles de abundancia diurno y nocturno, ubicándose este indicador alrededor de los $2,5 \mathrm{~kg} / \mathrm{h}$. Durante los años 2002 y 2003 la abundancia del recurso en el día fue significativamente mayor que en la noche; las tasas de captura diurnas fueron 5,3 y $3,1 \mathrm{~kg} / \mathrm{h}$ en los años 2002 y 2003, respectivamente (Figura II$30)$. 
Haemulon steindachneri (Cherechere)

La distribución espacial y temporal de abundancia relativa nominal de $H$. steindachneri para los años evaluados, revela que es una especie con amplio rango de distribución espacial, encontrándose en toda el área de estudio con importantes niveles de abundancia relativa. El área de mayor abundancia se ubica en el cuadrante costero de los yacimientos (320), y la de menor abundancia está en el cuadrante 'offshore' (220) de los yacimientos (Figura II-37). En el resto de los cuadrantes, la abundancia es relativamente equiparable, aunque se observa que hay una mayor presencia de la especie en los cuadrantes alejados de la costa $(217,218$ y 219), con respecto a los que se encuentran próximos a ella. La abundancia estacional se ve reflejada durante el cuarto trimestre del año en la mayoría de los cuadrantes $(218,219,318$ y 319). Sin embargo, en el cuadrante de mayor abundancia relativa de $\mathrm{H}$. steindachneri, esta se refleja de manera significativa durante el tercer trimestre del año (320), mientras que en el cuadrante 'offshore' la abundancia mayor ocurre en el segundo trimestre del año. 


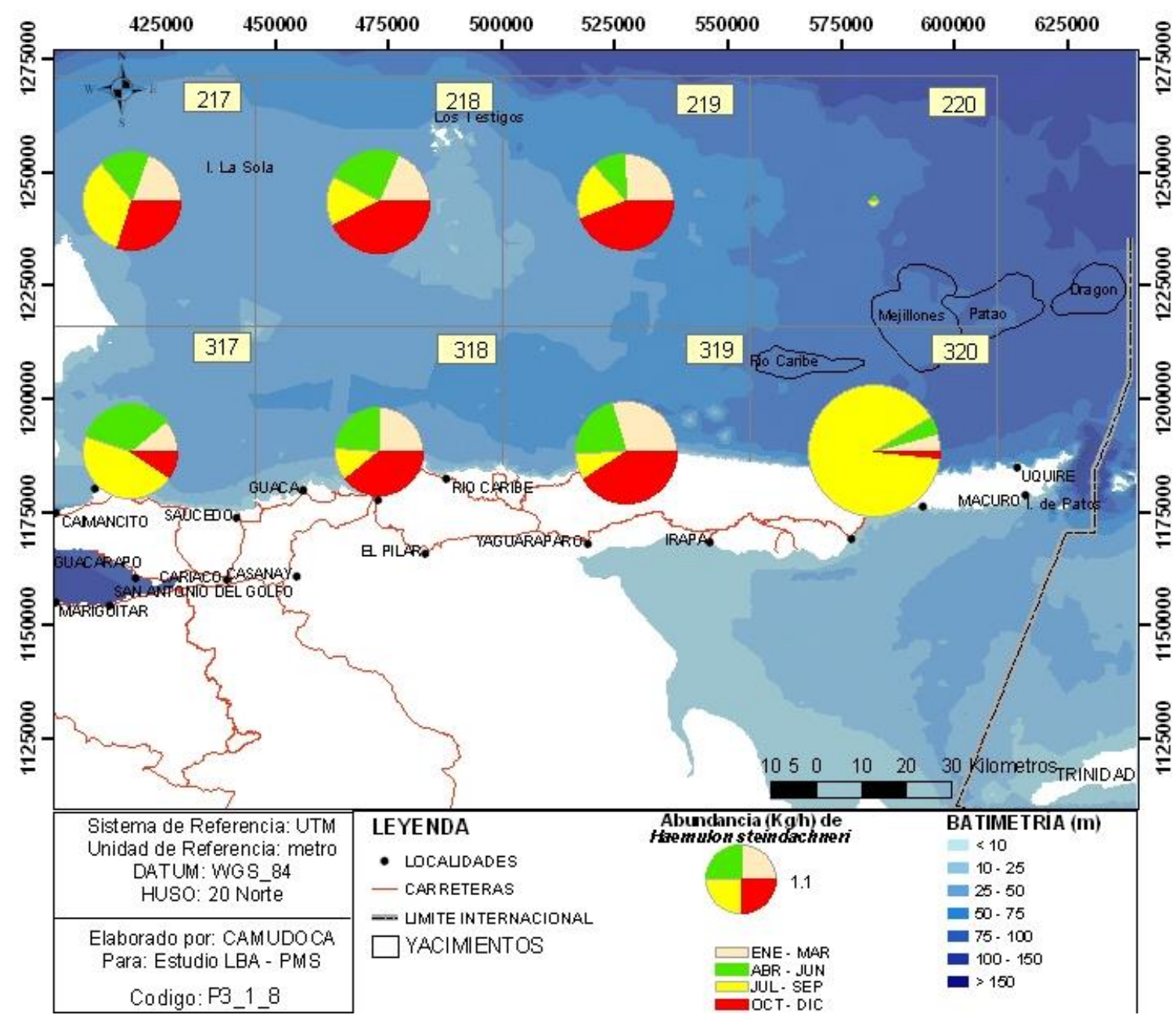

Figura II-37.- Haemulon steindachneri. Distribución espacial y temporal (trimestral) de la abundancia por años combinados para el período 2000-2003.

El análisis temporal de los niveles de abundancia de $H$. steindachneri por estratos de profundidad indica que la especie mantiene niveles altos de abundancia relativa hasta 81 metros de profundidad (Figura II-38). Se encuentra que para el año 2000, la especie era más abundante en el estrato 28-36 m, donde se observaron indicadores de rendimiento hasta de $7 \mathrm{~kg} / \mathrm{h}$ y durante el cuarto trimestre; en los estratos 37-45 m y 46-63 m, los niveles de abundancia alcanzaron hasta 1,5 kg/h, siendo máximos en los dos primeros trimestres del año. Igualmente, se observaron altos niveles de abundancia $(5 \mathrm{~kg} / \mathrm{h})$ en el estrato $73-81 \mathrm{~m}$, y durante el cuarto trimestre. Durante el año 2001, la situación de la distribución de la especie varía, ya que los indicadores de abundancia son cuantitativamente más bajos, encontrándose 
la especie distribuida hasta los $81 \mathrm{~m}$ de profundidad. La especie resultó ser más abundante en los estratos $20-63 \mathrm{~m}$, con tendencia a ser mayores en los dos primeros trimestres del año, con excepción del estrato 20-27 m, donde la abundancia fue mayor en el tercer trimestre del año.
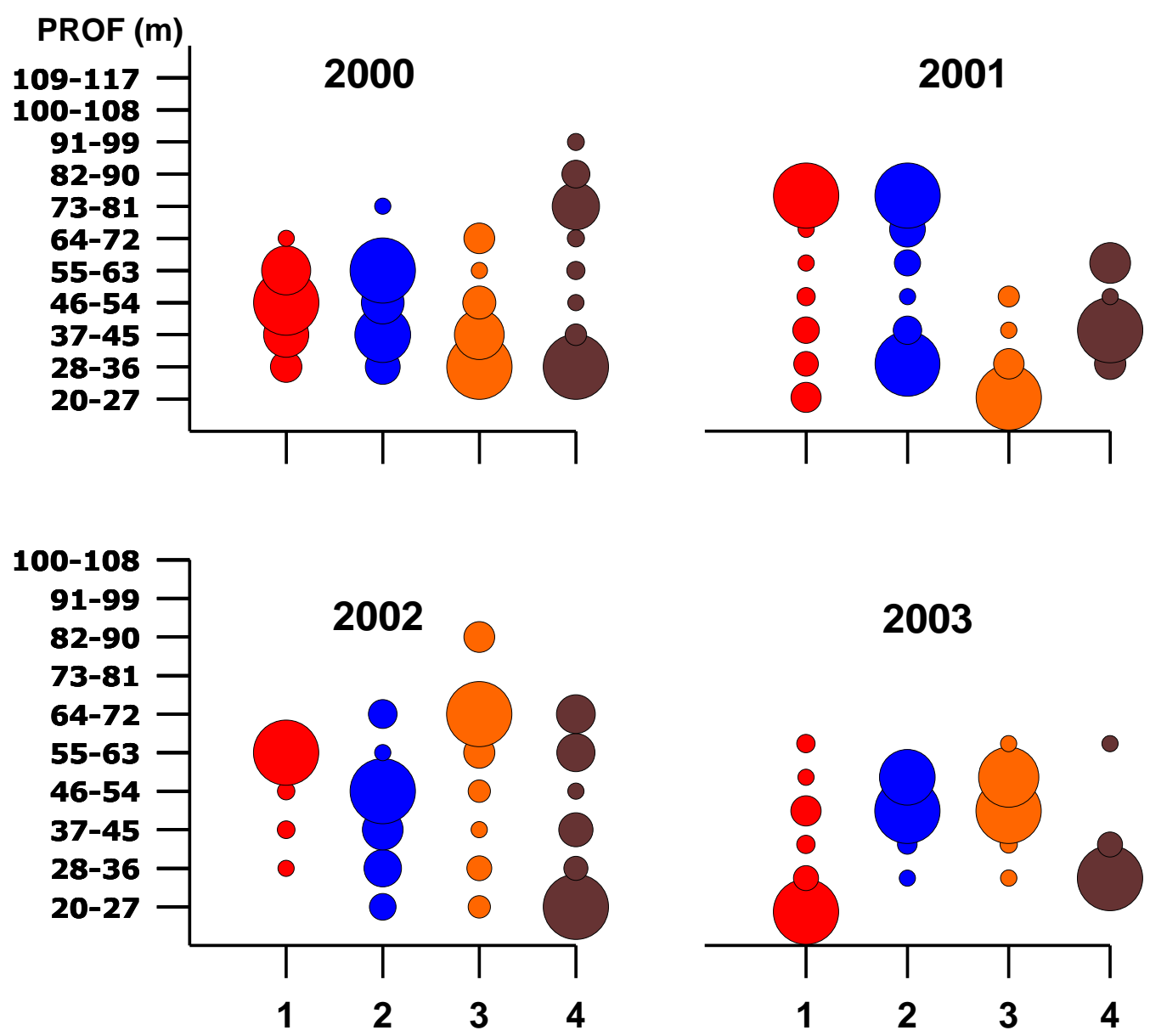

\section{Haemulon steindachnieri}

Figura II-38.- Haemulon steindachneri. Distribución estacional (trimestral) por estratos de profundidad por año.

En relación al análisis periódico de la abundancia, la especie no presenta un patrón definido de abundancias entre las capturas de día o de noche. Durante los años 2000, 2001 y 2003, la especie resultó ser ligeramente más abundante durante la noche, con indicadores de abundancia de $1,0 \mathrm{~kg} / \mathrm{h}$ en el 2000, 0,7 kg/h en el 2001 
y $0,83 \mathrm{~kg} / \mathrm{h}$ en el 2003, mientras que durante el día se situaron alrededor de los 0,5 $\mathrm{kg} / \mathrm{h}$. En el 2002 el indicador de abundancia se invirtió, resultando ligera pero no significativamente más alto durante el día $0,21 \mathrm{~kg} / \mathrm{h}$ en comparación con $0,19 \mathrm{~kg} / \mathrm{h}$ en la noche (Figura II-30).

Farfantepenaeus brasiliensis (Camarón marrón con manchas)

El análisis de la distribución espacial y temporal de la abundancia relativa nominal del camarón revela que es una especie con amplio rango de distribución espacial en la región, con niveles de abundancia muy variables durante el período de estudio. Las áreas de mayores niveles de abundancia se ubican en los cuadrantes costeros al oeste de la Península de Paria (317 y 318), y en menor grado alrededor de Los Frailes y Los Testigos (217, 218 y 219) (Figura II-39). Los cuadrantes alrededor de los yacimientos son los que aparecen con la menor abundancia, siendo el 'offshore' el que presenta densidades más bajas de la especie. La abundancia estacional es similar para todo el año en la zona donde se observa la mayor presencia de la especie (318), pero varia ligeramente en los cuadrantes circunvecinos $(317,217,218$ y 219), con la excepción de la zona de Cabo Tres Puntas (319) donde se observa una mayor abundancia durante el segundo semestre del año. La abundancia estacional alrededor de los yacimientos es mayor durante el segundo trimestre del año (220 y 320). 


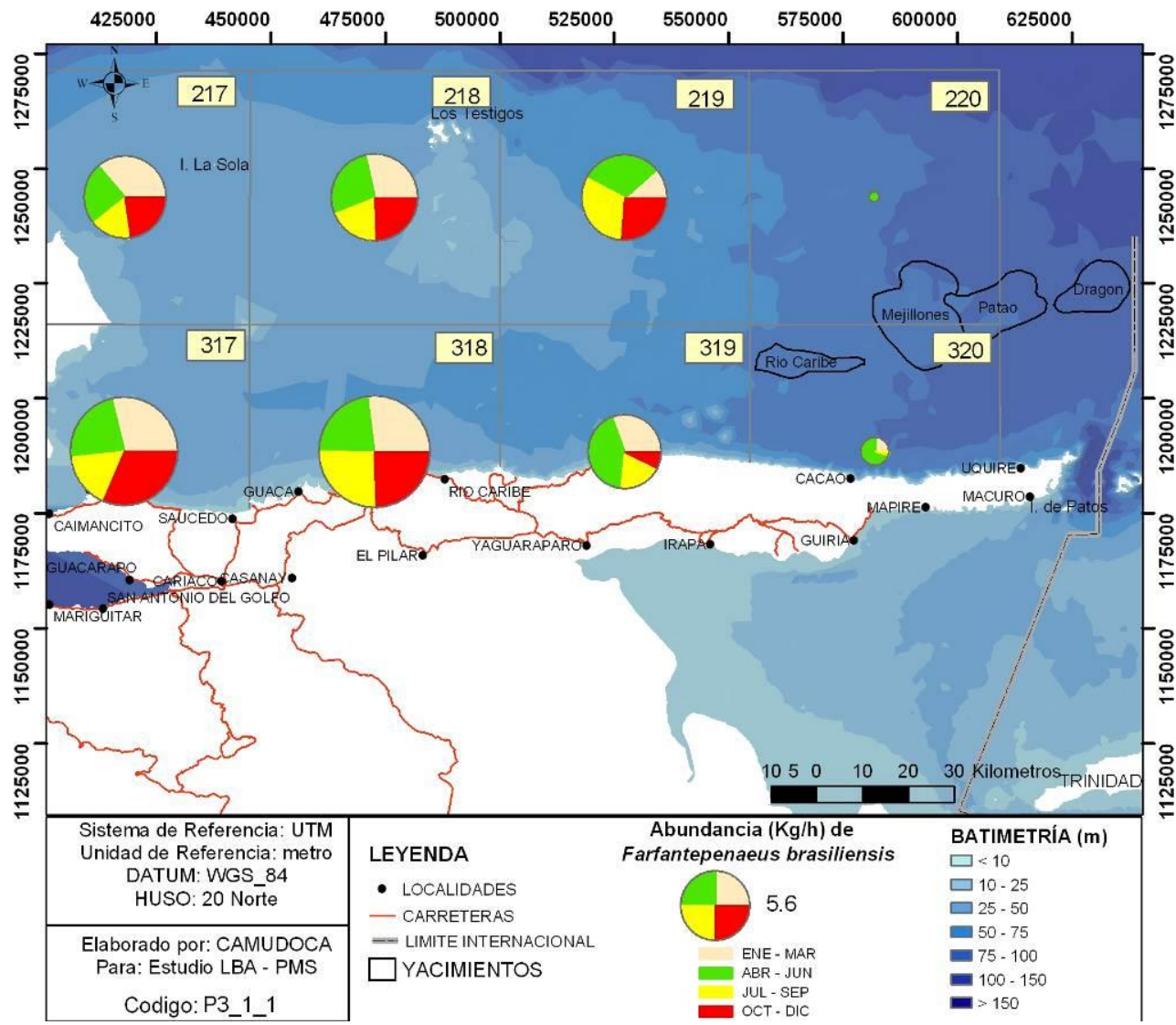

Figura II-39.- Farfantepenaeus brasiliensis. Distribución espacial y temporal (trimestral) de la abundancia por años combinados para el período 2000-2003.

Es probable que las mayores abundancias observadas durante el primer semestre del año se deban a que esta pesquería tiene dos períodos de veda (15 dic15ene y 15mayo-15 jun), y se evidencia que los rendimientos son mayores luego de las vedas.

El análisis estacional de los niveles de abundancia del camarón por estratos de profundidad indica un amplio rango de distribución batimétrica, entre 20 y $72 \mathrm{~m}$ de profundidad. Las mayores abundancias se concentran en los estratos 28-36 m, 37-45 $m$ y 55-63 m, y tienen lugar durante los dos primeros trimestres del año 2000 (Figura II-40). Esta tendencia se observa en todos los estratos de profundidad, con excepción del 46-54 m y 73-81 m, donde los niveles de abundancia fueron mayores en los dos últimos trimestres del año. Durante el 2001, la distribución batimétrica de la especie fue similar al año anterior, apreciándose niveles de abundancia máximos 
en los estratos $46-54$ y $55-63 \mathrm{~m}$ de profundidad, con valores hasta de $6,0 \mathrm{~kg} / \mathrm{h}$ y durante el primer trimestre en el segundo estrato. En todos los estratos, con excepción del 46-54 m, se aprecia que los máximos rendimientos se obtuvieron en el primer trimestre del año. En el 2002 las mayores abundancias se registraron en los intervalos de profundidad entre 37 a $54 \mathrm{~m}$ y mayormente durante los dos primeros trimestres. Durante el año 2003, la mayor abundancia se registró en los intervalos 20-36 m, con una caída progresiva de la abundancia con la profundidad. La abundancia más alta se registró durante los dos primeros trimestres del año, pero el momento de mayor rendimiento fué distinto a diferentes profundidades.
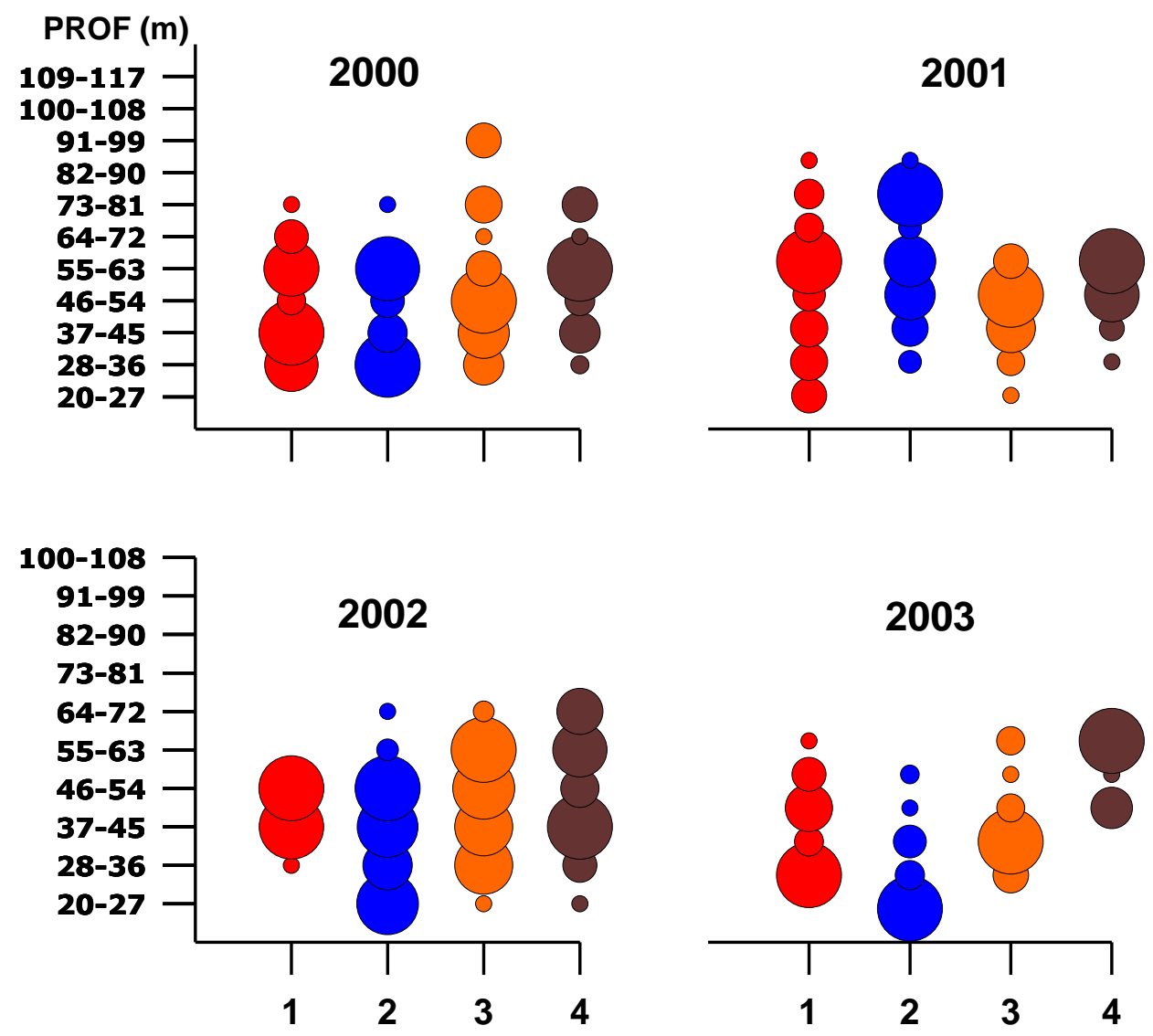

Farfantepenaeus brasiliensis

Figura II-40.- Farfantepenaeus brasiliensis. Distribución estacional (trimestral) por estratos de profundidad por año. 
Con relación al análisis periódico de la abundancia, la especie resultó ser marcadamente más abundante durante la noche, con un indicador de abundancia nocturna entre 2,5 y $4,0 \mathrm{~kg} / \mathrm{h}$, en el período de estudio. Los indicadores de abundancia diurnos fueron menores, con valores de 0,6 y 1,9 kg/h (Figura II-30).

\section{Octopus vulgaris (pulpo)}

Al contrario que muchas de las especies analizadas, el pulpo común, $O$. vulgaris, no tiene un amplio rango de distribución espacial en la zona de estudio. La especie se distribuye mayormente en áreas de pesca situadas al este y noreste de la Isla de Margarita, en los cuadrantes 217 al 219 (Figura II-41). En los cuadrantes costeros también se presentan abundancias relativamente altas, pero en menor grado que los cuadrantes 'offshore'. Un hecho a destacar es la casi total ausencia de O. vulgaris en los cuadrantes alrededor de los yacimientos, donde sólo se manifiesta en el cuadrante costero (320). La abundancia estacional es marcada en esta especie, la cual predomina durante el tercer trimestre, seguido en menor grado por el cuarto trimestre del año. La ausencia durante el primer trimestre y parte del segundo tiene que ver con la historia de vida de esta especie y la vulnerabilidad de la misma al arte de pesca durante la temporada de agregación por apareamiento. 


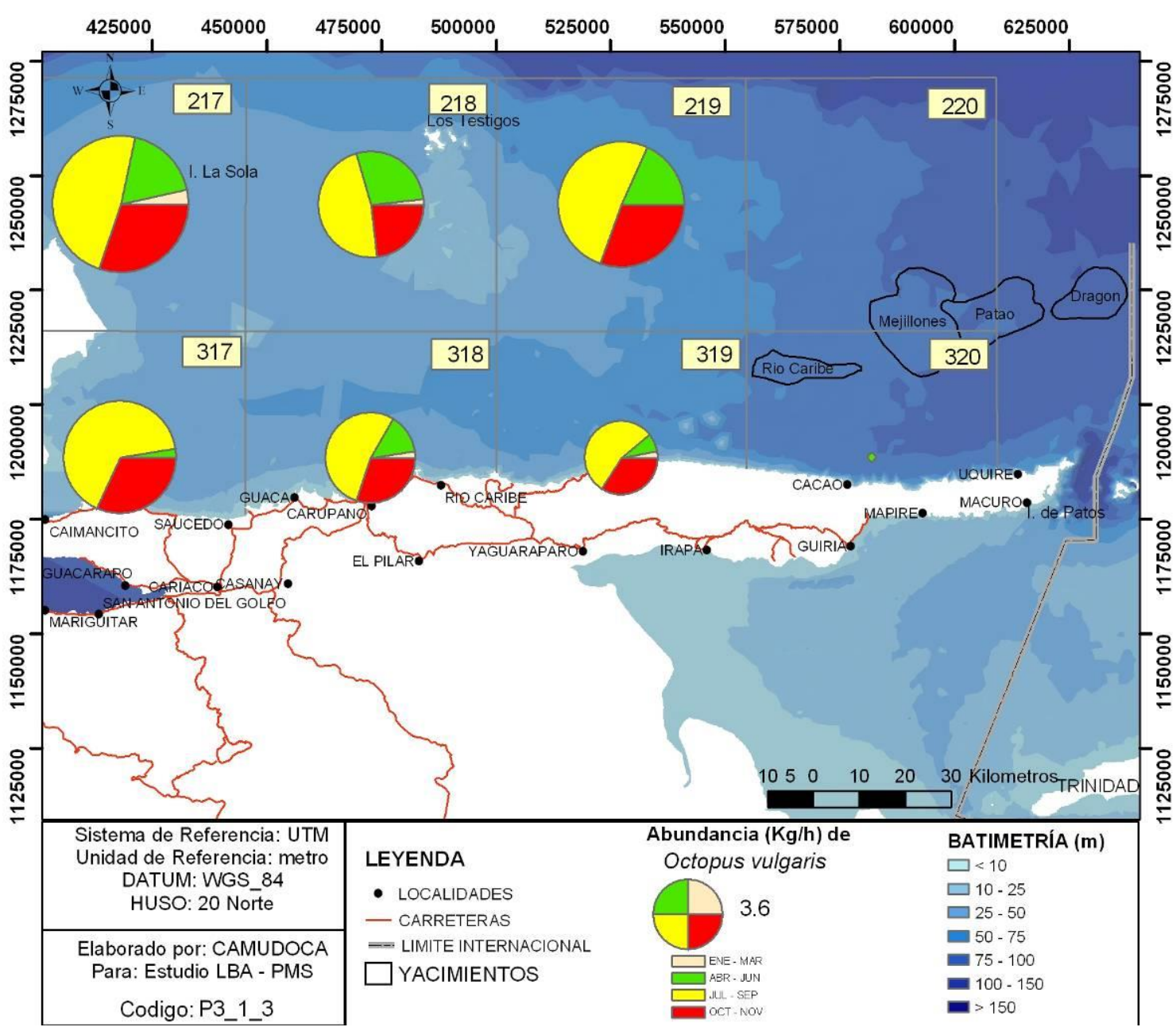

Figura II-41.- Octopus vulgaris. Distribución espacial y temporal (trimestral) de la abundancia por años combinados para el período 2000-2003.

El análisis temporal de los niveles de abundancia de $O$. vulgaris por estratos de profundidad indica que es una especie que habita en fondos someros de la zona nerítica de la plataforma continental, encontrándose con niveles de abundancia significativos hasta los 70 metros de profundidad (Figura II-42). Para 2000 se observaron niveles de abundancias excepcionalmente altos $(58 \mathrm{~kg} / \mathrm{h})$ entre 28 y $45 \mathrm{~m}$ de profundidad y durante el tercer y cuarto trimestres, particularmente en el cuarto trimestre del año. Entre los años 2001 y 2003, el intervalo de su distribución batimétrica fue más amplio, encontrándose hasta los $70 \mathrm{~m}$ de profundidad. Durante el año 2001 las mayores abundancias se observaron en los estratos 20 a 36 m con valores hasta de $13 \mathrm{~kg} / \mathrm{h}$, mientras que durante el 2002 se observaron entre 55 a 72 
$\mathrm{m}$, pero con un rendimiento muy bajo, menor a $1,3 \mathrm{~kg} / \mathrm{h}$. Las mayores abundancias se registraron entre 46 y $72 \mathrm{~m}$ durante el año 2003. En todos los estratos de profundidad, los máximos indicadores de abundancia fueron observados en el tercer y cuarto trimestres del año.
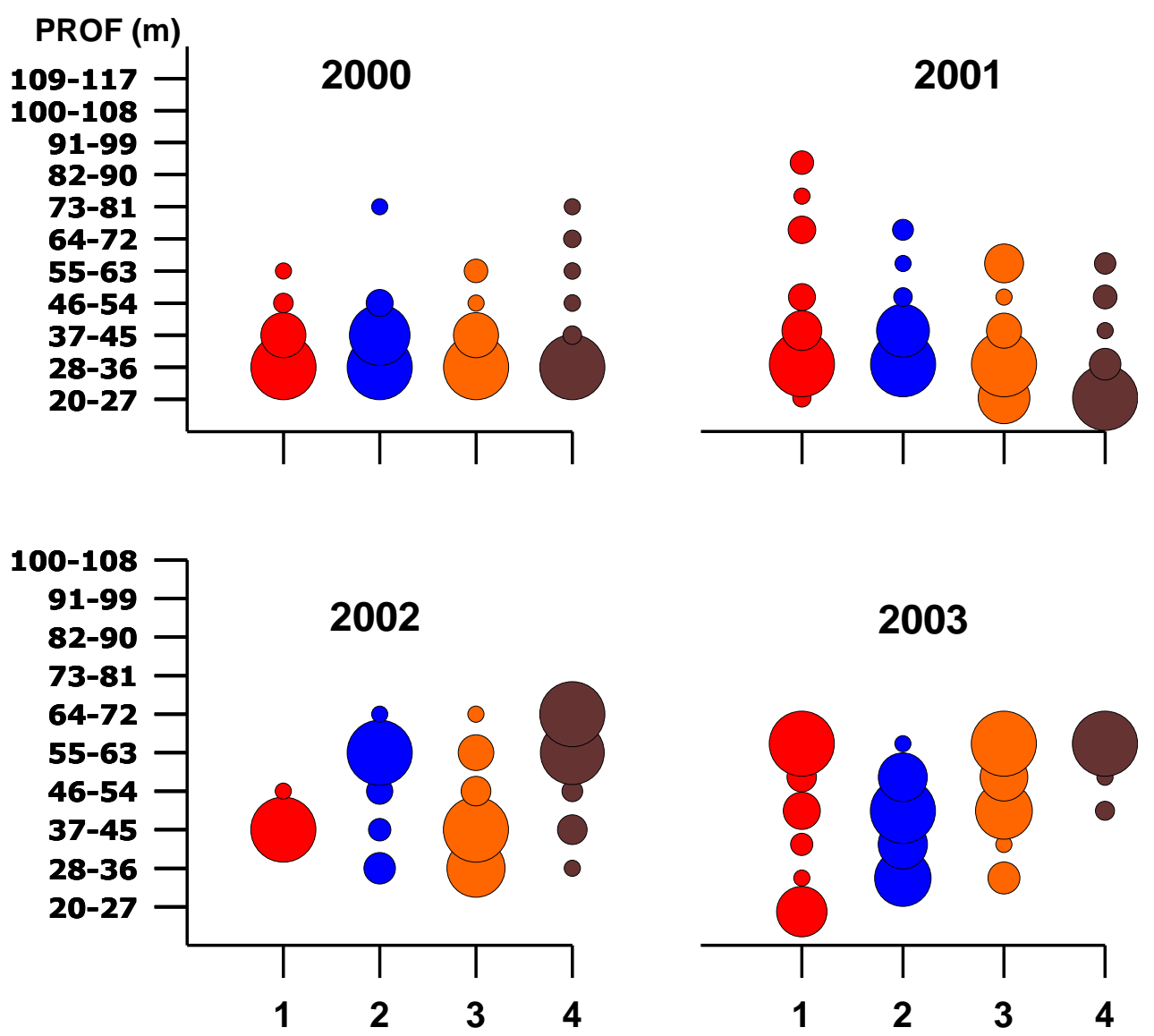

\section{Octopus vulgaris}

Figura II-42.- Octopus vulgaris. Distribución estacional (trimestral) por estratos de profundidad por año.

Con relación al análisis periódico de la abundancia, durante los años estudiados no parece haber diferencias significativas entre los indicadores de abundancia diurno y nocturno, con valores entre 0,3 y $4,0 \mathrm{~kg} / \mathrm{h}$, con una importante reducción promedio a 0,5 kg/h en el 2002 (Figura II-30). 


\section{Loligo plei, Loligo pealei (Calamares)}

Los calamares tienen un amplio rango de distribución espacial en la zona de estudio. El análisis de la distribución espacial y temporal de su abundancia relativa nominal revela que son más abundantes en áreas de pesca situadas al este y noreste de la Isla de Margarita, cuadrantes 217 y 218 (Figura II-43). Similar a $O$. vulgaris, en los cuadrantes costeros también se presentan abundancias relativamente altas, pero en menor grado que en los cuadrantes 'offshore'. En Loligo, se observa una característica similar a la observada en algunas especies de peces como lo es la disminución progresiva de la abundancia relativa en dirección de los yacimientos, donde se registran las menores abundancias del área. En el cuadrante costero (320), la abundancia de Loligo es importante. La abundancia estacional es bastante marcada en la zona de Los Frailes (217), donde las mayores densidades se presentan en el primer trimestre, mientras que en el resto del área las mayores abundancias se presentan durante el segundo trimestre del año. 


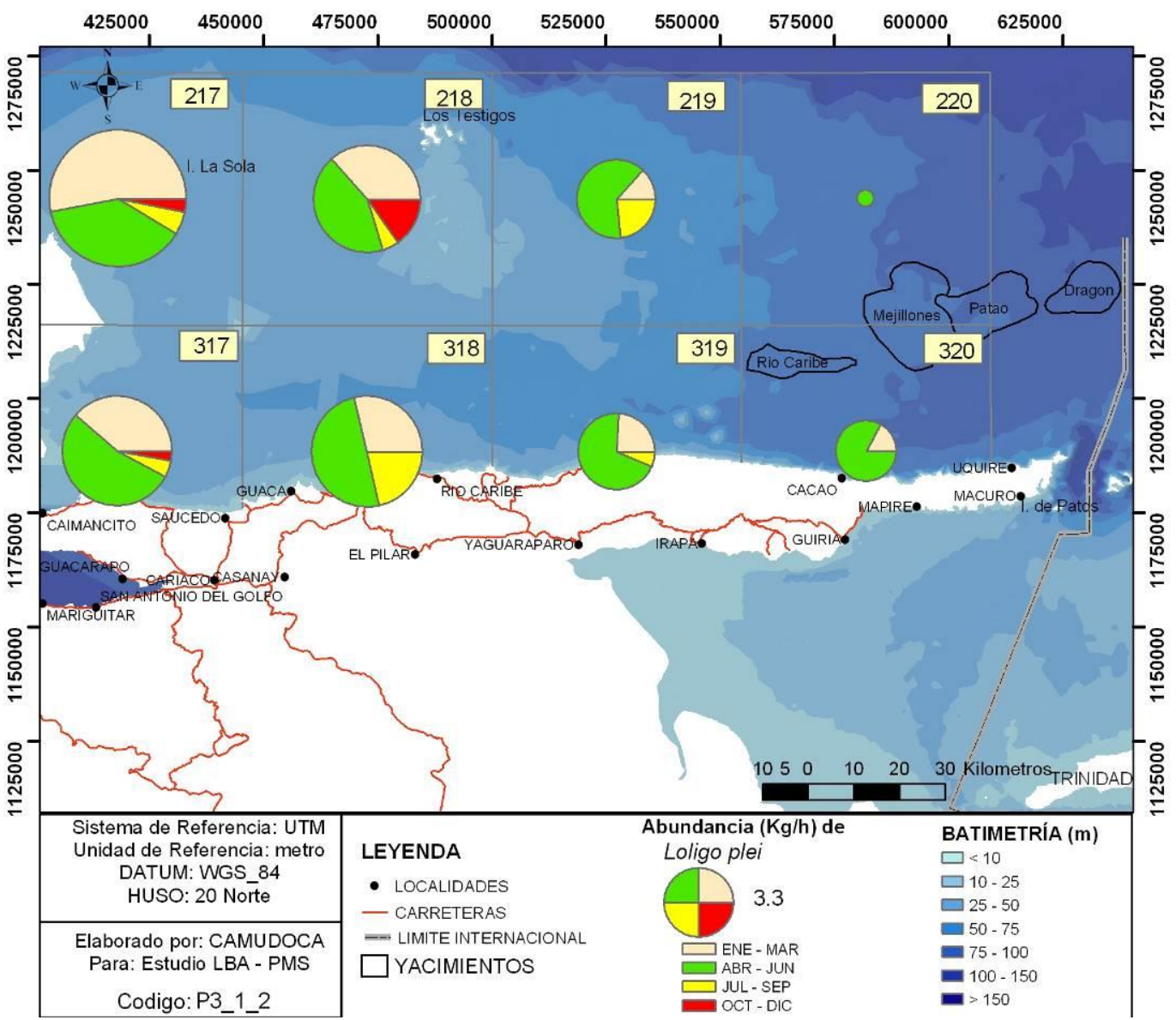

Figura II-43.- Loligo plei/Loligo pealei. Distribución espacial y temporal (trimestral) de la abundancia por años combinados para el período 2000-2003.

El análisis temporal de los niveles de abundancia de los calamares, Loligo pleil L. pealei por estratos de profundidad indica que es un grupo de especies que habitan en regiones someras de la zona nerítica de la plataforma continental, encontrándose con niveles de abundancia considerables, desde el punto de vista económico, hasta los $90 \mathrm{~m}$ de profundidad (Figura II-44). Para el 2000, Loligo presentó altos niveles de abundancia $(9,0 \mathrm{~kg} / \mathrm{h})$ hasta los 72 metros de profundidad, en el primer y segundo trimestre, y particularmente en el segundo trimestre del año. Durante los años 2001 y 2002, el intervalo de su distribución batimétrica fue más amplio, encontrándose hasta los $90 \mathrm{~m}$ de profundidad, siendo los estratos intermedios a profundos ( 37 a $81 \mathrm{~m}$ ) donde se obtuvieron los mayores índices de abundancia, con valores hasta de 12,0 kg/h. En el 2003 la mayor abundancia se registró en el intervalo más profundo $(64-72 \mathrm{~m})$, con un rendimiento de $18,5 \mathrm{~kg} / \mathrm{h}$. En 
todos los estratos de profundidad, los máximos indicadores de abundancia fueron observados en el primer y segundo trimestres del año. Se destaca el segundo trimestre como la época del año en la que suele observarse la mayor abundancia para el grupo de los calamares.
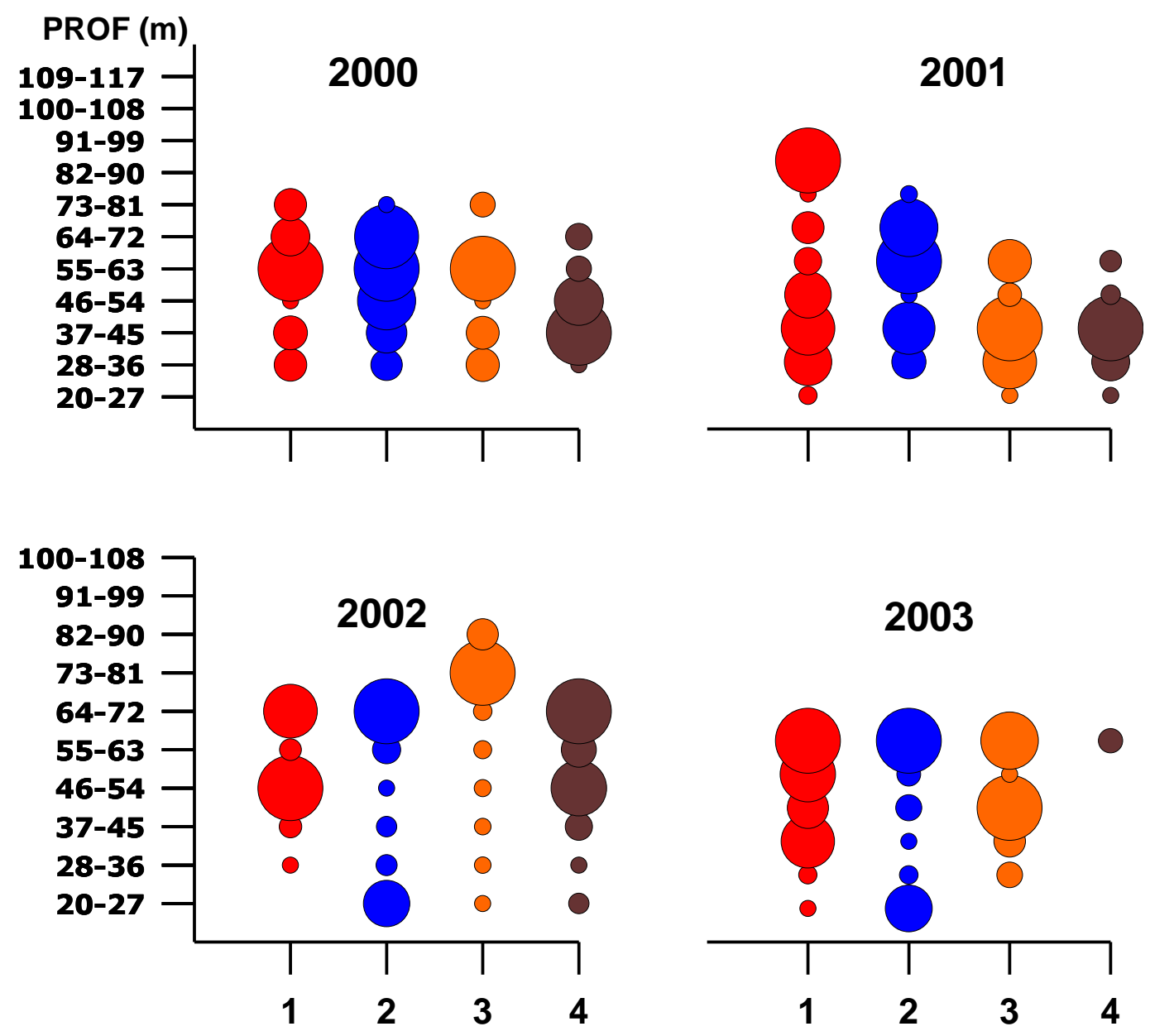

\section{Loligo plei/Loligo pealei}

Figura II-44.- Loligo plei/Loligo pealei. Distribución estacional (trimestral) por estratos de profundidad por año.

Con relación al análisis periódico de la abundancia, en el período estudiado la especie resultó ser más abundante durante el día, con un indicador de abundancia entre 2,6 y $10 \mathrm{~kg} / \mathrm{h}$. La abundancia en el área de pesca durante la noche se reduce 
significativamente, con rendimientos de 1,4 a $5 \mathrm{~kg} / \mathrm{h}$ para el mismo período de tiempo (Figura II-30).

\section{II.5.2 Análisis de los recursos pesqueros capturados por la pesquería industrial de arrastre}

El roncador, Micropogonias furnieri, es una especie de gran importancia pesquera tanto en la región oriental venezolana como en los países del noreste de América del Sur (Trinidad, Guayanas y Brasil) (Booth et al., 2001). La importancia de esta especie parece estar más asociada a la calidad de su carne y la talla que puede alcanzar, más que a la magnitud de sus desembarques. Durante el período estudiado, los desembarques de roncador representaron el $3 \%$ del total de rubros pesqueros descargados por la flota arrastrera industrial que operó entre la Isla de Margarita y el norte de la península de Paria. Es una especie de amplia distribución en el país, capturada mayormente por pescadores artesanales. El aporte de estos últimos representa el $65 \%$ del total nacional desembarcado de esta especie, sobre todo en la región occidental del país (Novoa et al., 1998). En la zona contigua al área de estudio, como es el Golfo de Paria y Delta del Río Orinoco, Alvarez et al. (1999) y Alió et al. (2000) reportan que esta especie es intensamente explotada por pescadores de Trinidad y Venezuela, con sistemas de pesca artesanales e industrial de arrastre, y que en varias ocasiones los desembarques superaron el máximo rendimiento sostenible. Durante su desarrollo, los ejemplares de esta especie efectúan migraciones desde las zonas de crianza, localizadas en ambientes salobres cercanos a bocas de ríos, hasta las zonas mas profundas y de mayor salinidad. En el oriente venezolano, la especie muestra una amplia distribución espacial, aunque con importantes variaciones, tanto geográficas como temporales. Durante el período evaluado, se observó una mayor abundancia en las cercanías de Isla de Margarita, sobre todo en los cuadrantes del norte del área estudiada, reduciéndose hacia los cuadrantes del sur y hacia los yacimientos gasíferos. Este hecho contrasta con los reportes históricos efectuados sobre la distribución de esta especie durante los primeros 20 años de explotación por la flota de arrastre industrial (1971 a 1990; Mendoza et al., 1994). Indican estos autores que durante los inicios de la pesquería 
industrial de arrastre, la especie predominaba en los cuadrantes más cercanos a las costas de la Península de Paria, y que su reducción puede haber estado asociada a la presión pesquera ejercida en esa zona.

La especie muestra una amplia distribución vertical, pero suele ser más abundante hacia las profundidades superiores a $50 \mathrm{~m}$. En este estudio se observó que la batimetría en la cual están los grupos de mayor densidad de la especie puede cambiar dentro de un mismo año, o de un año a otro; así, se registró una mayor abundancia en el estrato 64 - $108 \mathrm{~m}$ de profundidad durante 2000 y el primer semestre de 2001, y en el estrato 20 - 45 m entre el segundo semestre 2001 y 2003. En los cuatro años de estudio, se registró un solo grupo de mayor abundancia con la batimetria. Por su parte, Mendoza et al. (1994) reportan una distribución bimodal para la abundancia de esta especie con la batimetría, siendo abundante en los estratos 20 - 30 m y $50-100$ m. En cuanto a la distribución estacional, estos autores indican que la especie es más abundante durante el cuarto trimestre del año. Sin embargo, en el presente estudio se observa que los períodos de mayor densidad relativa también pueden cambiar de un año a otro, registrándose una mayor abundancia en el tercer trimestre del año 2000 y en el primer trimestre del año 2001. La especie no parece mostrar variaciones marcadas en sus índices de captura durante el día o la noche.

Es probable que los pulsos de abundancia de esta especie estén asociados a fenómenos ambientales que condicionan la abundancia de alimento para los consumidores primarios en la región, como son los fenómenos de surgencia, más notables en la época de mayor intensidad de los vientos alisios durante el primer semestre del año (Aparicio, 1986; Muller-Karger y Varela, 1990), y la pluma de descarga del río Orinoco, cuya influencia es mas notoria entre agosto y septiembre (Muller-Karger y Varela, op. cit;; Freon y Mendoza, 1991). No es fácil discernir cual de estos fenómenos ambientales, influye de manera más determinante sobre la abundancia del roncador, pues la variabilidad interanual de la abundancia de esta especie bien pudiera ser consecuencia de la influencia de ambos fenómenos. 
Entre las especies de peces desembarcadas por la flota industrial de arrastre en el área de estudio, el corocoro, Orthopristis ruber, es una de las que tiene mayor valor económico. Entre los años 1970 y 89 llegó a representar la mayor parte de los desembarques de peces en la región (Mendoza et al. 1994), pero desde 1990 al presente los desembarques descendieron apreciablemente y no se han recuperado a sus niveles históricos. Durante el período de estudio, el corocoro representó 5,1\% de los desembarques de la flota arrastrera. Novoa et al. (1998) indican que es una especie con amplia distribución geográfica en el país y puede encontrarse hasta una profundidad de $200 \mathrm{~m}$. Se la captura en igual proporción con implementos de pesca artesanales e industrial de arrastre. Del oriente del país proviene el 53\% de los desembarques, estando localizada la zona principal de pesca al norte y al este de la Isla de Margarita. En el presente estudio se evidenció la presencia de esta especie en toda el área cubierta, y la disminución de su abundancia disminuía desde las cercanías de la Isla de Margarita hacia los yacimientos gasíferos y de manera similar en los cuadrantes cercanos y alejados de la costa. La pesca de corocoro se efectúa todo el año, pero la abundancia de la especie mostró cambios estacionales que variaron según el cuadrante de pesca. La mayor abundancia en la zona de los yacimientos se registró durante el segundo trimestre del año, mientras que hacia el oeste la mayor abundancia ocurrió durante el tercero o cuarto trimestres. El corocoro suele abundar en estratos intermedios de profundidad, de 28 a 54 m, observándose altas densidades de manera ocasional a profundidades de $90 \mathrm{~m}$ (tercer trimestre 2002). En este sentido, Mendoza et al. (1994) también reportan que la especie predomina hasta los $50 \mathrm{~m}$ de profundidad, y que su abundancia desciende con este parámetro, siendo capturada todo el año pero con menor intensidad durante el segundo trimestre. El patrón de abundancia de esta especie no está bien definido entre el día y la noche, pues varía de un año a otro.

La lamparosa, Selene setapinnis, es un pez carángido con características morfológicas propias de las especies pelágicas (Cervigón, 1993), pero los juveniles de esta especie se encuentran en aguas salobres cercanas a la costa, mientras que los adultos se localizan en aguas más oceánicas (Novoa et al.,1994). Esta especie se captura en volúmenes significativos mediante el sistema industrial de arrastre y a 
profundidades mayores de 40 metros (Marcano et al., 2001). La especie es capturada en casi igual proporción con sistemas de pesca artesanales e industriales de arrastre, proviniendo el $74 \%$ de los desembarques de la región oriental del país. En el presente estudio la lamparosa representó el 4,1\% de los desembarques evaluados. Esta especie mostró mayor abundancia hacia aguas oceánicas, en los cuadrantes más alejados de la costa, observándose las menores concentraciones en las cercanías de los yacimientos. Se observaron marcadas diferencias en la abundancia en los diferentes cuadrantes de pesca a lo largo del año, pero los períodos de ocurrencia cambian según la zona geográfica; en los cuadrantes más alejados de la costa la mayor abundancia se observó en el primer y segundo trimestres del año, mientras que cerca de la costa la mayor abundancia tuvo lugar de manera alternada entre el primer y tercer trimestre. La distribución vertical de la lamparosa en la columna de agua resultó ser muy amplia, entre 20 y $120 \mathrm{~m}$ de profundidad, pudiendo encontrarse los grupos de mayor abundancia a diversas profundidades, aunque preferentemente de manera unimodal y cerca de los $55 \mathrm{~m}$. En ciertos momentos, segundo trimestre de los años 2001 y 2002, la abundancia en esta especie mostró una distribución bimodal con la profundidad. El patrón de abundancia de la lamparosa es muy marcado entre el día y la noche, siendo capturada predominantemente de día con el sistema de arrastre. Estos patrones corroboran el carácter pelágico de los hábitos de esta especie, la cual parece realizar migraciones verticales diarias en la columna de agua, abandonando el fondo marino durante la noche.

Desde el punto de vista económico, la catalana, Priacanthus arenatus, es una de las especies con mayor importancia para la flota arrastrera de la región oriental del país. Su carne es altamente apreciada, alcanza tallas considerables, y representó la principal especie desembarcada en el período de estudio, alcanzando $14,3 \%$ del total. Según Cervigón (1991) es una especie abundante en toda el área de surgencia de la región nororiental, siendo capturada con artes de anzuelo, nasas y redes de arrastre. Novoa et al. (1998) indican que el $88 \%$ de los desembarques de esta especie provienen de la región oriental y en un $56 \%$ del sector artesanal. TapiaGarcía et al. (1995) reportan que esta especie domina en las comunidades del sur 
del Golfo de México, en donde se la encuentra a profundidades mayores de $36 \mathrm{~m}$. Es una especie marina, no asociada a estuarios, que efectúa migraciones reproductivas hacia la costa, en zonas con poca influencia de descargas continentales. Los juveniles y adultos migran hacia aguas profundas luego de la reproducción. Los resultados del presente estudio revelan que la especie presenta una amplia distribución geográfica en la zona de estudio, con bajos rendimientos relativos. Las mayores abundancias se observaron en el cuadrante costero central de la Península de Paria y cercano al Archipiélago Los Testigos. No se registró una clara tendencia a que la especie predomine en la región en un momento determinado del año, lo cual coincide con las observaciones de Novoa et al. (1998) y Mendoza et al. (1994), quienes reportan que no hay estacionalidad en las capturas de esta especie. La distribución batimétrica de la especie es igualmente amplia, encontrándose desde 20 a $120 \mathrm{~m}$, pero concentrándose durante la mayoría de los trimestres del período evaluado entre 55 y $72 \mathrm{~m}$ de profundidad. Los grupos de abundancia se muestran por lo general unimodales, aunque de manera ocasional se observaron bimodales (cuatro trimestre 2000 y primero del 2001). El patrón de abundancia de la catalana fue marcado entre el día y la noche, siendo capturada predominantemente de día con el sistema de arrastre, aunque durante el año 2001 las diferencias de este patrón fueron poco apreciables. Es posible que la flota venezolana esté explotando una fracción de la población de catalana, pues la especie puede distribuirse hacia aguas mucho más profundas. En este sentido, Haimovici et al. (1994) reportan que la especie estuvo presente en el estrato de 180 a $249 \mathrm{~m}$ de profundidad en la zona subtropical al sur de Brasil. Sin embargo, los resultados de Toledo et al. (2000), luego de evaluar la pesquería de catalana en la región oriental, sugieren que la especie puede estar sobreexplotada, lo cual es un llamado de cautela sobre las capturas de esta especie en la región.

El cherechere, Haemulon steindachneri, es un pez hemúlido, al igual que el corocoro, pero de tamaño más pequeño pues no suele superar $25 \mathrm{~cm}$ de longitud total. Es una especie consumida frecuentemente en el oriente del país, de donde provienen la totalidad de los desembarques (Novoa et al. 1998). Las capturas durante el período de estudio alcanzaron un $2,9 \%$ del total. La distribución de la 
especie es amplia en la zona de estudio, con una abundancia relativamente baja y poco variable entre los distintos cuadrantes de pesca. Suele ser más abundante durante el tercer y cuarto trimestres del año, particularmente en el cuarto en la zona costera de los yacimientos gasíferos. Aunque se registró su presencia entre 20 y 99 $\mathrm{m}$ de profundidad, suele ser más abundante entre 20 y $63 \mathrm{~m}$ de profundidad, por lo general con distribuciones unimodales de la abundancia. El patrón de capturas de esta especie entre el día y la noche no es bien definido, siendo las capturas de noche ligeramente más elevadas.

El rubro camarón es el más importante económicamente para la flota industrial de arrastre que opera en la región, ya que es su objetivo principal. Representó durante este estudio el 9,7\% de los desembarques, pero en valor puede llegar a alcanzar el $50 \%$ de la captura. Este grupo está conformado por dos especies, conocidas comercialmente como camarón marrón o camarón rosado con mancha, Farfantepenaeus brasiliensis, y el camarón rosado, F. notialis, ó camarón marrón sin mancha. El primero es el más abundante en la zona y representa el $90 \%$ de las capturas totales. Por ello al grupo camarón se le conoce como complejo marrón (Marcano et al. 1999). El camarón rosado con mancha es de las especies de su género presentes en Venezuela el que se distribuye de manera más amplia batimétricamente, pudiendo encontrarse entre 3 y $365 \mathrm{~m}$, sobre fondos fangosos, aunque es más abundante entre 40 y $100 \mathrm{~m}$ de profundidad. Los desembarques de camarón rosado con mancha provienen en un $70 \%$ del occidente del país, y $27 \%$ del oriente (Novoa et al. 1998). F. brasiliensis se distribuye de manera amplia en la zona de estudio, pero resulta ser más abundante en los cuadrantes de pesca costeros. La abundancia de camarón rosado con mancha es muy baja hacia la zona de los yacimientos gasíferos, seguramente debido al tipo de fondo (de cascajo) que allí predomina (Gines, 1972). Las capturas muestran un patrón estacional poco marcado, aunque se observan ligeras alzas en los rendimientos durante el primer y segundo trimestre, seguramente asociadas, a que luego de los períodos de veda, la captura por unidad de esfuerzo se eleva momentáneamente. $F$. brasiliensis tuvo una distribución batimétrica desde 20 a $99 \mathrm{~m}$, pero se observó que las mayores abundancias se presentaron en los estratos de profundidad 28 a $63 \mathrm{~m}$, con cierta 
variabilidad entre trimestres. Esta especie de camarón muestra un fuerte patrón de capturas entre el día y la noche, siendo pescado mayormente de noche con un rendimiento que supera casi tres veces al rendimiento diurno. Las evaluaciones efectuadas a la pesquería de camarón en la zona de estudio, indican que es un recurso que pareciera estar explotado en su máximo rendimiento sostenible (Die et al., 2004).

El pulpo, Octopus vulgaris, es uno de los recursos demersales más valiosos en la zona de estudio, cuyos desembarques representaron un 5,4\% del total. Es una especie con amplia distribución en los mares tropicales del mundo. En Venezuela, la especie es abundante en la costa del Mar Caribe de la región oriental y en el Golfo de Venezuela, proviniendo de la primera, el $91 \%$ de las capturas (Novoa et al., 1998; Marcano et al., 2001). Hasta 1995, el $90 \%$ de los desembarques de pulpo provenían del sector industrial de arrastre. Sin embargo, desde hace unos diez años la pesca artesanal de pulpo con 'garrapiño' ha superado por mucho los desembarques industriales y en el año 2003 alcanzó a desembarcar 1,200TM, comparado con 200TM por parte del sector industrial (Torrens et al. 2005). A diferencia del resto de las especies consideradas en este estudio, el pulpo tiene una distribución restringida en la zona de estudio, predominando en los cuadrantes mar afuera y en las cercanías de las Isla de Margarita. Resulta notoria su ausencia en los cuadrantes de los yacimientos gasíferos. El pulpo es una especie con una marcada distribución estacional, pudiendo ser capturado entre el segundo y cuarto trimestre del año, con mayor abundancia durante el tercer trimestre. Si bien la especie puede encontrarse entre 20 y $90 \mathrm{~m}$ de profundidad, la mayor abundancia se registró entre 28 y $45 \mathrm{~m}$ en 2000 y 2001 , y entre 28 y 72 m en los años 2002 y 2003. No se registró una marcada diferencia en el patrón de capturas de día o de noche. El comportamiento estacional de las capturas coincide con el de la concha vieira (Amusium papiraceum), componente principal de su dieta en la zona (Arocha y Urosa, 1982).

El rubro calamar está integrado en la zona de estudio por dos especies perteneciente a la familia Loliginidae, muy abundante en la región nororiental de Venezuela. Estas especies son el calamar común, Loligo plei y el calamar flecha, $L$. 
pealei, difíciles de distinguir una de otra. De acuerdo a estudios realizados en 1988, la composición de las capturas estaba conformada por $70 \%$ de $L$. plei y $30 \%$ de $L$. pealei (IMR, 1989; Arocha y Urosa, 1991). Este grupo representa el segundo rubro más importante desde el punto de vista económico para la flota industrial de arrastre, sistema con el que se captura en mayores volúmenes (Marcano et al., 2001). Durante este estudio, los desembarques de calamares representaron el $10,7 \%$ del total, siendo el segundo rubro en importancia en volumen después de la catalana. Novoa et al. (1998) indican que los calamares suelen distribuirse mayormente entre 10 y $80 \mathrm{~m}$ de profundidad, pudiendo llegar a $350 \mathrm{~m}$. Aunque estas especies tienen una distribución amplia en el país, el $61 \%$ de los desembarques provienen de la región oriental. En la zona de estudio los calamares muestran su mayor abundancia en los cuadrantes mar afuera y hacia la Isla de Margarita, reduciéndose progresivamente la abundancia en dirección a los yacimientos gasíferos. La estacionalidad de la abundancia es bien marcada, concentrándose las capturas en los dos primeros trimestres del año. Este patrón de distribución espacial y temporal de la abundancia coincide con lo reportado para la región por Mendoza et al. (1994) en un estudio histórico de las pesquerías de arrastre industrial de 1970 al 1990. Los calamares muestran una amplia distribución batimétrica, entre 20 y $90 \mathrm{~m}$, pero las mayores abundancias se registraron entre 28 y 72 m (rango de distribución preferente de $L$. pleI), siendo con frecuencia multimodales en un mismo trimestre. El patrón de captura de estas especies es fuertemente sesgado hacia el día como resultado del comportamiento natural de los calamares, reduciéndose la tasa de captura a menos de la mitad durante la noche.

\section{II.5.3 Conclusiones}

- La distribución observada de la mayoría de las especies seleccionadas es amplia, tanto geográfica como verticalmente en la columna de agua. Por ello, la composición de especies puede ser común en la mayor parte de los fondos marinos de la zona, entre 20 y 120 m de profundidad, aunque las especies que predominen en una misma zona varíen estacional y verticalmente. 
- Las especies de peces pudieran agruparse en tres clases, según la profundidad donde suelen ser más abundantes: las de zonas llanas, con profundidades de 20 - $40 \mathrm{~m}$ (cherechere); las de zonas de profundidad intermedia, 40 - $70 \mathrm{~m}$ (corocoro, lamparosa); y las de zonas más profundas, entre 80 y 120 m, cercanas al límite donde opera la flota arrastrera industrial (roncador, catalana).

- Tres especies: roncador, corocoro y cherechere muestran tasas de captura similares de día y noche, mientras que la captura de lamparosa y catalana son mayores durante las horas diurnas.

- Los invertebrados con capacidad de natación más limitada, como los camarones, suelen ocupar estratos de profundidad entre llanos a intermedios (20 - $70 \mathrm{~m})$ y encontrarse en zonas más cercanas a la costa. Los invertebrados con mayor capacidad natatoria, como los calamares, suelen encontrarse en estratos de profundidad más variables $(30-90 \mathrm{~m})$. La estacionalidad de estos grupos de invertebrados es menos marcada que en el grupo de los peces, con tendencia a mostrar mayor abundancia durante el primer semestre del año.

- El pulpo resultó ser una especie de distribución restringida, tanto geográfica como estacional. Predomina al noreste de la isla de Margarita hasta los $70 \mathrm{~m}$ de profundidad, con mayores abundancias entre 25 y $45 \mathrm{~m}$ y durante el segundo y tercer trimestres del año. Es característica su ausencia de las zonas de yacimientos gasíferos, donde la profundidad suele ser mayor de 80 $\mathrm{m}$.

\section{II.6 Estimaciones de Biomasa por el Método de Área Barrida sobre la PNPP}

Se realizó la campaña de pesca para obtener estimados de la biomasa de especies demersales con importancia económica en las inmediaciones de los campos gasíferos Dragón, Patao, Mejillones y Río Caribe, localizados al norte de la 
Península de Paria, cuya explotación desea iniciar la empresa PDVSA. El propósito de la campaña fue la estimación de biomasa de toda la PNPP, pero debido a que las artes resultaron ser inoperantes en la zona de los yacimientos, la campaña fue interrumpida por la ruptura total del arte de pesca empleado. En este apartado se presentan los resultados de la información obtenida de las estaciones aledañas a los yacimientos antes del accidente que interrumpió la campaña.

La campaña se planificó en 42 estaciones localizadas entre Carúpano $\left(10^{\circ} 44,30 \mathrm{~N}, 63^{\circ} 10,45 \mathrm{~W}\right)$ y el Promontorio de Paria $\left(10^{\circ} 47,05 \mathrm{~N}, 61^{\circ} 50,20 \mathrm{~W}\right), 20 \mathrm{de}$ ellas localizadas a distancia variable desde la costa (3,6 - 5,4 km), y 22 adicionales situadas entre 10 y $25 \mathrm{~km}$ de la costa (Figura II-45 y Tabla II-23). Las primeras ofrecerían información de la región costera por donde pasarían las tuberías de gas, desde los campos de extracción hacia el complejo CIGMA en Güiria. Mientras que en las últimas se cubriría el sustrato localizado directamente encima de los campos gasíferos y el Bajo Cumberland, de particular importancia para la actividad pesquera y posible zona de reclutamiento de especies importantes para la explotación pesquera. 


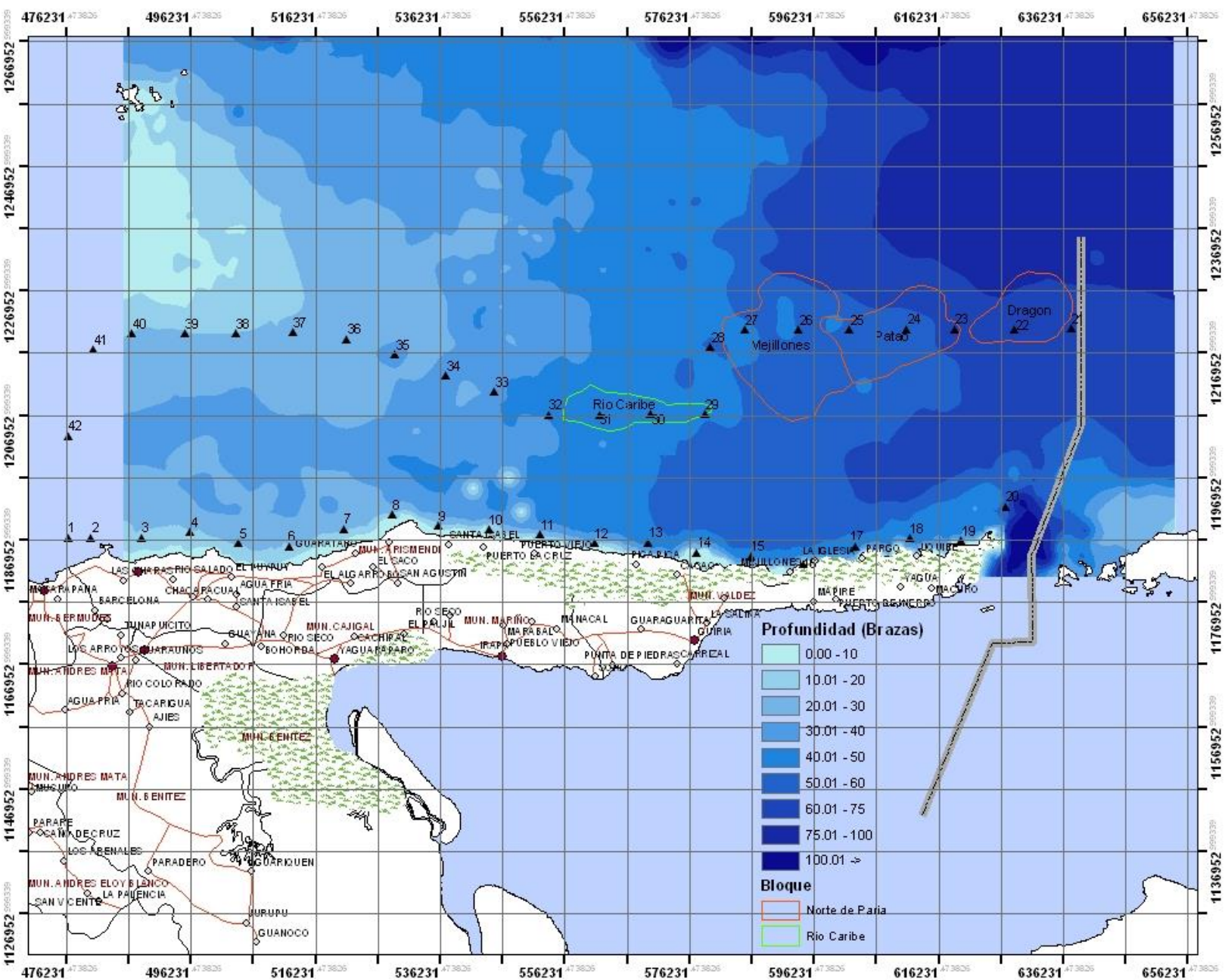

Figura II-45.- Estaciones seleccionadas para las estimaciones de biomasa por el método de área barrida sobre la PNPP. 
Tabla II-23.-Estaciones a cubrir en la campaña de estimación de biomasa por el método de área barrida sobre la PNPP.

\begin{tabular}{|c|c|c|c|c|c|c|c|c|c|}
\hline Estación & Nombre estación & $\begin{array}{l}\text { Profundidad } \\
(\mathrm{m})\end{array}$ & Latitu & ud $\mathrm{N}$ & & Longitud W & & $\begin{array}{c}\text { Distancia a } \\
\text { costa }\end{array}$ & $\begin{array}{l}\text { Punto más cercano en } \\
\text { la costa }\end{array}$ \\
\hline 1 & Carúpano I & 18 & 104 & 44 & 30 & 6310 & 45 & 3 & Carúpano \\
\hline 2 & Pto. Santo & 18 & 104 & 44 & 30 & 6310 & 45 & 2 & Morro Puerto Santo \\
\hline 3 & Caribe & 32 & 104 & 44 & 30 & 6362 & 20 & 2 & Río Caribe \\
\hline 4 & Medina & 36 & 104 & 45 & 0 & 632 & 0 & 3 & Ens. Medina \\
\hline 5 & Puy Puy II & 36 & 104 & 44 & 0 & 6257 & 45 & 2 & Puy Puy \\
\hline 6 & Cangua I & 36 & 104 & 43 & 45 & 6253 & 15 & 2 & Morro Cangua \\
\hline 7 & Muros & 36 & 104 & 45 & 15 & 62483 & 30 & 2 & Punta Muros \\
\hline 8 & Tres Puntas & 36 & 104 & 46 & 30 & 6244 & 15 & 1,3 & Cabo Tres Puntas \\
\hline 9 & P. Tacarigua I & 36 & 104 & 45 & 30 & 6240 & 15 & 1,3 & Punta Tacarigua \\
\hline 10 & Ens. Tacarigua I & 36 & 104 & 45 & 10 & 6235 & 45 & 1,3 & Ens. Tacarigua \\
\hline 11 & Angoleta I & 36 & 104 & 44 & 45 & 6231 & 15 & 1 & Punta Angoleta \\
\hline 12 & P. La Pava & 36 & 104 & 44 & 0 & 6226 & 30 & 1 & Punta La Pava \\
\hline 13 & P. Tolete & 72 & 104 & 44 & 0 & 6221 & 45 & 1 & Punta Tolete \\
\hline 14 & Cacao & 76 & 104 & 43 & 10 & 6217 & 30 & 1 & Punta cacao \\
\hline 15 & P. Caribe & 76 & 104 & 42 & 50 & 6212 & 45 & 1 & Punta Caribe \\
\hline 16 & Hermita & 81 & 104 & 42 & 10 & 628 & 10 & 1,3 & Oeste de Pta. Hermita \\
\hline 17 & Pargo & 83 & 104 & 43 & 40 & 623 & 30 & 1 & Punta Pargo \\
\hline 18 & Sn. Fco. & 72 & 104 & 44 & 20 & 6158 & 45 & 1 & Cabo Sn Francisco \\
\hline 19 & Palmar & 72 & 104 & 44 & 5 & 6154 & 15 & 1,5 & Punta Palmar \\
\hline 20 & P. Paria & 90 & 104 & 47 & 5 & 6150 & 20 & 3 & Promotorio de Paria \\
\hline 21 & Dragón I & 122 & 11 & 2 & 30 & 6144 & 30 & 20 & Punta Mejillón \\
\hline 22 & Dragón II & 113 & 11 & 2 & 30 & 6149 & 30 & 18 & Punta Mejillón \\
\hline 23 & Patao I & 108 & 11 & 2 & 30 & 6154 & 45 & 19 & Punta Palmar \\
\hline 24 & Patao II & 97 & 11 & 2 & 30 & 6159 & 0 & 20 & Cabo Sn Francisco \\
\hline 25 & Patao III & 99 & 11 & 2 & 30 & 624 & 0 & 20 & Prom.Paria \\
\hline 26 & Mejillón I & 90 & 11 & 2 & 30 & 628 & 30 & 21 & Ens. Mejillónes \\
\hline 27 & Mejillón II & 81 & 11 & 2 & 30 & 6213 & 15 & 22 & Punta Caribe \\
\hline 28 & Mejillón III & 90 & 11 & 1 & 0 & 6216 & 15 & 19 & Punta Cacao \\
\hline 29 & Río Caribe I & 86 & 105 & 55 & 10 & 6216 & 45 & 13 & Punta Cacao \\
\hline 30 & Río Caribe II & 83 & 105 & 55 & 10 & 6221 & 30 & 12 & Punta Tolete \\
\hline 31 & Rio Caribe III & 79 & 105 & 55 & 10 & 6226 & 0 & 12 & Punta la Pava \\
\hline 32 & Angoleta II & 76 & 104 & 44 & 45 & 6230 & 30 & 12 & Punta Angoleta \\
\hline 33 & Ens. Tacarigua II & 68 & 105 & 57 & 10 & 6235 & 15 & 13 & Ens. Tacarigua \\
\hline 34 & P. Tacarigua II & 70 & 105 & 58 & 35 & 6239 & 30 & 14 & Pta. Tacarigua \\
\hline 35 & Tres Puntas II & 58 & 11 & 0 & 25 & 6244 & 0 & 13 & Cabo Tres Puntas \\
\hline 36 & P. Tigrillo & 41 & 11 & 1 & 45 & 6248 & 15 & 18 & Punta Tigrillo \\
\hline 37 & Cangua II & 43 & 11 & 2 & 20 & 6253 & 0 & 20 & Morro Cangua \\
\hline 38 & Puy Puy II & 36 & 11 & 2 & 15 & 6258 & 0 & 20 & Puy Puy \\
\hline 39 & Cumberland I & 36 & 11 & 2 & 15 & 632 & 30 & 20 & Ensenada medina \\
\hline 40 & Cumberland II & 38 & 11 & 2 & 15 & 637 & 10 & 20 & Río Caribe \\
\hline 41 & Cumberland III & 36 & 11 & 0 & 50 & 6310 & 30 & 18 & Morro Puerto Santo \\
\hline 42 & Cumberland IV & 54 & 105 & 53 & 20 & 6312 & 45 & 12 & Carúpano \\
\hline
\end{tabular}

La estimación de biomasa presente de fauna demersal se realizó utilizando el área barrida con dos redes de arrastre simultáneamente de 22,2 m de relinga superior. Los arrastres se efectuaron a bordo de la embarcación JANNADOMARI del 
tipo Florida, (propiedad de la empresa FLODIPESCA de Cumaná). La embarcación tiene una eslora de $33 \mathrm{~m}$ y una potencia de motor de $800 \mathrm{HP}$. Se decidió iniciar la protección por la estación 21 y continuar hacia el oeste, para luego finalizar con el estrato de costa. Sin embargo, se realizaron dos muestreos para prueba de equipos en estaciones de baja profundidad (Cangua II y Puy Puy II, de 30 a $40 \mathrm{~m}$ de profundidad). Las estimaciones de la posición de la embarcación, velocidad de crucero y distancias recorridas, se efectuaron utilizando un equipo GPS portátil.

El lanzamiento de la red se hacía con la corriente (la corriente predominante, en la estación Patao II, tenía una velocidad de $5 \mathrm{~km} / \mathrm{h}$ ó $2,8 \mathrm{kn}$, y provenía del este). El tiempo de arrastre se empezaba a contar a partir del momento que la red tocara fondo, y durante el mismo la embarcación mantenía un desplazamiento lineal por 30 minutos (Tabla II-24), con rumbo cercano a 270 grados y una velocidad de 5 - 6 $\mathrm{km} / \mathrm{h}(2,8-3,3 \mathrm{kn})$. Al finalizar el tiempo de arrastre se iniciaban las maniobras de recuperación de las redes a bordo, para lo cual la embarcación debía colocarse contra la corriente, por lo que debía dar un giro de 180 grados. La duración de esta última maniobra varió de 6 a 9 min. (Tabla II-24). La distancia recorrida en cada estación dependió de la velocidad promedio que mantuvo la embarcación y varió entre 4,2 y 6 km (Tabla II-25). En el caso de la estación, PMS1-24, no hubo indicios que las redes estaban rotas y la calada se mantuvo hasta el final del período estimado. En el caso de la estación PMS1-29, la calada se abortó una vez que se hizo evidente que las redes estaban rotas.

Tabla II-24.-Posición de los lances efectuados sobre la PNPP durante el muestreo realizado a bordo de la embarcación Jannadomary entre los días 28 y 29/OCT/2005.

\begin{tabular}{|c|c|c|c|c|c|c|c|c|c|}
\hline $\begin{array}{l}\text { Código } \\
\text { estación }\end{array}$ & $\begin{array}{l}\text { Nombre } \\
\text { estación }\end{array}$ & $\begin{array}{l}\text { Hora } \\
\text { inicio }\end{array}$ & $\begin{array}{l}\text { Hora } \\
\text { final }\end{array}$ & $\begin{array}{l}\text { Prof. } \\
\text { inicio } \\
\text { (m) }\end{array}$ & $\begin{array}{c}\text { Prof. } \\
\text { final } \\
(\mathrm{m})\end{array}$ & $\begin{array}{l}\text { Latitud } \\
\text { inicio }\end{array}$ & $\begin{array}{c}\text { Longitud } \\
\text { inicio }\end{array}$ & $\begin{array}{l}\text { Latitud } \\
\text { final }\end{array}$ & $\begin{array}{c}\text { Longitud } \\
\text { final }\end{array}$ \\
\hline PMS1_38 & Puy puy II & $23: 13$ & $23: 43$ & 32 & 41 & $11^{\circ} 02^{\prime} 13^{\prime \prime}$ & $62^{\circ} 57^{\prime} 55^{\prime \prime}$ & $11^{\circ} 01^{\prime} 55^{\prime \prime}$ & $62^{\circ} 56^{\prime} 06^{\prime \prime}$ \\
\hline PMS1_37 & Cangua II & $1: 18$ & $1: 48$ & 43 & 38 & $11^{\circ} 01^{\prime} 59^{\prime \prime}$ & $62^{\circ} 52^{\prime} 52^{\prime \prime}$ & $11^{\circ} 02^{\prime} 27^{\prime \prime}$ & $62^{\circ} 51^{\prime} 30^{\prime \prime}$ \\
\hline PMS1_24 & Patao II & $10: 13$ & $10: 44$ & 101 & 104 & $11^{\circ} 01^{\prime} 28^{\prime \prime}$ & $61^{\circ} 58^{\prime} 52^{\prime \prime}$ & $11^{\circ} 01^{\prime 2} 29^{\prime \prime}$ & $61^{\circ} 56^{\prime} 25^{\prime \prime}$ \\
\hline PMS1_29 & Río Car. I & $15: 09$ & $15: 25$ & 88 & 94 & $10^{\circ} 55^{\prime} 39^{\prime \prime}$ & $62^{\circ} 14^{\prime} 08^{\prime \prime}$ & $10^{\circ} 55^{\prime} 10^{\prime \prime}$ & $62^{\circ} 13^{\prime} 56^{\prime \prime}$ \\
\hline
\end{tabular}


Tabla II-25.-Distancia de barrido en los lances efectuados sobre la PNPP durante el muestreo realizado a bordo de la embarcación Jannadomary entre los días 28 y 29/OCT/2005.

\begin{tabular}{|cccccc|}
\hline $\begin{array}{c}\text { Código } \\
\text { estación }\end{array}$ & $\begin{array}{c}\text { Nombre } \\
\text { estación }\end{array}$ & Fecha & $\begin{array}{c}\text { Distancia } \\
\text { recorrida } \\
\text { (porción } \\
\text { recta) } \\
\text { (m) }\end{array}$ & $\begin{array}{c}\text { Distancia } \\
\text { recorrida } \\
\text { (maniobra) }\end{array}$ & $\begin{array}{c}\text { Distancia } \\
\text { recorrida total } \\
(\mathbf{m})\end{array}$ \\
\hline PMS1_38 & Puy puy II & 28 & 3.870 & 300 & \\
PMS1_37 & Cangua II & 29 & 3.410 & 1.400 & 4.170 \\
PMS1_24 & Patao II & 29 & 4.970 & 1.040 & 6.010 \\
PMS1_29 & Río Car. I & 29 & 1.990 & 810 & 2.800 \\
\hline
\end{tabular}

Una vez que el copo de cada red se descargaba a bordo, la captura se agrupaba con palas y con ellas se dividía, primero en dos mitades y luego en otras dos. De esta manera, una cuarta parte de cada red se separaba y colocaba en un recipiente. Seguidamente, de cada recipiente (por separado) se separaban las especies seleccionadas para el estudio y se pesaban en una balanza con capacidad $20 \mathrm{~kg}$ y precisión $50 \mathrm{~g}$. Los restos vegetales y material inerte fueron descartados. Las especies seleccionadas y el resto del material biológico fueron colocados en bolsas plásticas separadas, etiquetadas y conservadas bajo congelación para ser trasladadas al Instituto Oceanográfico de la Universidad de Oriente en Cumaná, para su posterior análisis.

La biomasa de cada especie por estación se estimó como el peso de su captura dividido por el área barrida. Esta última se estimó como:

$$
A=d \times L \times 0,5
$$

Donde, $A$ es el área barrida $\left(\mathrm{m}^{2}\right), d$ es la distancia recorrida por la embarcación $(\mathrm{m})$ durante los arrastre (porción recta más maniobra de recuperación de las redes), $L$ es la longitud de la relinga superior $(22,2 \mathrm{~m})$ y 0,5 es un factor de estimación de la abertura de la red (Sparre y Venema 1997). La biomasa promedio 
de cada especie por estación y su desviación estándar (estimada cuando ambas redes proveyeron captura) se calculó en base a los resultados de las dos redes.

\section{II.6.1 Operación de captura de muestras y observaciones sobre el sustrato en el área de estudio}

La operación de las redes sobre las dos estaciones de prueba no presentó inconvenientes. El fondo era fangoso y las redes operaron bien. Sin embargo, el fondo en los campos gasíferos de Patao y Río Caribe era irregular, como se podía apreciar en la pantalla del ecosonda, y su textura era fangosa y pedregosa, con numerosas conchas de moluscos recubiertas por comunidades incrustantes de origen calcáreo, estas últimas produjeron severas roturas en las redes. La fuerte corriente en la zona de los yacimientos provocaba que las redes se cruzaran durante la maniobra de izado, por lo que debían desenredarse cuando llegaban a la superficie. Durante el arrastre en la estación Patao II (PMS1-24) los copos llegaron vacíos por la ruptura de la red. Durante el arrastre efectuado en la estación Río Caribe I (PMS1-29), los copos tenían material biológico resultante del arrastre, aunque por la corta duración del mismo (16 min.) el volumen de la captura fue mucho menor que los arrastres efectuados a menor profundidad. Por el rompimiento de las redes en PMS1-29, los resultados de la estación no permiten estimar la biomasa de fauna demersal de este lugar, y tan solo reflejan la diversidad de especies presentes en el sitio.

Luego de la ruptura de la totalidad de las redes disponibles a bordo, y ante la evidencia de que la embarcación no podía efectuar los arrastres exploratorios en las zonas más importantes, como son los campos gasíferos, se decidió suspender la campaña el día 29/oct y regresar a Cumaná.

\section{II.6.2 Estimaciones de biomasa}

La variedad de especies observada en las capturas en la zona de muestreo fue elevada, con un predominio de especies de la familia Haemulidae y Lutjanidae. 
La biomasa estimada en las estaciones de menor profundidad y fondo fangoso (PMS1-37 y 38) fue relativamente alta, 2.416 y $3.522 \mathrm{~kg} / \mathrm{km}^{2}$, respectivamente (Tabla II-26). Así mismo, la composición de especies en estas estaciones fue más parecida entre si, que la observada en la estación de fondos más profundos y pedregosos, PMS1-29.

Tabla II-26.-Estimación de la biomasa $\left(\mathrm{kg} / \mathrm{km}^{2}\right)$ de especies demersales seleccionadas, en las estaciones evaluadas sobre la PNPP durante el muestreo realizado a bordo de la embarcación Jannadomary entre los días 28 y 29/OCT/2005.

\begin{tabular}{lccc}
\multicolumn{1}{c}{ BIOMASA (kg/km ${ }^{2}$ ) } & \multicolumn{3}{c}{ Profundidad } \\
& $\begin{array}{ccc}18-23 \\
\text { PMS1 - 38 }\end{array}$ & $\begin{array}{c}21-24 \\
\text { PMS1-37 }\end{array}$ & $\begin{array}{c}49-50 ~ \\
\text { PMS1-29* }\end{array}$ \\
Captura total & $3.521,5$ & $2.416,1$ & 581,7 \\
F. brasiliensis (C. manchado) & 10,4 & 16,9 & 2,6 \\
Loligo pealei (calamar) & 0,0 & 0,4 & 46,3 \\
Amusium papyraceum (vieira) & 4,3 & 1,9 & 3,9 \\
Euvola ziczac (vieira) & 15,1 & 10,1 & 0,0 \\
Calappa sulcata & 0,0 & 0,0 & 25,7 \\
Calappa flamea & 4,3 & 9,4 & 0,0 \\
Priacantus arenatus (catalana) & 4,3 & 18,7 & 0,0 \\
Trachurus lathami (cataco) & 0,0 & 0,0 & 20,6 \\
Cynoscion jamaicensis (tonquicha) & 17,3 & 0,0 & 0,0 \\
Otros rubros & $3.465,8$ & $2.358,8$ & 482,6 \\
Rubros comercial-seleccionados & 55,7 & 57,3 & 99,1
\end{tabular}

*Las redes en las estaciones PMS1-24 y PMS1-29 se rompieron durante la calada. En el caso de la estación PMS1-29, se logró retener captura en el copo, pero las estimaciones de biomasa son limitadas.

En general, las especies seleccionadas para las evaluaciones en la zona de estudio presentaron una abundancia muy reducida, con valores entre 55,7 y 99,1 $\mathrm{kg} / \mathrm{km}^{2}$ (Tabla II-26).

Entre los invertebrados, se registró la presencia del camarón rosado con mancha, Farfantepenaeus brasiliensis, con una abundancia de 2,6 y $16,9 \mathrm{~kg} / \mathrm{km}^{2}$. La mayor abundancia se observó en la estación PMS1-37 a 24 m de profundidad y la menor a $50 \mathrm{~m}$. La abundancia de calamar (posiblemete de Loligo pealei, por ser más común en zonas profundas) se manifiesta en la estación mas profunda con 46,3 $\mathrm{kg} / \mathrm{km}^{2}$ (Figura II-46). Las vieiras mostraron una baja biomasa que no parece verse afectada por la profundidad, pero su presencia fue persistente en todas las estaciones muestreadas. La vieira más común fue Euvola ziczac, con una biomasa de 10,1 a $15,1 \mathrm{~kg} / \mathrm{km}^{2}$, mientras que Amusium papyraceum mostró una biomasa de 
1,9 a $4,3 \mathrm{~kg} / \mathrm{km}^{2}$. Finalmente, la biomasa de cangrejos moros (Calappa spp) aumentó con la profundidad, desde 4,3 a $25,7 \mathrm{~kg} / \mathrm{km}^{2}$. Solo se observaron juveniles de Calappa flammea en las estaciones menos profundas, mientras que un adulto de $C$. sulcata se observó en la estación más profunda.

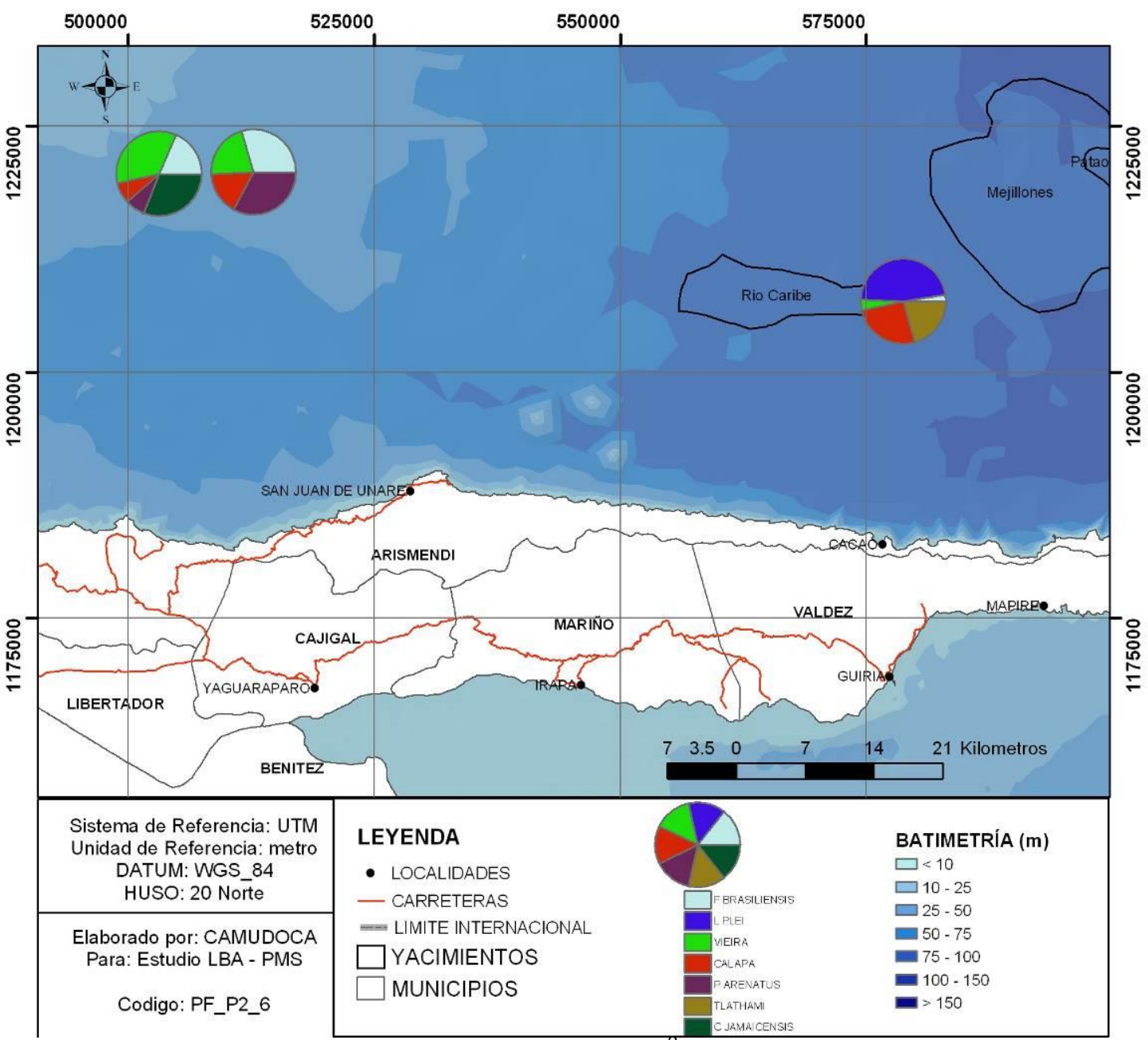

Figura II-46.- Distribución porcentual de la biomasa $\left(\mathrm{kg} / \mathrm{km}^{2}\right)$ de las especies seleccionadas durante la campaña de la embarcación JANNADOMARI.

Entre las cinco especies de peces seleccionadas, se registró la presencia de tres de ellas, la catalana, Priacanthus arenatus, la tonquicha, Cynoscion jamaicensis, y el cataco, Trachurus lathami. Las dos primeras especies se registraron solamente en las estaciones de menor profundidad con una biomasa de catalana de 4,3 a 18,7 $\mathrm{kg} / \mathrm{km}^{2}$ y de tonquicha de $17,3 \mathrm{~kg} / \mathrm{km}^{2}$ en la primera estación (PMS1-38), mientras 
que el cataco se observó en la estación más profunda con una biomasa promedio de $20,6 \mathrm{~kg} / \mathrm{m}^{2}$.

El resto de las muestras ('Otros rubros') estuvo integrado por una elevada variedad de especies, muchas representadas por un bajo número de ejemplares (peces murciélago, bagres, pez sapo), y otras con un dominio evidente de la muestra (aguamala, Aurelia sp.; corocoro rayado, Haemulon boschmae; candil; pez volador). El procesamiento de las muestras se dificultaba por la frecuente presencia de especies espinosas, como candil, pez volador, pez puercoespín. La biomasa de este grupo de especies varió de 482,6 a $3.465,8 \mathrm{~kg} / \mathrm{km}^{2}$. Se reseña la presencia de varias especies de pargo en las estaciones de menor profundidad, que aunque, bajo en número de ejemplares por especie, destacaban por su elevada talla. Así mismo, se reseña la captura de 6 langostas espinosas, Panulirus argus, en la primera estación muestreada (PMS1-38), una de ellas, macho de por lo menos $50 \mathrm{~cm} \mathrm{LT.}$

\section{II.6.3 Conclusiones}

- Las artes utilizadas por las embarcaciones comerciales del tipo florida no son adecuadas para estimaciones de biomasa en el área de estudio, por lo que se recomienda el uso de rolines en la relinga inferior que permita a la red desplazarse sobre el fondo sin que se rompa.

- La estimación de biomasa localizada en las estaciones muestreadas fue relativamente alta, observándose valores entre 581,7 y $3.521,5 \mathrm{~kg} / \mathrm{km}^{2}$.

- Se pudo determinar que las especies de mayor importancia porcentual en la composición de las capturas fueron los invertebrados con un $71 \%$ de la captura comercial, el resto fue de peces. Entre las especias mas destacadas están: Loligo pealei (22\%), Farfantepenaeus brasiliensis (14\%), Calappa ( 17\%), Euvola ziczac ( 12\%), seguido de Priacanthus arenatus, Trachurus lathami y Cynoscion jamaicensis, con 10,8\%, 9,7\% y 8,1\%, respectivamente. 


\section{III.- ANALISIS DE LA ACTIVIDAD PESQUERA Y RECURSOS PESQUEROS AL NORTE DEL GP}

\section{III.1 Pesquería Artesanal Costanera Multiespecifica}

El sur de la Península de Paria, es un área marina bajo la influencia de aguas continentales ricas en materia orgánica y mineral, proveniente de los Ríos Esequibo y Orinoco, cuyo transporte a través de la Corriente de Guayana origina una zona de importante potencial pesquero conformado por camarones y especies de peces, principalmente bagres (Ariidae), carites (Scombridae), pargos (Lutjanidae), cazones (Carcharhinidae), roncador, curvinatas (Sciaenidae) y rayas (Rajidae) entre otros, que han sido el soporte por muchos años de la actividad pesquera artesanal que constituye la de mayor importancia en la zona, la cual es realizada casi exclusivamente por pescadores de la costa sur de la Península de Paria, utilizando tradicionalmente filetes de ahorque derivante, cordeles, palangres y nasas como artes de pesca (Gómez, 1999). Dado el importante desarrollo de la industria petrolera que se pondrá en marcha en esta región, existe la necesidad de conocer y evaluar aspectos fundamentales de las pesquerías de la región, con el objeto de obtener los insumos necesarios para ofrecer un diagnóstico de la misma. Como objetivo se planteó determinar la distribución espacio-temporal del esfuerzo de pesca y las capturas de las especies pelágicas y demersales explotadas por la pesca artesanal costanera multiespecífica de las comunidades pesqueras comprendidas entre Yaguaraparo y Macuro (ambas inclusive).

Se decidió seleccionar a las comunidades pesqueras de Güiria, Irapa, Yaguaraparo y Macuro por ser las de mayor importancia en el área de influencia del PMS. Se consideró el número de embarcaciones que conforma cada flota, población y tradición pesquera. Como estrategia para obtener la información se usó el mismo plan de monitoreo fundamentado en encuestas y entrevistas directas, descrito en el apartado del análisis de comunidades pesqueras del norte de la Península de Paria. 


\section{III.1.1 Caracterización de las comunidades pesqueras al norte del GP}

En términos generales y para esta primera fase se realizaron un total de 17 encuestas de 'Inspección Pesquera' y 58 encuestas de 'Diagnostico Pesquero' que se distribuyeron entre las comunidades visitadas como se expresa en la Tabla III-1.

Tabla III-1- Comunidades pesqueras seleccionadas para el estudio.

\begin{tabular}{|c|c|c|}
\hline $\begin{array}{c}\text { Comunidad } \\
\text { Pesquera }\end{array}$ & $\begin{array}{c}\text { Encuestas de Inspección } \\
\text { pesquera }\end{array}$ & $\begin{array}{c}\text { Encuestas de Diagnostico } \\
\text { pesquero }\end{array}$ \\
\hline Yaguaraparo & 3 & 12 \\
Macuro & 4 & 16 \\
Güiria & 5 & 15 \\
Irapa & 5 & 15 \\
TOTAL & $\mathbf{1 7}$ & $\mathbf{5 8}$ \\
\hline
\end{tabular}

\section{III.1.1.1 YAGUARAPARO}

\section{Características de la flota}

Para esta comunidad no existe información previa confiable de los censos pesqueros realizados durante las décadas de 1980 y 1990 (Cárdenas, 1999). E número de unidades artesanales que conforman la flota de Yaguaraparo contabilizadas en el presente estudio es de 26 embarcaciones, de las cuales todas están operativas. Estas cifras coinciden con las estimaciones realizadas en esta comunidad durante la evaluación del sector pesquero de los proyectos en ejecución costa afuera. El $80 \%$ de las embarcaciones son de tipo peñero, mientras que el resto (20\%) son de tipo curiara. Esta flota genera alrededor de 100 empleos directos en el sector primario de la pesca artesanal. Los peñeros tienen un mínimo de eslora de 7 $\mathrm{m}$ y un máximo de $10 \mathrm{~m}$. En las curiaras la eslora se ubica entre $4 \mathrm{~m}$ y $7 \mathrm{~m}$; se propulsan con canaletes y motores. Mientras que los peñeros utilizan motores fuera de borda de marca Yamaha y su potencia varía entre 25 a $75 \mathrm{HP}$, destacándose los motores de $40 \mathrm{HP}$ (Tabla III-2). La flota de peñeros faena con 3 o 4 pescadores por embarcación, realizando campañas de pesca de 8 a 12 días, las cuales se prolongan ocasionalmente hasta por 21 días. 
Tabla III-2.- Características de la flota de Yaguaraparo.

\begin{tabular}{|l|c|c|c|c|c|c|}
\hline & Min & Max & Promedio & № Total & Operativas & № del Anzuelo \\
\hline Eslora peñero $(\mathrm{m})$ & 7 & 10 & 8,17 & - & - & - \\
Manga & 1,80 & 2,9 & 2,45 & - & - & - \\
Eslora curiara $(\mathrm{m})$ & 4 & 7 & 5,5 & - & - & - \\
Manga & 0,5 & 1,80 & 1,20 & - & - & - \\
Potencia Motor (hp) & 25 & 75 & 40 & - & - & - \\
No de Pescadores & 3 & 4 & 4 & - & - & - \\
Embarcaciones & - & - & - & 26 & 26 & - \\
Palangre & - & - & - & 32 & 16 & $7,8,9$ \\
Red filetes & - & - & - & 37 & 16 & - \\
\hline
\end{tabular}

\section{Artes de pesca}

La información suministrada permitió inferir que la flota de peñeros (al menos 16 de ellos) de Yaguaraparo se caracterizó por el uso de los artes red de filete superficial y palangre. Los filetes tienen una longitud que se ubica entre $500 \mathrm{~m}$ y $1.000 \mathrm{~m}$, con altura de 6 a $10 \mathrm{~m}$, y diámetro de malla de 4 a $6 \mathrm{~cm}$. Los palangres se caracterizan por tener secciones de 200 a 400 anzuelos, colocados en líneas 0 rendales de una brazada (1,8 m) de longitud, con anzuelos № 5,6,7 y 8 . Las curiaras utilizan el palangre como arte de pesca.

\section{Áreas de pesca}

La flota artesanal costanera de Yaguaraparo realiza su mayor actividad pesquera en los caños al noroeste del GP, pero también ejerce un esfuerzo importante hacia el suroeste del GP y en sectores del sureste GP (fuera del área del PMS); por lo general las profundidades donde opera la flota van desde los 10 a los $30 \mathrm{~m}$, pero pueden llegar a operar a profundidades de $50 \mathrm{~m}$ (Figura II-1). Los pescadores señalaron como puntos de referencia el bajo de Yaguaraparo, Punta Cotorra, Caño Ajíes, Caño la Coleta, frente a Pedernales, Aruca, Caño Jacao, Caño Negro y Caño del Perro. 


\section{$\underline{\text { Composición de las capturas }}$}

La composición de las capturas de la flota de Yaguaraparo, en opinión de los pescadores entrevistados, está principalmente representada por unas 10 familias de peces, unos 11 géneros y 9 especies identificadas (Tabla III-3). Estos grupos de especies constituyen los grupos de mayor interés comercial para la flota.

Tabla III-3- Principales especies capturadas por la flota artesanal de Yaguaraparo según encuestas realizadas a pescadores artesanales.

\begin{tabular}{|c|c|c|}
\hline FAMILIA & NOMBRE COMUN & NOMBRE CIENTIFICO \\
\hline & Bagre blanco & Arius proops \\
ARIIDAE & Bagre cacumo & Bagre marinus \\
& Bagre mucuro & Arius rugispinnis \\
& Bagre negro & Arius sp. \\
SCIAENIDAE & Curvina blanca & Cynosción sp. \\
RAJIDAE & Curvina amarilla & Cynosción sp. \\
RHINOPTERIDAE & Raya & Raja sp. \\
HYPOSTOMIDAE & Mancha & Rhinoptera sp. \\
SERRANIDAE & Guaraguara & Gypostomus punctatus \\
HAEMULIDAE & Guasa & Epinephelus itajata \\
MUGILIDAE & Torroto & Genyatremus luteus \\
CENTROPOMIDAE & Lisa & Mugil curema \\
MEGALOPIDAE & Lebranche & Mugil lisa \\
& Róbalo & Centropomus sp. \\
\hline
\end{tabular}

Distribución temporal de la abundancia de los recursos pesqueros

Temporada Alta

Los pescadores entrevistados de la comunidad Yaguaraparo coincidieron en señalar un amplio período de máximos rendimientos para la flota durante la temporada alta, que ubicaron entre septiembre y diciembre (Tabla III-4). En cuanto a la composición de las especies y sus niveles de abundancia relativa promedio (kg/día) y porcentual, durante la referida temporada de pesca, se observa que son varias las especies en las que se presentan niveles altos; mencionándose en primer lugar al lebranche con $345 \mathrm{~kg} /$ día (12,8\%), les siguen un conjunto de especies de bagres y scianidos que conforman el $23,1 \%$ y $19 \%$, respectivamente. También hay otras especies como el mero guasa y la lisa cuyos niveles de abundancia relativa no son despreciables (255 kg/día y $250 \mathrm{~kg} /$ día, respectivamente). El nivel de la 
abundancia relativa promedio total de especies que captura la flota se estimó en 177,06 kg/día. La distribución espacial de la abundancia relativa del total de los recursos desembarcados durante la temporada alta se presenta en la Figura II-2.

Tabla III-4.- Comportamiento por temporada alta y baja de la abundancia relativa (kg/día) de las especies capturadas por la flota de Yaguaraparo.

\begin{tabular}{|l|c|c|c|c|c|c|}
\hline \multicolumn{1}{|c|}{ ESPECIES } & CPUE T. Alta & $\%$ & Meses T. Alta & CPUE T. Baja & $\%$ & Meses T. Baja \\
\hline Bagre blanco & 255,50 & 9,62 & SEP-DIC & 65,00 & 12,53 & ENE-AGO \\
Bagre cacumo & 175,50 & 6,61 & SEP-DIC & 35,00 & 6,75 & ENE-AGO \\
Bagre mucuro & 185,50 & 6,98 & SEP-DIC & 45,55 & 8,78 & ENE-AGO \\
Bagre negro & 245,00 & 9,22 & SEP-DIC & 65,75 & 12,68 & ENE-AGO \\
Curvina blanca & 255,60 & 9,62 & SEP-DIC & 25,60 & 4,94 & ENE-AGO \\
Curvin.amarilla & 245,50 & 9,24 & SEP-DIC & 30,65 & 5,91 & ENE-AGO \\
Raya & 75,00 & 2,82 & SEP-DIC & 32,45 & 6,26 & ENE-AGO \\
Mancha & 55,50 & 2,09 & SEP-DIC & 35,50 & 6,85 & ENE-AGO \\
Guaraguara & 45,50 & 1,71 & SEP-DIC & 15,35 & 2,96 & ENE-AGO \\
Guasa & 255,65 & 9,63 & SEP-DIC & 50,00 & 9,64 & ENE-AGO \\
Torroto & 70,55 & 2,66 & SEP-DIC & 10,35 & 2,00 & ENE-AGO \\
Lisa & 250,00 & 9,41 & SEP-DIC & 20,50 & 3,95 & ENE-AGO \\
Lebranche & 340,55 & 12,82 & SEP-DIC & 45,57 & 8,79 & ENE-AGO \\
Róbalo & 155,50 & 5,85 & SEP-DIC & 25,55 & 4,93 & ENE-AGO \\
Sábalo & 45,00 & 1,69 & SEP-DIC & 15,75 & 3,04 & ENE-AGO \\
Promedio & $\mathbf{1 7 7 , 0 6}$ & & & & & \\
\hline
\end{tabular}

\section{Temporada Baja}

Los niveles de abundancia promedio para la temporada baja se encuentran entre enero y agosto cuando alcanzan niveles de $34,7 \mathrm{~kg} /$ día (Tabla III-4). En cuanto a los niveles de abundancia relativa por especie para el referido período; las estimaciones evidencian que el grupo de los bagres con niveles de abundancia relativa promedio del orden de los $50 \mathrm{~kg} /$ día (aproximadamente $40 \%$ del total) constituyen el grupo mejor representado en los desembarques. El resto de las especies no representan niveles de abundancia relativa significativas durante la temporada baja. La distribución espacial de la abundancia relativa del total de los recursos desembarcados durante la temporada baja se presenta en la Figura II-3.

\section{Aspectos socioeconómicos}

La información suministrada por los pescadores artesanales de la comunidad de Yaguaraparo permitió determinar que el nivel educativo de éstos y su grupo 
familiar está caracterizado por los niveles primaria completa e incompleta. Sin embargo, se destaca que algunos miembros de la comunidad han logrado avanzar hacia niveles de educación superior (TSU y Universidad), que por razones económicas no han podido completar. Esta información coincide parcialmente con la señalada en la evaluación socio-económica de los proyectos costa afuera en esta comunidad, ya que se determinó que en Yaguaraparo alrededor del $5 \%$ de la población tendría estudios superiores incompletos. Sin embargo, en ese mismo estudio se estimó que alrededor del $40 \%$ de la población estaba conformada por personas con niveles de bachillerato incompleto, bachillerato completo y estudios superiores completos, lo cual no se reflejó para el sector pesquero en el presente estudio.

La flota, en su mayor parte, tiene una actividad pesquera por campañas de 8 a 12 días, operando 2 campañas por mes. Se deduce también que las embarcaciones tienen un consumo de combustible que en promedio está en unos 400 a 500 It/campaña, a razón de unos $70 \mathrm{Bs} / \mathrm{lt}$ y un consumo de aceite de unos 12 lt/campaña a razón de $5000 \mathrm{Bs} / \mathrm{lt}$. Entre los gastos mayores que realizan los dueños de las embarcaciones, se mencionan el mantenimiento semestral que le hacen a los motores el cual se estimó entre Bs. 1.300 .000 y 1.500 .000 y el gasto anual de mantenimiento que se le hace a las embarcaciones, el cual se estimó entre Bs. 500.000 y 1.200 .000 Bs. Otros gastos considerados menores son los realizados para compra de insumos para la campaña, tales como alimentación que se estiman alrededor de Bs. 80.000 y Bs. 100.000 por campaña, al igual que el gasto por compra de hielo que alcanza los Bs. 150.000 por campaña. Estos valores implican que los valores mensuales de los costos operativos de las embarcaciones se sitúan alrededor de Bs. 970.000 .

Respecto a los beneficios económicos de la actividad pesquera, la información permitió inferir que un $75 \%$ de los pescadores entrevistados recibe ingresos entre 540.001-720.000 Bs/mes, un $20 \%$ manifestó recibir ingresos entre 360.001 y $540.000 \mathrm{Bs} / \mathrm{mes}$, y un $5 \%$ percibe ingresos entre 180.000 y 360.000 $\mathrm{Bs} / \mathrm{mes}$. Estos niveles de ingresos de los pescadores artesanales son sensiblemente 
superiores a los estimados para el conjunto de la comunidad obtenidos durante la realización de la evaluación socio-económica de los proyectos costa afuera, ya que en ese estudio alrededor del $70 \%$ de la población señalo ingresos inferiores a Bs. 360.000 mensuales.

Esta comunidad no cuenta con una infraestructura de servicios para la pesca artesanal. Entre los aspectos que inciden negativamente en la actividad productiva, los pescadores señalaron la presencia de la palometa peluda, los deficientes servicios de luz y transporte, la inseguridad en la zona costera (piratería marina), la actividad petrolera (tubos utilizados para la extracción de petróleo dañan sus artes de pesca), falta de ferreterías marinas, surtidores de combustible y la ausencia de planes de crédito para la actividad pesquera.

\section{III.1.1.2 MACURO}

\section{Características de la flota}

La flota pesquera de Macuro ha estado en años recientes constituida por un número de embarcaciones de tipo peñero que oscila entre 30 y 40 unidades (Cárdenas, 1999). La información recopilada en el presente estudio permite estimar que la flota está constituida por unas 43 embarcaciones de las cuales solamente 23 están operativas. El número de embarcaciones operativas indica una disponibilidad de alrededor de 90 puestos de trabajo en el sector primario de la actividad pesquera. Estas embarcaciones tienen una eslora mínima de $7 \mathrm{~m}$ y un máximo de $9 \mathrm{~m}$ y las dimensiones de la manga se ubicó entre 1,7 y 2,17 m (Tabla III-5). La información obtenida permitió determinar además que las embarcaciones realizan faenas diarias por la orilla, pero dado que la pesca se realiza utilizando carnada viva, al momento de escasear la carnada, la flota migra al extremo norte de la PNPP. Normalmente operan con una tripulación de 4 marinos por embarcación, siendo estas propulsadas por 2 motores fuera de borda con potencia media de $65 \mathrm{HP}$. 
Tabla III-5.- Características de la flota de Macuro.

\begin{tabular}{|l|c|c|c|c|c|c|}
\hline & Min & Max & Promedio & № Total & Operativas & № del Anzuelo \\
\hline Eslora $(\mathrm{m})$ & 7,12 & 9,00 & 8,16 & - & - & - \\
Manga & 1,7 & 2,17 & 2,12 & - & - & - \\
Potencia Motor (hp) & 40 & 75 & 65 & - & - & - \\
No de Pescadores & 3 & 4 & 4 & - & - & - \\
Embarcaciones & - & - & - & 43 & 23 & - \\
Cordel & - & - & - & 368 & - & $6,7,8,9,10,11$ \\
Palangre & - & - & - & 23 & - & $6,7,8,9$ \\
Red filetes & - & - & - & 4 & - & $500-2000 \mathrm{~m}$ red \\
\hline
\end{tabular}

\section{Artes de pesca}

Todas las embarcaciones operativas utilizan el cordel como arte de pesca, normalmente usan de 4 a 8 por pescador, aunque hay pescadores que usan hasta 8 cordeles, los anzuelos son de los № 6 al 11. También utilizan como arte de pesca líneas de palangre con secciones de 300 a 600 anzuelos, con anzuelos del № 6 al 10. Otros peñeros utilizan red de filete superficial con una altura de 6 a $10 \mathrm{~m}$ y una longitud de 500-2.000 m, y de abertura de malla de 5-6 cm.

\section{$\underline{\text { Áreas de pesca }}$}

La flota artesanal de Macuro realiza sus operaciones de pesca con mayor intensidad en zonas bien definidas al norte del GP, una al sur franco tomando como puntos de referencia frente a la población de Macuro, la Isla de Patos y la Boca de Dragón (Figura II-1). Adicionalmente, se tienen otros puntos de referencia, entre los cuales los pescadores indicaron a Los Morochos, Caño Arauca, Caño Antica, frente Caripito, frente Pedernales, Caño Ajíes, Cocuina y Punta Arenas. Cuando escasea la sardina (carnada) en el Golfo, algunos pescadores migran hacia la costa norte de Paria tomando como referencia la Punta del Viejo, y las Bahías de San Francisco, Mejillones y Uquire.

\section{$\underline{\text { Composición de las capturas }}$}

La composición de las capturas por grupos y especie, se muestra en la Tabla III-6. Se observa que la misma estuvo conformada por 7 familias de peces, 12 géneros y 5 especies identificadas. 
Tabla III-6.- Principales especies capturadas por la flota artesanal de Macuro según encuestas realizadas a pescadores artesanales.

\begin{tabular}{|c|c|c|}
\hline ESPECIE & NOMBRE COMUN & NOMBRE CIENTIFICO \\
\hline \multirow{2}{*}{ CARANGIDAE } & Cojinúa & Caranx sp. \\
& Jurel & Caranx hippos \\
SCOMBRIDAE & Cámpano & Trachinotus sp. \\
& Sierra & Scomberomorus sp. \\
& Albacora & Acanthocybium solandrí \\
SCIAENIDAE & Carachana & Thunnus sp. \\
& Roncador & Auxis sp. \\
POMATOMIDAE & Curvina & Micropogonias furnieri \\
CARCHARHINIDAE & Anchoa & Cynoscion sp. \\
SERRANIDAE & Cazón & Rhizoprionodon sp. \\
& Guasa & Epinephelus itajara \\
LUTJANIDAE & Mero & Epinephelus sp. \\
\hline
\end{tabular}

Distribución temporal de la abundancia de los recursos pesqueros

Temporada Alta

Los pescadores de la comunidad de Macuro ubicaron el período de máxima abundancia relativa entre los meses mayo a diciembre (Tabla III-7). Donde se señala que los mayores aportes a la composición de las especies y sus niveles de abundancia relativa promedio ( $\mathrm{kg} / \mathrm{d}$ ía) y porcentual durante la referida temporada de pesca correspondieron al jurel con $716 \mathrm{~kg} / \mathrm{día}(21,8 \%)$, el cazón con $483 \mathrm{~kg} / \mathrm{día}$ $(14,2 \%)$, el mero con $366 \mathrm{~kg} /$ día (11\%), y la albacora con $250 \mathrm{~kg} /$ día $(7,6 \%)$ que en su total representan el $54,6 \%$ de la abundancia relativa promedio total de especies que desembarca la flota, estimada en mas de $242,38 \mathrm{~kg} /$ día. La distribución espacial de la abundancia relativa del total de los recursos desembarcados durante la temporada alta se presenta en la Figura II-2. 
Tabla III-7.- Composición de las principales especies capturadas por la flota artesanal de Macuro según encuestas realizadas a pescadores artesanales.

\begin{tabular}{|c|c|c|c|c|c|c|}
\hline ESPECIES & CPUE T. Alta & $\%$ & Meses T. Alta & CPUE T. Baja & $\%$ & Meses T. Baja \\
\hline Albacora & 250,00 & 7,63 & MAY-DIC & 55,00 & 13,15 & ENE-ABR \\
Sierra & 163,33 & 4,98 & MAY-DIC & 40,00 & 9,56 & ENE-ABR \\
Carachana & 183,33 & 5,60 & MAY-DIC & 48,33 & 11,55 & ENE-ABR \\
Jurel & 716,67 & 21,87 & MAY-DIC & 36,67 & 8,76 & ENE-ABR \\
Cojinúa & 193,33 & 5,90 & MAY-DIC & 21,67 & 5,18 & ENE-ABR \\
Carite & 216,67 & 6,61 & MAY-DIC & 21,67 & 5,18 & ENE-ABR \\
Anchoa & 200,00 & 6,10 & MAY-DIC & 6,67 & 1,59 & ENE-ABR \\
Roncador & 126,67 & 3,87 & MAY-DIC & 56,67 & 13,55 & ENE-ABR \\
Cazón & 483,33 & 14,24 & MAY-DIC & 58,33 & 13,94 & ENE-ABR \\
Pámpano & 23,33 & 0,71 & MAY-DIC & 8,33 & 1,99 & ENE-ABR \\
Pargo & 135,00 & 4,12 & MAY-DIC & 23,33 & 5,58 & ENE-ABR \\
Guasa & 193,33 & 5,90 & MAY-DIC & 13,33 & 3,19 & ENE-ABR \\
Mero & 366,67 & 11,19 & MAY-DIC & 13,33 & 3,19 & ENE-ABR \\
Curvina & 141,67 & 4,32 & MAY-DIC & 15,00 & 3,59 & ENE-ABR \\
\hline Promedio & $\mathbf{2 4 2 , 3 8}$ & & & $\mathbf{2 9 , 8 8}$ & & \\
\hline
\end{tabular}

Temporada Baja

La Tabla III-7 también indica los niveles de rendimiento para la temporada baja la cual se ubicó entre los meses enero y abril, en la que se señalan niveles de abundancia relativa promedio total de 29,88 kg/día. Los mayores aportes a la composición de las especies y sus niveles de abundancia relativa promedio (kg/día) y porcentual durante la referida temporada de pesca correspondieron al cazón $(13,9 \%)$, roncador $(13,5 \%)$, albacora $(13,1 \%)$, carachana $(11,5 \%)$, y sierra $(10 \%)$ que en su total representan el $62,5 \%$ de la abundancia relativa total de especies que desembarca la flota durante la temporada baja. La distribución espacial de la abundancia relativa del total de los recursos desembarcados durante la temporada baja se presenta en la Figura II-3.

\section{$\underline{\text { Aspectos socioeconómicos }}$}

La información suministrada por los pescadores artesanales de la comunidad de Macuro permitió determinar que el nivel educativo de éstos y su grupo familiar, fundamentalmente se ubica en los niveles de primaria incompleta y primaria completa. Es destacable un significativo número de personas que alcanzan el nivel de instrucción secundaria completa e incompleta y que algunos han avanzado a 
estudios superiores (TSU y Universidad). Estas características del nivel educativo de los pescadores de Macuro coinciden, en líneas generales, con los indicadores del Municipio Valdez obtenidos durante la evaluación socio-económica de los proyectos costa afuera.

Se observó que la flota tiene una actividad pesquera diaria en faenas de unas 12 horas de pesca. La información suministrada indica que las embarcaciones tienen un consumo de combustible de unos 300 It/día a razón de $70 \mathrm{Bs} / \mathrm{tt}$, y unos 10 lt de aceite por salida a un costo de 6.000 Bs./It. En faenas dentro del GP se incurre en el gasto para carnada viva que equivale a Bs. 10.000 /día para la compra de una mara y media de sardina viva. Cuando la faena se realiza sobre la PNPP se utilizan unas 12 cajas de sardina (muerta) por día a un costo de $7.000 \mathrm{Bs} / \mathrm{caja}$. Entre los gastos mayores que realizan los dueños de las embarcaciones, se mencionan el mantenimiento semestral que le hacen a los motores el cual se estimó entre Bs. 500.000 y Bs 1.500 .000 y los costos anuales de mantenimiento que se le hace a las embarcaciones calculado entre Bs. 1.000 .000 y Bs. 2.000.000. Otros gastos incluye la compra de nylon de unos $1.000 \mathrm{~m} / \mathrm{mes}$ a un costo de Bs. 160.000, la compra de anzuelos a razón de 1 caja (100 anzuelos) por semana al costo de Bs. 7.000 c/u. Estas cifras indican que los costos operativos mensuales de las embarcaciones de Macuro estarían alrededor de Bs. 2.600.000.

Las compras de los insumos de la pesca se hace generalmente a través de los agentes intermediarios. En el caso de los pescadores de Macuro, existen intermediarios instalados en la ensenada de Cariaquito, contigua a Macuro, donde se recibe el producto, se conserva en cavas con hielo y de allí se transporta a Güiria, para luego tomar otros destinos como Carúpano, Puerto Ordaz, Puerto La Cruz, y Caracas.

En relación a los beneficios económicos de la actividad pesquera, la información permitió determinar que $39 \%$ recibe ingresos entre 360.000-540.000 $\mathrm{Bs} / \mathrm{mes}$, un $23 \%$ reciben ingresos superiores a $720.000,00 \mathrm{Bs} / \mathrm{mes}$, y un $15 \%$ señaló recibir entre 180.000 y $360.000 \mathrm{Bs} /$ mes y entre $540.000-720.000 \mathrm{Bs} / \mathrm{mes}$. Mientras que un $8 \%$ manifestó recibir ingresos inferiores a $180.000 \mathrm{Bs} / \mathrm{mes}$. Estos niveles de 
ingresos declarados son superiores a los estimados para el conjunto de los pobladores del Municipio Valdez mediante la evaluación socio-económica de los proyectos en ejecución costa afuera.

Existe poca infraestructura de apoyo a la producción, ya que la población cuenta solamente con un muelle, carpinterías de ribera y algunos depósitos para combustibles y aparejos de pesca. Los pescadores de Macuro, señalaron como aspectos negativos que inciden en la actividad pesquera la inseguridad en la zona costera (piratería marina), la falta de vialidad y transporte terrestre y la interferencia de la flota arrastrera al operar en áreas prohibidas. Por otro lado, la ausencia de infraestructura pesquera adecuada como una ferretería marina y un centro de acopio con servicios básicos se mencionan también como limitantes.

\section{III.1.1.3 GÜIRIA}

Características de la flota

El análisis de los censos pesqueros de embarcaciones artesanales (Cárdenas, 1999) indica que el número de unidades en esta población presenta una tendencia decreciente, al disminuir desde más de 130 embarcaciones en 1990 a menos de 100 en la actualidad. El número de unidades artesanales registradas en el presente estudio para la flota de Güiria es de 84 peñeros, de los cuales alrededor de 65 están operativos. Esto indica que el número de puestos de trabajo en este sector primario se ubicaría alrededor de 195. La eslora de las embarcaciones varía entre $5 \mathrm{~m}$ a 12 m, mientras que la dimensión de la manga varía entre 1,7m y 2,98 m. La flota faena con 3 pescadores/embarcación, realizando salidas de pesca diarias, con duración de 12 a 15 horas. Operan 6 días a la semana y utilizan motores fuera de borda con potencia de 40 HP y 75 HP (Tabla III-8). 
Tabla III-8- Características de la flota de Güiria.

\begin{tabular}{|l|c|c|c|c|c|c|}
\hline & Min & Max & Promedio & $\mathrm{N}^{\circ}$ Total & Operativas & $\mathrm{N}^{\circ}$ del Anzuelo \\
\cline { 2 - 6 } Eslora $(\mathrm{m})$ & 5 & 12 & 9,54 & - & - & - \\
Manga & 1,4 & 1,7 & 1,5 & - & - & - \\
Potencia Motor (HP) & 40 & 75 & 48 & - & - & - \\
No de Pescadores $^{\circ}$ & 3 & 3 & 3 & - & - & - \\
Embarcaciones & - & - & - & 84 & 67 & - \\
Palangre & - & - & - & 50 & 25 & $7,8,9$ \\
Red filetes & - & - & - & 40 & 40 & - \\
Nasas & - & - & - & 50 & 2 & - \\
\hline
\end{tabular}

\section{Artes de pesca}

La información suministrada permitió determinar que la flota de Güiria se caracterizó por el uso del palangre, 2 por embarcación, para un total de alrededor de 50 para la flota. Estos se caracterizan por tener secciones de 300 anzuelos, colocados en líneas o rendales de una brazada $(1,8 \mathrm{~m})$ de longitud, con anzuelos del $N^{\circ}$ 7, 8 y 9. Los filetes o trenes de superficie son alrededor de 40, cuyo rango de longitud, por lo general, se ubica entre los $1.000 \mathrm{~m}$ y $2.800 \mathrm{~m}$, con una altura de 10 $\mathrm{m}$, y diámetro de malla de 4 a $6 \mathrm{~cm}$. Además de estos artes, algunas embarcaciones (2) usan nasas, las cuales son construidas con alambre galvanizado tipo gallinero, con diámetro de malla de $5 \mathrm{~cm}$ de forma hexagonal, utilizando como soporte o esqueleto varas de árboles de la región.

\section{Áreas de pesca}

La flota artesanal costanera de Güiria realiza su mayor actividad pesquera en áreas del noreste y centro del Golfo de Paria, pero también ejerce un esfuerzo importante hacia el suroeste, sobre profundidades que van desde los $10 \mathrm{~m}$ a $30 \mathrm{~m}$, aunque pueden llegar a operar a profundidades de $50 \mathrm{~m}$ (Figura II-1). Los pescadores señalaron como puntos de referencia de la costa noreste del GP a Boca de Dragón, Ensenada Güinimita, Pta. Cereza, Ensenada Uquirito, Islotes, Los Garzos, Ensenada Patao, Pta. Garcitas, Puerto de Hierro, Ensenada Cariaquito, Ensenada Río Grande, Pta. Picúa, Los Paticos, Macuro, Las Salinas, Pta Macurito, Morrocoy, Yácua, La Planchada, Salinita, Los Patos. En cuanto a las referencias de los pescadores para la costa suroeste, los puntos de orientación señalados fueron, Carrizo, Guaraguara, Soro, La Chica, Irapa, Pta. de Piedras, Los Manglares, Los 
Morochos, Guayabero y Yaguaraparo. Fuera del área de estudio, en la costa sureste, hay otras zonas de pesca que fueron referidas por pescadores de Güiria entre las que se encuentran, Río Grande, El Salao, Punta el Burro, Los Manglares, norte Frigorífico, norte de Isla Cotorra e Isla Venado.

\section{$\underline{\text { Composición de las capturas }}$}

La composición de las capturas de la flota de Güiria, en función de la información suministrada por los pescadores entrevistados, está principalmente representada por 8 familias de peces, 12 géneros y 12 especies identificadas (Tabla III-9). Estos constituyen los grupos de mayor interés comercial para la flota.

Tabla III-9- Principales especies capturadas por la flota artesanal de Güiria según encuestas realizadas a pescadores artesanales.

\begin{tabular}{|c|c|c|}
\hline FAMILIA & NOMBRE COMUN & NOMBRE CIENTIFICO \\
\hline & Bagre Cacumo & Bagre marinus \\
ARIIDAE & Bagre Amarillo & Arius parkeri \\
& Bagre Blanco & Arius proops \\
& Mucuro & Arius rugispinnis \\
& Güirimera & Bagre bagre \\
LUTJANIDAE & Cunaro & Rhomboplitea aurorubens \\
& Guanapo & Lutjanus synagris \\
SCOMBRIDAE & Cabaña & Auxis sp. \\
& Carite & Scomberomorus brasiliensis \\
& Curvinata & Cynoscion sp. \\
SCIAENIDAE & Curvina amarilla & Cynoscion sp. \\
& Roncador & Micropogonias furnieri \\
CARANGIDAE & Jurel & Caranx hippos \\
CARCHARHINIDAE & Cazón & Rhizoprionodon sp. \\
HAEMULIDAE & Torroto & Genyatremus luteus \\
POMATOMIDAE & Anchoa & Pomatomus saltator \\
\hline
\end{tabular}

Distribución temporal de la abundancia de los recursos pesqueros

Temporada Alta

Los pescadores de la comunidad Güiria coincidieron en señalar un amplio período de máximos rendimientos para la flota durante la temporada alta, que ubicaron entre mayo y diciembre (Tabla III-10). En cuanto a la composición de las especies y sus niveles promedios de abundancia relativa ( $\mathrm{kg} / \mathrm{día})$ y porcentual, durante la referida temporada de pesca, se puede indicar que son varias las especies 
en que presentan niveles altos; mencionándose en primer lugar a la güinimera y la cabaña con 275,00 kg/día (13,84\%), el mucuro con 200,00 kg/día $(10,07 \%)$, el roncador con 168,89 kg/día $(8,50 \%)$, el torroto con 162,50 kg/día $(8,18)$, el jurel con $104,29 \mathrm{~kg} /$ día $(5,25 \%)$, el bagre amarillo con $110,00 \mathrm{~kg} /$ día $(5,54 \%)$ y el bagre cacumo con $100,00 \mathrm{~kg} / \mathrm{día}(5,03 \%)$, en conjunto contribuyeron con el $70,25 \%$ de la abundancia relativa total de especies que captura la flota. Un segundo grupo lo conformaron las especies bagre blanco con 96,67 kg/día (4,86\%), curvina amarilla con $98,00 \mathrm{~kg} /$ día $(4,93 \%)$ y curvinata con $97,50 \mathrm{~kg} /$ día $(4,91 \%)$. El nivel de la abundancia relativa promedio del total de especies que captura la flota se estimó en $124,19 \mathrm{~kg} /$ día. La distribución espacial de la abundancia relativa del total de los recursos desembarcados durante la temporada alta se presenta en la Figura II-2.

\section{Temporada Baja}

Los niveles de rendimiento para la temporada baja se encuentran entre enero y Abril cuando alcanzan niveles totales promedio de 17,25 kg/día (Tabla III-10). En cuanto a los niveles de abundancia relativa por especie para el referido período; las estimaciones evidencian que el roncador con $31 \mathrm{~kg} / \mathrm{día}(11,23 \%)$, la guinimera y el torroto con $30 \mathrm{~kg} /$ día (10,87\%), el bagre amarillo y bagre cacumo con 23,33 kg/día (8,45\%), el Jurel y cazón con 20,71 kg/día (7,50\%) fueron las especies mas representativas durante el referido período. La distribución espacial de la abundancia relativa del total de los recursos desembarcados durante la temporada baja se presenta en la Figura II-3. 
Tabla III-10- Comportamiento por temporada alta y baja de la abundancia relativa ( $\mathrm{kg} / \mathrm{día})$ de las especies capturadas por la flota de Güiria.

\begin{tabular}{|c|c|c|c|c|c|c|}
\hline ESPECIES & $\begin{array}{c}\text { CPUE T. } \\
\text { Alta }\end{array}$ & $\%$ & $\begin{array}{c}\text { Meses T. } \\
\text { Alta }\end{array}$ & $\begin{array}{c}\text { CPUE T. } \\
\text { Baja }\end{array}$ & $\begin{array}{c}\text { Meses T. } \\
\text { Baja }\end{array}$ \\
\hline Roncador & 168,89 & 8,50 & MAY-DIC & 31,00 & 11,23 & ENE-ABR \\
Cunaro & 10,00 & 0,50 & MAY-DIC & 5,00 & 1,81 & ENE-ABR \\
Curvina Amarilla & 98,00 & 4,93 & MAY-DIC & 8,60 & 3,12 & ENE-ABR \\
Jurel & 104,29 & 5,25 & MAY-DIC & 20,71 & 7,50 & ENE-ABR \\
Cazón & 160,00 & 8,05 & MAY-DIC & 20,71 & 7,50 & ENE-ABR \\
Curvinata & 97,50 & 4,91 & MAY-DIC & 10,50 & 3,80 & ENE-ABR \\
Guanapo & 36,67 & 1,85 & MAY-DIC & 7,50 & 2,72 & ENE-ABR \\
Mucuro & 200,00 & 10,07 & MAY-DIC & 10,50 & 3,80 & ENE-ABR \\
Bagre Amarillo & 110,00 & 5,54 & MAY-DIC & 23,33 & 8,45 & ENE-ABR \\
Bagre Blanco & 96,67 & 4,86 & MAY-DIC & 18,33 & 6,64 & ENE-ABR \\
Bagre Cacumo & 100,00 & 5,03 & MAY-DIC & 23,33 & 8,45 & ENE-ABR \\
Torroto & 162,50 & 8,18 & MAY-DIC & 30,00 & 10,87 & ENE-ABR \\
Cabaña & 275,00 & 13,84 & MAY-DIC & 15,00 & 5,43 & ENE-ABR \\
Sierra & 47,50 & 2,39 & MAY-DIC & 12,50 & 4,53 & ENE-ABR \\
Anchoa & 45,00 & 2,26 & MAY-DIC & 9,00 & 3,26 & ENE-ABR \\
Güinimera & 275,00 & 13,84 & MAY-DIC & 30,00 & 10,87 & ENE-ABR \\
\hline Promedio & $\mathbf{1 2 4 , 1 9} 19$ \\
\hline
\end{tabular}

\section{Aspectos socioeconómicos}

La información suministrada por los pescadores artesanales de la comunidad de Güiria permitió determinar que el nivel educativo de éstos y su grupo familiar, está caracterizado por los niveles de primaria incompleta y primaria completa. Estos indicadores son inferiores a los obtenidos para este centro poblado durante la evaluación socio-económica de los proyectos en ejecución costa afuera, ya que en ese estudio se determinó que más del $60 \%$ de la población tenía niveles superiores a los estudios primarios.

Los pescadores encuestados señalaron que las embarcaciones tienen un consumo diario de combustible que en promedio está en unos 120 a 140 It/día, a razón de unos $70 \mathrm{Bs} / \mathrm{lt}$ y un consumo de aceite de unos 4 a 6 It/día a $5000 \mathrm{Bs} / \mathrm{lt}$. Entre los gastos mayores que realizan los dueños de las embarcaciones, se mencionan el mantenimiento semestral que le hacen a los motores el cual se estimó entre Bs 500.000 y 1.500 .000 , el gasto anual de mantenimiento que se le hace a las embarcaciones, calculado entre Bs 500.000 y 1.600 .000 . Otros gastos considerados 
menores son los realizados para la compra de insumos de pesca como "nylon" y anzuelos, varían entre los 4.000 y 10.000 Bs/día; así como gastos de pintura que varian entre Bs200.000 y 500.000 semestrales. Estas cifras permiten estimar los costos operativos de las unidades de pesca, los cuales se ubicarían alrededor de Bs. 1.300 .000 mensuales.

Respecto a los benéficos económicos de la actividad pesquera, la información suministrada por los pescadores permitió inferir que un $40 \%$ recibe ingresos superiores a $720.000 \mathrm{Bs} / \mathrm{mes}$, un $20 \%$ manifestó recibir ingresos entre 180.000 y $360.000 \mathrm{Bs} / \mathrm{mes}$, otro $20 \%$ ingresos de $360.001-540.000 \mathrm{Bs} /$ mes y otro $20 \%$ ingresos de 540.001-720.000 Bs/mes. Estos valores son significativamente superiores a los reportados para el conjunto de esta comunidad en la reciente evaluación socio.económica de los proyectos en ejecución costa afuera, puesto que alrededor del $62 \%$ de la población señalo ingresos mensuales inferiores a Bs. 360.000.

Por ser el mayor puerto pesquero de la Península de Paria, en Güiria existe una importante infraestructura de apoyo a la pesca, tanto artesanal como industrial. Entre los aspectos que inciden negativamente en la actividad productiva, los pescadores señalaron la falta de una política crediticia y la actividad de la flota arrastrera en áreas prohibidas.

\section{III.1.1.4 IRAPA}

Características de la flota

La información histórica sobre el número de embarcaciones (Cárdenas, 1999) en esta comunidad presenta fuertes fluctuaciones de una año a otro, lo que la hace poco confiable. La información recopilada durante este estudio permite señalar que la flota está conformada por 90 embarcaciones, de las cuales 60 están operativas. Este número de embarcaciones operativas es ligeramente inferior al estimado durante la evaluación pesquera de los proyectos en ejecución costa afuera. El número de embarcaciones operativas actualmente y el número promedio de pescadores por embarcación indican que la cantidad de puestos de trabajo disponibles en el sector primario de la pesca en esta comunidad se ubica alrededor de 180. Las embarcaciones tienen una eslora mínima de $7 \mathrm{~m}$ y un máximo de $12 \mathrm{~m}$, la longitud de 
manga se ubicó entre 1,5 y 3,5 m (Tabla III-11.). La información obtenida permitió determinar, además que las embarcaciones realizan campañas de 7 a 10 días, unas 2 por mes, con una tripulación de 3 marinos por embarcación, siendo propulsadas por motores fuera de borda con potencia mínima de 40 HP ó de 75 HP.

Tabla III-11- Características de la flota de Irapa.

\begin{tabular}{|l|c|c|c|c|c|c|}
\hline & Min & Max & Promedio & $N^{\circ}$ Total & Operativas & $N^{\circ}$ del Anzuelo \\
\cline { 2 - 7 } Eslora $(\mathrm{m})$ & 7 & 12 & 10,09 & - & - & - \\
Manga & 1,5 & 3,5 & 2,60 & - & - & - \\
Potencia Motor (HP) & 40 & 75 & 50 & - & - & - \\
No de Pescadores & 3 & 3 & 3 & - & - & - \\
Embarcaciones & - & - & - & 90 & 60 & \\
Palangre & - & - & - & 60 & 30 & $6,7,8,9$ \\
Red filetes & - & - & - & 60 & 60 & - \\
\hline
\end{tabular}

\section{$\underline{\text { Artes de pesca }}$}

Todas las embarcaciones operativas utilizan la red filete o tren superficial como arte de pesca, estos tienen un diámetro de malla de 4-6 cm, altura entre 6-10 $\mathrm{m}$, y un largo de 1.000 a $2.800 \mathrm{~m}$. Sin embargo, se señala que éstos pueden llegar a alcanzar hasta $4.000 \mathrm{~m}$; los pescadores indicaron además que 30 embarcaciones utilizan palangres, 2 por embarcación, los cuales por lo general están conformados por secciones de unos 250 a 350 anzuelos del № 6,7,8,9. Mencionaron también que algunos utilizan el tren jala pa' tierra para la captura de camarones.

\section{Áreas de pesca}

La flota artesanal de Irapa realiza sus operaciones de pesca con mayor intensidad en dos zonas bien definidas, la costa noreste del GP y al este de Irapa, donde opera a profundidades entre los 30 y $50 \mathrm{~m}$, pudiendo llegar a profundidades de $75 \mathrm{~m}$ (Figura II-1). Como puntos de referencia, los pescadores indicaron a Pta. Narizona, Boca de Dragón, Ensenada Güinimita, Bahía Cereza, Pta. Cereza, Ensenada Uquirito, Los Islotes, Los Garzos, Ensenada Patao, Pta. Garcitas, Puerto de Hierro, Cumaca, Ensenada Cariaquito, Ensenada Río Grande, Pta. Picúa, Ensenada Mapire, Los Paticos, Macuro, Salinas, Pta Macurito, Morrocoy, Yacua, La Planchada, Salinita, Los Patos, Bajo Alcatraz, La Ceiba y Los Taladros. También operan fuera del área de estudio, al sureste del GP, se señalan como puntos de 
referencia a Río Grande, El Salao, Río Salao, Punta el Burro, Los Manglares, norte Frigorífico, norte de Isla Cotorra y norte de Isla Venado.

\section{Composición de las capturas}

La composición de las capturas por grupos y especie, se muestra en la Tabla III-12. Se observa que la misma estuvo conformada por 10 familias de peces, 12 géneros y 9 especies identificadas.

Tabla III-12- Principales especies capturadas por la flota artesanal de Irapa según encuestas realizadas a pescadores artesanales.

\begin{tabular}{|c|c|c|}
\hline FAMILIA & NOMBRE COMUN & NOMBRE CIENTIFICO \\
\hline & Bagre & Arius $s p$. \\
ARIIDAE & Bagre Amarillo & Arius parkeri \\
& Bagre Blanco & Arius proops \\
& Mucuro & Arius rugispinnis \\
SERRANIDAE & Güirimera & Bagre bagre \\
& Guasa & Epinephelus itajara \\
SCIAENIDAE & Curvinata & Cynoscion sp. \\
& Curvina Amarilla & Cynoscion sp. \\
CENTROPOMIDAE & Roncador & Micropogonias furnieri \\
RAJIDAE & Robalo & Centropomus sp. \\
RHINOPTERIDAE & Raya & Raja sp. \\
MUGILIDAE & Mancha & Rhinoptera sp. \\
HAEMULIDAE & Lebranche & Mugil lisa \\
POMACANTHIDAE & Torroto & Genyatremus luteus \\
MEGALOPIDAE & Cachama & Pomacanthus sp. \\
\hline
\end{tabular}

\section{Distribución temporal de la abundancia de los recursos pesqueros}

Temporada Alta

Los pescadores de la comunidad Irapa ubicaron el período de máxima abundancia relativa entre los meses mayo a diciembre (Tabla III-13). Donde se señala que los mayores aportes a la composición de las especies y sus niveles de abundancia relativa promedio ( $\mathrm{kg} / \mathrm{día}$ ) y porcentual durante la referida temporada de pesca correspondieron a la guinimera y el bagre mucuro con $400 \mathrm{~kg} / \mathrm{día}(18,60 \%)$, cada uno seguido de otras especies de bagre no identificadas con 250,00 kg/día (11,62\%), el torroto con 238,33 kg/día (11,08\%), el lebranche con 210,22 Kg/día $(9,77 \%)$ y el bagre blanco con $67,00 \mathrm{~kg} / \mathrm{día}(7,76 \%)$, los cuales, en su total representan el $77,33 \%$ de la abundancia relativa promedio del total de especies que 
captura la flota, estimada en 134,43 kg/día. La distribución espacial de la abundancia relativa del total de los recursos desembarcados durante la temporada alta se presenta en la Figura II-2.

\section{Temporada Baja}

La Tabla III-13 también indica los niveles de rendimiento para la temporada baja, la cual se ubicó entre los meses enero y abril, en la que se señalan niveles de abundancia relativa promedio total de 48,82 $\mathrm{kg} /$ día. Los mayores aportes a la composición de las especies y sus niveles de abundancia relativa promedio ( $\mathrm{kg} / \mathrm{día}$ ) y porcentual durante la referida temporada de pesca correspondieron a las mismas especies que lo aportaron en la temporada alta. En este caso, con niveles de rendimiento menores por tratarse de la temporada baja, pero destacando el aporte de las especies mucuro con $180 \mathrm{~kg} /$ día (23,53\%) y guinimera con $150 \mathrm{~kg} / \mathrm{día}$ $(19,60 \%)$. La distribución espacial de la abundancia relativa del total de los recursos desembarcados durante la temporada baja se presenta en la Figura II-3.

Tabla III-13- Composición de las principales especies capturadas por la flota artesanal de Irapa según encuestas realizadas a pescadores artesanales.

\begin{tabular}{|c|c|c|c|c|c|c|}
\hline ESPECIES & $\begin{array}{l}\text { CPUE T. } \\
\text { Alta }\end{array}$ & $\%$ & $\begin{array}{l}\text { Meses T. } \\
\text { Alta }\end{array}$ & $\begin{array}{c}\text { CPUE T. } \\
\text { Baja }\end{array}$ & $\%$ & $\begin{array}{c}\text { Meses T. } \\
\text { Baja }\end{array}$ \\
\hline Curvinata & 68,57 & 3,19 & MAY-DIC & 25,00 & 3,27 & ENE- ABR \\
\hline Róbalo & 55,00 & 2,56 & MAY-DIC & 14,00 & 1,83 & ENE- ABR \\
\hline Raya & 60,71 & 2,82 & MAY-DIC & 24,00 & 3,14 & ENE- ABR \\
\hline Mancha & 53,75 & 2,50 & MAY-DIC & 12,50 & 1,63 & ENE- ABR \\
\hline Lebranche & 210,22 & 9,77 & MAY-DIC & 71,33 & 9,32 & ENE- ABR \\
\hline Bagre & 250,00 & 11,62 & MAY-DIC & 75,00 & 9,80 & ENE- ABR \\
\hline Bagre Amarillo & 92,14 & 4,28 & MAY-DIC & 29,29 & 3,83 & ENE- ABR \\
\hline Bagre Blanco & 167,00 & 7,76 & MAY-DIC & 60,00 & 7,84 & ENE- ABR \\
\hline Torroto & 238,33 & 11,08 & MAY-DIC & 66,67 & 8,71 & ENE- ABR \\
\hline Guasa & 25,00 & 1,16 & MAY-DIC & 12,67 & 1,66 & ENE- ABR \\
\hline Curvina Amarilla & 47,67 & 2,22 & MAY-DIC & 11,67 & 1,52 & ENE- ABR \\
\hline Cachama & 27,50 & 1,28 & MAY-DIC & 8,00 & 1,05 & ENE- ABR \\
\hline Sábalo & 30,00 & 1,39 & MAY-DIC & 10,00 & 1,31 & ENE- ABR \\
\hline Roncador & 25,00 & 1,16 & MAY-DIC & 15,00 & 1,96 & ENE- ABR \\
\hline Mucuro & 400,00 & 18,60 & MAY-DIC & 180,00 & 23,53 & ENE- ABR \\
\hline Guinimera & 400,00 & 18,60 & MAY-DIC & 150,00 & 19,60 & ENE- ABR \\
\hline Promedio & 134,43 & & & 48,82 & & \\
\hline
\end{tabular}




\section{Aspectos socioeconómicos}

La información suministrada por los pescadores artesanales de la comunidad de Irapa, permitió determinar que el nivel educativo de éstos y su grupo familiar, fundamentalmente se ubica en los niveles de primaria incompleta y primaria completa. Estos niveles de instrucción de los pescadores y sus grupos familiares están por debajo de los niveles reportados para el conjunto del Municipio Mariño en los estudios previos realizados.

Se observó que la flota tiene una actividad pesquera por campañas de unos 3 a 7 días de duración que realizan de 3 a 4 al mes; no obstante, se sabe de algunas con actividad diaria. Se deduce también que las embarcaciones campañeras tienen

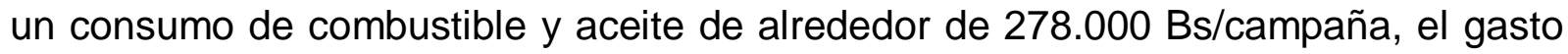
de hielo alcanza aproximadamente unos 160.000 Bs/campaña, e igual monto para comida, mientras que para el caso de las que usan palangres hay un gasto adicional para carnada, estimado entre 10.000 y 15.000 Bs/campaña. Entre los gastos mayores que realizan los dueños de las embarcaciones, se mencionan el mantenimiento semestral que le hacen a los motores, el cual se estimó entre Bs.1.200.000 y 1.500 .000 y los costos anuales de mantenimiento que se le hace a las embarcaciones calculado entre Bs500.000 y 1.500.000. Estas cifras permiten estimar un costo operativo mensual de las embarcaciones de esta comunidad que se ubicaría alrededor de Bs. 2.450.000.

En relación a los ingresos declarados por los pescadores se pudo determinar que un $30 \%$ recibe ingresos superiores a $720.000,00 \mathrm{Bs} / \mathrm{mes}$, otro $30 \%$ entre 180.000 y $360.000 \mathrm{Bs} / \mathrm{mes}$ y un $30 \%$ adicional recibiría entre $360.000-540.000$ $\mathrm{Bs} / \mathrm{mes}$; mientras que un $10 \%$ recibe ingresos entre $540.000-720.000 \mathrm{Bs} / \mathrm{mes}$. Al igual que en otras de las comunidades analizadas, estos niveles de ingresos superan los reportados para el conjunto de la comunidad durante la evaluación socioeconómica de los proyectos costa afuera.

La comunidad de Irapa cuenta con cierta infraestructura de apoyo a la pesca artesanal: rancherías, carpinterías de ribera, depósitos y talleres de reparación de motores. Estos pescadores, al igual que los de Güiria, señalaron como aspecto 
negativo en la actividad, la falta de una política crediticia para adquisición de insumos de pesca, la falta de una ferretería marina y la interferencia de la flota arrastrera al operar en áreas prohibidas.

\section{III.1.2 Análisis de los indicadores pesqueros y socio-económicos de las comunidades pesqueras al norte del GP}

En cuanto al número de embarcaciones, los resultados obtenidos en el presente estudio y su comparación con estudios previos indicarían que la flota pesquera artesanal se ha mantenido relativamente estable en los últimos 20 años, a excepción de la flota artesanal de Güiria que muestra una tendencia a la disminución. Para el conjunto de las 4 comunidades estudiadas se contabilizó un total de 243 embarcaciones, en su mayoría peñeros. Del total de embarcaciones contabilizadas se estimó que alrededor del $72 \%$ estarían operativas, sin embargo este porcentaje alcanzó su valor mínimo en la población de Macuro donde se estimó un valor de $53 \%$. El número de embarcaciones operativas genera alrededor de 565 puestos de trabajo directos en el sector primario de la pesca artesanal en estas comunidades.

La flota artesanal de esta región realiza sus actividades de pesca en la totalidad del área del Golfo de Paria. Sin embargo, existe una sectorización de la actividad en función de las comunidades, puesto que los pescadores de Macuro realizan faenas en el sector oriental del Golfo de Paria e incluso en la costa nororiental de la península, mientras que los pescadores de Yaguaraparo realizan sus actividades de pesca fundamentalmente en el sector occidental y suroccidental del golfo. Por otra parte, existe un solapamiento de las áreas de pesca de las comunidades de Irapa y Güiria, en las cuales las actividades de pesca tienden a concentrarse en el sector central y nororiental del golfo. Esta sectorización se refleja en la composición de las capturas por especies, la cual se caracteriza por la predominancia de especies estuarinas en las capturas de Yaguaraparo y de especies de características marinas en Macuro, mientras que las capturas de Güiria e Irapa presentan una mezcla de especies estuarinas y marinas. La composición por especies estimada en el presente estudio coincide con la señalada por Gómez (2003) en una análisis sobre un período de 4 años. 
En lo que se refiere a las temporadas de pesca, los pescadores de la región coinciden en señalar mayores rendimientos durante el segundo semestre del año, lo cual coincide con lo señalado por los pescadores de la zona norte de la Península de Paria. Esta estacionalidad fue también señalada por Gómez (2003) en su análisis de la pesca artesanal en el Golfo de Paria. Vale destacar que en ese estudio se determinó que las especies explotadas de la región presentaron una tendencia a la disminución en términos de abundancia relativa durante un período de 4 años. Por otra parte, la percepción de los pescadores del conjunto de las comunidades en cuanto a las variaciones de abundancia entre las temporadas alta y baja indica que los valores medios de abundancia en la temporada baja serían del orden del $20 \%$ de los observados en la temporada alta.

La comunidades estudiadas presentan 2 modalidades de pesca bien diferenciadas. Por un lado, en Yaguaraparo e Irapa los pescadores realizan campañas de pesca de varios días de duración, mientras que los pescadores de Güiria y Macuro realizan faenas de pesca diarias desde sus puertos base. Estas modalidades de pesca inciden de manera diferente sobre los costos operativos de las unidades de pesca. En la pesca diaria realizada en Macuro y Güiria, el costo de la gasolina y el aceite son predominantes y representan el $75 \%$ y el $63 \%$, respectivamente de los costos operativos mensuales; mientras que para las flotas campañeras de Yaguaraparo e Irapa los costos del hielo y los alimentos representan alrededor del $50 \%$ del total de los costos operativos mensuales.

Los niveles educativos de los pescadores y sus grupos familiares tienden a ser inferiores a los observados en el conjunto de los pobladores de las comunidades estudiadas. Sin embargo, se pudo observar en ciertos casos un nivel de estudios más avanzados a los estimados en las comunidades del norte de la Península de Paria.

En cuanto a la distribución del ingreso mensual de los pescadores de las diferentes comunidades estudiadas, éstos señalan percibir una remuneración mensual que supera significativamente la distribución del resto de los pobladores en estas comunidades. En las poblaciones de Irapa y Macuro el porcentaje de 
pescadores que percibe ingresos inferiores a Bs. 540.000 mensuales se estimó en $60 \%$ y $54 \%$, respectivamente. Mientras que en Yaguaraparo y Güiria este segmento de la población correspondió al $25 \%$ y $40 \%$, respectivamente. Por lo tanto, aparentemente, los niveles de ingresos no estarían relacionados con la modalidad de pesca (diaria o campaña), puesto que en Irapa se realizan campañas y en Macuro las faenas son diarias. Sin embargo, en estas comunidades los pescadores señalaron costos operativos mensuales más elevados (Bs. 2.600.000 en Macuro y Bs. 2.440.000 en Irapa), lo cual pudiera determinar ingresos netos de menor cuantía.

\section{III.1.3 Conclusiones}

- Dos modalidades de pesca fueron definidas para la actividad pesquera artesanal del GP: embarcaciones campañeras semanales y embarcaciones de pesca diaria.

- El período de mayo - diciembre está definido como el de mayor abundancia relativa por ambas flotas.

- El número de embarcaciones y puestos de trabajo directos en la pesca artesanal del norte del Golfo de Paria indican un relativo estancamiento de la actividad en los últimos 20 años.

- La gasolina y el aceite son los factores que mayor incidencia tienen en la flota que opera diariamente, mientras que el hielo y los alimentos tienen mayor incidencia en la flota campañera.

- La piratería marina, la ausencia de infraestructura de apoyo a la pesca, la pesca de arrastre y la ausencia de créditos son percibidos por los pescadores como los factores que más negativamente impactan la actividad pesquera artesanal. 


\section{III.2 Estimaciones de Biomasa por el Método de Área Barrida en el Norte del GP}

La mayor información sobre los recursos demerasales en el GP proviene de los estudios realizados sobre la pesquería de arrastre industrial que opera en la fachada Atlántica y en la zona central del GP. Se estima que la producción pesquera de la fachada Atlántica venezolana (incluyendo el GP) alcanzó en el 2001 cerca de 12.055 TM, de las cuales 3.293 TM fueron desembarcadas por la flota artesanal y 8.762 TM por la flota industrial de arrastre (Marcano, 2002). En aguas pertenecientes al lado trinitario del GP, los desembarques alcanzaron 2.800 TM, de las cuales 1.300 TM corresponden a desembarques de camarón y 1.500 TM a peces de fondo (Kuruvilla et al., 2000).

La actividad pesquera en el GP es ejecutada por pescadores artesanales que no poseen ningún desarrollo tecnológico y tienen poco nivel organizacional. La actividad está dispersa a lo largo de toda la costa norte del GP, destacando las comunidades de Macuro, Guiria, Irapa y Yaguaraparo, con la mayor actividad de servicios y desembarque de la flota. Alrededor de 63 especies marinas son capturadas por las flotas artesanales e industrial de arrastre, siendo los peces los que contribuyen con el $90 \%$ de las capturas (Marcano et al., 2001). Los recursos demersales más importantes desde el punto de vista comercial que se distribuyen en el área son los crustáceos de la familia Penaeidae (camarones), peces de las familias Sciaenidae (curvinata, roncador, curvinas), Lutjanidae (pargos), Ariidae (bagres), y chuchos de la familia Dasyatidae.

Las investigaciones efectuadas sobre los recursos asociados al norte del GP, desde el punto de vista pesquero, son muy limitadas. Los pocos estudios tratan sobre los aspectos poblacionales y pesqueros del camarón blanco, Litopenaeus schmitti, capturado por pescadores artesanales entre Punta de Piedras e Irapa (Altuve et al.,1995; Altuve, 1997); también sobre los aspectos reproductivos y poblacionales del torroto, Genyatremus luteus, y del pargo, Lutjanus synagris (Gómez et al., 2001, 2002). 
No existen referencias documentadas sobre los niveles de biomasa de los recursos demersales que se distribuyen dentro del GP. En este sentido, solo han sido realizadas estimaciones para los recursos pelágicos y demersales de la zona Atlántica, al sur de Trinidad y norte del Delta del Río Orinoco, durante el año 1988 durante las expediciones del B/P Fridtjof Nassen, estimandose 70.000 TM de biomasa disponible para el grupo de los pelágicos, esencialmente sardinas, mientras que para los peces de fondo fue de 30.000 TM (NORAD-FAO/UNDP; 1988). En el año 2001, se realizó una evaluación sobre la biodiversidad de la zona sur del Golfo de Paria, en la cual se identificaró un importante número de especies bentónicas asociadas a la desembocadura del caños Macarebo y del Río San Juan (AquaRAP, 2002).

En vista de los desarrollos que tiene PDVSA previstos en la zona norte del GP se requiere determinar los niveles de biomasa y la estructura demográfica de los recursos demersales (peces y crustáceos decápodos) de importancia pesquera en el estrato costero del norte del GP. Para ello se realizaron dos campañas de prospección pesquera en el área de estudio, la primera en marzo y la segunda en septiembre de 2005.

El muestreo para la estimación de biomasa se estableció para nueve estaciones en cada campaña, que van desde la Ensenada de Cardiaquito, al este hasta Los Troncones al oeste de Irapa (Figura III-1). Cada estación fue dividida en dos estratos de profundidad $(\mathrm{m})$ para efectos del muestreo: de 0-5 $\mathrm{m}$ y 5-10. En cada estrato se realizaron dos lances para la toma del material biológico desde un bote peñero de $5 \mathrm{~m}$ de longitud, propulsado con un motor fuera de borda $48 \mathrm{HP}$ utilizando una red de arrastre artesanal (por popa) denominada comúnmente como "CHICA" (Foto III-1), cuyas características estructurales se presentan en la Tabla III-14. 


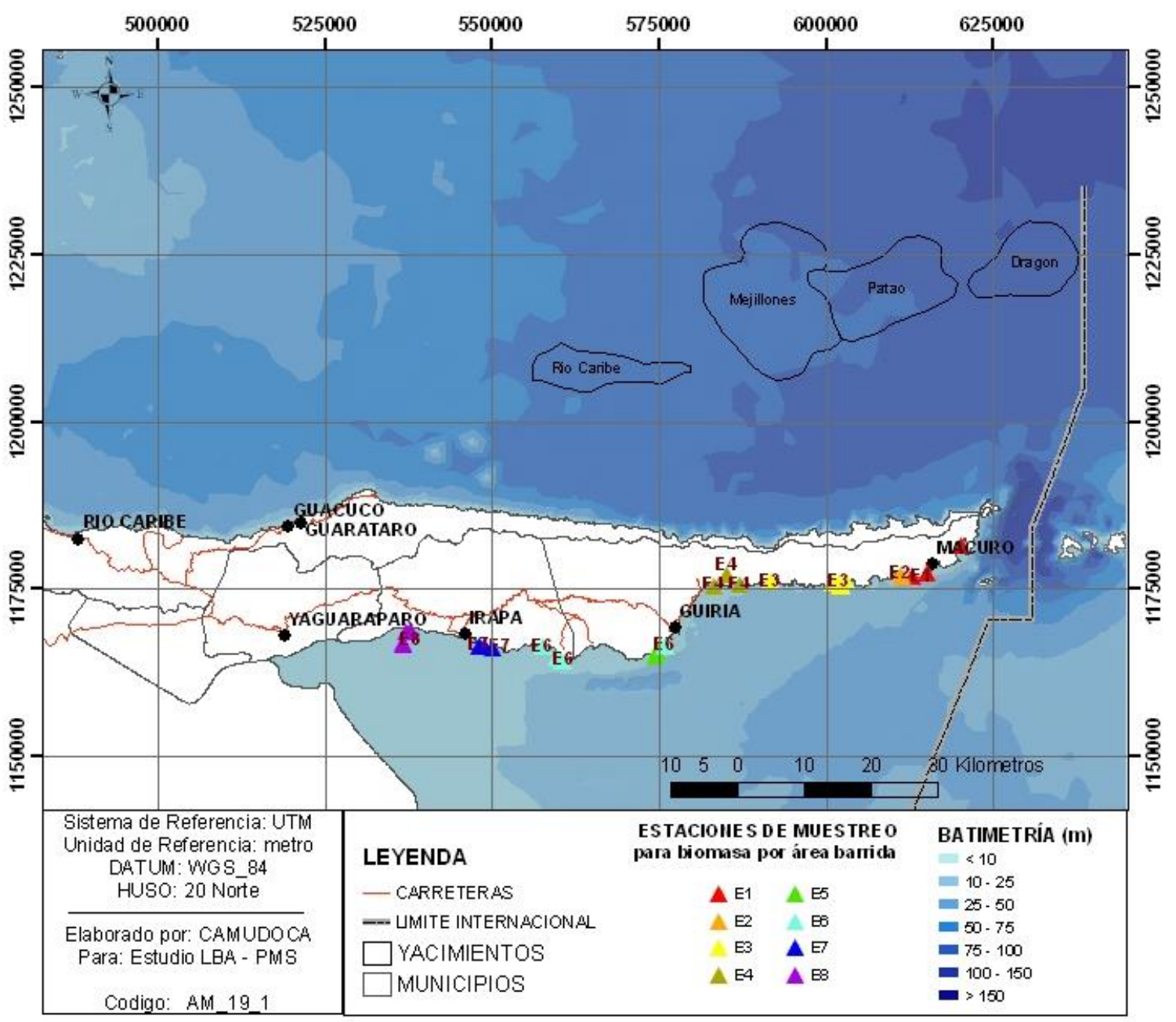

Figura III-1.- Estaciones de muestreo para estimaciones de biomasa por área barrida en el norte del GP. 
Tabla III-14- Características estructurales del arte de pesca utilizado para estimaciones de biomasa por área barrida en el norte del GP.

\begin{tabular}{|ll|}
\hline Componente de la Red & Variable ( descripción) \\
\hline & \\
Largo Relinga Superior & Longitud: $11,20 \mathrm{~m}$ \\
Largo Relinga Inferior & Longitud $10,70 \mathrm{~m}$ \\
Largo Cuerpo & Longitud extendido: $9,52 \mathrm{~m}$ \\
Largo Copo & Longitud extendido : $2,56 \mathrm{~m}$ \\
Luz de malla cuerpo & Distancia entre nudos extendidos : $34,86 \mathrm{~mm}$ \\
Luz de malla copo & Distancia entre nudos extendidos $26,15 \mathrm{~mm}$ \\
Diámetro Copo & Número de mallas perímetro 100 \\
Masa Portalones & $19,325 \mathrm{~kg}$ \\
\hline
\end{tabular}

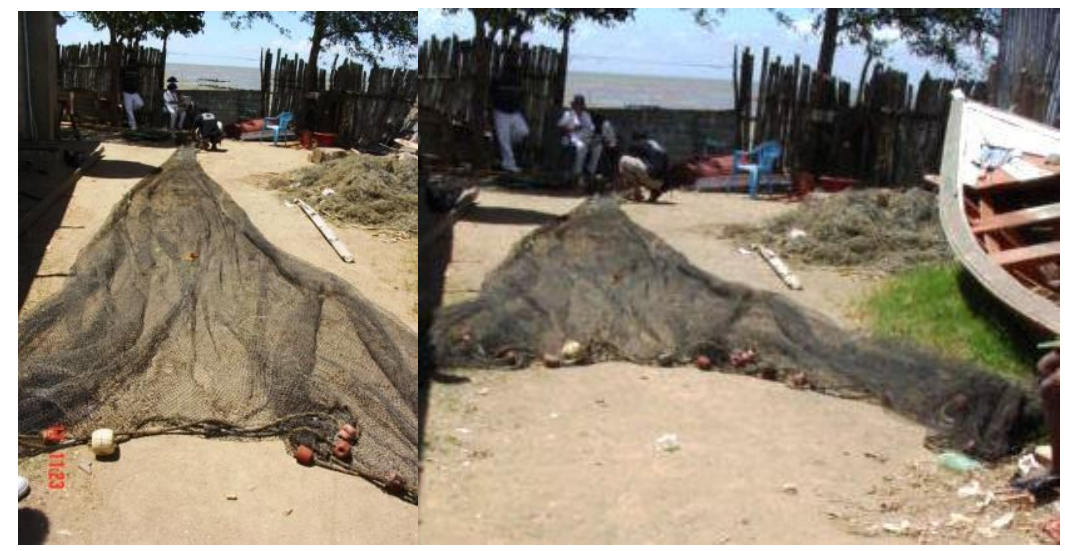

Foto III-1.- Red 'CHICA' utilizada en las campañas para estimaciones de biomasa por área barrida al norte del GP.

Durante cada lance se registraron los siguientes parámetros: salinidad, con un refractómetro óptico Atago (1 psu de apreciación); concentración de oxígeno (mg/l+/-) y temperatura $\left(0,1^{\circ} \mathrm{C}\right.$ de apreciación), con un equipo YSI de campo; las coordenadas geográficas de inicio del arrastre (lance), el tiempo de duración del lance y velocidad de arrastre con un GPS de campo.

Después de cada lance de pesca, los organismos eran separados en dos grupos, peces y crustáceos decápodos, que fueron pesados en una balanza de 100 $\mathrm{g}$ de apreciación, y colocados en bolsas plásticas debidamente identificadas. Las muestras en bolsas se colocaron en cavas con hielo hasta su traslado a la ciudad de Guiria donde fueron congeladas el mismo día de captura. Al finalizar la campaña, las 
muestras congeladas se trasladaron al laboratorio del Instituto Oceanográfico en Cumaná, para su análisis.

En el laboratorio, se procedió a la identificación taxonómica de las especies siguiendo las claves de Cervigón (1991, 1993 y 1994). Del análisis en el laboratorio se obtuvieron los datos para el cálculo de la biomasa por área barrida, que incluía: especies por familia y peso por especie. Para el cálculo de los niveles biomasa, los datos correspondientes al peso fueron agrupados por familias de mayor importancia pesquera y contribución porcentual en las muestras. Las estimaciones fueron hechas por el Método de Área Barrida (Sparre y Venema, 1997),

$$
B_{T}=\frac{(\overline{C p / a}) \times A}{X 1}
$$

Donde,

$B_{T}$ es la biomasa total del área, $C p / a$ es la captura promedio en peso por unidad de área, $A$ es el área total del estudio que se definió en $426,64 \mathrm{~km}^{2}$, y $X 1$ es la proporción retenida de peces/crustáceos en el área barrida. Para este último parámetro de siguió el criterio de Dickson (1974) y se igualó a 1,0.

\section{III.2.1 Observaciones sobre el Sustrato y Mareas en la Zona de Estudio.}

Los tipos de fondos observados durante los muestreos fueron en general fangosos y fangoso-arenosos, salvo hacia el extremo este de la Península donde predominaron los fondos rocosos. Entre las localidades de Las Piedras y Soro, el material predominante es grava.

En cuanto a las mareas se pudo constatar que existen cuatro diferentes niveles durante las 24 horas, dos altas y dos bajas. Este comportamiento rige el movimiento de aguas en la zona costera, donde se pudo observar que al momento de las mareas 
mas bajas, podían quedar descubiertas importantes áreas del fondo, acentuado esto por la baja profundidad imperante en el área próxima a la costa. Se observaron fuertes corrientes de marea al momento de realizar los arrastres, las cuales dificultaron las operaciones de pesca en algunos casos. Por otra parte, en las primeras estaciones, Cariaquito y Macuro, el tipo de fondo muy accidentado (rocoso) hizo imposible la toma de muestras.

\section{III.2.2 Parámetros Ambientales en las Estaciones de Muestreos.}

Se evidencia un gradiente en la distribución horizontal de la salinidad en el estrato costero al norte del GP. Los valores observados se distribuyen en un rango entre 13 y 30 psu, en los extremos oriental y occidental (Tabla III-15).

Tabla III-15- Resultados de los parámetros físico-químicos observados en las masas de agua superficiales durante la primera campaña al norte del Golfo de Paria.

\begin{tabular}{|c|c|c|c|c|c|c|}
\hline CAMPAÑA & FECHA & \multicolumn{2}{|l|}{ LOCALIDAD } & $\begin{array}{c}S \\
\text { (psu) }\end{array}$ & $\begin{array}{c}\mathrm{O}_{2} \\
\mathrm{mg} / \mathrm{l}\end{array}$ & \\
\hline \multirow{12}{*}{ PRIMERA } & \multicolumn{3}{|c|}{ 08/03/2005 ENSENADA CARIAQUITO } & 30 & 2,75 & 28,9 \\
\hline & \multicolumn{3}{|c|}{ 08/03/2005 ENSENADA CARIAQUITO } & 30 & 4,39 & 28,4 \\
\hline & \multicolumn{3}{|c|}{ 08/03/2005 MACURO OESTE } & 30 & 4,42 & 28,3 \\
\hline & \multicolumn{3}{|c|}{ 09/03/2005 PTO. HIERRO ESTE } & 30 & 4,74 & 28,5 \\
\hline & \multicolumn{3}{|c|}{ 09/03/2005 PTO. HIERRO ESTE } & 30 & 5,34 & 29 \\
\hline & \multicolumn{3}{|c|}{ 09/03/2005 LA SALINA } & 29 & 5,31 & 30,2 \\
\hline & \multicolumn{3}{|c|}{ 10/03/2005 GUAYABERO } & 27 & 4,9 & 28,1 \\
\hline & \multicolumn{3}{|c|}{ 10/03/2005 SORO } & 23 & 5,04 & 29,3 \\
\hline & \multicolumn{3}{|c|}{ 10/03/2005 EL CURI } & 25 & 5,3 & 30,2 \\
\hline & \multicolumn{3}{|c|}{$11 / 03 / 2005$ LOS TRONCONES } & 24 & 5,08 & 30,1 \\
\hline & \multirow{2}{*}{\multicolumn{2}{|c|}{$11 / 03 / 2005$ LOS TRONCONES }} & & 19 & 5,9 & 31,1 \\
\hline & & & PROMEDIO & 27 & 4,83 & 29,3 \\
\hline \multirow{9}{*}{ SEGUNDA } & \multicolumn{3}{|c|}{ 19/09/2005 ENSENADA CARIAQUITO } & 22 & 4,32 & 30,8 \\
\hline & \multirow{2}{*}{\multicolumn{3}{|c|}{$\begin{array}{l}\text { 19/09/2005 MACURO OESTE } \\
\text { 20/09/2005 PTO. HIERRO }\end{array}$}} & 22 & 5,5 & 30 \\
\hline & & & & 21 & 4,38 & 29,5 \\
\hline & \multicolumn{3}{|c|}{ 20/09/2005 LAS SALINAS } & 19 & 5,5 & 31,6 \\
\hline & \multicolumn{3}{|c|}{ 21/09/2005 GUAYABERO } & 20 & 5,21 & 29,3 \\
\hline & \multicolumn{3}{|c|}{$21 / 09 / 2005$ SORO } & 16 & 4,8 & 31,2 \\
\hline & \multicolumn{3}{|c|}{ 21/09/2005 CURI } & 19 & 4,65 & 31,6 \\
\hline & \multirow{2}{*}{\multicolumn{3}{|c|}{ 22/09/2005 LOS TRONCONES }} & 13 & 4,56 & 31,2 \\
\hline & & & & 19 & 4,87 & 30,7 \\
\hline
\end{tabular}


En el mes de marzo, el promedio de salinidad resultó mayor que el de septiembre. Las lluvias continuas en la región desde marzo 2005, parece haber provocado la disminución del parámetro por el aumento de los aportes de agua dulce del Caño Ajies y del Río San Juan. También es apreciable, en la costa norte del GP, una marcada variabilidad en la salinidad superficial en sentido oeste. Este resultado parece estar relacionado con la baja profundidad de la región, la influencia de las mareas y los aportes de agua dulce a partir de la localidad del Caño Curí.

El oxígeno disuelto presentó límites entre 2,75 y 5,9 mg/l (Tabla III-15). promedio obtenido de este parámetro hacia el este de Güiria fue de 4,9 mg/l, mientras que en el sentido oeste el estimado fue de $4,87 \mathrm{mg} / \mathrm{l}$. No parecen ser importantes las variaciones observadas en los niveles superficiales de oxigeno disuelto en las dos temporadas de muestreo, por lo que el oxígeno disuelto se puede considerar una variable estable a lo largo del estrato muestreado.

La temperatura exhibió la menor variabilidad en la zona de estudio, con valor promedio general de $29,9^{\circ} \mathrm{C}$, con un intervalo de 28,1 y 31,6 grados (Tabla III-15). Los registros más altos se encontraron desde Güiria hacia Los Troncones, con un promedio de $30,7^{\circ} \mathrm{C}$. A pesar de que el rango de temperatura fue de $3^{\circ} \mathrm{C}$, se puede observar que las temperaturas menos altas se presentaron en la campaña de marzo.

Las condiciones ambientales del norte del GP son marcadas entre el lado occidental y oriental de la ciudad de Guiria. Los resultados muestran que hacia el extremo oriental del norte del GP, la costa tiene características marinas, producto de la entrada de masas de agua al GP a través de Boca de Dragón. Al contrario, en el extremo occidental del área de estudio, las aguas tienen un comportamiento estuarino, originado por una fuerte estratificación horizontal de las masas de aguas producto de la descarga del Río San Juan y de los caños del Delta del Orinoco.

\section{III.2.3 Operaciones de pesca exploratoria}

Se capturó un total de $287,73 \mathrm{~kg}$, producto de 46 lances de pesca realizados durante las dos campañas de prospección. El tiempo total de barrido de ambas campañas fue de 813 min., con capturas por lance que variaron entre 0,3 (La Salina) 
y 41,9 kg (Los Troncones) (Tabla III-16). Hubo lances en los cuales el registro de captura fue cero. Ello se debió a dificultades durante el arrastre, como por ejemplo, la existencia de grandes rocas en el sustrato y fuertes corrientes de mareas.

Un análisis estadístico (ANOVA) determinó que no hubo diferencias estadísticamente significativas al comparar los promedios de captura/lance entre las dos campañas de prospección (Anova, $p=0,32$ ). También se determinó que no hubo diferencias estadísticamente significativas al ser contrastados los factores: lances $(p=0,76)$, profundidad $(p=0,95)$ y estratos de pesca $(p=0,13)$. Estos análisis permiten inferir que la variabilidad en las capturas analizadas no es atribuible a la operación de pesca. En consecuencia, se puede decir que el desempeño durante las operaciones de muestreo con la red CHICA fue adecuado para las estimaciones de biomasa con este arte de pesca.

Al analizar la distribución espacial de las capturas se observa que existen diferencias estadísticamente significativas (Anova, $p=0,02$ ) entre los promedios de captura por lance $(\mathrm{kg} / \mathrm{l})$. La prueba estadística $L S D$ (menor diferencia significativa) permite unir las estaciones que muestran las menores diferencias. El resultado indica la existencia de dos grupos, el primero, representado por las estaciones 1 a la 7 y el segundo, constituido por las estaciones 8, 6 y 7 (Figura III-2). Este análisis permite inferir que existe una distribución diferenciada de la captura por lance a lo largo de la zona de estudio que puede ser debido a características del medio ambiente entre las estaciones o al comportamiento de las especies capturadas. 
Tabla III-16- Localidades, posiciones, capturas, duración y distancia barrida por la red 'Chica' durante la primera campaña en la costa norte del Golfo de Paria (COD.: Código; E1-9: estaciones ; Estratos I (0-5 m) y II (5-10 m).; 1-3: número del lance).

\begin{tabular}{|c|c|c|c|c|c|c|c|c|}
\hline CAMPAÑA & FECHA & LOCALIDAD & COD. & $\begin{array}{c}\text { LATITUD } \\
\text { NORTE } \\
\left({ }^{\circ}\right)\end{array}$ & $\begin{array}{c}\text { LONGITUD } \\
\text { OESTE } \\
\left({ }^{\circ}\right)\end{array}$ & $\begin{array}{l}\text { CAPTURA } \\
(\mathrm{kg})\end{array}$ & $\begin{array}{l}\text { TIEMPO } \\
\text { (min) }\end{array}$ & $\begin{array}{l}\text { VELOCIDAD } \\
(\mathrm{mn} / \mathrm{h})\end{array}$ \\
\hline \multirow{30}{*}{ PRIMERA } & \multirow{8}{*}{$08 / 03 / 2005$} & CARIAQUITO & E1I1 & 10,685 & 61,901 & 2,765 & 15 & 2 \\
\hline & & CARIAQUITO & E1 I 2 & 10,688 & 61,899 & 3,3 & 15 & 1,9 \\
\hline & & CARIAQUITO & E1 II 1 & 10,650 & 61,948 & 0 & 10 & 2,1 \\
\hline & & CARIAQUITO & E1 II 1 & 10,644 & 61,966 & 2 & 15 & 1,9 \\
\hline & & MACURO & E2 I I1 & 10,644 & 61,966 & 0 & 15 & 2 \\
\hline & & MACURO & E2 I 1 & 10,646 & 62,483 & 1,6 & 15 & 1,5 \\
\hline & & MACURO & E2 I 2 & 10,649 & 61,983 & 2,2 & 15 & 1,9 \\
\hline & & PTO. HIERRO & E3 I 1 & 10,636 & 62,075 & 13,1 & 30 & 1,9 \\
\hline & \multirow{7}{*}{ 09/03/2005 } & PTO. HIERRO & E3 I 2 & 10,639 & 62,058 & 4,1 & 19 & 2,3 \\
\hline & & PTO. HIERRO & E3 I 3 & 10,634 & 62,065 & 1,5 & 30 & 1,9 \\
\hline & & PTO. HIERRO & E3 II 1 & 10,637 & 62,067 & 0,6 & 30 & 2,6 \\
\hline & & PTO. HIERRO & E3 II 2 & 10,638 & 62,160 & 0 & 0 & 2,4 \\
\hline & & LA SALINA & E3 II 1 & 10,635 & 62,204 & 0,3 & 8 & 1,9 \\
\hline & & LA SALINA & $\mathrm{E} 4 \mathrm{I} / 2$ & 10,648 & 10,221 & 0,55 & 20 & 2 \\
\hline & & LA SALINA & E4 E I 1 & 10,633 & 62,239 & 2,55 & 20 & 2 \\
\hline & \multirow{11}{*}{$10 / 03 / 2005$} & GUAYABERO & E5 I2 & 10,544 & 62,317 & 0,45 & 30 & 1,9 \\
\hline & & GUAYABERO & E5 E II 1 & 10,551 & 62,312 & 1,5 & 30 & 2,3 \\
\hline & & GUAYABERO & E5 II 2 & 10,538 & 62,320 & 2,55 & 30 & 2,3 \\
\hline & & SORO & E6 II 1 & 10,536 & 62,453 & 15,35 & 30 & 2,5 \\
\hline & & SORO & E6 II 2 & 10,532 & 62,446 & 32,9 & 29 & 1,5 \\
\hline & & SORO & E6 I 1 & 10,551 & 62,474 & 6,5 & 15 & 2,4 \\
\hline & & SORO & E6 I 2 & 10,551 & 62,306 & 2,1 & 14 & 2,4 \\
\hline & & EL CURI & E7 I 1 & 10,550 & 62,542 & 1,9 & 15 & 1,9 \\
\hline & & EL CURI & E7 I 2 & 10,551 & 62,552 & 2,5 & 15 & 2,2 \\
\hline & & EL CURI & E7 II 1 & 10,552 & 62,560 & 6,9 & 15 & 2,2 \\
\hline & & EL CURI & E7 II 2 & 10,552 & 62,561 & 0,35 & 15 & 2,2 \\
\hline & \multirow{4}{*}{$11 / 03 / 2005$} & LOS TRONCONES & E8 II 1 & 10,555 & 62,664 & 13,75 & 15 & 2,6 \\
\hline & & LOS TRONCONES & E8 II 2 & 10,556 & 62,664 & 9,1 & 15 & 2,5 \\
\hline & & LOS TRONCONES & E8 I 1 & 10,572 & 62,660 & 6,5 & 15 & 2,3 \\
\hline & & LOS TRONCONES & E8 I 2 & 10,572 & 62,653 & 4,3 & 15 & 2,1 \\
\hline \multirow{19}{*}{ SEGUNDA } & \multirow{4}{*}{ 19/09/2005 } & CARIAQUITO & $\mathrm{E} 1 \mathrm{I} 1$ & 10,688 & * & 6,7 & 16 & 2,90 \\
\hline & & CARIAQUITO & E1 I 2 & 10,685 & 61,883 & 8,2 & 16 & 2,65 \\
\hline & & MACURO & E2 I 1 & 10,643 & 61,951 & 0,8 & 15 & 2,90 \\
\hline & & MACURO & E2 I 2 & 10,638 & 61,955 & 6,8 & 15 & 2,65 \\
\hline & \multirow{4}{*}{ 20/09/2005 } & PTO. HIERRO & E3 I 1 & 10,635 & 62,138 & 17,9 & 15 & 2,80 \\
\hline & & PTO. HIERRO & E3 I 2 & 10,634 & 10,634 & 4,2 & 15 & 2,65 \\
\hline & & LA SALINA & E4 I 1 & 10,626 & 62,222 & 1,2 & 17 & 2,60 \\
\hline & & LA SALINA & $\mathrm{E} 4 \mathrm{I} 2$ & 10,625 & 62,235 & 5,01 & 15 & 2,65 \\
\hline & \multirow{9}{*}{$21 / 09 / 2005$} & GUAYABERO & E5 I 1 & 10,554 & 62,305 & 0,8 & 15 & 2,40 \\
\hline & & GUAYABERO & E5 I 2 & 10,551 & 62,307 & 3,7 & 15 & 2,65 \\
\hline & & GUAYABERO & E5 II 1 & 10,551 & 62,304 & 2,6 & 13 & 2,65 \\
\hline & & GUAYABERO & E5 II 2 & 10,537 & 62,303 & 2,5 & 17 & 2,65 \\
\hline & & SORO & E6 I 1 & 10,526 & 62,436 & 5,7 & 14 & 2,60 \\
\hline & & SORO & E6 I 2 & 10,534 & 62,442 & 1,2 & 16 & 2,65 \\
\hline & & SORO & E6 I 3 & 10,543 & 62,467 & 1,2 & 15 & 2,65 \\
\hline & & EL CURI & E7 I 1 & 10,542 & 62,508 & 3,1 & 8 & 2,40 \\
\hline & & EL CURI & E7 I 2 & 10,874 & 62,534 & 13 & 15 & 2,65 \\
\hline & \multirow{2}{*}{ 22/09/2005 } & LOS TRONCONES & E8 I 1 & 10,568 & 62,672 & 41,9 & 15 & 2,60 \\
\hline & & LOS TRONCONES & E8 I 2 & 10,571 & 62,658 & 20 & 16 & 2,65 \\
\hline
\end{tabular}




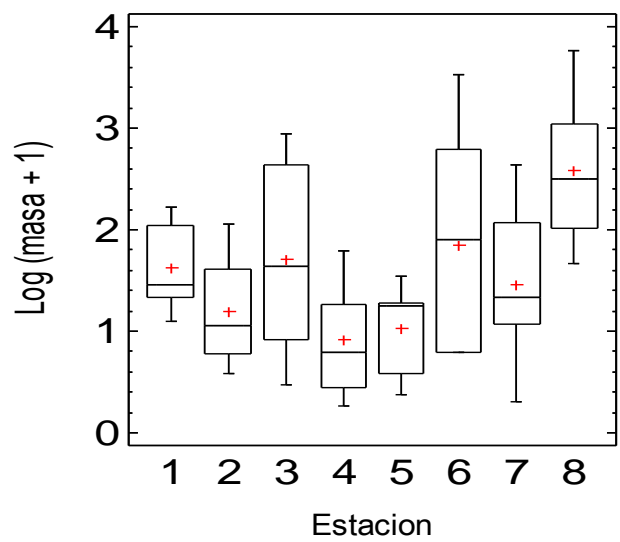

Figura III-2.- Resultado del la prueba LSD de promedios transformados de captura/lance por estaciones de muestreo (se transformó la biomasa a log×(peso+1).

\section{III.2.4 Cuantificación y composición de los grupos demersales}

Se recolectó un total de 6.076 de ejemplares durante las dos campañas de pesca exploratoria, donde el $95 \%$ de las especies fueron peces y el $5 \%$ crustáceos. Se identificaron 114 especies pertenecientes a 33 familias de peces y 3 de crustáceos decápodos en el norte del GP (Tabla III-17). Las especies ícticas demersales de mayor importancia comercial capturadas en los muestreos fueron: Arius herzbergii, Bagre marinus, Dasyatis guttata, Cynoscion acoupa, C. jamaicensis, C. leiarchus, C. microlepidotus, C. virescens, Micropogonias furnieri, Lutjanus analis, L. griseus, L. purpureus y L. synagris. Entre los crustáceos decápodos, los camarones Litopenaeus schmitti y los cangrejos Callinectes sp. resultaron ser los de mayor importancia comercial. 
Tabla III-17- Composición de entes taxonómicos observados durante las campañas de prospección pesquera en la costa norte del GP.

\begin{tabular}{|c|c|c|c|c|c|c|c|}
\hline \multirow[t]{2}{*}{ FAMILIA } & \multirow[t]{2}{*}{ ESPECIES } & \multicolumn{2}{|c|}{ CAMPAÑAS } & \multirow[t]{2}{*}{ FAMILIA } & \multirow[t]{2}{*}{ ESPECIES } & \multicolumn{2}{|c|}{ CAMPAÑAS } \\
\hline & & 1 & 2 & & & 1 & 2 \\
\hline \multirow[t]{3}{*}{ Achiridae } & Achirus achirus & & $x$ & Lutjanidae & Lutjanus sp. & & $x$ \\
\hline & Achirus lineatus & $x$ & $x$ & & Lutjanus analis & $\mathrm{x}$ & \\
\hline & Aprionichthys dumerili & $x$ & $x$ & & Lutjanus griseus & $x$ & \\
\hline Albulidae & Albula vulpes & $x$ & & & Lutjanus purpureus & $x$ & $\mathrm{x}$ \\
\hline \multirow[t]{2}{*}{ Anguliforme } & Symphurus tessellatus & & $\mathrm{x}$ & & Lutjanus synagris & $x$ & $x$ \\
\hline & Synmphurus diomedianus & $\mathrm{x}$ & & Majidae & Epialtus bituberculatus & $x$ & \\
\hline \multirow[t]{6}{*}{ Ariidae } & Arius grandicassis & $x$ & & & Lactophrys quadricornis & & $x$ \\
\hline & Arius herzbergii & & $x$ & & Microphrys bicornutus & $\mathrm{x}$ & $x$ \\
\hline & Arius quadriscutis & $x$ & $x$ & Mugilidae & Mugil curema & & $x$ \\
\hline & Bagre bagre & $x$ & $x$ & Ostraciidae & Lactophrys quadricornis & $\mathrm{x}$ & \\
\hline & Bagre marinus & $x$ & $x$ & Paralichthyidae & Paralichthys tropicus & & $x$ \\
\hline & Cathorops spixii & $x$ & $x$ & & Syacium papillosum & $\mathrm{x}$ & $x$ \\
\hline \multirow[t]{2}{*}{ Batrachoididae } & Amphichthys cryptocentrus & & $x$ & Penaeidae & Litopenaeus schmitti & $x$ & $x$ \\
\hline & Batrachoides surinamensis & $\mathrm{x}$ & $x$ & & Xyphopenaeus kroyeri & $x$ & $x$ \\
\hline \multirow[t]{10}{*}{ Carangidae } & Chloroscombrus chrysurus & $x$ & $\mathrm{x}$ & Portunidae & Callinectes bocourti & $\mathrm{x}$ & $\mathrm{x}$ \\
\hline & Hemicaranx amblirhynchus & & $x$ & & Callinectes exasperatus & & $x$ \\
\hline & Hemicaranx amblyrhynchus & $x$ & & & Callinectes ornatus & $x$ & $x$ \\
\hline & Oligoplites palometa & $x$ & $\mathrm{x}$ & & Callinetes sapidus & & $x$ \\
\hline & Oligoplites saurus & $x$ & $x$ & & Portunus sp. & $\mathrm{x}$ & \\
\hline & Selene setapinnis & $x$ & & Scaridea & Nicholsina usta & $x$ & \\
\hline & Selene vomer & $x$ & $\mathrm{x}$ & Sciaenidae & Bairdiella rhonchus & $x$ & \\
\hline & Trachinotus carolinus & & $x$ & & Bairdiella sanctaeluciae & $x$ & $\mathrm{x}$ \\
\hline & Trachinotus cayenensis & $\mathrm{x}$ & $x$ & & Cynoscion acoupa & $\mathrm{x}$ & $x$ \\
\hline & Trachinotus falcatus & & $x$ & & Cynoscion jamaicensis & $x$ & \\
\hline Centropomidae & Centropomus ensiferus & & $x$ & & Cynoscion leiarchus & $x$ & $x$ \\
\hline \multirow[t]{5}{*}{ Clupeidae } & Odontognathus mucronatus & $x$ & $x$ & & Cynoscion microlepidotus & $x$ & $x$ \\
\hline & Opisthonema oglinum & $x$ & & & Cynoscion virescens & $x$ & $x$ \\
\hline & Pellona harroweri & $\mathrm{x}$ & $\mathrm{x}$ & & Equetus acuminatus & & $\mathrm{x}$ \\
\hline & Rhinosardinia sp & & $x$ & & Equetus umbrosus & & $x$ \\
\hline & Sardinella aurita & & $x$ & & Isopisthus parvipinnis & $\mathrm{x}$ & \\
\hline Cynoglossidae & Symphurus tessellatus & $x$ & & & Larimus breviceps & $x$ & $x$ \\
\hline Cyprinodontidae & Cyprinodon dearborni & $x$ & & & Lonchurus lanceolatus & $x$ & \\
\hline \multirow[t]{3}{*}{ Dasyatidae } & Dasyatis geijskesi & $x$ & & & Macrodon ancylodon & $x$ & $\mathrm{x}$ \\
\hline & Dasyatis guttata & $x$ & $x$ & & Menticirrhus americanus & $x$ & $x$ \\
\hline & Himentura schmardae & $x$ & & & Micropogonias furnieri & $x$ & $x$ \\
\hline Echeneidae & Echeneis naucrates & $x$ & & & Nebris microps & $x$ & $x$ \\
\hline \multirow[t]{7}{*}{ Engraulidae } & Anchoa hepsetus & $x$ & $x$ & & Odontoscion dentex & $x$ & \\
\hline & Anchoa parva & $x$ & & & Ophioscion sp. & $\mathrm{x}$ & \\
\hline & Anchoa spinifer & $x$ & & & Opistognathus macrognathus & $x$ & \\
\hline & Cetengraulis edentulus & $x$ & $x$ & & Stellifer microps & $x$ & $x$ \\
\hline & Harengula jaguana & & $x$ & & Stellifer rastrifer & $x$ & $x$ \\
\hline & Lycengraulis grossidens & $x$ & $x$ & & Stellifer stellifer & $x$ & \\
\hline & Pterengraulis atherinoides & $x$ & & Scorpaenidae & Scorpaena plumieri & $x$ & $x$ \\
\hline \multirow[t]{2}{*}{ Ephippidae } & Chaetodipterus faber & $x$ & $x$ & Siluridae & Arius pasany & $x$ & $x$ \\
\hline & Chilomycterus antillarum & & $x$ & Sparidae & Archosargus rhomboidalis & $x$ & $x$ \\
\hline Gerriidae & Diapterus auratus & $x$ & & & Nicholsina usta & $x$ & \\
\hline & Diapterus rhombeus & $x$ & $x$ & Sphyraenidae & Sphyraena barracuda & & $x$ \\
\hline & Diplectrum radiale & & $x$ & & Sphyraena guachancho & $x$ & \\
\hline & Eucinostomus argenteus & $x$ & $x$ & & Sphyraena picudilla & & $x$ \\
\hline & Eucinostomus gula & $x$ & $x$ & Syngnathidae & Syngnathus caribbaeus & $x$ & \\
\hline Gobidae & Gobionelus sp. & $x$ & $x$ & Synodontidae & Synodus foetens & $x$ & $\mathrm{x}$ \\
\hline Gymnuridae & Gymnura micrura & & $x$ & Tetraodontidae & Colomesus psittacus & $x$ & $x$ \\
\hline & Gymnura sp & $x$ & & & Sphoeroides splengleri & & $x$ \\
\hline Haemulidae & Anisotremus surinamensis & $x$ & & & Sphoeroides testudineus & $x$ & $x$ \\
\hline & Anisotremus virginicus & $x$ & & Trichiuridae & Trichiurus lepturus & $\mathrm{x}$ & \\
\hline & Genyatremus luteus & $x$ & $\mathrm{x}$ & Triglidae & Prionotus punctatus & & $\mathrm{x}$ \\
\hline & Haemulon bonariense & $x$ & $x$ & & & & \\
\hline & Pomadasys crocro & $\mathrm{x}$ & & & & & \\
\hline
\end{tabular}


Un análisis gráfico de la dispersión de tallas de los peces capturados en la primera y segunda campaña de prospección reflejó que durante la primera campaña (marzo 2005), la dispersión de tallas se encontró entre 9,3 y 488,0 mm LT, con un valor promedio de 94,20 mm LT en 4.093 ejemplares; destacándose que el 80,77 \% de los mismos presentaban longitudes totales por debajo de 96,15 mm (Figura III-3 $A, B)$. En la campaña del mes de septiembre, la dispersión de tallas de los peces capturados fue similar a la de la primera; aunque en esta última campaña se capturaron 1.707 peces que midieron entre 12,0 y 433,0 $\mathrm{mm} \mathrm{LT}$, con un promedio de $106,83 \mathrm{~mm} \mathrm{LT}$ y el $70 \%$ de las especies resultando ser menores de 90,0 mm LT (Figura III-3 C,D).
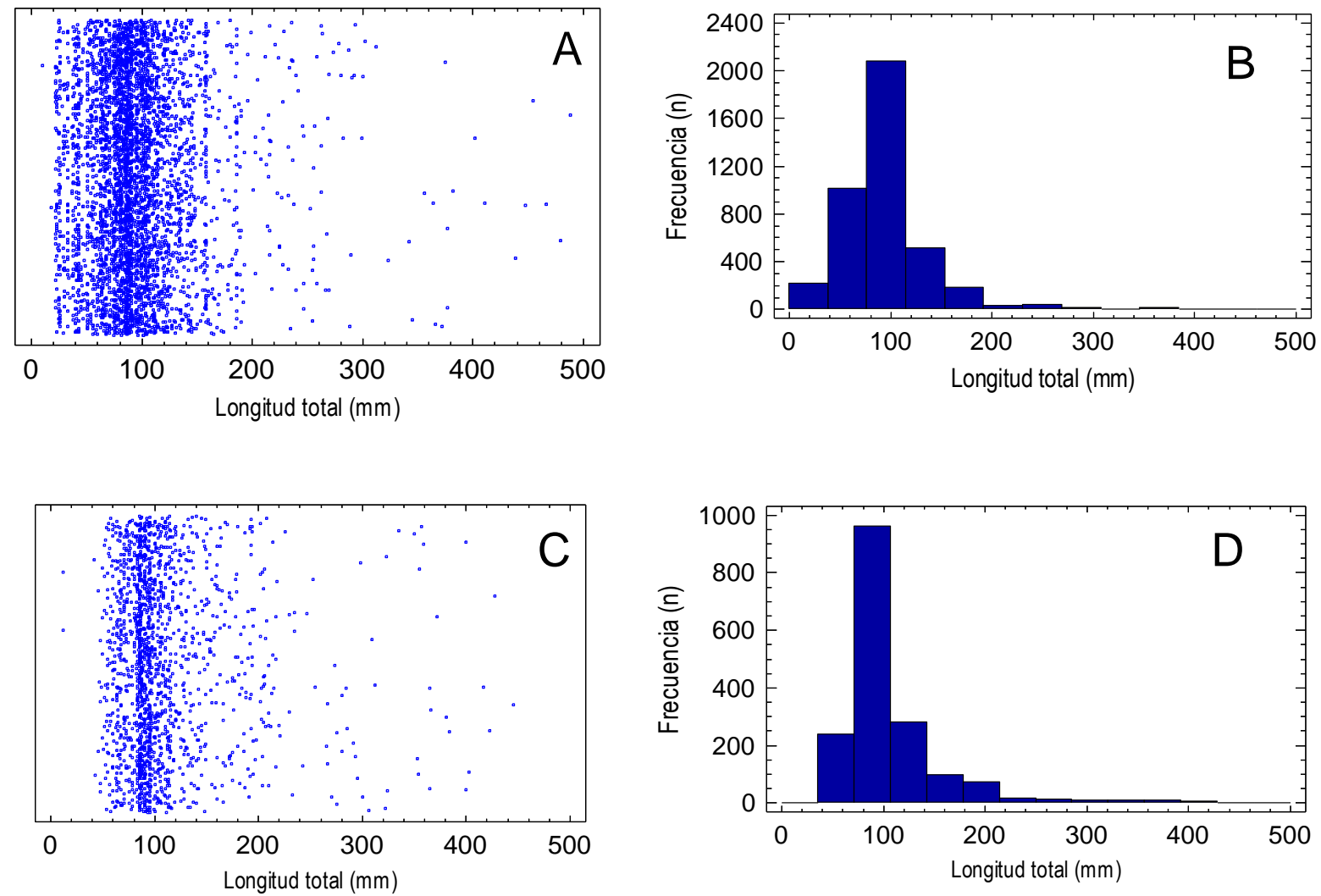

Figura III-3.- Dispersión y distribución de tallas de peces menores de $500 \mathrm{~mm}$, capturados durante la primera $(\mathbf{A}, \mathbf{B})$ y segunda $(\mathbf{C}, \mathbf{D})$ campaña en la costa norte del GP.

Al revisar la estructura de tallas de los organismos fue evidente el limitado número de ejemplares de tallas grandes. Solo once (11) individuos pertenecientes a 
las familias Batrachoididae, Trichiuridae y Dasyatidae presentaron una longitud total entre 525 y $1.512 \mathrm{~mm}$.

Estos resultados permiten inferir que la mayoría de las especies de peces presentes en la zona se encontraban en fase juvenil. La mayor parte de las especies de ésta ictiofauna juvenil, se encuentra como adultas (con algunas excepciones) en fondos arenoso-fangosos de aguas más profundas del GP y de la plataforma deltana, entre las que vale mencionar a miembros de las familias Triglidae, Gerriidae, Carangidae, Ariidae, Clupeidae, y Sciaenidae.

El taxón Crustácea representado por las familias Penaeidae, Portunidae y Majidae, estuvo fuertemente representado en las muestras. Los camarones peneidos a pesar de los bajos valores en las capturas, tienen un valor importante para un considerable número de pescadores dedicados a la extracción casi exclusiva del camarón blanco Litopenaeus schmitti, entre Irapa y Soro.

Las familias entre las que se incluyen las especies consideradas de interés comercial por los pescadores de la zona, y que son consideradas como indicadoras, representan fielmente los rubros desembarcados por las flotas artesanales e industrial de arrastre en los puertos bases de Güiria, Irapa y Yaguaraparo.

El grupo indicador de especies lo conforman nueve familias de peces que representaron el $83 \%$ de las capturas en ambas campañas, mientras las restantes especies ícticas alcanzaron un valor alrededor del 13,6\%, las cuales se agruparon en una categoría denominada "RESTO ICTICAS" para facilitar la presentación de los resultados (Tabla III-18). Entre los invertebrados comerciales, los crustáceos decápodos representaron $2,6 \%$ y 2,8\% de la composición de las capturas en marzo y septiembre, no pudiéndose apreciar una variación entre las dos campañas en este rubro. 
Tabla III-18- Rendimientos y porcentajes por familias de mayor importancia en las capturas por campaña de exploración.

\begin{tabular}{|l|cc|cc|}
\cline { 2 - 5 } \multicolumn{1}{c|}{} & \multicolumn{2}{c|}{ Campaña I } & \multicolumn{2}{c|}{ Campaña II } \\
\hline \multirow{2}{*}{ FAMILIA } & \multicolumn{2}{c|}{ CAPTURA } & \multicolumn{2}{c|}{ CAPTURA } \\
& $\mathrm{Kg}$ & $(\%)$ & $\mathrm{Kg}$ & $(\%)$ \\
\hline Dasyatidae & 19,92 & 21,46 & 14,39 & 22,39 \\
Ariidae & 15,26 & 16,44 & 11,14 & 17,34 \\
Sciaenidae & 9,94 & 10,71 & 5,22 & 8,13 \\
Tetraodontidae & 7,31 & 7,88 & 6,83 & 10,63 \\
Lutjanidae & 5,87 & 6,32 & 3,69 & 5,74 \\
Gymnuridae & 8,76 & 9,43 & 0,15 & 0,23 \\
Batrachoididae & 2,75 & 2,96 & 4,95 & 7,69 \\
Achiridae & 1,72 & 1,85 & 5,30 & 8,25 \\
Clupeidae & 5,63 & 6,07 & 1,17 & 1,81 \\
RESTO ICTICAS & 12,86 & 13,86 & 8,54 & 13,29 \\
Penaeidae & 1,45 & 1,56 & 0,25 & 0,39 \\
Portunidae & 1,32 & 1,42 & 2,57 & 4,00 \\
Majidae & 0,04 & 0,04 & 0,07 & 0,11 \\
\hline
\end{tabular}

Las diferencias en la composición de la comunidad demersal entre las camapañas de muestreo no fueron significativas, como se observa en las principales familias indicadoras: Dasyatidae, Scieanidade, Ariidae y Lutjanidae. Sin embargo, existen cambios notables entre las capturas (\%) de las dos campañas en familias como Gymnuridae, Achiridae, Clupeidae, Portunidade, y Peneidae.

\section{III.2.5 Estimaciones de biomasa}

El área barrida durante la primera y la segunda campaña de evaluación de los recursos demersales al norte del GP fue de 174.214 y $112.939 \mathrm{~m}^{2}$, respectivamente. El área total sobre la que se infieren los resultados entre las estaciones 1 y 8 corresponde a $426.640 .000 \mathrm{~m}^{2}$.

La biomasa total promedio para las estaciones fue $20.387 \mathrm{~kg} / \mathrm{km}^{2}$ en la primera campaña y de $48.063 \mathrm{~kg} / \mathrm{km}^{2}$ en la segunda campaña (Tabla III-19). Destacan durante la segunda campaña las biomasas promedios de las estaciones Los Troncones (E8), El Curí (E7), y Pto. Hierro (E3) ya que fueron las mas altas 
obtenidas en el estudio. Mientras que las biomasas menores se registraron en La Salina (E4) y Guayabero (E5) durante la primera campaña.

Tabla III-19- Biomasa total $\left(\mathrm{kg} / \mathrm{km}^{2}\right)$ estimada para cada estación al norte del GP durante las campañas de prospección pesquera.

\begin{tabular}{|c|c|c|}
\hline ESTACION & Campaña I & Campaña II \\
\hline E1 & 2.469 & 4.217 \\
E2 & 1.975 & 2.523 \\
E3 & 1.371 & 7.082 \\
E4 & 844 & 1.997 \\
E5 & 258 & 1.673 \\
E6 & 4.933 & 1.993 \\
E7 & 2.411 & 8.386 \\
E8 & 6.126 & 20.193 \\
Total & 20.387 & 48.063 \\
\hline
\end{tabular}

Estos resultados reflejan la existencia de una mayor disponibilidad de biomasa durante el segundo periodo de muestreo, incrementándose en dirección oeste a partir de la estación 6 en la primera campaña y a partir de la estación 7 en la segunda campaña. También se observa un incremento substancial de la biomasa en dirección este a partir de la estación 3. Mientras que en las estaciones intermedias (E4 y E5) las biomasas estimadas son bajas con respecto a las otras estaciones, aunque el aumento de biomasa entre campañas es notable entre estas últimas estaciones.

Las familias Dasyatidae $\left(10.761 \mathrm{~kg} / \mathrm{km}^{2}\right)$ y Ariidae $\left(8.334 \mathrm{~kg} / \mathrm{km}^{2}\right)$ mostraron los máximos valores durante la segunda campaña (Tabla III-20). Excluyendo a la familia Tetrodontidae (que no tiene mucho interés comercial), le siguen en biomasa las especies de las familias Sciaenidae (curvinas y rocadores) y Lutjanidae (pargos) con valores alrededor de 2.000-3.900 kg/km² y de $1.000-2.700 \mathrm{~kg} / \mathrm{km}^{2}$, respectivamente. 
Tabla III-20- Biomasa $\left(\mathrm{kg} / \mathrm{km}^{2}\right)$ estimada para cada grupo (familia) de importancia pesquera al norte del GP durante las campañas de prospección pesquera.

\begin{tabular}{|l|r|r|}
\hline \multicolumn{1}{|c|}{ FAMILIAS } & CAMPAÑA I & CAMPAÑA II \\
\hline Dasyatidae & 4.377 & 10.761 \\
Ariidae & 3.352 & 8.334 \\
Sciaenidae & 2.183 & 3.908 \\
Tetraodontidae & 1.607 & 5.109 \\
Lutjanidae & 1.290 & 2.759 \\
Gymnuridae & 1.924 & 111 \\
Batrachoididae & 604 & 3.696 \\
Achiridae & 377 & 3.965 \\
Clupeidae & 1.237 & 870 \\
RESTO ICTICAS & 2.826 & 6.388 \\
Penaeidae & 317 & 187 \\
Portunidae & 284 & 1.923 \\
Majidae & 8 & 53 \\
TOTAL & 20.387 & 48.063 \\
\hline
\end{tabular}

En el caso de los camarones peneidos fue notoria la disminución de la biomasa entre campañas, pasando de $317 \mathrm{~kg} / \mathrm{km}^{2}$ en marzo a $187 \mathrm{~kg} / \mathrm{km}^{2}$ en septiembre (Tabla III-20). Un comportamiento inverso fue observado en la biomasa de los cangrejos portúnidos, grupo en el cual se registró el máximo valor de biomasa para crustáceos, alcanzando $1.923 \mathrm{~kg} / \mathrm{km}^{2}$ en septiembre. Ambas familias de crustáceos se distribuyeron a lo largo del lado oeste de Güiria.

Los cambios espaciales en las biomasas estimadas por estación y por campaña responden a las características de medio ambiente y a la historia de vida de cada especie encontrada. A partir de los resultados de las estimaciones de biomasa por estación podemos inferir que el área se podría clasificar en tres zonas que se agruparían en función de los valores promedios que presentaron las menores diferencias significativas según la prueba estadística LSD (menor diferencia significativa), de allí que una zona estaría conformada por las estaciones que corresponden a las localidades de Los Troncones y El Curí (Zona A), otra zona estaría conformada por las estaciones desde el extremo occidental de La Salina hasta el final oriental de la Ensenada de Guayabero (Zona C), y la última zona, la 
comprenderían una estación intermedia a las dos anteriores y las del extremo oriental (Zona B).

Las estaciones de los Troncones y El Curí (Zona A) (Figuras III-4y5), exhibieron consistentemente la mayor disponibilidad de recursos durante el estudio y similitud en las condiciones de sustrato, profundidad, temperatura y oxigeno disuelto; solo una marcada diferencia en la salinidad fue ya mencionada. La proximidad geográfica de las localidades pudiera contribuir también a explicar la homogeneidad establecida. La biomasa estimada para esa zona fue estimada en $9.279 \mathrm{~kg} / \mathrm{km}^{2}$. 


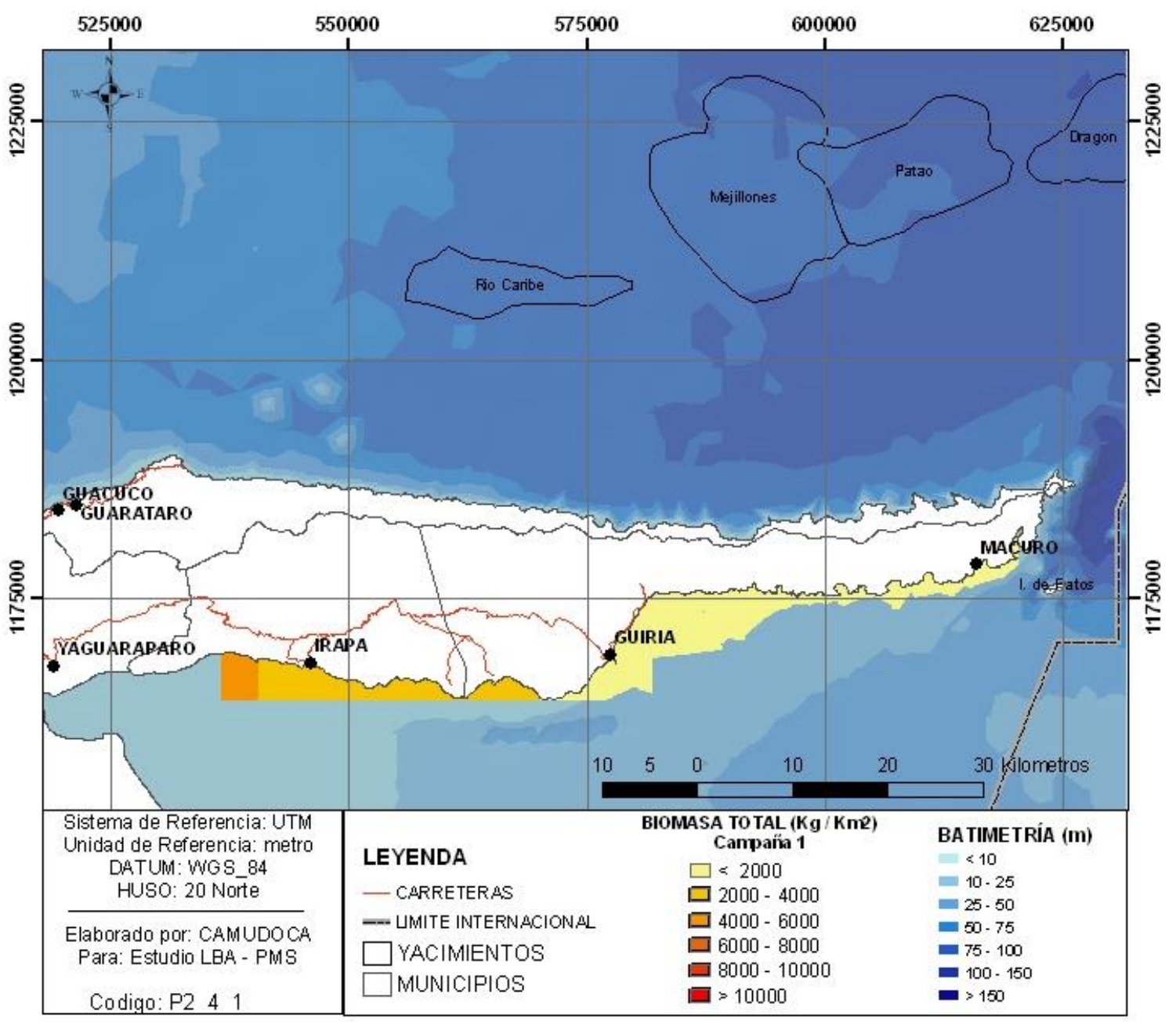

Figura III-4.- Distribución de la biomasa total $\left(\mathrm{kg} / \mathrm{km}^{2}\right)$ en el estrato costero (0-15 m) al norte del GP en marzo 2005. 


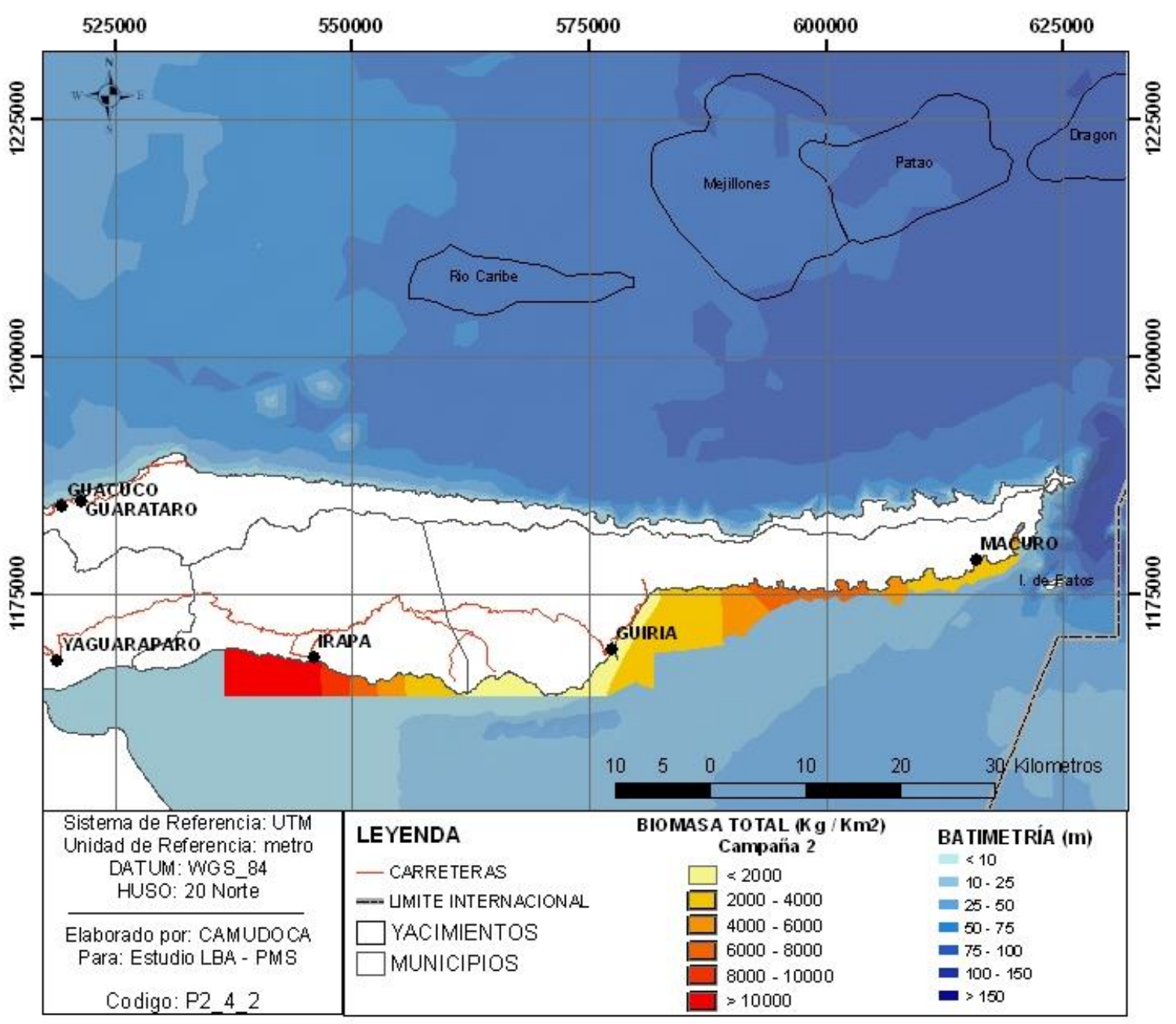

Figura III-5.- Distribución de la biomasa total $\left(\mathrm{kg} / \mathrm{km}^{2}\right)$ en el estrato costero (0-15 m) al norte del GP en septiembre 2005.

Las estaciones desde el extremo occidental de La Salina hasta el final oriental de la Ensenada de Guayabero (Zona C) presentan el estimado más bajo de biomasa de demersales $\left(1.193 \mathrm{~kg} / \mathrm{km}^{2}\right)$ disponible en el área, localizándose esta zona en ambos lados de la ciudad de Güiria (Figuras III-4 y 5). Las condiciones ambientales naturales son de fondos de sustrato arenosos, mediana profundidad y masas agua de tipo marino. 
La Zona B, está subdividida en dos zonas discontinuas. La primera localizada entre la Ensenada de Cariaquito hasta Puerto de Hierro, y la segunda la conforman los alrededores de la localidad de Soro. Esta Zona se caracteriza por presentar niveles de biomasa intermedios $\left(3.320 \mathrm{~kg} / \mathrm{km}^{2}\right)$ y una mayor área de superficie (Figuras III-4 y 5). Es particularmente común en esta Zona la presencia de sustratos fango-arenosos y profundidades superiores a $10 \mathrm{~m}$ próximas a la línea de costa.

La biomasa total estimada de recursos demersales en la zona sublitoral menor de $15 \mathrm{~m}$ fue de 8.697 TM en marzo y 20.505 TM en septiembre. Esta variabilidad temporal en la biomasa depende de los cambios en las condiciones abióticas y bióticas que actúan sobre el comportamiento de las especies y sobre los cambios en la historia de vida de algunas especies.

\section{III.2.6 Análisis de las Estimaciones de Biomasa por Área Barrida en el norte del GP}

Este es el primer estudio realizado en Venezuela utilizando el método de área barrida para estimaciones de biomasa en el GP. Las estimaciones de biomasa por área barrida realizadas en Venezuela cuando fueron evaluados los recursos pesqueros de la plataforma venezolana con el buque Fridtjof Nansen (IMR,1989) no incluyeron el Golfo de Paria. Además, es preciso señalar que las estimaciones obtenidas en el presente estudio solo pueden ser extrapoladas desde la costa hasta una profundidad de $15 \mathrm{~m}$, ya que la mayoría de los arrastres se realizaron hasta los $10 \mathrm{~m}$ de profundidad, por lo que extrapolaciones por debajo de los $15 \mathrm{~m}$ estarían sensiblemente sesgadas.

El estudio evidencia que la biomasa encontrada en ambas campañas está conformada por especies juveniles que habitan el estrato costero durante esta etapa de su vida y de especies que son comunes en el estrato costero del GP que suelen ser de talla pequeña. Ello se refleja en la dispersión de tallas encontradas en ambas campañas. Este resultado era de esperarse ya que el GP se puede considerar como un ecosistema estuarino, aunque con características particulares, y en los ecosistemas estuarinos es común que especies tanto marinas como del mismo sistema estuarino utilicen las zonas menos profundas para la cría de juveniles 
(Blaber, 2000). Las especies de mayor peso encontradas y con la mayor biomasa son las que habitan este tipo de ecosistema, como fue el caso de las especies de las familias Dasyatidae (chuchos) y Ariidae (bagres).

Los cambios en las condiciones de las masas de agua asociados a las épocas seca y lluviosa condiciona la distribución y disponibilidad de especies dentro de los ambientes estuarinos (Yánez-Arancibia et al.,1994). La mayor biomasa estimada fue en el mes de septiembre, durante la segunda campaña y alcanzó $48.023 \mathrm{~kg} / \mathrm{km}^{2}$, en contraste con la campaña de marzo cuando solo se estimó alrededor de 20.000 $\mathrm{kg} / \mathrm{km}^{2}$. Este contraste ocurre en sistemas estuarinos entre la temporada lluviosa (elevada biomasa) y seca (baja biomasa). En el periodo de lluvias, las influencias de origen terrestre son importantes, como es el caso de grandes aportes de agua dulce, nutrientes y sedimentos que se producen en el área estuarina. Esto afecta directamente la productividad del área generando cambios en la disponibilidad de alimento. En septiembre (segunda campaña) hubo una caída significativa en la salinidad promedio pasando de 27 a 19 psu, lo cual refleja las condiciones de un incremento de agua dulce seguramente ocasionado las lluvias.

La biomasa de todo el Golfo de Paria (Venezuela+Trinidad) fue estimada en $8,89 \mathrm{TM} / \mathrm{km}^{2}$ utilizando un modelo de dinámica trófica (Manickhand-Heileman et al., 2004). Sin embargo este modelo basó sus estimados en las capturas de las pesquerías de arrastre de ambos países, sin considerar las capturas de las pesquerías artesanales de la zona, las cuales son elevadas. En consecuencia, los resultados de biomasa se basan en la captura de individuos adultos principalmente. Los resultados obtenidos en las estimaciones realizadas en este estudio no son nada despreciables, y nos pueden dar indicación de una sub-estimación para las estimaciones previamente realizadas en el GP. Sin embargo, en evaluaciones poblacionales de recursos demersales se ha podido comprobar la existencia de mucha variabilidad de la biomasa de acuerdo al hábitat de los organismos. Por ejemplo, Cady y Sharp (1988) consideraron como bajos valores de biomasa el rango entre $0,4-0,5 \mathrm{TM} / \mathrm{km}^{2}$, obtenidos en las plataformas de muchas islas del Caribe; por otra parte, exponen que un alto valor de densidad, como $18 \mathrm{TM} / \mathrm{km}^{2}$, se ha obtenido 
en nichos particulares del Océano Indico hacia el lado del Pacífico. Las estimaciones de biomasa por el método de área barrida con valores entre 8.700 y 20.500 TM permiten tener un estimado de referencia para la zona somera del norte del Golfo de Paria, compuesta principalmente por curvinas y roncadores (Sciaenidae), bagres (Ariidae), y pargos (Lutjanidae) en fase juvenil, que reclutan posteriormente a las aguas interiores del Golfo de Paria y margen costero del delta del Orinoco donde son capturados como adultos por las pesquerías de la región. La biomasa estimada de los recursos demersales del estrato costero del GP resultó en valores relativamente altos, de aquí se puede inferir que el Golfo de Paria tiene una importancia ecológica y pesquera que demanda un monitoreo periódico y continuo en el tiempo.

\section{III.2.7 Conclusiones}

- Las especies capturadas fueron juveniles de peces, representando más del 80 $\%$ de las muestras y con tallas inferiores a $110 \mathrm{~mm}$ de longitud total.

- Las familias de mayor importancia pesquera fueron: Dasyatidae (chuchos), Ariidae (bagres), Sciaenidae (curvinas y roncadores) y Lutjanidae (pargos).

- La biomasa durante el mes de marzo fue de 20.387 y durante el mes de septiembre de $48.063 \mathrm{~kg} / \mathrm{km}^{2}$.

- La biomasa total para el estrato costero hasta los $15 \mathrm{~m}$ de profundidad fue de 8.700 TM en la primera campaña (marzo) y de 20.500 TM en la segunda campaña (septiembre).

- Se observó una variabilidad en la distribución espacial y temporal de las biomasas durante la investigación atribuible a factores medio ambientales, principalmente la salinidad.

\section{III.3 Estructura Demográfica de los Grupos de Especies Relevantes a la Pesca al Norte del GP}

\section{III.3.1 Peces}

Entre las regiones pesqueras más importantes del país está el GP y el Delta del Orinoco, ambas conforman una unidad geográfica con características particulares 
cada una de ellas y han sido abordadas de manera diferente en lo que se refiere a su estudio científico, particularmente en los peces. Se han realizados importantes trabajos en la zona del Delta donde se reportan unas 190 especies de peces pero la cuenca del GP, particularmente en la zona norte, los estudios referidos a los peces son prácticamente inexistente (PDVSA-GAS 2003). La información que se ha producido sobre los peces en la cuenca del GP proviene de los informes elaborados por el INIA, relativos a la pesca artesanal e industrial que se desarrolla en la zona (Ecology and Environment, 2003). Por otra parte, el conocimiento de la fauna y flora de la parte norte del GP, incluyendo el Parque Nacional Turuépano, es muy restringida y en relación a algunos grupos de vertebrados es inexistente. En este apartado se analiza la estructura demográfica en los diferentes grupos de especies por estrato geográfico con particular énfasis en las especies que representan la fuente de la actividad pesquera más importante de la región al norte del GP.

El área de estudio corresponde al norte del GP, incluyendo el estrato hasta $10 \mathrm{~m}$, tal como está definido en las estimaciones de biomasa por área barrida en la zona. En la zona se distinguen claramente dos regiones: al oeste de Güiria, donde predominan las playas arenosas, bordeadas de manglares grandes, con fondos blandos y fangosos, con aguas turbias y salobres; mientras que al este de Güiria es frecuente la presencia de acantilados rocosos, aunque también hay manglares, pero los fondos son arenosos y rocosos; las aguas son mas claras y la salinidad alcanza las 30 psu.

Se realizaron dos campañas de capturas, una en marzo de 2005 y la otra en septiembre del mismo año. Cada campaña abarcó las mismas ocho (8) estaciones, con la estación uno (E1) ubicada en el área más oriental de la costa y la ocho (E8) en la más occidental. Además, durante la segunda campaña se realizaron censos visuales y lances con 'chinchorro playero' en localidades preseleccionadas. El muestreo se estableció por estratos, seleccionando dos por estación, uno hasta $3 \mathrm{~m}$ y el otro a $5 \mathrm{~m}$ de profundidad (ver Sección III-2). Los ejemplares de cada captura (lance y estrato) fueron pesados y colocados en bolsas plásticas debidamente etiquetadas, luego fueron preservados en cavas con hielo hasta su llegada al Instituto Oceanográfico de Venezuela en Cumaná. En el laboratorio se identificaron 
las especies siguiendo las claves de Cervigón $(1991,1993,1994,1996)$ y la de Cervigón y Alcalá (1999), se les midió la longitud total (LT) y estándar (L.est.) con un ictiómetro de $1 \mathrm{~mm}$ de apreciación y finalmente fueron pesados en una balanza de 0,1 g de apreciación, utilizandose en caso de ejemplares de gran tamaño una balanza comercial de $1 \mathrm{~g}$ de apreciación. En un análisis preliminar se determinó que no hubo diferencias significativas entre estratos y lances, por lo que las muestras se agruparon por estación.

\section{III.3.1.1 RIQUEZA DE ESPECIES Y ABUNDANCIA}

En la primera campaña (marzo 2005), se recolectó un total de 4.233 organismos con un peso de 66.957,30 g, en su mayoría juveniles. Se identificaron 77 especies de teleósteos distribuidas en 27 familias y 5 de elasmobranquios distribuidas en 3 familias, las cuales en su conjunto están agrupadas en un total de 12 órdenes. El orden Peciformes estuvo representado por el mayor número de especies (47), seguido por Clupeiformes (9) y Siluriformes (6); Los órdenes restantes tuvieron cuatro o menos especies (Figura III-6). Las familias más diversas fueron Scianidae (20 especies), Carangidae (7 especies), Engraulidae y Ariidae (6 especies cada una); el resto de las familias contaron 4 o menos especies (Figura III-7). Diez especies representaron el $86,1 \%$ del total de peces capturados, siendo los más abundantes, Cathorops spixii (38,89\%), Pellona harroweri (16,29\%), Stellifer rastrifer $(9,90 \%)$, Bagre bagre $(5,42 \%)$, Diapterus rhombeus $(5,25 \%)$, Odontognathus mucronatus $(4,03 \%)$, Lutjanus synagris (2,92\%), Selene vomer (1,91\%), Eucinostomus gula $(1,84 \%)$ y Colomesus psittacus (1,39\%) (Figura III-8).

En la segunda campaña (septiembre 2005), se colectó un total de 1.890 organismos con un peso de 66.032,53 g. Se identificaron 79 especies de teleósteos distribuidas en 30 familias y 2 de elasmobranquios en 2 familias, agrupadas en un total de 11 órdenes. El orden Perciformes estuvo representado por el mayor número de especies (44), seguido por Clupeiformes (10) y Siluriformes (6) (Figura III-6); Los 
órdenes restantes tuvieron cuatro o menos especies. Las familias más diversas fueron Scianidae (15 especies), Carangidae (9 especies), Clupeidae y Ariidae (6 especies cada una); el resto de las familias tuvieron 4 o menos especies (Figura III7). Las especies más abundantes en el total de los muestreos fueron Cathorox spixii $(32,75 \%)$, Diapterus rombeus $(8,20 \%)$, Stellifer rastrifer $(6,19 \%)$ Sardinilla aurita $(6,08 \%)$ y Hexanematichthys herzbergii (5,03\%), Sphoeroides testudineus (3,60\%), Achirus lineatus (3,55\%), Pellona harroweri $(2,74 \%)$, Colomesus psittacus $(2,33 \%)$ y Lutjanus synagris (1,87\%)(Figura III-8).
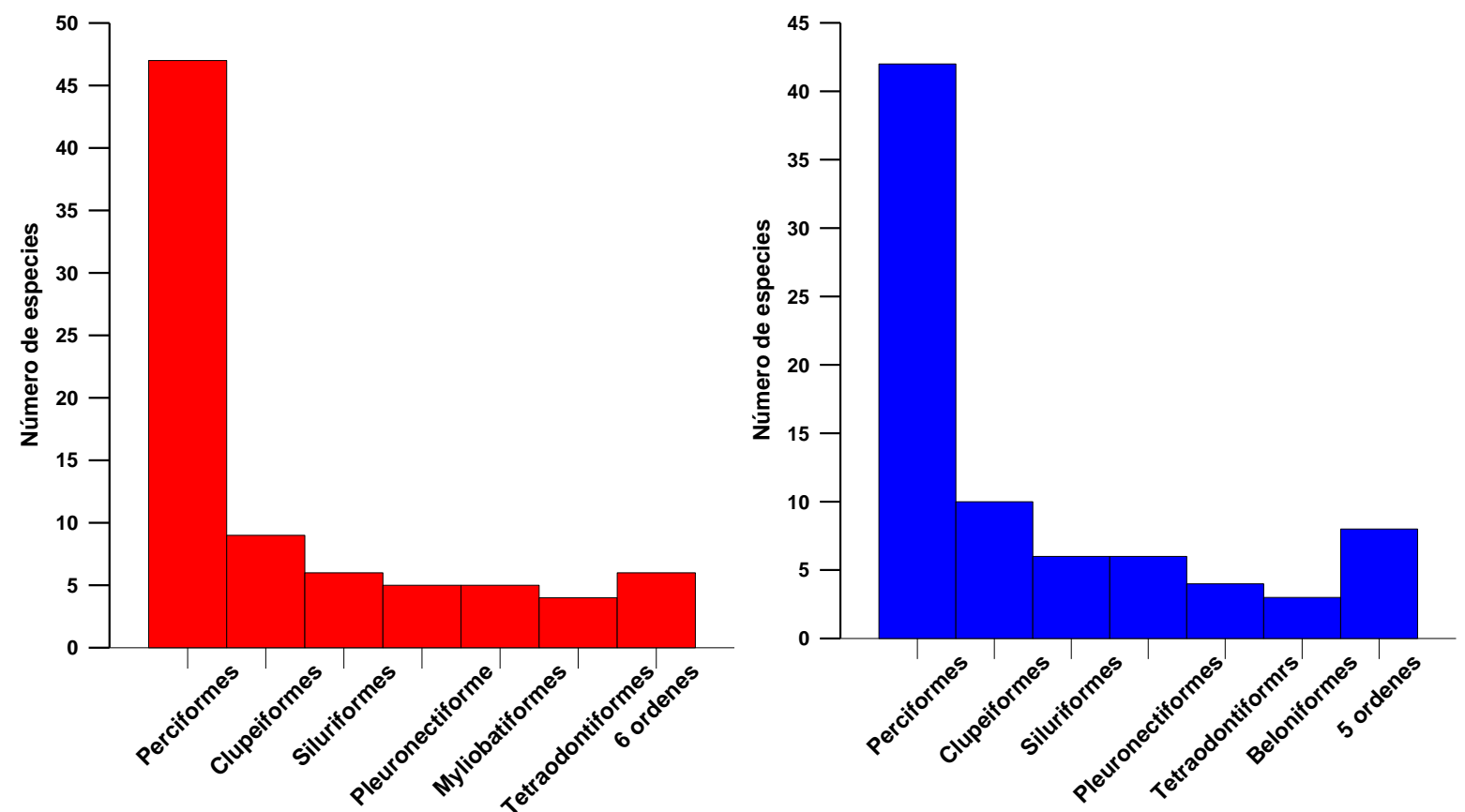

Figura III-6.-.- Número de especies por Orden capturadas con red de arrastre artesanal tipo 'Chica' en las campañas de área barrido al norte del GP: Marzo 2005 (rojo), Septiembre 2005 (azul). 

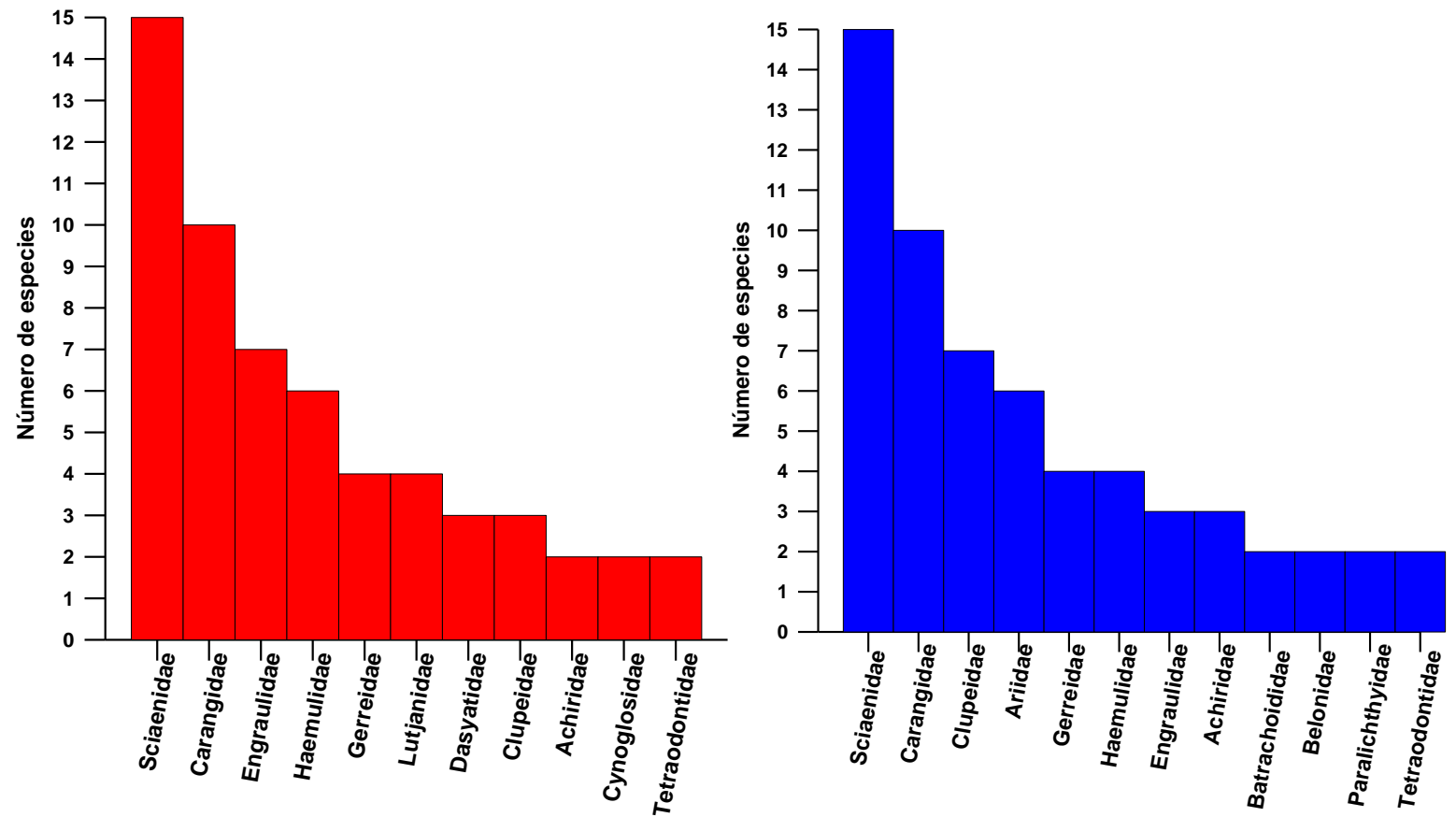

Figura III-7.- Número de especies por familia capturada con red de arrastre artesanal tipo 'Chica' en las campañas de área barrido al norte del GP: Marzo 2005 (rojo), Septiembre 2005 (azul).

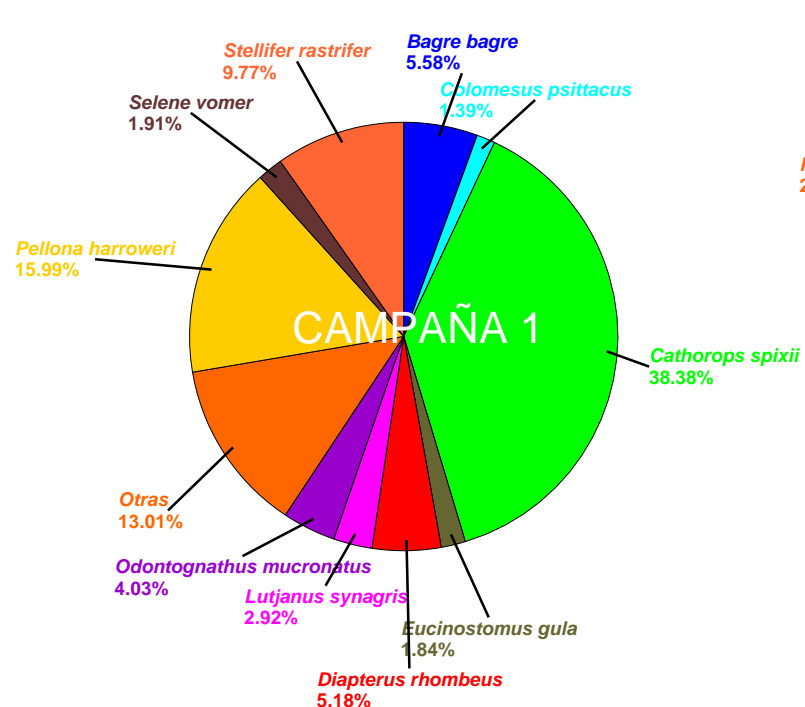

$5.18 \%$

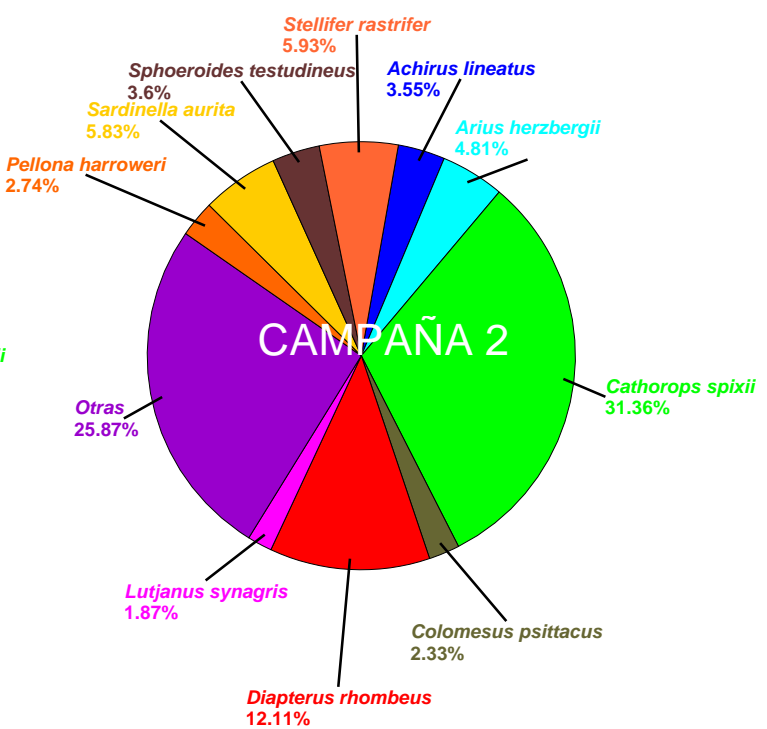

$12.11 \%$

Figura III-8.- Distribución porcentual de las especies más abundantes capturadas mediante red de arrastre artesanal tipo 'Chica' en las campañas de área barrido al norte del GP.

\section{III.3.1.2 ABUNDANCIA POR ESTACIONES}

En la campaña de marzo 2005, de las ocho estaciones muestreadas en la costa norte del GP, en la estación de la zona de Macuro (E2) no se capturaron peces, 
debido a que el sustrato era rocoso e impedía el manejo de la red utilizada. Sin embargo, en la segunda campaña (septiembre 2005) pudieron capturarse ejemplares en esa estación (Macuro). Por las razones indicadas, en las estaciones ubicadas en la región occidental el número de especies y organismos fue menor que en las estaciones de la región oriental (Figura III-9).
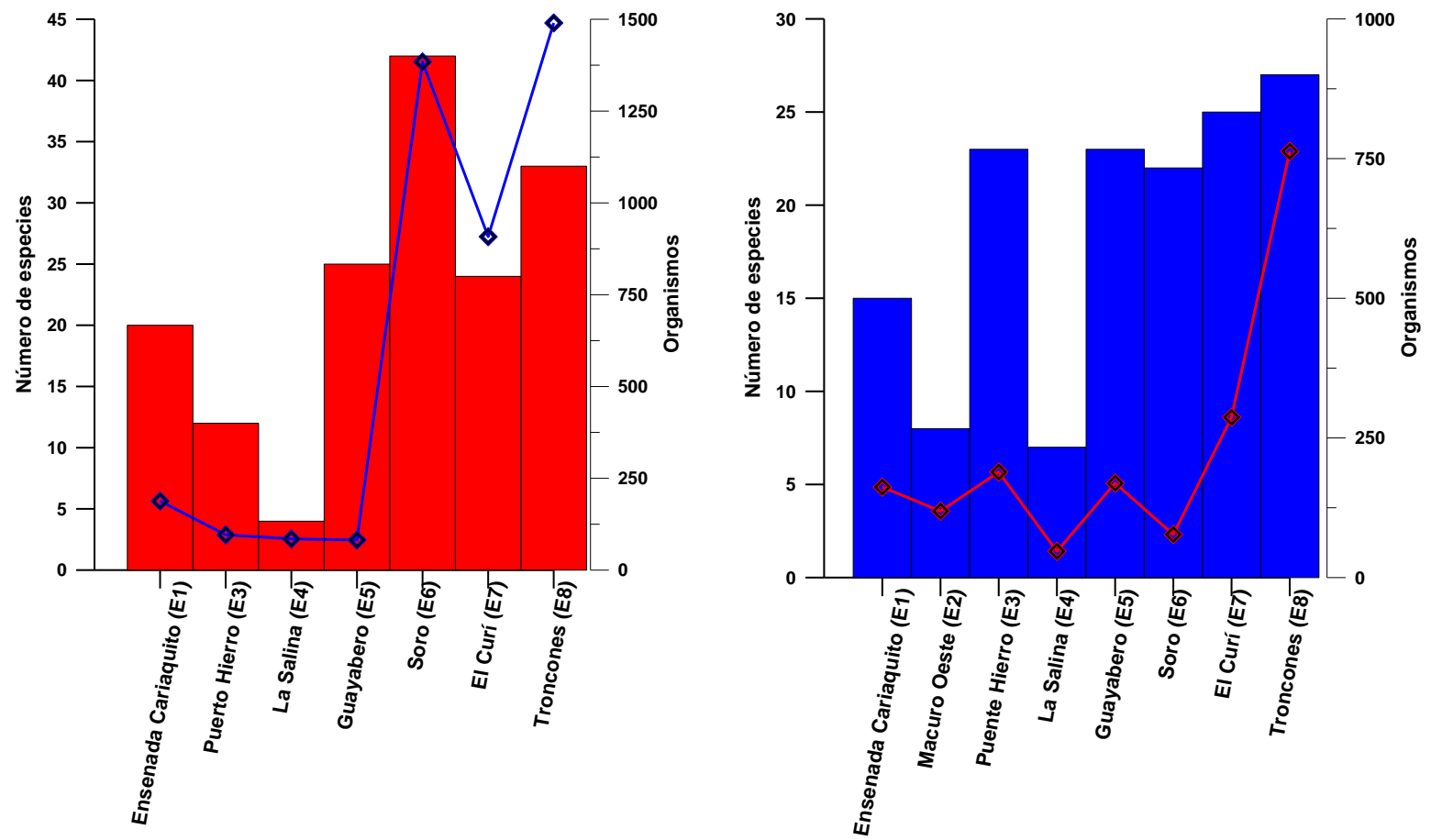

Figura III-9.-Número de especies de peces y organismos por localidad recolectadas al norte del GP durante las campañas de área barrido: Marzo 2005 (barras rojas), Septiembre 2005 (barras azules).

La lista de especies y número de organismos registrados por estación, durante las campañas de marzo y septiembre de 2005 se presentan en el Apéndice I. En el Apéndice II, se presenta el orden taxonómico y los nombre comunes de las especies muestreadas en el área de estudio del PMS.

Estación 1.- Ensenada Cariaquito

En la primera campaña, se capturaron 188 organismos con un peso de 8174,9 g e identificaron 20 especies de 13 familias. Seis especies representaron el 90,96\%, 
siendo las más abundantes Diapterus rhombeus (51,60 \%) y Lutjanus synagris $(25,53 \%)$. Las familias con mayor número de especies fueron Gerreidae, Haemulidae y Sciaenidae con 3 especies y Lutjanidae con 2. Once especies estuvieron representadas por un solo individuo.

En la segunda campaña, se capturaron 162 organismos con un peso de $11.172,54 \mathrm{~g}$ e identificaron 15 especies de 13 familias. Seis especies representaron el 88,90\% de las capturas, siendo las más abundantes Achirus lineatus $(37,04)$, Diapterus rhombeus $(29,01 \%)$ y Syacium papillosum $(29,01 \%)$. Con relación al peso se destacó la presencia de tres ejemplares de Dasyatis guttata $(2.426,95 \mathrm{~g})$. La familia con mayor número de especies fue Sciaenidae con tres especies. Tres especies estuvieron representadas por un solo individuo.

\section{Estación 2.- Macuro.}

Se realizaron los lances respectivos pero no hubo captura en razón de lo pedregoso del fondo que impidió el arrastre del arte. Sin embargo, en la segunda campaña se muestreó al oeste de Macuro y se capturaron 119 organismos, representados por 8 especies, pertenecientes a dos familias, Scianidae con cinco y Batrachoididae con una. Tres especies representaron el 95,80 5 de las capturas, siendo las más abundantes Stellifer rastrifer $(77,31 \%)$ y Bairdiella sanctaeluciae $(12,61 \%)$. Cinco especies estuvieron representadas por un solo organismo.

\section{Estación 3.- Puerto Hierro}

En esta estación para el muetreo de marzo, se capturaron 100 organismos destacándose la presencia de 3 ejemplares del orden Myliobatiformes (Rayas) de gran tamaño y peso (Rhinoptera bonasus, Himantura smardae y Dasyatis guttata). Se identificaron 15 especies de 10 familias. Seis especies representaron el 92,73\% del total de la captura, siendo los más abundantes Lutjanus synagris $(66,67 \%)$ y el sciánido Larimus breviceps (9,38 \%). Ocho especies estuvieron representadas por un individuo. Para el muestreo de septiembre se capturaron 189 organismos 
destacándole la presencia de 3 ejemplares de Dasyatis guttata con un peso de $4.554,75 \mathrm{~g}$. Se identificaron 23 especies de 14 familias, las mejores representadas en relación al número de especies fueron Gerreidae (4), Lutjanidae, Scianidae y Carangidae (con tres especies cada una). Seis especies representaron el 87,83\% del total de la captura, siendo los más abundantes Diapterus rhombeus (45,50\%), Harengula jaguana $(14,29 \%)$ y Lutjanus synagris $(12,17 \%)$. Catorce especies estuvieron representadas por un individuo.

\section{Estación 4.- La Salina}

En la primera campaña de esta estación se capturaron 85 organismos de solo 4 especies, 3 de la familia Gerreidae y una de Lutjanidae; las más abundantes fueron Eucinostomus gula que representó el $72,12 \%$ de la abundancia y Lutjanus synagris el 11,76\%. En el segundo muestreo se capturaron organismos 47, organismos siete especies de cinco familias, siendo las más representativas Gerreidae y Lutjanidae con dos especies cada una. Las especies más abundantes fueron Eucinostomus argenteus, E. gula, Lutjanus synagris y Selene vomer, que sumaron un $89,36 \%$ de la abundancia.

\section{Estación 5.- Guayabero}

En marzo 2005 se identificaron 25 especies de 13 familias. El clupéido Anchoa hepsetus fue la especie más abundante y representó el 28,05 \% de la captura. La familia mejor representada, en relación al número de especies, fue Sciaenidae (7 especies) seguida de Engraulidae (3), Clupeidae y Carangidae (2 especies cada una). En septiembre se identificaron 23 especies de 17 familias. El clupéido Sardinella aurita fue la especie más abundante y representó el 50,30 \% del total de la captura. Las familias mejores representadas, en relación al número de especies, fue Sciaenidae (4 especies) seguida de Gerreidae y Lutjanidae (2 especies cada una). 


\section{Estación 6.- Soro}

En esta estación, en la primera campaña, se identificó el mayor número de especies (42) y de familias (17). Ocho especies representaron el $91,26 \%$ de la captura total, siendo las mas abundantes el bagre Cathorops spixii (44,44\%), el sciánido Stellifer rastrifer (20,99\%), el clupéido Pellona harroweri (12,86\%) y el gérrido Diapterus rhombeus $(8,24 \%)$. Las familias mejor representadas fueron Sciaenidae (13 especies), Ariidae (5 especies) y Carangidae (4 especies). En la segunda campaña se identificaron 22 especies pertenecientes a 13 familias. Catorce especies representaron el 89,63\% de las capturas, siendo las más abundantes el tamboril Sphoeroides testudineus (38,96\%), el gérrido Diapterus rhombeus $(9,09 \%)$, el sciánido Micropogonias furnieri (9,09\%) y el haemúlido Genyatremus luteus (6,49 $\%)$. Las familias mejores representadas, con relación al número de especies fueron Carngidae (4), Engrauludae (3), Tetraodontidae, Gerreidae, Sciaenidae y Ariidae (2 especies cada una).

\section{Estación 7.- El Curí}

En la primera campaña de muestreo se identificaron 24 especies de 9 familias. Siete especies representaron el 94,38 \% de las capturas, siendo las más abundantes Pellona harroweri (54,63\%), Cathorops spixii (17,40\%), Odontognathus mucronatus $(11,56 \%)$ y Selene vomer $(4,52 \%)$. Las familias mejor representadas fueron Sciaenidae (6 especies), Ariidae (4), Carangidae (4) y Engraulidae (3). Para el segundo muestreo (septiembre 2005) Se identificaron 24 especies de 12 familias. Siete especies representaron el $89,77 \%$ de las capturas, siendo las más abundantes Cathorops spixii (47,18\%), Pellona harroweri (19,01\%), Hexanematichthys passany $(9,86 \%)$ y Sphoeroides testudineus $(5,63 \%$.). Las familias mejores representadas fueron Ariidae y Carangidae (4) y Engraulidae (3).

Estación 8.- Los Troncones 
Esta fue la segunda estación con mayor número de especies (33) de 14 familias, en el primer período. Siete especies representaron el 91,34\% de las capturas, siendo las de mayor abundancia relativa Cathorops spixii $(57,38)$, Bagre bagre $(14,23 \%)$, Stellifer rastrifer (6,44\%), Odontognathus mucronatus (3,86\%) y Bagre marinus $(3,29 \%)$. Las familias mejor representadas fueron Scieanidae (10 especies), Ariidae (6) y Engraulidae (4). En el segundo período, igualmente, fue la estación donde se identificó el mayor número de especies (27) de 11 familias. Ocho especies representaron el 90,82 \% de las capturas, siendo las de mayor abundancia relativa Cathorops spixii (63,56 \%), Hexanematichthys herzbergii (10,09\%), Colomesus psittacus (5,90\%), Stellifer rastrifer (3,28\%) y Odontognathus mucronatus $(2,88 \%)$. Las familias mejor representadas fueron Scieanidae (8 especies), Ariidae (5) y Engraulidae (3).

\section{III.3.1.3 ESPECIES REGISTRADAS CON TREN DE ARRASTRE PLAYERO}

Los resultados de los muestreos cercanos a la costa con un tren de arrastre playero, realizados solamente en el segundo período, fueron los siguientes:

En Playa Dorada, cerca de Guayabero, se colectaron 30 organismos e identificaron 14 especies de 10 familias (Tabla III-21). Siete especies representaron el 76,60\% del total de la captura, siendo las más abundantes Sphoeroides testudineus $(23,33 \%)$, Atherinella brasiliensis (13,33\%), Hyporhamphus unifasciatus (10,00\%) y Anchoa hepsetus (10.00\%). 
Tabla III-21- Especies de peces, número de individuos (№ ind.), porcentaje relativo (\%), peso y porcentaje relativo, recolectados en Playa Dorada, costa norte del GP.

\begin{tabular}{|l|c|c|}
\hline \multicolumn{1}{|c|}{ Especies } & № & $\%$ \\
\hline Sphoeroides testudineus & 7 & 23,3 \\
Atherinella brasiliensis & 4 & 13,3 \\
Hyporhamphus unifasciatus & 3 & 10 \\
Anchoa hepsetus & 3 & 10 \\
Oligoplites palometa & 2 & 6,67 \\
Lycengraulis grossidens & 2 & 6,67 \\
Eucinostomus melanopterus & 2 & 6,67 \\
Strongylura marina & 1 & 3,33 \\
Prionotus Punctatus & 1 & 3,33 \\
Pomadasys croco & 1 & 3,33 \\
Eucinostomus gula & 1 & 3,33 \\
Oligoplites saurus & 1 & 3,33 \\
Harengula clupeola & 1 & 3,33 \\
Sardinella aurita & 1 & 3,33 \\
\hline Total especies $=14$ & $\mathbf{3 0}$ \\
\hline
\end{tabular}

Las Garzas, en el extremo occidental de la península, antes de Cariaquito, (Tabla III22). Se colectaron 50 organismos e identificaron ocho especies; siendo las más abundante Sardinella aurita con $58,00 \%$ de la captura y Trachinotus goodei $14,00 \%$.

Tabla III-22- Especies de peces, número de individuos (№ ind.), porcentaje relativo (\%), peso y porcentaje relativo, recolectados en Las Garzas, costa norte del GP.

\begin{tabular}{|l|c|c|}
\hline \multicolumn{1}{|c|}{ Especies } & № & $\%$ \\
\hline Sardinella aurita & 29 & 58 \\
Trachinotus goodei & 7 & 14 \\
Harengula jaguana & 4 & 8 \\
Opistonema oglinum & 4 & 8 \\
Tylosurus crocodilus & 2 & 4 \\
Trachinotus falcatus & 2 & 4 \\
Conodon novilis & 1 & 2 \\
Umbrina coroides & 1 & 2 \\
\hline Total especies $=8$ & $\mathbf{5 0}$ \\
\hline
\end{tabular}




\section{III.3.1.4 ESPECIES REGISTRADAS CON CENSOS VISUALES.}

En la campaña del mes de septiembre 2005 se realizaron censos visuales, mediante nado libre con una hora de duración, en fondos rocosos en la línea de costa y pequeños parques de Thalassia, y algas, donde las condiciones de claridad del agua lo permitían, en las estaciones E1, E2, E3 y E4. Se visualizó un total de 456 organismos correspondientes a 31 especies, de las cuales 21 no habían sido registradas en los muestreos realizados con la red de arrastre tipo "CHICA", ni con el chinchorro playero (Tabla III-23).

Cariaquito (E1).- Se observaron 174 organismos de 17 especies, pertenecientes a 11 familias. Ocho especies representaron el 91,37\%, siendo las más abundantes Halichoeres bivittatus (24,14\%), Haemulon aurolineatum (12,64\%), Lutjanus jocus (12,07\%), Lutjanus griseus $(11,49 \%)$ y Abudefduf saxsatilis $(11,49 \%)$. Las familias con mayor número de especies fueron Haemulidae, Lutjanidae y Pomacanthidae con tres especies cada una.

Macuro oeste (E2).- Se observó un total de 81 organismos de ocho especies, pertenecientes a cinco familias, de las cuales Lutjanidae, Pomacentridae y Haemulidae estuvieron representadas por dos especies cada una. Las especies más abundantes fueron Halichoeres bivittatus (32,10\%), Lutjanus griseus $(24,69 \%)$ y Abudefduf saxsatilis (24,69\%). 
Tabla III-23- Lista de familias y número de especies observadas (censos visuales) en la costa norte del GP durante la segunda campaña. Asteriscos refieren a especies no capturadas en los muestreos.

\begin{tabular}{|c|c|c|c|c|}
\hline Especies & E1 & E2 & E3 & E4 \\
\hline Abudefduf saxatilis* & 12 & 8 & 2 & 6 \\
\hline Abudefduf taurus* & 20 & 20 & 4 & 6 \\
\hline Acanthurus bahianus* & 2 & - & - & - \\
\hline Anisotremus surinamensis & 9 & 2 & 11 & - \\
\hline Anisotremus virginicus & - & - & 1 & - \\
\hline Archosargus rhomboidalis & - & - & 10 & - \\
\hline Caranx latus* & 1 & - & - & - \\
\hline Centropomus undecimalis & - & - & 4 & - \\
\hline Chaetodipterus faber & 1 & - & 20 & - \\
\hline Diodon histrix ${ }^{*}$ & 1 & - & 1 & 1 \\
\hline Diplodus argenteus* & - & - & 2 & - \\
\hline Eucinostomus melanopterus & 1 & - & - & - \\
\hline Gerres cinereus* & - & - & 1 & - \\
\hline Haemulon aurolineatum* & 42 & - & 7 & - \\
\hline Haemulon bonariense & 2 & - & 32 & - \\
\hline Haemulon flavolineatum* & - & - & 1 & - \\
\hline Halichoere bivittatus* & 42 & 26 & 4 & 1 \\
\hline Kyfosus $s p^{*}$ & - & 1 & - & - \\
\hline Lutjanus cyanopterus & - & - & 4 & - \\
\hline Lutjanus griseus & 20 & 20 & 57 & - \\
\hline Lutjanus jocu* & 21 & 1 & 10 & 2 \\
\hline Lutjanus synagris & 5 & - & 3 & - \\
\hline Malacoctenus macropus* & 1 & - & - & 3 \\
\hline Megaalops athanticus* & - & - & 5 & - \\
\hline Mycteroperca bonaci* & - & - & 2 & - \\
\hline Pomacantus paru* & - & - & 2 & - \\
\hline Scartella cristata* & - & - & - & 1 \\
\hline Selene vomer & - & - & 1 & - \\
\hline Sparisoma sp* & 1 & - & - & - \\
\hline Stegastes sp* & 13 & - & 1 & - \\
\hline
\end{tabular}

Puerto Hierro (E3).- En esta área rocosa se observó el mayor número de organismos (186) y de especies (24). El número de familias registradas fue de 14, siendo las más diversas, Haemulidae con 5 especies, Lutjanidae con 4, Pomacentridae con 3 y Sparidae con 2. La especies más abundantes fueron, 
Lutjanus griseus (30,65\%), Haemulon bonariense (17,20\%), Chaetotipterus faber $(10,75 \%)$, Anisotremus surinamensis (5,91\%), Lutjanus jocus (5,38 \%) y Megalops atlanticus $(2,69 \%)$.

La Salina (E4).- Se observaron 15 organismos de seis especies, pertenecientes a cuatro familias, siendo la más representativa Pomacentridae con dos especies: Abudefduf taurus y $A$. saxatilis que representaron el $53,33 \%$ de los organismos observados.

\section{III.3.1.5 ESTRUCTURA DEMOGRÁFICA POR ESPECIE}

\section{Elasmobranchii}

\section{Familia Dasyatidae}

Dentro de los Elasmobranchii la Familia Dasyatidae fue la más abundante en el presente estudio, y estuvo representada por 3 especies:

\section{Dasyatis guttata}

Es una especie frecuente en las aguas del GP y relativamente abundante. En el primer muestreo se encontró a todo lo largo de la zona estudiada: estaciones 1, 3, 6 y 8 , siendo en esta última donde su abundancia fue mayor (6 ejemplares). Las tallas variaron entre 224 - $570 \mathrm{~mm} \mathrm{LT}$, y la talla máxima reportada es de casi $2 \mathrm{~m}$. Es de fondos someros y de sustrato blando de aguas marinas y salobres. Se ha reportado para el Delta del Orinoco (Cervigón 1999).

En el segundo muestreo se colectaron 12 ejemplares, 8 machos y 4 hembras de tallas comprendidas entre114 -1.512 mm de LT y peso entre 215,75 y $4.554,75 \mathrm{~g}$; estuvieron presentes en las estaciones 1, 3, 4, 6, y 7. (Cervigón 1999)

\section{Dasyatis geijskesi}

Se reporta solamente para el primer muestreo, en la estación 8 un solo ejemplar de $249 \mathrm{~mm}$ de anchura, pudiendo alcanzar hasta $1 \mathrm{~m}$ de anchura o más. Esta asociada 
a fondos blandos de aguas salobres de baja salinidad, características que se da en la estación 8 donde fue colectada.

\section{Himanthura schmardae}

Representada por un solo ejemplar que apareció en el primer muestreo, proveniente de la estación 3, de $880 \mathrm{~mm}$ de LT, siendo la talla máxima reportada en el país, de $1.80 \mathrm{~m}$, pudiendo pesar hasta $200 \mathrm{Kg}$. Esta relacionada con fondos someros de sustratos blandos desde aguas hipersalinas hasta aguas salobres. La estación donde fue colectada, la 3 , se ubica dentro de las de aguas marinas, 30 de salinidad. Es aprovechada para el consumo humano.

\section{Familia Rhinopteridae}

\section{Rhinoptera bonasus}

Se recolectó un solo ejemplar en los muestreos de marzo, en la estación 3, una hembra de $830 \mathrm{~mm}$ de anchura, pudiendo alcanzar hasta $910 \mathrm{~mm}$. Ha sido reportada en el occidente del país por Valdez y Aguilera (1987), y por Novoa (1999) para el delta del Orinoco. Es comestible pero no es objeto de pesquerías importantes por su escasa abundancia.

\section{Familia Gymnuridae}

\section{Gymnura micrura}

Esta especie difiere de la descripción de Cervigón (1999) en el color de la parte ventral, señalada como blanca, mientras que en los ejemplares capturados aquí se presenta de color anaranjado vivo. En el primer muestreo se recolectaron tres ejemplares, dos en la estación 8 y uno en la 6, con un intervalo de anchura entre 166 - $323 \mathrm{~mm}$. Las tallas máximas reportadas para el país son de $565 \mathrm{~mm}$ de anchura. Es una especie eurihalina, ya que se captura tanto en lagunas hipersalinas como en las aguas salobres del delta inferior del Orinoco. Es comestible. En el segundo muestreo se recolectaron también tres ejemplares en las estaciones 7 y 8 de 115$155 \mathrm{~mm}$ LT. Esta especie es eurihalina, frecuente en aguas salobres estuarinas como las del delta inferior del Orinoco, y en lagunas hipersalinas. Es comestible. 


\section{Actinopterygiii}

\section{Familia Lutjanidae}

\section{Lutjanus synagris}

Especie de interés comercial, distribuida desde la costa este de los EEUU hasta Brasil. Se encuentra desde $10 \mathrm{~m}$ de profundidad hasta los $400 \mathrm{~m}$. En la campaña de marzo 2005 se capturó en el estrato 1, el cual alcanza hasta los tres metros. Las tallas oscilaron entre $29-289 \mathrm{~mm} \mathrm{LT}$, con promedio de 107,98 $\pm 41,96 \mathrm{~mm}$; el $85 \%$ de los ejemplares se ubicaron entre 50 y $130 \mathrm{~mm}$ LT (Figura III-10), lo que sugiere que esta es una zona de reclutamiento de juveniles de la especie. Solo se observaron 4 ejemplares maduros, (2 hembras y dos machos). Una de las hembras tenia $255 \mathrm{~mm} \mathrm{LT}$ y una grado de madurez de IV y la otra $289 \mathrm{~mm} \mathrm{LT} \mathrm{y} \mathrm{V} \mathrm{de}$ madurez. Estos valores de madurez coinciden con lo reportado por Cervigón (1993), quien señala como talla reproductiva los $300 \mathrm{~mm}$ LT. El examen del contenido estomacal revelo que de 75 estómagos examinados 35 contenían alimentos (46\%), con un grado de repleción promedio de II. El alimento predomínate eran crustáceos: camarones y cangrejos, además de peces en menor proporción. Igual señalamiento hace Cervigón (1993). La especie se capturó en mayor abundancia en las estaciones 1, 3 y 4 y en la estación 5 solo un ejemplar, lo que relaciona esta especie con aguas de mayor salinidad. En la campaña de septiembre se capturó en las estaciones 1, 3, 4 y 5, con un máximo de 7 ejemplares en la estación 5 . Las tallas oscilaron entre 80$280 \mathrm{~mm} \mathrm{LT}$, estando el $90 \%$ de los ejemplares sobre $140 \mathrm{~mm} \mathrm{LT}$, talla superior a la encontrada durante la campaña del mes de marzo. 

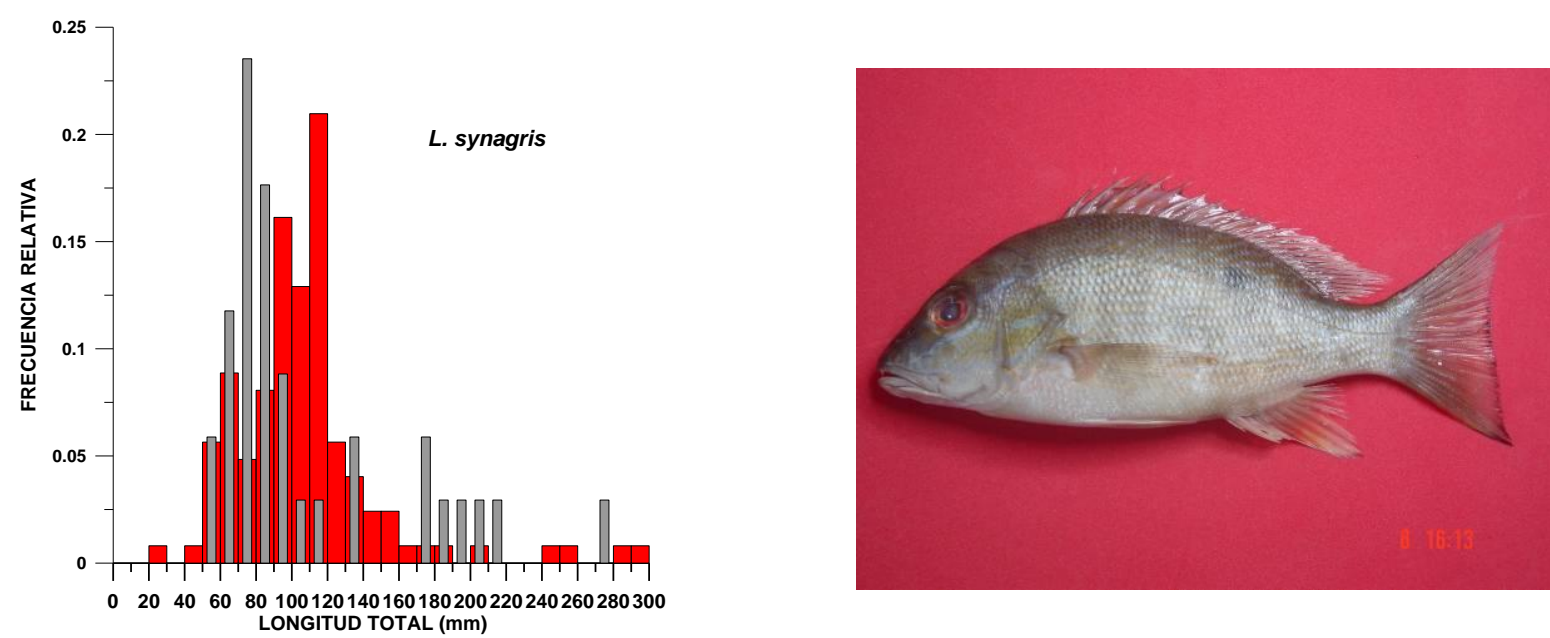

Figura III-10.-. Distribución de tallas de L. synagris durante las campañas de área barrida en el norte del GP (marzo 2005, barras rojas; septiembre 2005, barras gries).

\section{Lutjanus griseus y L. analis}

Son especies de Lutjanidae encontradas en las estaciones 1, 3 y 4, pero en menor proporción. De L. griseus solo se reporto un ejemplar de $101 \mathrm{~mm} \mathrm{LT}$, y de L. analis 5 individuos con tallas entre 255 y $312 \mathrm{~mm}$ de LT (promedio $=279 \pm 21,71 \mathrm{~mm}$ ) de los cuales cuatro eran hembras maduras (I) y con los estómagos llenos (grado de repleción 3 y 4), conteniendo jaibas y camarones.

En el segundo período estas especies no salieron en los muestreos con la red, pero Lutjanus griseus fue observada en los censos visuales en cantidades importantes, 20, 5 y 57 en las tres estaciones efectuadas (1, 2 y 3), habían tanto juveniles como adultos.

\section{Lutjanus purpureus}

En el mes de marzo se capturó un solo ejemplar en la estación 5, macho II, de 262 $\mathrm{mm}$ LT con un contenido estomacal de 2 jaibas y restos de bivalvos. Esta reportado para el delta del Orinoco. En septiembre se colectaron 22 ejemplares en las estaciones 3, 4 y 5, en la estación 3 (Puerto Hierro) se obtuvo la mayor cantidad, 13 ejemplares. Las tallas oscilaron entre $62-293$ mm LT. 


\section{Lutjanus jocu y Lutjanus cyanopteros}

Estas especies fueron observadas en los censos visuales realizados en septiembre. Se registraron 21 individuos de $L$. jocu en la estación 1, uno en la estación 2, y 10 en la estación 3. L. cyanopteros solo fue observado en la estación 3 (4 individuos).

\section{Familia Gerreidae}

\section{Diapterus rhombeus}

En marzo esta especie se recolectó en tres estaciones del noreste del GP (1, 3 y 4), en la E1se capturaron 97 ejemplares con talla entre 37 y $112 \mathrm{~mm}$ de LT (promedio = $66,33 \pm 20,63 \mathrm{~mm}$ ) y en una del sector oeste $(E 6)$ (promedio $=80,93 \pm 10,44 \mathrm{~mm}$ ). Su abundancia es alta ya que en la estación 1 , estrato 1 , constituye el $81,5 \%$ del total del la captura. En las estaciones 3 y 4 es mas bien escasa, solo 2 ejemplares en cada una de ellas. En la estación 6 se capturaron 114 organismos con tallas comprendidas entre 65-125 mm LT (con promedio = 80,93 $\pm 10,44$ ), constituyendo el $47,5 \%$ del total capturado. Las tallas reportadas en esta campaña corresponden, en su mayoría, a estados juveniles y preadultos, ya que se señala como talla máxima 300 mm LT (Figura III-11). D. rhombeus es una especie eurihalina (Cervigón 1993), se constata esta condición al ser capturada tanto en la zona de alta salinidad (30 psu) como en la estuarina (25 psu).
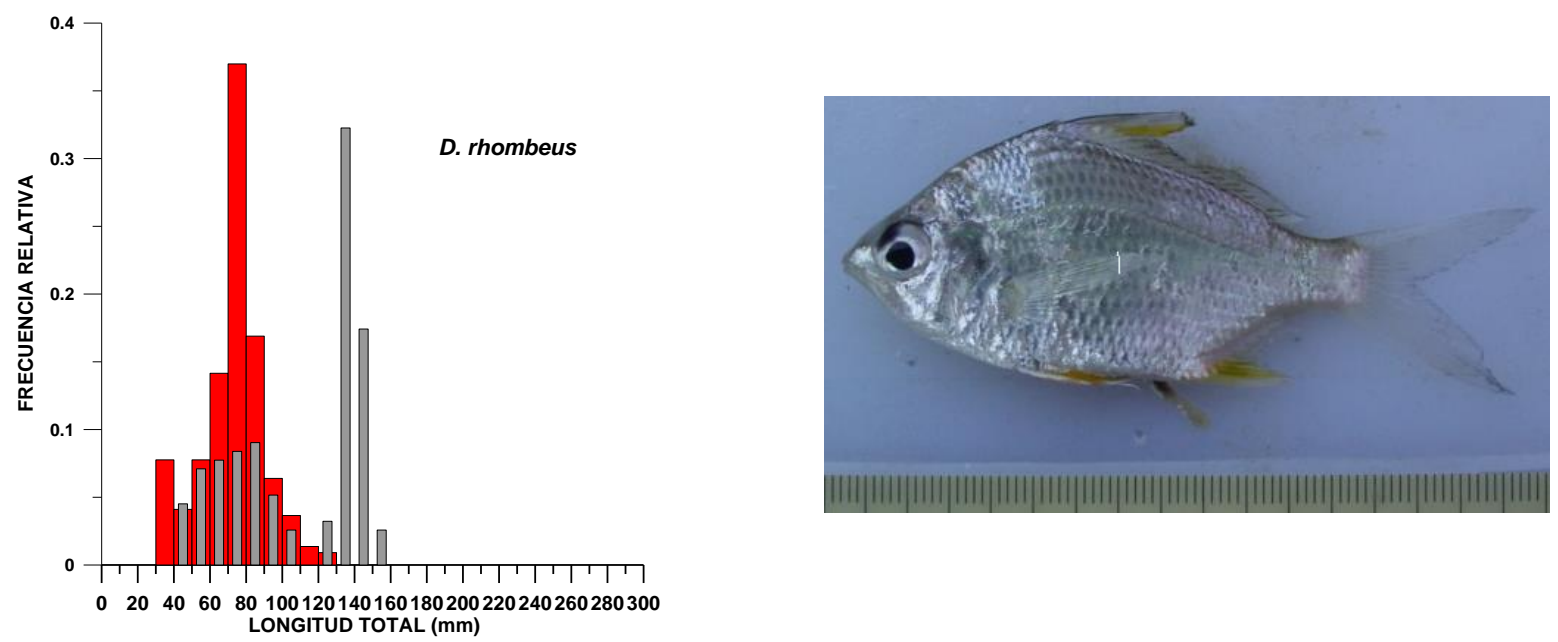

Figura III-11.- Distribución de tallas de $D$. rhombeus durante las campañas de área barrida en el norte del GP (marzo 2005, barras rojas; septiembre 2005, barras gries). 
En septriembre, esta especie fue abundante en la estación 1 (47 ejemplares) y en menos proporción en las estaciones 3, 5, 6 y 8, en donde aparecen con muy pocos individuos (entre 1 y 9). Las tallas variaron entre 48-150 mm LT, similares a las encontradas en la campaña del mes de marzo 2005. Se realizo una calada adicional con un tren de arrastre playero de $30 \times 1 \mathrm{~m}$ en una laguna litoral ubicada en la estación 3 donde se capturaron 84 ejemplares en tallas comprendidas entre 128-150 $\mathrm{mm} \mathrm{LT}$.

\section{Eucinostomus gula y E. argenteus}

Especies capturadas en mucha menos proporción que Diapterus rhombeus. E. gula fue la más abundante con tallas comprendidas entre 40 y 100 mm LT (Figura III-12), encontrándose hembras en estado de madurez II, 96 mm LT. Las tallas referidas por Cervigón (1993) alcanzan hasta 227 mm LT. Ambas especies solo estuvieron presentes en las estaciones del sector este del GP. Ambas especies son eurihalinas.
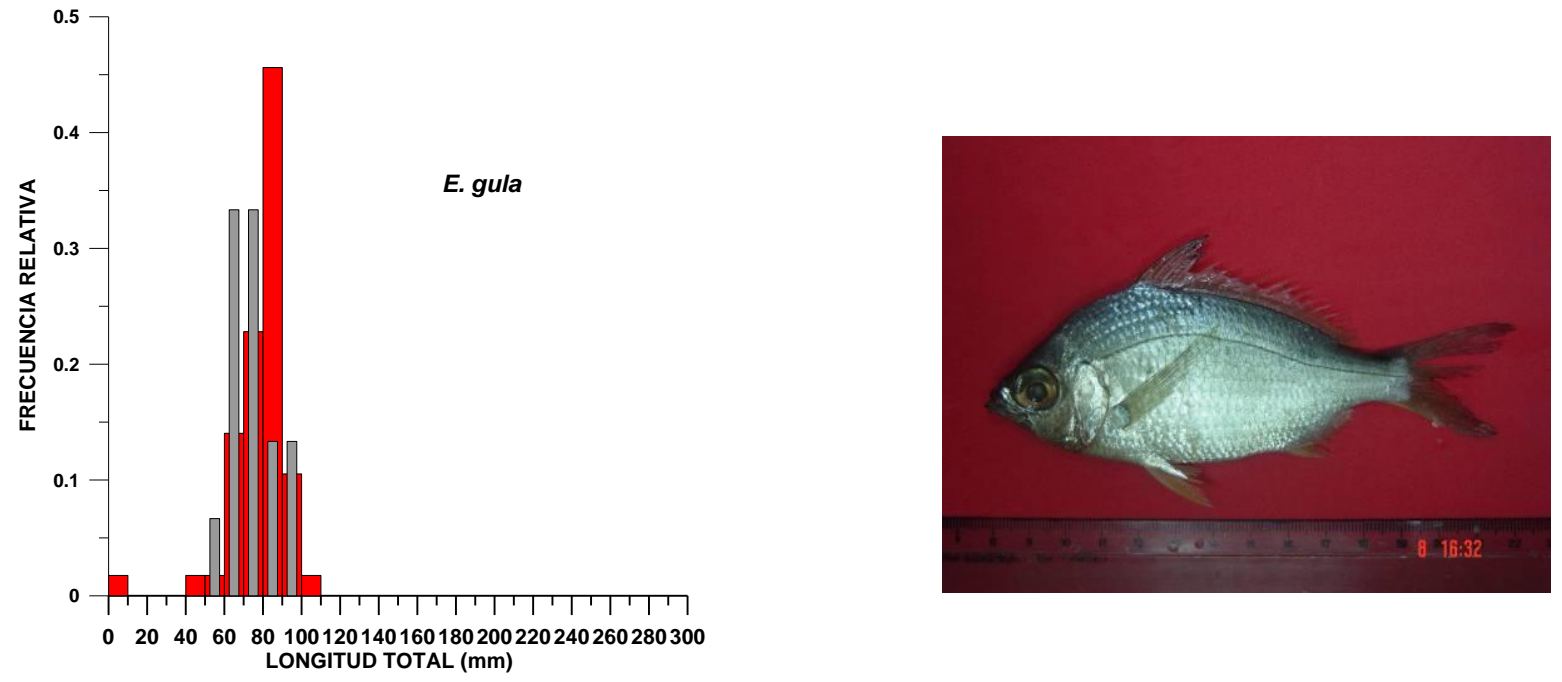

Figura III-12.- Distribución de tallas de E. gula durante las campañas de área barrida en el norte del GP (marzo 2005, barras rojas; septiembre 2005, barras gries).

En el segundo período Eucinostomus argenteus fue reportada tanto en las estaciones del sector este ( 3 y 4 ) como en las del oeste ( 5 y 6 ) del GP. En todas en muy poca cantidad (entre 1 y 12 individuos). Las tallas oscilaron entre 55-117 mm LT (Figura III-13). Eucinostomus gula se distribuyó en las estaciones 3, 4 y 7, en todas con muy pocos ejemplares (entre 1 y 12 ). Las tallas encontradas oscilaron entre 55- 
126 mm LT (Figura III-12). En el muestreo realizado en la laguna de la estación 3, las tallas fueron mayores (127-140), aunque la abundancia fue igualmente baja, solo 5 ejemplares.
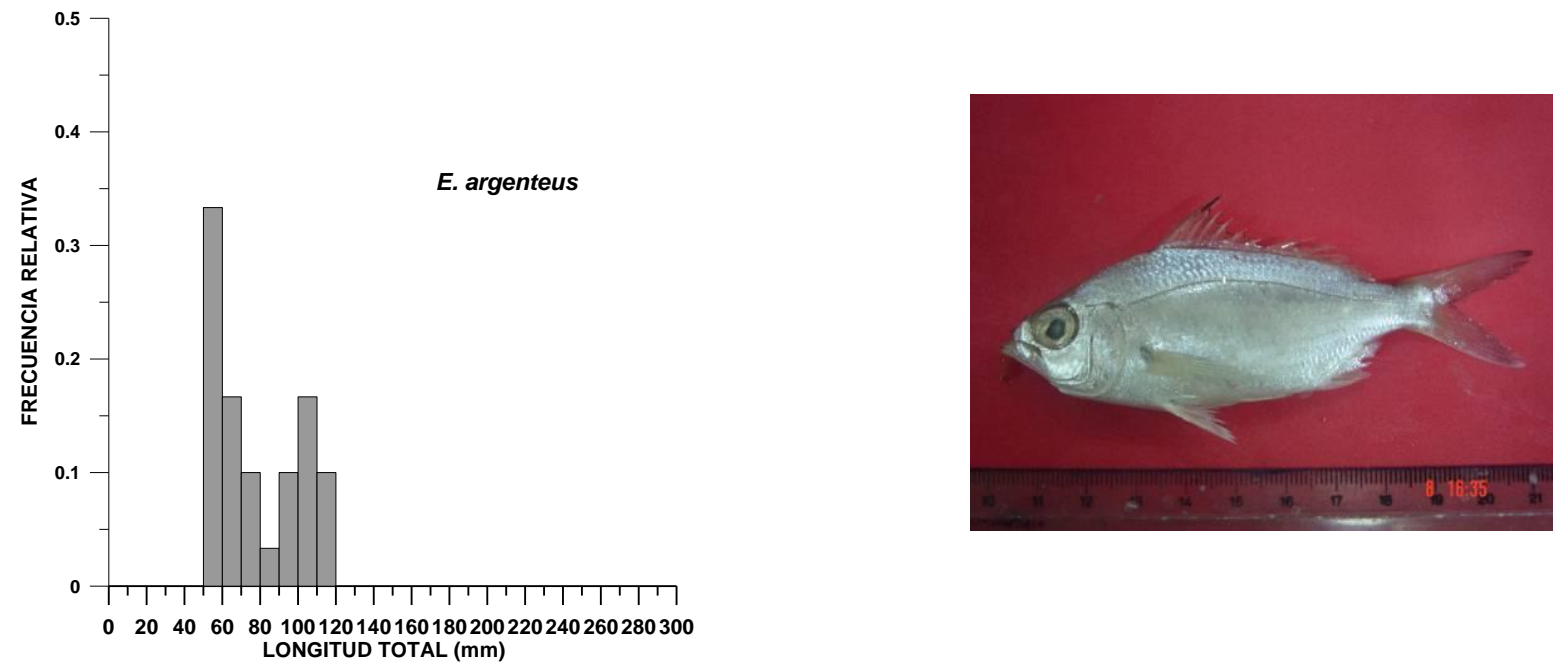

Figura III-13.- Distribución de tallas de E. argenteus durante las campañas de área barrida en el norte del GP (marzo 2005, barras rojas; septiembre 2005, barras gries).

\section{Eucinostomus melanopterus}

Se capturó un ejemplar de 148 mm LT en la estación 3 en el mes de septiembre. También se reportan 2 ejemplares en la estación 1, observados en los censos visuales.

\section{Familia Clupeidae}

\section{Pellona harroweri}

Esta especie de sardina se capturo en el mes de marzo solamente en las estaciones 5, 6 y 7, correspondiendo esto con sus hábitos de fondos fangoso-arenosos y de aguas salobres. Se capturó tanto en el estrato 1 como en el 2. En la estación 7 constituyó el 59,1\% del total de la captura. Las tallas encontradas son menores a 185 mm de LT (Figura III-14), talla máxima reportada por Cervigón (1991); en las capturas de la costa norte del GP la talla osciló entre 46 y $152 \mathrm{~mm}$ de LT con promedio de 95,34 $\pm 15,04$. 

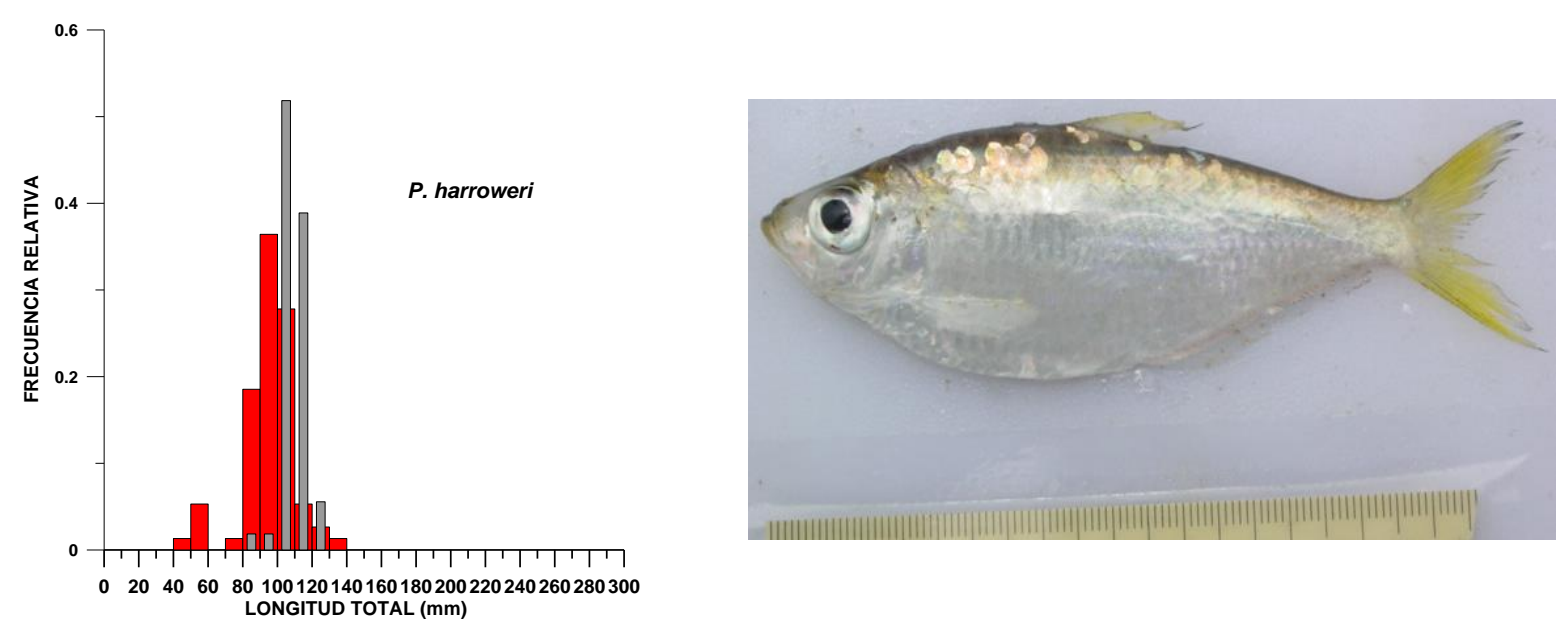

Figura III-14.-. Distribución de tallas de P.harroweri durante las campañas de área barrida en el norte del GP (marzo 2005, barras rojas; septiembre 2005, barras gries).

En el mes de septiembre se capturó solo en la E7, con 54 ejemplares. El intervalo de talla estuvo entre 90-128 mm LT, similar al primer muestreo (70-128).

\section{Opisthonema oglinum}

Solo se capturaron 7 ejemplares de esta especie en el mes de marzo, localizados en las estaciones 1 y 5 , con tallas entre 93 y $143 \mathrm{~mm} \mathrm{LT}$, con promedio de 112,43 \pm 21,71. O. oglinum es una especie reportada para aguas neríticas continentales e islas oceánicas (Cervigón 1991); sin embargo, no se señala, para la región de Paria.

\section{Odontognathus mucronatus}

En los muestreos de marzo esta especies se distribuyó en las estaciones 6,7 y 8, lo que indica su preferencia por aguas estuarinas. fue más abundante en la estación 8 donde alcanza el $61,7 \%$ de la captura total. Las tallas encontradas variaron entre 32-176 mm LT (Figura III-15), con promedio de 121,78 \pm 27,9. Cervigón (1991) refiere que $O$. mucronatus puede alcanzar mas de $160 \mathrm{~mm} \mathrm{LT}$, igualmente refiere que la coloración es blanco amarillento y con áreas negruscas en el dorso, lo que no coincide con lo observado ya que eran totalmente blancas y casi transparentes. 

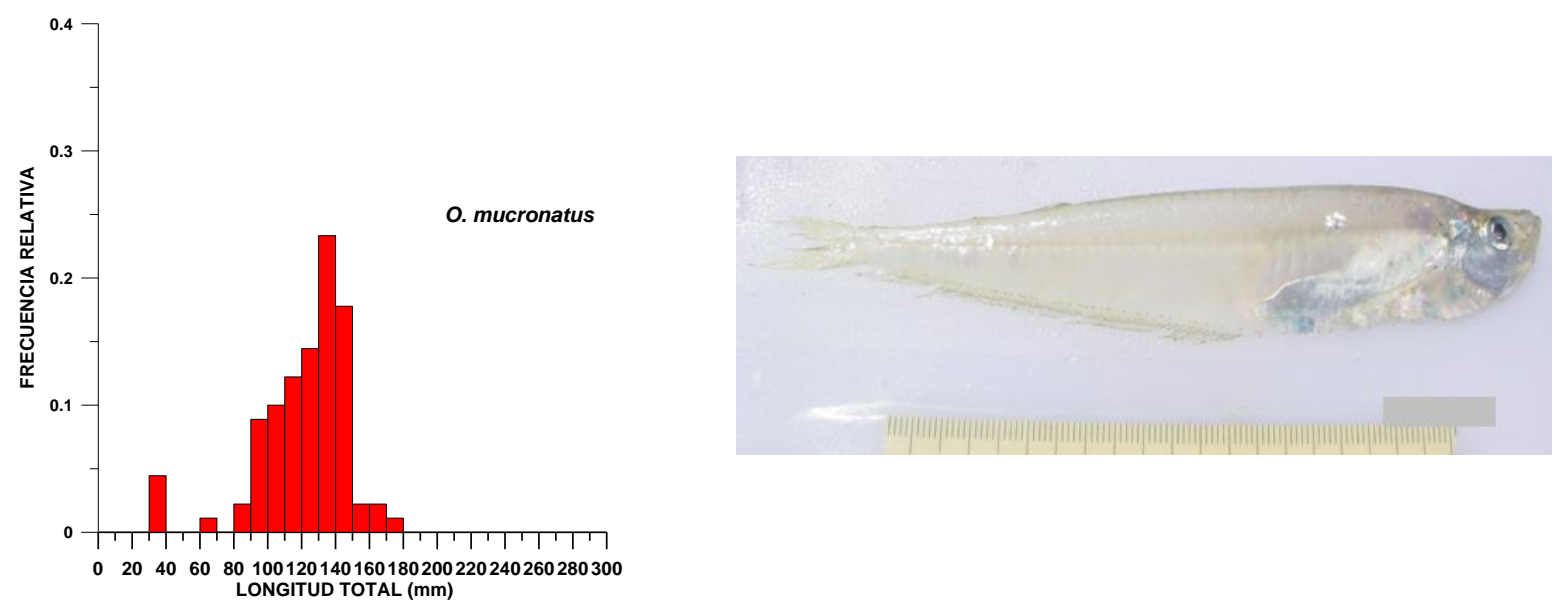

Figura III-15.-. Distribución de tallas de O.mucronatus durante la campaña de área barrida en el norte del GP en marzo 2005.

En septiembre los ejemplares capturados de esta especie fueron muy escasos (entre 9 y 13) y solo aparecieron en las estaciones 7 y la 8 . Las tallas oscilaron entre 68 $165 \mathrm{~mm}$ de LT.

\section{Sardinella aurita}

Se capturo en los muestreos de septiembre en la estación 5 en un lance efectuado con un tren de arrastre playero de $30 \times 1 \mathrm{~m}$. Fue la especie mas abundante de ese arrastre, 85 ejemplares, con tallas entre 50-80 mm LT (Figura III-16). No se reportó en la campaña anterior.
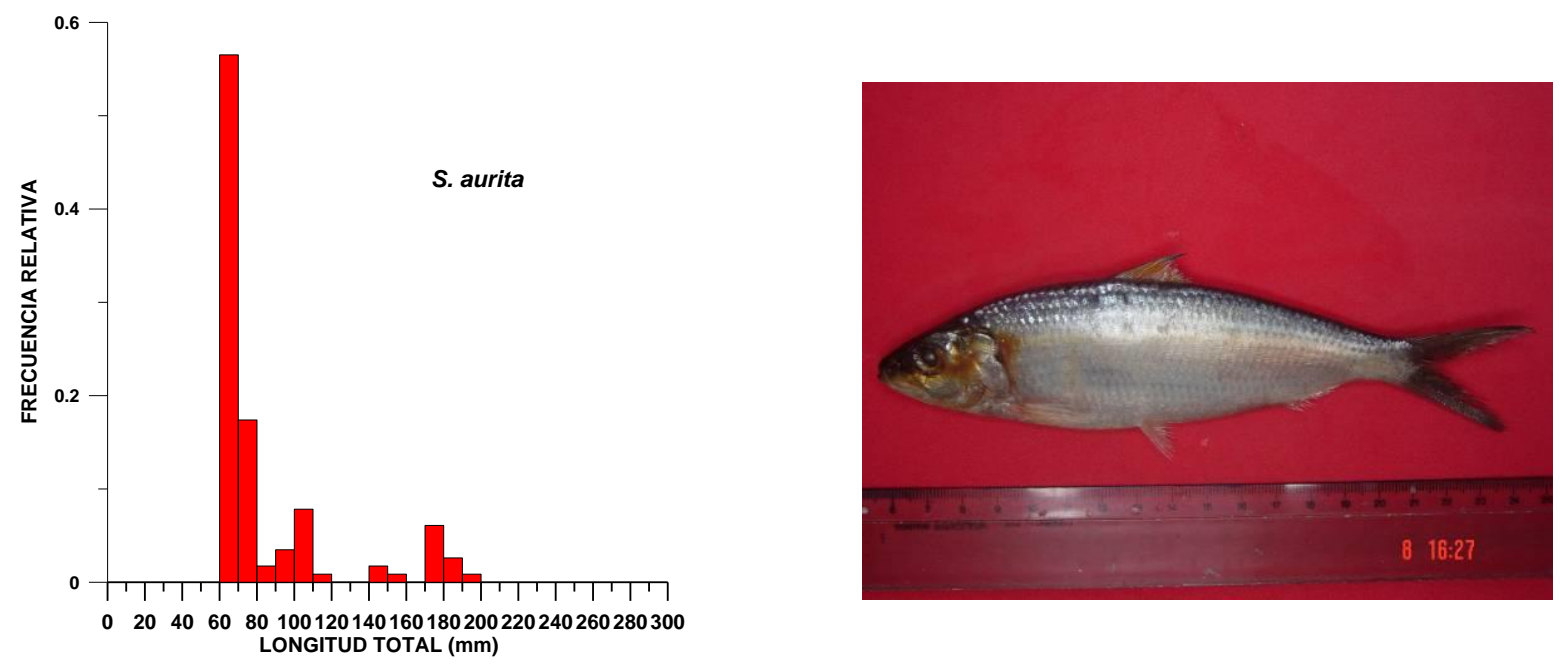

Figura III-16.- Distribución de tallas de S.aurita durante la campaña de área barrida en el norte del GP en septiembre 2005. 


\section{Rhinosardinia sp}

Especie de agua dulce, capturada en la estación 8, con una salinidad muy baja. Se reportó solo en la campaña de septiembre.

\section{Harengula jaguana}

Especie capturada en el arrastre playero efectuado en la estación 3. Fue la especie mas abundante de esa calada, 27 ejemplares de tallas comprendidas entre 92-127 mm LT. Se reportó solo en la campaña de septiembre.

\section{Familia Engraulidae}

Se encontraron 6 especies de Engraulidae, todas con muy escasa abundancia, a excepción de Anchoa hepsetus recolectada en la estación 5 con 23 ejemplares y restringidas a las estaciones 6,7 y 8 , por lo que son las especies estuarinas de este grupo.

\section{Cetengraulis eduntulus}

Se colectaron en total 11 ejemplares en las estaciones 6,7 y 8 , con tallas entre 70 $134 \mathrm{~mm}$ LT. Esta especie puede alcanzar hasta $165 \mathrm{~mm}$ LT. Está reportada como abundante en el GP, así como en las aguas neríticas de la plataforma y en la zona de surgencia de la región nororiental.

\section{Lycengraulis grossidens}

Igual que la especie anterior, estuvo presente en las estaciones 6,7 y 8 , con solo 10 ejemplares; las tallas oscilaron entre 103-145 mm LT. Es una especie característica de aguas estuarinas.

\section{Anchoa hepsetus}

Especie de aguas neríticas de la plataforma, no esta señalada para las aguas del GP. Se capturaron 5 ejemplares de tallas entre $63-73 \mathrm{~mm}$ de LT, lo que se corresponde con tallas medias, ya que puede alcanzar hasta $120 \mathrm{~mm} \mathrm{LT}$, en las estaciones 7 y 8 (salinidades de 16 y 19 , respectivamente).

\section{Familia Ephippidae}

\section{Chaetodipterus faber}


De esta especie se recolectaron 10 ejemplares en los muestreos de marzo, distribuidos desde la estación 1 hasta la 8, lo que confirma su carácter eurihalino. Las tallas encontradas oscilaron entre 33 y $342 \mathrm{~mm} \mathrm{LT}$, con promedio de 121,86 \pm 113,67; el ejemplar de mayor talla fue una hembra en estado de madurez $\mathrm{V}$ y el contenido estomacal estaba constituido en su totalidad por algas filamentosas. En el mes de septiembre Ch. faber se colecto en las estaciones 5 y 6 , y solo tres ejemplares con tallas de 113, 126 y 285 . Además, fue observada en los censos visuales de las estaciones 1 y 3 , en esta última se censaron 20 ejemplares. Se confirma así su presencia a lo largo de toda la costa norte del GP.

\section{Familia Tetraodontidae}

\section{Colomesus psittacus}

Perteneciente a la misma familia del mondeque o futre. C. psittacus a pesar de alcanzar tallas superiores a $200 \mathrm{~mm}$ de LT, carece de valor comercial. En los muestreos de marzo se colectó en las estaciones 1,6, 7 y 8 , siendo en esta última donde se observó la mayor abundancia, 53 ejemplares (58,89\% del total de los ejemplares capturados). Alcanza la madurez sexual a los $94 \mathrm{~mm}$ LT y el $43 \%$ de los ejemplares estaban maduros, teniendo las hembras un estado de madurez promedio de II. Las tallas oscilaron entre 32 - 176 mm LT (Figura III-17), con promedio de $121,78 \pm 27,90$. Aunque $C$. psittacus es reportada para aguas salobres y turbias, aquí se encontró un ejemplar en aguas de salinidad 30 psu y en aguas claras (estación 1).

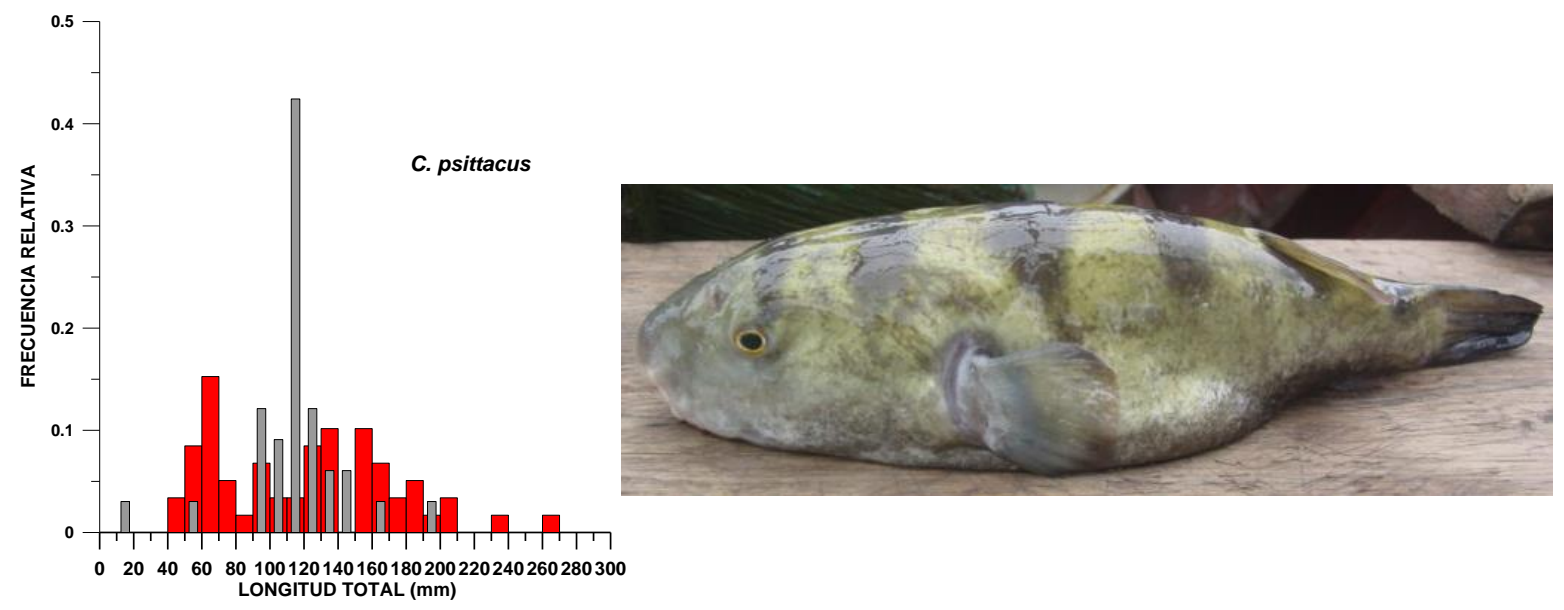

Figura III-17.-. Distribución de tallas de C. psittacus durante las campañas de área barrida en el norte del GP (marzo 2005, barras rojas; septiembre 2005, barras gries). 
En los muestreos de septiembre se capturo en las estaciones 1, 7 y 8 , siendo en esta ultima donde presenta la mayor abundancia, 45 ejemplares. Las tallas variaron entre 60-284 mm LT. Estos datos coinciden con los obtenidos para el mes de marzo.

\section{Sphoeroides testudineus}

Esta especie estuvo presente solo en los muestreos de septiembre, con relativa abundancia, en todas las estaciones del sector oeste del GP (5, 6, 7 y 8). Las mayores abundancias se encontraron en las estaciones 5,6 y $7 \quad(13,21$ y 16 ejemplares, respectivamente). Las tallas variaron entre 70-230 mm LT. Esta especie esta reportada como abundante para el delta inferior del Orinoco. (Cervigón, 1996)

\section{Sphoeroides spengleri}

Se capturo un solo ejemplar en el mes de septiembre en la estación 6 , de talla pequeña, $56 \mathrm{~mm} \mathrm{LT}$, ya que puede alcanzar hasta $156 \mathrm{~mm} \mathrm{LT}$. La salinidad de esta estación fue de 19 ups, lo que corrobora lo señalado por Shipp (1974, en Cervigón, 1996), que puede existir en aguas salobres. En Venezuela esta señalada solamente para el área del Caribe y no ha sido reportada en aguas de fondos fangosos y aguas turbias, ni en las salobres del delta inferior del Orinoco. (Cervigón, 1996)

\section{Familia Siluridae}

\section{Cathorops spixii}

En la campaña de marzo se capturó un total de 1.495 organismos en las estaciones $5,6,7$ y 8 , constituyendo en esta última el $51.6 \%$ del total de la captura. Las tallas estuvieron comprendidas entre 22 y $258 \mathrm{~mm} \mathrm{LT}$, con promedio de 86,95 \pm 33 ,79; el mayor porcentaje se ubicó entre 65 - 115 mm LT (Figura III-18). La talla máxima reportada para la especie es de $300 \mathrm{~mm}$ de LT. Se encontraron hembras en estado de madurez I y III con tallas desde $115 \mathrm{~mm}$ LT. Por debajo de $100 \mathrm{~mm}$ todos era de sexo indeterminado. Etchevers (1978) reporta que la talla mínima de madurez es de 149 mm L st., muy por encima de las señaladas aquí. 

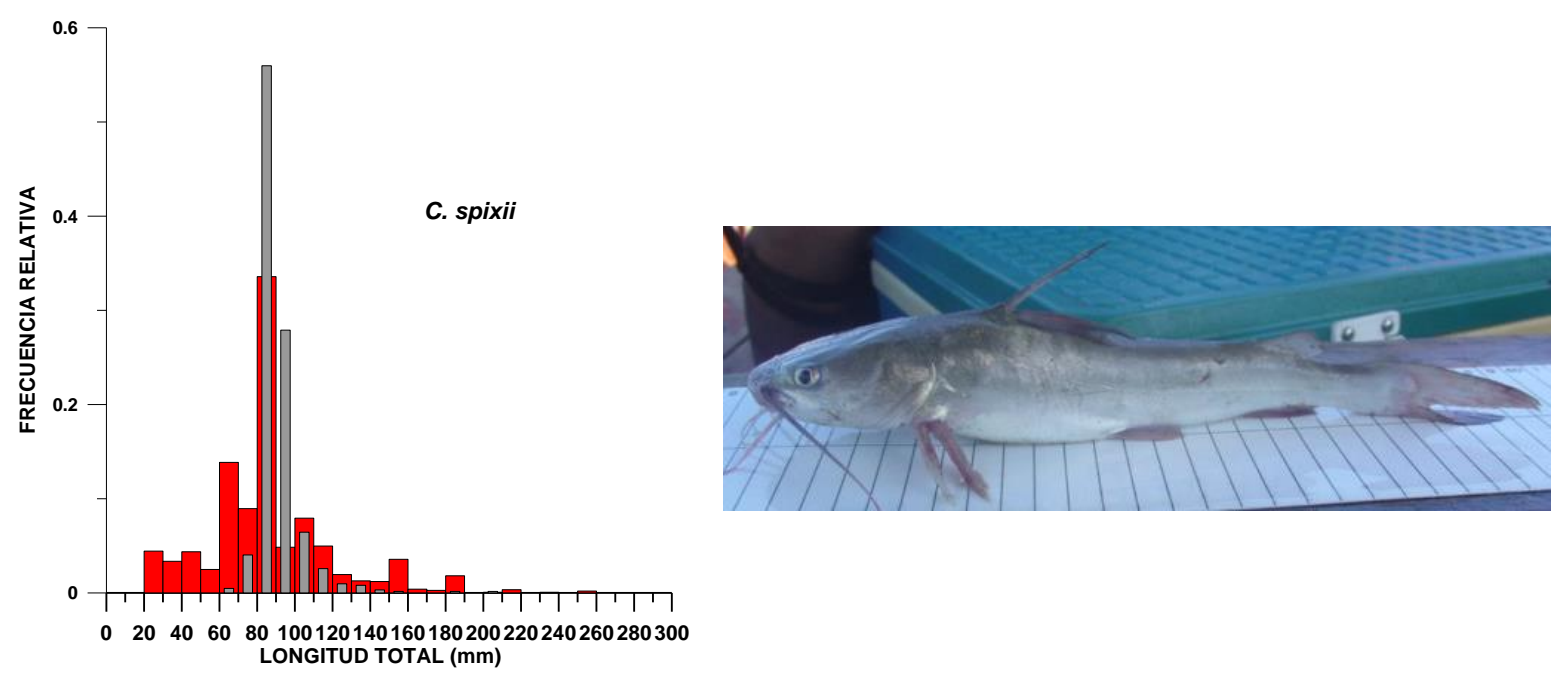

Figura III-18.- Distribución de tallas de C. spixii durante las campañas de área barrida en el norte del GP (marzo 2005, barras rojas; septiembre 2005, barras gries).

En la segunda campaña esta especie fue igualmente abundante en las estaciones 8 (486 ejemplares) y 7 (134 ejemplares), con tallas comprendidas entre 61-207 mm LT.

\section{Bagre marinus}

Esta especie está reportada como el bagre más estrictamente marino, por lo que su presencia solo en las estaciones 6 y 8 , indican que puede alcanzar las aguas salobres del GP. En la primera campaña se capturaron 52 ejemplares con talla comprendidas entre 77 y $179 \mathrm{~mm}$ de LT, el 69,2\% estuvo entre 120 y $135 \mathrm{~mm}$ de LT, con promedio de $118,38 \pm 16,49$. La talla máxima registrada en la muestra estuvo muy por debajo de la reportada para la especie (600 mm LT). Para la segunda campaña se capturaron solo 2 individuos en la estación 8, de tallas 167 y 295 mm LT. Es importante recalcar que esta especie de bagre es propia de aguas saladas y aquí fue colectado en aguas de salinidad 13 psu.

\section{Bagre bagre}

Es una especie comestible, pero de carne poco apreciada. Es de aguas marinas y estuarinas. En la primera campaña se reporta solo en las estaciones 7 (15 ejemplares) y 8 (300 ejemplares), de tallas entre 25 y $213 \mathrm{~mm} \mathrm{LT}$, con promedio de $78,86 \pm 38,44 \mathrm{~mm}$; el $50,50 \%$ de los ejemplares estuvo entre 80,29 y $124,5 \mathrm{~mm}$. Esta especie puede alcanzar hasta $500 \mathrm{~mm}$ de LT. Es una especie carnívora con 
preferencia por los crustáceos y peces. En la segunda campaña esta especie fue muy escasa, solo 7 ejemplares en la estación 7. Al igual que la especie anterior, las tallas se consideran pequeñas, $124-180 \mathrm{~mm} \mathrm{LT}$, ya que puede alcanzar hasta 500 $\mathrm{mm} \mathrm{LT}$.

\section{Arius quadriscutis}

Especie de escasa presencia en la zona (22 ejemplares en los muestreos de marzo), repartidas entre las estaciones 3, 6, 7 y 8, de tallas comprendidas entre 97 y 345 $\mathrm{mm}$ LT, con promedio de 199,36 $\pm 62,09 \mathrm{~mm}$; el ejemplar de mayor tamaño era una hembra con grado I de madurez. La especie se alimenta de crustáceos. En el segundo período se capturaron pocos ejemplares, solo 4 ejemplares en las estaciones 6, 7 y 8 . Las tallas variaron entre 110-235 mm LT. Estos resultados son similares a los obtenidos en la campaña anterior, salvo que, en esa ocasión, también apareció en la estación 3.

\section{Hexanematichthys pasany}

Especie comestible que puede alcanzar tallas de hasta $1 \mathrm{~m}$ y con $15 \mathrm{~kg}$ de peso (Cervigón 1991). En marzo se capturaron 48 ejemplares, la mayoría en la estación 8 (38) y en los dos estratos. Las tallas registradas variaron entre 60-146 mm de LT (Figura III-19), con promedio de 86,66 $\pm 27,31$, lo que indica que eran juveniles. En Venezuela solo se había reportado para el Delta inferior del Orinoco.
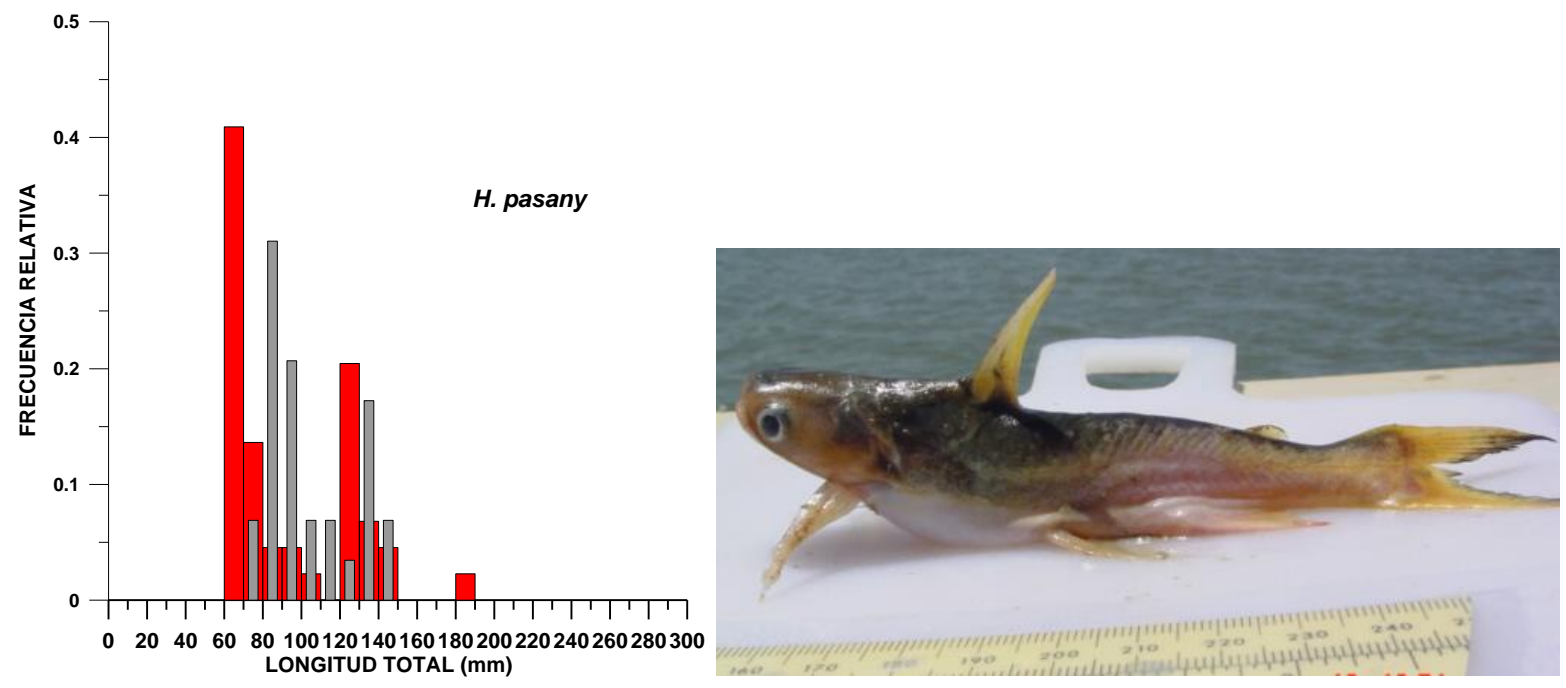

Figura III-19.- Distribución de tallas de $H$. pasany durante las campañas de área barrida en el norte del GP (marzo 2005, barras rojas; septiembre 2005, barras gries). 
En septiembre se capturó en las estaciones 7 y 8 , con 28 y 1 ejemplar, respectivamente. Las tallas variaron entre $75-149$, las cuales se consideran pequeñas ya que alcanza tallas de hasta $1 \mathrm{~m}$.

\section{Arius grandicassis}

Especie poco abundante (12 ejemplares), que apareció sólo en el mes de marzo y estuvo presente en las estaciones 6 y 8 . Las tallas se distribuyeron entre 117 -242 $\mathrm{mm} \mathrm{LT}$, con promedio de 170,08 $\pm 50,95 \mathrm{~mm}$. La talla máxima reportada para esta especie es de $510 \mathrm{~mm} \mathrm{LT}$.

\section{Hexanematichthys herzbergii}

Esta especie no fue reportada en la campaña de marzo 2005, sin embargo en la segunda campaña apareció a todo lo largo de la costa norte del GP, en las estaciones 1, 3, 4, 6 y 8 , con muy pocos ejemplares en las primeras cuatro estaciones (entre 1 y 7 ), pero fue muy abundante en la estación 9 donde se colectaron 77 ejemplares. Las tallas en las estaciones 1, 3, 4 y 6 fueron relativamente grandes, entre 245 y $403 \mathrm{~mm} \mathrm{LT}$, ya que puede alcanzar hasta 545 mm de LT. En la estación 8, donde fue más abundante las tallas oscilaron entre 64$130 \mathrm{~mm}$ de LT (Figura III-20). A. herzbergii es una especie que tiene presencia tanto en aguas salobres como hipersalinas; en nuestro caso las salinidades oscilaron entre 13 y 22 psu en las estaciónes 8 y 1 , respectivamente. 

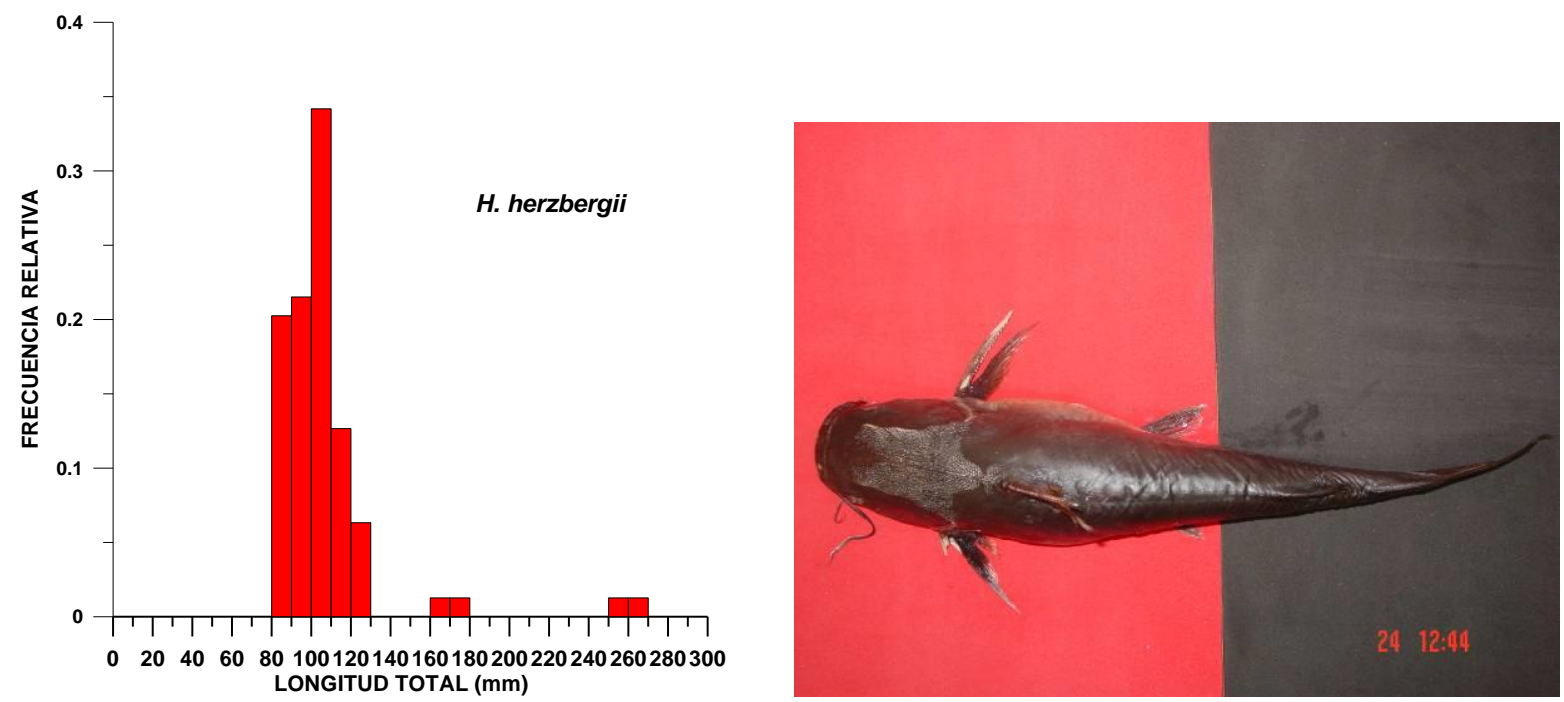

Figura III-20.-. Distribución de tallas de $H$. herzbergii durante la campaña de área barrida en el norte del GP en marzo 2005.

\section{Familia Sciaenidae}

\section{Stellifer rastrifer}

Fue la especie más abundante dentro de los sciánidos. Habita en aguas estuarinas y de fondos someros. Se capturó un total de 411 organismos en las estaciones 1, 5, 6 y 7 , siendo mas abundante en la E5 con 289 ejemplares, que correspondió al 20,88 $\%$ de la captura total de esa estación. Las tallas oscilaron entre 55 y $157 \mathrm{~mm}$ de LT (Figura III-21), con promedio de 95,59 $\pm 17,74$. $S$ rastrifer es una especie de pequeño tamaño que probablemente pueda alcanzar los $200 \mathrm{~mm}$ de LT. En la segunda campaña la captura mas abundante de esta especie ocurrió en la estación 2, con 92 ejemplares, de tallas entre 48 y $125 \mathrm{~mm} \mathrm{LT}$, recolectándose 77 ejemplares de tallas pequeñas entre 9,5 y $113 \mathrm{~mm} \mathrm{LT}$. 

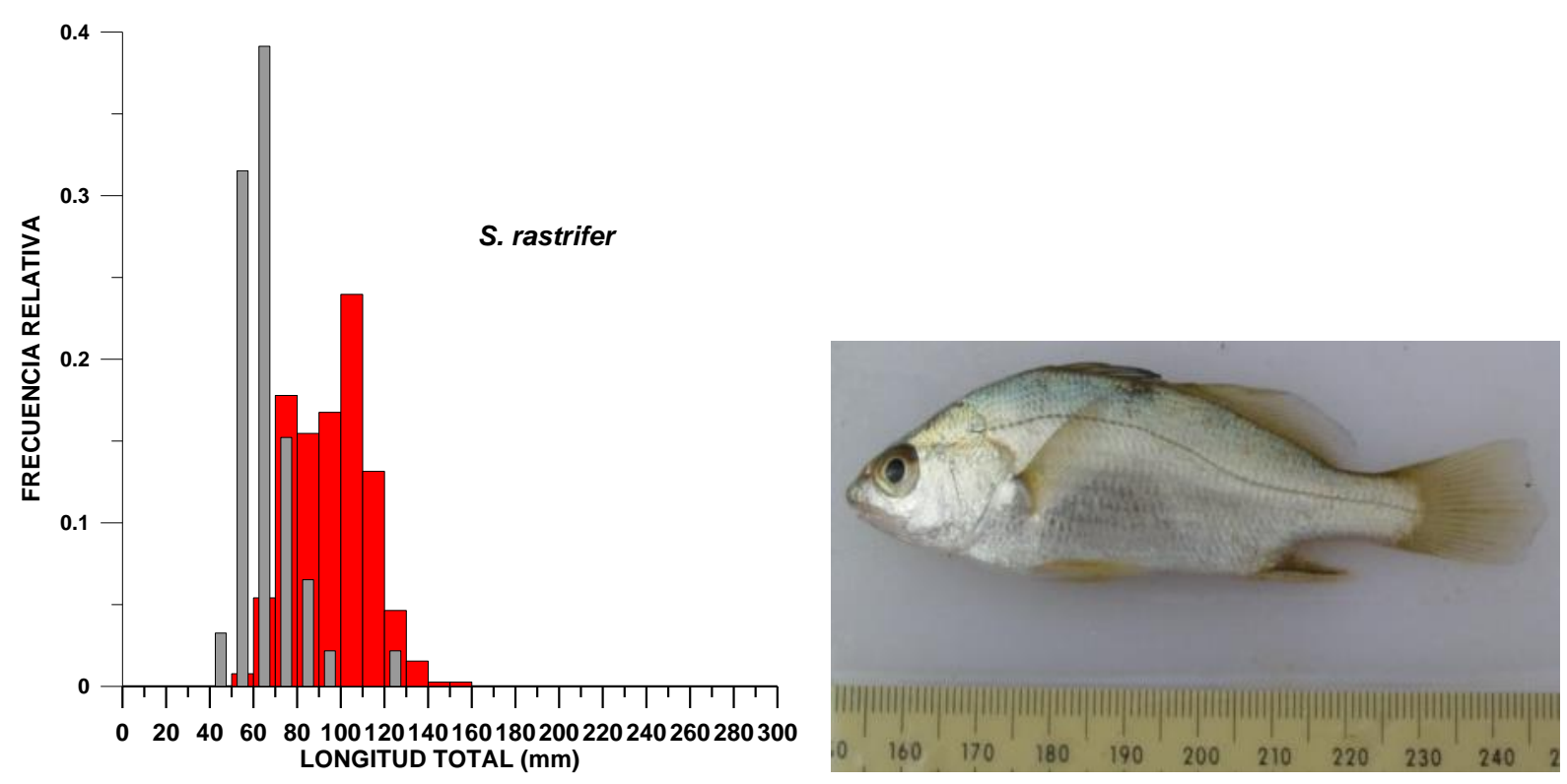

Figura III-21.-. Distribución de tallas de $S$. rastrifer durante las campañas de área barrida en el norte del GP (marzo 2005, barras rojas; septiembre 2005, barras gries).

\section{Cynoscion virescens}

Especie de interés comercial, propia de aguas estuarinas, por lo que se capturó solamente en las estaciones 4, 5 y 7 , aunque fueron pocos ejemplares capturados (25 ejemplares); Las tallas oscilaron, entre 74 y $377 \mathrm{~mm} \mathrm{LT}$, con promedio de 214,12 $\pm 95,47$. Los organismos capturados fueron de talla relativamente pequeñas, puesto que la especie alcanza hasta $950 \mathrm{~mm}$ LT. Se reporta un macho maduro (V), de 377 $\mathrm{mm}$ LT. C. virescens se alimenta de camarones y peces. En la segunda campaña esta especie se capturó solo en la estación 7, capturándose 9 ejemplares con tallas entre 97 y $181 \mathrm{~mm} \mathrm{LT}$.

\section{Bairdiella sanctaeluciae}

Especie de amplia distribución en el GP, estaciones 1, 3, 5 y 8, pero de escasa abundancia (12 ejemplares). El intervalo de tallas oscila entre $83-147 \mathrm{~mm} \mathrm{LT}$, lo que corresponde a tallas medias, ya que Cervigón (1991), reporta tallas entre 120 $147 \mathrm{~mm} \mathrm{LT}$. Se encontraron hembras y macho maduros (II y IV) a partir de $135 \mathrm{~mm}$ de LT. El contenido estomacal estaba constituido por gusanos anélidos. Esta especie no tiene interés comercial. 


\section{Micropogonias furnieri}

Es una especie de interés comercial, pero en esta región es poco abundante. Se colecto en las estaciones 6 y 8 , pero solo tres ejemplares, entre $83-145 \mathrm{~mm}$ de LT. Pueden alcanzar hasta $525 \mathrm{~mm}$ LT. En la campaña de septiembre se capturó en las estaciones 1, 5, 6 y 7, pero con muy pocos ejemplares (entre 1 y 6 ). En la campaña de marzo solo estuvo presente en la estación 6 y 8 con tres ejemplares. Las tallas variaron entre 80 y $188 \mathrm{~mm} \mathrm{LT}$.

\section{Stellifer microps}

No tiene interés comercial, aunque se reporta como abundante en las zonas estuarinas del Delta del Orinoco. En esta ocasión su captura fue escasa, solo 13 ejemplares entre 67 - $148 \mathrm{~mm}$ LT. Esta presente en las estaciones 7 y 8 . En la campaña de septiembre esta especie solo apareció en las estaciones 2 y 8 . En ambos casos con muy pocos ejemplares, 1 y 8 respectivamente. Las tallas variaron entre 83 y $134 \mathrm{~mm} \mathrm{LT}$.

\section{Cynoscion leiarchus}

De esta especie se colectaron 12 ejemplares en las estaciones 1,7 y 8 , y las tallas estaban entre 96 y $210 \mathrm{~mm}$ LT. En la campaña anterior solo aparecieron dos ejemplares en la estación 7.

\section{Cynoscion acoupa}

Estuvo presente solo en las estaciones 2 y 8, con 7 ejemplares en la primera y 1 en la segunda. Las tallas (97-153 mm LT), y la abundancia son semejantes a las reportadas en los muestreos de marzo.

\section{Menticirrhus americanus}

Especie frecuente en las aguas estuarinas venezolanas, aparece en las estaciones 1, 3 y 6 con solo un ejemplar en cada una. Las tallas fueron 309,265 y $210 \mathrm{~mm} \mathrm{LT.,}$ respectivamente. No fue reportada en los muestreos del mes de marzo.

\section{Nebris microps}

Al igual que otros scianidos, se distribuye en las estaciones 2 y 8 , con 20 individuos en total ( 1 en la estación 2 y 19 en la 8). Los ejemplares son de tallas medias, entre 53 y $293 \mathrm{~mm} \mathrm{LT}$, ya que pueden alcanzar hasta $387 \mathrm{~mm} \mathrm{LT}$. 


\section{Larinus breviceps}

Solo un ejemplar capturado con el tren de arrastre playero, en la estación 3, de 80 $\mathrm{mm}$ de LT. Fue igualmente escasa en los muestreos de marzo.

\section{Equetus acuminatus}

De esta especie se capturaron 12 ejemplares en la estación 5 de tallas entre 97 y $154 \mathrm{~mm} \mathrm{LT}$, que se consideran pequeños, ya que la especie puede alcanzar $220 \mathrm{~mm}$ LT. Esta reportada por Cervigón (1994), para aguas claras y sustrato mas o menos duros y es común en fondos de corales córneos. No esta reportada para la zona estuarina y tampoco se colecto en la campaña de marzo.

\section{Equetus umbrosus}

Igual que E. acuminatus, no fue reportada en la campaña anterior. Es una especie común en aguas estuarinas del delta del Orinoco. Se capturo en la estación 5 , con solo 2 ejemplares, de 96 y 106 mm LT respectivamente.

\section{Macrodon ancyclodon}

Esta especie se capturó solamente en la estación 8 con tres ejemplares de tallas entre $204-230 \mathrm{~mm} \mathrm{LT}$.

\section{Familia Haemulidae}

De esta importante familia se reportan 4 especies, tres de ellas obtenidas en la estación 1 y una en la 6.

\section{Anisotremus surinamensis}

Esta especie que alcanza un gran tamaño, hasta $640 \mathrm{~mm} \mathrm{LT}$ y $5.500 \mathrm{~g}$ de peso, no es de carne muy apreciada. En el GP, se capturo solo en la estación 1, dos ejemplares de 345 y $364 \mathrm{~mm}$ LT, ambos hembras maduras, a punto de desovar (IV y V) y con el estomago vacío. Es una especie de hábitos más bien nocturnos y es señalada para fondos coralinos y rocosos.

\section{Anisotremus virginicus}

Especie relacionada con fondos rocosos y coralinos, de escasa abundancia, presente en la estación 1, con un solo ejemplar, de $278 \mathrm{~mm} \mathrm{LT}$, siendo la máxima 
talla reportada es de $350 \mathrm{~mm}$ LT. El contenido estomacal estaba conformado por: camarones, gusanos anélidos y cangrejos.

\section{Haemulon bonariense}

También localizado en la estación 1, se reportan dos ejemplares de 101 y 108 mm LT, la talla máxima reportada es de $350 \mathrm{~mm} \mathrm{LT}$. Es común en fondos someros y blandos. En septiembre, también fue localizado en la estación 1, se reportan dos ejemplares de 101 y $108 \mathrm{~mm} \mathrm{LT}$, la talla máxima reportada es de $350 \mathrm{~mm}$ LT. Es común en fondos someros y blandos.

\section{Pomadasys croco}

Especie mas relacionada a aguas estuarinas, por lo que su presencia solo en la estación 6 confirma este hecho. Se capturaron dos ejemplares de 99 y $114 \mathrm{~mm} \mathrm{LT} \mathrm{y}$ en Venezuela la talla máxima reportada es de 295 mm LT (Cervigón 1991). No es de interés comercial.

\section{Genyatremus luteus}

Este haemúlido es una especie propia de aguas salobres, abundante en el GP. Se localizo en las estaciones 6 y 8. Con 5 ejemplares en la estación 6, de 98-125 mm LT y 20 individuos en la estación 8, de 60-92 mm LT.

Haemulon aurolineatus, $H$. flavolineatus, Anisotremus surinamensis y A. virginicus. Estas cuatro especies fueron observadas en los censos visuales efectuados en la estación 3.

\section{Familia Carangidae}

Esta familia fue, después de la Sciaenidae (20 especies), la que presentó mayor número de especies presentó en esta área del GP (7 especies).

\section{Selene vomer}

Fue la especie más abundante de esta familia (54 ejemplares) y de más amplia distribución, estuvo presente en las estaciones 5 - 8. Presentó un intervalo de talla entre 28 y 169 mm de LT (Figura III-22). Esta especie puede alcanzar hasta 483 mm 
de LT, su presencia en esta zona se corresponde con su hábitat, ya que prefiere, en las etapas juveniles fondos someros de aguas salobres. Los grandes ejemplares se encuentran a profundidades de hasta $50 \mathrm{~m}$. Su distribución señala a los juveniles para la parte inferior del Delta del Orinoco. En la segunda campaña estuvo representada por pocos ejemplares, 8 en total, colectados en las estaciones 1, 3, 4 y 7. Las tallas oscilaron entre 55- 275 mm LT. Esta señalada para el GP, donde es objeto de pesca comercial.
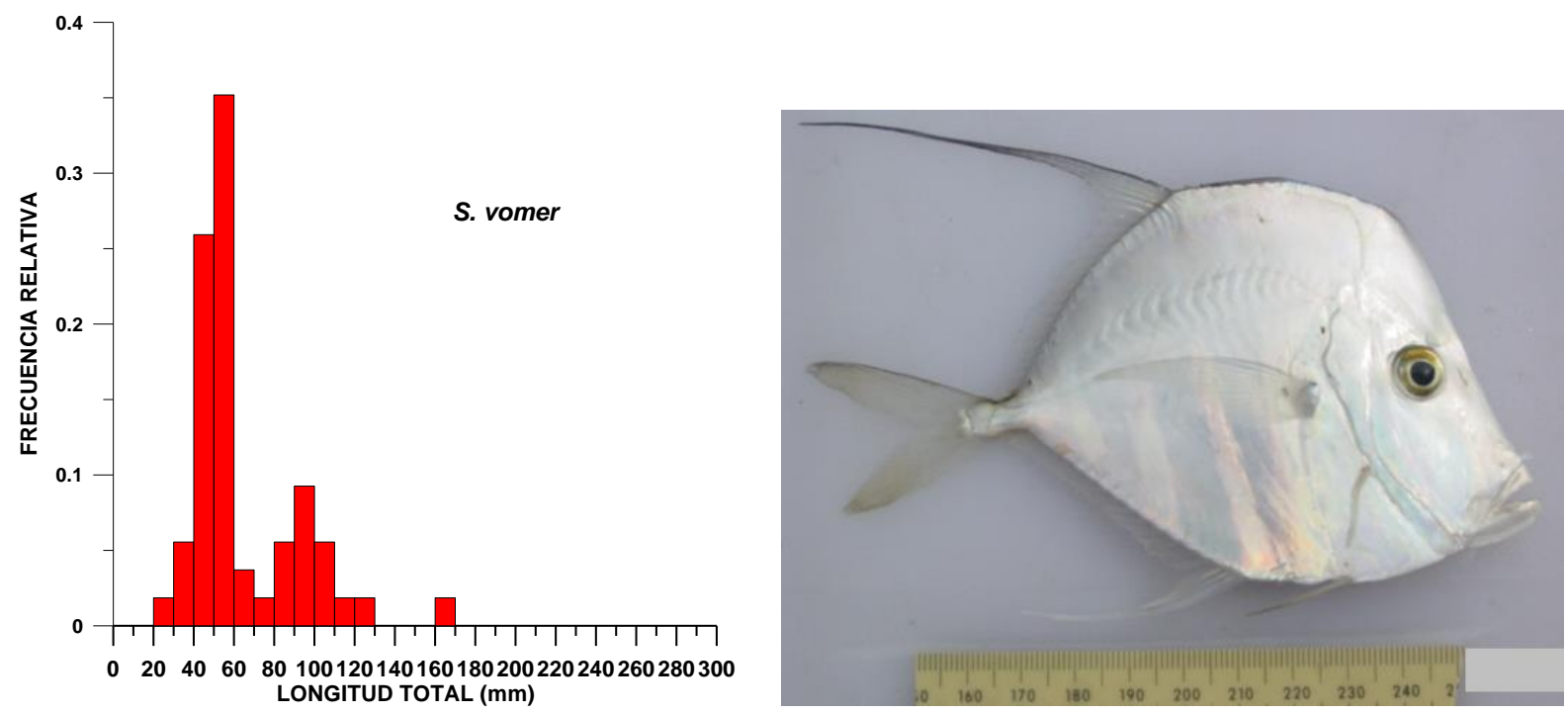

Figura III-22.-. Distribución de tallas de $S$. vomer durante la campaña de área barrida en el norte del GP en marzo 2005.

\section{Chloroscombrs chrysurus}

Durante la primera camapaña se capturaron tres ejemplares en la estación 6, de tallas comprendidas entre 86 y $124 \mathrm{~mm} \mathrm{LT}$. En la segunda campaña, estuvo presente en las estaciones 6 y 7 con solo tres ejemplares de 43, 63 y $118 \mathrm{~mm}$ LT. Esta especie puede alcanzar hasta $335 \mathrm{~mm}$ de LT.

\section{Trachinotus cayenensis}

De esta especie se capturó un solo ejemplar juvenil de $79 \mathrm{~mm}$ de LT (en la E7), aunque puede alcanzar tallas de $558 \mathrm{~mm}$ de LT. Es una especie comestible. En septiembre, solo se recolectaron tres ejemplares en las estaciones 6 y 7 . Las tallas estaban entre 220- $270 \mathrm{~mm} \mathrm{LT}$ y la maxima es de $558 \mathrm{~mm}$.

\section{Oligoplites palometa}


Se capturaron dos ejemplares de 88 y $224 \mathrm{~mm}$ de LT en la estación 7. Esta especie puede alcanzar tallas de hasta $497 \mathrm{~mm}$ de Lt, aunque la talla común de las capturas comerciales es de $350 \mathrm{~mm}$ de LT. Es abundante en aguas estuarinas y marinas. Se distribuye desde el Lago de Maracaibo hasta el Delta del Orinoco, inclusive en el Archipiélago de Los Roques. En septiembre, un ejemplar fue colectado con el tren de arrastre playero en la estación 3, y midió $80 \mathrm{~mm} \mathrm{LT}$. Otros dos ejemplares salieron en la estación 6 y sus tallas fueron 103 y 112 mm LT. Es una especie abundante tanto en aguas estuarinas como en aguas marinas.

\section{Oligoplites saurus}

Es una especie poco abundante en las aguas del Delta del Orinoco y aunque no se menciona su presencia en el GP, sus hábitos están relacionados con áreas estuarinas. Se capturaron dos ejemplares de 89 y $136 \mathrm{~mm}$ de LT. No tiene importancia comercial. En la segunda campaña, se capturaron tres ejemplares con el tren de arrastre playero en la estación 5, de talla 78- 130 mm LT.

\section{Hemicaranx amblyrhynchus}

Se colectaron dos ejemplares de 110 y $130 \mathrm{~mm}$ de LT en la estación 8. La máxima talla reportada para esta especie es de $455 \mathrm{~mm}$ LT para la Isla de Cubagua. Los juveniles habitan aguas someras y estuarinas, y los adultos en aguas saladas hasta $50 \mathrm{~m}$ de profundidad. Es comestible pero por su escasa abundancia no tiene interés comercial. En septiembre, se colectaron dos ejemplares en la estación 6 , de tallas pequeñas $(49-92 \mathrm{~mm} \mathrm{LT})$.

\section{Trachinotus falcatus}

Es una especie eurihalina y esta señalada para el GP. Se presento con muy poca abundancia (solo con un ejemplar por estación) en las estaciones 3, 5 y 7. Las tallas fueron 55, 204 y 417 mm LT. La talla maxima reportada es de 540 mm LT.

\section{Familia Diodontidae}

\section{Chilomycterus antillarum}

Se capturó un solo ejemplar en la estación 5, de talla pequeña, $120 \mathrm{~mm} \mathrm{LT}$ (puede alcanzar hasta $355 \mathrm{~mm}$ LT). Esta reportada para aguas claras, con fondos de 
praderas de Thallassia, pero aquí fue capturada en aguas turbias con salinidad de 20. Su distribución esta indicada desde el sureste de Florida y Bahamas, hasta el norte de Suramérica.

\section{Diodon hystrix}

Esta especie fue observada en los censos visuales, en las estaciones 1 y 3 , con un ejemplar por estación, eran de talla aproximada a $400 \mathrm{~mm}$ de LT. Se reporta para aguas de fondos someros con formaciones coralinas. No está señalada para el GP.

\section{Familia Ostraciidae}

\section{Lactophrys quadricornis}

Esta especie está señalada para fondos someros de aguas claras con desarrollo de formaciones coralinas (Cervigón, 1996). Sin embargo aquí fueron capturados 3 ejemplares en la estación 5, de fondos arenosos, con piedras, aguas turbias y salinidad de 20 psu con tallas pequeñas de 51, 58 y $120 \mathrm{~mm} \mathrm{LT}$. Esta especie puede alcanzar hasta $440 \mathrm{~mm}$ de LT.

\section{Familia Achiridae}

\section{Achirus lineatus}

Abundante en la estación 1, con 59 ejemplares, de tallas entre 74- 204 mm LT. También estuvo presente en las estaciones 3, 6, 7 y 8 con muy pocos ejemplares, entre 1 y 3 y de tallas que variaron entre $58-215 \mathrm{~mm} \mathrm{LT}$. Las tallas reportadas son grandes, ya que puede alcanzar una talla máxima de $226 \mathrm{~mm} \mathrm{LT}$. De acuerdo a Cervigón (1996) es una especie acusadamente eurihalina.

\section{Achirus achirus}

Aunque no fue reportada en la primera campaña, es una especie típica de la zona, se distribuye desde el GP hasta la desembocadura del Río Amazonas. Es abundante en el delta inferior del Orinoco. En la segunda campaña se colectaron 3 ejemplares en la estación 8, con tallas de 50-57 mm LT.

\section{Familia Paralichthydae}

\section{Syacium papillosum}

Se capturo en la estación 1, 3, 5 y 6, siendo mas abundante en la estación 1 (18 ejemplares). En el resto de las estaciones solo se recolectaron entre 1 y 5 
ejemplares. Las tallas oscilaron entre 63 y $191 \mathrm{~mm} \mathrm{LT}$, pudiendo alcanzar hasta 300 mm LT. No esta señalada para las aguas del GP.

\section{Paralichthys tropicus}

Se recolectó un ejemplar de $120 \mathrm{~mm}$ LT en la estación 5. Esta especie ha sido reportada para Trinidad y las costas de Guyana.

\section{Familia Cynoglosidae}

\section{Symphurus tesellatus}

Se recolectó un ejemplar en la estación 2, de 112 mm LT. Es común en fondos someros de sustrato blando, lo que se corresponde con las características de la estación 2.

\section{Familia Batrachoididae}

\section{Batrachoides surinamensis}

Especie propia de la región del GP, del delta inferior del Orinoco y de las costas de Guayana. Fue capturada en las estaciones 1 y 2 con dos y un ejemplar respectivamente. Las tallas estuvieron próximas a la talla máxima reportada que es $470 \mathrm{~mm} \mathrm{LT}$.

\section{Amphichthys cryptocentrus}

Se capturo en las estaciones 3 y 5 con un ejemplar en cada una, de 423 y $525 \mathrm{~mm}$ LT. Estas tallas son superiores a las señaladas por Cervigón (1991), que da una talla máxima de $396 \mathrm{~mm}$ LT. Esta especie no esta reportada para la zona del GP, es propia de las aguas neríticas de la plataforma. En los muestreos del mes de marzo no estuvo presente.

\section{Familia Synodontidae}

\section{Synodon foetens}

Esta reportada para el GP, entre otros hábitats; en la segunda campaña se capturó en la estación 1, con tres ejemplares de talla 75, 147 y $179 \mathrm{~mm}$ de LT, las cuales se pueden considerar pequeñas si tenemos en cuenta que la talla maxima es de 405 $\mathrm{mm}$ LT.

\section{Familia Triglidae}




\section{Prionotus punctatus}

Esta especie es característica de fondos fangosos y arenosos de las costas de Venezuela, particularmente entre Cabo Codera y Cabo Tres Puntas en el Estado Sucre (Cervigón 1991). Se colectaron solo dos ejemplares en las estaciones 5 y 6 , ambos considerados de tallas pequeñas ( 52 y $74 \mathrm{~mm} \mathrm{LT}$ ), si tomamos en cuenta que esta especie puede alcanzar hasta $357 \mathrm{~mm} \mathrm{LT}$.

\section{Familia Centropomidae}

\section{Centropomus ensiferus}

Especie de aguas estuarinas salobres, fue colectada en las estaciones 1 y 3 , con 5 y 1 individuo, respectivamente. Las tallas oscilaron entre 275-359 mm LT.

\section{Familia Sphyraenidae}

\section{Sphyraena picudilla}

De esta especie se recolectó un individuo pequeño (93 mm de LT) en la $E 1$, ya que se ha reportado que puede alcanzar tallas de $500 \mathrm{~mm} \mathrm{LT}$.

\section{Sphyraena barracuda}

Estuvo presente en la estación 2, donde fue colectado un ejemplar con el chinchorro de arrastre playero, el cual presentó una LT de $194 \mathrm{~mm}$. En la estación 6 se capturó otro organismo de $135 \mathrm{~mm}$ de LT, colectado con "la chica,". Esta especie es propia de aguas claras con formaciones rocosas o coralinas y no ha sido reportada para el GP.

\section{$\underline{\text { Miscelaneos }}$}

Solo quedan por mencionar 5 especies: Diplectrum radiale, Scorpaena plumieri, Mugil curema, Aprionichtys dumarilli y Archosargus rhomboidalis, las cuales están representadas por muy pocos ejemplares. 


\section{III.3.2 Análisis de la estructura demográfica de las comunidades de peces al norte del GP}

Los recursos vivos que habitan en el GP constituyen una riqueza biológica de grandes proporciones la cual ha permitido el sustento de numerosas poblaciones (indígenas y criollas) asentadas en sus márgenes tanto de Venezuela como de Trinidad.

El GP está señalado como una de la dos áreas de mayor relevancia para la biodiversidad en el cento-occidente del océano Atlántico (Carpenter, 2003). Esta riqueza se debe en parte al volumen de sedimento que aportan los grandes ríos, Orinoco y Amazonas, ricos en nutrientes y que contribuyen a la alta productividad de esa área, permitiendo el desarrollo de gran cantidad de recursos pesqueros; además, los manglares y humedales que lo rodean proporcionan refugio a juveniles de peces y soporta poblaciones de moluscos y particularmente camarones y cangrejos (Chan A Shing, 2001).

La fauna ictiológica ha sido ampliamente estudiada para la zona deltana: Gines y Cervigón (1967), Gines (1972), Cervigón (1982), Cervigón (1985), Novoa (1982), Novoa et al. (1982), Ramos et al. (1982), Novoa y Cervigón (1986), Novoa (2000), y Lasso et al. (2004). Sin embargo, en el área de la zona norte del GP, comienza a estudiarse con el estudio que se reporta.

En la campaña de marzo de 2005 se identificaron 82 especies que correspondieron a 77 peces óseos y 5 peces cartilaginosos, siendo las familias mejor representadas los Scianidade (roncadores y curvinas) con 20 especies, como Stillifer rastrifer el cual representó el $20 \%$ de la captura, siguendole en importancia de especies los Carangidos (lamaparosa y afines), los cuales estuvieron representados por individuos juveniles y no fueron muy abundantes. Los Ariidae (bagres) son la tercera familia con mas especies (6) y estos si constituyeron el mayor porcentaje de las capturas, particularmente en las estaciones 6, 7 y 8 donde alcanzaron hasta el $57 \%$ del total capturado, en la especie Cathorops spixii. 
En la segunda campaña (septiembre 2005) se reportan 103 especies distribuidas en 28 familias, siendo la familia Scianidae la mejor representada, con 15 especies; luego le siguen la Carangidae con 10, Clupeidae con 7 y Haemulidae, Lutjanidae y Ariidae, con 6 especies cada una.

En toda el área estudiada y en los dos períodos de muestreo se reportan 131 especies de 14 órdenes y 45 familias, siendo las familias más importantes: Sciaenidae con 23 especies, Carangidae con 11, Haemulidae con 8, Lutjanidae, Clupeidae y Ariidae con 7 y Engraulidae y Gerreidae con 6. Esta estructura comunitaria es semejante a la reportada por otros autores en zonas similares. Manickchand-Heileman et al. (1990) reporta los Sciaenidae con 11 especies, seguido de Carangidae con 9, Clupeidae y Haemulidae con 7 especies cada una. Los Sciaenidae copmom elemenytos dominantes son también reportados en otras localidades, como en Campeche, México, en la fauna acompañante de las pesquerías de camarones con 11 especies, en muestreos realizados mensualmente, durante un año (Ayala-Pérez et al., 2005)

El número de especies reportado en este estudio es elevado si lo comparamos con lo señalado por Manickchand-Heileman et al. (1990), quienes obtuvieron 99 especies en la costa noroccidental de Trinidad. Lazo et al. (2004) reportaron 48 especies para dos estaciones del extremo suroccidental del GP.

El empleo del tren de arrastre playero permitió incorporar peces de una laguna litoral (en la estación 3) y de la ictiofauna de la línea de costa en otras tres estaciones. Producto de estos lances se reportan 4 especies de Clupeidae que no aparecieron en la campaña de marzo: Harengula jaguana, H. clupeola, Sardinilla aurita $y$ Rhinosardinea sp., además de las especies Lutjanus sp. Sphyraena barracuda, Eucinostomus melanopterus, Mugil curema, y Trachinotus carolineus.

Los censos visuales elevaron el número de nuevos reportes en 21 especies, todas pertenecientes a ambientes rocosos de la línea de costa, con aguas relativamente claras del sector este del GP, y son: Malacoctenus macropus, Halichoeres bivittatus, Lutjanus jocu, L. cyanopterus Haemulon aurolineatum, H. flavolineatum, Abudefduf saxatilis, A. taurus, Caranx latus, Diodon histrix, Acanthurus bahianus, Kyphosus sp., 
Mycteroperca bonaci, Centropomus undecimalis, Gerres cinereus, Megalops atlanticus, Pomacanthus paru, Diplodus argenteus, Scartella cristata, Sparisoma sp., y Stegastes sp. Las familias Acanthuridae, Labridae, Pomacentridae y Pomacanthidae son típicas de sistemas arrecifales lo que le confiere a estos ambientes rocosos una particularidad dentro del ámbito general del GP.

Además de estas 30 especies, se colectaron por primera vez, con la red de arrastre o "chica" las siguientes especies: Trachinotus falcatus, Equetus acuminatus, E. umbrosus, Achirus lineatus, Paralichthys tropicus, Hexanematichthys herzbergi y Sphoeroides spengleri.

Las salinidades que se reportan en este período, variaron desde 35,2 en la costa norte (ensenada de Caraballo) hasta 24,0 ups en Las Garzas (costa lateral del extremo de la península), 22 y 13 ups en las estaciones 1 y 8 , respectivamente. La disminución de la salinidad en las estaciones del sector este del GP deben influir en la distribución de algunas especies, como es el caso de Lutjanus purpureus, que fue abundante en la estación 3 y escasa en la 4 y en la 5 . El resto de las especies (18), estuvo restringida a las estaciones 6, 7 y 8 (las de menor salinidad). En esta ocasión se reportan 15 especies de Scianidae, de las cuales 10 están presentes en ambos sectores: B. sanctaeluciae, Cynoscion acoupa, C. learchus, C.virescens, Larinus breviceps, Menticirrhus americanus, Micropogonias furnieri, Stellifer microps, S. rastrife y Nebris microps. Sólo 5 quedaron restringidas al sector oeste: Cynoscion microlepidotus, Macrodon ancylodon, Equetus acuminatus, E. umbrosus y Umbrina coroides.

Las especies de la familia Gerreidae también muestran una amplia distribución, ya que algunas que sólo fueron halladas en estaciones del sector este, ahora también se reportan en el sector oeste, como es el caso de Eucinostomus argenteus que se encontró en las estaciones 5 y 6 . E. gula también se presentó en la estación 7, además de estar en la 3 y en la 4 . Ambas especies son eurhalinas, lo que explica su ocurrencia en esa zona.

De la familia Clupeidae, dos especies repiten la misma distribución que en la campaña anterior: Pellona harroweri y Odontgnathus mucronatus, se capturaron sólo 
en las estaciones 7 y 8 . Pertenecientes a esta misma familia se incorporan a la lista de especies: Sardinella aurita, Rhinosardinia sp y Harengula jaguana, todas capturadas con el tren de arrastre playero, siendo Rhinosardinia una especie de agua dulce que se capturó en la estación 8 , la de más baja salinidad (13 psu).

Se observaron algunas particularidades con relación a la presencia de especies en ambientes que no le son propios. Tal es el caso de Sphoeroides spengleri, Chilomycterus antillarun, Lactophrys quadricornis, Equetus acuminatus y Prionotus punctatus, todas ellas reportadas como habitantes de aguas netamente marinas y claras que ahora fueron capturadas en estaciones del sector oeste, donde las salinidades son bajas (entre 19 y 13 psu) y las aguas turbias. Este reporte documenta la ampliación del ámbito de distribución de estas especies.

Un elevado porcentaje de las especies capturadas en los dos períodos (90\% aproximadamete), estuvo por debajo de las tallas máximas reportadas, siendo en su mayoría juveniles. Tal es el caso de Lutjanus synagris, en el que el $85 \%$ del total capturado se corresponde con estados juveniles (tallas entre 50 y $130 \mathrm{~mm}$ de LT), indeterminados sexualmente. En la pesquería artesanal del GP que opera a mayor profundidad, se han registrado tallas promedios de madurez sexual de $318 \mathrm{~mm} \mathrm{LT}$, oscilando las tallas de captura entre 210 -467 mm de LT (Gómez et al., 2001)

Los bagres, Bagre marino y Bagre bagre, también se colectaron en sus tallas juveniles. No así el Cathorps spixii que presentó algunos individuos con tallas próximas a los $300 \mathrm{~mm}$ de $\mathrm{LT}$, que es la talla máxima registrada, pero un porcentaje importante $(50 \%)$ de la captura se ubico entre 65 - $115 \mathrm{~mm} \mathrm{LT}$, correspondiente a etapas juveniles.

En los Scianidae también predominaron los juveniles, salvo en un ejemplar de Cynoscion virescens y otros de Bardiella sanctaeluciae, de la cual se encontraron hembras y machos maduros (estadios II y IV). La especie Micropogonias furnieri fue escasa en los muestreos, solo 3 ejemplares, pero ha sido reportada como muy abundante por Cervigón (1993) para el delta del Orinoco y la plataforma Guyanesa, igualmente es objeto de numerosos estudios en las costas de Trinidad por su gran importancia económica, (Manickchand-Dass 1980, Manickchand-Heileman y Kenny 
1990). Aunque los juveniles de esta especie están asociados a aguas someras y estuarinas, es decir que debería estar mejor representada en estos muestreos, quizás no coincidió con la época de desarrollo de los juveniles o quizás este no sea su hábitat preferencial.

Los Haemulidos se capturaron en muy poca cantidad, pero los ejemplares de las especies Anisotremus surinamensis y $A$. virginicus casi alcanzaban la talla máxima reportada y se encontraban en estados de madurez avanzado (IV y V), esto sugiere que utilizan esta zona como área de desove.

De los Clupeides solo Odontognathus mucronatus presentó un rango de tallas máximas, pero no se observaron individuos maduros.

El norte del GP está fuertemente influenciado por las descargas de los Ríos Orinoco, Caño San Juan y otros ríos menores, esto ha configurado en esta zona dos ambientes bien característicos: una al este de Güiria con aguas relativamente claras y con salinidades de 30 ups, con fondos arenosos y pedregosos, y otro ambiente al oeste de Güiria de aguas turbias y de salinidades menores de hasta 23 ups. Estos ambientes generan dos comunidades ícticas, la primera, al este, se caracteriza por la presencia dominante de Lutjanus synagris y de los Gerreidade, Diapterus rhombeus y Eucinostomus gula y la segunda, al oeste, son los Scianidae, Ariidae y Clupeides los que predominan, en número de especies y en abundancia. Esta distribución se corresponde con las características ecológicas de las especies.

\section{III.3.3 Conclusiones}

- La ictiofauna de la costa norte del GP, especialmente la región occidental, estuvo representada en su mayoría por juveniles, por lo que se debe considerar la zona como área de refugio, alimentación y hábitat de numerosas especies para reproducirse. Lo que sugiere que estas áreas deben ser protegidas y monitoreandas regularmente, para evitar daños irreparables al ecosistema.

- La riqueza de especies de peces, obtenidas a través de los tres métodos empleados ('CHICA', tren de arrastre playero y censos visuales), se considera 
alta con 132 especies, representadas por 5 especies de elasmobranquios y 128 de teleósteos.

- Empleando la "chica" y el tren de arrastre playero se capturaron 82 especies en cada período para un total de 111 especies. A través de los censos visuales se reportaron 21 especies.

- Se observó un predominio de las familias Lutjanidae y Gerreidae en la región oriental de la zona estudiada, y de las familias Scianidae, Ariidae y Clupeidae en la región occidental. Estas familias estan representadas por un elevado número de especies de gran importancia económica, que soportan pesquerias importantes en toda la zona del GP, tanto para la costa oriental de venezuela como para la costa occidental de Trinidad.

- Las familias mejor representadas, en relación con el número de especies, para los dos muestreos fueron: Scianidae (23 especies), Carangidae (11), Haemulidae (8), Clupeidae (7) y Ariidae, Lutjanidae (7), Gerreidae (6) y Engraulidae (6).

- A pesar de que en cada estación se realizaron dos lances a diferentes profundidades, esto no introdujo ninguna diferencia significativa en las capturas.

\section{III.3.4 Invertebrados (Crustáceos y Moluscos)}

Las características estuarinas del Golfo de Paria originan una zona específica de producción secundaria importante, donde se ejerce una actividad pesquera artesanal notable. Entre los recursos capturados por las pesquerías artesanales se encuentran algunos invertebrados, en los que los crustáceos poseen una importancia relevante. En vista de lo anteriormente señalado, y teniendo en cuenta las actividades de la industria petrolera que se desarrollaran en el área, la identificación de invertebrados con posibilidad de explotación, tales como crustáceos y moluscos, 
adquiere importancia en los estudios de línea base ya que luego seran utilizados en actividades de proyecciones de impacto ambiental en la zona.

Las muestras provinieron de los lances realizados para la estimación de biomasa por área barrida (Sección III-2). Los crustáceos recolectados en esos lances fueron identificados siguiendo claves descritas por Rodríguez (1980). El arreglo taxonómico utilizado para la clasificación sistemática en las jerarquías superiores, hasta familia, siguió la clasificación propuesta por Martin y Davis (2001). Todos los organismos fueron contabilizados por estación, medidos en su longitud máxima determinandose su peso total, con un vernier (0,01 $\mathrm{mm}$ de apreciación) y una balanza (0,01 g de apreciación), respectivamente. Para tener una idea de la población de las especies con mayor importancia, se realizó una distribución de la tallas en las estaciones donde la cantidad de organismos permitía una ponderación cuantitativamente adecuada ( $>30$ organismos).

\section{III.3.4.1 ABUNDANCIA Y ESTRUCTURA DEMOGRÁFICA POR ESPECIE Primera Campaña (Marzo 2005)}

En la primera evaluacion, periodo de sequia (marzo 2005), todos los organismos capturados fueron crustáceos. Tan sólo un molusco, el gasterópodo Melongena melongena fue capturado en la estación 8 , el cual debido a su poca abundancia, no es considerado en el presente informe, al igual que otros invertebrados como celenterados que carecen de importancia comercial.

Todas las especies identificadas (6) en la primera expedicion pertenecieron a la clase Malacostraca, específicamente del orden Decapada (Tabla III-24). Cuantitativamente las especies de la familia Penaeidae (Litopenaeus schmitii y Xyphopenaeus kroyeri) fueron las mas representativas, aportando el $75 \%$ de los organismos capturados. Luego le siguió el aporte de la familia Portunidae con el $22 \%$. Los organismos restantes, representaron tan solo un $3 \%$ del total, los cuales pertenecieron a las especies Epialtus bituberculatus y Microphrys bicornutus, especies agrupadas en la superfamilia Majoidae. En total se colectaron 264 individuos y el número de cada especie por estación se indica en la tabla III-25 y la biomasa en la tabla III-26. 
Tabla III-24.- Especies identificadas con su ubicación sistemática

Phylum:ARTHROPODA

Subphylum Crustacea Brünnich, 1772

Clase: Malacostraca Latreille, 1806

Subclase: Eumalacostraca Grobben, 1892

Superorden: Eucarida Calman, 1904

Orden: Decapoda Latreille, 1803

Suborden: Dendrobranchiata, Bate 1888

Superfamilia: Penaoidea, Rafinesque, 1815

Familia: Penaeidae, Rafinesque, 1815

Litopenaeus schmitii Boone, 1931

Xyphopenaeus kroyeri (Heller, 1862)

Suborden: Pleocyemata Burkenroad, 1963

Superfamilia: Majoidae Samouelle, 1819

Familia: Epialtidae, Macleay, 1838

Epialtus bituberculatus, Milne Edwards, 1880

Familia: Mithracidae, Balss, 1929

Microphrys bicornutus (Latreille 1825)

Superfamilia: Portunoidea Rafinesque, 1815

Familia: Portunidae Rafinesque, 1815

Callinectes sapidus Rathbun, 1895

Portunus spinimanus Latreille, 1819

Tabla III-25.- Abundancia en número de organismos capturados de crustáceos.

\begin{tabular}{|c|c|c|c|c|c|c|c|c|c|}
\hline \multirow[b]{2}{*}{ Especies } & \multicolumn{9}{|c|}{ Estaciones } \\
\hline & 1 & 2 & 3 & 4 & 5 & 6 & 7 & 8 & TOTAL \\
\hline Xyphopenaeus kroyeri & & & & & & & & 33 & 33 \\
\hline Litopenaeus schmittii & & & & & & 14 & 14 & 138 & 166 \\
\hline Callinetes sapidus & 1 & & & 1 & 8 & 2 & 13 & 11 & 36 \\
\hline Portunus spinimanus & 1 & & & & & & & 21 & 22 \\
\hline Microphrys bicornutus & & & 5 & & & & & & 5 \\
\hline Epialtus bituberculatus & & & 2 & & & & & & 2 \\
\hline TOTAL & 2 & 0 & 7 & 1 & 8 & 16 & 27 & 203 & 264 \\
\hline
\end{tabular}

Tabla III-26.- Biomasa (g) de crustáceos capturados.

\begin{tabular}{|c|c|c|c|c|c|c|c|c|c|}
\hline \multirow[b]{2}{*}{ Especies } & \multicolumn{9}{|c|}{ Estaciones } \\
\hline & 1 & 2 & 3 & 4 & 5 & 6 & 7 & 8 & TOTAL \\
\hline Xyphopenaeus kroyeri & & & & & & & & 11 & 11 \\
\hline Litopenaeus schmittii & & & & & & 306 & 225 & 803 & 1334 \\
\hline Callinetes sapidus & 2 & & & 1 & 134,8 & 181 & 309,3 & 350,7 & 978,8 \\
\hline Portunus spinimanus & 4 & & & & & & & 310 & 314 \\
\hline Microphrys bicornutus & & & 35,5 & & & & & & 35,5 \\
\hline Epialtus bituberculatus & & & 0,7 & & & & & & 0,7 \\
\hline TOTAL & 6 & 0 & 36,2 & 1 & 134,8 & 487 & 534,3 & 1474,7 & 2674 \\
\hline
\end{tabular}


Tanto en número de organismos como en biomasa, así como en el número de especies, con la excepción de la superfamilia Majoidae, que se presentó tan solo en la estación 3 (Puerto de Hierro Este), la captura de crustáceos fue mas representativa en las estaciones occidentales de la costa Sur de Paria; de esta manera, en la estación más occidental (8, Oeste de Irapa, Los Tancones) se capturaron 4 de las 6 especies, que representaron el 77 y $55 \%$ de los organismos y la biomasa de crustáceos capturados, respectivamente.

Los organismos capturados en las diferentes estaciones $(6,7$ y 8$)$ de Litopenaeus schmittii, presentaron una distribución de talla bimodal, con mayor frecuencia entre 80 y $105 \mathrm{~mm}$ en la moda principal y organismos de $135-140 \mathrm{~mm}$ en la segunda (Figura III-23). De igual manera existe una tendencia a disminuir la talla promedio de la estación de la 6 a la 8 (Tabla III-27, ANOVA, p<0,05). La otra especie de camarón, Xyphopenaeus kroyeri, (Figura III-23) tan sólo se encontró en la estación 8 y su talla se encontró desde 60 a 110 mm, con la mayoría de organismos entre los 60 y $90 \mathrm{~mm}$.

En relación a Callinectes sapidus la composición de clases de tallas fue unimodal, estando las más representativas entre 30 y $40 \mathrm{~mm}$. Las tallas a lo largo de las estaciones no presentó mucha variabilidad (Tabla III-27, ANOVA, p>0,1). 

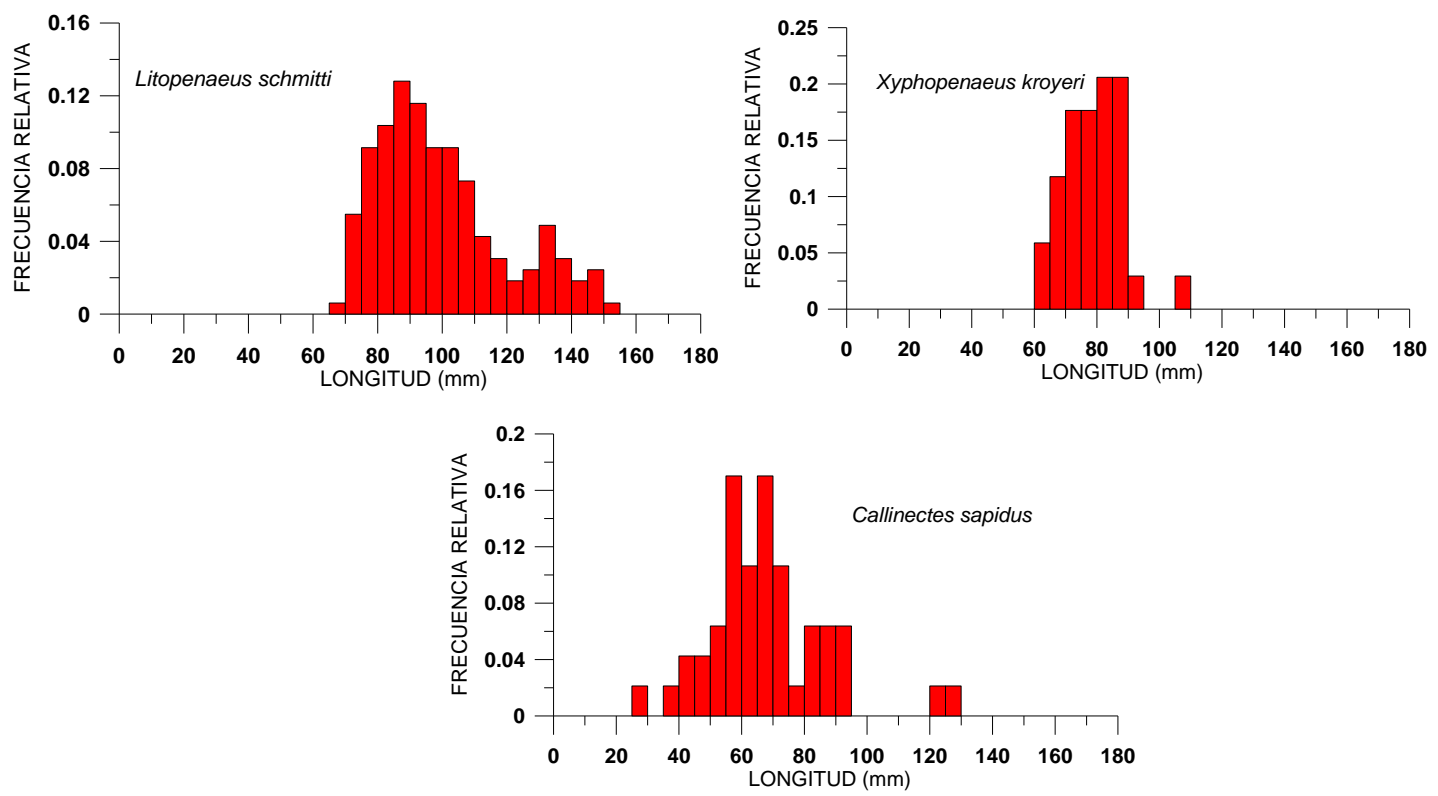

Figura III-23.- Distribución de tallas de las especies de invertebrados más importantes capturadas con red de arrastre artesanal tipo 'chica' en la primera campaña al norte del Golfo de Paria.

Tabla III-27.- Talla promedio y su desviación estándar (sd) de las especies capturados de crustáceos.

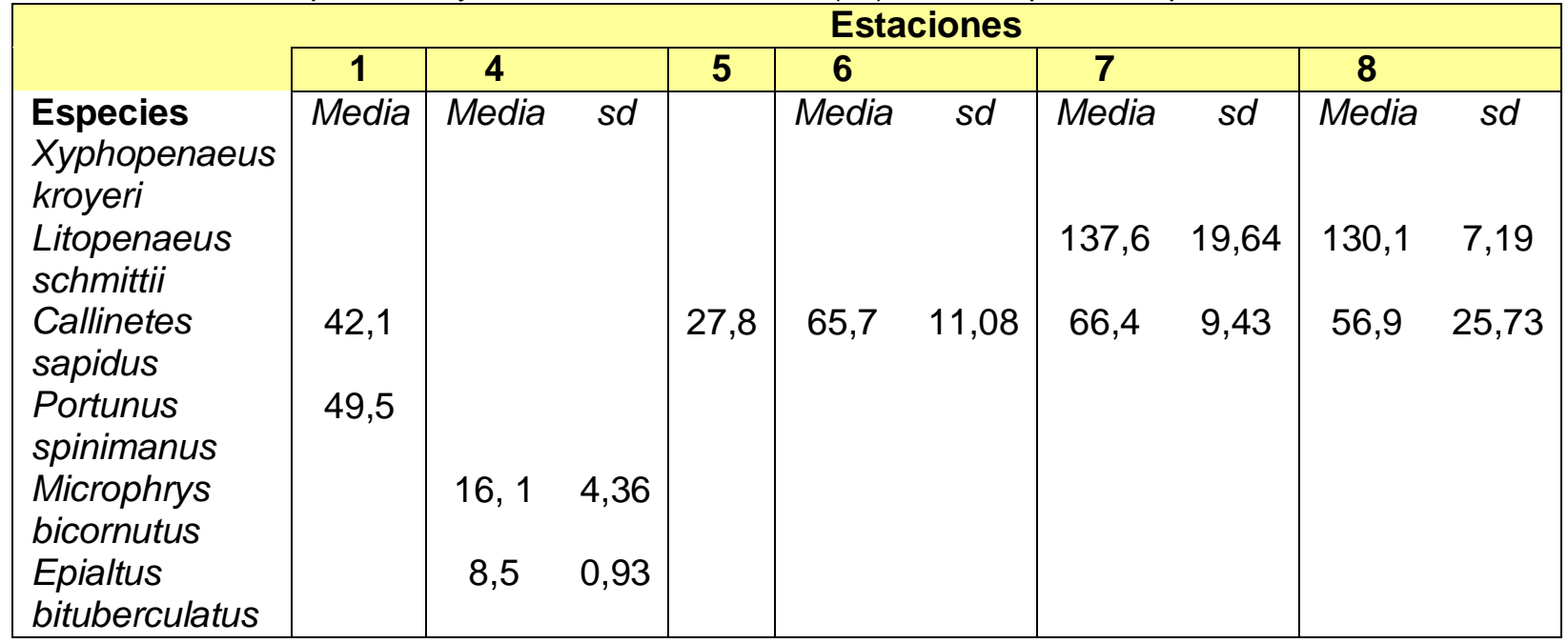

\section{Segunada Campaña (Septiembre 2005)}

En la segunda campaña (periodo lluvioso, octubre 2005), la mayoría de los organismos capturados fueron crustáceos, y escasos moluscos, Los gasterópodos Melongena melongena y Chicoreus brevifrons, capturados en las estaciones 8 y 2 , y Fasciloria tulipa, y Phyllonotus pomun, en la estación 4. Debido a su poca abundancia, no son considerados en el presente informe, al igual que otros 
invertebrados como estrellas de mar y esponjas los cuales carecen de importancia comercial.

Todas las especies identificadas (7) pertenecen a la clase Malacostraca, específicamente del orden Decapada (Tabla III-28).

Tabla III-28.- Especies identificadas con su ubicación sistemática.

\begin{tabular}{|l|}
\hline Phylum:ARTHROPODA \\
Subphylum Crustacea Brünnich, 1772 \\
Clase: Malacostraca Latreille, 1806 \\
Subclase: Eumalacostraca Grobben, 1892 \\
Superorden: Eucarida Calman, 1904 \\
Orden: Decapoda Latreille, 1803 \\
Suborden: Dendrobranchiata, Bate 1888 \\
\\
Superfamilia: Penaoidea, Rafinesque, 1815 \\
Familia: Penaeidae, Rafinesque, 1815 \\
Litopenaeus schmitii Boone, 1931 \\
Xyphopenaeus kroyeri (Heller, 1862) \\
Suborden: Pleocyemata Burkenroad, 1963 \\
Superfamilia: Majoidae Samouelle, 1819 \\
Familia: Mithracidae, Balss, 1929 \\
Microphrys bicornutus (Latreille 1825) \\
Superfamilia: Portunoidea Rafinesque, 1815 \\
Familia: Portunidae Rafinesque, 1815 \\
Callinectes sapidus Rathbun, 1895 \\
Callinectes bocourti Rathbun, 1895 \\
Callinectes ornatus Rathbun, 1895 \\
Callinectes exasperatus Rathbun, 1895 \\
\hline
\end{tabular}

Cuantitativamente las especies de la familia Penaeidae (Litopenaeus schmitii y Xyphopenaeus kroyeri) fueron las mas representativas, aportando el $75 \%$ de los organismos capturados. Luego le siguió el aporte de la familia Portunidae con el $22 \%$. Los organismos restantes, representaron tan solo un $3 \%$ del total, perteneciendo a las especies Arenaeus crbarius y Microphrys bicornutus, agrupadas en la superfamilia Majoidae (Tabla III-29). Esta misma tendencia fue determinada también en relación a la en biomasa (Tabla III-30). 
Tabla III-29.- Abundancia en número de organismos capturados de crustáceos.

\begin{tabular}{|c|c|c|c|c|c|c|c|c|c|}
\hline \multirow[b]{2}{*}{ Especies } & \multicolumn{9}{|c|}{ Estaciones } \\
\hline & 1 & 2 & 3 & 4 & 5 & 6 & 7 & 8 & TOTAL \\
\hline Xyphopenaeus kroyeri & & 12 & & & & & & 11 & 23 \\
\hline Litopenaeus schmittii & 2 & & & & & 2 & & 55 & 59 \\
\hline Callinetes sapidus & & & & & & & & 1 & 1 \\
\hline Callinectes bocourti & 1 & & & & & & & 4 & 5 \\
\hline Callinectes ornatus & 46 & 27 & 4 & 79 & 10 & 6 & 2 & & 174 \\
\hline Callinectesexasperatus & & & & 6 & & & & & 6 \\
\hline Microphrys bicornutus & & & & 1 & & & & & 1 \\
\hline TOTAL & 49 & 39 & 4 & 86 & 10 & 8 & 2 & 71 & 269 \\
\hline
\end{tabular}

Tabla III-30.- Biomasa (g) de crustáceos capturados.

\begin{tabular}{|c|c|c|c|c|c|c|c|c|c|}
\hline \multirow[b]{2}{*}{ Especies } & \multicolumn{8}{|c|}{ Estaciones } & \multirow[b]{2}{*}{ TOTAL } \\
\hline & 1 & 2 & 3 & 4 & 5 & 6 & 7 & 8 & \\
\hline Xyphopenaeus kroyeri & & 48,9 & & & & & & 25,4 & 74,3 \\
\hline $\begin{array}{l}\text { Litopenaeus schmittii } \\
\text { Callinetes sapidus } \\
\text { Callinectes bocourti }\end{array}$ & 6,3 & & & & & & & $\begin{array}{c}223,2 \\
13,1 \\
405,3\end{array}$ & $\begin{array}{c}229,5 \\
13,1 \\
405,3\end{array}$ \\
\hline Callinectes ornatus & 29 & 214 & 182 & 1905 & 87,7 & 46,1 & 35,5 & & 2499,3 \\
\hline Callinectes exasperatus & & & & 77 & & & & & 77 \\
\hline Microphrys bicornutus & & & & 9 & & & & & 9 \\
\hline TOTAL & 35 & 262,9 & 182 & 1991 & 87,7 & 46,1 & 35,5 & 667 & 3307,5 \\
\hline
\end{tabular}

Tanto en número de organismos como en biomasa, así como en el número de especies, con la excepción de la superfamilia Majoidae, que se presentó tan solo en la estación 4 (Guayabero), la captura de crustáceos fue mas representativa en las estaciones occidentales de la costa sur de Paria; de esta manera, en la estación más occidental (8, oeste de Irapa, Los Troncones) se capturaron 4 de las 6 especies, que representaron el $77 \%$ y $55 \%$ de los organismos y la biomasa de crustáceos capturados, respectivamente.

Los organismos capturados en las diferentes estaciones $(1,6$ y 8$)$ de Litopenaeus schmittii, presentaron una distribución de talla unimodal, con mayor frecuencia entre 80 y $115 \mathrm{~mm}$ en la moda principal y organismos de $135-140 \mathrm{~mm}$ en 
la segunda moda (Figura III-24). De igual manera existe una tendencia a disminuir la talla promedio de la estación de la 6 a la 8 (Tabla III-31). La otra especie de camarón, Xyphopenaeus kroyeri, tan sólo se encontró en la estación 8 y su talla se encontró desde 60 a $141 \mathrm{~mm}$, con la mayoría de organismos entre los 60 y $90 \mathrm{~mm}$.

En relación a Callinectes sapidus la composición de clases de tallas fue unimodal, estando las más representativas entre 30 y $40 \mathrm{~mm}$. Las tallas a lo largo de las estaciones no presentó mucha variabilidad (Tabla III-31, ANOVA P>0.1).
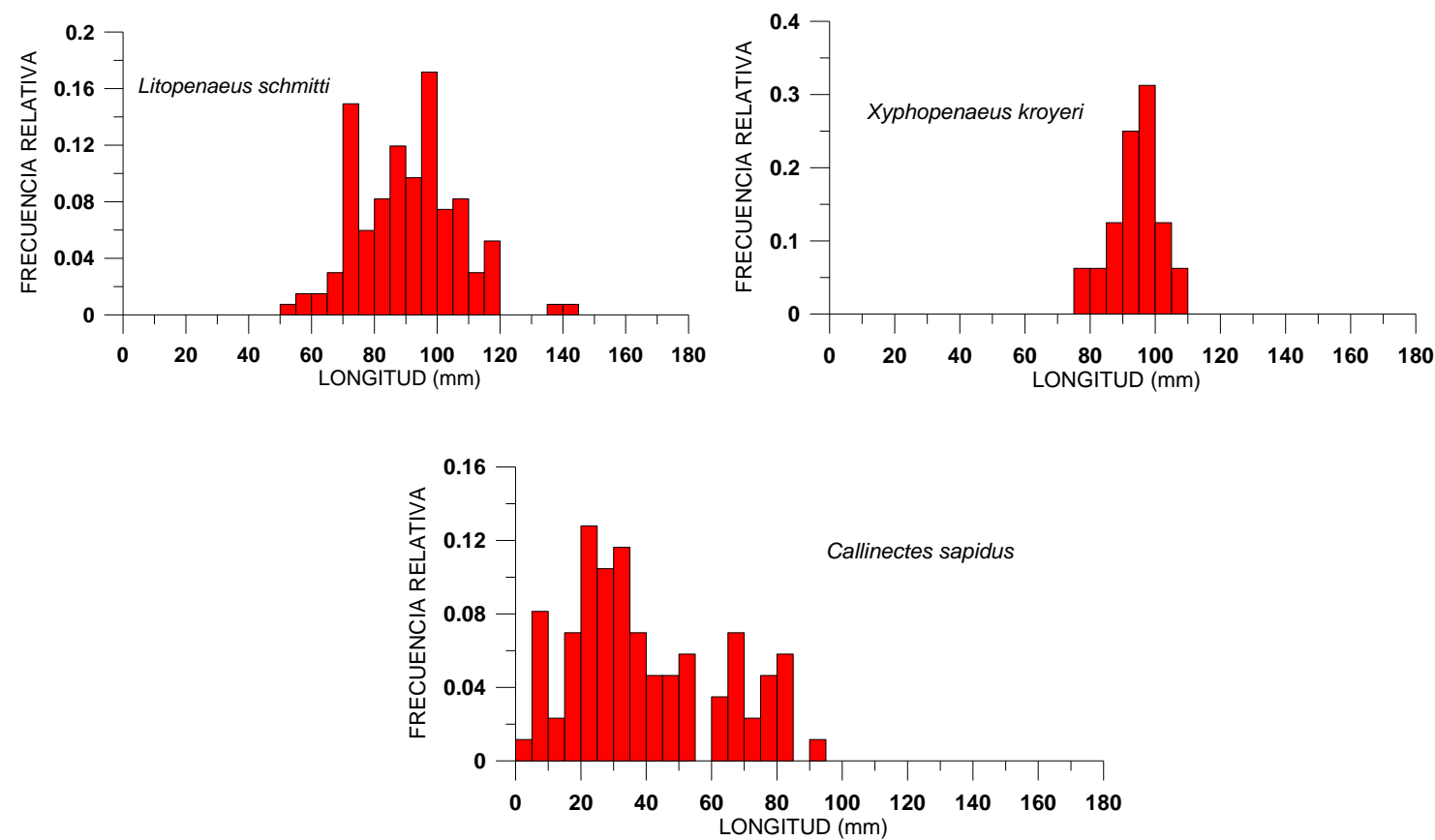

Figura III-24.- Distribución de tallas de las especies de invertebrados más importantes capturadas con red de arrastre artesanal tipo 'chica' en la segunda campaña al norte del Golfo de Paria.

Tabla III-31.- Talla promedio y su desviación estándar $(s d)$ de las especies capturados de crustáceos.

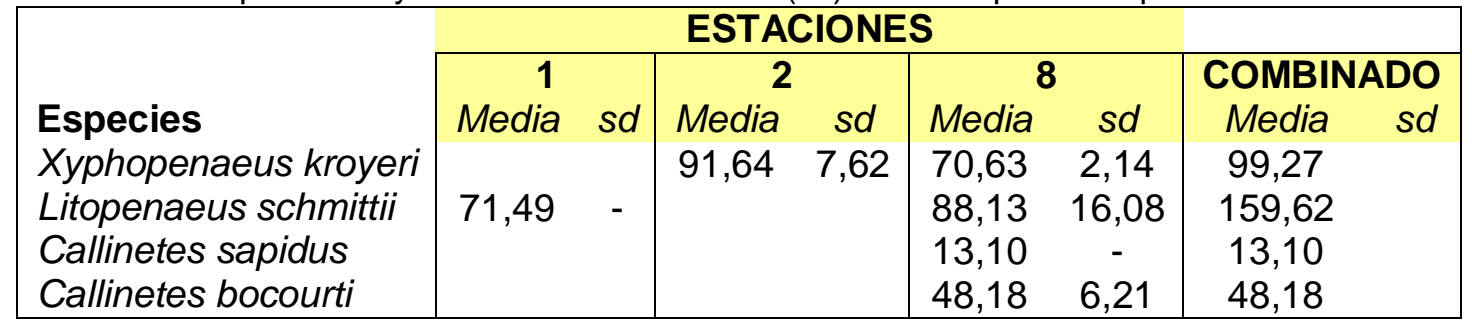




\section{III.3.5 Análisis de la estructura demográfica de las comunidades de invertebrados al norte del Golfo de Paria}

Estudios previos realizados en el Golfo de Paria han reportado que los crustáceos constituyen el segundo grupo taxonómico más abundante, alternándose con moluscos y poliquetos (Benthos Estudios y Proyectos, 2003).

En nuestro estudio la familia Penaeidae fue la que presentó especies de mayor importancia comercial: camarones Litopenaeus schmitii y Xyphopenaeus kroyeri. Estas especies, particularmente, el camarón Litopenaeus schmitii, es muy importante para la pesca artesanal, por su alto valor comercial, sobre todo de la zona oriental de la costa sur de Paria, donde existió mayor abundancia. La distribución del promedio de tallas de esta especie en la zona occidental del área muestreada, disminuye hacia la última estación, indicando probablemente una migración gradual de este a oeste, aunque su abundancia disminuyó drásticamente en el periodo lluvioso. Altuve (1997) estudió la distribución del camarón blanco, Litopenaeus schmitti, explotado por pescadores artesanales de la costa norte del Golfo de Paria, reportando que la especie se distribuye desde Irapa hasta Punta de Piedras, en las inmediaciones de la Ensenada de Guayabero, sugiriendo una migración hacia aguas mas profundas para la reproducción. Aunque, nuestro estudio puede seguir un patrón correlativo con la mayor salinidad u otros factores debido a los procesos hidrológicos presentes en el Golfo de Paria, un estudio mas exhaustivo y específico debe realizarse para comprobar la hipótesis antes señalada.

A pesar de que en ambas campañas el numero de organismos colectados fue muy semejante, la biomasa en la segunda campaña (periodo lluvioso) fue significativamente mas alta, debido a la presencia de 3 especies mas de Callinectes, en especial de $C$. ornatus, no colectado en la primera campaña, la cual fue la especie mas abundante en todas las estaciones; y cuya presencia puede estar relacionada con el aumento de los recursos alimenticios en el periodo lluvioso.

El camarón Xyphopenaeus kroyeri es una especie pequeña que, aunque se comercializa en Venezuela y otros países, es de menor importancia que Litopenaeus 
schmitii; no obstante, esta especie se encontró también con cierta abundancia, en la estación mas occidental (estación 9 al Oeste de Irapa, Los Troncones).

Otras especies en importancia son las pertenecientes a la familia Portunidae, especialmente Callinectes sapidus, que en la primera campaña fue la más representativa en cuanto al número de estaciones donde se encontró, por lo que pareciera que se distribuye a lo largo de toda la costa sur de Paria, aunque fue cuantitativamente mas importante hacia el este. Las tallas se concentraron entre $30 \mathrm{y}$ $40 \mathrm{~mm}$, lo cual es una talla pequeña para la talla alcanzada por estos organismos, lo que sugiere una distribución de tallas relativa a una época reproductiva específica. $C$. ornatus por el contrario se colecto solo en el periodo lluvioso con una alta abundancia en todas las estaciones a excepción de la estacion 9. Las especies restantes, carecen de importancia comercial y fueron, las que se consiguieron en menor proporción.

\section{III.3.6 CONCLUSIONES}

- Los crustáceos de importancia comercial de la costa sur de la Península la de Paria están representados por la clase Decapoda, principalmente por las familias Penaeidae (camarones Litopenaeus schmitii, Xyphopenaeus kroyeri) y Portunidae (jaibas Callinectes sapidus, Portunus spinimanus, Callinectes ornatus).

- Los camarones Litopenaeus schmitii, Xyphopenaeus kroyeri y la jaiba Callinectes sapidus, son las especies de mayor relevancia económica capturadas.

- En la estación 8 (oeste de Irapa) se recolectó la mayor cantidad de crustaceos en el periodo seco, mientras que en el periodo lluvioso se obtuvieron en la 4 y la 8.

- Litopenaus schmitti fue la especie mas abundante en numero en el periodo de sequia, mientra que Callinectes ornatos lo fue en el periodo de lluvia. 
- La mayor biomasa obtenida en dos muestreos del período seco se debieron a la presencia de $C$. ornatos.

- Existe un grado de importancia cualitativa y cuantitativa de especies y organismos de crustáceos de importancia comercial hacia la región occidental de la costa sur de la Península de Paria.

\section{IV.- EVALUACION DE LOS BANCOS DE MOLUSCOS BIVALVOS AL NORTE DE LA PENÍNSULA DE PARIA Y EN EL NORTE DEL GOLFO DE PARIA}

Los moluscos son un grupo de invertebrados del bentos muy importante en el área del Proyecto Mariscal Sucre. Desde el punto de vista comercial muchas especies pertenecientes a esta clase pueden contribuir significativamente a las pesquerías, o bien ser cultivadas masivamente para el consumo humano. En el Edo. Sucre, particularmente en la Península de Araya y al oeste de la costa Norte Paria existen varias especies que sostienen pesquerías de mucha importancia (Novoa et al. 1998; Lodeiros et al. 1999), siendo la zona este de la costa norte de Paria y la costa sur poco estudiada o explorada. Debido a que la explotación de dichos bancos es el sustento de varias familias de las comunidades costeras, y dada su ubicación intermareal, estos recursos están expuestos al desarrollo del PMS. En esta primera fase se determina la ubicación, extensión, parámetros poblacionales y de producción de los bancos de moluscos bivalvos en el área de influencia del PMS.

En zonas profundas del norte de la PNPP cerca del Pozo Dragon, Monente et. al, (2001) identificaron 89 especies de moluscos bentónicos resaltando la abundancia de Polystira albida y la existencia de 3 nuevas especies para Venezuela (Colubrabaria lineolata, Scaphadera wassoni y Vernicularia sprata), mientras que en el estudio FLASA-LAGOVEN (1993) en 23 estaciones se identificaron 8 especies de 7 familias de moluscos. 
En un análisis de moluscos del nororiente, Capelo y Buitriago (1998) reportaron 76 especies de moluscos para la península de Paria, un número mucho menor que en Araya (1225 especies) lo cual se debe a la escasez de estudios en la zona.

En la presente investigación se indican datos sobre la evaluación de bancos de moluscos, en el norte y en el sur de la Península de Paria, haciendo énfasis en especies de importancia comercial

\section{IV.1 Descripción de los muestreos}

Los estudios exploratorios se realizaron del 10 al 17 de marzo (Período de Sequía) y del 25 de octubre al 03 de noviembre de 2005 (Periodo de lluvia) y comprendió la costa, en orientación oeste-este, desde la localidad Playa Copey (Carúpano) hasta Uquire en el Norte y desde Irapa hasta la localidad de Los Paticos (al Este de Macuro) en el Sur, con la ayuda de un trasporte de doble tracción y expediciones en embarcación. En las localidades investigadas, donde existen bancos de especies comerciales de moluscos, se determinó con un muestreo preliminar el ancho de banda o extensión del banco, definida ésta por el área que contiene la especie ocupada en la localidad y estimada por su longitud y ancho. Para el caso de Donax denticulatos, el ancho de banda fue estimado en $3 \mathrm{~m}$ sobre la zona intermareal y para Tivela mactroides, un ancho de $30 \mathrm{~m}$, en la zona sublitoral somera, especificando la longitud de la extensión del banco en cada localidad. Para el caso de los mejillones y otras especies de sublitoral se estimó el área ocupada en los bancos por percepción visual. Muchas de las evaluaciones sobre la distribución y ancho de banda de algunos bancos, fueron estimados siguiendo informaciones de lugareños a través de entrevistas "in situ".

En la identificación y ubicación taxonómica de las especies se consideró seguir la sistemática clásica propuesta por Thièle (1929-1935), siguiendo el esquema de obras generales como la de Abbott (1974), Díaz y Puyana (1994) y Lodeiros et al. 1999, trabajos que también sirvieron para la identificación de los organismos siguiendo sus claves y descripciones. 
Para la evaluación de los bancos de las especies $T$. mactroides, $D$. denticulatus y Asaphis deflorata se realizaron censos ecológicos al azar, en estaciones situadas cada $50 \mathrm{~m}$, utilizando una cuadrata de $20 \times 20 \mathrm{~cm}$ de lado. El total de sedimento extraído en cada censo fue tamizado a través de una malla 4 $\mathrm{mm}$. En el caso de especies más grandes ubicadas en el sublitoral, se utilizó una cuadrata de 50x50 cm de lado, extrayendo las muestras por buceo en apnea y en algunas ocasiones utilizando una rastra metálica de boca rectangular de $55 \mathrm{~cm}$ de ancho $\times 28 \mathrm{~cm}$ de altura.

Una vez colectadas las muestras, estas se colocaron en un recipiente con agua por mar por $4 \mathrm{~h}$, con el fin de realizar una autodepuración, luego se almacenaron en una cava refrigerada hasta su posterior análisis en el laboratorio.

En el laboratorio a cada ejemplar se le realizaron mediciones morfométricas, con especial referencia a la longitud máxima con un vernier (0,01 mm de apreciación) y el peso total con una balanza de $0,001 \mathrm{~g}$ de apreciación. Estas mediciones conformaron la base de datos que junto la densidad, abundancia y el ancho de banda o extensión de los bancos permitieron estimar la biomasa total o producción de los bancos.

\section{IV.2 Especies con potencialidad comercial identificadas}

Las especies con valor comercial identificadas se listan en orden sistemático en la Tabla IV-1. Se identificaron 32 especies, 26 bivalvos y 6 gasterópodos de importancia comercial; no obstante, solo 9 especies (7 bivalvos y 2 gasterópodos) se encontraron con una abundancia que soportan o podrían soportar una explotación de subsistencia o artesanal. Estas especies fueron para la costa Norte el chipichipe Donax denticulatus, el guacuco Tivela mactroides, la ostra perla Pinctada imbricata, los mejillones, verde Perna viridis y marrón Perna perna, además del caracol Phyllonotus pomum. Para la costa Sur, se encontraron el caracol longo Melongena melongena, la almeja Asaphis deflorata y la ostra americana Crassostrea virgínica, con alguna abundancia de Perna perna y Perna viridis. A continuación se presenta una descripción de dichas especies: 
Tabla IV-1.- Lista de especies de moluscos con valor comercial. Las especies están nombradas y ubicadas sistemáticamente.

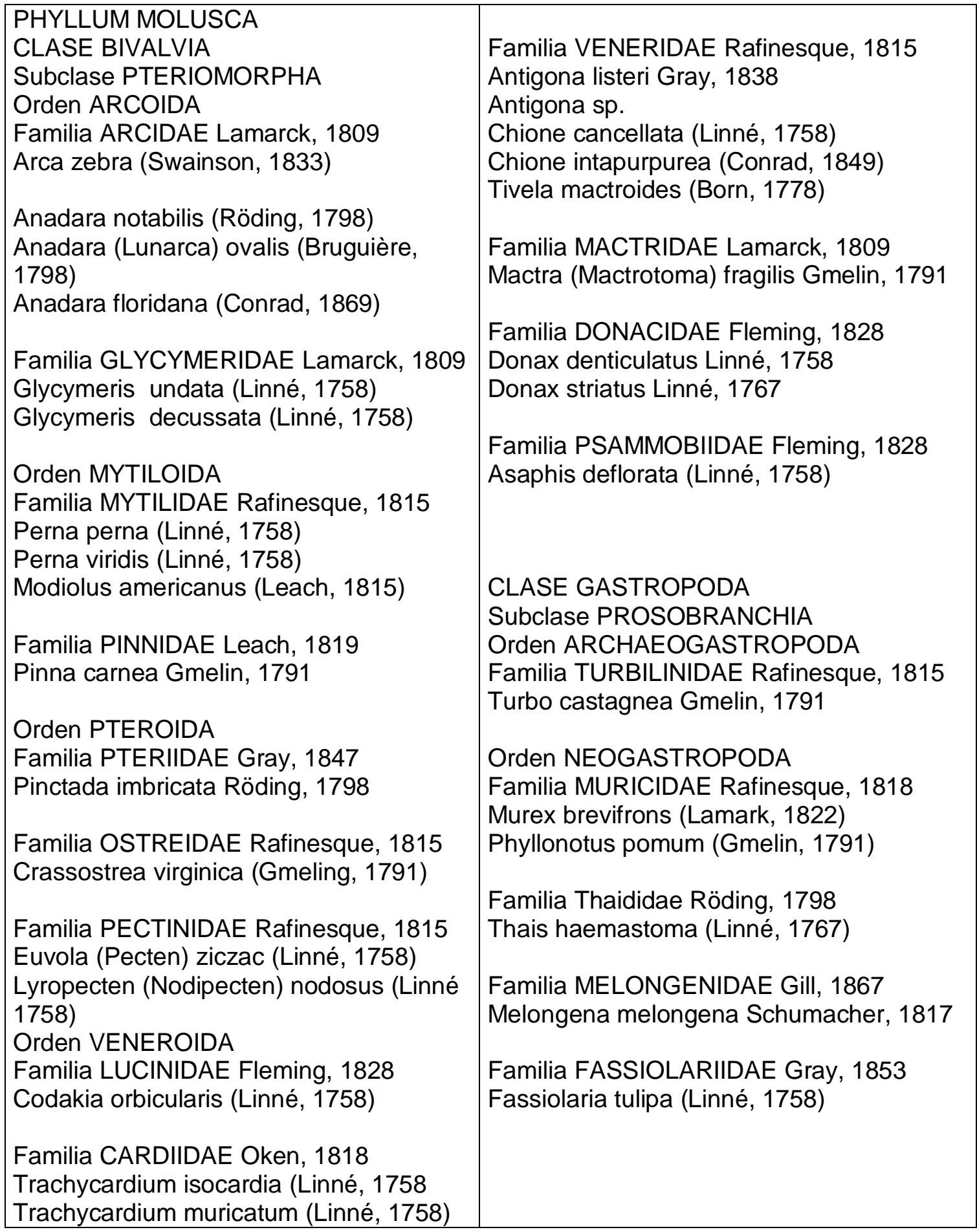




\section{$\underline{\text { Costa Norte }}$}

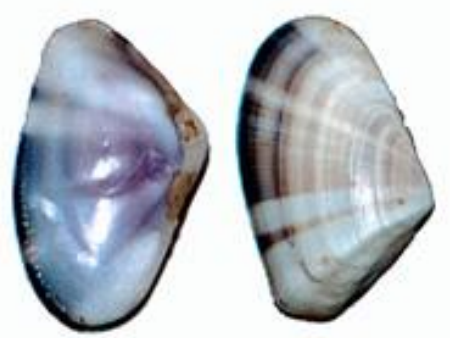

Donax denticulatus Linné, 1758

Nombre vulgar: Chipichipe

Distribución: Mar Caribe y costa continental de

Suramérica, hasta costas centrales de Brasil.

Especie pequeña, hasta $30 \mathrm{~mm}$, concha fuerte y gruesa, triangular y alargada, de color blanco con radios normalmente marrón a gris y violeta, interior generalmente de color violeta, porción posterior con tendencia a ángulo recto con dos crestas, y numerosas líneas en forma de zigzag. Abundante en la zona de barrido de las olas en playas arenosas de alta energía. $D$. denticulatus soporta una explotación artesanal a pequeña escala en la región nororiental de Venezuela.
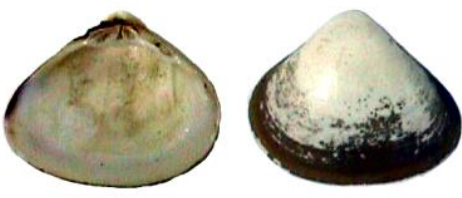

Tivela mactroides (Born, 1778)

Nombre vulgar: Guacuco

Distribución: Mar Caribe y costas de Suramérica, desde Yucatán hasta el sur de Brasil.

Especie mediana, hasta $45 \mathrm{~mm}$, concha triangular, fuerte, de color generalmente marrón con bandas radiales amplias, margen posterior más largo que el anterior, umbo centralizado. Común y abundante en la zonas litorales de playas arenosas y turbulentas. $T$. mactroides soporta una explotación artesanal a pequeña escala en la región nororiental de Venezuela.

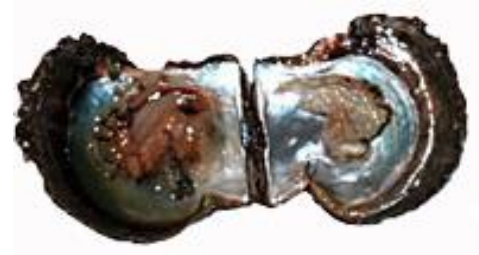

Pinctada imbricata Röding, 1798

Nombre vulgar: Madre perla, concha e perla, ostra perla

Distribución: Atlántico occidental, desde Carolina del Norte hasta Brasil.

Especie de mediana-grande 50-80 mm, concha redondeada, frágil, de color variable desde marrón a amarillo hasta el verde, interiormente nacarada. El periostraco se encuentra formando láminas concéntricas con proyecciones espinosas frágiles, más evidente en los individuos juveniles. Antiguamente explotada por sus formaciones perlíferas y actualmente explotada con fines alimenticios. Comúnmente encontrada en sustratos duros de aguas someras, formando poblaciones densas. Ocasionalmente se puede encontrar en praderas de Thalassia testudinun 


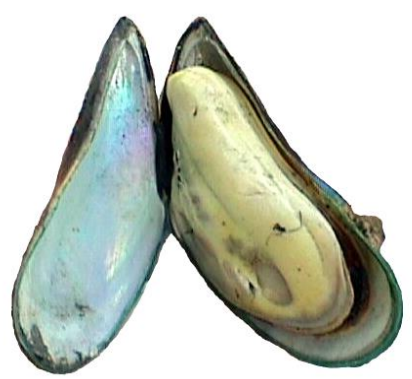

Perna viridis (Linné, 1758)

Nombre vulgar: Mejillón verde

Distribución: $P$. viridis es una especie originaria del Indopacífico, pero fue detectada en el Atlántico por primera vez en Trinidad en 1990 y ha sido extendida hacia la parte oriental de Venezuela, detectándose en el Golfo de Paria y Norte del), Estado Sucre (Agard et al. 1992), Isla de Margarita y Golfo de Cariaco (observación personal). Recientemente, organismos vivos de gran talla (160-190 mm) de esta especie fueron encontrados en Unare, Edo. Miranda. (Lodeiros et al. 1999). Por su carácter tropical y su alta fecundidad, aunado a características de resistencia y desarrollo larvario de larga duración, se piensa que esta especie pueda colonizar fácilmente la extensión costera de Venezuela y gran parte del Caribe.

Especie grande, hasta $200 \mathrm{~mm}$, parecida a $P$. perna pero perfectamente distinguible por el color verdoso del periostraco, sobre todo en la parte ventral y en organismos grandes. La concha internamente es más nacarada que $P$. perna.
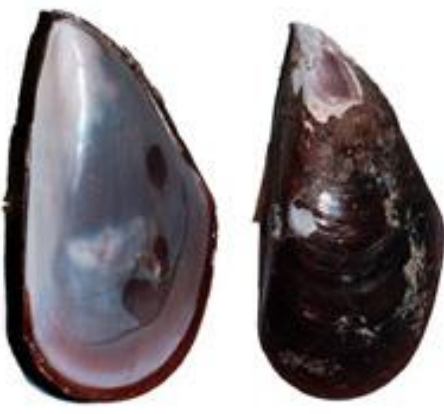

Perna perna (Linné, 1758)

Nombre vulgar: Mejillón, mejillón marrón

Distribución: Su distribución abarca las costas occidentales de Africa y de Asia Austral, costa atlántica de Suramérica desde Uruguay hasta las costas nororientales de Venezuela.

Especie grande, hasta $170 \mathrm{~mm}$, concha de color blanco violáceo con periostraco de color variado, de marrón claro a negro azulado, lisa con margen posterior recto, charnela con 1-2 dientes. Común en zonas rocosas y turbulentas.

$P$. perna es explotada comercialmente y ha sido cultivada en las costas nororientales de Venezuela.

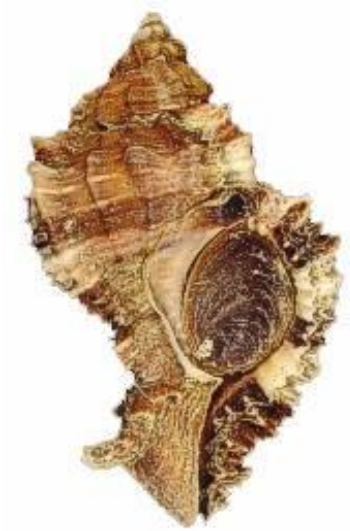

Phyllonotus pomum (Gmelin, 1791)

Nombre vulgar: Arrechón

Distribución: Atlántico occidental, desde Carolina del Norte hasta las costas de Suramérica y las antillas menores.

Concha grande (150 mm), globosa y pesada; colúmnela con pústulas; 3-4 várices con tubérculos o espinas romas; color marrón grisáceo o amarillento con bandas anchas marrón, abertura y callo parietal amarilloso. Se encuentra comúnmente en aguas someras sobre sustratos duros y en áreas de manglares. Es explotada como especie secundaria en bancos del nororiente de Venezuela, en especial del árcido Arca zebra en la Península de Araya. 


\section{Costa Sur}
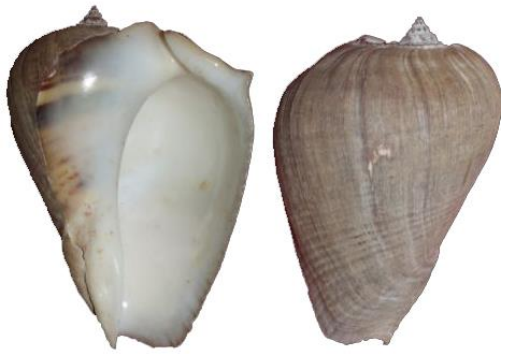

Melongena melongena (Linné, 1758)

Nombre vulgar: Longo

Distribución: Golfo de México y Mar Caribe

Concha grande (200 mm), ovalada, gruesa; ultimo giro muy amplio y globosa, ornamentado con 1 a 3 hileras espirales de espinas triangulares hacia la periferia y otra mas hacia la base. El desarrollo de las espinas es muy variable. La abertura es amplia, con canal sifonal corto y ancho; canal anal conspicuo, área parietal cubierta por un callo. Color variable, usualmente blanco sucio a amarillento, con bandas marrón o púrpura. Es común sobre todo tipo de sustratos en aguas turbias y someras en zonas de manglar.
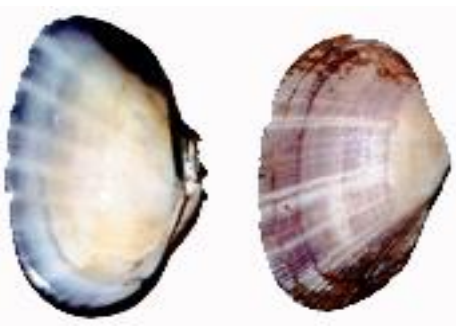

Asaphis deflorata (Linné, 1758)

Nombre vulgar: Almeja

Distribuición: Atlántico occidental, desde Bermudas y el sur de Florida hasta la costa norte de Suramérica e islas oceánicas de Brasil, también se encuentra en el Indopacífico.

Especie mediana a grande, hasta $80 \mathrm{~mm}$, concha delgada pero fuerte, moderadamente inflada, de color variable

interna y externamente, blanco, gris hasta rosado, naranja y amarillo. Ornamentada con numerosas líneas concéntricas, y ásperas costillas radiales más evidentes en la porción anterior. Común en la zona intermareal en sustratos de arena gruesa con cascajo. La especie soporta una explotación artesanal en la región nororiental de Venezuela.
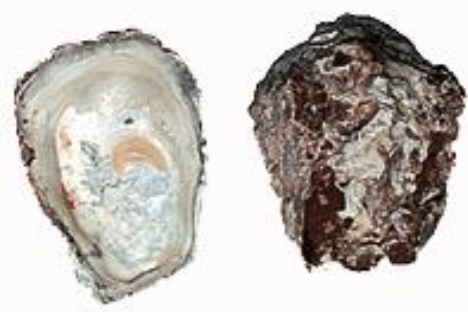

Crassostrea virginica (Gmeling, 1791)

Nombre vulgar: Ostra americana, ostra de Guariquen

Distribución: Desde el Golfo de San Lorenzo hasta las Indias occidentales y Venezuela.

Especie grande hasta más de $200 \mathrm{~mm}$, concha fuerte, muy variable tanto en forma como en tamaño, periostraco de forma laminar y de aspecto irregular. Los bordes de las valvas pueden ser ondulados o no. Abundante adherida a raíces de mangle. Crassostrea virginica muestra variabilidad morfológica de sus poblaciones. La huella muscular central en las poblaciones del nororiente de Venezuela no se encuentra coloreada, a diferencia de las poblaciones de $C$. virginica de América del Norte. Esta especie ha sido explotada comercialmente y se ha cultivado de forma experimental con una elevada factibilidad biológica. 


\section{IV.3 Distribución geográfica de los bancos}

\section{IV.3.1 Primera campaña (Período de Sequía)}

Se evaluaron 32 bancos, 19 en la costa Norte y 13 en la Sur. En la costa norte los bancos ubicados a la región occidental desde Playa Copey hasta Guarataro fueron más diversos, contenían de 2 a 4 especies de importancia comercial. Los bancos de Donax denticulatus y Tivela mactroides se encontraron siempre asociados a playas de alta energía, en la zona litoral y sublitoral, respectivamente, característico del habita infaunal de estas especies. La distribución de dichos bancos se aprecia en la Figura IV-1. En contraste, tanto Perna viridis como Perna perna se encontraron asociadas siempre a sustratos duros costeros (rocas y cascajos, eventualmente Perna viridis en blandos), característicos de su habitat epifaunal. Los bancos de Perna viridis se establecen hacia la zona oeste de la Península y los de Perna perna a la zona este de la costa norte de Paria. El caracol Phyllonotus pomum fue un recurso menos expandido y solo se encontró con abundancia de explotación de subsistencia o artesanal esporádica en Areito-Morro de Pto. Santo. En los muestreos realizados en el sublitoral de la zona Oeste de la Península de Paria entre San Playa Copey (Foto IV-1) y San Juan de las Galdonas (Foto IV-2), asociados a Perna viridis, se observaron siempre, varias especies de moluscos, indicando la existencia de una alta diversidad. 


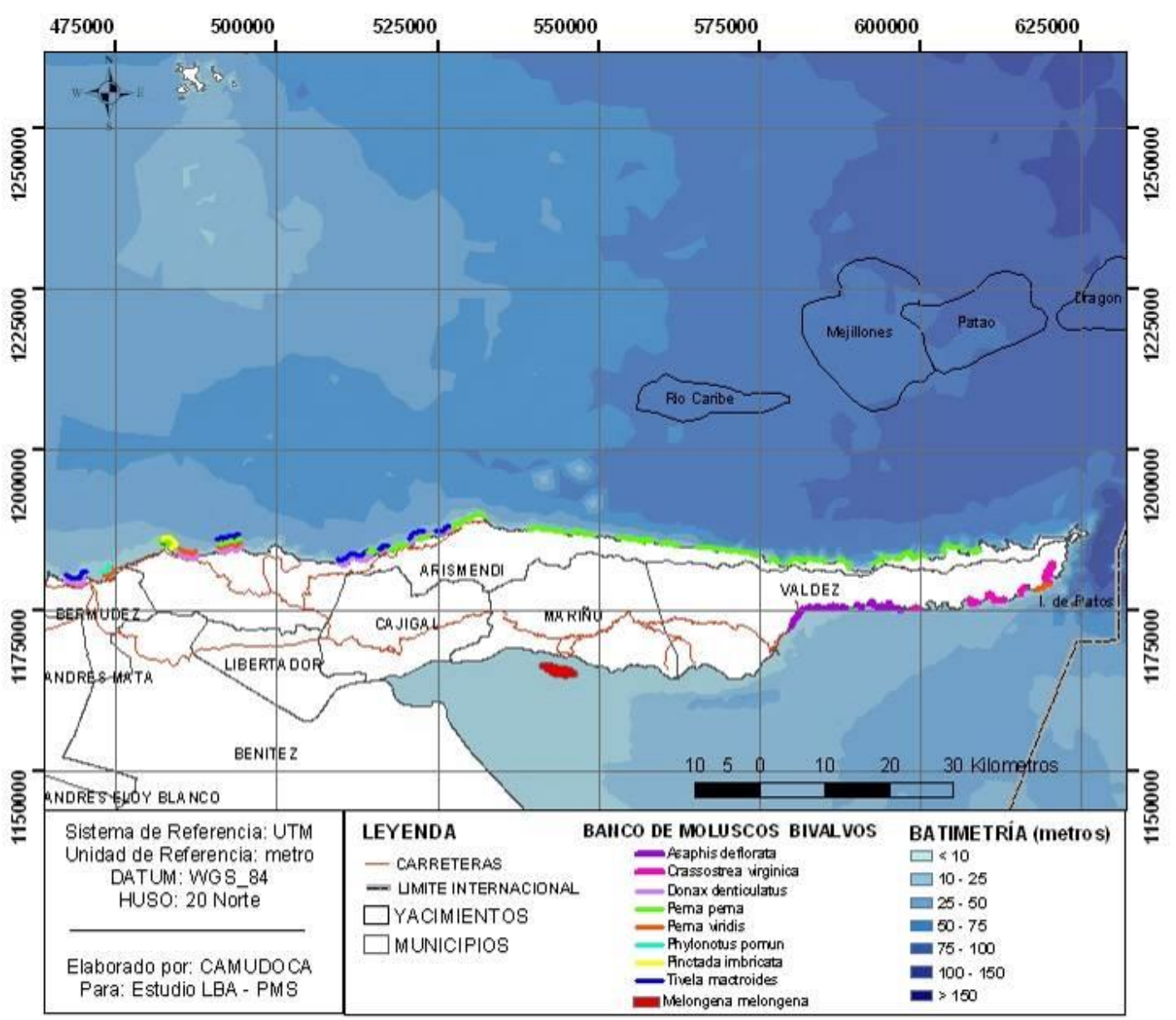

Figura IV-1.- Distribución espacial de los Bancos de Moluscos identificados durante las campañas del PMS. 


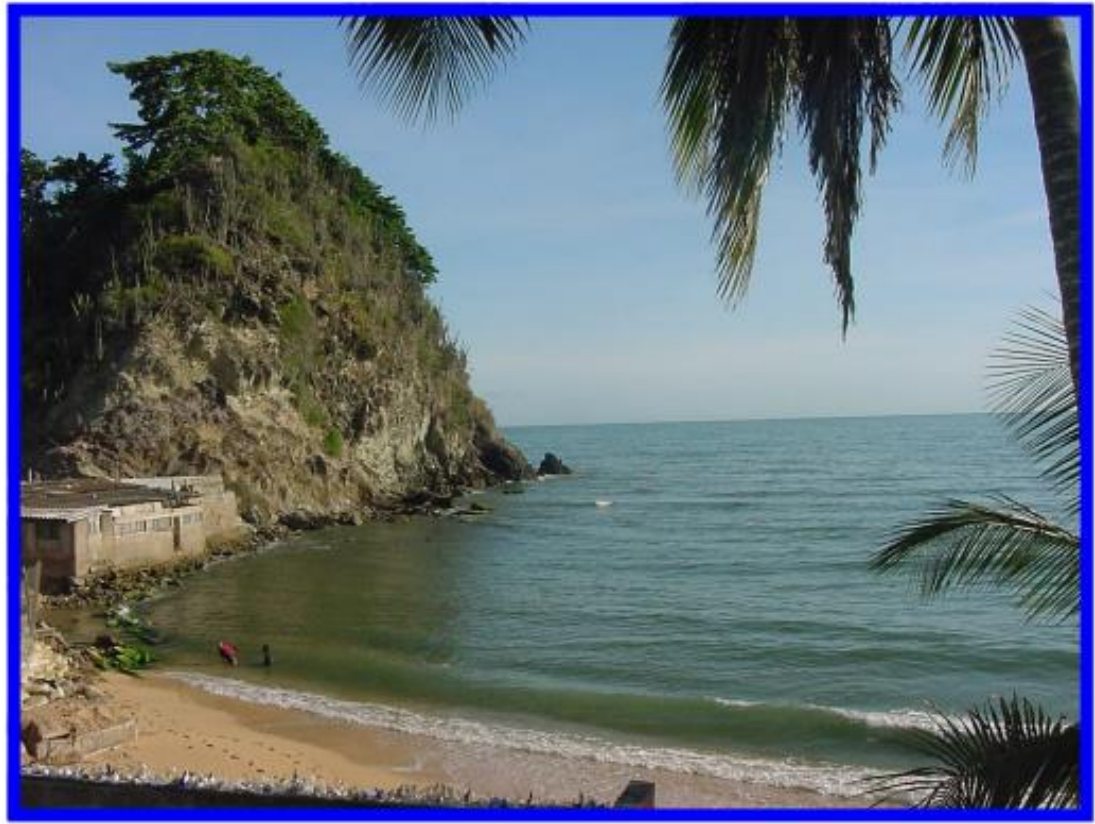

Foto IV-1.- Playa Copey

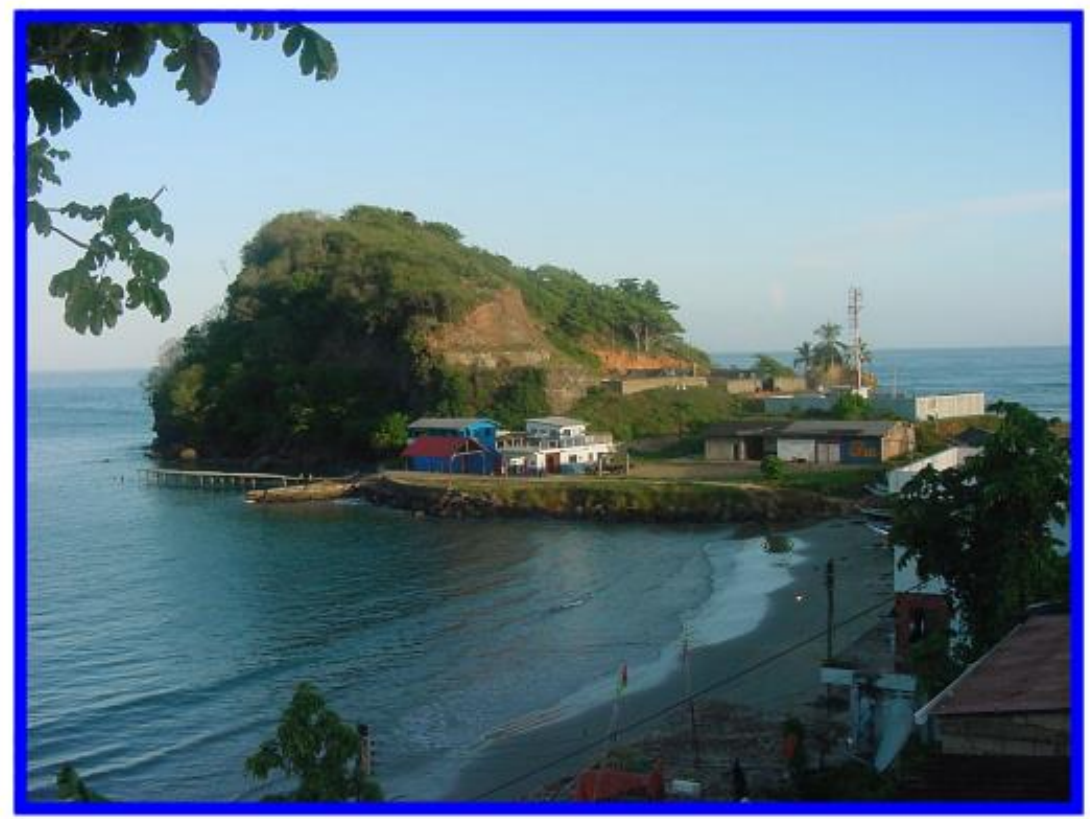

Foto IV-2.-. San Juan de las Galdonas.

En la costa Sur, un banco relevante, establecido en la zona submareal, fue el del caracol longo Melongena melogena en las cercanías de la población de Irapa, 
donde es explotado por la comunidad. En la zona media de la costa sur de Paria se establecen los bancos de la almeja Asaphis deflorata, la cual representa una especie de explotación artesanal en algunas localidades, como playa la Salina y Juan Diego (Foto IV-3 y Foto IV-4). Esta especie se encuentra siempre en la zona litoral asociado a piedras pequeñas que le brindan protección en un hábitat de arena con alto contenido en materia orgánica. La especie Antigona listeri, también se encontró con abundancia asociada a estos bancos y es también aprovechada por los lugareños. La distribución de ostra americana $C$. virginica se encuentra localizada en la zona este de la costa sur de Paria, siempre asociada a raíces de los mangles de la especie Rhizophora mangle. En Los Paticos, en la zona este extrema de la costa Sur de la península, se determino la presencia del mejillón Perna viridis, aunque en muy poca abundancia.

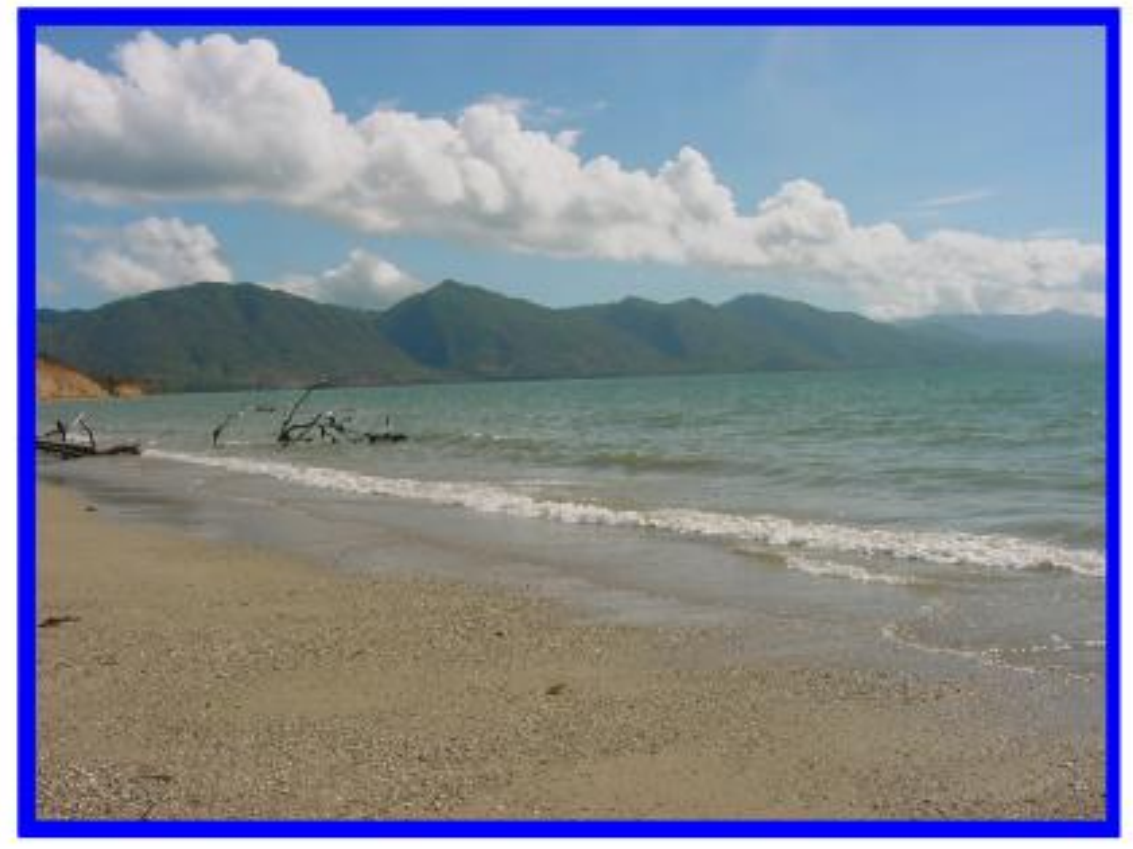

Foto IV-3.-. Playa La Salina 


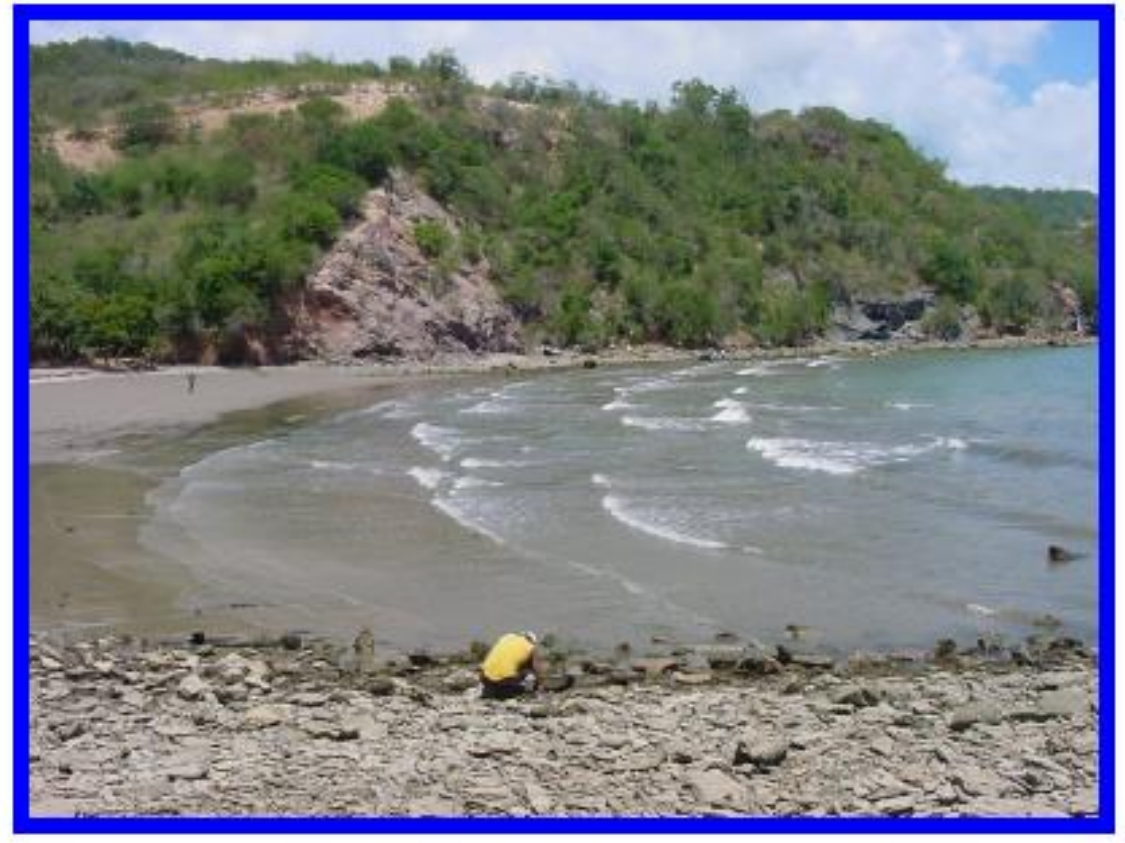

Foto IV-4.-. Playa Juan Diego

\section{IV.3.1.1 EVALUACIÓN DE LOS BANCOS}

Los resultados de las evaluaciones en la costa norte de la Península de Paria, indican que las máximas biomasas en peso total se observaron en la especie Perna perna para las localidades situadas en el sector oriental de la península, particularmente en los bancos situados desde Guarataro-San Juan de Unare hasta Uquire, con valores de biomasa total estimada de 18 hasta $65 \mathrm{TM}$, la otra especie de mitílido Perna viridis, no coexiste, al menos en abundancia en dicha zona, y se concentra en bancos en localidades del sector occidental con biomasas de 15-26 TM (Tabla IV-8). 
Tabla IV-2.- Parámetros de evaluación de los bancos de moluscos de la costa norte de la Península de Paria. $1^{\text {ra }}$ expedición exploratoria de LBAPMS.

\begin{tabular}{|c|c|c|c|c|c|c|}
\hline Localidad & Especie & $\begin{array}{l}\text { Extensión } \\
\left(\mathrm{m}^{2}\right)\end{array}$ & $\begin{array}{l}\text { Densidad } \\
\left(\operatorname{lnd} / \mathbf{~ m}^{2}\right)\end{array}$ & $\begin{array}{l}\text { Densidad } \\
\text { T. }\end{array}$ & $\begin{array}{l}\text { Biomasa } \\
\left(\mathrm{g} / \mathrm{m}^{2}\right)\end{array}$ & $\begin{array}{l}\text { Biomasa } \\
\text { (TM) }\end{array}$ \\
\hline & D.denticulatus & 600 & 50,8 & 30.480 & 32,81 & 0,019686 \\
\hline Playa & T. mactroides & 6.000 & 6,3 & 37.800 & 45,02 & 0,27012 \\
\hline \multirow[t]{2}{*}{ Copey } & $P$. viridis & 28.700 & 28,6 & 820.820 & 610,7 & 17,527 \\
\hline & P. perna & 1.600 & 5,8 & 9.280 & 150,05 & 0,24008 \\
\hline \multirow{2}{*}{ Areito } & $P$. viridis & 27.500 & 42 & 1.155 .000 & 964,74 & 26,53035 \\
\hline & P. perna & 16.000 & 8,3 & 132.800 & 160,1 & 2,56016 \\
\hline Morro de & $P$. viridis & 32.500 & 34 & 1.105 .000 & 780,98 & 25,38185 \\
\hline $\begin{array}{l}\text { Pto. } \\
\text { Santo }\end{array}$ & P. perna & 12.600 & 15,3 & 192.780 & 230,1 & 2,89926 \\
\hline \multirow{2}{*}{$\begin{array}{l}\text { (Los } \\
\text { Olivitos) }\end{array}$} & P. imbricata & 32.500 & 8,3 & 269.750 & 128,3 & 4,169 \\
\hline & D.denticulatus & 1.600 & 128,3 & 205.280 & 51,32 & 0,082112 \\
\hline \multirow[t]{2}{*}{ Canguas } & T. mactroides & 12.000 & 13,1 & 157.200 & 104,8 & 1,2576 \\
\hline & P. perna & 1.200 & 28,5 & 34.200 & 598,5 & 0,7182 \\
\hline Juan & D.denticulatus & 1.800 & 27,3 & 4.9140 & 11,74 & 0,021132 \\
\hline de las & T. mactroides & 18.000 & 8,5 & 153.000 & 59,5 & 1,071 \\
\hline Galdonas & P. perna & 3.600 & 11,3 & 40.680 & 339 & 1,2204 \\
\hline Playa La & D.denticulatus & 300 & 8,3 & 2.490 & 2,91 & 0,000873 \\
\hline Purga & T. mactroides & 6.000 & 31,8 & 190.800 & 159 & 0,954 \\
\hline Playa & D.denticulatus & 400 & 195,8 & 78.320 & 89,7 & 0,03588 \\
\hline \multirow[t]{3}{*}{ Guacuco } & T. mactroides & 6.000 & 21,6 & 129.600 & 172,2 & 1,0332 \\
\hline & D.denticulatus & 340 & 3,5 & 1.190 & 1,14 & 0,0003876 \\
\hline & T. mactroides & 5.100 & 2,8 & 14.280 & 6,7 & 0,03417 \\
\hline \multirow[t]{3}{*}{ Guarataro } & P. pomum & 225 & 5,3 & $1.192,5$ & 153,7 & 0,0345825 \\
\hline & $P$. viridis & 225 & 4,7 & $1.057,5$ & 77,6 & 0,01746 \\
\hline & P. perna & 18.000 & 26,3 & 473.400 & 1004,397 & 18,079146 \\
\hline Puerto & D.denticulatus & 600 & 31,25 & 187.50 & 15,32 & 0,009192 \\
\hline Caballo & T. mactroides & 1.500 & 1,38 & 2.070 & 8,28 & 0,01242 \\
\hline \multirow{3}{*}{$\begin{array}{l}\text { Playa } \\
\text { Colorada }\end{array}$} & D.denticulatus & 1.000 & 15,7 & 15.700 & 4,71 & 0,00471 \\
\hline & P.perna & 6.000 & 19,6 & 117.600 & 787,92 & 4,72752 \\
\hline & $P$. vrididis & 12.000 & 15,1 & $181 . .200$ & 382,332 & 4,587984 \\
\hline \multirow{2}{*}{$\begin{array}{l}\text { S. Juan } \\
\text { de Unare } \\
\text { Santa } \\
\text { Isabel }\end{array}$} & P. perna & 36.000 & 38,6 & 1.389 .600 & 1495,75 & 53,847 \\
\hline & P. perna & 18.000 & 48,1 & 865.800 & 1832,61 & 32,98698 \\
\hline \multicolumn{5}{|l|}{ Viejo } & 2647,9642 & 47,6633556 \\
\hline Pica pica & $P$. perna & 21.000 & 81,6 & 1.713 .600 & 3070,608 & 64,482768 \\
\hline Cacao & P. perna & 15.000 & 100,5 & 1.507 .500 & 3863,22 & 57,9483 \\
\hline Mejillones & $P$. perna & 30.000 & 30 & 900.000 & 1116,9 & 33,507 \\
\hline La Iglesia & $P$. perna & 18.000 & 43 & 774.000 & 1672,7 & 30,1086 \\
\hline Pargo & $P$. perna & 24.000 & 25 & 600.000 & 897,5 & 21,54 \\
\hline Uquire & P. perna & 45.000 & 7 & 315.000 & 256,06 & 11,5227 \\
\hline
\end{tabular}


La segunda especie en importancia según la biomasa en la costa norte de Paria es el guacuco Tivela mactroides; no obstante, las biomasas generadas alcanzan tan solo 1TM. Donax denticulatus no mostró biomasas importantes. Estas especies presentaron poca biomasa como bancos, pero fueron concentrados en menor área que las anteriores. La ostra perla Pinctada imbricata y Phyllonotus pomun, en los Olivitos y en Guarataro, mostraron biomasas muy bajas $(<4.16-0.03$ TM respectivamente).

En el Sur de Paria (Tabla IV-9) las especies de la ostra Crassostrea virginica, la almeja Asaphis deflorata y particularmente el caracol Melongena melongena, presentaron una estimación de biomasa de sus bancos relevantes. En una localidad aledaña a Irapa, el longo Melongena melongena y Crassostrea virginica en Patao, alcanzan las 10 TM; de la misma manera en Caurantica la biomasa de Asaphis deflorata sobrepasa las 5 TM.

Tabla IV-3.- Parámetros de evaluación de los bancos de moluscos de la costa sur de la Península de Paria.

\begin{tabular}{|c|c|c|c|c|c|c|}
\hline Localidad & Especie & $\begin{array}{l}\text { Extensión } \\
\left(\mathrm{m}^{2}\right)\end{array}$ & $\begin{array}{l}\text { Densidad } \\
\left.\text { (Ind/ } \mathrm{m}^{2}\right)\end{array}$ & $\begin{array}{l}\text { Densidad } \\
\text { T. }\end{array}$ & $\begin{array}{l}\text { Biomasa } \\
\left(\mathrm{g} / \mathrm{m}^{2}\right)\end{array}$ & $\begin{array}{l}\text { Biomasa } \\
\text { (TM) }\end{array}$ \\
\hline $\begin{array}{l}\text { Irapa } \\
\text { (El Playón) }\end{array}$ & M.melogena & 9.000 & 8,2 & 73.800 & 1.148 & 10,332 \\
\hline La Salina & $\begin{array}{l}\text { A. deflorata } \\
\text { A deflorata }\end{array}$ & $\begin{array}{l}2.000 \\
7.200\end{array}$ & $\begin{array}{l}97,5 \\
255\end{array}$ & $\begin{array}{l}195.000 \\
1.836 .000\end{array}$ & $\begin{array}{l}390 \\
739,5\end{array}$ & $\begin{array}{l}0,78 \\
5,3244\end{array}$ \\
\hline Caurantica & $\begin{array}{l}\text { Antigona } \\
\text { spp. }\end{array}$ & 7.200 & 45 & 324.000 & 94,5 & 0,6804 \\
\hline & A. deflorata & 1.250 & 41,75 & 52.183 & 167 & 0,20875 \\
\hline Cibisa & $\begin{array}{l}\text { Antigona } \\
\text { spp. }\end{array}$ & 1.250 & 15 & 18.750 & 42 & 0,0525 \\
\hline Playa & A. deflorata & 1.000 & 22,5 & 22.500 & 67,5 & 0,0675 \\
\hline Yaguara & $\begin{array}{l}\text { Antigona } \\
\text { spp. }\end{array}$ & 1.000 & 12,5 & 12.500 & 25 & 0,025 \\
\hline Juan Diego & $\begin{array}{l}\text { C. virginica } \\
\text { A. deflorata }\end{array}$ & $\begin{array}{l}2.500 \\
2.500\end{array}$ & $\begin{array}{l}1,2 \\
3\end{array}$ & $\begin{array}{l}3.000 \\
12.500\end{array}$ & $\begin{array}{l}33,6 \\
12,5\end{array}$ & $\begin{array}{l}0,084 \\
0,03125\end{array}$ \\
\hline $\begin{array}{l}\text { Puerto de } \\
\text { Hierro }\end{array}$ & C. virginica & 2.500 & 5 & 12.500 & 145 & 0,3625 \\
\hline $\begin{array}{l}\text { Cariaquito } \\
\text { Boca de } \\
\text { Cariaquito }\end{array}$ & $\begin{array}{l}\text { C. virginica } \\
\text { P. viridis } \\
\text { P. perna }\end{array}$ & $\begin{array}{l}2.500 \\
2.500 \\
2.500\end{array}$ & $\begin{array}{l}9 \\
11,2 \\
10,5\end{array}$ & $\begin{array}{l}22.500 \\
28.000 \\
26.250\end{array}$ & $\begin{array}{l}225 \\
291,2 \\
207,9\end{array}$ & $\begin{array}{l}0,5625 \\
0,728 \\
0,51975\end{array}$ \\
\hline $\begin{array}{l}\text { Boca de } \\
\text { Los Paticos }\end{array}$ & P. viridis & 1.500 & 12 & 18.000 & 240 & 0,36 \\
\hline $\begin{array}{l}\text { Macuro } \\
\text { Yacua }\end{array}$ & $\begin{array}{l}\text { P. viridis } \\
\text { C. virginica }\end{array}$ & $\begin{array}{l}500 \\
2.000\end{array}$ & $\begin{array}{l}10 \\
1,5\end{array}$ & $\begin{array}{l}5.000 \\
3.000\end{array}$ & $\begin{array}{l}229,7 \\
63,48\end{array}$ & $\begin{array}{l}0,11485 \\
0,12696\end{array}$ \\
\hline Patao & C. virginica & 15.000 & 15 & 22.500 & 634,7 & 9,5205 \\
\hline
\end{tabular}




\section{IV.3.1.2 DISTRIBUCIÓN DE LA TALLA DE LAS ESPECIES E ÍNDICE DE CONDICIÓN DE LOS BANCOS}

En la Figura IV-2. se muestra la distribución de intervalos de la longitud máxima de las especies en sus bancos principales de la Costa Norte de la Península de Paria, para el tiempo de muestreo. En el Morro de Puerto Santo, la distribución de la talla de Pinctada imbricata fue polimodal oscilando desde $35-70 \mathrm{~mm}$, con una mayor frecuencia de organismos que median de 50 a $65 \mathrm{~mm}$. En los mitílidos, la distribución fue similar, los organismos presentaron tallas de 60-70 mm a 110-115, concentrándose en tallas de 80 a 100 mm (Perna viridis de Areito y Perna perna de Picapica). En Canguas, Tivela mactroides mostró tallas de 15 a $45 \mathrm{~mm}$, concentrándose entre 20 y $35 \mathrm{~mm}$ y Donax denticulatus desde 2.5 a $25 \mathrm{~mm}$, predominando tallas pequeñas $(2.5-10 \mathrm{~mm})$. 

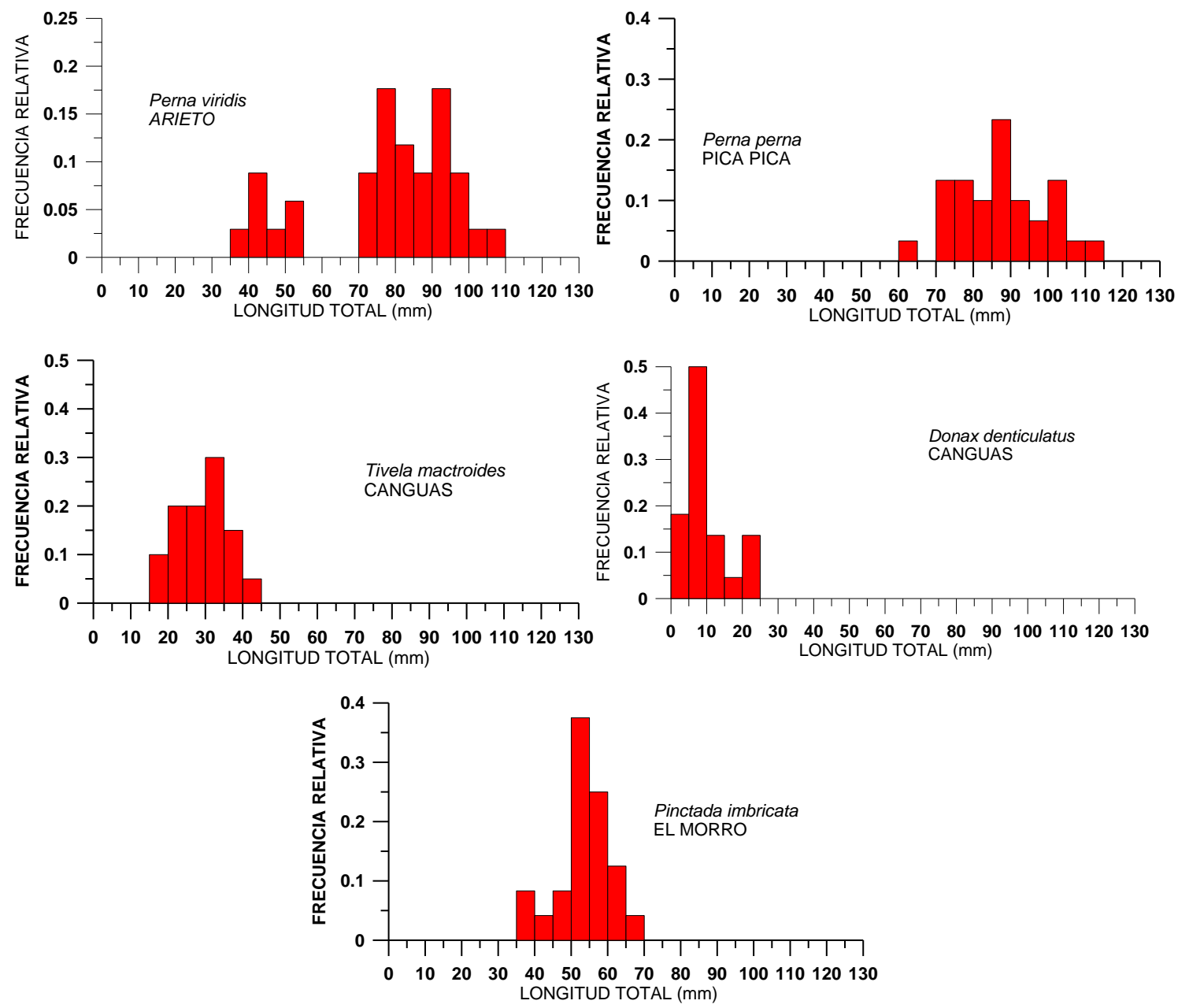

Figura IV-2.- Distribución de tallas (longitud máxima) de las diferentes especies en los bancos más representativos de la costa Norte de la Península de Paria. $1^{\text {ra }}$ expedición exploratoria de LBAPMS

En la costa Sur (Figura IV-3) las almejas Asaphis deflorata (Caurantica) se distribuyeron en talla de 20 a $65 \mathrm{~mm}$, siendo más frecuentes los organismos de 20 a $40 \mathrm{~mm}$. La otra americana Crassostrea virginica, en Patao, se distribuyó con grandes tallas que van desde los 45 a los $100 \mathrm{~mm}$, concentrándose en el intervalo de 60-80 $\mathrm{mm}$ y en el banco de Irapa de Melongena melongena los organismos de distribuyeron de 25 a $75 \mathrm{~mm}$, siendo organismos grandes los que en mayor frecuencia se encontraron $(50-75 \mathrm{~mm})$. 

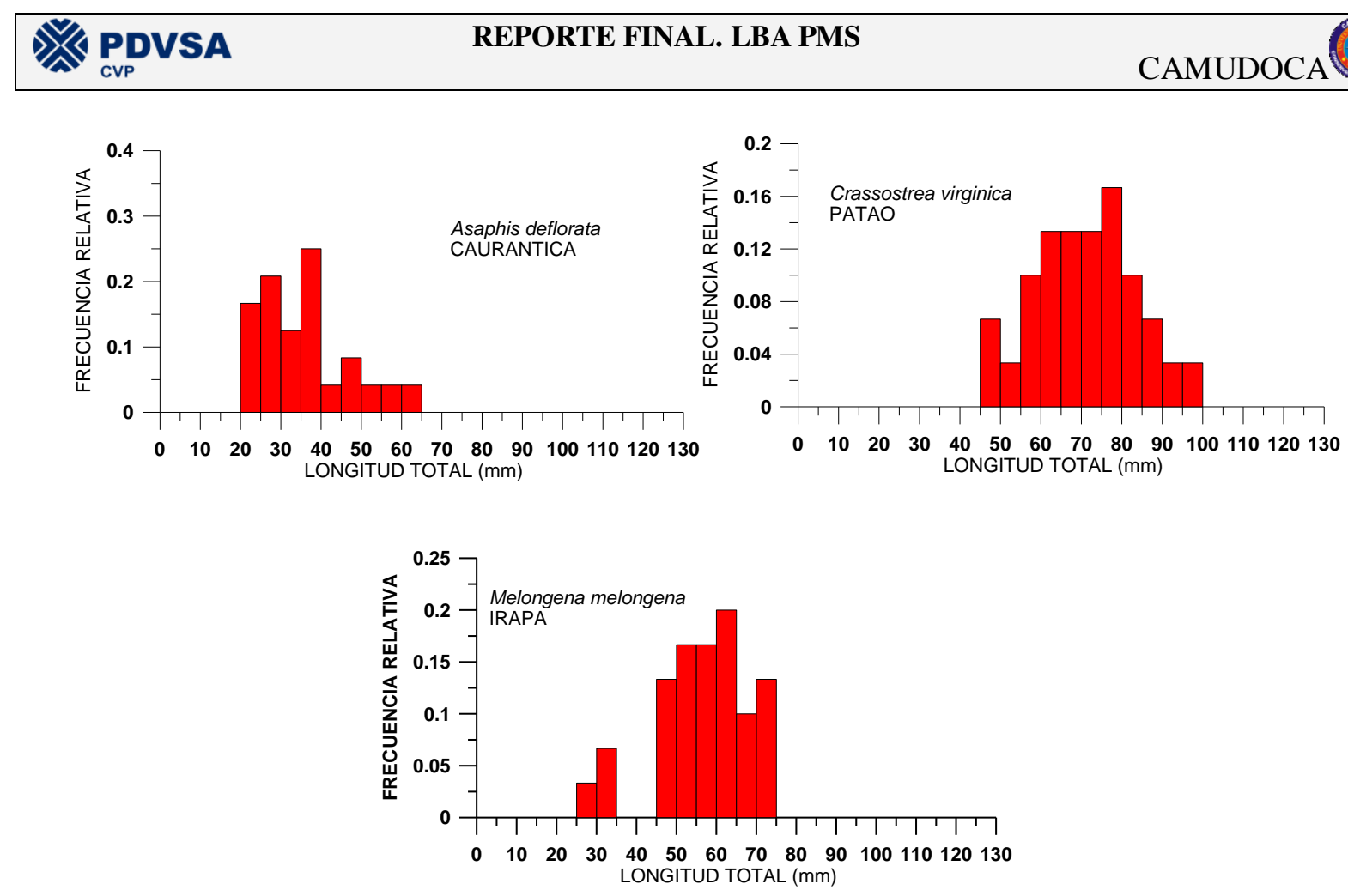

Figura IV-3.- Distribución de tallas (Iongitud máxima) de las diferentes especies en los bancos mas representativos de la costa Sur de la Península de Paria. $1^{\text {ra }}$ expedición exploratoria de LBAPMS

\section{IV.3.2 Segunda campaña (Periodo lluvioso)}

\section{IV.3.2.1 EVALUACIÓN DE LOS BANCOS}

Los resultados de las evaluaciones en la costa norte de la Península de Paria, indican que las máximas biomasas en peso total se observaron en la especie Perna perna para las localidades situadas en el sector oriental de la península, particularmente en los bancos situados en San Juan de Unare, Picapica y Mejillones, con valores de biomasa total estimada de 53, 56 y 80 TM, respectivamente; la otra especie de mitílido Perna viridis, tambien no coexiste, al menos en abundancia en dicha zona, y se concentra en bancos del sector occidental con biomasas maximas en Playa Copey (17 TM) y los Olivitos (25 TM) (Tabla IV-4). 
Tabla IV-4.- Parámetros de evaluación de los bancos de la costa norte de la Península de Paria.

\begin{tabular}{|c|c|c|c|c|c|c|}
\hline Localidad & Especie & $\begin{array}{l}\text { Extensión } \\
\left(\mathrm{m}^{2}\right)\end{array}$ & $\begin{array}{l}\text { Densidad (Ind/ } \\
\mathrm{m}^{2} \text { ) }\end{array}$ & $\begin{array}{l}\text { Densidad } \\
\text { T. }\end{array}$ & $\begin{array}{l}\text { Biomasa } \\
\left(\mathrm{g} / \mathrm{m}^{2}\right)\end{array}$ & $\begin{array}{l}\text { Biomasa } \\
\text { (TM) }\end{array}$ \\
\hline \multirow{4}{*}{ Playa Copey } & D.denticulatus & 1.800 & 31,2 & 56.160 & 14,30 & 0,0257 \\
\hline & T. mactroides & 18.000 & 10,2 & 183.600 & 65,2 & 1,1736 \\
\hline & $P$. viridis & 28.700 & 20,6 & 59120 & 600,2 & 17,225 \\
\hline & P. perna & 1.600 & 3,8 & 6080 & 130,05 & 0,2080 \\
\hline \multirow{2}{*}{ Areito } & P. viridis & 15.000 & 45 & 570000 & 581,2 & 8,7180 \\
\hline & P. perna & 16.000 & 7,8 & 124800 & 130,1 & 2,0816 \\
\hline \multirow{2}{*}{$\begin{array}{l}\text { Morro de Pto. } \\
\text { Santo }\end{array}$} & $P$. viridis & 32.500 & 30,5 & 991250 & 742,3 & 24,124 \\
\hline & P. perna & 12.600 & 10,8 & 136080 & 215,8 & 2,7190 \\
\hline \multirow{3}{*}{$\begin{array}{l}\text { Santo } \\
\text { (Los Olivitos) }\end{array}$} & P. imbricata & 32.500 & 98,5 & 601250 & 240,1 & 7,8032 \\
\hline & P.viridis & 1.500 & 0 & 675000 & 627,2 & 9.4080 \\
\hline & D.denticulatus & 1.600 & 105,8 & 169280 & 46,71 & 0,0747 \\
\hline \multirow[t]{2}{*}{ Canguas } & T. mactroides & 12.000 & 13,84 & 166080 & 107,3 & 1,2876 \\
\hline & P. perna & 1.200 & 20,80 & 24960 & 585,2 & 0,7022 \\
\hline \multirow{3}{*}{$\begin{array}{l}\text { S. Juan de las } \\
\text { Galdonas }\end{array}$} & D.denticulatus & 1.800 & 32,2 & 56160 & 14,30 & 0,0257 \\
\hline & T. mactroides & 18.000 & 10,2 & 183.600 & 65,2 & 1,1736 \\
\hline & P. perna & 3.600 & 9,3 & 33.480 & 237 & 0,8532 \\
\hline \multirow{2}{*}{ Playa La Purga } & D.denticulatus & 300 & 9,2 & 2.760 & 4,40 & 0,00132 \\
\hline & T. mactroides & 6.000 & 29,7 & 178.200 & 143,3 & 0,8598 \\
\hline \multirow{3}{*}{ Playa Guacuco } & D.denticulatus & 340 & 7,1 & 2.414 & 2,39 & 0,0008 \\
\hline & T. mactroides & 5.100 & 6,5 & 33.150 & 15,8 & 0,0805 \\
\hline & D.denticulatus & 340 & 3,5 & 1.190 & 1,14 & 0,0003876 \\
\hline & T. mactroides & 5.100 & 2,8 & 14.280 & 6,7 & 0,03417 \\
\hline \multirow[t]{3}{*}{ Guarataro } & P. pomum & 225 & 7,4 & 1.665 & 180 & 0,0405 \\
\hline & $P$. viridis & 225 & 6,0 & 1.350 & 91,2 & 0,0205 \\
\hline & P. perna & 18.000 & 24,8 & 446.400 & 985,10 & 17,73 \\
\hline \multirow{3}{*}{ Puerto Caballo } & D.denticulatus & 600 & 25,10 & 15.060 & 13,40 & 0,0080 \\
\hline & T. mactroides & 1.500 & 2,60 & 3.900 & 18,70 & 0,0280 \\
\hline & D.denticulatus & 1.000 & 18,5 & 18.500 & 5,32 & 0,005320 \\
\hline \multirow[t]{2}{*}{ Playa Colorada } & P.perna & 6.000 & 13,7 & 82.200 & 625,60 & 3,7536 \\
\hline & P. vrididis & 12.000 & 20,2 & 242.400 & 417,13 & 5,0055 \\
\hline S. Juan de Unare & P. perna & 36.000 & 30,20 & 1.087 .200 & 1251,30 & 45,0468 \\
\hline Santa Isabel & P. perna & 18.000 & 20,7 & 372.600 & 819,25 & 14,7465 \\
\hline Puerto Viejo & P. perna & 18.000 & 65,10 & 1.171 .800 & 2153,87 & 38,76 \\
\hline Pica pica & P. perna & 21.000 & 72,13 & 1.414 .730 & 2698,10 & 56,6601 \\
\hline Cacao & P. perna & 15.000 & 91,80 & 1.377 .000 & 3127,91 & 46,9186 \\
\hline Mejillones & P. perna & 30.000 & 75,13 & 2.163 .900 & 2673,8 & 80,214000 \\
\hline La Iglesia & P. perna & 18.000 & 49,17 & 885.060 & 1635,2 & 29,4336 \\
\hline Pargo & P. perna & 24.000 & 20,1 & 482.400 & 707,90 & 16,9896 \\
\hline Uquire & P. perna & 45.000 & 10,60 & 477.000 & 289,38 & 13,02210 \\
\hline
\end{tabular}

La segunda especie en importancia según la biomasa en la costa norte de Paria es el guacuco Tivela mactroides; no obstante, las biomasas generadas alcanzan tan solo 1 TM. Donax denticulatus no mostró biomasas importantes. Estas especies presentaron poca biomasa como bancos, pero fueron concentrados en menor área que las anteriores. La ostra perla Pinctada imbricata y Phyllonotus pomun, en los Olivitos y en Guarataro, mostraron biomasas muy bajas (<0.5 TM).

En la costa Sur las máximas biomasas las presentaron $C$. virginica en Patao (13 TM) y A. deflorata en Caurantica (5 TM), mientras que las especies restantes presentaron valores muy bajos (Tabla IV-5) 
Tabla IV-5.- Parámetros de evaluación de los bancos de la costa sur de la Península de Paria.

\begin{tabular}{|c|c|c|c|c|c|c|}
\hline Localidad & Especie & $\begin{array}{l}\text { Extensión } \\
\text { (m2) }\end{array}$ & $\begin{array}{l}\text { Densidad } \\
\text { (Ind/ m2) }\end{array}$ & $\begin{array}{l}\text { Densidad } \\
\text { T. }\end{array}$ & $\begin{array}{l}\text { Biomasa } \\
(\mathrm{g} / \mathrm{m} 2)\end{array}$ & $\begin{array}{l}\text { Biomasa } \\
\text { (TM) }\end{array}$ \\
\hline $\begin{array}{l}\text { Irapa } \\
\text { (El Playón) }\end{array}$ & M.melogena & 9.000 & 1,2 & 10.800 & 143,5 & 1,291 \\
\hline La Salina & $\begin{array}{l}\text { A. deflorata } \\
\text { A deflorata }\end{array}$ & $\begin{array}{l}2.000 \\
7.200\end{array}$ & $\begin{array}{l}48,2 \\
230\end{array}$ & $\begin{array}{l}96.400 \\
1.656 .000\end{array}$ & $\begin{array}{l}210 \\
720\end{array}$ & $\begin{array}{l}0,42 \\
5,184\end{array}$ \\
\hline Caurantica & $\begin{array}{l}\text { Antigona } \\
\text { spp. }\end{array}$ & 7.200 & 71 & 511.200 & 126,2 & 0,9086 \\
\hline & A. deflorata & 1.250 & 53,60 & 67.000 & 201 & 0,2512 \\
\hline Cibisa & $\begin{array}{l}\text { Antigona } \\
\text { spp. }\end{array}$ & 1.250 & 12 & 15.000 & 36 & 0,0450 \\
\hline Playa & A. deflorata & 1.000 & 31,3 & 31.300 & 78,2 & 0,0782 \\
\hline Yaguara & $\begin{array}{l}\text { Antigona } \\
\text { spp. }\end{array}$ & 1.000 & 11,7 & 11.700 & 22 & 0,0220 \\
\hline Juan Diego & $\begin{array}{l}\text { C. virginica } \\
\text { A. deflorata }\end{array}$ & $\begin{array}{l}2.500 \\
2.500\end{array}$ & $\begin{array}{l}2,8 \\
8,2\end{array}$ & $\begin{array}{l}7.000 \\
20.500\end{array}$ & $\begin{array}{l}71,8 \\
35,7\end{array}$ & $\begin{array}{l}0,1795 \\
0,0892\end{array}$ \\
\hline $\begin{array}{l}\text { Puerto de } \\
\text { Hierro }\end{array}$ & C. virginica & 2.500 & 7,1 & 17.750 & 182 & 0,4550 \\
\hline $\begin{array}{l}\text { Cariaquito } \\
\text { Boca de } \\
\text { Cariaquito }\end{array}$ & $\begin{array}{l}\text { C. virginica } \\
P . \text { viridis } \\
P . \text { perna }\end{array}$ & $\begin{array}{l}2.500 \\
2.500 \\
2.500\end{array}$ & $\begin{array}{l}12,3 \\
15,7 \\
7,1\end{array}$ & $\begin{array}{l}3.075 \\
3.925 \\
17.750\end{array}$ & $\begin{array}{l}301 \\
320,7 \\
153,6\end{array}$ & $\begin{array}{l}0,7525 \\
0,8017 \\
0,38400\end{array}$ \\
\hline $\begin{array}{l}\text { Boca de } \\
\text { Los Paticos }\end{array}$ & $P$. viridis & 1.500 & 8,3 & 12.450 & 183 & 0,2745 \\
\hline Macuro & $P$. viridis & 500 & 13,3 & 6.650 & 301,8 & 0,1509 \\
\hline Yacua & C. virginica & 2.000 & 2,3 & 4.600 & 110,5 & 0,2210 \\
\hline Patao & C. virginica & 1.500 & 21,8 & 32.700 & 993,5 & 13,402 \\
\hline
\end{tabular}

\section{IV.3.2.2 DISTRIBUCIÓN DE LA TALLA DE LAS ESPECIES E ÍNDICE DE CONDICIÓN DE LOS BANCOS}

La distribución de talla expresada en longitud máxima de las especies en sus bancos principales de la Costa Norte de la Península de Paria se presenta en la Figura IV-4. En el Morro de Puerto Santo, la distribución de la talla de Pinctada imbricata osciló entre $35-70 \mathrm{~mm}$, con una mayor frecuencia de organismos entre 50 a $65 \mathrm{~mm}$. En los mitílidos, la distribución fue similar, los organismos presentaron una talla desde 60 - $115 \mathrm{~mm}$, concentrándose en tallas de 80 a $100 \mathrm{~mm}$ (Perna viridis de Areito y Perna Perna de Picapica). En Canguas, Tivela mactroides mostró una distribución unimodal con tallas entre 20 - $45 \mathrm{~mm}$, mientras que en Donax denticulatus predominaron tallas entre 0 y $10 \mathrm{~mm}$, 

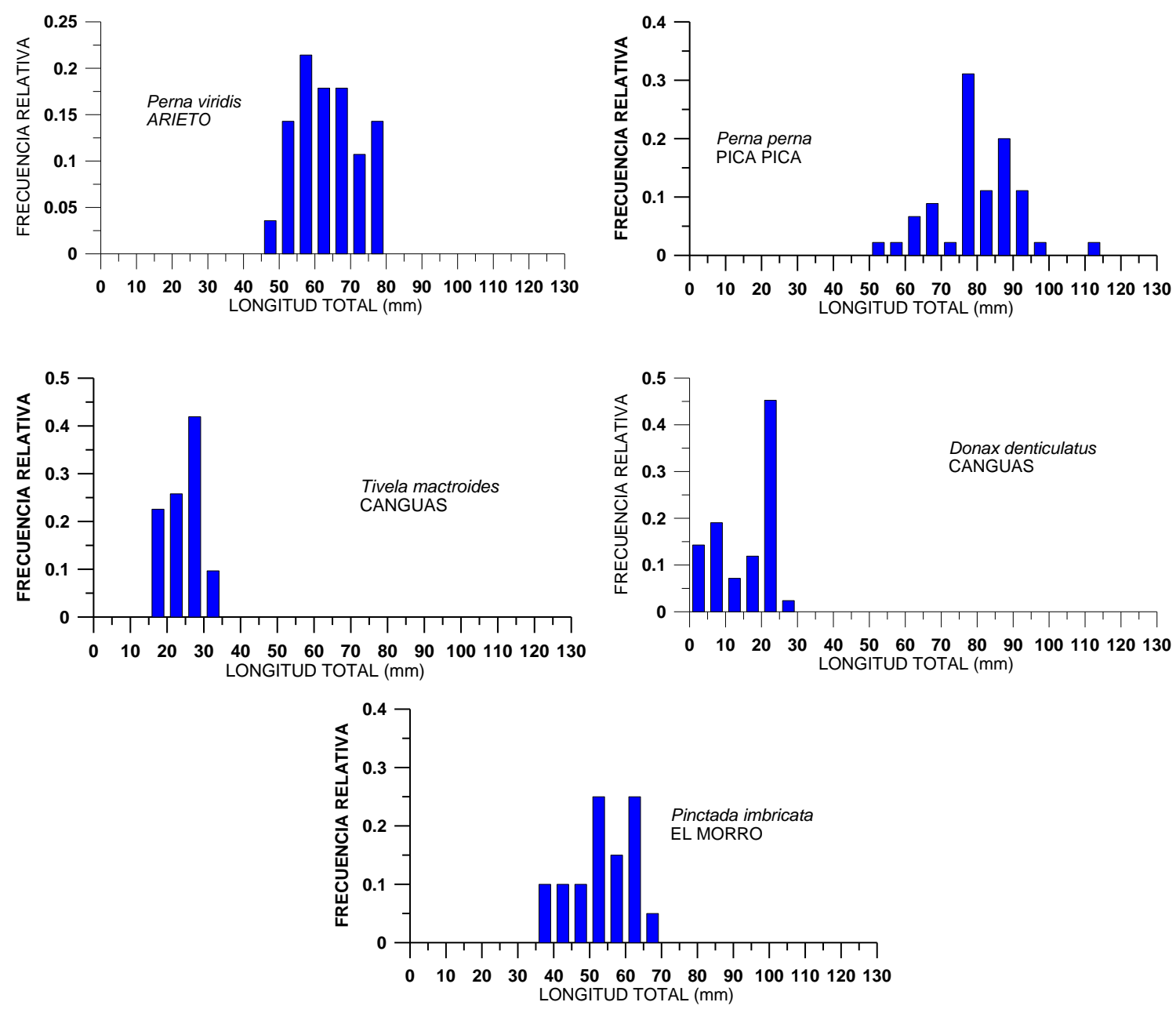

Figura IV-4.- Distribución de tallas (longitud máxima) de las diferentes especies en los bancos más representativos de la costa Norte de la Península de Paria.

En la costa Sur (Figura IV-5), en el banco localizado en Irapa de Melongena melongena, la talla de los organismos se distribuyó de 25 a $75 \mathrm{~mm}$, siendo organismos grandes los que se encontraron entre 50 y $75 \mathrm{~mm}$ ). La almeja Asaphis deflorata (Caurantica) se distribuyó en tallas de 20 a $65 \mathrm{~mm}$, siendo más frecuentes los organismos de 20 a $40 \mathrm{~mm}$. 

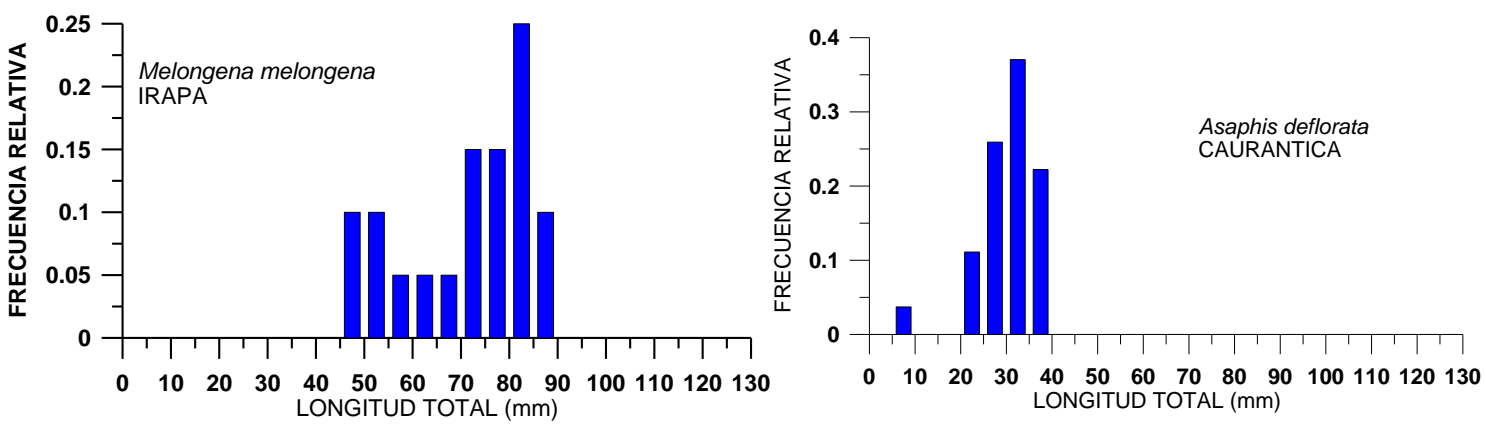

Figura IV-5.- Distribución de tallas (longitud máxima) de las diferentes especies en los bancos más representativos de la costa sur de la Península de Paria.

\section{IV.4 Análisis de los bancos de moluscos bivalvos al norte de la Península de Paria y en el norte del Golfo de Paria}

La distribución de las especies comerciales de moluscos en la costa de Paria está determinada principalmente por características del sustrato, así las comunidades asociadas a los mismos están adaptadas a los parámetros granulométricos y físicos de cada tipo de sedimento y factores dinámicos y oceanográficos de cada área en particular. Una característica resaltante de estas áreas es la confluencia del aporte de aguas del Río Orinoco al Golfo de Paría y la confluencia de este fenómeno con el de la surgencia en la costa norte de la Península, siendo de mayor energía la establecida en la zona oriental.

En la costa norte de la Península de Paria la morfología costera es típica y en el sector oriental, desde Carúpano hasta la localidad de Santa Isabel, se caracteriza por la presencia de ensenadas con playas arenosas en la parte central y elevaciones con sustratos rocosos en cada extremo, a veces con pendientes abruptas. Las playas existentes que sirven de áreas de nidificaciones de tortugas marinas, contienen sedimentos homogéneos con escasos restos de conchas en la zona intermareal, y una alta proporción de arena gruesa (>95\%) y escasa cantidad de sedimentos finos producidos por la intensa meteorización y turbulencia del oleaje (Prieto, 1983). En los sustratos de la zona infralitoral aumenta gradualmente la proporción de limo y arcilla con la profundidad, caracterizando la existencia de bancos con especies de la infauna como Donax denticulatus en el litoral y Tivela mactroides en el sublitoral a bajas profundidades. 
El mejillón Perna viridis, es una especie exótica que se caracteriza por colonizar una diversidad de sustratos, y a diferencia de Perna perna, contribuye a la mayor diversidad de bancos de la zona occidental de la costa norte de la Península de Paria. Probablemente, la mayor colonización de Perna viridis en esta zona se deba a la preferencia de zonas de menor energía que generan las corrientes y olas en la zona costera occidental en comparación con la oriental de Paria, donde es notorio el aumento de costas rocosas. Estos sustratos duros, con elevada energía producida por las corrientes y olas, proporcionan una alta oxigenación, generando un ambiente propicio para la especie Perna perna, y no para otras especies, incluyendo Perna viridis. Estas características dependientes de substratos y energía en las costas, repercute en bancos con mayor densidad y biomasa de Perna viridis en la zona occidental y de Perna perna en la zona oriental. Observaciones en crecimiento bajo condiciones de cultivo de estas especies, muestran que el biso (estructura filamentosa para sostenerse del sustrato) de Perna viridis es mas débil que Perna perna soportan la hipótesis antes señalada. (Urbano et al., 2005).

En la costa norte del GP, la morfología costera es diferente por las condiciones físicas y químicas imperantes, las playas costeras son más amplias en el borde occidental con escasos afloramientos costeros y un sedimento complejo con altos porcentajes de grava y limo. Este es el ambiente litoral de preferencia de Asaphis deflorata, donde se concentra en bancos con biomasas elevadas que permiten una actividad de explotación. Hacia el borde oriental, la presencia de manglares es típica en algunos sectores en los cuales es común encontrar la especie Crassostrea virginica, y allí se establece cierta abundancia de esta especie; no obstante es poco explotado, debido a la poca accesibilidad al recurso debido al manglar y la protección por ley del sistema manglar.

El análisis de las biomasas en las diferentes especies de moluscos en ambos periodos de evaluación en la costa norte mostró muy poca variación, aunque se observa mayor biomasa y densidad de Perna perna en el periodo de sequía que en el de lluvia; caso contrario se observo en la ostra Pinctada imbricata que fue mas abundante en el periodo de lluvia. En relación a las biomasas de las especies de la 
costa sur, las principales diferencias se observaron en Crassostrea virgínica que fue mas abundante en el periodo lluvioso y en el longo Melongena melongena cuya biomasa disminuyó drásticamente en el periodo lluvioso, debido probablemente al exceso de pesquería o/a la migración de los individuos hacia áreas mas profundas.

Al analizar la distribución de tallas principales de moluscos en costa norte, en ambos períodos, no se observó diferencia apreciable, salvo en las especies Pinctada imbricata que presentó una distribución polimodal en el período seco, el mejillón Perna perna que en la localidad de Areito presentó con juveniles con tallas entre 35 y 55 en el período lluvioso y Donax denticulatus que en Canguas mostró una distribución binomial más acentuada en el período seco. En relación a las especies de la costa Sur no se observaron diferencias apreciables.

Las densidades observadas en Donax denticulatus en algunas localidades son mayores que las reportadas recientemente por García et al. (2003) en Playa Brava, Península de Araya pero son muy inferiores a las reportadas, hace más de 20 años, por Vélez et al. (1985) en la Punta de Araya, Península de Araya, y Etchevers (1976) en La Restinga, Isla de Margarita. Esto y en adición a que las tallas en los individuos de la Península de Paria pudieron alcanzar valores superiores a las poblaciones de la Península de Araya (Vélez et al. 1985) muestran indicios de menor intervención antropogénica para las poblaciones de la península de Paria. Una característica de las poblaciones de Donax denticulatus colectadas en el Norte de Paria es la alta proporción de individuos juveniles observados, lo cual muestra que para el muestreo, gran cantidad de reclutas se están incorporando a la población, tendencia que ha sido reportada para poblaciones del Caribe por Wade (1969), y García et al. (2003).

Las densidades del guacuco Tivela mactroides colectados en casi todas las playas de la costa norte, fueron muy bajas, si se comparan con las reportadas para localidades cercanas a la ciudad de Carúpano como Playa Gúiria (Prieto 1983) y la Ensenada La Guardia, Isla de Margarita (Mendoza y Marcano, 2000) que contienen densidades y biomasas mas altas; probablemente esto obedece a tres razones fundamentales: 1) La época o fecha de muestreo se caracteriza por bajas densidades y escaso reclutamiento, 2) Alta contaminación o perturbación de la zona 
y 3) Excesiva pesquería. Por lo general, Tivela mactroides es un venerido cuya densidad está sujeta a una gran variedad de factores tanto bióticos como abióticos, presentando una extrema variación. Las densidades más altas para Venezuela han sido reportadas por Egañez en Carenero, Edo. Miranda, alcanzando los (29000 org $\left./ \mathrm{m}^{2}\right)$ y Etchevers (1976) en la Guardia, Edo. Nueva Esparta $\left(17000 \mathrm{org} / \mathrm{m}^{2}\right.$ ) y las mas bajas por Godoy (1997) en la zona suroriental del Golfo de Venezuela (40-60 org $/ \mathrm{m}^{2}$ ). Los valores mas altos de densidad; sin embargo, no se comparan con las de otra especie del mismo género, Tivela stultorum, la cual en playas de California (USA) presenta densidades superiores a los $20000 \mathrm{org} / \mathrm{m}^{2}$ (Fitch, 1950).

Tanto Donax denticulatus como Tivela mactroides, no soportan bancos con gran biomasa ( $<1 \mathrm{TM}$ ), lo cual podría sugerir su poca importancia; no obstante, son especies de ciclo de vida corto con altos cocientes de producción de biomasa. Además siempre se encuentran asociadas, por lo cual la actividad de explotación puede ser en conjunto, lo cual potencia su importancia para la zona. Es importante señalar que estas especies son de fácil extracción por las comunidades costeras.

Entrevista con pescadores han referido que en algunas zonas profundas mayores de 20 metros existen agregaciones importantes de la pepitona Arca zebra los cuales no pueden ser explotados debido a la profundidad a la cual se encuentran y que en las labores de rastreo le ocasionan problemas por el peso, presentando daños a las redes y otros implementos de pesca.

Los bancos de las especies de Phylonotus pomun y Pinctada imbricata, se encontraron en solo bancos específicos (los Olivitos y Guarataro), con biomasas bajas (<0.5 TM); no obstante, en dichos bancos se presentan, de forma secundaria otras especies que soportan biomasas relevantes para su explotación (Perna viridis y Perna perna, respectivamente), lo cual contribuye a fortalecer la importancia de dichos bancos.

El longo Melongena melongena solo fue detectado en abundancia en la zona aledaña a Irapa, donde una comunidad lo extrae del sublitoral, estimándose una elevada biomasa de 10 TM y representando un banco importante en la zona, en la primera campaña, sin embargo disminuyo drásticamente en la segunda evaluación 
con una biomasa muy baja. Esta disminución podría explicarse por la interna pesquería de que es objeto para exportación hacia Trinidad o como señalan los pescadores por su migración reproductiva hacia áreas mas profundas.

Es importante resaltar que algunas de estas especies presentan características favorables para el incremento de su producción a través de actividades de acuicultura, como lo son los mejillones $P$. perna y $P$. viridis, la almeja A. deflorata y la la ostra americana $C$. virginica, a las cuales se le han hecho estudios de factibilidad biológica de su crecimiento, siendo algunas producidas comercialmente como $P$. perna y C. virginica (Lodeiros 1999). Por otra parte, la especie M. melogena, por sus características de hábitat y comportamiento y la calidad del producto, pareciera una buena opción para considerarla para el cultivo.

Estos resultados muestran que los bancos de moluscos, conforman sistemas de apreciable importancia socioeconómica en la Península de Paria, tanto en su costa norte como la sur. Además de estar ubicados en su mayoría en la zona litoral, constituyen un componente susceptible a perturbaciones, por lo cual especial atención debe prestarse a los impactos ambientales que sobre ellos podrían ocasionar los futuros desarrollos asociados a la operatividad de la explotación gasífera.

\section{IV.5 Conclusiones}

- Existe una gran variedad de moluscos comerciales en las zonas costeras de Paria: 32 especies de las cuales 26 son bivalvos y 6 gasterópodos.

- Siete especies de bivalvos se encuentran en bancos con abundancia capaz de soportar actividades de explotación de subsistencia o artesanal. Entre ellas podemos citar, el chipichipe Donax denticulatus, el guacuco Tivela mactroides, la ostra perla Pinctada imbricata, los mejillones verde Perna viridis y marrón Perna perna, la almeja Asaphis deflorata y la ostra americana Crassostrea virgínica y 2 gasteropodos: el arrechón Phyllonotus pomum y el longo Melongena melongena. 
- Los bancos de mejillones, fueron los que presentaron mayor biomasa. Al oeste de la costa norte predominaron bancos con mayor biomasa de Perna viridis y en el este de Perna perna. En el costa sur son particularmente importantes el banco de longo Melongena melongena y los bancos de la almeja Asaphis deflorata y del mejillón verde Perna viridis.

- En algunas áreas someras de la costa norte de Paria, pequeños bancos de Phylonotus pomum y Pinctada imbrcata se encuentran asociados a comunidades de fondos mezclados ( arena - piedra) de Thalassia testudinum que contienen también otras especies de moluscos comestibles como Arca zebra, Chione cancellata, Murex brevifrons, Mactra fragilis, entre otros.

- Debido al escaso tiempo utilizado para este estudio exploratorio, es recomendable realizar un estudio más detallado de los principales bancos de moluscos en ambas áreas de la Península a fin de estimar su verdadera potencionalidad. 


\section{V.-ANÁLISIS GENERAL DE LA ACTIVIDAD PESQUERA Y POBLACIONES DE RECURSOS MARINOS EXPLOTADOS COMERCIALMENTE (Peces e Invertebrados) EN EL ÁREA DEL PMS}

Considerando lo establecido en los resultados de los componentes abiótico y biótico de este estudio, las características hidrodinámicas y ecológicas del área de influencia del PMS, obligan a que el análisis de la actividad pesquera y de los recursos pesqueros se analice sectorialmente, separandose la zona norte de la Península de Paria de aquella correspondiente al norte del Golfo de Paria. Esta separación obedece a que cada ente se considera un ecosistema distinto. En términos generales, el GP es un ecosistema estuarino influenciado por corrientes de marea y un importante flujo fluvial marcado estacionalmente. Mientras que la PNPP es un ecosistema marino de plataforma con una influencia importante de surgencia costera también marcada estacionalmente.

La zona donde se localizan los yacimientos que serán explotados por el PMS, en la PNPP, está influenciada por un régimen de surgencia costera el cual se extiende temporalmante desde finales del cuarto trimestre del año hasta mitad del segundo trimestre del año siguiente. En términos generales, este régimen de surgencia costera, es responsable del afloramiento de aguas frías, ricas en nutrientes que genera concentraciones importantes de nutrientes en la zona subsuperficial del mar. Este hecho contribuye a las agregaciones de peces pelágicos pequeños (sardinas y anchoas) que se desplazan por toda el área de la PNPP y la convierte en una de las zonas de mayor explotación pesquera en Venezuela. Durante la otra parte del año, cuando el régimen de surgencia decae ostensiblemente (junio-noviembre), el flujo de masas de agua de carácter estuarino que entra a la PNPP por la Boca de Dragón, se incrementa notablemente, generando frentes de densidad (o termohalinos) los cuales contribuyen a la formación de giros o remolinos temporales en la PNPP. Esta dinámica va a contribuir a fomentar agregaciones de diversas 
etapas de vida de varias especies de peces, según se infiere de las agregaciones de ictioplancton y de peces que han sido presentados en el informe de los componentes Biótico y Pesquero del presente estudio.

En grandes líneas generales, los dos factores hidrodinámicos del área de la PNPP, mencionados arriba, contribuyen a las agregaciones de diversas especies de peces que hacen que la actividad pesquera sea elevada durante casi todo el año. Inclusive, los bancos de moluscos bivalvos también son nutridos por estas características hidrodinámicas del área, que los ha convertido en fuente de sustento e ingreso de muchas de las comunidades costeras del norte de la Península de Paria.

La actividad pesquera y los recursos explotados en la PNPP son variados, existen poblaciones de peces demersales (capturados por las pesquerías de arrastre industrial y de media altura demersal con arte de línea), así como poblaciones de peces pelágicos (capturados por las pesquerías artesanales costaneras y de media altura pelágica con arte de línea) según lo muestran los mapas de abundancia relativa de recursos pesqueros. Entre las poblaciones de peces demersales con caladeros de pesca en la zona alrededor de los yacimientos están, los pargos, el cunaro y en menor grado los meros, que en su conjunto son objeto, principalmente de la pesquería artesanal de media altura demersal (Ver Mapas P1_9_1, P1_9_2, P1_10_1, P1_10_2), cuya bases de operaciones están principalmente en puertos de la Isla de Margarita (Juan Griego y Boca de Río), y el Morro de Pto. Santo en Sucre (Sección II.3). También existe cierta actividad llevada a cabo por la pesquería artesanal costanera multiespecifica que dirige su esfuerzo hacia la captura de estas poblaciones de recursos de alto valor comercial (pargo, mero y cunaro), desde las poblaciones de Carúpano, Guacuco, Guarataro y Macuro, y que tienen sus caladeros naturales en los alrededores de los yacimientos, principalmente al sur de los mismos (Secciones II.1 y III.1). La abundancia relativa nominal observada en estas poblaciones (pargo, mero y cunaro) presenta una variabilidad interanual según la serie analizada (2000-2003) en la pesca artesanal de media altura. Esta variabilidad interanual parece ser el denominador común en casi todas las poblaciones de peces explotadas del área. 
En el caso de las poblaciones demersales que captura la pesquería de arrastre industrial, la abundancia relativa nominal es menos evidente alrededor de los yacimientos (Sección II.5) (ver Mapas P3_2_1 y P3_2_2). Principalmente, debido a el tipo de arte utilizadazo por esta pesquería y a la naturaleza de los fondos, que según se pudo observar en los arrastres experimentales realizados en las inmediaciones del yacimiento Río Caribe en la campaña de octubre 2005, las redes fueron destruidas por lo irregular del fondo. Sin embargo, existen fondos en las inmediaciones de los yacimientos que permiten utilizar este tipo de artes. Ello se observa en la abundancia promedio para los años 2000-2003 de calamares y roncador al sur de los yacimientos en el segundo trimestre del año, la del corocoro al norte de los yacimientos en el segundo trimestre del año, la de la catalana y la lamparosa al norte y sur de los yacimientos durante el primer semestre del año, y particularmente la elevada abundancia del cherechere al sur de los yacimientos en el tercer trimestre del año. Si bien la mayor abundancia de estas especies se encuentran más al oeste de los yacimientos, las observadas no dejan de ser importantes, más aun cuando estas especies son objeto de las pesquerías artesanales costaneras multiespecificas de las comunidades que se encuentran al este de Río Caribe y en la costa norte de la Península de Paria.

El otro componente sobre el que actúa la actividad pesquera en la PNPP son las poblaciones de peces pelágicos. Aquí tenemos dos grupos, las poblaciones que se consideran grandes peces pelágicos que son altamente migratorios o migratorios costeros (e.g., dorado, palagar, tiburones y carite-lucio), y las que se consideran pequeños peces pelágicos, fundamentalmente sardina, pero que también incluyen al cataco, entre otras especies. El primer grupo es capturado principalmente por la pesquería artesanal de media altura, mientras que el segundo grupo es capturado por la pesquería artesanal costanera de sardina y la multiespecifica con artes de red. El grupo de especies que conforman los grandes pelágicos son los que reflejan abundancias relativas importantes alrededor de los yacimientos (Ver Mapas P1_9_1, P1_9_2, P1_10_1, P1_10_2), de hecho el esfuerzo de pesca (o actividad pesquera) se concentra para los tres grupos importantes de especies que son capturadas por la pesquería artesanal de media altura (Sección II.4). La principal, el carite-lucio, se 
captura principalmente en el $2^{\text {do }}$ y $3^{\text {er }}$ trimestre del año sobre el yacimiento Río Caribe, pero hay concentraciones importantes alrededor de los otros yacimientos. La segunda especie en importancia es el dorado, que se captura principalmente en el $4^{\text {to }}$ y $1^{\text {er }}$ trimestre del año, también sobre el área de los yacimientos. Ambas especies son las que representan importantes entradas económicas a los pescadores de la región, particularmente los que efectúan la captura del carite-lucio. Las otras especies capturadas, como el palagar y tiburones, tienen niveles de abundancia relativa importante en el área de los yacimientos.

Los pequeños pelágicos, como la sardina, son objeto de una pesquería dirigida a ese recurso, que se restringe a la zona costera comprendida entre la Esmeralda y el Morro de Pto. Santo (Sección II.2). La captura que realiza dicha pesquería representa cerca del $50 \%$ del total de las capturas de sardina en toda la región nororiental del país. Sin embargo, existen capturas de sardina a lo largo de las costas de la Península de Paria efectuadas por la pesquería artesanal costanera que sirve de carnada para la captura de otras especies de mayor valor económico. Aunque la pesquería de sardina en el área de estudio no parece afectar visiblemente el área de influencia directa del PMS (como los alrededores de los yacimientos), es importante destacar que la población de sardina hasta ahora conocida, es una sola y que está distribuida por toda la plataforma nororiental del país, ya que cumple su ciclo de vida en esa área de distribución. Ello implica que la sardina tiene una amplia distribución en la zona, incluyendo los alrededores de los yacimientos.

La amplia distribución de la sardina por toda la plataforma nororiental (incluyendo la PNPP), se infiere por dos hechos. El primero, tiene que ver con las agregaciones importantes de las diversas poblaciones de peces que se concentran en la PNPP y área adyacentes como dorado, carite-lucio, palagar, cunaro, calamares, cabañas, y que son depredadores de cardúmenes de pequeños pelágicos, que en el área es mayoritariamente sardina (Sardinella aurita). La sardina desempeña una función preponderante en la cadena trófica de la plataforma nororiental venezolana (Mendoza, 1993). Se le puede considerar como el centro de la cadena trófica en la región, ya que la hidrodinámica de la región contribuye a mantener una elevada población de sardina con el afloramiento de nutrientes, lo que 
permite a su vez mantener las agregaciones de peces/invertebrados pelágicos medianos y grandes, incluyendo a mamíferos marinos y aves marinas en el área dado el carácter de presa abundante que tiene la sardina.

El segundo hecho, tiene que ver con la sobrevivencia de larvas y el reclutamiento de la sardina. Tal como se postula en la sección de ictioplancton del componente Biótico del presente estudio, se hace referencia a que hay evidencia de un corredor costero en la costa norte de la Península de Paria de alta concentración de larvas de clupeidos (sardinas), que incrementa progresivamente en dirección oeste-este. También se hace referencia a remolinos que parecen estar alrededor de los yacimientos (posiblemente originados por el flujo de agua que sale por Boca Dragón y una contra corriente costera en dirección este al norte de la PP) y que podrían contribuir a la retención temporal de larvas de peces (particularmente de sardina) en la zona, donde el crecimiento y la sobrevivencia de las mismas se maximiza.

Las postulaciones aquí presentadas podrían contribuir al mantenimiento de la población de sardina en la región. Lo señalado en este apartado (sobre la población de sardina) tiene implicaciones serias en caso de una disrupción en los mecanismos de retención de las larvas (particularmente de sardina), que podrían impactar negativamente la sobrevivencia de las mismas y por ende habría una falla en el reclutamiento (Fuiman y Werner, 2002). En cuyo caso, el resultado es una baja en el tamaño de la población de sardina con la grave consecuencia de producirse un desequilibrio en todo el ecosistema, donde la actividad pesquera de la región se vería seriamente afectada. Si bien, los fenómenos hidrodinámicos de la región que afectan las poblaciones de peces no parecen tener una relación directa con los yacimientos, la actividad que se generaría al inicio de las operaciones va a afectar los caladeros naturales de los pescadores de la región, en cuyo caso podrían presentarse cambios en el comportamiento de las poblaciones de peces que afectarían la abundancia de las diferentes especies explotadas en el área.

La otra área del PMS, el GP, es un sistema estuarino con masas de agua estratificadas y variaciones estaciónales importantes producto del flujo de agua de los Ríos Orinoco, San Juan y Caroní (del lado de Trinidad), la mezcla por las 
corrientes de marea, y el viento. En términos generales, existe un periodo de sequía que dura de noviembre a mayo, y un periodo de lluvias con un pico de julio a septiembre. En ecosistemas estuarinos, el carácter fangoso del sustrato tiene un alto contenido de detritus que sostiene una fauna rica y diversa de invertebrados (particularmente camarones y cangrejos), peces demersales y elasmobranquios (rayas y chuchos) (Blaber, 2000). Esa fauna en el GP es objeto de pesquerías importantes que operan en el GP, entre las que incluyen a la pesca de arrastre industrial y la pesca artesanal que tienen como especie objetivo a el camarón (principalmente Litopenaeus schmitti), especies de la familia Ariidae (bagres) y especies de la familia Scianidae (roncador y curvinatas) (Ecology \& Environment, 2003).

En el presente estudio, el área del PMS en el GP se restringe a la costa norte, en consecuencia, las observaciones y análisis realizados en el componente de pesquerías y poblaciones de peces se presentan en función de las estimaciones de biomasa por área barrida y de la información levantada en las comunidades visitadas.

Las estimaciones de biomasa se realizaron en periodos contrastantes, uno cuando el flujo agua dulce de ríos y caños fue bajo (marzo 2005) y otro cuando el flujo fue elevado (septiembre 2005), tal como se percibe en los cambios de la salinidad durante los periodos muestreados (Sección III-2). En el periodo de menor flujo y de salinidad alta (promedio de $27 \mathrm{psu}$ ), la biomasa total fue alrededor de dos veces y media mas baja que durante el periodo de mayor flujo y de salinidad baja (promedio de $19 \mathrm{psu}$ ). Sin embargo, en ambos periodos se presentó un gradiente en la biomasa total en dirección de este a oeste, donde los niveles más elevados se encontraron hacia la zona oeste de Irapa, pero que durante la temporada de baja salinidad (septiembre 2005) el gradiente en la biomasa no fue continuo (Ver Mapas P2_4_1, P2_4_2). Si bien, la biomasa más elevada se encontró al oeste de Soro, entre Macuro y Güiria hay una zona de elevada biomasa entre ambos extremos (alrededores de Puerto de Hierro). La biomasa elevada hacia el oeste, era de esperarse por ser la zona con las condiciones más estuarinas de la zona estudiada, y donde las especies de la familia Ariidae (bagres) son más comunes y abundantes. 
Pero la elevada biomasa en los alrededores de Puerto de Hierro fue ocasionada por la captura de ejemplares adultos de la familia Dasyatidae (chuchos) (Sección III.3).

La estructura poblacional analizada de las poblaciones de peces e invertebrados (principalmente camarones y cangrejos) demuestra que para el caso de las poblaciones de peces, cerca del $80 \%$ de las especies muestreadas se encontraban en fase juvenil o pre-adulto, mientras que para las de invertebrados la mayoría de las especies de interés comercial eran pre-adultos (Secciones III.2, III.3, III.4). Este resultado era de esperarse ya que los ecosistemas estuarinos, particularmente los tropicales, albergan un elevado numero de especies y las zonas costeras son área de refugio y cría de juveniles de la mayoría de las especies que cuando adultos se desplazan a aguas marinas mas profundas donde son objeto de las pesquerías de la región, como es el caso de varias especies de la familia Scianidae (roncadores, curvinas y curvinatas) y de la familia Lutjanidae (pargos). Lo mismo sucede con las especies de camarones de la región. Esta condición característica de este tipo de ecosistemas debe ser preservada con el mayor esfuerzo, ya que la degradación de las zonas costeras del norte del GP acarrearía la pérdida de hábitat esencial de varias especies de elevada importancia económica ya que esas especies al alcanzar la fase adulta constituyen el objeto de las pesquerías de la región y conforman el sustento de los pobladores de la comunidades del GP.

Otro de los grupos de organismos marinos con mucha relevancia comercial y social en el área de influencia del PMS son los moluscos, particularmente los bivalvos (Sección IV). Se demostró que la distribución de las especies comerciales de moluscos en la costa de Paria está determinada principalmente por características del sustrato; así las comunidades asociadas a los mismos están adaptadas a los parámetros granulométricos y físicos de cada tipo de sedimento y a los factores hidrodinámicos de cada área en particular. Una característica resaltante de estas áreas es la confluencia del aporte de aguas del Río Orinoco y San Juan al GP y la confluencia de este fenómeno con el de la surgencia en la costa norte de la PP, siendo de mayor energía (de oleaje) la establecida en la zona oriental. 
Se identificaron siete especies de moluscos bivalvos que se encuentran en bancos con abundancia capaz de soportar actividades de explotación de subsistencia o artesanal. Ellas son: el chipichipe Donax denticulatus, el guacuco Tivela mactroides, la ostra perla Pinctada imbricata, los mejillones verde Perna viridis y marrón Perna perna, la almeja Asaphis deflorata y la ostra americana Crassostrea virgínica y 2 gasteropodos: el arrechón Phyllonotus pomum y el longo Melongena melongena (Ver Mapa P2_3). Sin embargo, los bancos de mejillones en la costa norte de la PP, fueron los que presentaron la mayor biomasa potencial. Al oeste de la costa norte predominaron bancos de Perna viridis y en el este el de Perna perna. En la costa norte del GP son particularmente importantes el banco de longo Melongena melongena y los bancos de la almeja Asaphis deflorata y del mejilón verde Perna viridis.

Los resultados obtenidos en la evaluación de los bancos de moluscos muestran que forman sistemas de importancia socioeconómica en la Península de Paria, en ambas costas, norte y sur. Además, al estar ubicados en su mayoría en la zona litoral, forman un componente susceptible a perturbaciones al se le debe prestar especial atención por los impactos ambientales que sobre ellos podría ocasionar el desarrollo gasífero a ser implementado por el PMS.

Las comunidades pesqueras de la región tienen un espacio preponderante en el área de influencia del PMS, ya que van a ser afectadas de alguna manera por los desarrollos del proyecto. Como se dijo al comienzo del documento, se estima que más del $70 \%$ de la producción pesquera nacional marítima se desembarca en la región nororiental del país, especialmente en los estados Sucre y Nueva Esparta, donde la pesca artesanal tiene particular relevancia y se estima que alrededor del $80 \%$ de la producción pesquera marítima artesanal proviene de la región nororiental.

En las 10 comunidades estudiadas, seleccionadas previo análisis del catastro pesquero, permitieron determinar la importancia de las mismas para la región (Secciones II.1 y III.1). Los pescadores señalan un período de máximas abundancias, de manera general, durante el segundo semestre del año, tanto en el sector norte de la PP como en el sector norte del GP. Por otra parte, las áreas de 
pesca de las comunidades de Río Caribe, Guacuco y Guarataro, en la costa norte de la Península de Paria, y de Güiria e Irapa, en la costa norte del Golfo de Paria, son las que presentan mayor grado de solapamiento con las futuras actividades del Proyecto Mariscal Sucre. En el caso del primer grupo las futuras interferencias estarían relacionadas con las actividades alrededor de los yacimientos, mientras que en el caso del segundo grupo las interferencias se presentarían con las actividades ser desarrolladas por el Proyecto CIGMA.

Los niveles educativos de los pescadores y sus grupos familiares tienden a ser inferiores a los observados en el conjunto de la población de las comunidades estudiadas, siendo éstas diferencias más marcadas en las comunidades del norte de la Península de Paria. Por otro lado, si bien los niveles de ingresos de los pescadores tienden a ser superiores a los del resto de los pobladores de las comunidades estudiadas, es importante destacar que los pescadores artesanales no perciben otros beneficios adicionales (vacaciones, aguinaldos, seguro social obligatorio, entre otros) que derivan de legislación laboral en nuestro país.

El análisis histórico de los datos sobre el número de embarcaciones censadas y las obtenidas en este proyecto indican un relativo estancamiento en la actividad pesquera artesanal y en su capacidad para generar puestos de trabajos en los últimos 20 años. Por otro lado, alrededor del $30 \%$ de las embarcaciones censadas no se encontrarían en capacidad operativa, siendo este porcentaje del orden de $50 \%$ en las comunidades más aisladas como Guarataro, Guacuco y Macuro. El factor que se considera más importante en la capacidad operativa de las embarcaciones está representado por las dificultades para reponer los motores fuera de borda, tanto por el elevado costo unitario como por las actividades delictivas relacionadas con el robo de motores.

Los pescadores del conjunto de la zona consideran que la piratería marina, fundamentalmente reflejada en el robo de motores, la ausencia de infraestructura pesquera, la interferencia con la pesca de arrastre y las dificultades para acceder a créditos como los factores más limitantes en el desarrollo de su actividad.

Una vez concluido el estudio sobre el análisis espacial y temporal de la actividad pesquera y de los recursos pesqueros sobre la PNPP y el norte del GP y 
dado a conocer la abundancia, riqueza y diversidad de especies de interés comercial e importancia económica y social del área de influencia del PMS, así como las comunidades que se sustentan del producto de sus actividades pesqueras, bien sea directa o indirecta; se concluye, que los desarrollos a ser implementados por el PMS van a afectar a ambos ecosistemas. El grado de afectación le corresponderá estimarlo al Estudio de Impacto Ambiental. Sin embargo, es imperioso recomendar el monitoreo continuo de los espacios que han sido identificados como hábitat esenciales para la sobrevivencia de las diversas especies, como aquellas zonas costeras con comunidades de manglares, y zonas de agregación de organismos, tanto costeras como oceánicas. De ello dependerá que los ecosistemas presentes en el área de influencia del PMS no pierdan su balance natural y afecten irreversiblemente el bienestar de las comunidades. 


\section{APÉNDICE I}

\begin{tabular}{|c|c|c|c|c|c|c|c|c|c|c|c|c|c|c|c|c|c|c|}
\hline \multirow[b]{2}{*}{ Especies } & \multicolumn{9}{|c|}{ CAMPAÑA 1} & \multicolumn{9}{|c|}{ CAMPAÑA 2} \\
\hline & E1 & E2 & E3 & E4 & E5 & E6 & E7 & E8 & Total & E1 & E2 & E3 & E4 & E5 & E6 & E7 & E8 & Total \\
\hline Achirus achirus & & & & & & & & & & - & - & - & - & - & 1 & - & 3 & 4 \\
\hline Achirus lineatus & 6 & - & - & - & - & 6 & - & 20 & 32 & 60 & - & 1 & - & - & - & 3 & 6 & 70 \\
\hline $\begin{array}{l}\text { Albula vulpes } \\
\text { Amphicthys }\end{array}$ & - & - & - & - & 1 & - & - & - & 1 & & & & & & & & & \\
\hline $\begin{array}{l}\text { criptocentrus } \\
\text { Anchoa }\end{array}$ & & & & & & & & & & - & - & 1 & & 1 & & & - & 2 \\
\hline $\begin{array}{l}\text { hepsetus } \\
\text { Aprionichthys }\end{array}$ & - & $\cdot$ & - & $\cdot$ & 23 & - & - & - & 23 & - & - & - & - & - & 2 & 5 & $\cdot$ & 7 \\
\hline $\begin{array}{l}\text { dumerili } \\
\text { Archosargus }\end{array}$ & & & & & & & & & & - & - & $\cdot$ & $\cdot$ & $\cdot$ & $\cdot$ & $\cdot$ & 1 & 1 \\
\hline rhomboidalis & & & & & & & & & & - & $\cdot$ & 1 & - & 1 & 1 & $\cdot$ & $\cdot$ & 3 \\
\hline Anchoa parva & - & - & - & - & 3 & - & - & - & 3 & & & & & & & & & \\
\hline $\begin{array}{l}\text { Anchoa spinifer } \\
\text { Anisotremus }\end{array}$ & - & - & - & - & - & 8 & 2 & 27 & 37 & & & & & & & & & \\
\hline $\begin{array}{l}\text { surinamensis } \\
\text { Anisotremus }\end{array}$ & 2 & $\cdot$ & - & - & - & - & - & - & 2 & & & & & & & & & \\
\hline $\begin{array}{l}\text { virginicus } \\
\text { Aprionicthys }\end{array}$ & 1 & $\cdot$ & - & - & $\cdot$ & - & $\cdot$ & - & 1 & & & & & & & & & \\
\hline $\begin{array}{l}\text { dumerili } \\
\text { Archosargus }\end{array}$ & $\cdot$ & - & - & - & - & - & - & 1 & 1 & & & & & & & & & \\
\hline $\begin{array}{l}\text { rhomboidalis } \\
\text { Arius }\end{array}$ & 1 & - & - & - & $\cdot$ & - & - & $\cdot$ & 1 & & & & & & & & & \\
\hline grandicassis & $\cdot$ & - & - & - & - & 4 & - & 8 & 12 & & & & & & & & & \\
\hline Arius herzbergii & & & & & & & & & & 2 & - & 10 & 3 & - & 2 & $\cdot$ & 77 & 94 \\
\hline $\begin{array}{l}\text { Arius pasany } \\
\text { Arius }\end{array}$ & - & - & $\cdot$ & - & - & 4 & 1 & 38 & 43 & - & - & - & - & - & - & 28 & 1 & 29 \\
\hline $\begin{array}{l}\text { quadriscutis } \\
\text { Atherinella } \\
\text { brasiliensis }\end{array}$ & - & $\cdot$ & 1 & - & - & 10 & 7 & 4 & 22 & $\cdot$ & $\cdot$ & $\cdot$ & $\cdot$ & $\cdot$ & 1 & 1 & 2 & 4 \\
\hline Bagre bagre & - & - & - & - & - & - & 15 & 212 & 227 & - & - & - & - & - & - & 7 & - & 7 \\
\hline $\begin{array}{l}\text { Bagre marinus } \\
\text { Bairdiella }\end{array}$ & - & - & - & - & - & 4 & - & 49 & 53 & - & - & - & - & - & - & $\cdot$ & 2 & 2 \\
\hline $\begin{array}{l}\text { ronchus } \\
\text { Bairdiella }\end{array}$ & $\cdot$ & - & $\cdot$ & - & - & 3 & - & - & 3 & & & & & & & & & \\
\hline $\begin{array}{l}\text { sanctaeluciae } \\
\text { Batrachoides }\end{array}$ & 3 & $\cdot$ & 4 & - & 4 & - & - & 1 & 12 & - & 15 & 1 & - & 1 & - & - & - & 17 \\
\hline surinamensis & - & - & - & - & $\cdot$ & 2 & $\cdot$ & - & 2 & 2 & 1 & - & - & - & - & - & $\cdot$ & 3 \\
\hline $\begin{array}{l}\text { Cathorops spixii } \\
\text { Centropomus }\end{array}$ & - & - & - & - & 2 & 615 & 158 & 855 & 1630 & - & - & - & - & - & - & 134 & 485 & 619 \\
\hline $\begin{array}{l}\text { ensiferus } \\
\text { Cetengraulis }\end{array}$ & & & & & & & & & & 5 & - & 1 & $\cdot$ & - & - & - & - & 6 \\
\hline $\begin{array}{l}\text { edentulus } \\
\text { Chaetodipterus }\end{array}$ & $\cdot$ & - & $\cdot$ & $\cdot$ & $\cdot$ & - & 1 & 2 & 3 & - & - & - & $\cdot$ & - & 2 & 1 & 8 & 11 \\
\hline $\begin{array}{l}\text { faber } \\
\text { Chilomycterus }\end{array}$ & 1 & - & 1 & - & - & 3 & 2 & 3 & 10 & - & - & - & - & 1 & 2 & - & - & 3 \\
\hline $\begin{array}{l}\text { antillarum } \\
\text { Chloroscombrus }\end{array}$ & $\cdot$ & - & 1 & - & - & - & - & - & 1 & - & - & - & - & 1 & - & $\cdot$ & - & 1 \\
\hline $\begin{array}{l}\text { crhysurus } \\
\text { Colomesus }\end{array}$ & $\cdot$ & $\cdot$ & $\cdot$ & - & - & 3 & $\cdot$ & 1 & 4 & - & - & - & $\cdot$ & $\cdot$ & 2 & 1 & - & 3 \\
\hline psittacus & - & - & - & - & - & 4 & 1 & 53 & 58 & - & - & - & - & - & - & 1 & 45 & 46 \\
\hline Conodon novilis & & & & & & & & & & - & - & - & - & - & - & - & - & 0 \\
\hline Cynoscion & - & - & - & - & 1 & - & - & 4 & 5 & - & 7 & - & - & - & - & - & 1 & 8 \\
\hline
\end{tabular}




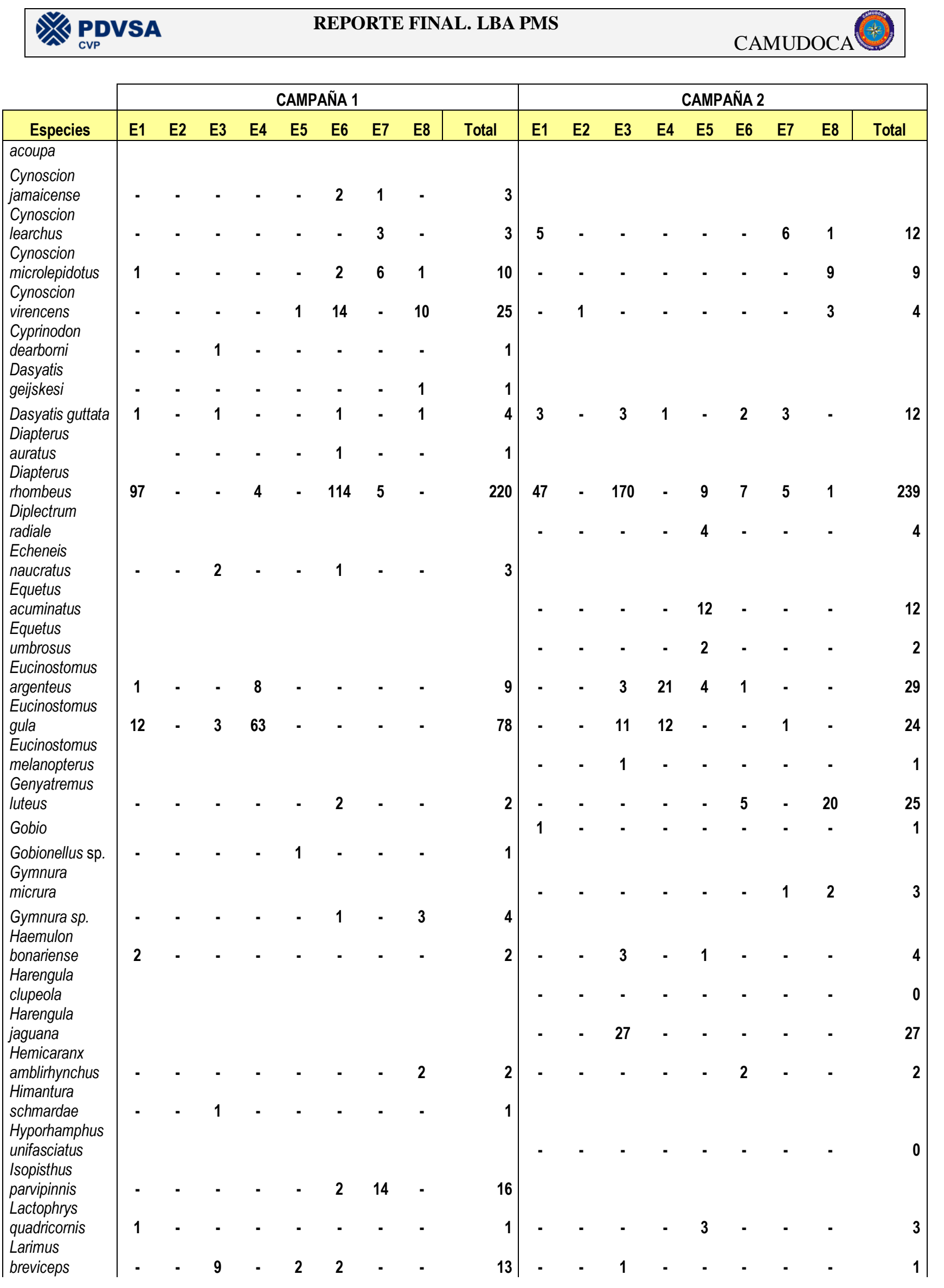




\begin{tabular}{|lll}
\hline PDP \\
PSA
\end{tabular} REPORTE FINAL. LBA PMS

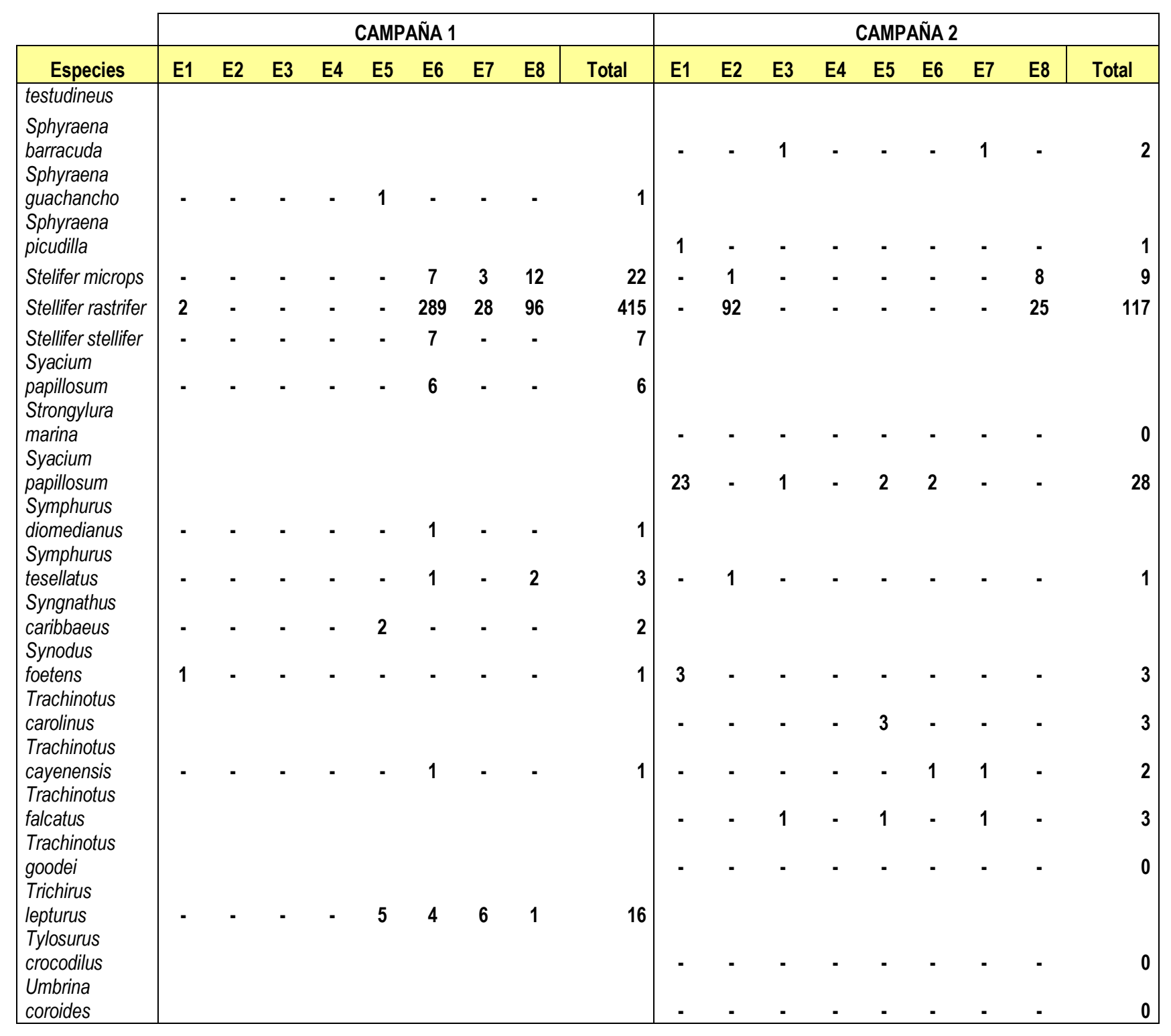




\section{APÉNDICE II}

\begin{tabular}{|c|c|c|}
\hline FAMILIAS & ORDENES y especies & $\begin{array}{l}\text { NOMBRES } \\
\text { COMUNES }\end{array}$ \\
\hline & MILIOBATIFORMES & \\
\hline \multirow[t]{3}{*}{ Dasyatidae } & Dasyatis guttata & Raya látigo hocicona \\
\hline & Dasyatis geijskesi & Raya látigo picúa \\
\hline & Himantura schmardae & Chupare \\
\hline Gymnuridae & Gymnura micrura & Guayanesa \\
\hline \multirow[t]{2}{*}{ Rhinopteridae } & Rhinoptera bonasus & Mancha \\
\hline & ALBULIFORMES & \\
\hline \multirow[t]{2}{*}{ Albulidae } & Albula vulpes & Ratón \\
\hline & ATHERINIFORMES & \\
\hline \multirow[t]{2}{*}{ Atherinidae } & Atherinella brasiliensis & Tinícalo \\
\hline & AULOPIFORMES & \\
\hline \multirow[t]{2}{*}{ Synodontidae } & Synodus foetens & Guaripete \\
\hline & BATRACHOIDIFORMES & \\
\hline \multirow[t]{3}{*}{ Batrachoididae } & Amphichthys cryptocentrus & Sapo bocón \\
\hline & Batrachoides surinmensis & Sapo \\
\hline & CYPRINODONTIFORMES & \\
\hline \multirow[t]{2}{*}{ Cyprinodontidae } & Cyprinodon dearborni & Petotica \\
\hline & ELOPIFORME & \\
\hline \multirow[t]{2}{*}{ Megalopidae } & Megalops atlanticus ${ }^{*}$ & Sábalo \\
\hline & BELONOFORMES & \\
\hline \multirow[t]{2}{*}{ Belonidae } & Strongylura marina & Marao \\
\hline & Tylosurus crocodilus & Marao ojón \\
\hline \multirow[t]{2}{*}{ Hemirhamphidae } & Hyporhamphus unifasciatus & Marao blanco \\
\hline & CLUPEIFORMES & \\
\hline \multirow[t]{7}{*}{ Clupeidae } & Harengula clupeola & Carapachona \\
\hline & Harengula jaguana & Carapachona \\
\hline & Odontognathus mucronatus & Sardinata \\
\hline & Pellona harroweri & Sardinata \\
\hline & Opisthonema oglinum & Machuelo \\
\hline & Rhinosardinia sp. & Sardina \\
\hline & Sardinella aurita & Sardina \\
\hline \multirow[t]{3}{*}{ Engraulidae } & Pterengraulis atherinoides & Camiguana \\
\hline & Cetengraulis edentulus & Rabo amarillo \\
\hline & Anchoa hepsetus & Camaiguana \\
\hline
\end{tabular}




\begin{tabular}{|c|c|c|}
\hline FAMILIAS & ORDENES y especies & $\begin{array}{l}\text { NOMBRES } \\
\text { COMUNES }\end{array}$ \\
\hline \multirow{7}{*}{$\begin{array}{l}\text { Acanthuridae } \\
\text { Blennidae } \\
\text { Labrisomidae }\end{array}$} & Lycengraulis grossidens & Camaiguana \\
\hline & Anchoa parva & Camaiguana \\
\hline & Anchoa spinifer & Camaiguana \\
\hline & PERCIFORMES & \\
\hline & Acanthurus bahianus* & Navajón o Sangrador \\
\hline & Scartella cristata* & Chivato \\
\hline & Malacoctenus macropus* & \\
\hline Gobiidae & Gobionellus sp. & \\
\hline Labridae & $\begin{array}{l}\text { Gobio sp. } \\
\text { Halichoere bivittatus* }\end{array}$ & Doncella verde \\
\hline \multirow[t]{2}{*}{ Scaridae } & Nicholsina usta & Loro jabonero \\
\hline & Sparisoma sp* & Loro \\
\hline Mugilidae & Mugil curema & lisa criolla \\
\hline \multirow[t]{11}{*}{ Carangidae } & Chloroscombrus chrysurus & Chicharra \\
\hline & Hemicaranx amblyrhynchus & Huele chicharra \\
\hline & Oligoplites saurus & Zapatero ligerito \\
\hline & Oligoplites palometa & Zapatero boquiguana \\
\hline & Selene vomer & Cara e caballo \\
\hline & Selene setapinnis & Lamparosa \\
\hline & Trachinotus cayenensis & Pámpano zapatero \\
\hline & Trachinotus carolinus & Pámpano amarillo \\
\hline & Trachinotus falcatus & Pámpano ericero \\
\hline & Trachinotus goodei & Pámpano listado \\
\hline & Caranx latus* & Ojo gordo \\
\hline Echeneidae & Echeneis naucrates & Pega \\
\hline \multirow[t]{2}{*}{ Centropomidae } & Centropomus ensiferus & Robalo maqueque \\
\hline & Centropomus undecimalis* & Robalo \\
\hline Ephippidae & Chaetodipterus faber & Paguara \\
\hline \multirow[t]{6}{*}{ Gerreidae } & Diapterus auratus & Caguicha \\
\hline & Diapterus rhombeus & Caitipa \\
\hline & Eucinostomus argenteus & Española de laguna \\
\hline & Eucinostomus gula & Española \\
\hline & Eucinostomus melanopterus & Banderita \\
\hline & Gerres cinereus* & Muñama \\
\hline \multirow[t]{4}{*}{ Haemulidae } & Anisotremus surinamensis & Pez burro \\
\hline & Anisotremus virginicus & Catalina \\
\hline & Genyatremus luteus & Toroto \\
\hline & Haemulon bonariense & Corocoro rayao \\
\hline
\end{tabular}




\begin{tabular}{|c|c|c|}
\hline FAMILIAS & ORDENES y especies & $\begin{array}{l}\text { NOMBRES } \\
\text { COMUNES }\end{array}$ \\
\hline \multirow{12}{*}{$\begin{array}{l}\text { Kyphosidae } \\
\text { Lutjanidae }\end{array}$} & Haemulos aurolineatum* & Cují \\
\hline & Haemulon flavolineatum* ${ }^{*}$ & Corocoro amarillo \\
\hline & Pomadasys croco & Cabeza dura \\
\hline & Conodon novilis & Canario \\
\hline & Kyphosus sp. * & Morocoto \\
\hline & Lutjanus analis & Pargo cebal \\
\hline & Lutjanus grisesus & Pargo dientón \\
\hline & Lutjanus purpureus & Pargo colorado \\
\hline & Lutjanus synagris & Pargo guanapo \\
\hline & Lujanus sp. & pargo \\
\hline & Lutjanus cianopterus* & Pargo Caballo \\
\hline & Lutjanus jocu* & Pargo perro \\
\hline \multirow[t]{3}{*}{ Pomacentridae } & Abudefduf saxatilis* & Petaca \\
\hline & Abudefduf taurus* & Petaca morocota \\
\hline & Stegastes sp* & Petaca \\
\hline Pomacanthidae & Pomacanthus paru* & Cachama negra \\
\hline \multirow[t]{22}{*}{ Sciaenidae } & Bairdiella ronchus & Caracare \\
\hline & Bairdiella sanctaeluciae & Caimure \\
\hline & Cynoscion acoupa & Curvina de lago \\
\hline & Cynoscion jamaicensis & Tonquincha \\
\hline & Cynoscion learchus & Curvina blanca \\
\hline & Cynoscion microlepidotus & Curvina dorada \\
\hline & Cynoscion virescens & Curvina \\
\hline & Isopisthus parvipinnis & Curvina \\
\hline & Larimus breviceps & Bonbache \\
\hline & Lonchurus lanceolatus & \\
\hline & Macrodon ancylodon & Curvinata de mar \\
\hline & Menticirrhus americanus & Lambe \\
\hline & Menticirrhus littoralis & Lambe plateado \\
\hline & Micropogonias furnieri & Roncador \\
\hline & Odontoscion dentex & Caimure de roca \\
\hline & Ophiscion sp. & \\
\hline & Stellifer microps & Burrito \\
\hline & Stellifer rastrifer & Burrito bocón \\
\hline & Stellifer stellifer & Burrito \\
\hline & Nebris microps & \\
\hline & Umbrina coroides & Petota \\
\hline & Equetus acuminatus & Obispo \\
\hline
\end{tabular}




\begin{tabular}{|c|c|c|}
\hline FAMILIAS & ORDENES y especies & $\begin{array}{l}\text { NOMBRES } \\
\text { COMUNES }\end{array}$ \\
\hline & Equetus umbrosus & Obispo lucio \\
\hline \multirow[t]{2}{*}{ Serranidae } & Diplectrum radiale & Bolo \\
\hline & Mycteroperca bonaci* & Cuna guarei \\
\hline \multirow[t]{2}{*}{ Sparidae } & Archosargus rhomboidalis & Cagalona \\
\hline & Diplodus argenteus* & San Pedra \\
\hline Trichiuridae & Trichiurus lepturus & Tajalí \\
\hline \multirow[t]{3}{*}{ Sphyraenidae } & Sphyraena picudilla & Picua china \\
\hline & Sphyraena guachancho & Picua lista amarilla \\
\hline & PLEURONECTIFORMES & \\
\hline \multirow[t]{3}{*}{ Achiridae } & Achirus lineatus & Arrevés lagunero \\
\hline & Achirus achirus & Arrevés lucio \\
\hline & Aprionichtys dumerilli & Arrevés ciego \\
\hline \multirow[t]{2}{*}{ Cynoglossidae } & Symphurus diomedianus & Lengua e'vaca pintada \\
\hline & Symphurus tessellatus & Lengua évaca \\
\hline \multirow[t]{3}{*}{ Paralichthyidae } & Syacium papillosum & Lenguado dientón \\
\hline & Paralichthys tropicus & Lenguado criollo \\
\hline & SCORPAENIFORMES & \\
\hline Scorpaenidae & Scorpaena plumieri & Sapo chaznete negro \\
\hline \multirow[t]{2}{*}{ Triglidae } & Prionotus punctatus & Gallina \\
\hline & SILURIFORMES & \\
\hline \multirow[t]{8}{*}{ Ariidae } & Arius grandicassis & Bagre vaca \\
\hline & Hexanematichthys herzbergii & Bagre guatero \\
\hline & Hexanematichthys passany & Bagre chato \\
\hline & Aspitor quadriscutis & Bagre \\
\hline & Bagre bagre & Bagre cacumo \\
\hline & Bagre marinus & Bagre cacumo \\
\hline & Cathorops spixii & Bagre guinche \\
\hline & SYNGNATHIFORMES & \\
\hline \multirow[t]{2}{*}{ Syngnathidae } & Syngnathus sp. & \\
\hline & TETARODONTIFORMES & \\
\hline \multirow[t]{3}{*}{ Tetraodontidae } & Colomesus psittacus & Corrotucho raylado \\
\hline & Sphoeroides testudineus & Corrotucho verde \\
\hline & Sphoeroides spengleri & corrotucho mataperros \\
\hline Ostraciidae & Lactrophys quadricornis & Torito azul \\
\hline \multirow[t]{2}{*}{ Diodontidae } & Chilomycterus antillarum & Tamboril erizo \\
\hline & Diodon histrix ${ }^{*}$ & Tamboril pintado \\
\hline
\end{tabular}




\section{VI.- BIBLIOGRAFIA}

Abbott R.T. 1974. American Seashells. 2nd Edition. Van Nostrand Reinhold Ltd., N.Y. 663 p.

Alió, J., Marcano, L., y Altuve, D.E. (en revisión). Incidental capture and mortality of sea turtles in the industrial shrimp trawl fishery from northeastern Venezuela. Ciencias Marinas.

Alió, J., Marcano, L., Paez-Costa, J. y Cochrane, K. 1999. Macrodon ancylodon stock within the Orinoco and Gulf of Paria region, pp. 191-195. FAO Fisheries Report, No. 600. 200 p.

Alió, J., Marcano, L., Soomai, S., Phillips, T., Altuve, D., Alvarez, R., Die, D., Cochrane, K. 2000. Analysis of industrial trawl and artisanal fisheries of whitemouth croaker (Micropogonias furnieri) of Venezuela and Trinidad and Tobago in the Gulf of Paria and Orinoco River Delta. Western Central Atlantic Fishery Commission. Report of the third Workshop on the Assessment of Shrimp and Groundfish Fisheries on the Brazil-Guianas Shelf. Belem, Brazil, 24 May - 10 June 1999. no. 628, pp. 138-148. FAO Fish. Rep. 2000.

Altuve D. 1997. Pesca artesanal de Litopenaeus schmitii en el noreste del GP. Tesis de Maestría. Postgrado en Ciencias Marinas, Universidad de Oriente.

Altuve D., J.J. Alió y L.A. Marcano. 1995. Preliminary results on the artisanal fishery of penaeid shrimps in the northeastern coast of the Gulf of Paria, Venezuela. Third Workshop on the biological and economical modeling of the shrimp resources on the Guyana-Brazil shelf. Paramaribo, Suriname, June, 1992. FAO Fish. Rep. No. 526 (Supplement):128-188.

Alvarez, R; Altuve, D; Alió, J.j., Marcano, L., Cochrane, K., Tandstad, M. 1999. Assessment of roncador (Micropogonias furnieri) within the Orinoco and Gulf of Paria region. Technical reports on shrimp and fish prepared at the second CFRAMP/FAO /DANIDA Stock Assessment Workshop on the Shrimp and Groundfish Fishery on the Brazil-Guianas Shelf held at Georgetown, Guyana, 18-29 May 1998. pp. 159-167. 1999.

Anónimo, 1994. Diagnóstico Socio-Económico de las Comunidades Pesqueras Ubicadas en el Estado Sucre y las Costas del Delta del Orinoco. Sector entre Carúpano y Araya. Convenio UDOLAGOVEN. Vols. 1 y 2.

Aparicio, R. 1986. Upwelling along the southern coast boundary of the Caribbean Sea: Physical characterization, variability and regional implications. Tesis Maestría, Florida Institute of Technology. 189 p.

Aparicio, R. 2003. Revisión de las características oceanográficas de la plataforma nororiental de Venezuela. En : Fréon, P. \& J. Mendoza (Eds.). The sardine Sardinella aurita its exploitation and environment in eastern Venezuela. Editions IRD, Paris. 550 p. 
Arocha, F. y L. J. Urosa. 1982. Cefalópodos del genero Octopus en el área nororiental de Venezuela. Bol. Inst. Oceangr. Venez. Univ. Oriente 21 (1-2): 167-189.

Arocha, F. y L.J. Urosa. 1991.Some biological studies of Loligo plei and occurence of Loligo pealii (Cephalopoda,Myopsida) in northeastern Venezuela. Acta Científica Venezolana, 42:145-152.

Arocha, F. y L. Marcano. 2006. Life history characteristics of Makaira nigricans, Tetrapturus albidus, and Istiophorus platypterus from the eastern Caribbean Sea and adjacent waters. Proceedings of the Fourth World Fisheries Congress. American Fisheries Society Symposium Series:587597(in press).

Arocha, F., L. Marcano, A. Larez, D. Altuve y J. Alio. 1999. The fishery, demographic size structure and oocyte development of dolphinfish, Coryphaena hippurus, in Venezuela and adjacent waters. Scientia Marina:63 (3-4):401-409.

Ayala-Pérez, L.A., Ramos-Miranda, J., \& Flores-Hernández, D. 2005. Los peces que acompañan la pesca del camarón en la porción occidental de la costa de Campeche, México. Resumen XXV Congreso Latinoamericano de Ciencias del Mar, Viña del Mar, Chile: 223 p.

Bazigos, G. P. 1974. The design of fisheries statistical surveys inland water. FAO Fish. Tech. Pap., (133): $122 \mathrm{P}$.

Blaber, S.J. 1997. Fish and Fisheries of Tropical Estuaries. Chapman\&Hall, London. 367 pp.

Blaber, S.J. 2000. Tropical Estuarine Fishes. Ecology, Exploitation and Conservation. Blackwell Science Ltd., London. 372 pp.

Benthos Estudios y Proyectos 2003. Estudio de línea base documental fase de producción CONOCO, GP. 80 pp.

Booth, A; Charuau, A., Cochrane, K., Die, D., Hackett, A., Larez, A., Maison, D., Marcano, L., Phillips, T., Soomai, S., Souza, R., Wiggins, S., IJspol, M. 2001. Regional assessment of the BrazilGuianas groundfish fisheries. Regional reviews and national management reports. Fourth Workshop on the Assessment and Management of Shrimp and Groundfish Fisheries on the Brazil-Guianas Shelf. Cumana, Venezuela, 2-13 October 2000. no. 651, pp. 22-36. [FAO Fish. Rep.]. 2001.

Capelo, J. 1990. Los moluscos de la Península de Paria. En: Informe sobre las actividades realizadas durante la salida a la Peninsula de Paria del 10 al 16 de abril con motivo del censo pesquero. Inf. Tecn. Editar. 12 p.

Cárdenas, J. 1999. Análisis de los censos de la flota artesanal marítima del oriente de Venezuela. Vol. III. En : Mendoza, J. y Arocha F. (Editores) Pesquerías y Recursos Pesqueros del Oriente de Venezuela. Convenio FUNDAUDO-PALMAVEN. Informe Final, Vols. I-V. 
Cárdenas, J. y Achury, A. 2000. Acústica pesquera de los recursos marinos del oriente de Venezuela: evaluación y seguimiento espacio-temporal del stock de sardina (Sardinella aurita). Memoria de la Fundación La Salle de Ciencias Naturales, 154:39-54.

Cárdenas, J., Silva, J. y Mendoza J. 1991. Evolución de la flota pesquera artesanal marítima del nororiente venezolano entre los años 1984 y 1990, Mem. Soc. Cienc. Nat. La Salle, 51, (135-136): 145-147.

Carpenter, K.E. (Ed.). 2003. An introduction to the Oceangraphy, geology, biogeography, and fishery of the tropical and subtropical western central Atlantic. FAO Species Identificación Guide for Fishery Purposes. The Living Marine Resources of the Western Central Atlantic. FAO, Roma. Vol 1.

Cervigón, F. 1982. La ictiofauna estuarina del Caño Mánamo y áreas adyacentes. En: Novoa, D. (Ed.). Los recursos pesqueros del río Orinoco y su explotación. Corporación Venezolana de Guayana. Caracas, Edit. Arte. 205-260 pp.

Cervigón, F. 1985. La ictiofauna de las aguas estuarinas del delta del río Orinoco en la costa atlántica occidental, Caribe. En: Yañez-Arancibia, A. (Edit.). Fish Community Ecology in Estuarios and Coastal Lagoons towards and Ecosystem Integration. UNAM Pres., México. 56-78 p.

Cervigón, F. 1991. Los peces Marinos de Venezuela. Fundación Cientifica Los Roques, Caracas, Venezuela. I: 425 pp.

Cervigón, F. 1993. Los peces Marinos de Venezuela. Fundación Cientifica Los Roques, Caracas, Venezuela. II: $498 \mathrm{pp}$.

Cervigón, F. 1994. Los Peces Marinos de Venezuela. Editorial Ex Libris, Caracas Venezuela. III: 295 pp.

Cervigón, F. 1996. Los Peces Marinos de Venezuela. Editorial Ex Libris, Caracas Venezuela. IV: 254 pp.

Cervigón, F. y A. Alcalá. 1999. Los Peces Marinos de Venezuela. Editorial Ex Libris.Caracas Venezuela. V: 230 pp.

Chan A Shing, Ch. 2001. Case study of the integrated coastal fisheries management Project: a pilot project for the gulf of Paria, Trinidad. Caribbean Natural Resources Technical Report № 280: $11 \mathrm{pp}$.

Díaz J.M., M. Puyana. 1994. Moluscos del Caribe Colombiano. Un Catálogo llustrado. COLCIENCIAS, Fundación Natura e INVEMAR, Bogotá. 367 p.

Die, D., J.J. Alió, L. Ferreira, L. Marcano y S. Soomai 2004. Assessment of demersal stocks shared by Trinidad \& Tobago and Venezuela. FAO/FishCode Review. No. 3, 32 p. 
Dickson, W. 1974. A review of the efficiency of bottom trawls. Bergen, Norway, Institute of Fisheries Technology and Research, 44pp.

Ecology and Environment. 2003. La actividad pesquera en el GP. Actualizacion del Estudio de Linea Base. Preparado para CONOCO-Phillips Venezuela C.A. 195 pp.

Etcheveres S. 1976. Notas ecológicas y cuantificación de la población del guacuco Tivela mactroides (Born, 1778) (Bivalvia: Verenidae), en la Ensenada de la guardia, Isla de Margarita, Venezuela.

FAO. 1982. La recolección de estadísticas y esfuerzo. FAO. Circ. Pesca, (730): 65 p.

Fitch J.E. 1950. The pismo clam. Calif. Fish. \& Game. 36: 285-312.

Flores, C. y R. Caceres. 1980. El género Astraea Roding, 1878 ( Archeogastropoda: Turbinidae) en las aguas costeras de Venezuela. Bol. Inst. Ocean. U.D.O. 19 (1-2): 59-72.

Freón, P. 1991. Seasonal and interannual variations of mean catch per set in the Senegalese sardine fisheries: fish behavior or fishing strategy?. In: Long - term Variabilty of Pelagic Fish Population and their Environment (eds Kawasaki, T., Tanaka, S., Toba, Y. \& Taniguchi, A), pp. 135 - 145. Pergamon Press, Oxford.

Fréon, P. \& J. Mendoza (Eds.). 2003. The sardine Sardinella aurita its exploitation and environment in eastern Venezuela. Editions IRD, Paris. 550 p.

Freón, P., Mullon, C. \& Pichon, G. 1991. CLIMPROD: a fully interactive expert- system software for choosing and adjusting a global production model which accounts for changes in environmental factors. In: Long - term Variabilty of Pelagic Fish Population and their Environment (eds Kawasaki, T., Tanaka, S., Toba, Y. \& Taniguchi, A), pp. 347 - 357. Pergamon Press, Oxford.

Freón, P, R. Guzmán y R. Aparicio. 1991. Relaciones entre capturas, esfuerzo y afloramiento en la pesquería de sardina del oriente de Venezuela. En la sardina y su medio ambiente en el oriente de Venezuela. Informe Taller 24 pp. (Mimeo)

Freón, P y O. Misund. 1998. Dynamics of pelagic fish distribution and behavior: Effects on fisheries and stocks assessment. Blackwell Science Ltd. Fishing News Books. 348 pp.

Fuiman, L.A. y R.G. Werner (Ed). 2002. Fishery Science. The unique contributions of early life stages. Blackwell Science Ltd. Oxford, UK. 325pp.

FUNINDES-UDO. 2004. Evaluación Socioeconómica de Los Proyectos Costa Afuera en Progreso en El Oriente del País. Preparado para PDVSA-GAS.

García N., A. Prieto, R. Anzola, C. Lodeiros. 2003. Crecimiento y distribución de tallas de Donax denticulatus (Mollusca:Donacidae) en Playa Brava, Península de Araya, Estado sucre, Venezuela. Revista Científica FCV-LUZ. 32:464-4. 
Ginés, Hno. (Editor) 1972. Carta Pesquera de Venezuela, 1- Areas del Nororiente y Guayana, Monografía No. 16, Fundación La Salle de Ciencias Naturales, Caracas. 328 pp.

Ginés, H. y F. Cervigón. 1967. Exploración pesquera en las costas de Guayana y Surinam. Men. Soc. Cien. Nat. La Salle. 28 (79):1-96.

Godoy A. 1997. Densidad poblacional, biomasa y rendimiento pesquero del guacuco Tivela mactroides 1778, en la zona Suroriental del Golfo de Venezuela (Zulia, Venezuela). Tesis de Licenciatura en Biología, La Universidad del Zulia, 59 pp.

Gómez, G. 1999. Análisis de la pesquería artesanal costanera del GP y Golfo de Santa Fe. Vol. III. En: Mendoza, J. y Arocha F. (Editores) Pesquerías y Recursos Pesqueros del Oriente de Venezuela. Convenio FUNDAUDO-PALMAVEN. Informe Final, Vols. I-V.

Gómez, G. 2002. Análisis de la captura y esfuerzo de la pesquería artesanal costanera del GP. Informe técnico INIA-Sucre/NE. 97 pp. (Mimeo).

Gómez, G. 2003. Análisis de la captura y esfuerzo de la pesquería artesanal costanera del GP. Informe técnico INIA-Sucre/NE. 67 pp. (Mimeo).

Gómez G., R. Guzmán y R. Chacón. 2002. Algunos aspectos de la biología reproductiva y poblacional del torroto, Genyatremus luteus, (Bloch, 1797) (Pisces: Haemulidae) en el GP, Venezuela Zootecnia Trop., 20(2):223-234.

Gómez G., R. Guzmán y R. Chacón. 2001. Parámetros reproductivos y poblacionales de Lutjanus synagris en el GP, Venezuela Zootecnia Trop., 19(3): 335-357.

Guppy, J. R. 1875. Notice on some marine shells found on the shores of Trinidad. Am. Mag. Nat. Hist. 4 (15): 50-52.

Guppy, J. R. 1877. First sketch of the marine invertebrates fauna of the gulf and its neighborhood. Proc. Sci. Assoc. Trinidad. 134-157.

Guppy, J. R. 1895. The mollusca of Gulf of Paria. Proc. Sci. Assoc. Trinidad. 2: 116-132.

Guzmán, R. 2000. Dinámica poblacional y pesquería de la sardina del nororiente de Venezuela. Informe INIA. 34 pp. (Mimeo).

Guzmán, R. 2001. Dinámica poblacional y pesquería de la sardina del nororiente de Venezuela. Informe INIA. 25 pp. (Mimeo).

Guzmán, R. 2003. Análisis de la pesquería artesanal de sardina en las comunidades de Guaca y Guatapanare. Informe técnico. INIA- Sucre. 6 pp. (Mimeo). 
Haimovici, M., A.S. Martins, J.L. de Figueiredo y P.C. Vieira 1994. Demersal bony fish of the outer shelf and upper slope of the southern Brazil subtropical convergence ecosystem. Mar. Ecol. Prog. Ser. 108(1-2): 59-77.

Institute of Marine Research (IMR). 1989. Surveys of the fish resources in the shelf areas between Suriname and Colombia 1988. Final report. Roports on Surveys with R/V Dr. Fridtjof Nansen. NORAD/UNDP/FAO Programme. Bergen. $135 \mathrm{pp}$.

Kuruvilla S., L. Ferreira \& S. Soomai 2000. The trawl fishery of Trinidad and Tobago. Fisheries Information Series No. 9, Fish. Div., Min. Agric., Land Mar. Res., Port of Spain, Trinidad and Tobago, $18 \mathrm{p}$.

Lárez, A. 1999. Análisis de los índices de abundancia y estructura de tallas de las principales especies desembarcadas por la flota pargo-mero de media altura en el oriente de Venezuela. Vol. II. En : Mendoza, J. y Arocha F. (Editores) Pesquerías y Recursos Pesqueros del Oriente de Venezuela. Convenio FUNDAUDO-PALMAVEN. Informe Final, Vols. I-V.

Lárez, A. y Mendoza, J. 1999. La pesca artesanal costanera de la Isla de Margarita. Vol. III. En : Mendoza, J. y Arocha F. (Editores) Pesquerías y Recursos Pesqueros del Oriente de Venezuela. Convenio FUNDAUDO-PALMAVEN. Informe Final, Vols. I-V.

Lasso, C.A., Lasso-Alcalá, O.M., Pombo, C. y M. Smith. 2004. Ictiofauna de las aguas estuarinas del delta del río Orinoco (Caños Pedernales, Manamo, Manamito y GP (río Guanipa: Diversidad, distribución, amenazas y criterios para su conservación. Biodiversidad y Aspectos sociales de los ecosistemas del Río Orinoco y el GP. Rap. Coloco-Phillips. 72-84.

LAGOVEN. 1997. Estudio de Impacto ambiental Proyecto Terminal de Aguas Profundas. Resumen Ejecutivo. Caracas. 24 pp.

Lemus, A. 1979. Las algas marinas del GP, Venezuela. 1. Chlorophyta y Phaeophyta. Bol. Inst. Oceanogr. Univ. Oriente. 18 (1\&2): 17 - 36.

Lodeiros C., B. Marín, A. Prieto. 1999. Catálogo de moluscos del nororiente de Venezuela. Clase Bivalvia. Edición APUDONS. 109p., 9 Láminas.

Manickchand-Dass, S. 1980. Studies of the biology of the croaker, Micropogonias furnieri (Desmarest, 1823) in Trinidad, West Indies. University of the West Indies. MPhil Thesis. 138 pp.

Manickchand-Dass, S. 1990. Spawning energetics of the white mouth croaker Micropogonias furnieri (Desmarest, 1823), and implications for exploitation in Trinidad, West Indies. University of Miami. Thesis PhD. 228 pp.

Manickchand-Dass, S. \& Julien, M. 1996. Species composition, seasonality and reproductive activity of a demersal fish stock in Trinidad, Wets Indies. Caribbean Marine Studies. 1(1): 11-21. 
Manickchand-Heileman, S. y M. Julien-Flus. 1990. Species composition and seasonality of a coastal demersal fish stock in Trinidad, West Indies. Caribbean Marine Studies 1(1): 11-21.

Manickchand-Heileman, S. y J. Kenny, 1990. Reproduction, age, and growth of the whitemouth croaker Micropogonias furnieri (Desmarest 1823) in Trinidad waters. Fish. Bull. 88:523-259.

Marcano J. S. 2003. Evaluación de la pesquería del carite lucio Scomberomorus cavalla en el oriente de Venezuela y áreas adyacentes. Informe Técnico. INIA: 17 pp.

Marcano, J. 1999. Pesquerías pelágicas de media altura en el oriente de Venezuela. Vol. II. En : Mendoza, J. y Arocha F. (Editores) Pesquerías y Recursos Pesqueros del Oriente de Venezuela. Convenio FUNDAUDO-PALMAVEN. Informe Final, Vols. I-V.

Marcano J. S., A. Lárez, A. Carrión y O. Heredia 1998. Pesquerías del carite rey Scomberomorua cavalla por la flota artesanal cordelera del estado Nueva Esparta en el Oriente de Venezuela y áreas adyacentes. Mem. Soc. Ciencias Nat. La salle. 149 (58).

Marcano J. S., A., Lárez, L., Marcano, C.,Gil, H, Salazar. y H. Pino 1995. Pesquerías artesanales pelágicas del Estado Nueva Esparta. Carite y Peces de pico. Col. Doc. Cient. ICCAT. 44(3): 238-245.

Marcano, L., 1990. Análisis de la situación de la industria de la pesca de arrastre durante el período 1985-1989. En: Resultados de los talleres sobre la pesca en Venezuela, pp. 25-52. Ministerio de Agricultura y Cría (MAC). 126 pp.

Marcano, L., D. Altuve y J. Alió, 1999. La Pesca de Arrastre en la Región Nororiental de Venezuela. Pesquerías y Recursos Pesqueros del Oriente de Venezuela. Vol. II. En : Mendoza, J. y Arocha F. (Editores) Pesquerías y Recursos Pesqueros del Oriente de Venezuela. Convenio FUNDAUDO-PALMAVEN. Informe Final, Vols. I-V.

Marcano, L.A.; J.J. Alió; D.E. Altuve, D. Novoa, R.A. Alvarez \& G. de Pasquier 2001. Revisión de la pesca de arrastre en Venezuela. En: FAO Tropical shrimp fisheries and their impact on living resources. FAO Fisheries Circular C 974:330-378.

Martin J., Davis G. 2001. An updated classification of recent crustacean. Contributions in science No. 39. Natural History Museum of Los Angeles Country. 124 pp.

Méndez Arocha, A. 1963. La pesca en Margarita. Monografía №7, Fundación La Salle de Ciencias Naturales, Caracas, Venezuela.

Mendoza, J. 1993. A preliminary biomass budget for the northeastern Venezuela shelf ecosystem. En: Christensen,V, and Pauly, D. (Eds), Trophic models of Aquactic Ecosystem. ICLARM Conference Proceedings 26, pp. 285-297,390. 
Mendoza, J. y F. Arocha. (Editores) 1999. Pesquerías y Recursos Pesqueros del Oriente de Venezuela. Convenio FUNDAUDO-PALMAVEN. Informe Final: Vols. I-V.

Mendoza, J. y F. Arocha. 2004. Los recursos pesqueros del oriente de Venezuela. 135 pp. En: Diagnóstico Socio-Económico de los Proyectos Costa Afuera. FUNINDES/USB - Proyectos Costa Afuera - PDVSA

Mendoza, J. y Lárez A. 1996. Abundance and distribution of snappers and groupers targeted by the medium range fishery off northeastern Venezuela (1981-1992) p. 266-276. En: F. ArreguínSánchez, J.L. Munro, M.C. Balgos and D. Pauly (eds.) Biology, fisheries and culture of tropical groupers and snappers. ICLARM Conf. Proc. 48, 449 p.

Mendoza J. y J. Marcano 2000. Abundancia, explotación y dinámica poblacional del guacuco Tivela mactroides (Born, 1778), (Mollusca: Bivalvia) en La Ensenada La Guardia, Isla de Margarita. Bol. Inst. Oceangr. Unv. Oriente. 39:79-91.

Mendoza, J., Sánchez L. y Marcano L. 1994. Variaciones en la Distribución y Abundancia de los Principales Recursos Demersales Explotados por la Pesquería de Arrastre del Nororiente de Venezuela. I. Peces. Memoria Soc. Cienc. Nat. La Salle, Vol. LIV, No. 142: 47-64.

Mendoza, J., L.A. Sánchez y L.A. Marcano 1994. Variaciones en la distribución y abundania de los principales recursos explotados por la pesquería de arrastre del nororiente de Venezuela. II. Invertebrados. Mem. Soc. CienC. Nat. La Salle 54(142): 65-81.

Muller-Karger, F. and R. Varela. 1990. Influjo del Rio Orinoco en el Mar Caribe: Observaciones con el CZCS desde el espacio. Mem. Soc. Cien. Nat. La Salle, 50(133-134):361-390.

Novoa, D. 2000. La pesca en el GP y Delta del Orinoco costero. CONOCO Venezuela. Edit. Arte. Caracas.

Novoa, D. (Ed.) 1982. Los recursos pesqueros del Río Orinoco y su explotación. Corporación Venezolana de Guayana. Edit. Arte Caracas. 382 pp.

Novoa, F. y F. Cervigón. 1986. Resultados de los muestreos de fondo en el área estuarina del Delta del Orinoco. En: IOC/FAO Workshop on recruitment in tropical coastal demersal communities. IOC Workshop report 44. Ciudad del Carmen, Mexico.

Novoa, D., Cervigón, F. y F. Ramos. 1982. Catalogo de los recursos pesqueros del Delta del Orinoco. En: D. Novoa (Comp.). Los recursos pesqueros del río Orinoco y su explotación. Corporación Venezolana de Guayana. Ed. Arte, Caracas. 263-323 pp.

Novoa D., J. Mendoza, L. Marcano, J. Cardenas. 1998. El atlas pesquero marítimo de Venezuela. MAC-SARPA, VECEP $197 \mathrm{pp}$.

PDVSA-GAS. 2003. Memoria Descriptiva. Proyecto Gas Licuado Mariscal Sucre. Caracas..33 pp. 
Prieto A. 1983. Contribución a la ecología de Tivela mactroides (Born, 1778). Aspectos reproductivos. Bol. Inst. Oceanogr. S. Paulo. 29(2): 323 - 328.

Ramos, F., Novoa, D. \& I. Itriago. 1982. Resultado de los programas de pesca exploratoria realizada en el delta del Orinoco. En: D. Novoa (Comp.). Los recursos pesqueros del río Orinoco y su explotación. Corporación Venezolana de Guayana. Ed. Arte, Caracas. 162-192 pp.

Rodríguez G. 1980. Crustáceos decápodos de Venezuela. IVIC, Caracas 444 pp.

Sparre and Venema (1997). Introducción a la Evaluación de Recursos Pesqueros Tropicales - Parte 1: Manual FAO DOCUMENTO TECNICO DE PESCA. 306/1. Rev. 2, 420 pp.

Suárez, M.M. y Bethencourt C. 1994. La pesca artesanal en la costa caribe de Venezuela. Editorial Fundación Biggott, Caracas, 269 p.

Tapia-Garcia, M., A. Yanez-Arancibia, P. Sanchez-Gil y M.C. Garcia-Abad 1995. Distribution, abundance and reproduction of Priacanthus arenatus Cuvier (Pisces: Priacanthidae) in the continental shelf of the Gulf of Mexico. Biotropica 27(2): 232-237.

Thièle J. 1929-1935. Handbuch der systematischen weichtierkunde. Gustav Fischer, Jena 1154 p.

Tineo, F. 1982. Reproducción de la lamparosa, Vomer setapinnis (Perciformes; Carangidae). Trab. Grado Lic. Biología, Univ. de Oriente, 99 pp.

Toledo, J., J. Mendoza y L.A. Marcano 2000. Crecimiento, mortalidad y tasa de explotación de Priacanthus arenatus (Perciformes: Priacanthidae), en la pesca de arrastre del nororiente de Venezuela. Rev. Biol. Trop. 48 Supl. 1: 133-136.

Torrens, C.E., L.A. Marcano, J.J. Alió, A. Lárez, F. Arocha, X. Gutiérrez, G. Vizcaíno y A. Urbaneja. 2005. Perspectivas de la pesquería del pulpo común, Octopus vulgaris, en el nororiente de Venezuela. 52ª Convención Anual Asovac, Caracas.

Urbano T., C. Lodeiros, M. DeDonato, V. Acosta, D. Arrieche, M. Núñez, J.H. Himmelman. 2005. Crecimiento y supervivencia de los mejillones Perna perna (Linné, 1758), Perna viridis (Linné, 1758) y de una variante morfológica bajo sistema de cultivo suspendido. Ciencias Marinas (aceptado)

Uyeno, T., K. Matsuura, and E. Fujii (Editores). 1983. Fishes trawled off Suriname and French Guyana. Japan Marine Fishery Resource Research Center. Tokio, Japan. 519 pp.

Varela, R., Carvajal, F. y Müller-Karger, F. 2003. El fitoplancton en la plataforma nororiental de Venezuela. En : Fréon, P. \& J. Mendoza (Eds.). The sardine Sardinella aurita its exploitation and environment in eastern Venezuela. Editions IRD, Paris. 550 p.

Vélez A., B. Venables . LL. Fitzpatrick. 1985. Growth and reproduction of the tropical beach clam Donax denticulatus (Tellinidae) in eastern Venezuela. Caribb. J. Sci. 21: 125-136. 
Wade B.A. 1969. Studies on the biology of West Indian beach clam, Donax denticulatus Linné. 1. Ecology. Bull. Mar. Sc. 17: 149-174. 